STEFAN KRONENBERGER

\title{
DIE INVESTITIONEN IM RAHMEN DER STAATSAUSGABEN
}




\section{STEFAN KRONENBERGER}

\section{DIE INVESTITIONEN IM RAHMEN DER STAATSAUSGABEN}

Obwohl die öffentlichen Investitionen gemeinhin eine besondere Wertschätzung erfahren, bleibt weitgehend offen, welche konstitutiven Elemente sie determinieren bzw. von anderen Ausgaben abgrenzen. Sie scheinen vielfach derart zu faszinieren, daß für eine wirtschaftspolitische Wertung schon die Semantik genügt. Vor diesem Hintergrund werden die öffentlichen Investitionen im Kontext der Staatsausgaben untersucht, und die theoretischen Ausführungen mit einer kritischen Analyse des empirischen Befundes konfrontiert.

Stefan Kronenberger wurde 1955 in Enkenbach geboren. Von 1975 bis 1980 Studium der Volkswirtschaftslehre an der Universität Mannheim. Anschliessend Assistent am Lehrstuhl für Volkswirtschaftslehre IV und wissenschaftlicher Mitarbeiter im Sonderforschungsbereich 5 "Staatliche Allokationspolitik im marktwirtschaftlichen System" der Universität Mannheim. 
Die Investitionen im Rahmen der Staatsausgaben 


\section{STAATLICHE ALLOKATIONSPOLITIK IM MARKTWIRTSCHAFTLICHEN SYSTEM}

Herausgegeben von

Heinz König, Hans-Heinrich Nachtkamp,

Uirich Schlieper, Eberhard Wille

\section{Band 26}

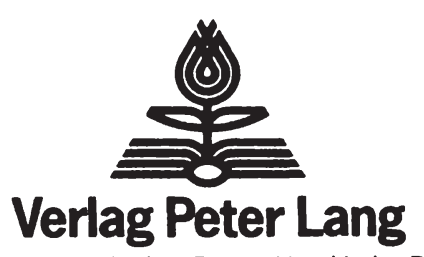

Frankfurt am Main · Bern - New York · Paris 


\section{STEFAN KRONENBERGER}
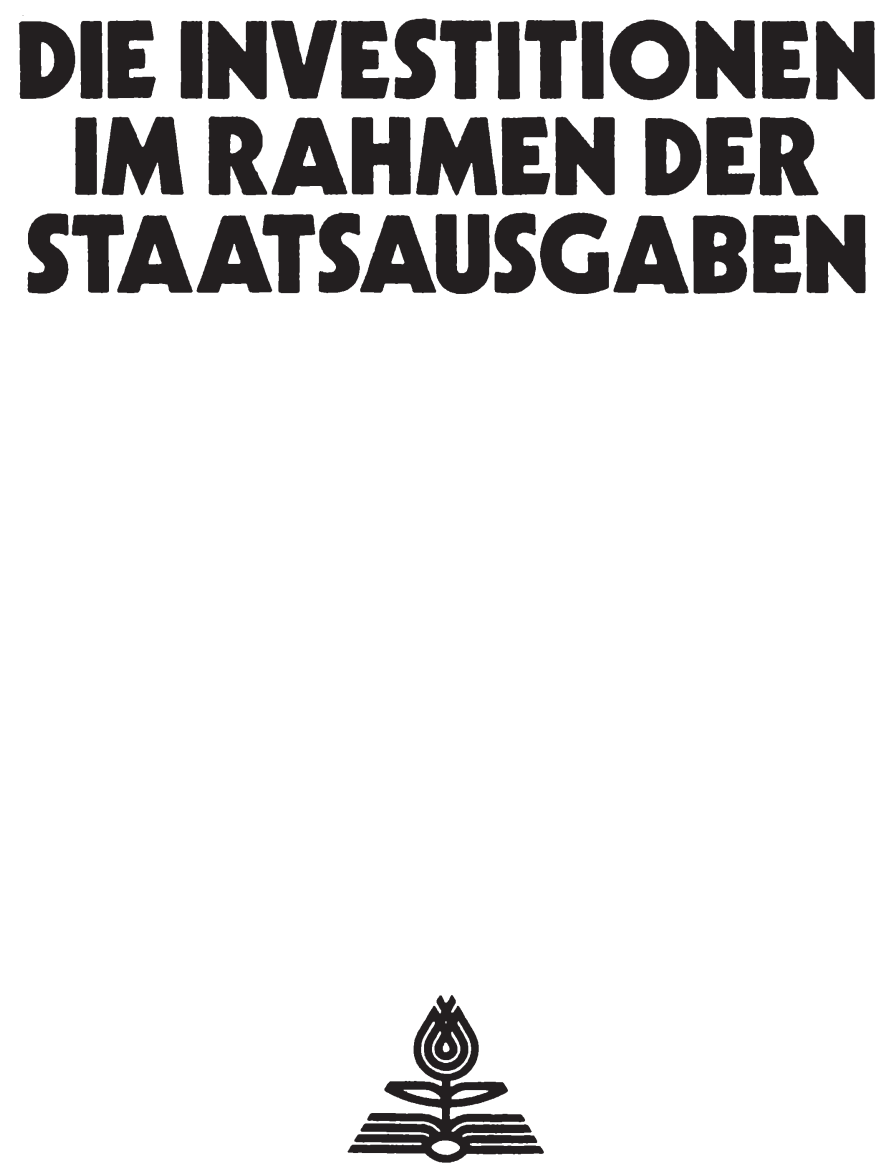

Verlag Peter Lang

Frankfurt am Main · Bern · New York · Paris 
CIP-Titelaufnahme der Deutschen Bibliothek

Kronenberger, Stefan:

Die Investitionen im Rahmen der Staatsausgaben / Stefan

Kronenberger. - Frankfurt am Main ; Bern ; New York ; Paris :

Lang, 1988

(Staatliche Allokationspolitik im marktwirtschaftlichen

System ; Bd. 26)

Zugl.: Mannheim, Univ., Diss., 1987

ISBN 3-8204-9996-2

NE: GT

Open Access: The online version of this publication is published on www.peterlang.com and www.econstor.eu under the international Creative Commons License CC-BY 4.0. Learn more on how you can use and share this work: http://creativecommons.org/ licenses/by/4.0.

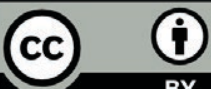

This book is available Open Access thanks to the kind support of ZBW - Leibniz-Informationszentrum Wirtschaft.

D 180

ISSN 0721-2860

ISBN 3-8204-9996-2

ISBN 978-3-631-75565-5 (eBook)

(c) Verlag Peter Lang GmbH, Frankfurt am Main 1988

Alle Rechte vorbehalten.

Das Werk einschließlich aller seiner Teile ist urheberrechtlich geschützt. Jede Verwertung außerhalb der engen Grenzen des

Urheberrechtsgesetzes ist ohne Zustimmung des Verlages unzulässig und strafbar. Das gilt insbesondere für

Vervielfältigungen, Übersetzungen, Mikroverfilmungen und die Einspeicherung und Verarbeitung in elektronischen Systemen.

Printed in Germany 


\section{Vorwort}

Gemessen an der Bedeutung, welche die Konjunktur- und Wachstumstheorie den öffentlichen Investitionen grundsätzlich beimißt, behandelt die wirtschaftswissenschaftliche Literatur diese Ausgabenart in Spezialuntersuchungen immer noch arg stiefmütterlich. Die wirtschaftspolitische Praxis verfährt ähnlich, wenn sie in öffentlichen Äußerungen den Investitionen des Staates eine besondere Wertschätzung entgegenbringt und dabei völlig offen läßt, welche konstitutiven Elemente diese Ausgaben determinieren bzw. von anderen abgrenzen. Die öffentlichen Investitionen scheinen die Ökonomen derart zu faszinieren, daß ihnen für eine wirtschaftspolitische Wertung vielfach schon die Semantik genügt und sie es nicht für notwendig erachten, den Investitionsbegriff zu konkretisieren. Vor diesem Hintergrund werden die öffentlichen Investitionen im Kontext der Staatsausgaben untersucht und die theoretischen Ausführungen mit einer kritischen Analyse des empirischen Befundes konfrontiert.

Die vorliegende Arbeit entstand während meiner Tätigkeit am Mannheimer Sonderforschungsbereich 5 "Staatliche Allokationspolitik im marktwirtschaftlichen System". Sie wurde im Sommersemester 1987 von der Fakultät für Volkswirtschaftslehre und Statistik der Universität Mannheim als Dissertation angenommen.

Mein Dank richtet sich in erster Linie an meine Eltern, ohne deren Opferbereitschaft, verständnisvolle Zuneigung und manchesmal auch energisches Lenken meine Ausbildung und damit die Grundlagen dieser Arbeit nicht möglich gewesen wäre. Mein besonderer Dank gilt auch Herrn Prof. Dr. Eberhard Wille, der diese Arbeit nicht nur angeregt, sondern stets mit seiner konstruktiven Kritik begleitet hat. Wertvolle Hinweise und Verbesserungsvorschläge verdanke ich meinen Kollegen im Sonderforschungsbereich 5. Ein herzlicher Dank geht auch an Frau Marion Börresen, die das Manuskript in die vorliegende Form brachte und mit vielen Verbesserungen im Detail nicht unwesentlich zur zeitgerechten Fertigstellung der Arbeit beitrug. 
Stefan Kronenberger - 978-3-631-75565-5

Downloaded from PubFactory at 01/11/2019 03:29:50AM

via free access 


\section{Inhaltsverzeichnis}

Seite

1. DIE BEDEUTUNG DER STAATSAUSGABEN IN DOGMENHISTORISCHER SICHT 1

1.1. Der Stellenwert der Ausgaben in der Finanzwissenschaft 1

1.1.1. Bestandsaufnahme 1

1.1.2. Disposition 4

1.1.3. Exkurs: Zum Verhältnis zwischen öffentlichen Ausgaben und $\begin{array}{ll}\text { Aufgaben } & 7\end{array}$

$\begin{array}{lll}1.2 & \text { Merkantilismus } & 10\end{array}$

1.2.1. Grundzüge der merkantilistischen Wirtschaftslehre $\quad 10$

1.2.2. Der kameralistische Ansatz 14

1.2.3. Ablösung der merkantilistischen Lehre $\quad 15$

$\begin{array}{lll}\text { 1.3 Klassischer Liberalismus } & 17\end{array}$

1.3.1. Die Staatsausgaben bei Adam Smith 17

1.3.2. Der Einfluß des Liberalismus in Deutschland 23

1.4. Sozialpolitisch motivierter Interventionismus 27

1.4.1. Die deutsche Finanzwissenschaft $\quad 27$

1.4.2. Die Staatsausgaben bei John Stuart Mill $\quad 38$

1.5. Die Integration der Staatsausgaben 43

1.5.1. Neuorientierung der Finanzwissenschaft 43

1.5.2. Die Organisation der Staats- und Privatwirtschaft 45

1.5.3. Die Beziehungen zwischen Staats- und Marktwirtschaft $\quad 47$

1.6. Fiscal Theory 51

1.6.1. Forderung nach aktiver Stabilisierungspolitik $\quad 51$

1.6.2. John Maynard Keynes 53

1.6.3. Das Prinzip der Functional Finance $\quad 63$

1.6.4. Das makroökonomische Modell $\quad 64$

1.7. Zum Stand der modernen Ausgabentheorie 66

1.7.1 Die Ausgaben im Dienste eines pluralistischen Aufgabenbündels $\begin{array}{ll}\text { des Staates } & 66\end{array}$

1.7.2. Ansätze zur Bestimmung öffentlicher Ausgaben 68

1.7.3. Ansätze über die Wirkung öffentlicher Ausgaben $\quad 73$ 
2. KRITERIEN ZUR EINTEILUNG DER STAATSAUSGABEN

2.1. Allgemeine Gliederungskriterien 76

2.1.1. Abhängigkeit von der wirtschaftlichen Entwicklung 76

2.1.2. Grad des privaten oder öffentlichen Nutzens $\quad 81$

2.1.3. Stellung im Wirtschaftskreislauf $\quad 85$

2.2. Haushaltsrechtliche Gliederungskriterien 95

2.2.1. Grundlagen des Haushaltsrechts 95

2.2.2. Gliederung nach institutionellen Gesichtspunkten 97

2.2.3. Gliederung nach Ausgabengruppen (Gruppierungsübersicht) 102

2.2.4. Gliederung nach Aufgabenbereichen (Funktionenübersicht) 106

2.2.5. Das Haushaltsrecht der Gemeinden 111

2.3. Gliederungskriterien der amtlichen Statistik 114

2.3.1. Die Beziehungen zwischen Finanzstatistik und Volkswirtschaftlichen Gesamtrechnungen (VGR) $\quad 115$

$\begin{array}{lll}\text { 2.3.2. } & \text { Finanzstatistische Gliederungen } & 117\end{array}$

2.3.3. Ansatzpunkte der Volkswirtschaftlichen Gesamtrechnungen 124

2.3.4. Ausgabengliederungen der Volkswirtschaftlichen

Gesamtrechnungen

3. ZUR ENTWICKLUNG DER INVESTITIONS-

AUSGABEN

3.1. Die öffentlichen Investitionen im Mittelpunkt des $\begin{array}{ll}\text { Interesses } & 136\end{array}$

3.1.1. Öffentliche Armut bei privatem Reichtum 137

3.1.2. Amtliche Stellungnahmen 141

3.2. Zur empirischen Entwicklung in der Finanzstatistik 144

$\begin{array}{lll}\text { 3.2.1. Der Investitionsbegriff } & 144\end{array}$

3.2.2. Die Investitionsquote im Öffentlichen Gesamthaushalt 152

3.2.3. Differenzierung nach Gebietskörperschaften 163

3.2.4. Sachinvestitionen versus Investitionsförderungsmaßnahmen 171 
3.3. Empirischer Befund der Volkswirtschaftlichen Gesamtrechnungen $\quad 179$

3.3.1. Konzeptionelle Unterschiede zur Finanzstatistik 179

3.3.2. Vergleich verschiedener Investitionsquoten 190

3.3.3. Die Struktur der Bruttoinvestitionen 193

3.3.4. Die Entwicklung in konstanten Preisen 198

3.4. Einige kritische Anmerkungen 205

4. DIE ÖFFENTLICHEN INVESTITIONEN IN FINALER SICHT $\quad 217$

4.1. Der Investitionsbegriff im allgemeinen 217

4.2. Wirkungstheoretische Abgrenzungsversuche 221

4.2.1. Öffentliche Investitionen und positiver Zukunftsnutzen 222

4.2.2. Öffentliche Investitionen und Wirtschaftswachstum 224

4.2.3. Öffentliche Investitionen und Vermögenszugang 231

4.3. Formale Abgrenzung öffentlicher Investitionen 234

5. ZUSAMMENFASSUNG 237

$\begin{array}{ll}\text { Tabellenanhang } & 247\end{array}$

$\begin{array}{ll}\text { Literaturverzeichnis } & 272\end{array}$ 
Stefan Kronenberger - 978-3-631-75565-5

Downloaded from PubFactory at 01/11/2019 03:29:50AM

via free access 


\section{Die Bedeutung der Staatsausgaben in dogmenhistorischer Sicht}

\subsection{Der Stellenwert der Ausgaben in der Finanzwissenschaft}

\subsubsection{Bestandsaufnahme}

In seinen einleitenden Bemerkungen zu den drei Artikeln des Handwörterbuches der Wirtschaftswissenschaft (HdWW), welche sich mit Geschichte, Theorie und Politik der Finanzwissenschaft beschäftigen, bezeichnet Kurt Schmidt "die Lehre vom finanzwirtschaftlichen Handeln des Staates, also in der Hauptsache von dem Teil der staatlichen Tätigkeit, der sich als Ausgaben und Einnahmen ın öffentlichen Haushalten niederschlägt",als Gegenstand der Finanzwissensshaft." Während die Aspekte und Probleme, die mit der staatlichen Einnahmenerzielung zusammenhängen, in der Finanzwissenschaft schon immer eingehend diskutiert wurden, fanden die Staatsausgaben jedoch vergleichsweise wenig Beachtung. ${ }^{2}$ Die Fragen bezüglich der öffentlichen Einnahmen standen lange Zeit eindeutig im Vordergrund, da, wie Gerhard Albrecht vermutet, viele finanzwissenschaftliche Autoren davon ausgingen, "daß die Einnahmenbeschaffung das eigentliche finanzwirtschaftliche Problem ist, während die zu deckenden Ausgaben die Rolle einer von vornherein notwendigen und unabänderlichen Gegebenheit, des selbst

1) Schmidt, K.: Vorbemerkungen zum Stichwort Finanzwissenschaft, in: Handwörterbuch der Wirtschaftswissenschaft (HdWW), hrsg. v. W. Albers et al., Bd. 3, Stuttgart et al. 1981, S.211-212, S. 211. Eine ähnliche Charakterisierung wählen auch Zimmermann/Henke. Vgl Zimmermann, H. und Henke, K.-D.: Finanzwissenschaft. Eine Einführung in die Lehre von der öffentlichen Finanzwirtschaft, 4. Aufl., München 1985, S. 1.

Die Bezeichnung Finanzwissenschaft ist allerdings im Hinblick auf den Wortteil "Finanz" nicht unumstritten. Vgl. Andel, N.: Finanzwissenschaft, Tübingen 1983, S. 6. Andel verweist in diesem Zusammenhang auf Musgrave, der von dem "useful German concept of Staatswirtschaft" sprach. Vgl. Musgrave, R.A.: The Theory of Public Finance. A Study in Public Economy, New York et al. 1959, S. VI.

2) Vgl. Albrecht, G.: Das Problem der öffentlichen Ausgaben in der älteren Finanzwissenschaft, in: Jahrbücher für Nationalökonomie und Statistik, Bd. 148, Jena 1938, S. 171-201, S. $171 \mathrm{ff}$. und Musgrave, R.A.: The Theory ..., a.a.O., S. V sowie Kolms, H.: Finanzwissenschaft, Bd. 1, 4. Aufl., Berlin, New York 1974, S. 81 f. und Neumark, F.: Hundert Jahre "Finanzarchiv", in: Finanzarchiv, hrsg. v. N. Andel und F. Neumark, N.F. Bd. 42, Tübingen 1984, S. 385-406, S. 396.

Vgl. auch Wille, E.: Die öffentlichen Ausgaben und die Entwicklung der Staatsquote. Zu entsprechenden Beiträgen im neuen "Handwörterbuch der Wirtschaftswissenschaft (HdWW)", in: ORDO. Jahrbuch für die Ordnung von Wirtschaft und Gesellschaft, Bd. 32 (1981), S. 297 311, S. 297. 
völlig unproblematischen Ausgangspunktes der Finanzwirtschaft spielen." ${ }^{3)} \mathrm{Ob}-$ wohl Gerhard Colm dieses Primat der (quasi vorgegebenen) Ausgaben in Frage stellte und die entstandene Lücke zwischen der Behandlung der Einnahmen und Ausgaben mit seinem Buch "Volkswirtschaftliche Theorie der Staatsausgaben"4), nach eigenem Bekunden, "wenigstens teilweise auszufüllen"5) glaubte, bezeichnete Wilhelm Gerloff noch in der zweiten Auflage des Handbuches der Finanzwissenschaft die "öffentliche Bedarfsdeckungswirtschaft" als Erfahrungsobjekt der Finanzwissenschaft. ${ }^{6}$ Die Finanzwissenschaft sei, so Gerloff, "ausschließlich daran interessiert. in welcher Weise die ökonomischen Mittel gewonnen und ihrer Bestimmung zugeführt werden, um in öffentliche Dienste und Leistungen umgewandelt zu werden." ') Die Bestimmung von Inhalt und Umfang der staatlichen Ausgaben weist er dabei anderen Wissenschaftszweigen $z u{ }^{8}{ }^{8}$ Das Interesse an der finanzwissenschaftlichen Behandlung staatlicher Ausgaben hatte allerdings schon zu Zeiten, als Gerloff seine oben aufgeführten Ansichten publizierte, deutlich zugenommen. ${ }^{9}$ In den letzten Jahrzehnten ist es auch weiter gestiegen, ${ }^{10}$

3) Albrecht, G.: Das Problem ..., a.a.O., S. 171.

4) Colm, G.: Volkswirtschaftliche Theorie der Staatsausgaben. Ein Beitrag zur Finanztheorie, Tübingen 1927.

5) Ebenda, S. IV.

6) Vgl. Gerloff, W.: Grundlegung der Finanzwissenschaft, in: Handbuch der Finanzwissenschaft, 2. Aufl., hrsg. v. W. Gerloff und F. Neumark, Bd. I, Tübingen 1952, S. 1-65, S. 17.

An gleicher Stelle bezeichnete er "die öffentlich-wirtschaftliche Beschaffung und Bereitstellung der einer öffentlichen Wirtschaft zur Erfüllung ihrer Zwecke erforderlichen Mittel" als Erkenntnisobjekt der Finanzwissenschaft.

7) Ebenda, S. 22.

8) Nach Gerloff wird vor allem dort die Grenze zu den Nachbarwissenschaften überschritten, wo "einzelne Autoren glauben, die Lehre von den öffentlichen Bedürfnissen im Rahmen der Finanzwissenschaft behandeln zu sollen" Ebenda, S. 22.

9) Vgl. Neumark, F.: Grundsätze und Arten der Haushaltsführung und Finanzbedarfsdekkung, in: Handbuch der Finanzwissenschaft, 2. Aufl., hrsg. v. W. Gerloff und F. Neumark, Bd. I, Tübingen 1952, S. 606-669, S. 606 ff.

10) Als Indiz hierfür kann die Behandlung der öffentlichen Ausgaben in den verschiedenen Auflagen des Handbuches der Finanzwissenschaft herangezogen werden. (Vgl. hierzu auch Blankart, C.B.: Das Handbuch der Finanzwissenschaft, eine Selbstdarstellung der deutschen Finanzwissenschaft?, in: Kyklos, vol. 39 (1986), S. 448-445, S. 448). In der ersten Auflage, herausgegeben von Wilhelm Gerloff und Franz Meisel (jeweils erschienen in Tübingen; Bd. I, 1926; Bd. II, 1927; Bd. III, 1929), werden die öffentlichen Ausgaben gerade in einem Artikel von Karl Englis behandelt. Die zweite Auflage, von Wilhelm Gerloff und Fritz Neumark herausgegeben (jeweils erschienen in Tübingen; Bd. I, 1952; Bd. II, 1956; Bd. III, 1958; Bd. IV, 1965), schenkte den öffentlichen Ausgaben schon mehr Beachtung. In den ersten fünf Artikeln des zweiten Bandes werden allgemeine und spezielle Probleme der Staatsausgaben angesprochen. In der unter Mitwirkung von Norbert Andel und Heinz Haller von Fritz Neumark herausgegebenen dritten Auflage (jeweils erschienen in Tübingen; Bd. I, 1977; Bd. II, 1980; Bd. III, 1981; Bd. IV, 1983) beschäftigen sich die sieben Artikel des sechsten Abschnitts: "Die Lehre von den öffentlichen Ausgaben" direkt mit den Problemen der Ausga- 
trotzdem begründete Andel seinen Entschluß zur Publikation eines finanzwissenschaftlichen Lehrbuches ${ }^{11}$ mit der Hoffnung, "Zustimmung zu finden für die Auffassung, daß mehr als bisher üblich die Ausgabenseite systematisch und in ähnlicher Breite wie die Einnahmen einbezogen werden sollten."12)

Nach Kolms liegt eine Erklärung für diese Vernachlässigung der Staatsausgaben durch die Finanzwissenschaftler darin, daß die Staatsausgaben gegenüber den staatlichen Einnahmen und hier insbesondere den Steuern, eine geringere Merklichkeit aufweisen. ${ }^{13)}$ Eine weitere, nach Buschor die wohl beste Erklärung ${ }^{14}$, liefert die Vierstufentheorie nationaler Ziele von Colm. ${ }^{15)}$ Danach hat mit der Entwicklung des Zielbewußtseins hin zu den Leistungszielen (achievement goals) die Bedeutung der staatlichen Ausgaben als Instrumentvariablen in den letzten 20 Jahren zugenommen. ${ }^{16)}$

benseite des Staates. Darüber hinaus ist in der dritten Auflage ein Abschnitt über "Planung und Kontrolle der finanzwirtschaftlichen Aktivität" aufgenommen worden, in dem, vor allem bei den sich mit der Planung beschäftigenden Artikeln, Fragen der Ausgabentheorie angesprochen werden. Die Berechtigung gerade das Handbuch der Finanzwissenschaft als Kriterium zur Stützung der oben aufgestellten Behauptung heranzuziehen, ergibt sich auch aus dem Anspruch, den die Herausgeber - jeweils im Vorwort - anmelden, mit dem Werk "eine den Tatsachen der jüngsten Vergangenheit wie den Bedürfnissen der Gegenwart gerecht werdende Darstellung der Finanzwissenschaft zu bieten".

Vgl. auch Wille, E.: Die offentlichen Ausgaben ..., a.a.O., S. 297. Wille belegt das gestiegene Forschungsinteresse an den offentlichen Ausgaben mit deren Behandlung im alten "Handwörterbuch der Sozialwissenschaften (HdSW)" und der ungleich größeren Beachtung im neuen "Handwörterbuch der Wirtschaftswissenschaft (HdWW)"

11) Andel, N.: Finanzwissenschaft, Tübingen 1983.

12) Ebenda, Vorwort.

13) Vgl. Kolms, H.: Finanzwissenschaft, a.a.O., S. 81.

14) Vgl. Buschor, E.: Theorie der Allokation der Staatsausgaben. Darstellung und kritische Würdigung der Theorie der Staatsausgaben unter dem Aspekt der Allokationsproblematik, Heerbrugg 1970, S. 3.

15) Colm, G.: On Goals Research, in: Neue Perspektiven aus Wirtschaft und Recht. Festschrift für Hans Schăffer, hrsg. v. C.P. Claussen, Berlin 1966, S. 67-78, S. 68 ff.

16) Die "National Goals Analysis "wurde von Gerhard Colm als Antwort auf die Arbeiten von Samuelson und Musgrave, die den Umfang der Bereitstellung öffentlicher Güter mittels eines Systems von Indifferenzkurven abzuleiten suchten, begründet. Er teilt die "nationalen Ziele" in zwei große Gruppen ein:

- performance goals (Funktionsziele), z.B. Vollbeschäftigung, Preisstabilität, Wirtschaftswachstum und

- achievement goals (Leistungsziele), z.B. Verbesserung der Ausbildung, Forschung.

Den Grad der Zustimmung der Gesellschaft zu diesen Zielen glaubt er in vier historischen Abschnitten darlegen zu kőnnen:

1. Vor der Weltwirtschaftskrise: Keine der beiden Zielgruppen wird vom Staat planmäßig betrieben; die Menschen streben zwar nach Verbesserung ihrer Lebensstandards, sehen aber nicht, daß der Staat stabilisierend in das Wirtschaftsleben eingreifen könnte.

2. Nach der Weltwirtschaftskrise: Die performance goals werden vom Staat planmäßig angestrebt und dringen als nationale Aufgabe ins Bewußtsein der Menschen.

3. Während und vor allem nach dem 2. Weltkrieg: Nachdem die performance goals etabliert sind, schieben sich die achievement goals in den Vordergrund.

4. Die achievement goals werden allgemein anerkannt. Der Staat ist ein sog. "Wohlfahrtsstaat", nur noch der Grad der Verwirklichung wird diskutiert. 


\subsubsection{Disposition}

Die oben angedeutete Vernachlässigung der Staatsausgaben in der finanzwissenschaftlichen Literatur ${ }^{17)}$ wurde in den letzten Jahren und Jahrzehnten von einer ständigen Steigerung der Staatsausgaben in der Realität begleitet. ${ }^{(8)}$ Die langfristige Entwicklung der Staatsausgabenquote, die vor allem im Zusammenhang mit dem sog. "Wagnerschen Gesetz" diskutiert wird, ist allerdings nicht Gegenstand dieser Arbeit. ${ }^{19)}$

Trotz der vielerorts beklagten Vernachlässigung der Staatsausgaben in der Finanzwissenschaft, bildeten diese schon immer den Gegenstand nationalökonomischer Forschung und Lehre. Allerdings besteht "zwischen der volkswirtschaftlich-theoretischen und der finanzwissenschaftlichen Dogmengeschichte ... insofern ein Unterschied, als erstere meist anationalen und letztere nationalen Charakter hat." ${ }^{20)}$ Etwa in diesem Sinne richtet sich das Interesse der folgenden Ausführungen auf die Rolle der Staatsausgaben in der Finanzwissenschaft, die, eingebettet in die großen Strömungen der Nationalökonomie untersucht werden. Von besonderer Bedeutung ist in dieser Hinsicht, daß gerade in den deutschsprachigen Ländern Sonderentwicklungen zu beobachten sind, die wohl nur vor dem Hintergrund der deutschen Kulturgeschichte verstanden werden können. ${ }^{21}$ ' Thomas Riha spricht in diesem Zusammenhang von der "pivotal position of social reality", welche dem Staat in der traditionellen deutschen Philosophie zukommt und vom deutschen "state mysticism", der eine große Rolle spielte. ${ }^{221}$

17) Vgl. auch Buschor, E.: Theorie der Allokation ..., a.a.O., S. 3.

18) Vgl. auch Liefmann-Keil, E.: Zur Entwicklung der Theorie der Bewilligung öffentlicher Einnahmen und Ausgaben, in: Finanzarchiv, hrsg. v. F. Neumark, N.F. Bd. 19 (1958/59), Tübingen 1959, S. 219-239, S. 219.

19) Vgl. hierzu Andic, S. and Veverka, $J$.: The Growth of Government Expenditure in Germany since the Unification, in: Finanzarchiv, hrsg. v. F. Neumark, N.F. Bd. 23, Tübingen 1964, S.169-278 und Littmann, K.: Art.: Ausgaben, offentliche II: Die "Gesetze" ihrer langfristigen Entwicklung, in: Handwörterbuch der Wirtschaftswissenschaft (HdWW), hrsg. v. W. Albers et al., Bd. 1, Stuttgart et al. 1977, S. 349-363. sowie Recktenwald, H.C.: Umfang und Struktur der öffentlichen Ausgaben in säkularer Entwicklung, in: Handbuch der Finanzwissenschaft, 3. Auf1., hrsg. v. F. Neumark, Bd. I, Tübingen 1977, S. 713-752. Zu den methodischen Fragen der Beurteilung der Entwicklung der Staatsquote vgl. Peacock, A.T. and Wiseman, J.: The Growth of Public Expenditure in the United Kingdom, London 1961, vor allem die Einleitung und die ersten beiden Kapitel sowie Wille, E.: Die öffentlichen Ausgaben ..., a.a.O., S. $305 \mathrm{ff}$.

20) Koch, W.: Art.: Finanzwissenschaft I: Geschichte, in : Handwörterbuch der Wirtschaftswissenschaft (HdWW), hrsg. v. W. Albers et al., Bd. 3, Stuttgart et al. 1981, S. 212-234, S. 212.

21) Vgl. Riha, T.: German Political Economy: The History of an Alternative Economics, Bradford 1985, S. 5.

22) Vgl. ebenda, S.7. 
Die Auffassungen über Umfang und Struktur der staatlichen Ausgaben in epochale Abschnitte zu unterteilen, ist sicher nicht unproblematisch, weil in einem gewissen Grade willkürlich, und nur mit der damit gewonnenen Übersichtlichkeit und Verständlichkeit zu rechtfertigen. Die chronologische Aneinanderreihung einzelner Perioden soll auch keine historische Weiterentwicklung im Sinne einer steten Höherentwicklung nahelegen. Bei der Darstellung wird im Gegenteil deutlich werden, "daß gewisse Erkenntnisse im Verlauf der Geschichte verloren gehen, jedoch in späterer Zeit - oftmals ohne historische Abhängigkeit - wiederkehren und erst dann ihre stärkste Wirkung entfalten." ${ }^{23)}$

Der dogmenhistorische Rückblick beginnt mit der Darstellung der Auffassungen im 17. Jahrhundert, für die in aller Regel die Bezeichnung Merkantilismus ${ }^{24)}$ gewählt wird, und versucht, die Spur der Staatsausgaben von dort bis in die Gegenwart zu verfolgen. Wenn man als wesentliches und konstitutives Element staatlicher Wirtschaft den Umstand ansieht, "daß Güter für den kollektiven Bedarf entweder durch die bestehende öffentliche Wirtschaft selbst produziert oder aus dem Verfügungsbereich der privaten Wirtschaft auf die öffentliche übertragen werden"25), so müßte auch die Wirtschaft der Gemeinwesen des Altertums und Mittelalters in die Untersuchung einbezogen werden. ${ }^{26)}$ Der Grund, die Betrachtungen gerade in dieser Zeit anzusetzen, liegt vor allem in den fundamentalen Unterschieden, die die Staatswirtschaft des 17. und 18. Jahrhunderts gegenüber früheren Formen aufweist. Für sie galt, daß erstens "die naturalwirtschaftlichen Elemente ... weitgehend zugunsten der Geldwirtschaft zurückgedrängt" waren, und zweitens "begünstigt durch Geldwirtschaft und geistesgeschichtliche Ent-

23) Mann, F.K.: Abriß einer Geschichte der Finanzwissenschaft, in: Handbuch der Finanzwissenschaft, 3. Aufl., hrsg. v. F. Neumark, Bd. I, Tübingen 1977, S. 77-98, S. 77.

24) Zum Streit darüber, ob das Wort Kameralismus nur eine andere deutsche Bezeichnung für Merkantilismus ist oder, ob es grundlegende Unterschiede zwischen beiden gibt vgl. Tautscher, A.: Geschichte der deutschen Finanzwissenschaft bis zum Ausgang des 18. Jahrhunderts, in: Handbuch der Finanzwissenschaft, 2. Aufl, hrsg. v. W. Gerloff und F. Neumark, Bd. I, Tübingen 1952, S. 382-415, S. 387 sowie Bierie, S.: Zur Stellung der frühen deutschen Finanzwissenschaft. Unter besonderer Berücksichtung von Jakob, Soden, Lotz und Malchus, Zürich 1968, S. 11 und Riha, T.: German Political Economy ..., a.a.O., S. 10 ff.

25) Häuser, K.: Abriß der geschichtlichen Entwicklung der öffentlichen Finanzwirtschaft, in: Handbuch der Finanzwissenschaft, 3. Aufl., hrsg. v. F. Neumark, Bd. I, Tübingen 1977, S.351, S. 5.

26) Vgl. hierzu ebenda, S. 3-40 und Schumpeter, J.A.: Geschichte der ökonomischen Analyse, 2 Bände, Göttingen 1965, S. 89-196. 
wicklung (Aufklärung), Rationalismus und Wirtschaftlichkeit für die Staatswirtschaft eine zunehmend bedeutsamere Rolle zu spielen" begannen. ${ }^{27)}$

Im Anschluß an die Betrachtung merkantilistischer und kameralistischer Auffassungen werden die Staatsausgaben bei den Klassikern ins Blickfeld gerückt. Die Beschäftigung vor allem mit dem Werk von Adam Smith zeigt, daß er, wie die meisten Klassiker, "den Staatsausgaben erhebliche Beachtung schenkte." ${ }^{28)}$ Im dritten Abschnitt werden unter der Überschrift "Sozialpolitisch motivierter "Interventionismus" sehr vielfältige Strömungen zu erfassen versucht. Zum einen ist in diesem Zeitabschnitt, im Gefolge der philosophischen Arbeiten von Hegel, Fichte und Schelling ${ }^{29}$, eine Wandlung der Wertschätzung zum Staat hin zu beobachten, und zum anderen gewinnt in dieser Zeit die soziale Frage zunehmend an Bedeutung. Gleichzeitig entsteht, wie Riha formuliert "formed through opposition to the German version of classical economics"30), die Methode der "Historischen Schule", die gerade die deutsche Nationalökonomie, insbesondere auch die Finanzwissenschaft, lange und nachhaltig beeinflußte. Im Anschluß daran werden die Arbeiten von Gerhard Colm und Arthur Cecil Pigou vorgestellt, die insofern einen Umbruch in der Finanzwissenschaft markieren, als sie die Staatsausgaben in finanzwissenschaftliche Fragestellungen integrieren. ${ }^{31)}$ Mit den Arbeiten von John Maynard Keynes gewinnen schließlich die Staatsausgaben auch als Instrument der Stabilisierungspolitik an Bedeutung. Die dieses Kapitel abschließenden Ausführungen zielen darauf ab, die Verästelungen der aktuellen Diskussion über die Staatsausgaben systematisch zu erfassen.

27) Häuser, K.: Abriß der geschichtlichen ..., a.a.O., S. 40. Als einen weiteren Grund führt Häuser auf, daß "der für die mittelalterliche Staatswirtschaft charakteristische Dualismus zwischen Territorialherrschaft und Reich einerseits und zwischen Territorialherren und Landständen andererseits durch entscheidende verfassungsrechtliche Änderungen vermindert, teilweise sogar beseitigt" wurde. Auf der nachfolgenden Seite bezeichnet er die Kameralisten als frühe Finanzwissenschaftler.

28) Wille, E.: Die öffentlichen Ausgaben ..., a.a.O., S. 297. Vgl. auch Koch, W.: Finanzwissenschaft I: Geschichte, a.a.O., S. 213.

29) Vgl. auch Riha, T.: German Political Economy ..., a.a.O., S. $52 \mathrm{ff}$.

30) Ebenda, S. 70.

31) Vgl. Mann, F.K.: Abriß einer Geschichte ..., a.a.O., S. 94. 


\subsubsection{Exkurs: Zum Verhältnis zwischen öffentlichen Ausgaben und Aufgaben}

Bei der Betrachtung des Verhältnisses zwischen öffentlichen Ausgaben und Aufgaben kann man vorab feststellen, daß Wort und Begriff der öffentlichen Aufgabe "häufig ohne Erläuterung wie selbstverständlich verwendet werden und deshalb

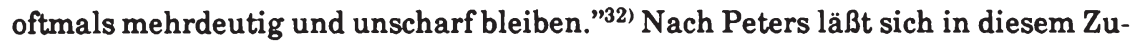
sammenhang trotz umfangreicher wissenschaftlicher Beschäftigung noch immer "ein babylonisches Sprachgewirr" konstatieren, das er zum einen auf die große Spannweite des Aufgabenbegriffes selbst zurückführt und zum anderen damit erklärt, daß sich verschiedene wissenschaftliche Disziplinen mit diesem Fragenbereich beschäftigen. ${ }^{331}$ Innerhalb der Wirtschaftswissenschaften wird in aller Regel auf die Zielorientierung des Begriffes Aufgabe abgestellt. ${ }^{34)}$ Ähnliches schlägt auch Bull vor, ${ }^{351}$ so daß als wesentliches Kennzeichen einer Aufgabe "ihr

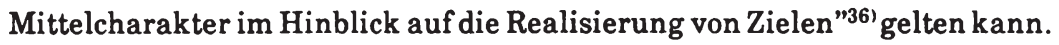

Die Beziehungen zwischen den öffentlichen Ausgaben und Aufgaben werden zunächst dadurch charakterisiert, daß die Ausgaben ein direktes Instrument zur öffentlichen Aufgabenerfüllung darstellen. Neben den Ausgaben und den staatlichen Einnahmen, die zusammen den budgetintensiven Weg der staatlichen Auf-

32) Peters, A.: Ökonomische Kriterien für eine Aufgabenverteilung in der Marktwirtschaft. Eine deskriptive und normative Betrachtung für den Allokationsbereich, Frankfurt/Main 1985, S. 18

Vgl. auch Mäding, E.: Aufgaben der öffentlichen Verwaltung, in: Die Verwaltung. Zeitschrift für Verwaltungswissenschaft, hrsg. v. E. Forsthoff, Bd. 6, Berlin 1973, S. 257-282, der sich vor allem auf den ersten Seiten des Artikels mit der nicht immer eindeutigen Handhabung des Begriffes auseinandersetzt.

33) Vgl. Peters, A.: Ökonomische Kriterien ..., a.a.O., S. 7.

Zur Verwendung des Aufgabenbegriffs in den Rechts-, Verwaltungs- und Politikwissenschaften vgl. ebenda, S. $7 \mathrm{ff}$.

34) Vgl. hierzu Peters, A.: Ökonomische Kriterien ..., a.a.O., S. 19; Ring, U.: Öffentliche Planungsziele und staatliche Budgets. Zur Erfüllung öffentlicher Aufgaben durch nicht-staatliche Entscheidungseinheiten, Frankfurt/Main 1985, S. 1ff. sowie Wille, E.: Art.: Öffentlicher Haushalt IV: Finanz- und Aufgabenplanung, in: Handwörterbuch der Wirtschaftswissenschaft (HdWW), hrsg. v. W. Albers et al., Bd. 5, Stuttgart et al. 1980, S. 591-620, S. $605 \mathrm{ff}$.

35) Vgl. Bull, H.P.: Die Staatsaufgaben nach dem Grundgesetz, 2. Aufl., Kronberg/Ts. 1977, S.44. Bull schreibt: "Das Wort 'Aufgabe' läßt ... deutlich die Hinordnung auf ein Ziel erkennen".

36) Peters, A.: Ökonomische Kriterien ..., a.a.O., S. 19. 
gabenerfüllung bilden ${ }^{37}$, bietet die Möglichkeit zu Normsetzungen weitere Instrumente staatlicher Aufgabenerfüllung. Mit Hilfe von Normsetzungen versuchen staatliche Entscheidungseinheiten, die Bürger über Ge- und Verbote zu bestimmten Handlungen zu veranlassen (z.B. Umweltschutzbereich) oder fordern durch gesetzliche Auflagen unentgeltliche Leistungen von diesen ein (z.B. Schöffen- und Militärdienst). ${ }^{38)}$ Bei dieser Art der Aufgabenerfüllung bestehen die notwendigen staatlichen Ausgaben lediglich aus den sog. "Gemeinkosten für die Erhaltung des Staatsapparates, der diese Normen aufstellt und durchsetzt." ${ }^{\text {39) }}$ Es wird damit deutlich, daß die öffentliche Aufgabenerfüllung mit einer unterschiedlichen Verausgabungsintensität öffentlicher Mittel einhergehen kann. ${ }^{40)}$ Nach Socher und Lehner läßt sich dabei in hochindustrialisierten Gesellschaften eine Tendenz zur budgetintensiven Aufgabenerfüllung erkennen, die sie damit erklären, daß die Gesellschaftsmitglieder "immer stärker einkommensorientiert" seien und zweitens diese "Maßnahmen größere Möglichkeiten zur Differenzierung" böten. ${ }^{41)}$ Im Grundsatz bestätigt auch Kolms diese Aussage, der davon ausgeht, da $B$ bei der heute vorherrschenden geldwirtschaftlichen Organisation der Volkswirtschaft die Verausgabung finanzieller Mittel die wichtigste Rolle bei der Erfüllung öffentlicher Aufgaben spiele. ${ }^{42)}$ Die Staatsausgaben bilden zwar nicht in jedem Fall das monetäre Äquivalent der öffentlichen Aufgabenerfüllung, stellen aber in den meisten Fällen eine notwendige Voraussetzung dar, um öffent-

37) Vgl. Gantner, M.: Meßprobleme öffentlicher Aktivitäten. Staatsquoten, Preissteigerungen, Outputkonzepte, Baden-Baden 1984, S. 67 ff.

38) Vgl. Wille, E.: Die öffentlichen Ausgaben ..., a.a.O., S. 307 f. und Ring U.: Öffentliche Planungsziele ..., a.a.O., S. 37 ff. sowie Zimmermann H. und Henke, K.-D.: Finanzwissenschaft ,.., a.a.O., S. $23 \mathrm{ff}$.

39) Zimmermann, H.: Die Ausgabenintensităt der öffentlichen Aufgabenerfüllung, in: Finanzarchiv, hrsg. v. F. Neumark, N.F. Bd. 32 (1973/74), Tübingen 1974, S. 1-20, S. 1.

40) Vgl. ebenda, S. 2 sowie Socher, K. und Lehner, G.: Einführung, in: Ausgabenintensität öffentlicher Ausgaben, hrsg. v. Institut für Angewandte Sozial- und Wirtschaftsforschung, Wien 1982, S. 1-7, S. 2 ff.

Das Verhältnis von aufgewendeten öffentlichen Ausgaben zur Erfüllung einer bestimmten Aufgabe wird als Ausgabenintensität umschrieben. Vgl. Socher, K. und Lehner, G.: Einführung, a.a.O., S. 2 sowie Zimmermann, H.: Die Ausgabenintensität ..., a.a.O., S. 8.

41) Socher, K. und Lehner, G.: Einführung, a.a.O., S. 4.

42) Vgl. Kolms, H.: Finanzwissenschaft, a.a.O., S. 14. 
liche Aufgaben verwirklichen zu können. ${ }^{43)} \mathrm{Zwischen} \mathrm{den} \mathrm{budgetären} \mathrm{Ausgaben}$ und den mit ihnen angestrebten Zielwerten öffentlicher Aufgaben lassen sich, und das ist ein weiterer Aspekt der Beziehung zwischen öffentlichen Ausgaben und Aufgaben, mehrere Ziel-Mittel-Ebenen mit unterschiedlichen Operationalisierungsgraden unterscheiden. ${ }^{44}$

Die in der wirtschaftswissenschaftlichen Literatur ${ }^{45}$ ' weitgehend synonyme Verwendung der Termini "staatlich" und "öffentlich" bildet ebenfalls einen Aspekt der kurz beleuchtet werden soll. Aus den Bestimmungen des Grundgesetzes folgt zwar, daß für dessen Geltungsbereich nur Bund und Länder "als Institutionen der Staatlichkeit" angesehen werden, während die Kommunen "Verbände der Selbstverwaltung ohne Staatsqualität" darstellen. ${ }^{46)}$ Gleichwohl werden die Gemeinden und Gemeindeverbände mit ihren ökonomischen Aktivitäten zum Staat gezählt, zumal ja nach Art. 106 GG ihre Einnahmen und Ausgaben "im Rahmen der Steuerverteilung als Einnahmen und Ausgaben ihrer Länder" gelten. ${ }^{47)}$ Was nun im einzelnen staatlich, was öffentlich genannt werden soll, ist allerdings nicht im Sinne ökonomischer Sachlogik zwingend, sondern fast immer eine Frage der Konvention. ${ }^{48)}$ Unstrittig ist, die Gebietskörperschaften zum Staat

43) Vgl. Ring, U.: Öffentliche Planungsziele ..., a.a.O., S. 1.

Jede Abhandlung über die Aufgabenerfüllung muß der Vollständigkeit halber auf die oikenmäßige und leiturgische Form der Bedarfsdeckung hinweisen, die vor allem in der Wirtschaft des Mittelalters und früher eine große Rolle spielten. Vgl. hierzu Kolms, H.: Finanzwissenschaft, a.a.O., S. 13 f. "Unter oikenmāßiger Deckung ... des Bedarfs versteht man die unmittelbare naturalwirtschaftliche Aufbringung von Leistungen aus der die Leistung verbrauchenden Wirtschaft selbst" (S. 13), während "als leiturgische Bedarfsdeckung ... eine unmittelbare unentgeltliche Heranziehung der Mitglieder des öffentlichen Gemeinwesens zu Diensten und Leistungen" (S. 13) bezeichnet wird. Elemente leiturgischer Bedart'sdeckung finden sich heute noch im Schöffendienst und in der Ableistung der Wehrpflichi

44) Vgl. Ring, U.: Öffentliche Planungsziele ..., a.a.O., S. 1 ff. Zur Einbindung der Ausgaben in ein Ziel-Mittel-Schema siehe auch Wille, E.: Rationalität, Effizienz und Effektivität aus der Sicht des Ökonomen, in: Effizienz und Effektivität medizinischer Diagnostik. Bericht über ein Symposion der Internationalen Gesellschaft für Gesundheitsökonomie, Mainz, hrsg. v. H.R. Vogel, Stuttgart 1985, S. 15-37, S. 24 f.

Vgl. hierzu auch Zimmermann, H.: Die Ausgabenintensität ..., a.a.O., S. 9.

45) Vgl. Zimmermann, H.: Die Ausgabenintensität ..., a.a.O., S. 1 ff.; Kolms, H.: Finanzwissenschaft, a.a.O., S. 14; Ring, U.: Öffentliche Planungsziele ..., a.a.O., S. 1.

46) Münch, I. von (Hrsg.): Grundgesetz-Kommentar, Bd. 2 Art. 21 bis Art. 69, 2. Aufl., München 1983, S. 199 (Art. 28/7).

47) Münch, I. von (Hrsg.): Grundgesetz-Kommentar, Bd. 3 Art. 70 bis Art 146 und Gesamtregister, 2. Aufl., München 1983, S. 803 (Art. 106/8).

48) Vgl. Andel, N.: Finanzwissenschaft, a.a.O., S. 4. 
zu zählen. ${ }^{49)}$ Inwieweit aber andere, "nicht-staatliche Entscheidungseinheiten als Anbieter öffentlicher Leistungen" ${ }^{\text {"50) }}$ einzubeziehen sind, ist nur im Hinblick auf eine konkrete Fragestellung zu beantworten. Ob der so abgegrenzte Bereich dann "Staat" oder "Öffentlicher Bereich" genannt wird, spielt eine untergeordnete Rolle.

Sofern die wirtschaftswissenschaftliche Literatur zwischen beiden Begriffen unterscheidet, werden die staatlichen Ausgaben oder Aufgaben als Teil der öffentlichen ${ }^{511}$ bzw. der Staat als Teilobjekt der öffentlichen Körperschaften ${ }^{52)}$ angesehen.

\subsection{Merkantilismus}

\subsubsection{Grundzüge der merkantilistischen Wirtschaftslehre}

Ungeachtet der scharfen Verurteilung der merkantilistischen Auffassungen durch die überwiegende Mehrheit der nachfolgenden Wissenschaftler ${ }^{53)}$, ausgehend von Adam Smith ${ }^{54)}$, und unter Vernachlässigung des Vorwurfs, daß der

49) Vgl. Andel, N.: Finanzwissenschaft, a.a.O., S. 4.

50) Ring, U.: Öffentliche Planungsziele ..., a.a.O., S. 8 f.

Die Bezeichnung öffentliche oder staatliche Aufgabe ist nach Hans Peter Bull mißverständlich. Selbst das Bundesverfassungsgericht halte die Begriffe öffentliche und staatliche Aufgaben nicht sauber auseinander. Vgl. Bull, H.P.: Die Staatsaufgaben ..., a.a.O., S. $47 \mathrm{ff}$. und S. 448.

51) Vgl. Andel, N.: Finanzwissenschaft, a.a.O., S. 4 f. und Timm, H.: Zur Finanzierung staatlicher Investitionen unter dem Aspekt der gerechten zeitlichen Lastverteilung, in: Staat und Politische Ökonomie heute. Horst Claus Recktenwald zum 65. Geburtstag, hrsg. v. H.Hanusch, K.W. Roskamp und J. Wiseman, Stuttgart, New York 1985, S. 319-331, S. 319.

52) Vgl. Kolms, H.: Finanzwissenschaft, a.a.O., S. 7.

53) Vgl. Schumpeter, J.A.: Geschichte der ökonomischen ..., a.a.O., S. 423 ff.

54) Vgl. Smith, A.: An Inquiry into the Nature and Causes of the Wealth of Nations, ed. by R.H. Campbell and A.S. Skinner, Textual Editor W.B. Todd, Oxford 1976, S. 428 ff. Diese Ausgabe erschien als Band II der "Glasgow Edition of the Works and Correspondence of Adam Smith".

Die Kritik von Adam Smith wird dabei den Auffassungen der Merkantilisten nicht immer gerecht. Vgl. hierzu Klein, E.: Die englischen Wirtschaftstheoretiker des 17. Jahrhunderts, Darmstadt 1973, S. 2 und Schmölders, G.: Geschichte der Volkswirtschaftslehre, Wiesbaden 1961, S. 19 f. sowie Tautscher, A.: Geschichte der deutschen ..., a.a.O., S. 387 f. 
Merkantilismus ${ }^{55}$ kein umfassendes System, keine geschlossene Wirtschaftslehre sei ${ }^{56)}$, hat sich der Begriff als Bezeichnung für die ökonomischen Ansichten dieses geschichtlichen Abschnittes eingebürgert. ${ }^{571}$ Dabei darf allerdings nicht außer Acht bleiben, daß es "angesichts der großen Unterschiede im Hinblick auf den Grad der wirtschaftlichen Entwicklung sowie auf den politisch-gesellschaftlichen Rahmen in den einzelnen europäischen Ländern zu sehr unterschiedlichen Ausprägungen dessen kam, was Merkantilismus genannt wird." ${ }^{58)}$ So wird die französische Ausprägung des Merkantilismus auch mit dem Namen Colbertismus ${ }^{59)}$ belegt und für den deutschsprachigen Raum oft die Bezeichnung Kameralismus gewählt. Obwohl Thomas Riha den Kameralismus als eine "individual version of mercantilism"60) bezeichnet, betont er sehr nachdrücklich, daß trotz vieler Gemeinsamkeiten die Inhalte des Kameralismus und Merkantilismus nicht identisch seien. ${ }^{61}$ Mit dem Begriff Merkantilismus wird im folgenden das Muster der Wirtschaftspolitik im Zeitalter des Absolutismus und die ihm zugrunde liegenden Wirtschaftslehren gekennzeichnet, die, trotz der Unterschiede in den einzelnen europäischen Staaten, wich tige Gemeinsamkeiten aufweisen. ${ }^{62)}$

55) Die Kontroverse, ob die Bezeichnung Merkantilsmus für das ökonomische Gedankengebäude der Wissenschaft und Praxis des 17. und der ersten Hälfte des 18. Jahrhunderts gerechtfertigt ist, soll hier nicht aufgerollt werden. Hinzu kommt, daß gerade in der merkantilistischen Epoche eine Unterscheidung zwischen der wissenschaftlichen Auseinandersetzung und dem allfälligen politischen Tun, vor allem wegen des empirischen Bezuges und der auf die Anwendung hin gezielten Vorschläge der Merkantilisten, nur schwer zu erkennen ist. Vgl. hierzu Littmann, K.. Zunehmende Staatstätigkeit und wirtschaftliche Entwicklung. Versuche über die Wirkungen staatswirtschaftlicher Prozesse in der spätkapitalistischen Periode, Köln, Opladen 1957, S. 15 ff.

56) Vgl. Hesse, G.: Staatsaufgaben. Zur Theorie der Legitimation und Identifikation staatlicher Aufgaben, Baden-Baden 1979, S 39 f. und Klein, E.: Die englischen Wirtschaftstheoretiker ..., a.a.O., S. 3.

57) Vgl. Heckscher, E.F.: Der Merkantilismus. Autorisierte Übersetzung aus dem Schwedischen von Gerhard Mackenroth, Bd. I, Jena 1932, S. 1.

58) Klein, E.: Die englischen Wirtschaftstheoretiker ..., a.a.O., S. 1. Vgl. auch Blaich, F.: Art.: Merkantilismus, in: Handwörterbuch der Wirtschaftswissenschaft (HdWW), hrsg. v. W. Albers et al., Bd. 5, Stuttgart et al. 1980, S. 240-251, S. 242 ff.

59) Jean Baptiste Colbert (1619-1683) war Wirtschafts- und Finanzberater Ludwigs XIV.

60) Riha, T.: German Political Economy ..., a.a.O., S. 10.

61) Vgl. ebenda, S. $10 \mathrm{ff}$.

62) Vgl. Blaug, M.: Systematische Theoriengeschichte der Ökonomie, Bd. I, München 1971, S.41 und Klein, E.: Die englischen Wirtschaftstheoretiker ..., a.a.O., S. $1 \mathrm{ff}$. 
Das Streben nach politischer und militärischer Macht und die Entwicklung der Wirtschaftskraft des eigenen Landes gilt als Leitbild merkantilistischer Wirtschaftspolitik, wobei davon ausgegangen wurde, daß ein Land nur auf Kosten eines anderen in Besitz der begrenzten Reichtümer gelangen kann. Deshalb lautet auch eine Grundempfehlung des Merkantilismus, eine "beggar-my-neighbour-Politik" zu betreiben ${ }^{63)}$. Dies äußerte sich vor allem in den Ratschlägen zur Gestaltung der Außenwirtschaftspolitik, wonach die Einfuhr von Rohstoffen und vor allem die Ausfuhr von Fertigwaren nach Kräften gefördert werden sollte. Instrumente einer solchen Politik waren in erster Linie die Zahlung von Subventionen, die Verleihung von Handels- und Produktmonopolen an private und staatliche Unternehmen sowie im Extremfall die Entfesselung von regelrechten Handelskriegen. ${ }^{64)}$

Im Mittelpunkt der wirtschaftspolitischen Zielsetzung stand also die Entwicklung der äußeren und inneren Macht sowie eine vermeintlich auf die Zukunft gerichtete Wirtschaftsförderungspolitik ${ }^{65)}$ Finanzpolitische Maßnahmen sollten die Kassen des Staates bzw. Fürsten füllen und verdienten dann besondere Anerkennung, wenn sie zur Anlage eines Staats- oder Kriegsschatzes führten. Hier liegt auch ein Motiv der oft einseitigen Ausrichtung der Finanzwissenschaft auf dieStaatsfinanzierungsfunktion. ${ }^{66}$

63) Vgl. Blaug, M.: Systematische Theoriengeschichte ..., a.a.O., S. 48 und Hesse, G.: Staatsaufgaben ..., a.a.O., S. $37 \mathrm{ff}$.

64) Vgl. Blaich, F.: Merkantilismus, a.a.O., S. $241 \mathrm{f}$.

65) Vgl. Kolms, H.: Art.: Finanzwirtschaft, öffentliche IV: Geschichte, in: Handwörterbuch der Wirtschaftswissenschaft (HdWW), hrsg. v. W. Albers et al., Bd. 9, Stuttgart et al. 1982, S.764-782, S. 765.

66) Vgl. Mann, F.K.: Abriß einer Geschichte ..., a.a.O., S. 78 f. Die Bildung von Überschüssen im Bundeshaushalt Anfang der 50er Jahre, die man in Anlehnung an den gleichnamigen Turm der alten Spandauer Festungsanlage, in dem bis 1914 ein Teil der französischen Kriegsentschädigung aufbewahrt wurde, Juliusturm nannte, als "typischen Rückfall in die kameralistische Tradition" (Mann F.K.: Abriß einer Geschichte ..., a.a.O., S. 80) zu bezeichnen, geht sicher zu weit. Sie entstanden vornehmlich aufgrund nicht benötigter Bewilligungen für Verteidigungszwecke als Folge der Verzögerungen bei der Wiederbewaffnung der Bundesrepublik Deutschland, die ursprünglich im Rahmen einer Europäischen Verteidigungsgmeinschaft vor sich gehen sollte. Genausowenig wäre es gerechtfertigt, die Bildung von Konjunkturausgleichsrücklagen mit den merkantilistischen Auffassungen in Verbindung zu bringen, denn die Beweggründe hierfür sind gänzlich anders. Vgl. hierzu Dreißig, W.: Zur Entwicklung der öffentlichen Finanzwirtschaft seit dem Jahre 1950, in: Währung und Wirtschaft in Deutschland 1876-1975, hrsg. v. der Deutschen Bundesbank, Frankfurt/Main 1976, S. 691-744, S. 700, 723 und 725. 
Kennzeichnend für die merkantilistische Wirtschaftslehre ist dabei die Auffassung, "den öffentlichen Ausgaben, insonderheit denen zur Förderung gewisser Wirtschaftszweige, komme eine so hohe Produktivität zu, daß hohe Ausgaben aus volkswirtschaftlichen Gründen prinzipiell erwünscht seien." ${ }^{\text {67) }}$ Der Staat erscheint als Motor der gesamtwirtschaftlichen Entwicklung und da kaum in Zweifel gezogen wurde, daß der Staat "omniscient" und der ihn repräsentierende Fürst "omnipotent" sei, neigte der Herrscher dazu, seine großzügige Aufwandwirtschaft als volkswirtschaftlich und sozial günstig hinzustellen. So bezeichnete es Ludwig XIV. als Verteilen von Almosen, wenn ein König viel verausgabt. ${ }^{68)}$

Das Ausgabengebaren der absolutistischen Herrscher führte dazu, daß vor allem in den kleineren deutschen Fürstentümern "durch die Hofhaltung ein Viertel des Gesamtbudgets oder mehr beansprucht" wurde. ${ }^{69)}$ Neben diesen repräsentativen und den militärischen Ausgaben erhielt die Staatswirtschaft aber auch "eine neue Orientierung, indem sie zwar weiterhin dem Wohl des Fürsten zu dienen, aber eben darum auch gesamtwirtschaftliche Ziele zu verfolgen und das Wohl der Gesamtwirtschaft zu fördern hatte ... Der Staat ging jeweils nicht nur mit öffent lichen Arbeiten voran, durch welche einzelne Landstriche erschlossen und die In frastruktur verbessert, d.h. Kanäle, Straßen und Brücken gebaut, Städte und Häfen angelegt, Sümpfe entwässert, Wälder gerodet und Bauern angesiedelt worden sind, sondern auch mit Manufakturen, der Gründung von Banken, Sparkassen und Leihinstituten usf., da er die unternehmerische Initiative oftmals erst anregen und die entscheidenden Schrittmacherdienste selbst leisten mußte."70) Dabei verbesserte er die materiellen Infrastruktur, z.B. durch den Ausbau von Landstraßen und Kanälen ${ }^{71}$, die ihre Höhepunkte erreichte, als in Frankreich 1681 der "Canal du Midi" eröffnet wurde, der den Seeweg um Spanien überflüssig machen sollte, und als unter Friedrich II. ein leistungsfähiges System von Kanälen fertiggestellt wurde, das Elbe, Oder und Weichsel miteinander verband. Daneben galt die Aufmerksamkeit vor allem dem Produktionsfaktor Arbeit. Mit bevölkerungspolitischen Maßnahmen, wie der Förderung der Einwanderung bei gleichzeitiger Verhinderung der Auswanderung sowie der Herabsetzung des Heirats-

67) Neumark, F.: Grundsätze und Arten ..., a.a.O., S. 610.

68) "Un roi fait l'aumône en dépensant beaucoup". Zitiert nach Neumark, F.: Grundsätze und Arten ..., a.a.O., S. 611.

69) Häuser, K.: Abriß der geschichtlichen ..., a.a.O., S. 42.

70) Ebenda, S. 41.

71) Vgl. Blaich, F.: Merkantilismus, a.a.O., S. 245. 
alters und der Förderung von Eheschließungen, sollte durch ein ständig hohes Angebot an Arbeitskräften ein niedrigeres Lohnniveau erhalten bleiben. Die Einwanderung wurde vor allem durch die Bezahlung höherer Löhne für ausländische Facharbeiter und die Gewährung von Schutz für religiöse und politisch Verfolg$\mathrm{te}^{72)}$ gezielt gefördert. Darüber hinaus verfolgte der Aufbau von Bildungseinrichtungen das Ziel, die "Arbeitskraft qualitativ zu verbessern", um "Facharbeiter für exportintensive Gewerbezweige" zu gewinnen. ${ }^{73)}$

\subsubsection{Der kameralistische Ansatz}

Der Kameralismus ist nach Tautscher "aus der Staats- und Verwaltungslehre des Absolutismus in den deutschen Landesfürstentümern" entstanden und blieb "in dieser Sonderart ... auf Deutschland beschränkt."74) Von den einen als deutsche Spielart des Merkantilismus bezeichnet, die "wegen der speziell finanzwirtschaftlichen Ausrichtung Kameralismus ... genannt"75) wird ${ }^{76)}$, preisen andere die Kameralwissenschaft als "Wissenschaft von der sozialen Wirtschaft und der zugehörigen Staatswirtschaft" und als "echte Wirtschaftstheorie ..., die alle Zusammenhänge vom Blickpunkt des Staates sah."77) Der Inhalt ihres Lehrangebotes umfaßte ein Konglomerat aus "Staats- und Regierungskunst, Rechtswissenschaft, allgemeiner Verwaltungslehre, Naturwissenschaften bis hin zu speziellen praktischen Fächern von Ackerbau über Technologie bis zur Handlungswissenschaft für den Kaufmann." ${ }^{\text {78) }}$ Es wird recht schnell deutlich, daß, wie es auch Riha for-

72) So gewährte Friedrich Wilhelm I., Kurfürst von Brandenburg (1640-1688), ungefähr 20.000 Hugenotten, die nach der Aufhebung des Edikts von Nantes im Jahre 1685 unter Strafandrohung auswanderten, Schutz und sicherte Brandenburg damit sehr viele gutausgebildete Handwerker, Kaufleute und Facharbeiter. Friedrich Wilhelm I., König von PreuBen (1713-1740) setzte diese Politik in dem von der Pest entvölkerten Ostpreußen fort, deren Höhepunkt die 1732 erfolgte Ansiedlung von 16.000, wegen ihres Glaubens aus dem Erzbistum Salzburg vertriebenen, Protestanten bildete.

73) Blaich, F.: Merkantilismus, a.a.O., S. 242

74) Tautscher, A.: Geschichte der deutschen ..., a.a.O., S. 388.

75) Winkel, H.: Art.: Wirtschaftswissenschaft I: Geschichte, in: Handwörterbuch der Wirtschaftswissenschaft (HdWW), hrsg. v. W. Albers et al., B. 9, Stuttgart et al. 1982, S. 413 425, S. 413.

76) Der Name Kameralismus wurde von dem lateinischen Wort "camera", mit dem die fürstliche Schatzkammer bezeichnet wurde, abgeleitet. Vgl. hierzu auch Riha, T.: German Political Economy ..., a.a.O., S. 11.

77) Tautscher, A.: Geschichte der deutschen ..., a.a.O., S. 388. Vgl. auch Backhaus, J. and Wagner, R.E.: The cameralists: A public Choice perspective, in: Public Choice, vol. 53 (1987), S. 3-20, S. 5 f.

78) Winkel, H.: Wirtschaftswissenschaft I: Geschichte, a.a.O., S. 414 f. 
mulierte, "the scope of cameralism (Kameralwissenschaft) was much broader than that of present day political or national economy (Volkswirtschaftslehre)."791 Auch Harald Winkel betont, daß ökonomische Fragestellungen nur einen geringen Teil des Vorlesungsprogramms der kameralistischen Lehrstühle ausmachten und, daß nationalökonomische Gedanken erst sehr spät, mit dem Erlöschen der kameralistischen Ausbildung im deutschsprachigen Raum Bedeutung erlangten ${ }^{80)}$ Herausragender Vertreter der späten Kameralwissenschaft war Johann Heinrich Gottlob von Justi (1717-1771), "der in vielen Schriften die österreichische und die preußische Kameralistenschule zusammenzufassen und der Wissenschaft den vielfach sehr engen konfessionellen Charakter abzustreifen wußte."81)

\subsubsection{Ablösung der merkantilistischen Lehre}

Die Ablösung der merkantilistischen Wirtschaftsauffassung erfolgte in den einzelnen Ländern Europas in unterschiedlichen Phasen. ${ }^{82)}$ In Frankreich, wo die Merkantilisten, aufgrund der ungeheueren höfischen Prachtentfaltung eine hohe Staatsverschuldung ${ }^{83)}$ und eine überhandnehmende Bürokratie hinterlassen hatten, endete ihre Ära mit dem Tod Ludwig XIV im Jahre $1715 .{ }^{84)}$ Sie wurde abgelöst durch die Bewegung der Physiokraten, als deren Hauptvertreter Francois Quesnay (1694-1774) gilt. Die 'Les economists', wie sie sich selbst nannten, bemühten sich, "die natürlichen Gesetzmäßigkeiten aufzudecken, welchen der Wirtschaftsprozeß unabhängig von Zeit und Raum unterworfen ist." ${ }^{85)}$ Verwurzelt im Rationalismus des 18. Jahrhunderts und vor dem Hintergrund der Philo-

79) Riha, T.: German Political Economy ..., a.a.O., S. 11.

80) Vgl. Winkel, H.: Wirtschaftswissenschaft I: Geschichte, a.a.O., S. $413 \mathrm{ff}$.

81) Schmölders, G.: Art.: Wirtschaftswissenschaft III: Theorienbildung in der Volkswirtschaftslehre, Geschichte, in: Handwörterbuch der Wirtschaftswissenschaft (HdWW), hrsg. v. W. Albers et al., Bd. 9, Stuttgart et al. 1982, S. 425-446, S. 427. Vgl. hierzu auch Riha, T.: German Political Economy ..., a.a.O., S. 20 ff.

82) Vgl. Blaich, F.: Merkantilismus, a.a.O., S. 240 und $242 \mathrm{ff}$.

83) Jean Baptiste Colbert, Finanzminister Ludwig XIV., war u.a. deswegen in Ungnade gefallen, weil er eine Einschränkung der Ausgaben forderte.

84) Ihr Hauptvertreter, der oben erwähnte J. B. Colbert, war schon 1683 gestorben.

85) Blaich, F.: Merkantilismus, Kameralismus, Physiokratie, in: Geschichte der Nationalökonomie, hrsg. v. O. Issing, München 1984, S. 35-47, S. 40. 
sophie der Aufklärung ${ }^{86)}$ kritisierten sie die merkantilistischen Auffassungen, insbesondere das System weitreichender Staatskontrolle und staatlicher Regulierung. ${ }^{87)}$ Stattdessen forderten sie einen Abbau der Zollschranken, eine stärkere Betonung der landwirtschaftlichen Produktion sowie die wirtschaftspolitische Zurückhaltung des Staates. Quesnay und seine Anhänger gingen "von der allgemeinen Vereinbarkeit ... der individuellen Interessen innerhalb einer auf Wettbewerb eingestellten Gesellschaft aus" ${ }^{\text {"8) }}$ und nahmen somit Grundsätze der klassischen Volkswirtschaftslehre vorweg. Als besonders fruchtbar erwies sich das "tableau economique"89), in dem Francois Quesnay modellhaft die Beziehungen zwischen drei Sektoren ${ }^{901}$ der Volkswirtschaft darstellte, und somit das Fundament für kreislauftheoretische Überlegungen legte.

In England verdrängte die einsetzende Industrialisierung und die heftige Krtitik durch Adam Smith ${ }^{911}$ und seine Nachfolger die merkantilistischen Auffassungen. Gleichzeitig wurde damit in einem offenen Bruch mit der Vergangenheit, der nach Schumpeter, wenigstens für Teilbereiche, "soweit es sich um die ökonomische Analyse handelt ... durchaus vermeidbar gewesen wäre"92), der Grundstein für den Liberalismus gelegt.

86) Quesnay selbst war einer von mehr als 150 Autoren der "Encyclopédie ou dictionnaire raisonné des sciences, des arts et des métiers". Dieses Riesenwerk der französischen Aufklärung, das von Diderot und d'Alembert herausgegeben wurde, erschien zwischen 1750 und 1780 in insgesamt 35 Bänden. Vgl. hierzu Lauener, H.: Französische Aufklärer, in: Klassiker der Philosophie, hrsg. v. O. Höffe, Bd. 1. Von den Vorsokratikern bis David Hume, München 1981, S. 405-433, S.410 ff.

87) Vgl. auch Riha, T.: German Political Economy ..., a.a.O., S. 25.

88) Schumpeter, J.A.: Geschichte der ökonomischen ..., a.a.O., S. 302.

89) Titel des Hauptwerkes von Francois Quesnay (1758) und gleichzeitig Name für die von ihm vorgenommene Kreislaufdarstellung einer Volkswirtschaft.

90) Als Sektoren unterschied Quesnay die Landwirtschaft ("La classe productive")

- die Grundeigentümer ("La classe des propriétaires") und

- die gewerbliche Wirtschaft ("La classe sterile").

91) Vgl. Smith, A.: An Inquiry into ..., a.a.O., S. 428 ff. sowie Schumpeter, J.A.: Geschichte der ökonomischen ..., a.a.O., S. 453, der die Kritik von Adam Smith für unklug und verurteilenswert hält. Vgl. auch Tautscher, A.: Geschichte der deutschen ..., a.a.O., S. $387 \mathrm{f}$.

92) Schumpeter, J.A.: Geschichte der ökonomischen ..., a.a.O., S. 471. Weiter schrieb er: "Wenn Smith und seine Schüler die "merkantilistischen" Lehrsätze verbessert und entwickelt hätten, anstatt sie zu verwerfen, hätte bis 1848 eine richtigere und reichhaltigere Theorie der internationalen wirtschaftlichen Beziehungen entwickelt werden können - und zwar eine, die nicht von den einen kompromittiert und von den anderen verachtet worden wäre" (ebenda, S. 472). 
Im deutschen Sprachraum hingegen, vor allem aber im preußischen Herrschaftsgebiet, blieb die Politik bis zum Ende des 18. Jahrunderts, von den Gedanken des Merkantilismus und Kameralismus bestimmt. Besonders nach $1763^{93}$ ' wurden unter Friedrich II. noch staatliche Manufakturen in großer Zahl gegründet. Obwohl "die Treibhausluft der Subventionen, Privilegien und Monopole, die das Manufakturwesen umgab, das Aufkommen eines Unternehmerstandes"94) verhinderte, wäre "der Sprung Preußens von der Stufe eines rückständigen und unterbevölkerten Agrarstaates in den Rang einer europäischen Großmacht" ohne diese lang andauernde merkantilistische Tradition wohl kaum gelungen. ${ }^{95)}$ Ein Grund, warum die positive Würdigung der wirtschaftlichen Rolle des Staates gerade in Deutschland so lange weiterlebte, ist sicherlich auch im langwierigen Prozeß der Staatsbildung zu sehen, dessen Leitbild das Ideal der nationalen Macht war.

\subsection{Klassischer Liberalismus}

Als "Klassischer Liberalismus"96) wird hier die Epoche der Wirtschaftsgeschichte bezeichnet, die mit dem Werk von Adam Smith (1723-1790) beginnt und bis zu den Arbeiten von John Stuart Mill (1806-1873) reicht. Sie umfaßt auch das Wirken so einflußreicher Wirtschaftswissenschaftler wie Jean Baptiste Say (1767 -1832) und David Ricardo (1772-1832). ${ }^{97)}$

\subsubsection{Die Staatsausgaben bei Adam Smith}

Nach Boeckle gebührt den Schöpfern des liberalen wirtschaftlichen Ordnungssystems "das historische Verdienst, erstmals zur gebundenen Wirtschaft des 'Ancien Regimes' das Gegenbild einer realisierbaren, offenen, marktwirtschaftlichen Organisationsform entwickelt zu haben. ${ }^{\text {"98) }}$ Dabei gewann mit Adam Smith die

93) Das Jahr 1763 markierte das Ende des siebenjährigen Krieges.

94) Blaich, F.: Merkantilismus, a.a.O., S. 247.

95) Ebenda, S. 248.

Vgl. auch Littmann, K.: Zunehmende Staatstätigkeit ..., a.a.O., S. 17 und insbesondere auf derselben Seite die Fußnote 17.

96) Zu den verschiedenen Ausprägungen und politischen Hintergründen des Liberalismus vgl. Boeckle, W.A.: Art.: Liberalismus, in: Handwörterbuch der Wirtschaftswissenschaft (HdWW), hrsg. v. W. Albers et al., Bd. 5, Stuttgart et al. 1980, S. 32-47.

97) Vgl. auch Recktenwald, H.C.: Die Klassik der ökonomischen Wissenschaft, in: Geschichte der Nationalökonomie, hrsg. v. O. Issing, München 1984, S. 49-71, S. 49.

98) Boeckle, W.A.: Liberalismus, a.a.O., S. 41. 
Auffassung, daß für die Staatswirtschaft grundsätzlich dieselben Überlegungen und Regeln zu gelten hätten wie für die Einzelwirtschaft, an Bedeutung. Sein Ansatzpunkt war in einem so hohen Grade "individualistisch, daß die Wesensunterschiede zwischen dem privaten und dem öffentlichen Sektor der Wirtschaft keiner tieferen Erklärung zu bedürfen schienen. Der Staatshaushalt wurde als ein Ebenbild des Privathaushalts, die Staatsschuld als ein Ebenbild der Privatschuld auf-

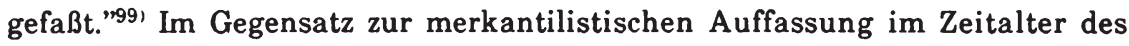
Absolutismus, die von der Allwissenheit und Allmacht des Herrschers ausging, für die "alles Eigentum der Bürger nur als Leihgabe des Fürsten galt, wird der Staat nunmehr in die Rolle eines Stipendiaten der Marktwirtschaft versetzt." ${ }^{100}$

Die Bedeutung von Adam Smith für die gesamte Wirtschaftswissenschaft wird gerade auch dadurch unterstrichen, daß viele Wirtschaftshistoriker den Beginn der Geschichte der Nationalökonomie mit seinem Werk gleichsetzen, andere wiederum diese Geschichte der Nationalökonomie in eine vorsmithische und nachsmithische Schule einteilen. ${ }^{101)}$ Für Erwin von Beckerath ist die Lehre von Adam Smith sogar von so zentraler Bedeutung, daß er als ein passendes Gliederungskriterium für die Einordnung der deutschen Finanzwissenschaftler der ersten Jahrzehnte des 19. Jahrhunderts deren Stellung zum Werk des schottischen Ökonomen vorschlägt. ${ }^{102}$ In Deutschland selbst fand Adam Smiths Werk 'An Inquiry into the Nature and Causes of the Wealth of Nations', das 1776 im englischen Original erschienen war und schon ein Jahr später in einer deutschen Übersetzung vorlag, aufgrund der lang anhaltenden kameralistischen Lehrtradition nur zögernd Widerhail. ${ }^{103)}$

99) Manr, F.K: Geschichte der angelsāchsischen Finanzwissenschaft, in: Handbuch der Finanzwissenschaft, 2. Aufl., hrsg. v. W. Gerloff und F. Neumark, Bd. I, Tübingen 1952 , S.469-488, S. 470.

100) Neumark, F.: Grundsätze und Arten ..., a.a.O., S. 611.

101) Vgl. Schmölders, G.: Geschichte der Volkswirtschaftslehre, a.a.O., S. 30 f.

102) Vgl. Beckerath, E. v.: Die neuere Geschichte der deutschen Finanzwissenschaft, in: Handbuch der Finanzwissenschaft, 2. Aufl., hrsg. v. W. Gerloff und F. Neumark, Bd. I, Tübingen 1952, S. 416-468, S. 417.

103) Vgl. Bieri, S.: Zur Stellung ..., a.a.O., S. 14 ff. und Riha, T.: German Political Economy ..., a.a.O., S. 24 sowie Timm, A.: Von der Kameralistik zur Nationalökonomie, in: Festschrift Herrmann Aubin zum 80. Geburtstag, hrsg. v. O. Brunner et al., Bd. I, Wiesbaden 1965, S.358-374, S. $366 \mathrm{ff}$. 
In der Literatur findet sich oft die Charakterisierung, daß der Liberalismus im Gegensatz zur merkantilistischen Wirtschaftsauffassung die Staatstätigkeit in möglichst enge Grenzen zu bannen sucht. ${ }^{104)}$ Als Begründung wird dabei zumeist auf die Behauptung von Jean Baptiste Say verwiesen, daß wenig auszugeben das beste staatliche Finanzprogramm und die beste Steuer immer die geringste sei ${ }^{105)}$; eine These, der sich auch David Ricardo anschloß. ${ }^{106}$ ' Desweiteren wird auch die Forderung von Jeremy Bentham nach größtmöglicher Staatsenthaltsamkeit ${ }^{107)}$ zur Bestätigung dieser Auffassung herangezogen. Obgleich man die auf Lasalle zurückgehende Bezeichnung vom "Nachtwächterstaat" ${ }^{108)}$ für die Bedeutung des Staates im klassischen Liberalismus als eine karikierende Überzeichnung werten kann, ist die Skepsis der liberalen Ökonomen dem Staat oder besser den staatlichen Entscheidungsträgern gegenüber nicht zu übersehen. ${ }^{109 \text { ) }}$ So beurteilte Adam Smith die Politiker, die sich anmaßen, in wirtschaftlichen Fragen für andere Personen entscheiden zu können, sehr abwertend. ${ }^{110)}$ Sein, wie

104) Vgl. hierzu exemplarisch die Ausführungen in: Littmann, K.: Problemstellung und Methoden der heutigen Finanzwissenschaft, in: Handbuch der Finanzwissenschaft, 3.Aufl., hrsg. v. F. Neumark, Bd. I, Tübingen 1977, S. 99-120, S. 111 sowie Mann, F.K.: Geschichte der angelsächsischen ..., a.a.O., S. 471 und Neumark, F.: Grundsätze und Arten ..., a.a.O., S.611.

105) Vgl. Say, J.B.: A Treatise on Political Economy, translated from the fourth Edition on French by C.R. Prinsep, reproduction of 1880 printing, New York 1964, S. 449.

106) Vgl. Ricardo, D.: Grundsätze der Volkswirtschaftlehre und Besteuerung, aus dem englischen Original (3. Aufl. 1821) ins Deutsche übertragen von O. Thiele, Jena 1905, S.235.

107) Vgl. Bentham, J.: Manual of Political Economy (1793-1795), in: Jeremy Bentham's Economic Writings, ed. by W. Stark, vol. I, London 1952, S. 221-273, S. $229 \mathrm{ff}$

108) Lasalle selbst sprach von der "Nachtwächteridee" des Staates. Vgl. Lasalle, F.. Das Arbeiterprogramm. Uber den besonderen Zusammenhang der gegenwärtigen Geschichtsperiode mit der Idee des Arbeiterstandes, in: Ferdinand Lasalle. Gesammelte Reden und Schriften, hrsg. v. E. Bernstein, 2. Bd., Berlin 1919, S. 131-202, S. 195 f.

109) Vgl. hierzu Stigler, G.J.: The Economist and the State, in: The American Economic Review, vol. LV (1965), S. 1-18, S. $1 \mathrm{ff}$.

110) Smith schrieb "The statesman, who should attempt to direct private people in what manner they ought to employ their capitals, would not only load himself with a most unnecessary attention, but assume an authority which could safely be trusted, not only to no single person, but to no council or senate whatever, and which would now here be so dangerous in the hands of a man who had folly and presumption enough to fancy himself fit to exercise it" (Smith, A.: An Inquiry into ..., a.a.O., S. 456). An anderer Stelle bezeichnet er den Politiker auch als ein "insidious and crafty animal". Smith, A.: An Inquiry into ..., S.468. Vgl. auch Wilson, T.: Invisible Hands: Public and Private, in: Staat und Politische Ökonomie heute. Horst Claus Recktenwald zum 65. Geburtstag, hrsg. v. H. Hanusch, K.W. Roskamp und J. Wiseman, Stuttgart, New York 1985, S. 13-21, S. 14 f.

Die Unternehmer bekommen bei Adam Smith aber ebenfalls keine besonders gute Bewertung. Vgl. hierzu Wille, E. und Gläser, M.: Staatsaufgaben bei Adam Smith - eine Würdigung unter Allokationsaspekten, in: ORDO. Jahrbuch für die Ordnung von Wirtschaft und Gesellschaft, Bd. 28 (1977), S. 34-77, S. 46 und Stigler G.J: The Economist and ..., a.a.O., S.3. 
v. Arnim schreibt, "realistisches Menschenbild"111) setzt stattdessen auf die Erkenntnis, daß "die stärkste Motivation für den wirtschaftenden Menschen ... das Bestreben (ist), seinen eigenen Vorteil und Nutzen zu mehren." ${ }^{112)}$ Eine solche freie, an den individuellen Interessen ausgerichtete Wirtschaft wurde von Adam Smith und seinen Anhängern nicht "um der ungegängelten Selbstbestimmung der Menschen willen gefordert"113), sondern weil diese Ordnung letztlich dem Wohle der Gesamtheit dient. ${ }^{114)}$

Trotzdem schenkte Adam Smith, wie die meisten Klassiker, entgegen weitverbreiteter Ansichten, den Staatsausgaben erhebliche Beachtung. ${ }^{115)}$ Im 5. Buch seines ökonomisches Hauptwerkes "An Inquiry into the Nature and Causes of the Wealth of Nations" beschäftigte er sich im ersten Kapitel ausschließlich mit den Ausgaben des Staates. ${ }^{116)}$ Obwohl das von ihm entwickelte (markt-) theoretische Instrumentarium nicht ausreicht, die finanzwirtschaftlichen Vorgänge in ihrer ganzen Bedeutung zu erfassen ${ }^{117)}$, vermied es Smith, "die Maßnahmen der öffent-

111) Vgl. Arnim, H.H.v.: Staatslehre der Bundesrepublik Deutschland, München 1984, S. 39.

112) Ebenda, S. 39.

113) Ebenda, S. 41.

114) Vgl. Ebenda, S. 40.

Adam Smith schrieb hierzu: "... man has almost constant occasion tor the help of his brethren, and it is in vain for him to expect it from their benevolence only. He will be more likely to prevail if he can interest their self-love in his favour, and show them that it is for their own advantage to do for him what he requires of them. Whoever offers to another a bargain of any kind, proposes to do this. Give me that which I want, and you shall have this which you want, is the meaning of every such offer; and it is in this manner that we obtain from one another the far greater part of those good offices which we stand in need of. It is not from the benevolence of the butcher, the brewer, or the baker that we expect our dinner, but from their regard to their own interest. We address ourselves, not to their humanity but to their self-love, and never talk to them of our own necessities but of their advantage". Smith, A.: An Inquiry into ..., a.a.O., S. 26 f.

Vgl. zu diesem Aspekt auch Schlecht, O.: Ethische Betrachtungen zur Sozialen Marktwirtschaft, Nr. 97 der Reihe: Vorträge und Aufsätze des Walter Eucken Instituts, Tübingen 1983, S. 10.

115) Vgl. Wille, E.: Die öffentlichen Ausgaben ..., a.a.O., S. 297 und Koch, W.: Finanzwissenschaft I: Geschichte, a.a.O., S. 213. Siehe auch Wille, E. und Gläser, M.: Staatsaufgaben bei ..., a.a.O., S. 34 ff. sowie Recktenwald, H.C.: Eine Adam-Smith-Renaissance anno 1976? Eine Neubeurteilung seiner Originalität und Gelehrsamkeit, in: Ethik, Wirtschaft und Staat. Adam Smiths Politische Ökonomie heute, hrsg. v. H.C. Recktenwald, Darmstadt 1985, S. 345-390, insbesondere S. $373 \mathrm{ff}$.

116) Die Überschrift des 5. Buches lautet: "Of the Revenue of the Sovereign or Commonwealth" und die des 1. Kapitels: "Of the Expences of the Sovereign or Commonwealth". Vgl. Smith, A.: An Inquiry into ..., a.a.O., S. 6.

117) Vgl. Littmann, K.: Zunehmende Staatstätigkeit ..., a.a.O., S. 19 und Stigler, G.J.: The Economist and ..., a.a.O., S. 3. 
lichen Wirtschaft von vornherein mit Störungen der Gesamtwirtschaft"118) zu identifizieren. Er, der dem Politiker sehr skeptisch gegenübersteht ${ }^{119)}$, läßt von dem Grundsatz, daß der Staat sich nicht in den Markt- und Preismechanismus einmischen sollte, einige wesentliche Ausnahmen zu. Danach fallen dem politischen Entscheidungsträger "three duties of great importance" zu: "First, the duty of protecting the society from the violence and invasion of other independent societies; secondly, the duty of protecting, as far as possible, every member of the society from the injustice or oppression of every other member of it, or the duty of establishing an exact administration of justice; and, thirdly, the duty of erecting and maintaining certain publick works and certain publick institutions, which it can never be for the interest of any individual, or small number of individuals, to erect and maintain; because the profit could never repay the expence to any individual or small number of individuals, though it may frequently do much more than repay it to a great society." ${ }^{120}$

Die Ausgaben für die Landesverteidigung und das Justizwesen bezeichnete Smith als unproduktiv, ohne dabei diese Ausgaben zu diskriminieren. ${ }^{121)}$ Den Ursprung und die Entwicklung beider Ausgabenarten erklärt er auf der Grundlage seiner historischen Stufenlehre ${ }^{122}$, wobei die Ausgaben für die Landesverteidigung, so Adam Smith, mit fortschreitender gesellschaftlicher Entwicklung deutliche Wachstumtendenzen aufweisen, wie auch die Notwendigkeit einer öffentlichen Justizverwaltung erst mit der Existenz privaten Eigentums entstanden sei. ${ }^{123)}$ Durch die von Smith aufgeführte dritte Kategorie staatlicher Aufgaben

118) Littmann, K.: Zunehmende Staatstätigkeit ..., a.a.O., S. 19.

119) Vgl. auch Kolms, H.: Finanzwirtschaft, öffentliche ..., a.a.O., S. 767.

120) Smith, A.: An Inquiry into ..., a.a.O., S. 687 f. Vgl. auch Skinner, A.: Adam Smith: Some Functions and Limitations of Government, in: Staat und Politische Ökonomie heute. Horst Claus Recktenwald zum 65. Geburtstag, hrsg. v. H. Hanusch, K.W. Roskamp und J.Wiseman, Stuttgart, New York 1985, S. 3-11, S. 5 ff.

121) Vgl. Smith, A.: An Inquiry into ..., a.a.O., S. $330 \mathrm{f}$.

Zum Smith'schen Produktivitätsbegriff vgl auch Stigler, G.J: The Economist as Preacher, Oxford 1982, S. 150 ff. sowie Wille, E. und Gläser, M.: Die Staatsaufgaben bei ..., a.a.O., S. $47 \mathrm{ff}$.

122) Vgl. Smith, A.: An Inquiry into ..., a.a.O., S. $689 \mathrm{ff}$. und $709 \mathrm{ff}$. sowie Wille, E. und Gläser, M.: Die Staatsaufgaben bei ..., a.a.O., S. $51 \mathrm{ff}$.

Die erste Stufe bildet die Jägergesellschaft, der die Hirten und Nomadenvölker folgen. Die dritte Stufe ist die einer Agrargesellschaft, der dann die fortgeschrittene arbeitsteilige Gesellschaft mit ausgeprägten Handwerks-, Gewerbe- und Handelszweigen nachfolgt.

123)

Vgl. Wille, E. und Gläser, M.: Die Staatsaufgaben bei ..., a.a.O., S. 51 und S. 54. 
bleibt der Umfang der von ihm geforderten oder gebilligten Staatstätigkeit weitgehend unbestimmt. Diese Güter und Dienstleistungen soll der Staat zur Verfügung stellen, da ihre Bereitstellung durch private Wirtschaftssubjekte nicht rentabel ist und eine Versorgung mit solchen Gütern in diesem Falle nicht erwartet werden kann, obwohl sie für die Gesellschaft insgesamt von großem Nutzen sind. Allerdings gibt Smith keine Erklärung, warum die marktwirtschaftliche Bereitstellung dieser gesellschaftlich nützlichen Güter keinen kostendeckenden Ertrag abwirft. ${ }^{124)}$ Diese von Individuen und kleineren Gruppen nicht rentabel zu bestreitenden Aufgaben erfordern seiner Meinung nach auch, entsprechend der Entwicklung der Gesellschaft, ein unterschiedliches Ausmaß staatlicher Verausgabung. ${ }^{125)}$ Die einzelnen Aufgaben, die Smith in dieser dritten Kategorie aufzählt, kann man in zwei Gruppen zusammenfassen, die man, heutigem Sprachgebrauch folgend, wohl Maßnahmen zur Förderung der materiellen und immateriellen Infrastruktur nennen würde. ${ }^{126)}$ Daneben führt er auch noch die Münzanstalt und die Post als staatliche Aufgaben auf, obwohl er selbst erkannte, daß sie mit seinem Kriterium der mangelnden Rentablität nicht vereinbar sind. ${ }^{127)}$ Zur Finanzierung der einzelnen Aufgaben zieht Adam Smith drei Arten öffentlicher Abgabenerhebung in Betracht: allgemeine Steuern, gruppenbezogene Beiträge und individuelle Gebühren. ${ }^{128)}$ "Die Frage, welche Finanzierungsform im Einzelfall vorzuziehen ist, möchte Smith nach der jeweiligen Inzidenz des Projektnutzens bzw. dessen Internalisierungsgrad entschieden wissen" ${ }^{129)}$, denn "it is unjust that the whole society should contribute towards an expence of which the benefit is confined to a part of the society." ${ }^{301}$

124) Vgl. Wille, E. und Gläser, M.: Die Staatsaufgaben bei ..., a.a.O., S. $58 \mathrm{f}$

Als mögliche Ursachen dieser fehlenden Rentabilität kommen nach Wille und Gläser zum einen externe Effekte in der Produktion und zum anderen eine im Vergleich zum gesellschaftlichen Nutzen zu geringe individuelle Wertschätzung in Frage. In der zweiten Begründung weist diese Aufgabengruppe von Smith Ähnlichkeiten mit dem merit-wants Konzept auf.

125) Vgl. Smith, A.: An Inquiry into ..., a.a. O., S. 723.

Smith schrieb: "The performance of this duty requires too very different degrees of expence in the different periods of society."

126) Vgl. ebenda, S. $59 \mathrm{ff}$.

Unter die Maßnahmen zur Förderung der materiellen Infrastruktur fallen der Bau von Straßen, Brücken, Kanälen und Häfen sowie die Errichtung von Botschaften, Forts und Garnisonen zum Schutze des Außenhandels. Der Förderung der immateriellen Infrastruktur dienen Ausgaben im Bildungs- und Gesundheitswesen. Die Bildungsausgaben nützen, so Smith, dabei sowohl dem Individuum, dem sie Chancen zur Entfaltung seiner geistigen Fähigkeit bieten, als auch dem Staat, da ein höherer Bildungsstand die Einsicht in die Regierungsmaßnahmen fördere und den Konsensfindungsprozeß erleichtere. Im Gesundheitswesen soll die Regierung dann tätig werden, wenn ansteckende Krankheiten negative externe Effekte erwarten lassen.

Vgl. Smith, A.: An Inquiry into ..., a.a.0., S. 787 f.

127) Vgl. ebenda, S. 724.

128) Vgl. Wille, E. und Gläser, M.: Die Staatsaufgaben bei ..., a.a.O., S. 57.

129) Ebenda, S. 57.

130) Smith, A.: An Inquiry into ..., a.a.O., S. 815. 
Quasi als Resümee kann man festhalten, daß die Grundhaltung, die das Smith'sche Wirtschaftssystem prägt, ohne jeden Zweifel liberal ist, daß er staatliches Handeln aber keineswegs per se negativ beurteilt. ${ }^{131)}$ Im Gegenteil, Smith hielt es für unerläßlich, daß "die staatlichen Entscheidungseinheiten ihren Bürgern innere und äußere Sicherheit garantieren, die wachstumsnotwendigen Infrastrukturleistungen erbringen und im privaten Wirtschaftssektor alle Maßnahmen unterlassen, die die Monopolbildung begünstigen."132)

Solche Erörterungen über die Staatsaufgaben und die zu ihrer Erreichung erforderlichen staatlichen Ausgaben ${ }^{133)}$, wie sie bei Smith in einem doch erheblichen Umfang zu finden sind, haben nach Ansicht von Gerhard Albrecht "herzlich wenig mit Finanzwirtschaft und Finanzwissenschaft zu tun." ${ }^{\text {34) }}$ Diese von Albrecht 1938 veröffentlichte Auffassung, die damals sicher im Zeittrend lag, wird heute nicht mehr geteilt. Insofern besteht das, was man gemeinhin Wissenschaftsfortschritt nennt, zumindest teilweise auch aus Rückbesinnung. ${ }^{135)}$

\subsubsection{Der Einfluß des Liberalismus in Deutschland}

Im deutschsprachigen Raum wurde das Werk von Adam Smith nach anfänglichem Zögern schließlich mit Begeisterung aufgenommen. ${ }^{136)}$ Die Gründe für die ursprüngliche Reserviertheit den klassisch-liberalen Gedanken gegenüber sind zum einen in der festverankerten kameralistischen Lehrtradition zu finden, sie wurzelten zum anderen aber auch in den spezifischen Charakteristika der deutschen Wirtschaft mit ihrer feudalen Agrarstruktur und der im Vergleich zu England unterentwickelten Industrie. ${ }^{137)}$ Erst zur Mitte des 19. Jahrhunderts wurden die Überlegungen der Klassiker mit einigen Modifikationen zur führenden Lehrmeinung in Deutschland, deren Inhalt von Karl Heinrich Rau (1792-1870) in sei-

131) Vgl. Wille, E. und Gläser, M.: Die Staatsaufgaben bei ..., a.a.O., S. 70.

132) Ebenda, S. 75.

133) Adam Smith schrieb zum Zusammenhang von Aufgaben und Ausgaben: "The proper performance of those several duties of the sovereign necessarily supposes a certain expence; and this expence again necessarily requires a certain revenue to support it." Smith A.: An Inquiry into ..., a.a.O., S. 688.

134) Albrecht, G.: Das Problem ..., a.a.O., S. 175.

135) Vgl. hierzu auch Helmstädter, E.: Die Geschichte der Nationalökonomie als Geschichte ihres Fortschritts, in: Geschichte der Nationalökonomie, hrsg. v. O. Issing, München 1984, S. 1-13.

136) Vgl. Bieri, S.: Zur Stellung ..., a.a.O., S. 14 ff. und Schumpeter, J.A.: Geschichte der ökonomischen ..., a.a.O., S. 615.

137) Vgl. Riha, T.: German Political Economy ..., a.a.O., S. 36. 
nem "Lehrbuch der politischen Ökonomie" zusammengetragen wurde. Dieses Buch, das in mehreren Auflagen verlegt wurde, erstmals im Jahre 1826, gilt heute als eine "enzyclopaedia of all aspects of economic science that up to this time had appeared in Germany."138)

Die Staatswirtschaft, so betont Rau, habe sich auf die Befriedigung der wahren Bedürfnisse des Staates zu beschränken. Dies bedeutete für ihn, daß der Staat nur dann in die Wirtschaft eingreifen solle, wenn die privaten Aktivitäten als nicht ausreichend angesehen werden. ${ }^{139)}$ Die Regierungswirtschaft muß sich daher "auf die gesellschaftlichen, in den Staatszwecken begründeten Bedürfnisse beschränken." ${ }^{40)} \mathrm{Da}$ diese Bedürfnisse aber seiner Meinung nach "auf verschiedenen Bildungsstufen der Völker in ungleicher Weise empfunden"141) werden, lassen sie sich nicht allgemein bestimmen, sondern sind "in jedem Land besonders aus der Geschichte desselben (zu) erkennen." ${ }^{142}$ ' Rau's Ansatzpunkt ähnelt damit dem, was von der sog. "Historischen Schule" propagiert wurde.

Die Ausgaben der Regierung, die ein Mittel zur Verwirklichung der Staatszwecke darstellen, sollen mittelbar oder unmittelbar gemeinnützige Wirkung haben. ${ }^{1431}$ Ihr Umfang wird durch das Wirtschaftlichkeitsprinzip bestimmt. So soll darauf geachtet werden, "daß gleich wichtige Z wecke zugleich besorgt werden und leichter verschiebliche Ausgaben erst nach der Deckung der nothwendigeren an die Reihe kommen", wobei der Grad der Dringlichkeit nach "der Stärke des aus der Unterlassung erwachsenden Nachtheiles bemessen" werden soll. ${ }^{144)}$ Für die staatlichen Ausgaben gilt aber, so Rau, vor allem der Grundsatz der Sparsam-

138) Riha, T.: German Political Economy ..., a.a.O., S. 38. Vgl. auch Schumpeter, J.A.: Geschichte der ökonomischen ..., a.a.O., S. 617.

In der Fußnote 70 (S. 617 f.) zeigt Schumpeter deutlich seine Einschätzung des Wirkens von Rau. Er schreibt: "Als Lehrer gebührt ihm ein Ehrenplatz in der Geschichte der Wirtschaftswissenschaft; zugunsten seines Lehrbuches läßt sich nur anführen, daß es eine saubere Anordnung von umfangreichem Tatsachenmaterial bringt - und da $\beta$ es gerade dem entsprach, was ein zukünftiger Jurist oder Beamter aufzunehmen fähig und bereit war".

139) Vgl. Rau, K.H.: Lehrbuch der politischen Ökonomie, Bd. III, 1. Abtheilung. Grundsätze der Finanzwissenschaft, 3. Aufl., Leipzig, Heidelberg 1855, S. 8 f.

140) Ebenda, S. 9.

141) Ebenda, S. 1.

142) Ebenda, S. 4.

Die Analogie zur historischen Stufenlehre von Adam Smith (Vgl. Abschnitt 1.3.1.) ist nicht zu übersehen.

143) Vgl. ebenda, S. 2 f. und S. 27.

144) Ebenda, S. 31. 
keit, den er im Sinne des ökonomischen Prinzips verstanden wissen wollte. ${ }^{145)}$

Rau wendete sich entschieden gegen die merkantilistische Auffassung, daß hohe staatliche Ausgaben dem Wohle der Bevölkerung dienen. Er erkannte zwar an, daß im Gefolge der staatlichen Verausgabung Einkommen gebildet werden, betonte aber, daß diese Verausgabung erst durch eine Gegenleistung der Bürger möglich wurde, so daß der Regierungsverbrauch an die Stelle privaten Verbrauchs trete. Staatliche Ausgaben seien letztlich nur durch das "wahre Bedürfnis" zu rechtfertigen, weil sonst "ein Theil der Bürger durch die Last der Staats. ausgaben zu schweren Entbehrungen genöthigt, ein anderer Theil derselben wenigsten von der nützlichen Anlegung seines reinen Einkommens abgehalten wird, ohne daß diese Nachtheile ... auf andere Weise vergütet würden." ${ }^{146)}$ Rau zeigte damit erste Ansätze einer gesamtwirtschaftlichen Betrachtung der Haus. haltsprobleme.

Die Staatsausgaben lassen sich, so auch Rau in seinem Lehrbuch, nach verschie denen Gesichtspunkten einteilen. Stellt man auf den Zweck der Ausgaben ab ${ }^{147}$, sind sie in die beiden Hauptabteilungen "Ausgaben, welche durch die Verfassung des Staates nothwendig werden" sowie "Regierungsausgaben, welche von der höchsten Gewalt für die Beförderung der einzelnen Staatszwecke vorgenommen werden"148) zuzüglich verschiedener Unterabteilungen zu gliedern. Gliederungen

145) Viele nachfolgende Wissenschaftler interpretierten diesen Grundsatz absolut, d.h. im Sinne eines minimalen Budgets (vgl. Albrecht, G.: Das Problem ..., a.a.O., S. 179 ff.), obwohl Rau ausdrücklich betonte, daß man den Grundsatz der Sparsamkeit mißverstehen würde, "wenn man, um ihm Genüge zu leisten, solche Ausgaben unterlassen und verkürzen wollte, von denen das Wohl des Staates oder einzelner Staatsanstalten wesentlich bedingt wird". Rau, K.H.: Lehrbuch der politischen ..., a.a.O., S. $31 \mathrm{f}$.

146) Ebenda, S. 30 f. Weiter schreibt Rau: "Es kann nicht als die Aufgabe der Staatsverbindung betrachtet werden, einzelne Gewerbsleute oder Lohnarbeiter auf Kosten der Gesamtheit in Nahrung zu setzen, weshalb es nicht fortwährend, sondern nur in schwierigen Umständen, z.B. bei einer Theuerung oder einer großen Stockung von Gewerben, zu billigen ist, da $\beta$ man auf Staatskosten Arbeiten anordnet, die blos zur Beschäftigung nahrungsloser Menschen bestimmt sind, und selbst dann hat man darauf zu sehen, daß zugleich Werke von dauerndem Vortheile zu Stande gebracht werden". Vgl. auch Albrecht, G.: Das Problem ..., a.a.O., S. 181.

147) Die von Buschor genannte Dreiteilung in Ausgaben für den Hofstaat, für die Civilverwaltung und für das Militärwesen ist nicht die von Rau verwendete oder vorgeschlagene Einteilung, sondern lediglich dessen Beispiel, womit man sich "ehemals begnügte". Vgl. Buschor, E.: Theorie der Allokation ..., a.a.O., S. 10 und Rau, K.H.: Lehrbuch der politischen ..., a.a.O., S. 39.

148) Rau, K.H.: Lehrbuch der politischen ..., a.a.O., S. $39 \mathrm{f}$. 
nach dem institutionellen Prinzip kritisierte Rau - nach Buschor als erster ${ }^{149)}$-, da "sie keine Übersicht des Ganzen gewähren und sich willkürlich noch weiter vermehren ließen, ... also nicht allgemein anwendbar und nicht aus dem Wesen der Sache geschöpft sind."150)

Die Auffassung, daß das, was man bezeichnenderweise mit dem Terminus 'staatliche Einmischung' belegte, eine Ausnahme darstellen müsse ${ }^{151}$, wurde von den meisten Ökonomen dieses Zeitabschnittes nicht nur wegen ihrer auf das Individuum gerichteten Grundeinstellung postuliert, sondern auch aus anderen Gründen für notwendig erachtet. ${ }^{152}$ 'So waren die Organe der öffentlichen Verwaltung damals kaum in der Lage, Lenkungs- und Kontrollmaßnahmen erfolgreich durchführen zu können. Selbst John Stuart Mill ${ }^{153}$ ), der als Protagonist einer positiveren Einstellung gegenüber dem Staat gelten kann ${ }^{154)}$,bestritt nicht, "die unter den damaligen Umständen einfach unbestreitbare Überlegenheit, die der Verwaltung produktiver Ressourcen durch den Geschäftsmann zugesprochen werden mußte im Vergleich zu dem, was man von einem Beamten jener Zeit er-

149) Vgl. Buschor, E.: Theorie der Allokation ..., a.a.O., S. 10.

150) Rau, K.H.: Lehrbuch der politischen ..., a.a.O., S. 39.

151) Vgl. Schumpeter, J.A.: Geschichte der ökonomischen ..., a.a.O., S. 670

152) Ähnlich bei Recktenwald, H.C.: Die Klassik ..., a.a.O., S. 65.

153) Zu Mill's Leben und den Inhalten seiner Veröffentlichungen vgl. Birnbacher, D.: John Stuart Mill, in: Klassiker der Philosophie, hrsg. v. O. Höffe, Bd. 2. Von Immanuel Kant bis Jean Paul Satre, München 1981, S. 132-152.

Die Unterschiede im geistig-philosophischen Fundament von Adam Smith und John Stuart Mill sind Gegenstand der Ausführungen von Hesse, G.: Staatsaufgaben .. , a.a.O., S. $55 \mathrm{ff}$.

Nach Hans Herbert v. Arnim ist Smith derjenige, der das marktwirtschaftliche Konkurrenzmodell als die dem Ziel der Wohlstandsmehrung geeignete Wirtschaftsverfassung erarbeitete und begründete, während er in John Stuart Mill den beredten und einflußreichen Theoretiker der freien öffentlichen Meinung sieht, für den die "Meinungsfreiheit und freie Diskussion die sichersten Mittel seien, der Wahrheit zumindest so nahe zu kommen, wie dies Menschen überhaupt möglich sei". Arnim, H.H.v.: Staatslehre ..., a.a.O., S. 43 f.

154) Vgl. auch Davis, E.G.: Mill, Socialism and the English Romantics: An Interpretation, in: Economica, vol. 52 (1985), S. 345-358, insbes. S. $347 \mathrm{ff}$.

John Stuart Mill stand den staatlichen Tätigkeiten nicht nur nicht dogmatisch negativ gegenüber, sondern wies dem Staat auch, stärker als Adam Smith, Verantwortung in sozialen Fragen zu. Stand er in seinen früheren Lebensjahren den liberalen Gedanken noch sehr nahe, so hat er sich in späteren Phasen seines Lebens, nicht zuletzt unter dem Einfluß seiner Frau, stark gewandelt und "nach einer Verbindung von Individualismus und Sozialismus in der Form eines 'qualified socialism' gesucht". (Mann, F.K: Geschichte der angelsächsischen ..., a.a.O., S. 482). Nach eigenen Angaben ging es ihm darum, "how to unite the greatest individual liberty of action, with a common ownership in the raw material of the globe, and an equal participation of all in the benefits of combined labour". Mill, J.St.: Autobiography. With an Appendix of hitherto unpublished Speeches and a Preface by Harold J. Lasky, London 1924, S. 196 (Erstveröffentlichung 1873). 
warten konnte."155) Zumindest teilweise deshalb, gingen fast alle Nationalökonomen der damaligen Zeit davon aus, daß die staatliche Tätigkeit generell unproduktiv sei, was von den wirtschaftlichen Verhältnissen, die die Merkantilisten hinterlassen hatten, untermauert zu werden schien. ${ }^{156)}$ Die Bedeutung der Klassiker und vor allem die Aktualität von Adam Smith wird seit der zweihundertsten Wiederkehr seines Hauptwerkes 'An Inquiry into the Nature and the Causes of the Wealth of Nations' allerorten hervorgehoben. ${ }^{157)}$

\subsection{Sozialpolitisch motivierter Interventionismus}

Die zunehmende Monopolisierung der Wirtschaft und die ungleiche Machtverteilung innerhalb der Wirtschaft zu Lasten der Nichtunternehmer verhinderte das Funktionieren des Wirtschaftsablaufs nach liberalen Vorstellungen ${ }^{158)}$ und so wurde der ökonomische Liberalismus im weiteren Verlauf des 19. Jahrhunderts vermehrt zum Gegenstand von Angriffen. ${ }^{159)}$

\subsubsection{Die deutsche ${ }^{160)}$ Finanzwissenschaft}

Als Reaktion auf die klassischen Lehren sind gerade im deutschsprachigen Raum eine Vielfalt unterschiedlicher, zum Teil gegenläufiger Strömungen zu beobachten. Zeitlich umspannen sie mit diversen Überlappungen den Abschnitt von der Mitte des 19. Jahrhunderts bis hin zum ersten Weltkrieg. Einen Aspekt bildet dabei der geradezu missionarische Eifer für Sozialreformen, der sich insbesondere in Deutschland im Gefolge der romantischen Verklärung des Staates ${ }^{161}$ ' sowie

155) Schumpeter, J.A.: Geschichte der ökonomischen ..., a.a.O., S. 671.

156) Vgl. Littmann, K.: Zunehmende Staatstātigkeit ..., a.a.O., S. $18 \mathrm{ff}$.

157) Vgl. Friedman, M.: Adam Smith's Relevance to Today, in: Challenge. The Magazine of Economic Affairs, vol. 20 (1977), S. 6-12.

Siehe hierzu auch die einzelnen Beitrāge in: Recktenwald, H.C. (Hrsg.): Ethik, Wirtschaft und Staat. Adam Smiths Politische Ökonomie heute, Darmstadt 1985.

158) Vgl. Wolfslast, J.C.: Bestimmungsfaktoren wachsender Staatsausgaben. Dargestellt am Beispiel des Deutschen Reiches, 1871 bis 1913, Hamburg 1967, S. 54 ff.

159) Vgl. auch Born, E.: Art.: Wirtschaftskrisen, in: Handwörterbuch der Wirtschaftswissenschaft (HdWW), hrsg. v. W. Albers et al., Bd. 9, Stuttgart et al. 1982, S. 130-141, S. 133 ff.

160) Wenn von der deutschen Finanzwissenschaft gesprochen wird, so ist damit geographisch meist der gesamte deutschsprachige Raum gemeint. Als Beispiel sei hier auf Lorenz von Stein verwiesen, der eine Professur in Wien hatte.

161) Vgl. Riha, T.: German Political Economy ..., a.a.O., S. 52 ff. 
angestachelt durch die Ideen des orthodoxen Sozialismus und der aufkommenden christlichen Soziallehre ausbreitete. Die hieraus abgeleiteten sozial-ethisch motivierten Vorschläge wiesen allesamt dem Staat eine bedeutendere Rolle im Wirtschaftsprozeß zu. ${ }^{162}$

Gleichzeitig fand eine Akademisierung der Nationalökonomie statt, in deren Verlauf immer mehr Ökonomen von den Universitäten kamen. ${ }^{163)}$ Ferner begründete die amerikanische Volkswirtschaftslehre innerhalb dieses Zeitabschnittes praktisch vom Nullpunkt aus, ihren nationalen und internationalen Status. ${ }^{164)}$ Weiterhin markiert das letzte Drittel des 19. Jahrhunderts den Beginn einer besseren Verbreitung wissenschaftlicher Arbeiten durch die Gründung von wissenschaftlichen Zusammenschlüssen und Zeitschriften. ${ }^{165}$,

Ausgehend von Deutschland breitete sich im 19. Jahrhundert auch die sog. "Historische Schule" aus, die alle ökonomischen Tatbestände von ihrer historischen Entwicklung her zu erklären versucht. ${ }^{166)}$ Konträr zu dieser begründeten, unabhängig voneinander, Carl Menger (1840-1921), Stanley Jevons (1835-1882) und Léon Walras (1834-1910) die Grenznutzenschule. ${ }^{167)}$ Während sich nun die Grenznutzentheorie in allen übrigen Ländern fast unangefochten durchsetzen konnte, kam es in Deutschland zu der, wie Schmölders sagt, "letztlich bis heute noch nicht geschlichteten Auseinandersetzung zwischen Menger und Schmoller"168) ,die unter dem Namen 'Methodenstreit' in die Geschichte einging. Gleichzeitig mit der Grenznutzentheorie und der damit verbundenen subjektiven Wertlehre, die die Grundlage der modernen mikroökonomischen Analyse bilden, fanden mathematische Methoden Eingang in die Arbeitswelt der Ökonomen. ${ }^{169}$

162) Vgl. Schumpeter, J.A.: Geschichte der ökonomischen ..., a.a.O., S. 927 ff.

163) Vgl. ebenda, S. $920 \mathrm{f}$. Die Akademisierung führte auch zu einer zunehmenden Spezialisierung der Volkswirtschaftslehre.

164) Vgl. ebenda, S. $1054 \mathrm{ff}$.

165) Vgl. ebenda, S. $922 \mathrm{f}$.

Der Verein für Socialpolitik wurde 1872 gegründet, die American Economic Association 1885 und die Royal Economic Society 1890. 1884 erschien auch der erste Band des "Finanzarchivs".

166) Vgl. Riha, T.: German Political Economy ..., a.a.O., S. 69 ff.

167) Vgl. hierzu Schumann, J.: Die Wegbereiter der modernen Preis- und Kostentheorie, in: Geschichte der Nationalökonomie, hrsg. v. O. Issing, München 1984, S. 121-146, S. 127 ff.

168) Schmölders, G.: Wirtschaftswissenschaft III: Theorienbildung ..., a.a.O., S. 434.

169) Vgl. auch Riha, T.: German Political Economy ..., a.a.O., S. $161 \mathrm{ff}$. 
Im Gefolge der philosophischen Arbeiten von Fichte und insbesondere von Hegel kam es zu einer Änderung der Einstellung zum Staat ${ }^{170)}$, die die Fragestellung der deutschen Finanzwissenschaft nachhaltig beeinflußte. Nach Littmann vollzog sich in dieser Zeit die Wendung hin zum finanzwissenschaftlichen Problem $^{171)}$, nämlich zu der Erkenntnis, "daß die Staatswirtschaft fest in dem System der Gesamtwirtschaft eingebettet" ist, mithin "der öffentliche und private Sektor der Wirtschaft ein nicht auflösbares Ganzes bilden." ${ }^{172)}$

Für Erwin von Beckerath bildet das Jahr 1860 ein Wendepunkt der deutschen Finanzwissenschaft, da in diesem Jahr die erste Auflage des Lehrbuches von Lorenz v. Stein ${ }^{173)}(1815-1890)$ erschien. ${ }^{174)}$ Dieses Lehrbuch, das nach Meinung Schumpeters keine Bedeutung erlangte ${ }^{175)}$, gilt für andere als ein Meilenstein in der $\mathrm{Ge}$ schichte der deutschen Finanzwissenschaft. ${ }^{176)}$

170) Nach Littmann beeinflußt "die Umkehrung des Verhältnisses Staat-Individuum, die ... von Fichte, weit einflußreicher noch von Hegel vorgenommen wurde, ... Fragestellung und Aus richtung vornehmlich der deutschen Finanzwissenschaft ... bis in unsere Tage" (Littmann, K.: Zunehmende Staatstätigkeit ..., a.a.O., S. 22). Vgl. auch Schumpeter, J.A.: Geschichtt der ökonomischen ..., a.a.O., S. 514-518 und S. 536.

$\mathrm{Zu}$ einer tiefergehenden Diskussion der Bedeutung von Staat und Gemeinschaft bei Hegel vgl. auch Avineri, S.: Hegel's Theory of the Modern State, Cambridge 1972, insbesondere $\mathrm{S} .176 \mathrm{ff}$. und Ottmann, H Individuum und Gemeinschaft bei Hegel, Bd. 1. Hegel im Spiegel der Interpretationen, Berlin, New York 1977.

171) Littmann beschreibt die Entwicklung der Finanzwissenschaft als Weg "vom Dogma zum Problem", mit den Stationen "dogmatische Grundpositionen", "Wendung zum Problem" und "Lösungen" - so die Überschriften des ersten Kapitels bzw. die seiner Unterabschnitte. Vgl. Littmann, K.: Zunehmende Staatstätigkeit ..., a.a.O., S. 13 ff.

172) Littmann, K.: Zunehmende Staatstätigkeit ..., a.a.O., S. 24.

173) Buschor gibt ihm fälschlicherweise den Namen Ludwig von Stein. Vgl. Buschor, E.: Theorie der Allokation ..., a.a.O., S. 9.

174) Vgl. Beckerath, E.v.: Die neuere Geschichte ..., a.a.O., S. 424.

175) Vgl. Schumpeter, J.A.: Geschichte der ökonomischen ..., a.a.O., S. 1038.

176) Vgl. Beckerath, E.v.: Die neuere Geschichte ..., a.a.O., S. 424 ff. und Littmann, K.: Zunehmende Staatstätigkeit ..., a.a.O., S. 22 ff.

Die unterschiedliche Bewertung der Leistung Stein's ist sicher auch Ausdruck unterschiedlicher Blickrichtungen. Schumpeters Buch ist eine Geschichte der ökonomischen Analyse, und auch Littmann konstatiert, daß Stein's Analyse fragwürdig sei (vgl. Littmann, K.: Zunehmende Staatstätigkeit ..., a.a.O., S. 23). Andere, wie Erwin von Beckerath, betrachten die Entwicklung der deutschen Finanzwissenschaft, und bei dieser Betrachtung ist die zentrale Bedeutung des Werkes von Lorenz v. Stein nicht zu übersehen. 
Nach Lorenz von Stein sind "die Staatsausgaben das in Geld ausgedrückte System der Staatsbedürfnisse", wobei diese Bedürfnisse "die materiellen Bedingungen der Entwicklung des Einzelnen durch das Ganze" enthalten. ${ }^{177)}$ Welche Staatsbedürfnisse im einzelnen als gerechtfertigt anzusehen sind, wird in Stein's Lehrbuch nicht näher problematisiert.

Der Staat fungiert, so Stein, als Vertreter individueller Interessen und Verwalter derjenigen Angelegenheiten, "welche sonst der Einzelne aus eigenen Mitteln vielleicht gar nicht, gewiß aber theuerer und schlechter besorgen würde." ${ }^{178)}$ Er hat dabei darauf zu achten, daß die Staatsausgaben den Staatsbürgern zugute kommen, denn erst "in dieser organischen Rückkehr der Abgaben und Leistungen der Einzelnen durch die Staatswirtschaft zum wirthschaftlichen Interesse der beisteuernden Einzelnen wird die Staatswirthschaft im höchsten Sinne des Worts zur Trägerin der Harmonie der wirthschaftlichen Interessen des Ganzen und der Einzelnen."179) Der Staat ist also Träger einer besonderen Leistung, die für die Volkswirtschaft notwendig ist und zwischen Staat und Individuen besteht eine unauflösliche Beziehung. ${ }^{180}$

Dem Postulat, daß aus ökonomischen Gründen größtmögliche Staatsabstinenz zu fordern sei, setzt Stein die These entgegen, daß Staatsausgaben durchaus volks wirtschaftlich produktiv sein können. ${ }^{181}$ Mithin sind die Staatsausgaben nur dann gerechtfertigt, wenn sie ihre eigenen wirtschaftlichen Bedingungen wiederzuerzeugen vermögen, andernfalls komme ihnen der Charakter eines Verlustes zu. ${ }^{182)}$ Diese sog. Reproduktionstheorie ${ }^{183)}$ steht im Mittelpunkt des Werkes von Stein und bildet für ihn auch ein Maßstab für die Zulässigkeit staatlicher Ausgaben. ${ }^{184)}$ "Ein Staat kann nie zuviel ausgeben, solange die Reproduction

177) Stein, L.v.: Lehrbuch der Finanzwissenschaft, 3. Aufl., Leipzig 1875, S. 95.

178) Ebenda, S. 100.

179) Ebenda, S. 100.

180) Vgl. Beckerath, E.v.: Die neuere Geschichte ..., a.a.O., S. 428.

181) Vgl. auch Littmann, K.: Zunehmende Staatstätigkeit ..., a.a.O., S. 23.

182) Vgl. Stein, L.v.: Lehrbuch der Finanzwissenschaft, a.a.O., S. 99 ff. und Albrecht, G.: Das Problem ..., a.a.O., S. $188 \mathrm{ff}$.

183) Die Reproduktionslehre durchzieht bei Stein die gesamte Staatswirtschaft und findet in der Steuerlehre ihren Ausdruck in dem Satz: "Die Steuerkraft soll die Steuer, die Steuer die Verwaltung, die Verwaltung aber wieder die Steuerkraft erzeugen". Zitiert nach Beckerath, E.v.: Die neuere Geschichte ..., a.a.O., S. 428.

184) Vgl. auch Riha, T.: German Political Economy ..., a.a.O., S. 76. 
seiner Ausgaben die Summe derselben mit dem landesüblichen Fuße verzinst und amortisiert." ${ }^{185)}$ Ein solches Kriterium, mit dessen Hilfe auch der Umfang staatlicher Ausgaben bestimmt werden könnte, war nötig, denn schon Lorenz v. Stein vertrat die Meinung, "daß mit der fortschreitenden Entwicklung der Völker und mit der sie begleitenden größeren Thätigkeit der Verwaltung auch die Ausgaben der Völker steigen."186)

Dieser Gedanke der Reproduktion staatlicher Ausgaben enthält den durchaus richtigen Kern, daß der Staat nicht nur Kostgänger der Marktwirtschaft ist. ${ }^{18 ?}$ Stein selbst gibt aber keinen Hinweis, welche staatlichen Ausgaben zur Reproduktion der Einnahmen führen. Er beruft sich hierbei in letzter Instanz auf die Entscheidung des Staatsmannes. Da die Reproduktion in diesem Falle nur auf einer Vermutung beruht, liefert sie kein allgemein befriedigendes Kriterium für die Zulässigkeit staatlicher Ausgaben.

Die Reproduktionslehre Stein's, die "einen wichtigen Meilenstein in der Entwicklung der Finanzwissenschaft"188) darstellte, denn sie vermittelte eine bis zu dieser Zeit nicht beachtete Sicht der Staatsausgaben, stieß sehr bald auf entschiedenen Widerspruch. Der Hauptvorwurf lautete, daß sie auf der Gegenüberstellung zweier nicht vergleichbarer Größen beruhe: auf der einen Seite die Leistungen des Staates, die zu einem großen Teil immaterieller Art sind und daher kaum abzuschätzen sind, und auf der anderen Seite die wirtschaftliche Leistungsfähigkeit der Volkswirtschaft, die durch die Beschaffung der öffentlichen Mittel belastet wird. ${ }^{189)}$

Neben diesen Aussagen zu den staatlichen Ausgaben insgesamt finden sich in den Werken Stein's auch Äußerungen zu speziellen Ausgabenkategorien. Zunächst schlägt Stein in seinem Lehrbuch der Finanzwissenschaft eine Dreiteilung der Staatsausgaben vor. Die erste Gruppe beinhaltet die Ausgaben für das

185) Stein, L.v.: Lehrbuch der Finanzwissenschaft, a.a.O., S. 102.

186) Ebenda, S. 102.

Damit nahm Lorenz von Stein die Formulierung des sog. "Wagnerschen Gesetzes" vorweg.

187) Vgl. Littmann, K.: Zunehmende Staatstätigkeit ..., a.a.O., S. 23.

188) Ebenda, S. 23.

189) Vgl. Albrecht, G.: Das Problem ..., a.a.O., S. 190. 
Staatsoberhaupt, die zweite die für die gesetzgebende Gewalt des Staates und die dritte und größte Gruppe die Ausgaben für die "Verwaltung" des Staates. ${ }^{190 \prime}$ Die Verwaltung des Staates umfaßt dabei sowohl das Verhältnis zu anderen Staaten als auch die Lebensverhältnisse im eigenen Staat. ${ }^{191)}$ Die Ausgaben im zuletzt genannten Teil der staatlichen Verwaltung dienen der wirtschaftlichen Sicherstellung der Existenz des Staates und beinhalten Ausgaben für die staatliche Rechtspflege und solche, die "dem Bedürfnis nach Entwicklung der Persönlichkeit, insofern dieselbe durch die Gemeinschaft bedingt wird"192) Rechnung tragen. Vor allem die wirtschaftliche Existenzsicherung des Staates bildet für Lorenz v. Stein den eigentlichen Gegenstand finanzwissenschaftlicher Forschung.

Insbesondere die Auflistung der "Ausgaben, die dem Bedürfnis nach Entwicklung der Persönlichkeit" dienen, macht deutlich, daß v.Stein dem Staat eine gewichtige Rolle bei der Lösung sozialer Fragen zuspricht. Noch deutlicher tritt dies allerdings in einem anderen Werk Stein's hervor, in dem er staatliche Stellen aufforderte, den Gegensatz von Arm und Reich zu mildern und die materielle Not sehr großer Teile der Bevölkerung zu lindern. ${ }^{193)}$ Sein Appell richtete sich zwar direkt an die französische Monarchie, eine Verallgemeinerung ist in diesem Fall aber sicher zulässig. Das Engagement staatlicher Stellen begründete er mit der machterhaltenden Wirkung einer solchen Politik, denn "alles Königtum wird fortan entweder ein leerer Schatten, oder eine Despotie werden, oder untergehen in Republik, wenn es nicht den hohen sittlichen Mut hat, ein Königtum der sozialen Reformen zu werden." ${ }^{194)}$ Diese Auffassung vom Umfang staatlicher Tätigkeit

190) Vgl. Stein, L.v.: Lehrbuch der Finanzwissenschaft, a.a.O., S. 105.

191) Vgl. ebenda, S. 3 f.

192) Ebenda, S. 4.

193) Vgl. Stein, L.v.: Geschichte der sozialen Bewegung in Frankreich von 1789 bis auf unsere Tage, Bd. 3. Das Königtum, die Republik und die Souveränität der französischen Gesellschaft seit der Februarrevolution 1848, Hildesheim 1959, S. 41 (Erstveröffentlichung 1850).

194) Ebenda, S. 41.

Die machtstabilisierende Funktion sozialer Reformen wird auch in einer Rede Bismarcks vor dem Reichstag am 18.5.1889 deutlich, in der er folgendes sagte: "Die Leute sagen: Wenn der Staat zu Schaden geht, dann verliere ich meine Rente; und wenn es 40 Franken im Jahre sind, so mag er sie nicht verlieren, und er hat Interesse für den Staat. Es ist ja menschlich natürlich. ... Wenn wir 700000 kleine Rentner, die vom Reiche ihre Rente beziehen, haben, gerade in diesen Classen, die sonst nicht viel zu verlieren haben und bei einer Veränderung irrthümlich glauben, daß sie viel gewinnen können, so halte ich das für einen außerordentlichen Vortheil; wenn sie auch nur 115 bis 200 Mark zu verlieren haben, so erhălt sie doch das Metall in ihrer Schwimmkraft; es mag noch so gering sein, es hält sie aufrecht". Kohl, H. (Hrsg.): Die Reden des Fürsten Bismarck, 12. Bd. 1886-1890, Stuttgart 1894, S. 639 f. 
unterscheidet sich ziemlich deutlich von dem, was Wilhelm von Humboldt fast gleichzeitig dazu veröffentlichte, wenngleich auch seine Ausführungen Interpretationsspielräume enthalten. Humboldt schreibt: "Der Staat enthalte sich aller Sorgfalt für den positiven Wohlstand der Bürger, und gehe keinen Schritt weiter, als zu seiner Sicherstellung gegen sich selbst und gegen auswärtige Feinde notwendig ist; zu keinem anderen Endzwecke beschränke er ihre Freiheit."195)

Stärker noch als Lorenz v. Stein wanden sich die Gründer des Vereins für Socialpolitik der sozialen Frage zu. Am 6. und 7. Oktober 1872 fand in Eisenach eine Tagung statt, zu der die Unterzeichner des Einladungsschreibens, unter ihnen Adolph Wagner, Gustav von Schmoller und Wilhelm Roscher, "Männer aller politischen Parteien, von denen sie annehmen zu können glaubten . ... daß sie das absolute laissez faire et laissez passer in der sozialen Frage nicht für das Richtige halten" zum Kommen aufgefordert hatten. ${ }^{1961}$ In seiner Eröffnungsrede betonte Gustav von Schmoller: "Der tiefe Zwiespalt, der durch unsere gesellschaftlichen Zustände geht, der Kampf, welcher heute Unternehmer und Arbeiter, besitzende und nichtbesitzende Klassen trennt, die mögliche Gefahr einer uns zwar bis jetzt nur von ferne, aber doch deutlich genug drohenden sozialen Revolution, haben ... Zweifel erregt, ob die ... herrschenden volkswirtschaftlichen Doktrinen, ... immer die Herrschaft behalten werden."197) Die Veranstalter stimmten weiter in einer Auffassung des Staates überein, "die gleich weit von der naturrechtlichen Verherrlichung des Individuums und seiner Willkür, wie von der absolutistischen Theorie einer alles verschlingenden Staatsgewalt ist. ... niemals aber betrachten sie ihn (den Staat: Anm. d. Verf.), wie das Naturrecht und die Manchesterschule, als ein notwendiges, möglichst zu beschränkendes Übel." ${ }^{198)}$ Aus dem Kreis der Eisenacher Tagung entstand dann ein Jahr später, am 13. Oktober 1873, der Verein für Socialpolitik , "mit einer doppelten Frontstellung gegen sozialreaktionäres Manchestertum und gegen sozialrevolutionären Sozialismus." ${ }^{99}$

195) Humboldt, W.v.: Ideen zu einem Versuch, die Grenzen der Wirksamkeit des Staates zu bestimmen, Stuttgart 1962, S. 44 (Erstveröffentlichung 1851).

196) Boese, F.: Geschichte des Vereins für Socialpolitik 1872-1932, Berlin 1939, Einladung zur Eisenacher Versammlung von 1872, S. 241.

197) Boese, F.: Geschichte des Vereins ..., a.a.O., S. 6.

198) Ebenda, S. 8.

199) Winkel, H.: Die deutsche Nationalökonomie im 19. Jahrhundert, Darmstadt 1977, S. 164. 
Wenn im folgenden die Stellung der Staatsausgaben am Werk Adolph Wagners aufgezeigt wird, so soll damit nicht der Eindruck erweckt werden, die Mitglieder des Vereins für Socialpolitik stimmten voll mit dessen staatssozialistischer Linie überein. Wagner erscheint vielmehr als ein extremer Vertreter staatlicher Interventionspolitik, wie kein anderer geeignet, die veränderte Haltung gegenüber dem Staat zu verdeutlichen. ${ }^{2001}$

Adolph Wagner (1835-1917), den man allgemein zur Gruppe der Kathedersozialisten $^{201)}$ zählt, war ein sehr engagierter Vertreter sozialpolitischer Reformen, der auch auf die politische Verwirklichung seiner Vorstellungen hinarbeitete. So gehörte er z.B. von 1882 bis 1889 als Mitglied dem preußischen Abgeordnetenhaus an. Nach der Beschreibung Schumpeters waren seine Vorträge und Vorlesungen sehr lebendige Veranstaltungen, in denen er schrie, mit den Füßen auf das Kathederpodest stampfte und imaginären Gegnern mit den Fäusten drohte. ${ }^{2021}$

Die wissenschaftlichen Leistungen der Kathedersozialisten werden auch heute noch sehr zurückhaltend beurteilt, da sie, so ein Vorwurf, in ihrem Eifer für soziale Reformen den "analytischen Apparat der Volkswirtschaftslehre ... eher verdorben als verbessert"203) haben. Obwohl die meisten von ihnen der Historischen Schule der Nationalökonomie nahestanden ${ }^{204)}$, fühlte sich Adolph Wagner selbst

200) Vgl. Albrecht, G.: Art.: Verein für Socialpolitik, in: Handwörterbuch der Sozialwissenschaften, hrsg. v. E. von Beckerath et al., 11. Bd., Stuttgart et al. 1961, S. 10-16, S. 12 f. und Winkel, H.: Die deutsche Nationalökonomie ..., a.a.O., S. 131.

201) Den Namen verdanken die Kathedersozialisten einem polemischen Pressestreit zwischen Heinrich Bernhard Oppenheim und Gustav Friedrich von Schöneberg. Die in spöttischer und abwertender Absicht zugedachte Bezeichnung wurde von ihnen alsbald als Ehrentitel angenommen. Vgl. hierzu Müssiggang, A.: Die soziale Frage in der historischen Schule der deutschen Nationalökonomie, Tübingen 1968, S. 144.

202) Vgl Schumpeter, J.A.: Geschichte der ökonomischen ..., a.a.O., S. 980.

203) Ebenda, S. 982.

204) Vgl. Schmölders, G.: Geschichte der Volkswirtschaftslehre, a.a.O., S. 72f.

Die Historische Schule unterteilt man in aller Regel in die "Ältere Historische Schule", die mit den Namen Hildebrand, Roscher und Knies in Verbindung gebracht wird und in die "Jüngere Historische Schule", die hauptsächlich mit dem Namen von Gustav von Schmoller verknüpft ist. Vgl. auch Riha, T.: German Political Economy ..., a.a.O., S. 69 ff. sowie Schumpeter, J.A.: Geschichte der ökonomischen ..., a.a.O., S. 987 ff. 
als Theoretiker im Sinne eines Gegners des Historismus. ${ }^{205)}$ Er reklamierte für sich, "nicht zur historischen Schule der Nationalökonomie" zu gehören, ihr aber insofern nahezustehen, als auch er "alle wirtschafts- und sozialpolitischen Fragen nur als relativ entscheidbar" ${ }^{206)}$ auffaßt.

Sein Eintreten für ein stärkeres soziales Engagement des Staates wird in der Rede, die Wagner am 12. Oktober 1871 in der Berliner Garnisonskirche gehalten hatte, sehr deutlich. In ihr forderte er nachdrücklich, "daß in der Nationalökonomie wieder sittliche Grundsätze zur Geltung kommen müßten, daß der Staat sozialen Notständen gegenüber mehr Aufgaben habe als die liberale Schule anerkenne."207) Die sichtbaren sozialen Spannungen waren für ihn generell Folgen des selbstherrlichen Gebrauchs des Vermögens und nur geeignete staatliche Interventionen konnten seiner Meinung nach eine krisenhafte Entwicklung verhindern. Schon hier wird sichtbar, daß Adolph Wagner Reformen und nicht eine Revolution anstrebte.

Wagners allgemeine Regel für die Bestimmung der staatlichen Tätigkeiten weist Ähnlichkeiten mit Formulierungen bei Adam Smith auf, sie lautet: "Der Staat hat diejenigen Thätigkeiten zur Befriedigung der Bedürfnisse seiner Angehöri gen selbst zu übernehmen, welche weder die Privatwirthschaften, noch freie, noch andere Zwangsgemeinschaften (Selbstverwaltungskörper) überhaupt oder welche alle diese nur weniger gut oder nur kostspieliger ausüben können." ${ }^{208)}$ Der

205) Vgl. Schumpeter, J.A.: Geschichte der ökonomischen ..., a.a.O., S. 1038 f.

Nach Schumpeters überspitzter Formulierung bestand das Programm der Historischen Schule hauptsächlich aus dem Bekenntnis, "daß das Werkzeug der Wirtschaftswissenschaftler in erster Linie ... aus den Resultaten und Verallgemeinerungen historischer Monographien bestehen sollte" (ebenda, S. 986). Schmölders gelangt zu einer positiveren Einschätzung des Historismus, dessen Kennzeichen seiner Meinung nach die Anschauung ist, daß "die Erkenntnis der wirtschaftlichen Zusammenhänge erst aus der Kenntnis der geschichtlichen Wirklichkeit des Wirtschaftslebens zu gewinnen sei" (Schmölders, G.: Geschichte der Volkswirtschaftslehre, a.a.O., S. 75). Ähnlich positiv ist das Urteil in folgendem Artikel desselben Autors: Schmölders, G.: Historische Schule, in: Geschichte der Nationalökonomie, hrsg. v. O. Issing, München 1984, S. 107-119.

206) Zitiert nach Damaschke, A.: Geschichte der Nationalökonomie, 13. Aufl., Bd. 2, Jena 1922, S. 73. Vgl. auch Schumpeter, J.A.: Geschichte der ökonomischen ..., a.a.O., S. 1039.

207) Zitiert nach Damaschke, A.: Geschichte der Nationalökonomie, a.a.O., S. 73.

208) Wagner, A.: Grundlegung der politischen Ökonomie, 3. Aufl., erster Theil. Grundlagen der Volkswirtschaft, zweiter Halbband, Buch 4-6, Leipzig 1893, S. 916. 
entscheidende Unterschied zu Smith liegt natürlich darin, daß Adolph Wagner der staatlichen Tätigkeit grundsätzlich weniger skeptisch gegenübersteht. Neben den Leistungen auf dem Gebiete des Rechts- und Machtzweckes, die nach Wagner aufgrund seiner allgemeinen Regel, prinzipiell dem Staat übertragen werden sollten, gibt es für ihn auch Leistungen, die sich nicht eindeutig zu den staatlichen Tätigkeiten rechnen lassen. ${ }^{209}$ ) Sie sollten dann vom Staat zur Verfügung gestellt werden, wenn gemeinsamer Konsum vorliegt bzw. ohne grössere Kosten möglich ist und längerfristige und allgemeine Interessen es erforderten. ${ }^{210}$ ) Letzteres begründete er damit, daß die privatwirtschaftliche Produktion nur einseitig das private Interesse wahrnehme, während der Staat imstande sei, in Generationen zu denken und allgemeine Interessen zu berücksichtigen. ${ }^{211)}$

Die von Adolph Wagner vorgeschlagene Gliederung der Staatstätigkeit macht eher als diese sehr allgemein gehaltenen Äußerungen deutlich, welche Bedeutung er den Staatsausgaben, insbesondere auch im sozialen Bereich zusprach. Zunächst unterteilte er die Staatstätigkeit in den Rechts- und Machtzweck sowie den Kultur- und Wohlfahrtszweck ${ }^{212)}$, wobei er den Rechts- und Machtzweck als den ersten und Hauptzweck des Staates betrachtete. Zu ihm zählte er die Pflege und Förderung der inneren Rechtsordnung sowie die Garantie der Unabhängig-

209) Vgl. hierzu auch Littmann, K.: Zunehmende Staatstätigkeit ..., a.a.O., S. 35 insbesondere die Fußnote 35.

210) Wagner spricht in diesem Zusammenhang davon, daß die adäquate Herstellung der betreffenden Leistung von der zeitlichen Nachhaltigkeit, der räumlichen Ausdehnung und der Einheitlichkeit oder Ausschließlichkeit in einer Hand abhänge. Vgl. Wagner, A.: Grundlegung der politischen ..., a.a.O., S. 916.

211) Vgl. ebenda, S. 917. Siehe auch Schmölders, G.: Geschichte der Volkswirtschaftslehre, a.a.O., S. 68 .

Als Beispiel für Tätigkeiten von allgemeinem Interesse führt Wagner u.a. die Justiz- und Polizeiorganisation auf, die darüber hinaus auch wegen des Kriteriums der Einheitlichkeit eine staatliche Aufgabe darstelle. Ebenfalls wegen der Einheitlichkeit sollten auch die Eisenbahnen, das Geld- und Münzwesen sowie das Versicherungs- und Schulwesen staatlich reguliert werden. Vgl. Wagner, A.: Grundlegung der politischen ..., a.a.O., S.917ff.

Der Rechtsschutz dient Wagner als Beispiel für eine allgemeine Leistung, die darüber hinaus noch Grenzkosten von nahezu Null habe, denn "nach der Idee des Rechts muß Allen der Vortheil des Rechtsschutzes zu Theil werden" und "dieselbe judicielle, polizeiliche, militärische, volkswirthschaftliche Thätigkeit vermag dann aber auch ohne oder nur mit relativ kleiner Kostensteigerung innerhalb gewisser Grenzen einer grösseren Anzahl Personen zu Gute zu kommen".Ebenda, S. 919.

212) Vgl. ebenda, S. 885 ff. und Fellmuth, R.: Staatsaufgaben im Spiegel politischer Ökonomie. Zum Verhältnis von Wirtschaft und Staatstätigkeit in Werken von Adam Smith und Adolph Wagner, München 1981, S. 278 ff. 
keit und Souveränität des Staates. Mit dem Kultur- und Wohlfahrtszweck fällt dem Staat, so Adolph Wagner, die Aufgabe zu, "die Staatsangehörigen in der Verfolgung ihrer Lebensaufgaben, der physischen, wirthschaftlichen, sittlichen, geistigen (und) religiösen Interessen"213) zu fördern, womit er den Staat in die soziale Verantwortung einbindet.

Insgesamt sind es sowohl technische als auch wirtschaftliche und sozialpolitische Gründe, die nach Wagner staatliches Eingreifen in den Wirtschaftsprozeß motivieren und rechtfertigen können. Der Staat übernimmt damit die Aufgabe, "Unvollkommenheiten, Härten und Disharmonien auszugleichen" und "für die Befriedigung der Gemeinbedürfnisse zu sorgen."214) Bei diesen Ausführungen über Wagners Ansichten zur staatlichen Tätigkeit muß zwangsläufig die Frage auftauchen, auf welchen Gebieten der Staat eigentlich nicht aktiv werden sollte. Obwohl Adolph Wagner für weitgehende Verstaatlichungen eintrat ${ }^{215)}$, redete er jedoch keinesfalls einer ungezügelten Ausdehnung des Staatsanteils das Wort. Er vertritt im Gegenteil die Ansicht, daß jede Art von Staatstätigkeit zu verwerfen sei, "welche der Gesamtheit ein höheres Opfer auferlegt, als die betreffende Staatsleistung nützt oder werth ist (absolute Verwerflichkeit) nder als sie nothwendig kostet, wenn sie ebenso gut, aber billiger von den Privaten, Vereinen oder anderen Organen für öffentliche Zwecke, wie den Gemeinden u.s.w., ausgeführt werden kann (relative Verwerflichkeit)" ${ }^{216)}$ Im nächsten Satz freilich verweist Wagner auf die Schwierigkeit, Wert und Kosten einer Staatsleistung festzustellen. Er betont allerdings, daß seiner Meinung nach "aus dem Pactiren der Regierung und der Volksvertretung Compromisse hervorgehen, durch welche das Interesse von Staat und Volk in der Bestimmung der Staatsthätigkeiten und des dafür erforderlichen Aufwandes noch am Besten gewahrt wird."217)

213) Wagner, A.: Grundlegung der politischen ..., a.a.O., S. 887.

214) Ebenda, S. 851.

215) Vgl. Wagner, A.: Theoretische Sozialökonomik oder Allgemeine und theoretische Volkswirtschaftslehre, erste Abteilung, Leipzig 1907, S. 178 ff. und Winkel, H.: Die deutsche Nationalökonomie ..., a.a.O., S. 131.

Mit der Verstaatlichung der Eisenbahnen hatte der staatssozialistische Gedanke seine wohl größte praktische Ausgestaltung. Vgl. Damaschke, A.: Geschichte der Nationalökonomie, a.a.O., S. 74.

216) Wagner, A.: Finanzwissenschaft, 2. Aufl, erster Theil, Leipzig, Heidelberg 1877, S. 61.

217) Ebenda, S. 61. 
Berühmtheit erlangte Wagner vor allem durch die ihm zugeschriebene Formulierung des Gesetzes über die "wachsende Ausdehnung der öffentlichen, bez. Staatsthätigkeiten." ${ }^{218)}$ Danach zeigen "geschichtliche (zeitliche) und räumliche, verschiedene Länder umfassende Vergleiche ..., dass bei fortschreitenden Culturvölkern, ... regelmässig eine Ausdehnung der Staatsthätigkeiten und der gesamten öffentlichen, durch die Selbstverwaltungskörper neben dem Staate ausgeführten Thätigkeiten erfolgt." ${ }^{19)}$ Aus dieser Ausdehnung der Staatstätigkeit resultierte für Wagner auch zwangsläufig eine "Ausdehnung des Finanzbedarfs"200), also das Anwachsen der Staatsausgaben. Dabei stellte er fest, daß nicht nur die absolute, sondern auch die relative Bedeutung des Staates "steigt, d.h. eine immer grössere und wichtigere Quote der Gesamtbedürfnisse ... wird durch den Staat statt durch andere Gemein- und Privatwirthschaften befriedigt." ${ }^{211}$ Unbeschadet der empirischen Relevanz dieses sog. Gesetzes ${ }^{222}$ ist in diesem Zusammenhang Schmölders zuzustimmen, welcher in dessen Formulierung den Sozialreformer Wagner erkennt, "der die bürgerliche Epoche von der sozialen oder staatssozialistischen abgelöst sehen wollte und die Entwicklung zu diesem Endziel hin begrüßte."223)

\subsubsection{Die Staatsausgaben bei John Stuart Mill}

Auch in England und den Vereinigten Staaten von Amerika fand der Gedanke Anhänger, eine Verbesserung der wirtschaftlichen Lebensbedingungen mit finanzpolitischen Mitteln anzustreben. Fritz Karl Mann verweist hierbei auf das Dreigestirn John Stuart Mill, Henry George und John Atkinson Hobson ${ }^{224)}$, wobei Schumpeter, gerade in diesem Kontext sehr nachdrücklich betont, daß die Art und Weise, wie dieser neue Geist in der Ökonomie auf die Analysemethoden der Wissenschaftler einwirkte, sich weitgehend von einem Land zum anderen unterschied. ${ }^{225)}$

218) Wagner A.: Grundlegung der politischen ..., a.a.O., S. 892. Vgl. auch die Ausführungen zu Lorenz v. Stein in Abschnitt 1.4.1.

219) Wagner, A.: Grundlegung der politischen ..., a.a.O., S. 893.

220) Wagner, A.: Finanzwissenschaft, a.a.O., S. 68

221) Wagner, A.: Grundlegung der politischen ..., a.a.O., S. $893 \mathrm{f}$.

222) Siehe hierzu auch Abschnitt 1.1.2. insbesondere Fußnote 19.

223) Schmölders, G.: Geschichte der Volkswirtschaftslehre, a.a.O., S. 70.

224) Vgl. Mann, F.K.: Geschichte der angelsächsischen ..., a.a.O., S. 481.

225) Vgl. Schumpeter, J.A.: Geschichte der ökonomischen ..., a.a.O., S. 978. 
Der erste aus diesem Dreigestirn, John Stuart Mill (1806-1873), war eine der zentralen Gestalten des intellektuellen Lebens im neuzehnten Jahrhundert. ${ }^{226)}$ Mit seinem Buch "Principles of Political Economy with some of their Applications to Social Philosophy"227) erzielte er einen enormen Erfolg, was, so Schumpeter, "in erster Linie die Folge einer glücklichen Kombination von wissenschaftlichem $\mathrm{Ni}$ veau und Zugänglichkeit"228) war. Mill's Anschauungen gehen von liberalen ökonomischen Gedanken aus, lassen aber auch unverkennbar Spuren der Berührung mit dem Sozialismus und Historismus erkennen. ${ }^{229)}$ So gibt es seiner Meinung nach keine unwandelbare natürliche Ordnung der Gesellschaft, weshalb jede wirtschaftliche Notwendigkeit weitgehend im Hinblick auf einen gegebenen $\mathrm{Zu}$ stand der sich wandelnden institutionellen Rahmenbedingungen analysiert werden muß. ${ }^{230)}$

Obwohl John Stuart Mill grundsätzlich eine größtmögliche Beschränkung staatlicher Einmischung propagierte, da "die meisten Personen ein richtigeres und vernünftigeres Urteil über eigene Interessen und deren Förderung besitzen, als es ihnen durch allgemeine gesetzliche Bestimmungen vorgeschrieben oder im einzelnen Falle durch einen öffentlichen Beamten gezeigt werden kann"231), ließ

226) Vgl. Schumpeter, J.A.: Geschichte der ökonomischen ..., a.a.O., S. 645. Siehe hierzu auch Davis, E.G.: Mill, Socialism and ..., a.a.O., S. 345.

227) Dieses Buch wurde erstmals 1848 veröffentlicht und bis zum Tode Mill's schließlich siebenmal neu aufgelegt.

228) Schumpeter, J.A.: Geschichte der ökonomischen ..., a.a.O., S. 652. Nach Schumpeter ist nichts aufschlußreicher hinsichtlich des Charakters der bürgerlichen Zivilisation, d.h. nichts beweise ihre echte Freiheit, aber auch ihre politische Schwäche besser "als die Tatsache, daß das Buch, das das Bürgertum so begeistert aufnahm, eine sozialistische Botschaft enthielt und von einem Gelehrten geschrieben wurde, der der Wertordnung der Industriebourgeoisie offensichtlich ablehnend gegenüberstand". Ebenda, S. 650 .

229) Vgl. die Einleitung von Heinrich Waentig zu Mill, J.St.: Grundsätze der politischen Ökonomie mit einigen ihrer Anwendungen auf die Sozialphilosophie. Nach der Ausgabe letzter Hand (7. Auflage 1871) übersetzt von Wilhelm Gehrig, Bd. 1, 2. Aufl., Jena 1924, S.XII f. Vgl. auch Schumpeter, J.A.: Geschichte der ökonomischen ..., a.a.O., S. 661 ff. und Davis, E.G.: Mill, Socialism and ..., a.a.O., S. $348 \mathrm{ff}$.

230) Vgl. Schumpeter, J.A.: Geschichte der ökonomischen ..., a.a.O., S. 650

231) Mill, J.St.: Grundsätze der politischen Ökonomie mit einigen ihrer Anwendungen auf die Sozialphilosophie. Nach der Ausgabe letzter Hand (7. Auflage 1871) übersetzt von Wilhelm Gehrig, Bd. 2, Jena 1921, S. 703.

In einem längeren Abschnitt dieses Buches (S. 678 ff.) zählt Mill einige Bedenken auf, die gegen ein zu großes staatliches Betätigungsfeld sprechen. Neben der in der Regel zwangsweisen Beschaffung der notwendigen Mittel, sei mit jeder zusätzlichen staatlichen Tätigkeit eine Vergrößerung der Macht des Staates verbunden und eine Ballung der Aktivitäten beim Staat widerspräche dem Gedanken der Arbeitsteilung. Sein wichtigster Einwand ist allerdings, daß "ein Volk, das sich nicht an freiwillige Tätigkeit zum gemeinsamen Wohl gewöhnt hat, das gewöhnlich von seiner Regierung eine Bevormundung in allen gemeinsamen Interessen erwartet ... seine Fähigkeit nur halb entwickelt" habe. Ebenda, S. 690. 
er einige wesentliche Ausnahmen zu. Im 5. Buch der "Principles", mit dem Titel "Über den Einfluß des Staates", unterscheidet er zwischen notwendigen und wahlfreien Aufgaben des Staates. ${ }^{232)}$ Die notwendigen Aufgaben sind nach Mill untrennbar "von der Vorstellung des Staates" und werden "ohne irgendeinen Widerspruch von allen Regierungen in ihr Tätigkeitsgebiet gezogen."233) Hierunter fallen das Verteidigungs- und Justizwesen ${ }^{234)}$ und andere Aufgaben, für deren staatliche Bereitstellung "als einziger Grund nur die allgemeine Bequemlichkeit angeführt werden kann." ${ }^{235)}$ Als Beispiele für die letztgenannte Kategorie führt er die staatliche Münzprägung, die Pflasterung und Reinigung von Straßen sowie den Bau und die Verbesserung von Häfen auf. ${ }^{236)}$

Da es nach John Stuart Mill kaum möglich ist, "einen für alle Aufgaben passenden Rechtfertigungsgrund zu finden, außer den allumfassenden der allgemeinen Zweckdienlichkeit"237), gibt es auch Aufgaben, deren Ausführungen durch den Staat durchaus kontrovers beurteilt werden können. ${ }^{238)}$ Er selbst zählt in seinen "Principles" fünf Fälle auf, bei denen der Staat, über die "notwendigen" Aufgaben hinaus, tätig werden soll, da seiner Meinung nach die Nachfrage auf dem Markt bei diesen Gütern keinen geeigneten Maßstab für deren Wert darstelle. ${ }^{239)}$ Die mangelnde Maßstabsfunktion der Marktnachfrage begründete er damit, daß es sich hier um Güter handelt, "deren Nutzen nicht in der Befriedigung von Neigungen besteht, die ... den täglichen Lebensbedürfnissen dienen."240)

232) Vgl. Mill, J.St.: Grundsätze der politischen ..., Bd. 2, a.a.O., S. 457. Mill führt dabei aus, daß der Ausdruck "wahlfrei" nicht im Sinne von Willkür ausgelegt werden darf. Er besage lediglich, "daß deren Ausführung durch den Staat nicht eine bestimmte Notwendigkeit ist, vielmehr zu den Fragen gehört, über welche verschiedene Meinungen bestehen oder bestehen können".

233) Ebenda, S. 456.

234) Vgl. ebenda, S. $457 \mathrm{ff}$.

235) Ebenda, S. 463.

236) Vgl. ebenda, S. 463.

237) Ebenda, S. 464.

238) Vgl. ebenda, S. 457.

239) "Da die Personen ... nur eine unvollkommene oder sogar falsche Auffassung von ihren Bedürfnissen haben, würde die durch die Nachfrage des Marktes hervorgerufene Versorgung etwas ganz anderes hervorbringen als das, dessen sie wirklich bedürfen." Ebenda, S.697 f.

240) Ebenda, S. 697. 
Als erstes verweist er in diesem Zusammenhang auf den Bereich der Bildung und Erziehung, wobei er, was den Elementarunterricht angeht, die Schulpflicht befürwortet. ${ }^{241)}$ Der zweite Fall liegt dann vor, "wenn jemand im gegenwärtigen Zeitpunkt die unwiderrufliche Entscheidung zu treffen sich unterfängt, was das beste für seine Interessen in künftigen und entlegenen Zeiten sein wird"242). Was das im Einzelnen bedeutet, bleibt aber weithin unklar. Drittens werde "alles was bei einer Überlassung an den privaten Unternehmensgeist nur durch den finanziellen Zusammenschluß Vieler geschehen kann, ... oft ebensogut ... bisweilen sogar besser durch den Staat erreicht." ${ }^{\text {243) }}$ Bei der weiteren Abhandlung dieses Punktes macht Mill deutlich, daß er mit der Übertragung auf den Staat hierbei vor allem die Verhinderung von Monopolbildungen im Auge hatte. Sodann kann die staatliche Einmischung zur Überwindung des Freifahrerproblems beitragen. ${ }^{244)}$ Die fünfte Aufgabe des Staates betrifft schließlich das "wichtige und sehr umstrittene Gebiet der öffentlichen Wohltätigkeit." ${ }^{245)} \mathrm{Er}$ hält es hierbei nicht für gerechtfertigt, Hilfsbedürftige - eine nähere Spezifizierung erfolgt nicht - aus schließlich der privaten caritativen Initiative zu überlassen. Mill forderte viel mehr "eine planmäßige Fürsorge, bei der die Gesellschaft durch ihr Organ, den Staat, handelt."246)

Mit diesen Ausführungen gab John Stuart Mill schon 1848, im Jahr der Erstauf lage der "Principles", eine meritorische Begründung öffentlicher Aufgaben, die gerade in den letzten Jahrzehnten, mit den Arbeiten von Musgrave eine tiefere Fundierung fand. Nach Schumpeter entsprechen die Inhalte dieses Teils der "Principles" im wesentlichen den Ausführungen bei Adam Smith. ${ }^{247)}$ Mill geht aber hier insofern über die Smithschen Überlegungen hinaus, als er die meritorische Begründung der sog. "wahlfreien" Aufgaben des Staates deutlicher markierte.

In seinen Betrachtungen über das Wirken und die Werke von John Stuart Mill offenbart Schumpeter sehr viel Sympathie für ihn, den er als die Verkörperung

241) Vgl. Mill, J.St.: Grundsätze der politischen ..., Bd. 2, a.a.O., S. 698 ff.

242) Ebenda, S. 707.

243) Ebenda, S. 709.

244) Vgl. ebenda, S. 715. Siehe hierzu auch Hesse, G.: Staatsaufgaben ..., a.a.O., S. 342.

245) Mill, J. St.: Grundsätze der politischen ..., Bd 2, a.a.O., S. 718.

246) Ebenda, S. 718.

247) Vgl. Schumpeter, J.A.: Geschichte der ökonomischen ..., a.a.O., S. 663. 
eines "evolutionären Sozialisten" bezeichnet ${ }^{248)}$, zumal dieser und seine Schüler sich nicht dazu hätten verleiten lassen, "mit den alten Werturteilen auch den wissenschaftlichen Apparat über Bord zu werfen." ${ }^{249)}$ Gerade diesen Vorwurf kann man aber den beiden anderen Personen des am Anfang erwähnten Dreigestirns, nämlich John Atkinson Hobson (1858-1940) und Henry George (1839-1897), machen. Der Einfluß von Hobson ${ }^{250)}$ und anderen englischen Wirtschaftswissenschaftlern, die sich zu tiefgreifenden sozialen Forderungen bekannten, blieb allerdings gering. ${ }^{251)}$ Dies ist wohl auch darauf zurückzuführen, daß sie in Opposition zu dem "großen Meister"252) dieser Epoche, Alfred Marshall (1842$1924)^{253)}$, standen ${ }^{254)}$, der mit der Integration des Grenznutzenkonzepts und der klassischen Theorie einen wichtigen Beitrag zur Wiederbelebung der ökonomischen Theorie leistete. In den Vereinigten Staaten von Amerika kritisierte vor allem Thorstein Veblen (1857-1929), stärker noch als der von Fritz Karl Mann erwähnte Henry George ${ }^{255)}$, die kapitalistische Wirtschaftsordnung und die sie

248) Vgl. Schumpeter, J.A.: Geschichte der ökonomischen ..., a.a.O., S. 650.

Die Begründung für diese Bezeichnung liegt nach Schumpeter darin, daß Mill einerseits den Sozialismus als Endziel anerkannte, andererseits aber die Idee des revolutionären Übergangs wegen der "unüberwindlich erscheinenden Schwierigkeiten der Wirtschaftsver waltung" zurückgewiesen habe. Vgl. ebenda, S. 651.

Vgl. hierzu auch Mann, F.K.: Geschichte der angelsächsischen ..., a.a.O., S. 482

249) Schumpeter, J.A.: Geschichte der ökonomischen ..., a.a.O., S. 978 f.

250) Hobson's Forschungsprogramm nennt Schumpeter historisch-soziologisch und vergleichbar mit dem deutscher Kathedersozialisten. Vgl. Schumpeter, J.A.: Geschichte der ökonomischen ..., a.a.O., S. 1005 (Fußnote 36), S. 1016 f. und S. 1017 (Fußnote 12).

251) Vgl. ebenda, S. $976 \mathrm{f}$.

252) Vgl ebenda, S. 1017.

253) Zu Alfred Marshall vgl. auch Schumann, J.: Die Wegbereiter ..., a.a.O., S. 131 ff. sowie Bowden, E.V.: Economic Evolution. Principles, Issues, Ideas. Through the Loobing Glass of Time, 2nd ed., Cincinnati (USA) 1985, S. 117 ff.

254) Vgl. hierzu auch Schumpeter, J.A.: Geschichte der ökonomischen ..., a.a.O., S. 1005 (Fußnote 36) und S. 1016 insbesondere Fußnote 11.

255) Henry George wird zwar zum Teil unter die sog. Agrarsozialisten eingereiht, seine Methoden, Begriffe und Grundsätze waren aber weitgehend individualistisch geprägt. Vgl. Mann, F.K.: Geschichte der angelsächsischen ..., a.a.O., S. 482 .

Schumpeter bezeichnet die Einstellung George's als liberalistisch (vgl. Schumpeter, J.A.: Geschichte der ökonomischen ..., a.a.O., S. 1043, Fußnote 48), denn "er war sorgfältig darauf bedacht, sein 'Heilmittel' (die steuerliche Konfiskation der Bodenrente, Anm. d.Verf.) so zu gestalten, daß er der Leistungsfähigkeit der auf den Privatunternehmer gegründeten Wirtschaft möglichst wenig schadete". Ebenda, S. 1056.

Zum oben angesprochenen 'Heilmittel' vgl. George, H.: Progress and Poverty. An Inquiry into the Cause of Industrial Depressions and of Increase of Want with Increase of Wealth. The Remedy, New York 1904, S. 326.

Vgl. auch Bowden, E.V.: Economic Evolution ..., a.a.O., S. $121 \mathrm{f}$. 
rechtfertigenden ökonomischen Auffassungen. ${ }^{256)}$ Methodisch lehnte sich Veblen dabei sehr stark an die "Historische Schule" an und begründete deren amerikanischen Zweig, den "Institutionalismus". ${ }^{257)}$

\subsection{Die Integration der Staatsausgaben}

\subsubsection{Neuorientierung der Finanzwissenschaft}

Im Gefolge der sozialen Forderungen änderte sich, wie schon oben angedeutet, vor allem in Deutschland, die methodische Vorgehensweise vieler Nationalökonomen. So blieb die Finanzwişsenschaft bis zu den zwanziger Jahren unseres Jahrhunderts in zwei Lager gespalten. ${ }^{258)}$ Auf der einen Seite die institutionelldeskriptive Ausrichtung, die ihren Höhepunkt in der sog. "Jüngeren Historischen Schule" fand ${ }^{259)}$, und auf der anderen Seite die funktionell-analytische Richtung, die in der Linie der klassischen Tradition der Ökonomie stand und vorwiegend im angelsächsischen Raum verbreitet war. Als Ergebnisse der erstgenannten Ausrichtung lagen um die Jahrhundertwende eine Fülle statistischer und histori. scher Ausarbeitungen vor, die, so die oft geäußerte Ansicht, "einer Generation

256) Vgl. Schumpeter, J.A.: Geschichte der ökonomischen ..., a.a.O., S. 979.

257) Vgl. hierzu Boulding, K.: A New Look at Institutionalism, in: The American Economic Review, vol. XLVII, Number 2, 1957, S. 1-12 und Montaner, A.: Der Institutionalismus als Epoche amerikanischer Geistesgeschichte, Tübingen 1948, insbesondere S. $44 \mathrm{ff}$.

Vgl. auch Schmölders, G.: Geschichte der Volkswirtschaftslehre, a.a.O., S. 108 ff. und Bowden, E.V.: Economic Evolution ..., a.a.O., S. 122.Siehe auch Williamson, O.E.: Reflections on the New Institutionalism, in: Zeitschrift für die gesamte Staatswissenschaft (Journal of Institutional and Theoretical Economics), Bd. 141 (1985), S. 187-195.

258) Vgl. Littmann, K.: Problemstellung und Methoden ..., a.a.O., S. 100. Siehe auch Mann, F.K.: Volkswirtschaftliche Analyse und Institutionalismus in der Finanzwissenschaft, in: Finanzarchiv, hrsg. v. F. Neumark, N.F. Bd. 17 (1956/57), Tübingen 1957, S. 451-467. Fritz Karl Mann sah diese Spaltung in zwei Lager auch noch in den finanzwissenschaftlichen Lehrbüchern der 50er Jahre.

259) Als wichtigster Repräsentant der "Jüngeren Historischen Schule" gilt Hugo Eisenhart Gustav von Schmoller (1838-1917), der seine Ausrichtung selbst nicht lediglich historisch, sondern historisch-ethisch nannte, was sein Eintreten für soziale Reformen unterstreicht und die gedankliche Verwandtschaft zu Adolph Wagner sichtbar macht. Vgl. Schumpeter, J.A.: Geschichte der ökonomischen ..., a.a.O., S. 992. Siehe auch Riha, T.: German Political Economy ..., a.a.O., S. $50 \mathrm{ff}$. 
von Studierenden die interessante Wissenschaft der Finanzen verleidet"260) haben und Franz Meisel zu dem Satz animierten: "Das große Sterben kam auf unsere Wissenschaft."261)

Mitte der zwanziger Jahre machte sich dann, nach der Überwindung von Krieg und Inflation, eine kräftige Belebung finanzwissenschaftlichen Denkens bemerkbar. ${ }^{262)}$ Wesentliche Motoren dieser Entwicklung, insbesondere im Hinblick auf die Staatsausgaben, waren Gerhard Colm mit der Veröffentlichung "Volkswirtschaftliche Theorie der Staatsausgaben"263) und Arthur Cecil Pigou mit dem Buch "A Study in Public Finance". ${ }^{264)}$ Beide sicherten den öffentlichen Ausgaben endgültig ein "Heimatrecht" in der Finanzwissenschaft, das von nun an nur noch vereinzelt bestritten wurde. ${ }^{265)}$ Das Objekt dieser erneuerten - oder besser: neueren -

260) Beckerath, E.v.: Die neuere Geschichte ..., a.a.O., S. 437. Vgl. auch Schumpeter, J.A.: Geschichte der ökonomischen ..., a.a.O., S. 989.

In seinem Werk 'Hedda Gabler' läßt Henrik Ibsen den Gatten Heddas, Dr. Tesmann, an einer Arbeit über die Leinenindustrie im Brabant des Mittelalters arbeiten, um so dessen Mediokrität zu unterstreichen.

261) Meisel, F.: Stand und Wert der deutschen Finanzwissenschaft, in: Schnıllers Jahrbuch für Gesetzgebung, Verwaltung und Volkswirtschaft im Deutschen Reich, hrsg. v. H. Schumacher und A. Spiethoff, 42. Jg., München 1918, S. 1147-1194, S. 1194. Arı anderer Stelle sagte Meisel: "Ueber deutsche Finanzwirtschaft und Finanzwissenschaft seit Beginn des Jahrhunderts bis zum Kriege können die sachlichen Urteile nicht auseinander. Mein Urteil über die Finanzwissenschaft kann ich nicht besser und schöner einkleiden als in Goethes Worte: Es ist kein Ernst da, der ins Ganze geht, kein Sinn dem Ganzen etwas zuliebe zu tun, sondern man trachtet, wie man sein eigenes Selbst bemerklich mache und es vor der Welt zur möglichen Evidenz bringe". Meisel, F.: Wo steht die deutsche Finanzwissenschaft?, in: Zeitschrift für die gesamte Staatswissenschaft, hrsg. v. K. Bücher, 75. Jg. (1920), Tübingen 1921, S. 54-131, S. 131. Das von Meisel angeführte Goethe-Zitat findet sich, mit marginalen Abweichungen, in den Aufzeichnungen seiner Gespräch mit Johann Peter Eckermann unter dem Datum des 20. April 1825. Goethe moniert dieses Bestreben als Zeichen seiner Zeit und vor allem der nachwachsenden Generation.

262) Vgl. Böhler, E.: Die Erneuerung der deutschen Finanzwissenschaft, in: Zeitschrift für die Schweizerische Statistik und Volkswirtschaft, 63. Jg. (1927), S. 583-597.

263) Colm, G.: Volkswirtschaftliche Theorie der Staatsausgaben. Ein Beitrag zur Finanztheorie, Tübingen 1927.

Es ist nicht zu verstehen, daß Buschor im zweiten Kapitel seines Buches, in dem er die "Entwicklung der Theorie der Staatsausgaben im deutschsprachigen Raum" untersucht, das Werk von Colm mit keinem Wort erwähnt und stattdessen das Buch "Die öffentlichen Ausgaben als volkswirtschaftliche Erscheinung" von Johannes Koulis, das 1948 in Frankfurt/Main erschienen ist, als "das erste umfassendere Werk, das ausschließlich der Theorie der Staatsausgaben gewidmet ist," preist. Vgl. Buschor, E.: Theorie der Allokation ..., a.a.O., S.14.

264) Pigou, A.C.: A Study in Public Finance, London 1928.

265) Gerloff vertrat zwar noch in der 2. Auflage des Handbuches der Finanzwissenschaft (1952) die Auffassung, daß sich die Finanzwissenschaft lediglich mit der Mittelbeschaffung zu beschäftigen habe (Gerloff, W.: Grundlegung der Finanzwissenschaft, a.a.O., S. 26 und S. 48), aber wie Böhler und vor allem Neumark deutlich machen, galt diese Meinung schon damals als überholt. Vgl. Böhler, E.: Die Erneuerung ..., a.a.O., S. 584 und Neumark, F.: Grundsätze und Arten ..., a.a.O., S. 607. 
Finanzwissenschaft "bildet die staatliche Aktivität schlechthin, soweit sie sich in öffentlichen Einnahmen oder/und Ausgaben niederschlägt." ${ }^{266)}$ Sie eröffnet so "fruchtbare Einblicke in den politisch-wirtschaftlichen Prozeß staatlicher Tätigkeiten und ergibt zugleich den Anstoß zu neuen Erkenntnissen."267)

Als programmatische Forderung an seine eigene Arbeit zitiert Colm den von Adolph Wagner für sich reklamierten Anspruch, "die Finanzwirtschaft in engeren Zusammenhang mit der volkswirtschaftlichen Lehre vom Staat und zwangsgemeinwirtschaftlichen System überhaupt" behandeln zu wollen, wobei er allerdings feststellte, daß Wagner seinem aufgestellten Postulat selbst nicht genügte. ${ }^{268)}$ Colm diskutierte in seinem Buch vornehmlich zwei Fragenkreise. Zum einen die Unterscheidungsmerkmale zwischen Staats- und Marktwirtschaft und zum anderen die Frage der Entstehung staatlicher Leistungserstellung. Zwischen beiden Fragenkomplexen bestehen unübersehbare Interdependenzen. Die Aufgabenteilung zwischen öffentlicher ${ }^{269}$ und privater Wirtschaft ist nur teilweise historisch erklärbar, zu einem anderen Teil folgt sie aus den Unterschieden der Organisationsarten beider Systeme, "denn gewisse Aufgaben lassen sich nur in einer der beiden Organisationsarten vollziehen."2701

\subsubsection{Die Organisation der Staats- und Privatwirtschaft}

Der Unterschied in der Organisation von Staats- und Privatwirtschaft liegt nach Colm darin, daß "in der Privatwirtschaft ... die freiwillige, wenn auch durch gesellschaftliche Sitte und Mode gebundene Einkommensverwendung über den Inhalt der wirtschaftlichen Leistung" entscheidet, während dies beim Staat durch "Beschluß der maßgeblichen Instanzen"271) geschieht. Für Colm bildet nicht der Zwangscharakter der Einnahmenbeschaffung das ausschlaggebende Kriterium

266) Littmann, K.: Problemstellung und Methoden ..., a.a.O., S. 100.

267) Ebenda, S. 100.

268) Vgl. Colm, G.: Volkswirtschaftliche Theorie ..., a.a.O., S. III.

269) Colm sagt ausdrücklich, daß er die Ausdrücke "öffentliche Wirtschaft" und "Staatswirtschaft" synonym gebraucht. Neben dem Staat (Gemeinden, Einzelstaaten, Bundesstaat) können auch Private oder zwischenstaatliche Institutionen (Kirchen, Verbände) Träger öffentlicher Wirtschaft sein, sofern sie dem Kriterium organmäßiger Bestimmung der Leistung entsprechen. Vgl. Colm, G.: Volkswirtschaftliche Theorie ..., a.a.O., S. 16.

270) Ebenda, S. 10.

271) Ebenda, S. 11. 
für die Abgrenzung der Staatswirtschaft, "sondern der Zwangs- (bzw. Organ-) charakter im Ansatz der Leistung." ${ }^{272)}$ Aus dieser Grundunterscheidung folgt für ihn, "daß für die Marktwirtschaft nur die kaufkräftige Nachfrage bestimmend sein kann", während "für die Entscheidung, was von der öffentlichen Wirtschaft geleistet werden soll ... jeder Gesichtspunkt maßgebend sein"273) kann. Anders ausgedrückt, in der Privatwirtschaft koordinieren die Preise, in der Staatswirtschaft staatliche Entscheidungen. Daraus folgt dann, daß die öffentlichen Leistungen sowohl an kulturellen als auch politischen Maßstäben orientiert sein können oder aber ihre Auswahl nach "dem machtvollsten Interesse"274) erfolgt. Dies führt zu der Einsicht, daß für die Arbeitsteilung zwischen Staats- und Privatwirtschaft nicht nur wirtschaftliche Gesichtspunkte maßgebend sind, sondern da $B$ "die Notwendigkeit der staatlichen Aufgabenerfüllung ... aus der jeweiligen politischen, kulturellen, sozialen und ökonomischen Situation"275) erwächst.

Nach Colm gibt es "gewisse wesensmäßige Funktionen, die jeder Staat ausüben muß, um eben Staat zu sein."276) Für den abendländischen Staat seien dies die Machterhaltung und die Rechtspflege. Daneben stehen seiner Meinung nach Konkurrenzgebiete zwischen staatlicher und privater Leistungserstellung, wie das Bildungswesen und die soziale Sicherung, "in denen die Aufgabenteilung von Land zu Land, ja vielfach von Jahr zu Jahr wechselt."277)

272) Colm, G.: Volkswirtschaftliche Theorie ..., a.a.O., S. 12.

Den Zwangscharakter der Einnahmenbeschaffung als Abgrenzungskriterium heranzuziehen würde bedeuten, daß die Struktur der Einnahmen bestimmt, was zur Staatswirtschaft zu zählen ist. Gleichartige Ausgabenarten würden dann, wenn darüber hinaus eine Zuordnung von Ausgaben und Einnahmen möglich ist, je nach Finanzierungsart der Staatswirtschaft zugeordnet oder nicht. Für die von Colm vorgeschlagene Unterscheidung gilt allerdings auch, daß Teile des 'Staates', sofern sie sich nach der kaufkräftigen Nachfrage orientieren, nicht zur Staatswirtschaft zählen.

273) Ebenda, S. 11.

274) Ebenda, S. 11.

275) Ebenda, S. 18.

Vgl. auch Böhler, E.: Die Erneuerung ..., a.a.O., S. $587 \mathrm{f}$.

276) Colm, G.: Volkswirtschaftliche Theorie ..., a.a.O., S. 17.

277) Ebenda, S. 10. 


\subsubsection{Die Beziehungen zwischen Staats- und Marktwirtschaft}

Neben der Organisation der Staats- und Privatwirtschaft machte Colm die Beziehungen zwischen der öffentlichen Wirtschaft und der Marktwirtschaft zu einem Hauptgegenstand seiner Arbeit. Er unterschied dabei zwei Gesichtspunkte, die für ihn dann auch die Ansatzpunkte zur Gliederung der öffentlichen Leistungen $^{278)}$ bildeten: Zum einen eine inhaltliche Beziehung, die durch den Zweck der öffentlichen Leistung bestimmt wird und zum anderen die Art und Weise der Aufgabenerfüllung, d.h. wie sich die Ausgaben in den Prozeß der Einkommensbildung und Einkommensverwendung eingliedern. ${ }^{279)}$

Unter dem Gesichtspunkt der inhaltlichen Beziehungen ergeben sich nach Colm vier verschiedene Gruppen staatlicher Aufgabengebiete: ${ }^{2801}$

1. Staatsaufgaben, die nach dem Inhalt ihrer Leistung in keiner unmittelbaren Beziehung zur Marktwirtschaft stehen. ${ }^{2811}$

2. Staatsaufgaben, die eine Bedingung für den Ablauf der Marktwirtschaft darstellen. ${ }^{282)}$

278) Colm verwendet die Begriffe "Ausgaben" und "Leistungen" synonym.

279) Vgl. Colm, G.: Volkswirtschaftliche Theorie ..., a.a.O., S. 17 und S. 34.

280) Vgl. ebenda, S. $18 \mathrm{ff}$.

281) Nach Colm sind dies alle Staatsleistungen zur Erhaltung und Sicherung der staatlichen Existenz. Im Einzelnen führt er auf:

- die Tätigkeit der obersten Organe der Legislative und Exekutive,

- Teile der Rechtspflege und die innere Verwaltung im engeren Sinne, nämlich den Regierungs- und Polizeiapparat, die Außenpolitik sowie die Maßnahmen der Landesverteidigung und schließlich

- die Finanzverwaltung.

Vgl. Colm, G.: Volkswirtschaftliche Theorie ..., a.a.O., S. 19 ff.

282) Unter diese Staatsleistungen, die Colm als Produktionsfaktoren für die Marktwirtschaft bezeichnet, zählt er

- generelle Staatsleistungen, die allen Unternehmen zukommen, wie die gesamte Rechtsgarantie, die Ordnung des Geldwesens und die Erschließung auswärtiger Absatzmärkte sowie

- spezielle Maßnahmen, die bestimmten Gruppen dienen, z.B. Aktienrecht.

Es gibt zwar, wie Colm selbst anmerkt, auch andere Produktionsfaktoren, die mehreren Wirtschaftseinheiten zugute kommen können (z.B. Dreschmaschine), aber marktwirtschaftlich bereitgestellt werden. Der Unterschied liegt allerdings darin, daß für sie die marktwirtschaftliche Bereitstellung gilt, während die oben aufgezählten Produktionsfaktoren von der Marktwirtschaft selbst nicht zur Verfügung gestellt werden können.

Vgl. Colm, G.: Volkswirtschaftliche Theorie ..., a.a.O., S. $21 \mathrm{ff}$. 
3. Staatsaufgaben, die neben oder in Ergänzung der Marktwirtschaft bestimmte Aufgaben auf den verschiedensten Kulturgebieten unmittelbar erfüllen ${ }^{2831}$ und schließlich

4. Staatsaufgaben, die einen Eingriff in die marktwirtschaftliche Versorgung bedeuten. ${ }^{284}$

Colm läßt keinen Zweifel daran, daß, wie bei fast jeder Klassifizierung, die Grenzen zwischen den verschiedenen Gruppen fließend sind.

Unter dem Aspekt der Art und Weise der Aufgabenerfüllung unterscheidet er zunächst "die Fälle, in denen der Staat selbst eine Leistung durchführt, von den Fällen in denen der Staat kraft seiner Hoheitsgewalt die Leistung von Untertanen veranlaßt." ${ }^{285)}$ Dies führt ihn dann zu folgender Klassifikation der staatlichen Aufgaben: ${ }^{286}$

1. Die eigentlichen Verwaltungsleistungen, die die Bezahlung der öffentlich $\mathrm{Be}$ diensteten und die Bereitstellung der sächlichen Geschäftsbedürfnisse umfas sen. ${ }^{287)}$ Der Ansatz öffentlicher Leistungen erfolgt hierbei im allgemeinen

283) Bei diesen sog. Kulturaufgaben des Staates besteht nach Colm kein prinzipieller Unter schied zwischen der öffentlichen und der privaten Bereitstellung. Er unterteilt sie in

- Aufgaben, bei denen die Versorgung, obwohl grundsätzlich möglich, ganz oder teilweise von der kaufkräftigen Nachfrage unabhängig gemacht werden soll, weil z.B. der Konsum des Gutes Bildung selbst bei kostenloser Bereitstellung "Zeit erfordert, über die nur derjenige beliebig verfügt, der den Zeitaufwand nicht zur Bestreitung seines Lebensunterhaltes gebraucht" (S. 25). Neben dem Unterrichtswesen erwähnt Colm in diesem Zusammenhang auch noch die Wasserversorgung und die Krankenhäuser. Die zweite Gruppe der Kulturaufgaben sind

- Aufgaben, bei denen "die marktwirtschaftlich erforderliche Preiserhebung für jede Benutzung unrationell, wenn nicht technisch undurchführbar wäre" (S. 25). Hier erwähnt er das Verkehrswesen.

Vgl. Colm, G.: Volkswirtschaftliche Theorie ..., a.a.O., S. 24 ff.

284) Bei den öffentlichen Eingriffen in die Marktwirtschaft unterscheidet Colm - erstens direkte Eingriffe in das Wirtschaftsgeschehen, wobei er Maßnahmen, die der Förderung des Produktionsablaufs dienen, z.B. Tätigkeit von Handelsvertretungen im Ausland und Errichtung von Berufs- und Fachschulen, von denen zur Erhaltung der Produktionsgrundlagen, z.B. im Bereich der Forstwirtschaft trennt und

- zweitens staatliche Maßnahmen, die nicht in erster Linie wirtschaftlichen Motiven entspringen, aber fördernden oder hemmenden Einfluß auf die Marktwirtschaft haben. Hier nennt er die Arbeitsfürsorge, öffentliche Unterstützungen und Eingriffe, "wo kulturelle Schäden durch Maßnahmen der freien Wirtschaft befürchtet werden" (S. 32), z.B. Reklameverbote zum Schutz der Landschaft, Alkoholverbote usw.

Vgl. Colm, G.: Volkswirtschaftliche Theorie ..., a.a.O., S. 26 ff.

285) Ebenda, S. $34 \mathrm{f}$.

286) Vgl. ebenda, S. $35 \mathrm{ff}$.

287) Vgl. ebenda, S. 35. 
nach den Kosten, weil der öffentlichen Leistungsorganisation im Gegensatz zur Konkurrenzwirtschaft nicht der Maßstab 'Marktpreis' zur Verfügung steht. Diese Kosten wiederum werden dann in Personal- und Sachausgaben gegliedert, wobei der überwiegende Teil des Aufwandes marktmäßig bestritten wird. ${ }^{288)}$ Der Staat nimmt hierbei persönliche und sächliche Produktionskräfte in Anspruch, m.a.W. es liegt "eine öffentliche Inanspruchnahme von Einkommen für die in Frage kommenden Staatszwecke vor."289)

2. Die Geldleistungen, bei denen "die staatliche Leistungsorganisation nur als Vermittlung tätig ist." ${ }^{290 \prime}$ Diese Geldleistungen erfolgen in Form von Unterstützungen, Subventionen, Zinszahlungen und Tributleistungen. ${ }^{291 /}$ Während bei der ersten Gruppe die Geldleistungen an andere (Beamte, Produzenten usw.) Voraussetzung für die eigentliche Verwaltungsleistung sind, stellt die Zahlung hier den Verwaltungsakt selbst dar. ${ }^{292)}$

Colm hat mit seiner umfassenden Analyse der Staatsausgaben das Erkenntnisobjekt der Finanzwissenschaft neu umschrieben und das Organisationsprinzip der Staatswirtschaft als systembegründendes Element in den Vordergrund gerückt, wodurch erst eine adäquate Beurteilung staatlicher Tätigkeiten möglich wurde. ${ }^{293)}$ Mit seiner Arbeit lieferte er eine Grundlage zur kreislauforientierten statistischen Erfassung staatlicher Ausgaben und nahm mit der volkswirtschaftlichen Behandlung öffentlicher Auf- und Ausgaben eine erste systematische Analyse der Staats- und Marktwirtschaft vor. Colm schuf damit auch die Ansätze zur Integration der klassischen Theorie, mit ihrer starken Betonung der marktwirtschaftlichen Vorgänge und der, in der kameralistischen Tradition verhafteten, staatswirtschaftlich orientierten deutschen Finanzwissenschaft des 19. Jahrhunderts.

288) Vgl. Colm, G.: Volkswirtschaftliche Theorie ..., a.a.O., S. 39.

Es ist auch denkbar, daß der Staat Arbeitskräfte nicht kraft Bezahlung, sondern kraft Hoheitsgewalt in Dienst stellt, z.B. Soldaten. In diesem Fall entspricht der Aufwand für die Staatsleistung nicht dem entsprechenden Ausfall in der Marktwirtschaft.

289) Ebenda, S. 39.

290) Ebenda, S. 35.

291) Vgl. ebenda, S. 35.

Die Gewährung von Unterstützungen und Subventionen sowie die Zinszahlungen auf die innere Schuld bewirken nach Colm eine Einkommensverschiebung im Inland, während die Verzinsung im Ausland aufgenommener Kredite und Tributleistungen an das Ausland eine Kaufkraftverschiebung zugunsten des Auslands darstellt.

292) Vgl. ebenda, S. 40.

293) Vgl. auch Böhler, E.: Die Erneuerung ..., a.a.O., S. 584. 
Neben Colm ist besonders Pigou hervorzuheben, der etwa zur gleichen Zeit die öffentlichen Ausgaben unter ökonomisch-theoretischen Aspekten behandelte und ebenfalls dazu beitrug, der Finanzwissenschaft eine neue Perspektive zu verleihen. ${ }^{294)}$ Die von Colm vorgenommene Unterscheidung der Staatsausgaben in Verwaltungs- und Geldleistungen, der die Einkommensbeanspruchung und die Einkommensumverteilung durch den Staat als Gliederungskriterium zugrunde liegt ${ }^{295)}$, findet ihr Gegenstück in der Pigouschen Bezeichnung als "real or exhaustive expenditures" für die erste Gruppe und "transfer expenditures"296) für die zweite. Nur die "real or exhaustive expenditures" bewirken einen direkten Güterverbrauch, während die "transfer expenditures" lediglich eine Verlagerung der Kaufkraft zur Folge haben; m.a.W. veränderte "Realausgaben führen in erster Linie zu einer Umverteilung der Produktionsfaktoren zwischen dem privaten und dem staatswirtschaftlichen Sektor, weiterhin aber auch zu Veränderungen innerhalb des privaten Sektors; Transferausgaben zeitigen allein Wirkungen der zweiten Art."297)

Mit dieser, wie Jecht meint, "anfangs überschätzte(n) Unterscheidung"298) war der Boden der "fiscal theory" endgültig bereitet, für die die kreislaufanalytische Betrachtung beider Seiten des Budgets selbstverständlich ist. In der 3. Auflage

294) Vgl. insbesondere Jecht, H.: Art.. Finanzwissenschaft, in: Handwörterbuch der Sozialwis senschaften, hrsg. v. E. von Beckerath et al., 3. Bd., Stuttgart et al. 1961, S. 707-722, S.712f Jecht zeigt, daß Colm und Pigou zwar die Protagonisten dieser Entwicklung waren, daß sie aber auch eine stattliche Zahl von Mitstreitern hatten.

295) Vgl. Kullmer, L.; Kriterien der Abgrenzung öffentlicher Ausgaben, in: Beiträge zur Theorie der öffentlichen Ausgaben, hrsg. v. H. Timm und H. Haller, Schriften des Vereins für Socialpolitik, N.F. Bd. 47, Berlin 1967, S. 9-35, S. 13.

296) Pigou, A.C.: A Study in Public Finance, a.a.O., S. 19 f.

Im weiteren Verlauf der 1. Auflage bezeichnet Pigou die erste Ausgabengruppe als "exhaustive expenditures". In der 2. Auflage (London 1929) seines Buches nennt er sie "real expenditures", während er sich in der 3. Auflage (London 1947) auf die Bezeichnung "nontransfer expenditures" beschränkt.

297) Littmann, K.: Zunehmende Staatstätigkeit ..., a.a.O., S. 99.

298) Jecht, H.: Finanzwissenschaft, a.a.O., S. 716. 
seines Buches weist Pigou zwar auf einige Zuordnungsprobleme hin ${ }^{299)}$, gleichwohl gilt diese Klassifikation als eine Pionierleistung, "deren Tragweite erst nach der Keynesschen Revolution ersichtlich wurde. Mit diesen Ausgabenkategorien ... gelingt es, staatliche und privatwirtschaftliche Aktivitäten im Wirtschaftskreislauf miteinander zu verbinden und dem Interdependenzaxiom Rechnung zu tragen." 300 )

\subsection{Fiscal Theory}

Obwohl die aus dem Englischen übernommene Namensgebung "fiscal theory" oder "fiscal policy" als Bezeichnung für den finanzwissenschaftlichen Problemkreis, der sich mit finanzpolitischer Stabilisierung befaßt, nicht sehr glücklich gewählt ist, - es stehen ja vorwiegend nichtfiskalische Ziele im Mittelpunkt der Betrachtung ${ }^{301)}$ - wird sie auch hier, der üblichen Kennzeichnung folgend ${ }^{3021}$, als Überschrift gewählt.

\subsubsection{Forderung nach aktiver Stabilisierungspolitik}

Neben der enormen quantitativen Veränderung der Staatsausgaben - ihr Anteil am Volkseinkommen stieg z.B. im Deutschen Reich von 16,5 vH im Jahre 1913

299) Vgl. Pigou, A.C.: A Study in Public Finance, 3rd ed., London 1947, reprinted London 1951, S. $19 \mathrm{ff}$.

Zuordnungsprobleme entstehen demnach beim Kauf bereits bestehender Vermögensgegenstände durch den Staat, die an sich den "non-transfer expenditures" zuzurechnen wären, aber da sie keine Inanspruchnahme von Produktivkräften darstellen, von diesen wiederum abzugrenzen sind. Quantitativ bedeutungsvoller sind nach Pigou die Schwierigkeiten bei Zahlungen an ausländische Wirtschaftseinheiten, z.B. Zinszahlungen für ausländische Schulden. Diese Auslandstransfers betrachtet er als eine besondere Form der "non-transfer expenditures". Desweiteren ist zu beachten, daß eine Reihe staatlicher Aufgaben alternativ von Privaten erbracht werden müßte, u.U. zu höheren Kosten, so daß eine Reduktion der staatlichen Ausgaben zu keinem Zuwachs an Produktivkräften zur freien Verwendung bei privaten Wirtschaftssubjekten führt, oder der Zuwachs geringer ist als der Verbrauch an Produktivkräften. Ferner gibt Pigou zu bedenken, daß staatliche Aktivitäten zur Beschäftigung sonst brachliegender Produktionskräfte führen kann, was ja bedeutet, daß der staatlichen Inanspruchnahme keine entsprechende Reduktion im privaten Bereich gegenübersteht.

300) Fecher, H.: Art.: Ausgaben, öffentliche I: Ansätze zu ihrer Analyse, in: Handwörterbuch der Wirtschaftswissenschaft (HdWW), hrsg. v. W Albers et al., Bd. 1, Stuttgart et al. 1977, S.334-349, S. 336.

301) Vgl. auch Mann, F.K.: Abriß einer Geschichte ..., a.a.O., S. 93.

302) Vgl. hierzu u.a. Littmann, K.: Problemstellung und Methoden ..., a.a.O., S. 100 und Mann, F.K.: Abriß einer Geschichte ..., a.a.O., S. 93. 
auf 41,0 vH in $1934^{303)}$ - vollzog sich nach dem ersten Weltkrieg eine grundlegende Änderung des politisch sozialen Denkens. Die periodisch wiederkehrenden Krisenerscheinungen galten bis dahin bei fast allen Ökonomen nicht nur als ein unabwendbares Übel, sondern als heilsame Erscheinungen. ${ }^{304)}$ Spiethoff pries den Wechsel von Aufschwung und Stockung des Wirtschaftslebens als "das stärkste Mittel, das hätte erdacht werden können, aus dem Menschen an wirtschaftlichem Kraftwillen herauszupressen, was er herzugeben vermag." ${ }^{305)}$ Für ihn bildet der Auf- und Abschwung sogar ein Kriterium für den Entwicklungsstand einer Volkswirtschaft. Ein Wirtschaftsverlauf in Wechsellagen, wie er es nannte, sei demnach "die Stufe mächtigster Bewegung, größter wirtschaftlicher Entfaltung, auf der äußerer Reichtum angesammelt wird" und die "jedes Volk mit weltgeschichtlicher Bedeutung ... durchlaufen"306) muß. Das Abrücken von dieser so begründeten passiven Einstellung des Staates gegenüber konjunkturellen Problemen oder präziser, die Forderung nach einer aktiven staatlichen Stabilisierungspolitik, führte zu einer Erweiterung des Untersuchungsfeldes der Finanzwissenschaft. Neben den Aufgaben, bestimmte Güter und Dienstleistungen bereitzustellen und soziale Ungerechtigkeiten abzuschwächen bzw. zu beseitigen wird nun der Finanzwirtschaft auch eine in zweifachem Sinne regulierende Funktion zugesprochen. Staatliche Aktivitäten, vor allem aber die öffentlichen Ausgaben, sollen dazu beitragen, ein gesamtwirtschaftliches Gleichgewicht wiederherzustellen bzw. zu erhalten und das Wirtschaftswachstum langfristig zu sichern. ${ }^{307)}$ Diese Ökonomisierung der Finanzpolitik ${ }^{308)}$, die Fritz Karl Mann auch als Übergang vom Anteil- zum Kontrollsystem ${ }^{309)}$ beschrieb, ist sehr eng mit dem Werk von John Maynard Keynes verbunden, der mit seinen Arbeiten, wie Littmann ausführte, den Bruch zwischen älterer und jüngerer Finanzwissenschaft deutlich markierte. ${ }^{310)}$

303) Vgl. Recktenwald, H.C.: Umfang und Struktur ..., a.a.O., S. 719.

304) Vgl. Meyer, F.W.: Glanz und Elend der Vollbeschäftigungspolitik, in: Grundtexte zur Sozialen Marktwirtschaft. Zeugnisse aus zweihundert Jahren ordnungspolitischer Diskussion, hrsg. v. W. Stützel et al., Stuttgart, New York 1981, S. 233-246, S. 233.

305) Spiethoff, A.: Art.:Krisen, in: Handwörterbuch der Staatswissenschaften, 4. Aufl., Bd. VI, Jena 1925, S. 8-91, S. 81

306) Ebenda, S. 85.

307) Vgl. Heller, W. et al.: Finanzpolitik im Dienste des wirtschaftlichen Gleichgewichts, Veröffentlichung der OECD, Dezember 1968, S. $13 \mathrm{f}$.

308) Vgl. Mann, F.K.: Die Staatswirtschaft unserer Zeit. Eine Einführung, Jena 1930, S. 29.

309) Vgl. ebenda, S. 1.

310) Vgl. Littmann, K.: Problemstellung und Methoden ..., a.a.O., S. 100. 


\subsubsection{John Maynard Keynes}

Es trifft sicher zu, daß wesentliche Methoden und Erkenntnisse der "fiscal theory", die heute allgemein mit dem Namen von Keynes in Verbindung gebracht werden, schon dessen Vorgängern bekannt waren. ${ }^{311)}$ Sein Verdienst wird dadurch aber keineswegs geschmälert, denn ihm gelang es, ein geschlossenes System dieser Ideen zu erarbeiten und somit auch die Finanzwissenschaft ein großes Stück voranzutreiben ${ }^{312)}$ oder, um es mit Röpkes Worten zu sagen, er war es, "der durch die Wucht und Kühnheit seines Auftretens die Geister in Bewegung gesetzt hat." ${ }^{313)}$

311) Vgl. Mann F.K.: Geschichte der angelsächsischen ..., a.a.O., S. 484. Vgl. auch Schumpeter, J.A.: Geschichte der ökonomischen ..., a.a.O., S. $1426 \mathrm{f}$. und vor allem Garvy, G.: Keynes and the Economic Activists of the Pre-Hitler Germany, in: Journal of Political Economy, vol. 83 (2), Chicago 1975, S. 391-405.

Insbesondere in der Nationalökonomie hat der Ausspruch: "Wer kann was Dummes, wer was Kluges denken, das nicht die Vorwelt schon gedacht?" (Faust, 2. Teil, 2. Akt, Vers 8609f. der Hamburger Ausgabe) seine unbestrittene Berechtigung. Denn gerade in dieser Wissenschaft können "alle Anschauungen ... irgendwie auf eine vorhergehende zurückgeführt werden" (Akerman, J.: Preise und Produktion. Rezension des gleichnamigen Buches von F.A. Hayek, in: Zeitschrift für Nationalökonomie, Bd. V (1934), S. 372-379, S. 373).

Zur Rolle von Keynes bei der Herausarbeitung der Elemente der "fiscal theory" schrieb Garvy: "However, what matters for the forward march of mankind is not who deserves credit of inventing any particular analytical apparatus or set of policy prescriptions, but who succeeded in making them widely accepted. This is the lasting contribution and impact of Keynes, who changed the entire focus of economic analysis" (Garvy, G.: Keynes and ..., a.a.O., S. 394). An anderer Stelle dieses Artikels zeigte sich Garvy verwundert darüber, daß Keynes, wie auch schon Adam Smith, seinen Vorläufern kaum Beachtung schenkte bzw. typischen Außenseitern unter ihnen größere Bedeutung beimaß (S. 391 f.). Zum einen gründet dies sicher in der Persönlichkeit von Keynes (vgl. hierzu Harrod, R.F.: Art.: Keynes, John Maynard, in: Handwörterbuch der Sozialwissenschaften, hrsg. v. E. von Beckerath et al., 5. Bd., Stuttgart et al. 1956, S. 606-614, S. 606 f.), zum anderen schreibt Garvy (S. 393) diesen Sachverhalt der Insellage Großbritanniens und insbesondere der Isolation der Cambridger Ökonomen zu.

Vgl. hierzu auch Schneider, E.: Der Streit um Keynes. Dichtung und Wahrheit in der neueren Keynes-Diskussion, in: Jahrbücher für Nationalökonomie und Statistik, Bd. 165 (1953), S. 89-122, S. 107 f. insbes. Fußnote 62.

Albert Hahn behauptet ebenfalls, schon 1920 wesentliche Ideen der "Keynesschen Lehren" erarbeitet zu haben. Vgl. Hahn, A.: Ewige Hochkonjunktur und kommandiertes Wachstum, Nr. 17 der Reihe: Vorträge und Aufsätze des Walter Eucken Instituts, Tübingen 1967, S. 7 f.

312) Vgl. Schneider, E.: Der Streit ..., a.a.O., S. 97.

313) Röpke, W.: Gegen die Brandung. Zeugnisse eines Gelehrtenlebens unserer Zeit, hrsg. v. A. Hunold, Zürich 1959, S. 364. 
Ausgehend von seiner Überzeugung "that capitalism, wisely managed, can probably be made more efficient for attaining economic ends than any alternative system yet in sight"314), sah John Maynard Keynes eine Hauptaufgabe der Ökonomen darin, "to distinguish afresh the Agenda of government from the Non-Agenda." ${ }^{215)}$ Dringlich und wünschenswert war seiner Meinung nach dabei die Herausarbeitung eines Kriteriums, das die Trennung von "services which are technical social from those which are technical individual"316) erlaubt. Weiter führte er aus: "The most important Agenda of the State relates not to those activities which private individuals are already fulfilling, but to those functions which fall outside the sphere of the individual, to those decisions which are made by no one if the State does not make them. The important thing for government is not to do things which individuals are doing already, and to do them a little better or a little worse; but to do those things which at present are not done at all." ${ }^{317)}$ Die Notwendigkeit staatlicher Aktivitäten begründete Keynes also allgemein damit, daß die privaten Wirtschaftssubjekte bestimmte Aufgaben, die er als wichtig unterstellt, nicht übernehmen. Insoweit ähnelt sein Allokationskriterium dem von Adam Smith. ${ }^{318)}$ Im Gegensatz zu diesem lieferte Keynes allerdings keinen Erklärungsversuch, "warum die privaten Wirtschaftssubjekte bestimmte Aufgaben, deren Erfüllung im gesellschaftlichen Interesse liegt, nicht übernehmen bzw. vernachlässigen." ${ }^{319}$ ' Er verwies diese Aufgabe vielmehr in den Bereich der praktischen Politik. ${ }^{320)}$ Konkreter wurde John Maynard Keynes in seinen Arbeiten erst dann, wenn er die aktive Rolle des Staates zur Bekämpfung der Arbeitslosigkeit beschrieb.

314) Keynes, J.M.: The End of Laissez-Faire, in: The Collected Writings of John Maynard Keynes, vol. IX. Essays in Persuasion, ed. by The Royal Economic Society, London 1972 , S.272-294, S. 294 (Erstveröffentlichung 1926).

315) Ebenda, S. 288.

Anschließend bemerkte Keynes auf derselben Seite: "... the companion task of politics is to devise forms of government within a democracy which shall be capable of accomplishing the Agenda" und führte dazu aus: "I believe that in many cases the ideal size for the unit of control and organisation lies somewhere between the individual and the modern State".

316) Ebenda, S. 291.

317) Ebenda, S. 291.

318) Vgl. Wille, E. und Gläser, M.: Staatsaufgaben bei ..., a.a.O., S. 58. Vgl. auch die Ausführungen in Abschnitt 1.3.1.

319) Wille, E. und Gläser, M.: Staatsaufgaben bei ..., a.a.O., S. 58.

320) Vgl. Keynes, J.M.: The End ..., a.a.O., S. 291. 
Trotz der Anfang der 30er Jahre sichtbaren großen ökonomischen Probleme kam Keynes zu der Schlußfolgerung, daß "assuming no important wars and no important increase in population, the economic problem may be solved, or be at least within sight of solution, within a hundred years. This means that the economic problem is not - if we look into the future - the permanent problem of the human race." ${ }^{321)}$ Ungeachtet der Tatsache, daß die Keynessche Analyse und das von ihm vorgeschlagene Instrumentarium sich in der Vergangenheit als nicht geeignet erwies, diese optimistische Prophezeiung als realistisch erscheinen zu lassen ${ }^{322)}$, ist es sein Verdienst, die Rolle des Staates als Teilnehmer und vor allem aktiver Mitgestalter des Wirtschaftsprozesses herausgestellt zu haben. Schon 1925 schrieb er, daß zukünftig "the government will have to take on many duties which it has avoided in the past" ${ }^{\text {"23), }}$, wobei er Minister und Parlamente für diese Zwecke als ungeeignet ansah und zur Dezentralisierung sowie zur Einrichtung von "semi-independent corporations and organs of administration"324) riet.

Da die von der klassischen Theorie unterstellte Tendenz zur Vollbeschäftigung seiner Meinung nach unter realitätsnahen Bedingungen nicht gelte, empfahl er eine aktivere Rolle des Staates bei der Bekämpfung des Beschäftigungsproblems. Vor dem Macmillan Committee ${ }^{325)}$ sagte er hierzu am 6. März 1930: "Neverthe

321) Keynes, J.M.: Economic Possibilities for our Grandchildren, in: The Collected Writings of John Maynard Keynes, vol. IX. Essays in Persuasion, ed. by The Royal Economic Society, London 1972, S. 321-332, S. 326 (Erstveröffentlichung 1930). Fairerweise muß angefügt werden, daß Keynes damit nicht sagen wollte, daß alle Bedürfnisse der Menschheit befriedigt werden könnten. Vielmehr beschränkte er die Aussage auf die "absolute needs", die in der Weise befriedigt sein werden, daß die Menschheit ihre Anstrengungen auf andere Probleme lenken kann.

Über 40 Jahre später sagte der damalige Finanzminister und spätere Bundeskanzler Helmut Schmidt in einem Spiegel-Interview: "Übrigens haben alle Regierungen der Welt kapiert, daß und wie man Rezessionen bekämpfen muß" (Der Spiegel, Nr. 40 vom 1.10.1973, S. 94), was wohl in dieselbe Richtung deutet.

322) Vgl. hierzu Schneider, H.K.: Ist der Keynesianismus ein taugliches Konzept zur Überwindung der Arbeitslosigkeit?, in: Perspektiven der deutschen Wirtschaftspolitik, hrsg. v. H. Siebert, Stuttgart 1983, S. 67-78 und Schlieper, U.: Der Keynesianismus als wirtschaftspolitische Doktrin, in: Perspektiven der deutschen Wirtschaftspolitik, hrsg. v. H. Siebert, Stuttgart 1983, S. 79-84.

323) Keynes, J.M.: Am I A Liberal?, in: The Collected Writings of John Maynard Keynes, vol.IX. Essays in Persuasion, ed. by The Royal Economic Society, London 1972, S. 295-306, S.301 (Erstveröffentlichung 1925).

324) Ebenda, S. 302.

Vgl. auch Keynes, J.M.: The End ..., a.a.O., S. 288 f. sowie die Fußnote 315 dieser Arbeit.

325) Lord Macmillan war Vorsitzender des unter dem Labour Schatzkanzler Lord Snowden am 4. November 1929 einberufenen "Committee on Finance and Industry", dessen Mitglied auch J.M. Keynes war. Vgl. Harrod, R.F.: The Life of John Maynard Keynes, New York 1966, S. 397. 
less I think the first impetus forward must come from action of this kind, that it must be Government investment which will break the vicious circle. If you can do that for a couple of years, it will have the effect, if my diagnosis is right, of restoring business profits more nearly to normal, and if that can be achieved then private enterprise will be revived. I believe you have first of all to do something to restore profits and then rely on private enterprise to carry the thing along."326) Dieses Zitat, wie auch seine anderen Reden und Antworten vor dem Macmillan Committee rechtfertigen nicht, in Keynes einen Anhänger oder gar geistigen Vater "des modernen Stagnationismus"327) zu sehen. Vielmehr betonte er ausdrücklich, daß lediglich ein erster Anstoß von der zusätzlichen staatlichen Nachfrage ausgehen sollte.

Vertrat Keynes ursprünglich noch die Meinung, eine wirtschaftliche Depression mit Hilfe monetärer Maßnahmen bekämpfen zu können, so kam er Ende der 20er Jahre zu der Ansicht, "der Staat müsse mit den verfügbaren Methoden Einfluß auf das Gesamtvolumen der inländischen Investitionen nehmen." ${ }^{228)}$ Zur Wiedergenesung der Wirtschaft sei eine höhere nationale Produktion nötig, die dann zu einer größeren Beschäftigung führe. Grundsätzlich sah er drei Möglichkeiten zur Ankurbelung der wirtschaftlichen Entwicklung: ${ }^{329 \text { ) }}$

- Erstens, indem die Individuen veranlaßt werden, einen größeren Teil ihres verfügbaren Einkommens auszugeben;

- zweitens, indem die Unternehmer, initiiert durch bessere Zukunftserwartungen oder geringere Zinsen, zusätzliche Einkommen bei den Beschäftigten schaffen und

- drittens, indem die öffentliche Hand durch zusätzliche kreditfinanzierte Ausgaben die laufenden Einkommen erhöht.

326) Keynes, J.M.: The Macmillan Committee, in: The Collected Writings of John Maynard Keynes, vol. XX. Activities 1929-1931. Rethinking Employment and Unemployment Policies, ed. by D. Moggridge, London 1981, S. 38-311, S. 146 f.

327) Schumpeter, J.A.: Geschichte der ökonomischen ..., a.a.O., S. 1425; vgl. hierzu auch Schneider, E.: Der Streit ..., a.a.O., S. 115.

328) Harrod, R.F.: Keynes, John Maynard, a.a.O., S. 609; vgl. auch Keynes, J.M.: The End ..., a.a.O., S. 292.

329) Vgl. Keynes, J.M.: An Open Letter, in: Readings in Fiscal Policy, ed. by A. Smithies and J.K. Butters, London 1955, S. 31-37, S. 33. 
Die erste Möglichkeit sah Keynes selbst als nicht vielversprechend an, während sich die zweite, nach einem erfolgten Umschwung, zur weiteren Ankurbelung durchaus als hilfreich erweisen könnte. Nur von den staatlichen Ausgabenerhöhungen erwartete er aber einen erfolgversprechenden "initial major impulse" ${ }^{330}$. Keynes selbst hat diese von ihm empfohlene Therapie sehr viel stärker in zwei Briefen, die unten ausschnittsweise zitiert sind, betont.Das erste Zitat entstammt einem Leserbrief an die Londoner "Times" vom 17. 10. 1932, der neben derjenigen von Keynes interessanterweise auch die Unterschrift von Pigou trug. Es lautet: "One thing is, in our opinion, clear. The public interest in present conditions does not point towards private economy; to spend less money than we should like to do is not patriotic. ... If the citizens of a town wish to build a swimming bath, or a library, or a museum, they will not, by refraining from doing this promote a wider national interest ... . Through their misdirected goodwill the mounting wave of unemployment will be lifted still higher. ${ }^{\text {"331) }}$ Das zweite Zitat stammt aus einem Brief, den John Maynard Keynes am 30. Dezember 1933 an den amerikanischen Präsidenten Franklin D. Roosevelt richtete: "Thus, as the prime mover in the first stage of the technique of recovery, I lay overwhelming emphasis on the increase of national purchasing power resulting from governmental expenditure which is financed by loans and is not merely a transfer through taxation, from existing incomes. Nothing else counts in comparison with this." 332

Nach Keynes müssen also staatliche Stellen einen Beitrag zur Erhöhung der kaufkräftigen Nachfrage leisten, um die Gewinnsituation privater Unternehmer zu verbessern. Dies bildet seiner Meinung nach die Voraussetzung dafür, daß mehr Beschäftigungsmöglichkeiten geschaffen werden. ${ }^{3331}$

330) Keynes, J.M.: An Open Letter, a.a.O., S. 33.

331) Zitiert nach Hutchison, T.W.: Economics and Economic Policy in Britain, 1946-1966. Some Aspects of Their Interrelations, London 1968, S. $20 \mathrm{f}$.

Zwei Tage später (19. Oktober 1932) erschien in derselben Zeitung eine Erwiderung, die u.a. von Hayek unterschrieben war und die, so Hutchison, sicher auch David Ricardo und Adam Smith mit Zustimmung aufgenommen hätten. Die Unterzeichner schrieben u.a.: "If the Government wish to help revival, the right way for them to proceed is, not to revert to their old habits of lavish excpenditure, but to abolish those restrictious on trade and the movement of capital ... which are at present impeding even the beginning of recovery". Zitiert nach Hutchison, T.W.: Economics and ..., a.a.O., S. 21.

Beide Leserbriefe zeigen eine Diskussion, die durchaus aktuelle Bezüge aufweist.

332) Keynes, J.M.: An Open Letter, a.a.O., S. 34.

333) Siehe hierzu auch Keynes, J.M.: The Great Slump of 1930, in: The Collected Writings of John Maynard Keynes, vol. IX. Essays in Persuasion, ed. by The Royal Economic Society, London 1972, S. 126-134, S. 134 (Erstveröffentlichung 1930) und Keynes, J.M.: The Means to Prosperity, in: The Collected Writings of John Maynard Keynes, vol. IX. Essays in Persuasion, ed. by The Royal Economic Society, London 1972, S. 335-366, S. 354 f. (Erstveröffentlichung 1933). 
Im Mittelpunkt der Diskussion um John Maynard Keynes steht dessen 1936 erstmals veröffentlichtes Werk "The General Theory of Employment, Interest and Money"334), obwohl andere, z.B. auch Harrod, der Auffassung sind, daß ein Student, "if he had to choose among Keynes' works, would get the best picture of his total contribution to economics in the Treatise." ${ }^{335)}$ Eine Ursache für diese starke Hervorhebung der "General Theory" ist sicherlich in den Zeitumständen ihrer Veröffentlichung zu finden. Das Werk zeigte den meisten durch die Erfahrungen der 30er Jahre ratlos gewordenen Wirtschaftstheoretikern einen Ausweg, den diese begierig aufgriffen. ${ }^{336)}$ Darüber hinaus bot der Inhalt der "General Theory" ob berechtigt oder nicht, soll an dieser Stelle nicht diskutiert werden - Ansatzpunkte für die unterschiedlichsten Interpretationen und somit ein vielfältiges Betätigungsfeld für junge Ökonomen. ${ }^{337)}$

H.K. Schneider unterscheidet zwei Hauptrichtungen der Keynes Diskussion. ${ }^{338}$ Zum einen die Auslegung von Hicks ${ }^{339)}$, der schon sehr bald nach dem Erscheinen der "General Theory" eine Integration der Keynesschen und Klassischen Gedan-

334) Keynes, J.M.: The General Theory of Employment, Interest and Money. in: The Collected Writings of John Maynard Keynes, vol. VII, ed. by The Royal Economic Society, London 1973 (Erstveröffentlichung 1936).

335) Harrod, R.F.: The Life ..., a.a.O., S. 403.

Das in diesem Zitat angesprochene Werk von Keynes lautet mit vollständigem Titel: "A Treatise on Money" und wurde 1930 erstmals veröffentlicht. Es ist zu finden in der Reihe: The Collected Writings of John Maynard Keynes, vol. V and VI, ed. by The Royal Economic Society, London 1971.

336) Vgl. Leijonhufvud, A.: On Keynesian Economics and the Economics of Keynes. A Study in Monetary Theory, New York 1968, S. 31.

Weitere Erklärungen, vor allem auch für die Wucht der Keynesschen Revolution, wie er es nennt, finden sich in: Johnson, H.G.: The Keynesian Revolution and the Monetarist Counter-Revolution, in: The American Economic Review, vol. LXI (1971), S. 1-14, insbesondere S. $3 \mathrm{ff}$.

337) Vgl. Leijonhufvud, A.: On Keynesian Economics ..., a.a.O., S. 16 f.

Erich Schneider sagt sogar, daß erst durch postkeynesianische Arbeiten deutlich wurde, was Keynes wohl meinte. Vgl. Schneider, E.: Der Streit ..., a.a.O., S. 107, Fußnote 62.

338) Vgl. Schneider, H.K.: Ist der Keynesianismus ..., a.a.O., S. $68 \mathrm{ff}$.

Einen hervorragenden Überblick über die Lektüre zur "General Theory" bietet der erste Teil des Anhangs zum 8. Kapitel in Richter, R., Schlieper, U. und Friedmann, W.: Makroökonomik. Eine Einführung, 4. Aufl., Berlin, Heidelberg, New York 1981, S. 570 ff.

339) Vgl. Hicks, J.R.: Mr. Keynes' Theory of Employment, in: The Economic Journal, vol. XLVI (1936), S. 238-253 sowie Hicks, J.R.: Mr. Keynes and the "Classics": A Suggested Interpretation, in: Econometrica, vol. 5 (1937), S. 147-159. 
ken versuchte und damit lange Zeit das Keynes-Bild bestimmte. ${ }^{340)}$ Zum anderen die neuere Interpretation von Leijonhufvud ${ }^{341}$, die Grossman in einer kritischen Erwiderung zu der Überschrift "Was Keynes a 'Keynesian'?"342) veranlaßte.

Während sich dieser Streit um die richtige Exegese des Keynesschen Werkes dreht, monieren andere den von Keynes selbst erhobenen Anspruch, eine allgemeinere Theorie als die Klassiker geschaffen zu haben. ${ }^{343)}$ Die Position der Klassiker, so Keynes in seinem Buch, habe mit der aktuellen wirtschaftlichen Wirklichkeit nichts gemein, sei also realitätsfern und die ihr zugrundeliegenden Annahmen hätten lediglich für einen Spezialfall Geltung. ${ }^{344)}$ Während Neumark noch vorsichtig einschränkt, "daß auch dem Keynesschen System in mancher Hinsicht nicht jene Allgemeingültigkeit und -anwendbarkeit zukommt, auf die es Anspruch erhebt", ihm aber attestiert, "daß seine Lehren in weit höherem Maße als die der älteren Theorie der heutigen Wirklichkeit adaequat sind"345), sprechen andere dem Keynesschen Werk den allgemeinen Charakter ab und gehen vielfach sogar soweit, in der Keynesschen Revolution einen gefährlichen Irrweg zu sehen. ${ }^{346)}$ Wilhelm Röpke konstatierte zwar, daß die große Depression der 30er

340) Vgl. hierzu auch Graf, G. Art Beschäftigungstheorie, in: Handwörterbuch der Wirt schaftswissenschaft (HdWW), hrsg. v. W. Albers et al., Bd. 1, Stuttgart et al. 1977, S. 513 543, S. $523 \mathrm{f}$.

341) Vgl. Leijonhufvud, A.: On Keynesian Economics ..., a.a.O.

Eine Schlüsselposition in dieser neueren Keynes Interpretation nimmt, nach Richter, Schlieper und Friedmann aber vor allem der Aufsatz von Clower, R.: The Keynesian Counterrevolution: A Theoretical Appraisal, in: The Theory of Interest Rates. Proceedings of a Conference held by the International Economic Association, ed. by F.H. Hahn and F.P R. Brechling, New York 1965, S. 103-125 ein. Vgl. auch Richter, R., Schlieper, U. und Friedmann, W.: Makroökonomik ..., a.a.O., S. 570 f.

342) Grossman, H.I.: Was Keynes a "Keynesian"? A Review Article, in: Journal of Economic Literature, vol. X (1972), S. 26-30.

343) In der ersten Fußnote der "General Theory" präzisiert Keynes, wen er zu den klassischen Ökonomen zählt. Als Auswahlkriterium gibt er ihre geistige Nähe zu Ricardo an und führt beispielhaft J.S. Mill, Marshall, Edgeworth und Pigou auf. Oliver Landmann weist darauf hin, daß er in diesen Fällen dogmenhistorisch die Bezeichnung "neoklassisch" für angebracht hält. Vgl. Landmann, O.: Keynes in der heutigen Wirtschaftstheorie, in: Der Keynesianismus, Bd. I. Theorie und Praxis keynesianischer Wirtschaftspolitik, hrsg. v. G. Bombach et al., Berlin, Heidelberg, New York 1976, S. 133-210, S. 203, Fußnote 3.

344) Vgl. Keynes, J.M.: The General Theory ..., a.a.O., S. 3.

345) Neumark, F.: Grundsätze und Arten ..., a.a.O., S. 621.

346) Vgl. u.a. Hayek, F.A.: Full Employment at Any Price? published by The Institute of Economic Affairs, London 1975 und Röpke, W.: Was lehrt uns Keynes? Die Revolution in der Nationalökonomie, in: Universitas, 7. Jg. (1952), S. 1285-1295. Zu einigen Gegenargumenten und Rechtfertigungen siehe auch Schneider, E.: Der Streit ..., a.a.O., S. 89 ff. 
Jahre "durch eine wie auch immer ausgelöste Kette von Einkommens- und Nachfrageausfällen" gekennzeichnet war, in der es galt, "in kühner Umkehrung gesunden wirtschaftlichen Denkens das Hauptgewicht auf das Ausgeben, auf die Vermehrung der wirksamen Nachfrage" ${ }^{\text {"347) }}$ zu legen. Insoweit stimmt er für diese außergewöhnliche Situation ${ }^{348}$ ' mit dem Therapievorschlag von Keynes überein, wirft ihm aber vor, sich damit nicht begnügt zu haben, sondern mit einer alleinigen Anpreisung des Denkens in Kreislaufgrößen "mehr Schaden als Nutzen gestiftet zu haben". Er kritisiert in diesem Zusammenhang, daß diese "wahre Revolution des wirtschaftlichen Denkens ... das meiste von dem, was Wissenschaft und gesunder Menschenverstand bis dahin für richtig und erprobt gehalten haben, wirklich auf den Kopf ${ }^{\text {"349) }}$ gestellt habe. Der Vorwurf, die Zeit- und Raumgebundenheit der Keynesschen Konzeption nicht deutlich genug gemacht zu haben, trifft aber wohl verstärkt bzw. in erster Linie seine Nachfolger und Interpreten, die aus seiner Analyse, wie Johnson sagte, ein "timeless and spaceless set of universal priciples" ${ }^{\text {350) }}$ machten.

Darüber hinaus wird an Keynes oft kritisiert, er habe längerfristige Aspekte außer Acht gelassen und als Beleg hierfür der Ausspruch "in the long run we are all dead" zitiert. Obwohl die Keynessche Theorie eine Theorie der kurzen Periode darstellt ${ }^{3511}$, wollte Keynes mit dem oben angeführten Zitat nicht einer "Nach-

347) Röpke, W.: Was lehrt uns ..., a.a.O., S. $1288 \mathrm{f}$.

348) Manche Autoren verweisen zusātzlich auf die besondere wirtschaftliche Lage Großbritanniens und sehen vor diesem Hintergrund eine weitere Einschränkung der Allgemeingültigkeit. Vgl. hierzu Hayek, F.A.: Full Employment ..., a.a.O., S. 18f.

349) Röpke, W.: Was lehrt uns ..., a.a.O., S. 1289.

An anderer Stelle dieses Artikels (S. 1291) ging Röpke noch sehr viel schärfer mit der Keynesschen Lehre ins Gericht. Er schrieb u.a.: "Wie man in äußerster Seenot die Masten kappen und die Ladung über Bord gehen lassen muß, so kann es auch im Wirtschaftsleben Orkane geben, die uns nötigen, vorübergehend die Grundsātze gesunder Wirtschafts- und Geldpolitik zu mißachten, aber nicht ungestraft erklärt man sie für überholt, weil sie einer Politik der Vollbeschäftigung unbequem sind, auf die man sich unter der Schockwirkung der großen Depression versteift hat."

350) Johnson, H.G.: The Keynesian Revolution ..., a.a.O., S. 6.

Vgl. auch Schneider, E.: Der Streit ..., a.a.O., S. 116, insbes. die Fußnote 88.

351) Vgl. Schneider, E.: Der Streit ..., a.a.O., S. 96.

Keynes argumentiert in der "General Theory" immer für eine Volkswirtschaft, bei der folgendes als gegeben vorausgesetzt wird: "... the existing skill and quantity of available labour, the existing quality and quantity of available equipment, the existing technique, the degree of competition, the tastes and habits of the consumer, as well as the social structure including the forces, other than our variables set forth below, which determine the distribution of the national income." Keynes, J.M.: The General Theory ..., a.a.O., S. 245. 
uns-die-Sintflut-Mentalität" das Wort reden, denn das vollständige Zitat lautet: "But this long run is a misleading guide to current affairs. In the long run we are all dead. Economists set themselves too easy, too viceless a task if in tempestuous seasons they can only tell us that when the storm is long past the ocean is flat again."352)

Die Widersacher der Keynesschen Lehren mußten sich bis fast in die jüngste Zeit vielerorts damit zufrieden geben, als Mahner in der Wüste ungehört zu bleiben, prägten doch gerade die Anhänger von Keynes in großem Maße die Politik vieler westlicher Länder nach dem 2. Weltkrieg. Das Keynessche Gedankengut fand Eingang in die Gestaltung der sog. "New Economics" in den USA, unter den Präsidenten Kennedy und Johnson sowie in die Formulierungen des im Juni 1967 in der Bundesrepublik erlassenen sog. "Stabilitäts- und Wachstumsgesetzes". ${ }^{3531}$ Die in diesem Gesetz verankerte Globalsteuerung des Wirtschaftsprozesses hat nach Karl Schiller, "das Gedankengut der Keynesianischen Botschaft, des Freiburger Imperativs und der neoklassischen Synthese für wirtschaftspolitische Entscheidungen aufbereitet" ${ }^{354)}$ und den wohl modernsten Werkzeugkasten konjunkturpolitischer Steuerungsmöglichkeiten geliefert. ${ }^{355)}$ Der mit dem Einfluß

352) Keynes, J.M.: A Tract on Monetary Reform, in: The Collected Writings of John Maynard Keynes, vol. IV, ed. by The Royal Economic Society, London 1971, S. 65 (Erstveröffentlichung 1923).

Vgl. auch Starbatty, J.: Marx, Keynes und Schumpeter zu aktuellen und grundsätzlichen Fragen. Ein fiktives Interview, in: Wirtschaftswissenschaftliches Studium (WiSt), 13. Jg. (1984), S. 33-39, S. $33 \mathrm{f}$.

353) Vgl. Jarchow, H.-J.: Der Keynesianismus, in: Geschichte der Nationalökonomie, hrsg. v. O. Issing, München 1984, S. 147-163, S. 161 und Hansmeyer, K.-H.: Ursachen des Wandels der Budgetpolitik, in: Budgetpolitik im Wandel, N.F. Bd. 149 der Schriften des Vereins für Socialpolitik, hrsg. v. K. Häuser, Berlin 1986, S. 11-32, S. 13 ff. sowie Arnim, H.H.v.: Staatslehre ..., a.a.O., S. 98f.; Bowden, E.V.: Economic Evolution ..., a.a.O., S. 175 ff. und Riha, T.: German Political Economy ..., a.a.O., S. 220 ff.

354) Schiller, K.: Konjunkturpolitik auf dem Wege zu einer Affluent Society, Vortrag im Institut für Weltwirtschaft an der Universität Kiel am 26. Januar 1968, Kieler Vorträge, N.F. Nr. 54, Kiel 1968, S. 7.

355) Vgl. Schiller, K.: Konjunkturpolitik auf _.., a.a.O., S. 9.

Otto Schlecht überschrieb den letzten Abschnitt eines Vortrags vor dem Walter Eucken Institut mit: "Geläuterte Einschätzung des StWG" und relativiert hierin auch seine eigenen optimistischen Erwartungen an die Möglichkeiten der Globalsteuerung. Vgl. Schlecht, O.: "Konjunkturpolitik in der Krise", Nr. 94 der Reihe:Vorträge und Aufsätze des Walter Eucken Instituts, Tübingen 1983, S. 47.

Nach Artur Woll berufen sich alle stabilitätspolitischen Konzepte der 60er Jahre zu Unrecht auf Keynes. Vgl. Woll, A.: Das Ende der Stabilitätspolitik, Nr. 93 der Reihe:Vorträge und Aufsätze des Walter Eucken Instituts, Tübingen 1983, S. 7 ff. 
des Keynesianismus verbundene Optimismus hinsichtlich der Steuerbarkeit konjunktureller Entwicklungen wird in einem Zitat von Paul A. Samuelson deutlich, der die Behauptung, daß "the probability of a great depression ... has been reduced to a negligible figure"356), als ein allgemein anerkanntes Fundament der Ökonomen bezeichnet. ${ }^{357)}$

Während eine keynesianisch orientierte Politik in den 60er Jahren "noch als erfolgreich angesehen wurde, zeichnete sich im Laufe der 70er Jahre eine gewisse Umorientierung in der Wirtschaftspolitik ab." ${ }^{358)}$ Diese Umorientierung gilt auch für die Bundesrepublik Deutschland, unbeschadet der Tatsache, daß vor allem noch in Gewerkschaftskreisen, unter dem Schlagwort einer "beschäftigungssichernden Finanzpolitik" von der "grundsätzlich ungebrochenen Gültigkeit keynesscher Handlungsanleitungen für staatliche Krisenbekämpfungen"359) ausgegangen wird. Nach dieser Richtungsänderung wird der Steuerungsmechanismus des Marktes stärker in den Vordergrund gerückt und ein Zurückdrängen staatlicher Einmischungen verlangt. ${ }^{360)}$ Otto Schlecht mahnt in diesem Zusammenhang "zur Vorsicht sowohl gegenüber einer allzu ehrgeizigen Antizyklik als auch gegenüber einer azyklischen Betrachtungsweise". Er verlangt stattdessen "wieder etwas mehr Gelassenheit und Akzeptanz gegenüber dem Zyklus als dem Wellenschlag ökonomischer Entwicklung."361) Ein vernichtendes Verdikt über das politische Vermächtnis von Keynes sprechen Buchanan und Wagner ${ }^{362)}$ aus, wobei sie aber vor allem die Unfähigkeiten der Politiker anprangern und kaum das theoretische Konzept von Keynes kritisieren. Die Politiker, so Buchanan und

356) Samuelson, P.A.: Economics, 11 th ed., New York 1980, S. 251.

357) Vgl. auch Schlieper, U.: Der Keynesianismus ..., a.a.O., S. 80 f.

358) Jarchow, H.-J.: Der Keynesianismus, a.a.O., S. 161.

Vgl. auch die einzelnen Beiträge in Siebert, H. (Hrsg.): Perspektiven der deutschen Wirtschaftspolitik, Stuttgart 1983.

359) Schäfer, C.: Beschäftigungssichernde Finanzpolitik. - Was sie ist und was sie kann. - Eine Einführung und Zusammenfassung, in: Beschäftigungssichernde Finanzpolitik. Eine Chance für Vollbeschäftigung, hrsg. v. C. Schäfer und H. Tofaute, Frankfurt/Main, New York 1981, S. 11-34, S. 14.

360) Vgl. Woll, A.: Das Ende ..., a.a.O., S. 30

Dies kontrastiert ganz offensichtlich mit jener "Art von Späth-Kapitalismus", die Graf Lambsdorff den "Industriepolitikern der deutschen Südstaaten" noch 1985 vorwarf. Vgl. Wirtschaftswoche Nr. 50 vom 6. Dezember 1985: Lambsdorffs Attacke, S. 22-25.

361) Schlecht, O.: Konjunkturpolitik in ..., a.a.O., S. 45.

362) Buchanan, J.M. and Wagner, R.E.: Democracy in Deficit. The Political Legacy of Lord Keynes, New York et al. 1977. 
Wagner, pickten sich nämlich in der Vergangenheit das ihnen Genehme aus den Keynesschen Lehren heraus und kamen dann zu einseitigen, als negativ anzusehenden Ergebnissen. ${ }^{363)}$ Gleichwohl wird an dieser Kritik von Buchanan und Wagner wiederum deutlich, daß die richtige Adresse vieler Angriffe gegen die Keynesschen Lehren nicht Keynes selbst ist, sondern vielmehr seine Nachfolger und die, die vorgeben in seinen Denkschemata zu wandeln.

\subsubsection{Das Prinzip der Functional Finance}

Unter dem Stichwort "Functional Finance" ist in der Literatur eine extreme Variante der Keynesschen Lehre zu finden, die vor allem von dem Keynes Schüler Abba P. Lerner entwickelt wurde. ${ }^{364)}$ Als zentrales Anliegen der "Functional Finance" postulierte Lerner, daß die Aktivitäten der staatlichen Haushaltspolitik "shall all be undertaken with an eye only to the results of these actions on the economy and not to any established traditional doctrine about what is sound or unsound." ${ }^{365)}$ In dieser allgemeinen Form findet das Postulat wenig Ablehnung. Lerner's Schlußfolgerung lautete allerdings, daß sich die Regierung einzig darauf zu konzentrieren habe, die Gesamtausgaben des Staates auf der Höhe zu halten, die geeignet sei, Erwerbslosigkeit und Inflation zu verhindern. ${ }^{366)}$ Alle finanzpolitischen Maßnahmen seien diesem Ziel unterzuordnen. Konkret heißt dies, daß Steuern nur erhoben werden sollen, "when it is desirable that the taxpayers shall have less money to spend" ${ }^{\text {367) }}$ und, daß der Staat, falls er Ausgaben tätigen will, dies durch Geldschaffung finanzieren sollte. ${ }^{368)}$ Entsprechend ist die Aufnah me von Anleihen nur dann ratsam, "if it is desirable that the public should have less money and more government bonds." ${ }^{369)}$ Die Höhe der staatlichen Verschul

363) Vgl. Buchanan, J.M. and Wagner, R.E.: Democracy in Deficit ..., a.a.O., S. $55 \mathrm{ff}$

364) Zur Vor- und Frühgeschichte der "functional finance" vgl. Schulz, F.: Die Vorschläge von Georg von Schanz zur antizyklischen Finanzpolitik in der Tradition der öffentlichen Arbeitsbeschaffung. Ein Beitrag zur Dogmengeschichte der "functional finance", in: Finanzarchiv, hrsg. v. N. Andel und F. Neumark, N.F. Bd. 42, Tübingen 1984, S. 542-552.

365) Lerner, A.P.: Functional Finance and the Federal Debt, in: Readings in Macroeconomics, ed. by M.G. Mueller, 2nd ed., London et al. 1971, S. 353-360, S. 354 (Erstveröffentlichung 1943).Vgl. auch Lerner, A.P.: The Economics of Control. Principles of Welfare Economics, New York 1949, S. 302 (Erstveröffentlichung 1944).

366) Vgl. Lerner, A.P.: Functional Finance ..., a.a.O., S. 354 und Mann, F.K.: Geschichte der angelsächsischen ..., a.a.O., S. 488.

367) Lerner, A.P.: Functional Finance ..., a.a.O., S. 354.

368) Vgl. ebenda, S. 354.

369) Ebenda, S. 354. 
dung spielte für Lerner ebenfalls keine besondere Rolle, weshalb er den Haushaltsausgleich auch über einen mehrperiodigen Zyklus nicht als erstrebenswertes Ziel staatlicher Finanzpolitik ansieht, denn "there is no reason for supposing that the spending and taxation policy which maintains full employment and prevents inflation must necessarily balance the budget over a decade any more than during a year or at the end of each fortnight." ${ }^{\text {"370l }}$ Außerdem sei die Zinslast der staatlichen Verschuldung kein Problem, denn "taxation must not be applied un less it is necessary to keep spending down to prevent inflation. The interest can be paid by borrowing still more." ${ }^{371)}$ Fritz Karl Mann kritisert, daß durch diese "ver blüffende Lehre ... die Finanzierung des Staates nur noch als Nebenfunktion der Finanzwirtschaft gelten dürfte."372)

Diese Verabsolutierung des beschäftigungs- und stabilisierungspolitischen Ziels als Aufgabe staatlicher Entscheidungseinheiten, hat sich allerdings in der modernen Finanzwissenschaft nicht durchgesetzt. ${ }^{373 \prime}$

\subsubsection{Das makroökonomische Modell}

Eine Aufgabe der "General Theory" bestand nach Keynes darin, "to discover what determines at any time the national income of a given economic system and (which is almost the same thing) the amount of its employment."374) Seine Analysemethoden waren dementsprechend makroökonomischer Art. Der entscheidende Unterschied "between the theory of the economic behaviour of the aggregate and the theory of the behaviour of the individual unit" liegt darin, daß man bei letzterer die Annahme treffen kann, "that changes in the individual's own demand do not affect his income." ${ }^{375)}$ Die aggregierte makroökonomische Betrachtungsweise bewertete Erich Schneider als "eine erneute Hinwendung zum Denken der Klassiker und zugleich (als) eine wesentliche Steigerung der Leistungsfähigkeit der

370) Lerner, A.P.: Functional Finance ..., a.a.O., S. 355.

371) Ebenda, S. 356.

372) Mann, F.K.: Abriß einer Geschichte ..., a.a.O., S. 96.

373) Vgl. auch Littmann, K.: Problemstellung und Methoden ..., a.a.O., S. 102.

374) Keynes, J.M.: The General Theory ..., a.a.O., S. 247.

375) Ebenda, S. 85. 
ökonomischen Theorie."376)

Während die einen nun diese makroökonomische Betrachtungsweise als zu dominierend und gefährlich ansahen, weil sie in der Aggregatbildung viele ökonomische Sachverhalte übertünche ${ }^{377)}$, sahen andere in ihr die Chance, "daß durch sie die Finanzwissenschaft eine allgemeine Basis erhalte, mit deren Hilfe die staatswirtschaftlichen Prozesse eindeutig zu analysieren seien." ${ }^{378)}$ Das hochaggregierte Modell von Keynes erlaube

- erstens, "den Staat als eine handelnde Wirtschaftseinheit aufzufassen, deren Aktivitäten vollständig in den ökonomischen Kreislaufzusammenhang einzuordnen sind". Ein solches Modell "läßt nicht nur eine simultane Behandlung von Staatseinnahmen und -ausgaben zu, sondern ... fordert geradezu die um fassende Betrachtung der Staatstätigkeit heraus"379);

- zweitens verbinde sich mit ihm "der Übergang von der Phase des systemati schen Ordnens und Beschreibens zur Phase des Analysierens staatswirt. schaftlicher Phänomene"380';

- schließlich provoziere drittens "die hohe Aggregation des makroökonomischen Modells die Aussonderung globaler Lenkungsaufgaben aus dem Markt-PreisSteuerungsmechanismus des Wirtschaftsprozesses." ${ }^{3811}$

Nach Littmann ist die makroökonomische Betrachtungsweise die den beschäftigungs- und stabilisierungspolitischen Fragen angemessene Sichtweise, gleichwohl versagt sie, wenn allokative und distributive Zusammenhänge zur Untersuchung anstehen. So gesehen erweist sich "die Stärke der 'fiscal theory' zugleich als ihre Schwäche. Sie erfaßt einen und nur einen Aspekt der staatlichen Aktivität, den sie konsequent analysiert." ${ }^{\text {"32) }}$ Trotzdem kann man konstatieren, daß mit

376) Schneider, E.: Der Streit ..., a.a.O., S. 100.

Keynes selbst sieht seine Theorie als Ergänzung und Erweiterung der bisherigen Theorien an. In einem posthum veröffentlichten Aufsatz schrieb er: "Here is an attempt to use what we have learnt from modern experience and modern analysis, not to defeat, but to implement the wisdom of Adam Smith". Keynes, J.M.: The Balance of Payments of the United States, in: The Economic Journal, vol. LVI (1946), S. 172-187, S. 186.

377) Vgl. die Aufzählung bei Schneider E.: Der Streit ..., a.a.O., S. 99 f.

378) Littmann, K.: Problemstellung und Methoden ..., a.a.O., S. 100.

379) Ebenda, S. 101.

380) Ebenda, S. 101.

381) Ebenda, S. 101.

382) Ebenda, S. 102. 
der 'fiscal theory' und damit mit den Arbeiten von Keynes die Stabilisierungspolitik als staatliche Aufgabe entdeckt wurde und insoweit auch Eingang in finanzwissenschaftliche Fragestellungen gefunden hat.

\subsection{Zum Stand der modernen Ausgabentheorie}

Wenn man der Aussage Schumpeter's zustimmt, daß eine Epoche um so weniger zu verstehen ist, je näher sie zeitlich liegt ${ }^{383)}$, so erscheint die Beurteilung und Einordnung der verschiedenen Strömungen der Gegenwart als ein höchst schwieriges Unterfangen.

\subsubsection{Die Ausgaben im Dienste eines pluralistischen Aufgabenbündels des Staates}

Die moderne Finanzwissenschaft weist dem Staat ein "pluralistisches Aufgaben. bündel"384) zu, was nach Littmann, von der Realitätsbezogenheit der Disziplin zeugt, aber auf der Gegenseite die Bildung konsistenter finanzwissenschaftlicher Systeme erschwert. ${ }^{385)}$ Die Dreiteilung staatlicher Aufgaben in die Allokations . Distributions- und Stabilisierungsaufgabe, wie von Musgrave vorgeschlagen ${ }^{386}$, deutet zwar den Umfang der finanzwissenschaftlichen Fragestellungen an, kann allerdings als Grundlage zur Einordnung der Ausgaben nicht herangezogen werden, da sie vor allem den Interdependenzen der öffentlichen Ausgaben kaum Rechnung zu tragen vermag. Hinzukommt, daß die Verteilungsaspekte in der Fi-

383) Vgl. Schumpeter, J.A.: Geschichte der ökonomischen ..., a.a.O., S. 927.

384) Littmann, K.: Problemstellung und Methoden ..., a.a.O., S. 102.

385) Vgl. ebenda, S. 102.

386) Vgl. Mlisgrave, R.A. and Musgrave, P.B.: Public Finance in Theory and Practice, 4th ed., New York et al. 1984, S. 6 ff. Eine frühere Darstellung findet sich in Musgrave, R.A.: A Multiple Theory of Budget Determination, in: Finanzarchiv, hrsg. v. F. Neumark, N.F. Bd. 17 (1956/57), Tübingen 1957, S. 333-343.

Kritische Anmerkungen zu der Dreiteilung der Budgetfunktionen sind dem Artikel von Colm, G.: Comments on Richard A. Musgrave's "A Multiple Theory of Budget Determination", in: Finanzarchiv, hrsg. v. F. Neumark, N.F. Bd. 18 (1957/58), Tübingen 1958, S. 52-55 zu entnehmen. Musgrave sieht auch heute in dieser Aufteilung nicht nur ein pädagogisches Hilfsmittel, sondern "a systematic approach to the structure of our science". Musgrave, R.A.: Public Finance, now and then, in: Finanzarchiv, hrsg. v. N. Andel und F. Neumark, N.F. Bd. 41, Tübingen 1983, S. 1-13, S. 3. 
nanzwissenschaft "noch nicht einmal ansatzweise systembildende Züge"387) aufweisen. Ebenso ist die weit verbreitete Einteilung der Ansätze zur Analyse öffentlicher Ausgaben in die antithetischen Kategorien normativ und positiv nicht geeignet, der Vielfalt der Forschungsrichtungen über die öffentlichen Ausgaben gerecht zu werden, insbesondere auch, weil allenthalben eine Mischung positiver und normativer Elemente zu beobachten ist. ${ }^{388)}$

Littmann unterscheidet zwei Hauptströmungen der gegenwärtigen Finanzwissenschaft: zum einen eine Ausrichtung, die in der Tradition institutionell-deskriptiver Methoden ${ }^{389)}$ die "politisch-gesellschaftlichen Bedingungen finanzpolitischer Entscheidungen stärker in das Blickfeld rückt" ${ }^{\text {390) }}$ und zum anderen einen durch die "fiscal theory" eingeleiteten Trend, der seine "systematische Basis gerade auf der Gegenseite, nämlich durch die Adaption der quantitativen Theorie der Wirtschaftspolitik"391' sucht. Selbstverständlich überlappen sich beide Strömungen und so ist auch der Versuch, die Ausgabentheorie hierin einzuordnen, vor diesem Hintergrund zu sehen. Korrespondierend hierzu kann man bei den Staatsausgaben ebenfalls zwei Themenkomplexe unterscheiden ${ }^{392)}$ : zahlreiche Ansätze stellen die Bestimmung der öffentlichen Aufgaben und damit auch der Ausgaben ${ }^{393)}$ in den Mittelpunkt und zielen folglich darauf ab, "die gesamtwirt schaftliche, und die Allokation im öffentlichen Sektor entweder positiv zu erklä ren oder normativ zu bestimmen." ${ }^{394)}$ Andere Ansätze hingegen heben "die Wirkung öffentlicher Ausgaben, also (die) Analyse ihres Einflusses auf die wirtschaftlichen und sozialen Bedingungen" ${ }^{395)}$ besonders hervor.

387) Littmann, K.: Problemstellung und Methoden ..., a.a.O., S. 105. Vgl. auch Fecher, H.: Ausgaben, offentliche ..., a.a.O., S. 347.

388) Vgl. Wille, E.: Die öffentlichen Ausgaben ..., a.a.O., S. 301. In ähnlicher Weise äußern sich Fecher und Littmann. Vgl. hierzu Fecher, H.: Ausgaben, öffentliche ..., a.a.O., S. 339 und Littmann, K.: Problemstellung und Methoden ..., a.a.O., S. $102 \mathrm{ff}$.

Einen Überblick über die verschiedenen Ansätze der sog. positiven Theorien der Staatsausgaben enthält der Beitrag von Schwarting, G.: Positive Theorien der Staatsausgaben: Ein kritischer Überblick, in: Schweizerische Zeitschrift für Volkswirtschaft und Statistik, 116.Jg. (1980), S. 67-92.

389) Mann nennt diese Tradition zum einen "Finanzmorphologie" (vgl. Mann, F.K.: Geschichte der angelsächsischen ..., a.a.O., S. 478), zum anderen auch "finanzwissenschaftlicher Institutionalismus" (vgl. Mann, F.K.: Abriß einer Geschichte ..., a.a.O., S. 97).

390) Littmann, K.: Problemstellung und Methoden ..., a.a.O., S. 105

391) Ebenda, S. 106.

392) Vgl. ebenda, S. 112.

393) Vgl. hierzu Abschnitt 1.1.2. insbesondere Fußnote 19.

394) Wille, E.: Die öffentlichen Ausgaben ..., a.a.O., S. 301.

395) Littmann, K.: Problemstellung und Methoden ..., a.a.O., S. 112. 


\subsubsection{Ansätze zur Bestimmung öffentlicher Ausgaben}

Was die "Bestimmung öffentlicher Ausgaben, d.h. (die) Rechtfertigung sowie Determination von Umfang und Art der staatlichen Aktivität"396) angeht, lassen sich einer Einteilung Wille's folgend momentan vier Forschungsbereiche unterscheiden: $:^{397)}$

1. die wohlfahrtsökonomische Theorie der öffentlichen Güter,

2. Ansätze im Rahmen der ökonomischen Theorie der Politik bzw. im Rahmen der Public Choice-Forschung,

3. Thesen zur langfristigen Entwicklung der Staatsausgaben und

4. Systeme und Methoden öffentlicher Aus- bzw. Aufgabenplanung.

Ad 1: Die wohlfahrtsökonomische Theorie der öffentlichen Güter deutet die öffentlichen Ausgaben als "monetären Ausdruck staatlicher Maßnahmen ..., die Unzu-

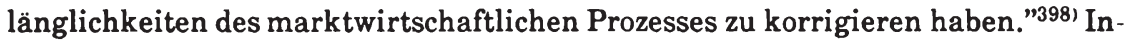
nerhalb dieses Forschungsschwerpunktes wurde zunächst nach Gütereigenschaften gesucht, "die eine theoretisch exakte Unterscheidung zwischen privaten und öffentlichen Gütern erlauben" ${ }^{399)}$, wobei die Nichtrivalität beim Konsum und die Nichtausschließbarkeit vom Konsum als spezifische Merkmale eines reinen öffentlichen Gutes angesehen wurden. ${ }^{400)}$ Neben der Bestimmung, was unter $\mathrm{Zu}$ -

396) Littmann, K.: Problemstellung und Methoden ..., a.a.O., S. 112

397) Vgl. Wille, E.: Die öffentlichen Ausgaben ..., a.a.O., S. 301. Ähnliche Einteilungen schlagen auch Fecher und Littmann vor. Vgl. Fecher, K.: Ausgaben, öffentliche .., a.a.O., S. 339 ff. und Littmann, K.: Problemstellung und Methoden ..., a.a.O., S. $112 \mathrm{ff}$.

398) Fecher, H.: Ausgaben, öffentliche ..., a.a.O., S. 339.

399) Wille, E.: Die öffentlichen Ausgaben ..., a.a.O., S. 301.

400) Diese Konzeption der öffentlichen Güter ist vor allem durch die Arbeiten von Samuelson und Musgrave angeregt worden. Vgl. hierzu, neben den zahlreichen Veröffentlichungen der beiden, auch Schmidt, K.: Kollektivbedürfnisse und Staatstätigkeit, in: Theorie und Praxis des finanzpolitischen Interventionismus. Fritz Neumark zum 70. Geburtstag, hrsg. v. H. Haller et al., Tübingen 1970, S. 3-27 sowie Thiemeyer, T.: Theorie der öffentlichen Güter als ökonom(ist)ische Staatstheorie, in : Öffentliche Güter und öffentliche Unternehmen. Beiträge zur Relevanz der Theorie der öffentlichen Güter für die öffentlichen Unternehmen, hrsg. v. K. Oettle, Baden-Baden 1984, S. 73-89, S. 73 ff.

Eine über die zwei Eigenschaften Nichtrivalität und Nichtauschließbarkeit hinausgehende Liste von zehn Merkmalen, "die durchaus gleichrangig als Bestimmungsmerkmale des Öffentlichkeitscharakters angesehen werden müssen" (S. 16) findet sich in Rittig, G.: Öffentliche Güter, öffentliche Unternehmungen und die oeconomia publica, in: Öffentliche Güter und öffentliche Unternehmen. Beiträge zur Relevanz der Theorie der öffentlichen Güter für die öffentlichen Unternehmen, hrsg. v. K. Oettle, Baden-Baden 1984, S. 15-57, S. 15 ff.

Einen hervorragenden Überblick bieten Blümel, W., Pethig, R. und von dem Hagen, O.: The Theory of Public Goods: A Survey of Recent Issues, in: Journal of Institutional and Theoretical Economics, vol. 142 (1986), S. 241-309. 
grundelegung der beiden Merkmale $e^{401)}$, als öffentliches Gut anzusehen ist, wurde gleichzeitig als weitere Kategorie nicht allein privatwirtschaftlich koordinierter Güter die sog. meritorischen Güter in die wissenschaftliche Diskussion eingeführt. ${ }^{402)}$ Kurt Schmidt bezeichnete diese Theorien von den Kollektivbedürfnissen und Kollektivgütern schon sehr früh als Irrweg, "insoweit sie normativen Charakter haben und dazu dienen sollen, Art und Umfang der finanzwirtschaftlichen Tätigkeit des Staates zu bestimmen." ${ }^{403)}$

Im Mittelpunkt der neueren Ansätze der Theorie der öffentlichen Güter steht das Freifahrerproblem, das zum einen im Rahmen der Gruppengröße und zum anderen als Problem anreizkompatibler Abstimmungsverfahren diskutiert wird. ${ }^{404)}$ Es geht hierbei um die Herausarbeitung von Mechanismen und institutionellen Gegebenheiten, die die Individuen zur Offenlegung ihrer Präferenzen hinsichtlich der Kollektivgüter bewegen könnten, um damit dann zu Aussagen über den Umfang staatlicher Budgets zu gelangen. Durch die stärkere Betonung institutioneller Aspekte ergeben sich zwangsläufig auch Berührungen dieser neueren Ansätze mit der Theorie der Property Rights ${ }^{405)}$, wobei allerdings deren Moglich keiten zur fruchtbaren Einwirkung eher zurückhaltend beurteilt werden. ${ }^{411 \hbar}$

Ad 2: Die ökonomische Theorie der Politik "stützt sich auf die These, daß offentliche Aktivitäten aus dem demokratischen Prozeß, aus dem Kampf um Macht

401) Musgrave selbst maß ihnen, in der Abfolge seiner Veröffentlichungen, durchaus unterschiedliche Gewichtigkeit zu. Vgl. Musgrave, R.A.: Finanztheorie. Studienausgabe, Tübingen 1974, S. 10 ff. (Erstveröffentlichung 1966) und Musgrave, R.A. and Musgrave, P.B.: Public Finance ..., a.a.O., S. 7 ff. sowie Schmidt, K.: Kollektivbedürfnisse und Staatstätigkeit, a.a.O., S. 4 f.

402) Vgl. Schmidt, K.: Kollektivbedürfnisse und Staatstätigkeit, a.a.O., S. 9 ff.

Die Konzeption der öffentlichen und meritorischen Güter ist, wenngleich nicht in der stringenten Form, schon in der älteren Literatur behandelt worden. Kurt Schmidt verweist hierbei auf Adolph Wagner und Margit Cassel sowie auf Emil Sax und Hans Ritschl (vgl. Schmidt, K.: Kollektivbedürfnisse und Staatstätigkeit, a.a.O., S. 10 f.). Ähnliche Gedanken finden sich, wie oben dargelegt, auch schon bei Adam Smith (vgl hierzu Abschnitt 1.3.1.) oder John Stuart Mill (vgl. Abschnitt 1.4.2.).

403) Schmidt, K.: Kollektivbedürfnisse und Staatstätigkeit, a.a.O., S. 3.

404) Vgl. Wille, E.: Die öffentlichen Ausgaben ..., a.a.O., S. 303.

405) Vgl. hierzu Leipold, H.: Theorie der Property Rights: Forschungsziele und Anwendungsbereiche, in: Wirtschaftswissenschaftliches Studium (WiSt), 7. Jg. (1978), S. 518-525, S. $519 \mathrm{ff}$. sowie Krüsselberg, H.G.: Property Rights-Theorie und Wohlfahrtsökonomik, in: Property Rights und ökonomische Theorie, hrsg. v. A. Schüller, München 1983, S. 45-77.

406) Vgl. Thoma, M.: Theorie der öffentlichen Güter, in: Wirtschaftswissenschaftliches Studium (WiSt), 14. Jg. (1985), S. 125-130, S. 128. 
und Ansehen resultieren"407), wobei zunächst von der sog. Stimmenmaximierungshypothese ausgegangen wurde. ${ }^{408)}$ Während die älteren Arbeiten auf diesem Gebiet einen sehr allgemeinen Zusammenhang zwischen Wählerstimmen und Umfang und Struktur des öffentlichen Budgets herstellten, zielen die neueren "unter Verwendung ökonometrischer Methoden unmittelbar darauf ab, posi-

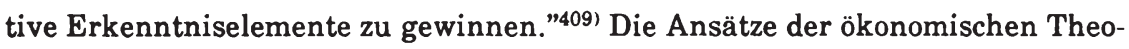
rie der Politik rücken in jüngster Zeit immer mehr von der Stimmenmaximierungshypothese ab und schenken stattdessen im Rahmen der Public-Choice Forschung den Mängeln des Koordinationsinstruments öffentliche Planung stärkere Beachtung. Diese Ausrichtung ist einerseits als Weiterentwicklung der Theorie der öffentlichen Güter anzusehen, die allzu einseitig auf die Mängel der markt wirtschaftlichen Koordination abstellte, steht andererseits aber auch im Zentrum der Public-Choice Forschung mit dem Versuch, eine "Theorie des Staatsversa gens' zu konzipieren. ${ }^{410}$ ) Die Untersuchungen über verschiedene Aspekte des Staats- bzw. Planungsversagens ${ }^{411)}$ liefern Argumente, die zur Vermutung Anlaß geben, daß die öffentlichen Ausgaben, wegen der fehlenden Anreize zu effizien tem Handeln, zu hoch sind. ${ }^{412)}$

Ad 3: Die Thesen zur langfristigen Entwicklung der Staatsausgaben finden fast al le ihren Ausgangspunkt im sog. Wagnerschen Gesetz. ${ }^{413)}$ Unbeschadet der Abgrenzungs- und Meßprobleme bei der Betrachtung der Entwicklung der Staatsquote und angeregt durch die mangelnde Begründung von Wagner selbst, wurden in der Folgezeit wiederholt Versuche unternommen, "das augenfällige Eintreten

407) Littmann, K.: Problemstellung und Methoden ..., a.a.O., S. 113.

408) Vgl. Fecher, H.: Ausgaben, öffentliche ..., a.a.O., S. 344 ff.; Thiemeyer, T.: Theorie der öffentlichen Güter ..., a.a.O., S. 81 ff. und Wille, E.: Die öffentlichen Ausgaben ..., a.a.O., S.304.

409) Wille, E.: Die öffentlichen Ausgaben ..., a.a.O., S. 304. Als Beispiel für eine neuere Arbeit auf diesem Gebiet sei verwiesen auf Kirchgässner, G.: Causality testing of the popularity function: An empirical investigation of the Federal Republic of Germany, 1971-1982, in: Public Choice, vol. 45 (1985), S. 155-173.

410) Vgl. Wille, E.: Die öffentlichen Ausgaben ..., a.a.O., S. 301 und S. 304.

411) Wille bevorzugt "den Terminus "Planungsversagen", weil dieser unmittelbar auf den Allokationsmechanismus abstellt." Wille, E.: Gesamtwirtschaftliche Allokation zwischen "Markt- und Staatsversagen" - ein ordnungspolitischer Überblick, in: Beiträge zur gesamtwirtschaftlichen Allokation, hrsg. v. E. Wille, Frankfurt/Main, Bern, New York 1983, S. 1-28, S. 7.

412) Vgl. ebenda, S. $8 \mathrm{ff}$.

413) Vgl. Abschnitt 1.4.1. sowie Littmann, K.: Ausgaben, öffentliche ..., a.a.O., S. $350 \mathrm{ff}$. 
der Wagnerschen Prognose" mit "neueren Argumenten zu stützen." ${ }^{\text {"14) }}$ Peacock und Wiseman erklären die Niveauverschiebung des Staatsanteils ("displacement effect") mit dem Absinken des Steuerwiderstandes in Zeiten sozialer Anspannungen ("social disturbance") ${ }^{415)}$, während Timm "die relative Ausdehnung der nichtkriegsbedingten Staatsausgaben mit mehreren Verzögerungseffekten ... bei der Nachfrage nach superioren Gütern"416) begründet. Sowohl bei Peacock und Wiseman als auch bei Timm handelt es sich um ex post-Aussagen zur Erklärung des Anstiegs der Staatsausgaben. ${ }^{417}$ Neuere Arbeiten versuchen, eine steigende nominale Staatsquote einerseits mit Hilfe spezifischer Bedingungen der öffentlichen Produktion, z.B. Preisstruktureffekt zuungunsten öffentlicher Güter und Dienste, zu erklären oder ziehen andererseits im Rahmen einer Theorie des Staatsversagens die Motive und Interessen der am politischen Willensbildungsund Entscheidungsprozeß beteiligten Personen und Personengruppen als Erklärung heran. ${ }^{418)}$

Ad 4: Die Systeme und Methoden öffentlicher Aus- bzw. Aufgabenplanung sind Ausdruck des Versuches, den Willensbildungs- und Entscheidungsprozeß öfentlicher Stellen rationaler zu gestalten und dabei auch gesamtwirtschaftlichen Interdependenzen mehr Beachtung zu schenken. Als ein theoretisch anspruchsvolles Planungskonzept gilt allgemein das "Planning-Programming-Budgeting-Sy-

414) Wille, E.: Die öffentlichen Ausgaben ..., a.a.O., S. 309.

415) Peacock und Wiseman schreiben: "As a result, the revenue and expenditure statistics of the government show a displacement after periods of social disturbance. Expenditures may fall when the disturbance is over, but they are less likely to return to the old level". Peacock, A.T. and Wiseman, J.: The Growth of ..., a.a.O., S. 27.

416) Vgl. Timm, H.: Das Gesetz der wachsenden Staatsausgaben, in: Finanzarchiv, hrsg. v. F. Neumark, N.F. Bd. 21, Tübingen 1961, S. 201-247, S. 234 ff.

417) Timm bemerkte hierzu: "Selbst wenn meine These akzeptiert wird, stellt sie, gemessen an den Vorstellungen und Erwartungen, die gewöhnlich mit dem Gesetz der wachsenden Staatsausgaben verbunden werden, natürlich ein ziemlich mageres Ergebnis dar. Denn einmal enthält sie keine Aussage über eine mehr oder minder kontinuierliche Entwicklung der Relation der Staatsausgaben zum Volkseinkommen; und üblicherweise stellt man sich unter dem Gesetz der wachsenden Staatsausgaben eine solche Aussage vor. Zum anderen ist sie eben lediglich eine nachträgliche Voraussage, nicht jedoch eine Prognose der zukünftigen Entwicklung". Timm, H.: Das Gesetz ..., a.a.O., S. 240.

418) Vgl. Wille, E.: Die öffentlichen Ausgaben ..., a.a.O., S. 310 f. und Wille, E.: Öffentliche Sachausgaben versus öffentliche Personalausgaben, in: Produktivitätsentwicklung staatlicher Leistungen, N.F. Bd. 145 der Schriften des Vereins für Socialpolitik, hrsg. v. K. Häuser, Berlin 1985, S. 11-122, S. 45 ff. 
stem" (PPBS) ${ }^{419)}$, das weltweite Beachtung fand ${ }^{420)}$ und von seinem Anspruch her als "ein umfassendes Entscheidungs- oder Managementsystem für komplexe Organisationen" "221) konzipiert war. Im staatlichen Bereich eingesetzt, stellte es den Versuch dar, "Steuerungsmechanismen ... im öffentlichen Sektor bereitzustellen, wie sie im privaten Sektor über die marktwirtschaftlichen Instrumente gegeben sind." ${ }^{422)}$ Auch wenn die Anwendung des PPBS in praxi den teilweise ambitiösen Ansprüchen nicht immer gerecht wurde, erscheint das System im Prinzip geeignet, wenigstens die Verbindung zwischen den Zielen und Mitteln transparent zu machen und Alternativen der Politik aufzuzeigen, die Entscheidungen abverlangen. ${ }^{423)}$ Im Rahmen des PPBS wurde auch das Anfertigen spezieller analytischer Studien ${ }^{424)}$ gefordert, die als Grundlagen der Entscheidungsfindung dienen sollten. Obwohl es sich grundsätzlich "um Untersuchungen und Methoden unterschiedlichster Art" ${ }^{\text {"25 }}$ handelte, dominierten bei diesen "special analytic studies" Kosten-Nutzen-Analysen und Kosten-Effektivitäts-Analysen. ${ }^{426)}$ Gerade die gesamtwirtschaftlich orientierte Kosten-Nutzen-Analyse, die seit 1969 durch die gleichlautende Vorschrift in §6 Abs. 2 HGrG und § 7 Abs. 2 BHO auch in der Bundesrepublik "für geeignete Maßnahmen von erheblicher finanzieller Bedeutung"gefordert wird ${ }^{427)}$ bietet sich nach Fecher "als Instrument zur Entscheidung über öffentliche Ausgaben an." ${ }^{\text {228) }}$ Die erheblichen Unschärfen bei der Bewertung von Nutzen und Kosten öffentlicher Projekte schränken allerdings, wie Fecher auch zugesteht, die Anwendbarkeit der Nutzen-Kosten-Analyse im Rahmen

419) Eine ausführliche Darstellung findet sich in Reinermann, H.: Programmbudgets in Regierung und Verwaltung. Möglichkeiten und Grenzen von Planungs- und Entscheidungssystemen, Baden-Baden 1975, S. 89 ff. Einen hervorragenden Überblick bietet Wille, E.: Öffentlicher Haushalt ..., a.a. O., S. $613 \mathrm{ff}$.

420) Vgl. Wille, E.: Öffentlicher Haushalt ..., a.a.O., S. 614. Das PPBS wurde 1961 im US-Verteidigungsministerium auf Initiative von McNamara und 1965 auf Anweisung von Präsident Johnson für die gesamte US-Bundesverwaltung verpflichtend eingeführt. In seiner verpflichtenden Form wurde das PPBS-Experiment 1971 beendet. Vgl. ebenda, S. 614.

421) Reinermann, H.: Programmbudgets in Regierung ..., a.a.O., S. 100.

422) Ebenda, S. 102.

423) Vgl. Littmann, K.: Problemstellung und Methoden ..., a.a.O., S. 120.

424) Vgl. Reinermann, H.: Programmbudgets in Regierung ..., a.a.O., S. $131 \mathrm{ff}$.

425) Wille, E.: Öffentlicher Haushalt ..., a.a.O., S. 614.

426) Vgl. ebenda, S. 614.

427) Vgl. Andel, N.: Nutzen-Kosten-Analysen, in: Handbuch der Finanzwissenschaft, 3. Auf1., hrsg. v. F. Neumark, Bd. I, Tübingen 1977, S. 475-518, S. 481.

428) Fecher, H.: Ausgaben, öffentliche ..., a.a.O., S. 344. 
öffentlicher Planungsbemühungen sehr stark ein. ${ }^{429)}$ Nicht zuletzt wegen der damit verbundenen Ernüchterung ist die Planungsfreudigkeit in den letzten Jahren zwar stark zurückgegangen, gleichwohl hat die Diskussion über die verschiedenen Systeme und Methoden öffentlicher Ausgaben- bzw. Aufgabenplanung dazu beigetragen, politische Entscheidungsprozesse und damit auch die faktische Bestimmung von Umfang und Art der öffentlichen Ausgaben, zumindest in Grenzen, durchschaubarer zu machen.

\subsubsection{Ansätze über die Wirkungen öffentlicher Ausgaben}

Die Wirkungen, die von Umfang und Struktur der öffentlichen Ausgaben ausgehen, erstrecken sich nicht nur auf die jeweilige konjunkturelle Situation, sondern umfassen auch allokative und distributive Aspekte. Das Hauptproblem einer allgemeinen Theorie der Ausgabenwirkungen gründet auf dem fundamentalen Sachverhalt, "daß nur die monetären, jedoch nicht die güterwirtschaftlichen Aktivitäten des Staates umfassend und mit hinreichender Genauigkeit zu bestimmen sind." ${ }^{40)}$ Die Ausgaben sind monetäre Inputs, mit denen die öffentlichen Entscheidungsträger sachliche und personelle Kapazitäten erwerben und/oder intrastaatliche Produktionsprozesse einleiten.431) "Budgetäre Ausgaben bilden somit Instrumente zur Erfüllung öffentlicher Aufgaben bzw. (in normativer Hinsicht) Mittel zur Wohlfahrtssteigerung. Jedoch lassen sich zwischen den Ausgaben und den mit ihnen angestrebten öffentlichen Aufgaben bzw. wohlfahrtsrelevanten Zielen mehrere Ziel- bzw. Mittelebenen unterscheiden." ${ }^{4321}$ Die Wirkungen öffentlicher Ausgaben auf die staatlichen Aufgaben bzw. Ziele entziehen sich im allgemeinen einer näheren quantifizierbaren Bestimmung ${ }^{433)}$, weshalb diese allokative Inzidenz kaum erfaßt werden kann.

Was die Verteilungswirkung der Ausgaben angeht, besteht dieses Problem zunächst nicht, denn ihre Analyse setzt an den Zahlungsströmen an. Will man die

429) Vgl. Fecher, H.: Ausgaben, öffentliche ..., a.a.O., S. 344 und Littmann, K.: Problemstellung und Methoden ..., a.a.O., S. 120.

430) Littmann, K.: Problemstellung und Methoden ..., a.a.O., S. 115.

431) Vgl. Wille, E.: Soziale Indikatoren als Ansatzpunkte wirtschaftspolitischer Zielbildung und Kontrolle - Verbesserung oder Verschleierung politischer Entscheidungsgrundlagen?, in: ORDO. Jahrbuch für die Ordnung von Wirtschaft und Gesellschaft, Bd. 31 (1980), S. 127. 151, S. $140 \mathrm{ff}$. und Wille, E.: Öffentliche Sachausgaben ..., a.a.O., S. $30 \mathrm{ff}$.

432) Ring, U.: Öffentliche Planungsziele ..., a.a.O., S. 1 f. Vgl. auch Abschnitt 1.1.2.

433) Vgl. Littmann, K.: Problemstellung und Methoden ..., a.a.O., S. 115. 
Inzidenz auf die personale Einkommensverteilung analysieren, bedarf es dazu auf den ersten Augenschein lediglich der Feststellung der Zahlungsempfänger. ${ }^{434)}$ Problematisch wird die Messung, wenn das Ergebnis für eine Ausgabenkategorie nicht in die gleiche Richtung zielt ${ }^{435}$ ) oder wenn die Ausgaben für Güter mit hohem Kollektivcharakter bestimmt sind. Die Verteilung der Ausgaben im Raum, also die Beantwortung der Frage, in welche Regionen die öffentlichen Mittel fließen, ist ebenfalls grundsätzlich meßbar.

Der weitaus größte Teil der Arbeiten, die sich mit den Wirkungen öffentlicher Aufgaben beschäftigen, erschöpft sich in der Multiplikatoranalyse, die ihren Reiz vor allem aus ihrer formalen Eleganz und ökonomisch vergleichsweise einfachen Interpretation gewinnt. Die Wirkungen der öffentlichen Ausgaben hängen in diesen Modellen davon ab, ob die verausgabten Mittel als Inanspruchnahme von Ressourcen oder als Transferzahlungen gelten. Trotz aller Probleme bei der Differenzierung der verschiedenen Kategorien von Ausgaben ${ }^{436)}$ eignet sich diese $\mathrm{Me}$ thode für stabilitätspolitiche Untersuchungen, d.h. hinsichtlich der Wirkungen auf Volkseinkommen und Beschäftigung.

434) Vgl. Zimmermann, H. und Henke K.-D.: Finanzwissenschaft ..., a.a.O., S. 223 f. und Musgrave, R.A.; Musgrave, P.B. und Kullmer, L.: Die öffentlichen Finanzen in Theorie und Praxis, Bd. 3, Tübingen 1977, S. $30 \mathrm{ff}$.

435) Die Subventionierung der Landwirtschaft ist derart vielfältig, daß einige Elemente eher grőßeren Betrieben zugute kommen, während andere eindeutig sozialen Charakter haben. Eine beliebige Disaggregation der Ausgaben, ein möglicher Ausweg aus diesem Dilemma, ist aus verschiedenen Gründen nicht immer möglich.

436) Vgl. Littmann, K.: Problemstellung und Methoden ..., a.a.O., S. 114 f. 


\section{Kriterien zur Einteilung der Staatsausgaben}

Die Ausgaben stellen ein wichtiges Instrument dar, um vorgegebene Zielwerte staatlicher Aufgaben anzustreben. Nachdem sie lange Zeit einer eher stiefmütterlichen Behandlung unterlagen, bildeten die staatlichen Ausgaben zunehmend den Gegenstand wissenschaftlicher Betätigung. Diese neueren Untersuchungen gehen dabei aus sehr unterschiedlichen Blickrichtungen an die Analyse der Probleme und Wirkungen staatlicher Ausgaben heran. Zu nennen sind hier zunächst Beiträge, die sich mit Niveau und Struktur der gesamten Staatsausgaben befas. sen. Sie können noch auf eine vergleichsweise lange Tradition zurückblicken. ${ }^{1}$ In den letzten Jahren nahm aber auch die Zahl der Arbeiten deutlich zu, die einzelnen Ausgabenkategorien stärkere Aufmerksamkeit schenkten. ${ }^{2}$ Dabei werden häufig bestimmten Ausgabengruppen unterschiedliche Wertschätzungen entge gengebracht. So finden z.B. die öffentlichen Investitionen, "verstanden als besonderer Sachverhalt der offentlichen Leistungserstellung ... nicht nur starke Be achtung,sondern in aller Regel auch a priori eine günstige Beurteilung." ${ }^{3)}$ Die fol

1) Schon Adam Smith beschäftigte sich mit diesem Problemkreis und erklärte die Entwicklung von Niveau und Struktur staatlicher Ausgaben auf der Grundlage seiner historischen Stu fenlehre. Vgl. Abschnitt 1.3.1.

Einen weiteren Meilenstein bei der Behandlung dieses Themenkomplexes bildeten die Arbei ten von Adolph Wagner (vgl. Abschnitt 1.4.1.) und die auf seiner These aufbauenden späteren Erklärungsversuche (vgl. Abschnitt 1.7.2.).

2) Als Beleg hierfür wird, wie auch schon im 1. Kapitel (vgl. Abschnitt 1.1.1. die Fußnote 10), die Behandlung der Staatsausgaben in den einzelnen Auflagen des Handbuches der Finanzwissenschaft herangezogen.

In der ersten Auflage befaßt sich lediglich ein sehr allgemein gehaltener Artikel von Karl Englis mit den öffentlichen Ausgaben. Im 2. Band der 2. Auflage, erschienen 1956, werden die öffentlichen Ausgaben insgesamt, aber auch spezielle Probleme wie das Besoldungswesen und die Sachausgaben angesprochen. In seinem Artikel verweist Kurt Heinig darauf, daß es "Spezialarbeiten über die Sachausgaben ... noch nicht" gibt, daß aber "die Sachausgaben im öffentlichen Haushalt ... neuerdings ständig gründlicher erörtert" werden (Heinig, K.: Die Sachausgaben im öffentlichen Haushalt, in: Handbuch der Finanzwissenschaft, 2. Auf1., hrsg. v. W. Gerloff und F. Neumark, Band II, Tübingen 1956, S. 143-160, S. 143). In der dritten Auflage des Handbuches finden sich dann schon fünf Artikel, die spezielle Ausgabenkategorien zum Gegenstand ihrer Analyse haben. Im einzelnen sind dies die "Öffentlichen Sachausgaben", die "Öffentlichen Personalausgaben", die "Transferzahlungen an Haushalte", die "Transferzahlungen an Unternehmen (Subventionen)" sowie die "Öffentlichen Darlehen und Gewährleistungen".

3) Littmann, K.: Art.: Öffentliche Investitionen, in: Handwörterbuch der Wirtschaftswissenschaft (HdWW), hrsg. v. W. Albers et al., Bd. 9, Stuttgart et al. 1982, S. 812-825, S. 812. 
genden Ausgabengruppierungen ${ }^{4)}$ wurden deshalb vor allem daraufhin untersucht, ob und wie sie die investiven von anderen öffentlichen Ausgabenkategorien trennen, um auch auf diesem Weg Hinweise für deren vergleichsweise wohlwollende Einschätzung zu erhalten.

\subsection{Allgemeine Gliederungskriterien}

Die Wahlmöglichkeiten hinsichtlich allgemeiner Kriterien zur Systematisierung der Staatsausgaben sind sehr reichhaltig. ${ }^{5)}$ Dies entspricht der großen Zahl ökonomischer Fragestellungen, die an die öffentlichen Ausgaben gerichtet werden können. Nachfolgend bilden die Kriterien

(1) Abhängigkeit von der wirtschaftlichen Entwicklung,

(2) Grad des privaten oder öffentlichen Nutzens und

(3) Stellung im Wirtschaftskreislauf

die Ausgangspunkte dieser Gruppierungen staatlicher Ausgaben. ${ }^{61}$

\subsubsection{Abhängigkeit von der wirtschaftlichen Entwicklung}

Die Frage der unterschiedlichen Determiniertheit einzelner Ausgabenarten durch die wirtschaftliche Entwicklung wurde in der ökonomischen Literatur bisher nur vereinzelt systematisch behandelt. Teile einer solchen Fragestellung enthält zwar schon das Erklärungsmuster der historischen Stufenlehre von Adam

4) Vgl. hierzu Kullmer, L.: Kriterien der Abgrenzung ..., a.a.O., S. 10 ff.; Kolms, H.: Finanzwissenschaft, a.a.O., S. 82 ff.; Ehrlicher, W.: Öffentliche Sachausgaben, in: Handbuch der Finanzwissenschaft, 3. Aufl., hrsg. v. F. Neumark, Bd. I, Tübingen 1977, S. 753-795, S. 757 ff. sowie Andel, N.: Finanzwissenschaft, a.a.O., S. 29 ff. und Zimmermann, H. und Henke, K.-D.: Finanzwissenschaft ..., a.a.O., S. $11 \mathrm{ff}$.

$\mathrm{Vgl}$. auch die verschiedenen Gliederungen, die im bisherigen Verlauf der Arbeit schon kurz vorgestellt wurden: Abschnitt 1.3.1. (Adam Smith); Abschnitt 1.3.2. (Karl Heinrich Rau); Abschnitt 1.4.1. (Lorenz von Stein); Abschnitt 1.5.2. (Gerhard Colm) und Abschnitt 1.5.3. (Arthur Cecil Pigou).

5) Vgl. Ehrlicher, W.: Öffentliche Sachausgaben, a.a.O., S. 762 und Kullmer, L.: Kriterien der Abgrenzung ..., a.a.O., S. 10.

6) Vgl. auch Ehrlicher, W.: Öffentliche Sachausgaben, a.a.O., S. $762 \mathrm{ff}$. 
Smith, ohne daß Smith sie aber in diesen Sachzusammenhang gestellt hätte. ${ }^{\text {) }}$ Obwohl Ehrlicher zahlreiche Ansatzpunkte zur Klassifizierung der Staatsausgaben nach der wirtschaftlichen Entwicklung vorschlägt ${ }^{8)}$, erlauben u.a. lediglich der Gliederungsversuch von Haller und mit Einschränkungen ein Systematisierungsversuch, der sich an den von Timm erarbeiteten "lags" orientiert, eine sinnvolle Einordnung nach dem oben aufgestellten Kriterium.

Die Verzögerungen, mit denen Timm die Entwicklung der Gesamtausgaben erklärt, lassen sich nach Ehrlicher "überwiegend mit unterschiedlichen Arten von Staatsausgaben in Zusammenhang bringen." 9 ) Timm selbst versuchte nach eigenem Bekunden, eine nachträgliche Erklärung "der relativen Ausdehnung der nicht-kriegsbedingten Staatsausgaben" für "die späte Phase der Entwicklung der kapitalistischen Länder"10) zu geben. Damit kommen für eine detaillierte Gliederung nach diesem Maßstab nur die Ausgaben in Betracht, die seit Anfang bzw. Mitte des letzten Jahrhunderts ${ }^{11}$, mit den entsprechenden "lags", zur Ausweitung der Budgets führten. Timm's Anliegen bestand keineswegs darin, eine Klassifikation der öffentlichen Ausgaben aufzustellen. Er wollte vielmehr die offensichtliche Bestätigung des Wagnerschen Gesetzes ex post begründen. Der Versuch, hieraus im Rückschluß eine Systematik staatlicher Ausgaben abzuleiten, kann letztlich nicht befriedigen und müßte darüber hinaus viele historische Son derheiten einbeziehen. ${ }^{12}$ )

7) Vgl. Smith, A.: An Inquiry into ..., a.a.O., S. $689 \mathrm{ff}$. und 709 ff. sowie Wille, E. und Gläser, M Die Staatsaufgaben ..., a.a.O., S. 51 ff. Vgl. hierzu auch die Ausführungen in Abschnitt 1.3.1

8) Ehrlicher verweist auch auf die "verschiedenen Prognosemodelle der Volkseinkommensentwicklung, in denen eine exogene und endogene Determiniertheit einzelner Staatsausgabenarten angenommen wird". Ehrlicher, W.. Öffentliche Sachausgaben, a.a.O., S. 763.

9) Ehrlicher, W.: Öffentliche Sachausgaben, a.a.O., S. 763.

10) Timm, H.: Das Gesetz ..., a.a.O., S. 234.

11) Vgl die Zeitangaben bei Timm. Siehe ebenda, S. 226 und S. 240.

12) Will man den Versuch der Gliederung trotzdem wagen, müßten die Staatsausgaben zunächst unterteilt werden in diejenigen, die zu Beginn "der späten Phase der Entwicklung in den kapitalistischen Ländern" allgemein anerkannt waren und in die, die seither maßgeblich zur Ausweitung der staatlichen Budgets beitrugen. Letztere könnte man dann, Timm's verschiedenen "lags" folgend, weiter untergliedern in:

(1) Staatsausgaben zur Befriedigung superiorer Bedürfnisse (z.B. Ausgaben im Schul- und Gesundheitswesen und für die soziale Sicherung), deren Etablierung in den öffentlichen Budgets selbst aber auch unterschiedliche Zeit beanspruchte.

(2) Staatsausgaben, die nach der Einkommensexpansion in den Vordergrund rückten (z.B. Ausgaben für den Ausbau des Verkehrswesens).

(3) Staatsausgaben, die soziale Kosten mindern bzw. beseitigen (z.B. Umweltschutzausgaben und Ausgaben zur Stadtsanierung).

(4) Ausgaben im Rahmen staatlicher Forschungs- und Entwicklungsaufgaben.

Diese Ausgabengruppen finden, mit großen Überlappungen, in der zeitlichen Abfolge nacheinander Eingang in die öffentlichen Budgets. 
Allein die von Haller, in seinem Beitrag zur Föhl-Festschrift ${ }^{13)}$, vorgeschlagene Einordnung staatlicher Ausgaben stellt eine Systematik im Sinne des oben aufgestellten Kriteriums dar. Haller selbst bezeichnet seine Überlegungen als "tastende Versuche"14) und nennt als ein Ziel seines Beitrages die Herausarbeitung von Entwicklungstendenzen bestimmter Ausgabengruppen in einer wachsenden Wirtschaft. ${ }^{15)}$ Dabei unterscheidet er zunächst "annähernd konstante Staatsausgaben", wobei er die Konstanz der Realgrößen unterstellt, und "variable Staatsausgaben", die in Abhängigkeit von der Entwicklung der privaten Nachfrage und des realen Sozialprodukts stehen. ${ }^{17)}$ Die "annähernd konstanten Staatsausgaben" umfassen diejenigen Ausgaben, "ohne die ein geordnetes, friedliches, in relativer Sicherheit sich vollziehendes Zusammenleben der Menschen in großen Gemeinschaften nicht realisierbar ist."17) Sie ermöglichen die staatlichen Grundleistungen und stellen damit "gleichsam das staatliche Existenzminimum dar." ${ }^{18)}$ Die "variablen Staatsausgaben" untergliedert er in einer ersten Stufe in "komplementäre" und "substituierbare" Staatsausgaben ${ }^{19)}$ Erstere sind durch eine Komplementaritätsbeziehung zwischen den privaten und öffentlichen Ausgaben gekennzeichnet, d.h. diese Staatsausgaben steigen in einer wachsenden Wirtschaft an. Die "substituierbaren Staatsausgaben" dagegen sinken bei steigenden Realeinkommen. Diese komplementären bzw. substituierbaren Staatsausgaben unterteilt Haller dann jeweils noch danach, "ob die betreffende Beziehung zu den privaten Konsumausgaben oder zu den privaten Investitionsausgaben gegeben

13) Haller, H.: Einige Gedanken zum Thema: Öffentliche Finanzen im Wirtschaftswachstum, in: Wirtschaftskreislauf und Wirtschaftswachstum. Carl Föhl zum 65. Geburtstag, hrsg. v. E.Schneider, Tübingen 1966, S. 57-74.

14) Ebenda, S. 57.

15) Vgl. ebenda, S. 60.

Kennzeichen der wachsenden Wirtschaft ist für Haller, die von Periode zu Periode fortschreitende Vergrößerung des realen Sozialprodukts. Die Bevölkerungszahl bleibt bei ihm annahmegemäß nahezu konstant.

16) Vgl. ebenda, S. 61.

17) Ebenda, S. 62.

Im einzelnen zählt er hierzu die Ausgaben für die Gesetzgebung, die Regierung und Verwaltung, die Rechtsprechung sowie die Ausgaben für die Polizei und den Militärapparat.

18) Ebenda, S. 62.

Hinsichtlich seiner These, daß kein Grund bestehe, "den realen Umfang der Dienste und Einrichtungen, die die unerläßlichen staatlichen Grundleistungen ermöglichen, auszuweiten" (ebenda, S. 62), weist Haller auf einige Störgrößen hin. Konkret nennt er in diesem Zusammenhang eine Veränderung der Siedlungsstruktur, die Zunahme der "Wohlstandskriminalität", sowie die Unsicherheiten, die vor allem bei militärischen Beschaffungen auftauchen.

19) Vgl. ebenda, S. 61. 


\section{Übersicht 2.1: Ausgabengliederung von Haller}

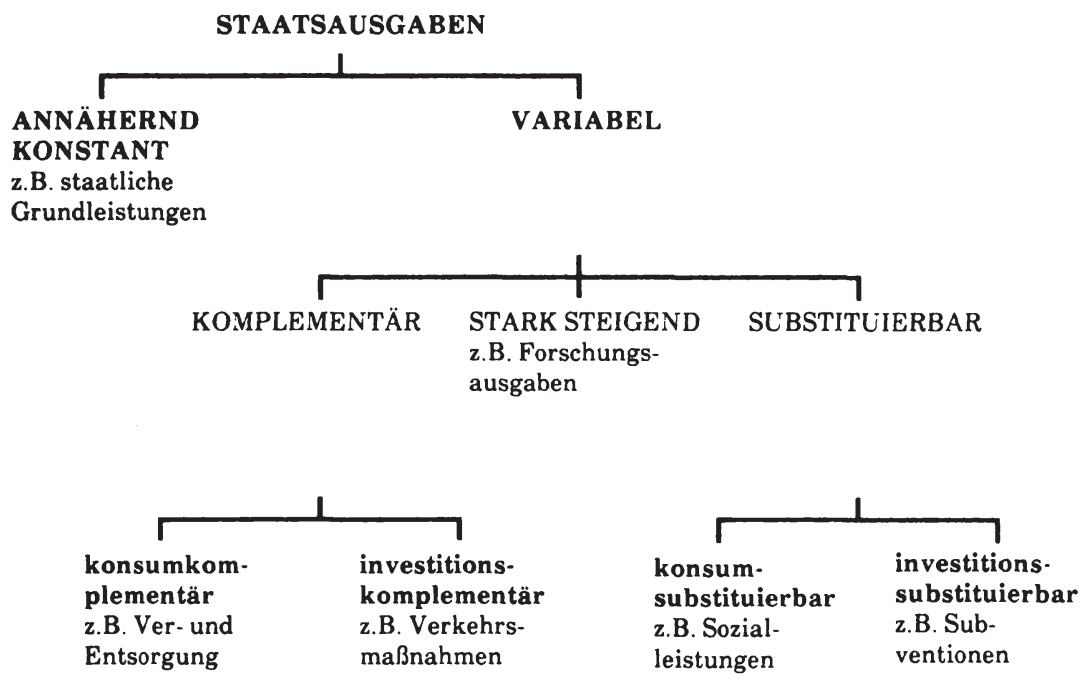

ist."20) Neben den komplementären und substituierbaren Staatsausgaben führt er zusätzlich als dritte Kategorie "Ausgaben mit stark wachsender Tendenz" auf, "die keinen oder einen höchstens sehr losen Zusammenhang aufweisen mit den wachsenden privaten Konsum- und Investitionsausgaben." ${ }^{21)}$

20) Haller, H.: Einige Gedanken ..., a.a.O., S. 61.

$\mathrm{Zu}$ den "konsumkomplementären Staatsausgaben" zählt er u.a. die Ausgaben für U'mgehungsstraßen, begründet durch die Zunahme des Automobilverkehrs (vgl. ebenda, S. 66 f.) sowie Maßnahmen im Bereich der Ver- und Entsorgung (vgl. ebenda, S. 68 f.).

Für den Bereich der "investitionskomplementāren Staatsausgaben" verweist Haller ebenfalls auf den Ausbau von Verkehrseinrichtungen und konstatiert, daß eine saubere Trennung zu den "konsumkomplementären" Ausgaben kaum möglich ist (vgl. ebenda, S. 69 f.).

Bei den "substituierbaren Staatsausgaben" nennt er die staatlichen Sozialleistungen ("konsumsubstituierbar") und die Subventionen ("investitionssubstituierbar").

21) Ebenda, S. 72.

Als Beispiel verweist Haller auf die Staatsausgaben für wissenschaftliche Forschung. 
Diese Überlegungen sollten"einen gewissen Damm der Objektivität gegen die subjektiven politischen Entscheidungen errichten helfen." ${ }^{22)}$ Folgerichtig erwartete Haller, "daß die Staatsausgaben nicht parallel mit dem realen Sozialprodukt wachsen, sondern hinter diesem zurückbleiben"23) und sich so Steuersenkungsreserven ergäben. Die Entwicklung der Gesamtausgaben hat, zumindest für die 70er und den Beginn der 80er Jahre, diese Erwartung nicht bestätigt. ${ }^{24)}$ Genausowenig wurden die Sozialleistungen und die Subventionen im Zuge des Wirtschaftswachstums abgebaut. ${ }^{25)}$

DieAusgabengliederung von Haller nimmt keine exakte Separierung der öffentlichen Investitionsausgaben vor, denn sie können sowohl unter die annähernd konstanten, wie auch unter die variablen Staatsausgaben fallen. Die Unterschei dung auf der dritten Gliederungsebene stellt auf die Komplementarität bzw. Substituierbarkeit zu den privaten Investitionen und den privaten Konsumausgaben ab. Ob alle, oder nur Teile der Staatsausgaben, die in Beziehung zu den privaten Investitionen stehen, zu den staatlichen Investitionen zählen, müßte im Einzelfall und unter Zuhilfenahme eines Abgrenzungskriteriums näher untersucht werden. Genausowenig ist eine abschließende Beurteilung der konsumkomplementären bzw. konsumsubstituierbaren staatlichen Ausgaben möglich, denn auch hier bildet die Charakterisierung des privaten Konsums die Richtschnur der Zuordnung.

22) Haller, H.: Einige Gedanken ..., a.a.O., S. 72 f.

23) Ebenda, S. 72.

24) Während das reale Bruttosozialprodukt im Zeitraum von 1970 bis $1974 \mathrm{um} \mathrm{12,9} \mathrm{vH}$ anstieg, nämlich von 957,5 Mrd. DM auf 1080,8 Mrd. DM, stiegen die Ausgaben des Öffentlichen Gesamthaushalts vor $196,32 \mathrm{Mrd}$. DM auf $318,26 \mathrm{Mrd}$. DM, was einer Steigerungsrate von 62,1 $\mathrm{vH}$ entspricht. Im Zeitraum von 1975 bis 1979 ist ähnliches zu beobachten, das reale Bruttosozialprodukt stieg um 16,7 vH während die Ausgaben um 30,3 vH zunahmen. $\mathrm{Zu}$ Beginn der $80 \mathrm{er}$ Jahre stieg das Ausgabenvolumen, bei einem stagnierenden realen Sozialprodukt, immer noch leicht an. Vgl. Sachverständigenrat zur Begutachtung der gesamtwirtschaftlichen Entwicklung: Chancen für einen langen Aufschwung, Jahresgutachten 1984/85, Stuttgart, Mainz 1984, Tab. 20* und 33*.

Die genannten Zahlen müßten noch genauer untersucht werden, inwieweit in ihnen auch Aufgabenverlagerungen enthalten sind. Sie bilden allerdings ein Indiz, daß die Erklärung von Haller nicht alle Einflußfaktoren berücksichtigt.

Vgl. auch Institut "Finanzen und Steuern" (Hrsg.): Entwicklung wesentlicher Daten der öffentlichen Finanzwirtschaft in der Bundesrepublik Deutschland von 1972 - 1982, Nr. 224, Bonn 1983, S. 2 ff.

25) Ihre Einschätzung als substituierbare Staatsausgaben kann somit empirisch zumindest nicht bestätigt werden. 


\subsubsection{Grad des privaten oder öffentlichen Nutzens}

Dieses Kriterium erlaubt die Zusammenfassung der Klassifikationen, die die Ausgaben nach der Kollektivguteigenschaft der damit erworbenen oder bereitgestellten Leistungen des Staates gruppieren ${ }^{26)}$ sowie derjenigen, die sie nach ihrer Beziehung zur Marktwirtschaft gliedern. ${ }^{27)}$

In seinem Gliederungsvorschlag unterteilt Ehrlicher die öffentlichen Ausgaben, ausgehend von dem Gesichtspunkt der größeren Nähe zu privaten oder kollektiven Bedürfnissen, in vier Gruppen. ${ }^{28)}$ Im einzelnen unterscheidet er Ausgaben zur Deckung

1. des reinen Kollektivbedarfs (z.B. Reparationen und Aufwendungen für Entwicklungshilfe),

2. des Kollektivbedarfs mit individuellen Interessen (z.B. Ausgaben, die aus der Erfüllung der Verwaltungs-, Organisations- und Sicherheitsaufgaben des Staates resultieren),

3. des kollektiv zu deckenden Individualbedarfs (z.B. Ausgaben im Bereich der öffentlichen Infrastruktur) und schließlich Ausgaben zur Deckung

4. des Individualbedarfs mit kollektivem Interesse (z.B. Bildungs- und Gesundheitsausgaben sowie Ausgaben im Bereich der Sozialen Sicherung und Ausgaben zur Wirtschaftsförderung).

Bei der Zuordnung einzelner Ausgabenarten ergeben sich, vor allem in den Grenzbereichen, einige Schwierigkeiten. Zu dem Bereich der ersten Gruppe wird man wohl nur solche Ausgaben rechnen dürfen, die ins Ausland fließen, denn nur bei ihnen wäre überhaupt vorstellbar, daß sie keinen oder zumindest keinen nennenswerten individuellen Nutzen in der eigenen Volkswirtschaft stiften. Aber selbst in diesem Fall sind Rückwirkungen auf inländische Personen bzw. Perso-

26) Vgl. Ehrlicher, W.: Öffentliche Sachausgaben, a.a.O., S. $764 \mathrm{f}$.

27) Vgl. Kullmer, L.: Kriterien der Abgrenzung ..., a.a.O., S. 16 f.

28) Vgl. Ehrlicher, W.: Öffentliche Sachausgaben, a.a.O., S. 764 f. Je nachdem, wie detailliert man die Kollektivguteigenschaft gliedert (vgl. hierzu Rittig, G.: Öffentliche Güter ..., a.a.O., S. 15 ff.), können weitere Systematiken ähnlicher Art aufgestellt werden. 
nengruppen denkbar. ${ }^{29)}$ Neben der generellen Schwierigkeit, die Ausgaben richtig einzugruppieren, besteht bei der obigen Systematik auch das spezielle Problem der Erfassung der Zinsausgaben. Wollte man sie dem gewählten Gliederungskriterium entsprechend einordnen, so müßten sie zunächst den aufgenommenen Krediten zugeordnet werden. In einem zweiten Schritt würden sie dann der Gruppe zugeschlagen, in deren Bereich die Verwendung des jeweiligen Kredits erfolgte. Diese Gliederung Ehrlichers nimmt keine Aussonderung der staatlichen Investitionsausgaben vor.

Die Klassifikationen, welche die Ausgaben nach ihrer inhaltlichen Beziehung zur Marktwirtschaft gliedern, gehen auf Colm zurück. ${ }^{30)}$ Er analysiert die Beziehungen zwischen den Leistungen der öffentlichen Wirtschaft und der Marktwirtschaft zunächst unter dem Gesichtspunkt inhaltlicher Art, ${ }^{31)}$ die "durch den Zweck der öffentlichen Leistung" ${ }^{\text {"2) }}$ angezeigt wird. Ausgehend von seiner Einteilung der staatlichen Aufgabengebiete, lassen sich vier Gruppen der zu ihrer Erfüllung nötigen Ausgaben bilden: ${ }^{331}$

1. Ausgaben für Leistungen, die in keiner unmittelbaren Beziehung zur Marktwirtschaft stehen (z.B. staatliche Willensbildung und Machtsicherung);

2. Ausgaben für Leistungen, die eine Bedingung für den Ablauf der Marktwirtschaft darstellen (in erster Linie Ausgaben für die Erhaltung des Ordnungsrahmens der Wirtschaft);

3. Ausgaben für Leistungen, die neben oder in Ergänzung der Marktwirtschaft Aufgaben auf den verschiedensten Kulturgebieten erfüllen (z.B. Ausgaben im Bereich des Verkehrs-, Schul- und Gesundheitswesens) und

29) Man kann sich durchaus vorstellen, daß durch die Gewährung von Entwicklungshilfe die Beziehungen zu dem betreffenden Entwicklungsland zu intensiveren, zunächst nicht intendierten Wirtschaftsbeziehungen führt.

30) Siehe auch Abschnitt 1.5.3.

31) Colm, G.: Volkswirtschaftliche Theorie ..., a.a.O., S. 17.

Neben diesem Gliederungskriterium inhaltlicher Art gliedert Colm auch die Staatsausgaben nach der Art und Weise, in der sie zur Aufgabenerfüllung beitragen. Siehe hierzu die Ausführungen weiter unten.

32) Colm, G.: Volkswirtschaftliche Theorie ..., a.a.O., S. 17.

Colm betont ausdrücklich, daß dieser Gesichtspunkt der Gliederung nicht ökonomischer Art sei, da diese inhaltliche Beziehung durch den Zweck der öffentlichen Leistung historisch bedingt sei (vgl. ebenda, S. 17). Der historischen Bedingtheit dieser Beziehung wird jeder zustimmen, der Aspekt bleibt aber trotzdem ökonomischer Art.

33) Vgl.ebenda, S. 18f. Vgl. auch Kullmer, L.: Kriterien der Abgrenzung ..., a.a.O., S. 16. 
4. Ausgaben für Leistungen, die einen Eingriff in die marktwirtschaftliche Versorgung darstellen (z.B. Ausgaben für Handelsvertretungen, Arbeitsfürsorge und öffentliche Unterstützungen).

Obwohl Colm wie zuvor Ehrlicher vier Ausgabengruppen unterscheidet, korrespondieren beide Systematiken inhaltlich kaum miteinander. Allerdings stellt sich das Problem der Einordnung der Zinsausgaben wie auch das der Separierung der investiven Ausgaben bei beiden in gleicher Weise.

Eine etwas andere Gliederung staatlicher Ausgaben, die sich aber ebenfalls unter dieses Kriterium subsummieren läßt, enthält der zweite Strukturbericht des Kieler Instituts für Weltwirtschaft. Die Verfasser des Berichts stellen bei ihrer Systematik auf die Empfänger der staatlichen Ausgaben ab und unterscheiden: ${ }^{34)}$

1. Hoheitliche Ausgaben, die der Aufrechterhaltung und Funktionsfähigkeit des Gemeinwesens dienen (z.B. Ausgaben für die politische Führung sowie im Bereich der inneren und äußeren Sicherheit).

2. Produzentenbezogene Ausgaben (z.B. Subventionen und Ausgaben für Verkehrswege, aber auch Ausgaben im Bereich der staatlichen Eigenproduktion).

3. Konsumentenbezogene Ausgaben (z.B. Ausgaben für die soziale Umverteilung, für das Bildungs- und Gesundheitswesen und für kommunale Gemeinschaftsdienste).

Die Verfasser des Sturkturberichts weisen ausdrücklich darauf hin, daß die Abgrenzung zwischen den drei Kategorien fließend ist und sich z.T. Schnittmengen ergeben. Im Vergleich zu den Gliederungen von Colm und Ehrlicher lassen sich jeweils gewisse Ähnlichkeiten erkennen, auch, was die Probleme angeht.

Der Gliederungsvorschlag von Johannes Koulis geht über die voranstehenden insoweit hinaus, als er neben den inhaltlichen Beziehungen zwischen Staats- und Marktwirtschaft auch intertemporale Aspekte berücksichtigt. Er unterscheidet

34) Vgl. Schmidt, K.-D. et al.: Im Anpassungsprozeß zurückgeworfen. Die deutsche Wirtschaft vor neuen Herausforderungen, Tübingen 1984, S. $64 \mathrm{f}$. 
fünf Ausgabengruppen: ${ }^{351}$

1. Ausgaben, die der gegenwärtigen Produktion dienen (z.B. Ausgaben im Bereich der Allgemeinen Verwaltung sowie Wirtschaftsförderungsmaßnahmen und Ausgaben im Gesundheitswesen).

2. Ausgaben, die der zukünftigen Produktion dienen (z.B. öffentliche Nettoinvestitionen und Ausgaben für das Bildungswesen).

3. Ausgaben zur direkten Steigerung des Volkswohlstandes (z.B. Ausgaben im Bereich der sozialen Sicherung sowie die Nettoausgaben öffentlicher Unternehmungen). ${ }^{36)}$

4. Verrechnungsausgaben für den Inlandsschuldendienst und für den Ankauf von Realkapital seitens der öffentlichen Hand.

5. Einseitige Leistungen an das Ausland (z.B. Auslandsschuldendienst und Reparationen).

Koulis erkennt, daß die Trennungslinie zwischen gegenwärtiger und zukünftiger Produktion nicht einwandfrei zu ziehen ist. ${ }^{37)}$ Darüber hinaus war er sich des Problems der der Einordnung der Schuldenlasten bewußt, hat es aber, was die Inlandsschulden angeht, außerhalb des gewählten Gliederungskriteriums gelöst. Die Gliederung legt die Gleichsetzung der öffentlichen Investitionen mit den "Ausgaben, die der zukünftigen Produktion dienen" nahe, was aber aus mehreren Gründen nicht unproblematisch. ${ }^{38)}$

35) Vgl. Koulis, J.: Die öffentlichen Ausgaben ..., a.a.O., S. 17 ff. Vgl. auch Kullmer, L.: Kriterien der Abgrenzung ..., a.a.O., S. 17. Es bleibt unklar, warum Kullmer in diesem Zusammenhang nur von vier Ausgabengruppen berichtet und die fünfte unterschlägt. Dies, obwohl sie in ihrer Fußnote 31 (vgl. ebenda, S. 17) die Fußnote 5 des Originals (vgl. Koulis, J.: Die öffentlichen Ausgaben ..., a.a.O., S. 19f.) zitiert, in der auch die fünfte Gruppe angesprochen wird.

36) Die Ausgaben im Bereich der sozialen Sicherung, die Koulis in diesem Zusammenhang aufzählt, stellen Ausgaben dar, welche keine Erhöhung des "Volkswohlstandes" sondern eine Umverteilung des Volkseinkommens bewirken. Vgl. Koulis, J.: Die öffentlichen Ausgaben ..., a.a.O., S. 18.

37) Ebenda, S. 20.

Er verweist darauf, daß die Ausgaben für äußere und innere Sicherheit die zukünftige Produktion sichern und damit teilweise auch dieser zweiten Gruppe zuzurechnen wären. Genauso können investive Ausgaben, die eine gegenwärtige konjunkturelle Flaute beheben sollen, nicht nur als der zukünftigen Produktion dienend bezeichnet werden.

38) Vgl. hierzu auch die Anmerkungen in der voranstehenden Fußnote. Es ist desweiteren nicht unproblematisch, alle Ausgaben für das Bildungswesen als der zukünftigen Produktion dienen, zu bezeichnen, wie es die Beispiele von Koulis suggerieren. 


\subsubsection{Stellung im Wirtschaftskreislauf}

Die Gliederungen der Staatsausgaben nach der Stellung im Wirtschaftskreislauf stehen im Vordergrund der Bemühungen um Gliederungen für Staatsausgaben. Diese Klassifikationen, die auf die volkswirtschaftlichen Wirkungen der Ausgaben abstellen ${ }^{39}$, gehen im wesentlichen auf die Arbeiten von Colm und Pigou zurück. ${ }^{40)}$ Letzterer unterschied zwei zentrale Ausgabenarten, die er in der dritten Auflage seiner Buches "A Study in Public Finance" schließlich"non-transfer expenditures" und "transfer expenditures" nannte. ${ }^{41}$ ' Den grundlegenden Unterschied sah er darin begründet, daß von den "non-transfer expenditures" ein unmittelbarer Einfluß auf die Höhe des Volkseinkommens ausgehe, während dies bei den "transfer expenditures" nicht der Fall sei. ${ }^{42)}$ Colm, der zu einer ähnlichen Zweiteilung der Ausgaben kam, ging bei seiner Analyse von einer anderen Ausgangsposition aus. Als Unterscheidungsmerkmal wählte er die Art und Weise, "in der sich die Staatsausgaben in den Prozeß der Einkommensbildung und Einkommensverwendung eingliedern."43) Die zwei Ausgabenkategorien nennt er zum einen Verwaltungsleistungen, mit der weiteren Untergliederung in Personal- und Sachausgaben und zum anderen Geldleistungen. Letztere untergliedert er in Unterstützungen, Subventionen, Zinszahlungen und Tributleistungen. Die Verwaltungsleistungen bestehen aus Ausgaben, die "eine Inanspruchnahme persönlicher und sächlicher Produktionskräfte bedingen." ${ }^{\text {44) }}$ Die Geldleistungen dagegen sind zur unmittelbaren Weitergabe an Dritte bestimmt und beinhalten keine Inanspruchnahme von Produktivkräften durch den Staat, sondern bilden auf

39) Vgl. auch Zimmermann, H. und Henke, K.-D.: Finanzwissenschaft ..., a.a.O., S. 12 ff.

40) Vgl. hierzu Kullmer, L.: Kriterien der Abgrenzung ..., a.a.O., S. 143 sowie Ehrlicher, W.: Öfentliche Sachausgaben, a.a.O., S. 755 und 765. Siehe auch Abschnitt 1.5.

41) Vgl. Pigou, A.C.: A Study in ..., 3rd ed., a.a.O., S. 19.

In früheren Auflagen desselben Buches gab Pigou den "non-transfer expenditures" auch die Bezeichnung "exhaustive expenditures" bzw. "real expenditures".

Die "non-transfer expenditures" sind nach Pigou "expenditures that purchase current services of productive resources for the use of ... (government) authorities" (ebenda, S. 19). Sie umfassen Ausgaben im Bereich der inneren und äußeren Sicherheit, des Erziehungswesens, der Rechtsprechung u.v.m.

Die "transfer expenditures" charakterisiert er als "expenditures which consist in payments made either gratuitously or in purchase of existing property rights to private persons" (ebenda, S. 19). Im einzelnen zählt Pigou die Zinsausgaben, Pensionszahlungen, die Unterstützungszahlungen bei Krankheit oder Arbeitslosigkeit u.ä. auf.

42) Vgl. Pigou, A.C.: A Study in ..., a.a.O., S. 19 sowie Ehrlicher, W.: Öffentliche Sachausgaben, a.a.O., S. 755.

43) Colm, G.: Volkswirtschaftliche Theorie ..., a.a.O., S. 34.

44) Ebenda, S. 39. 


\section{Übersicht 2.2: Ausgabengliederung von Colm}

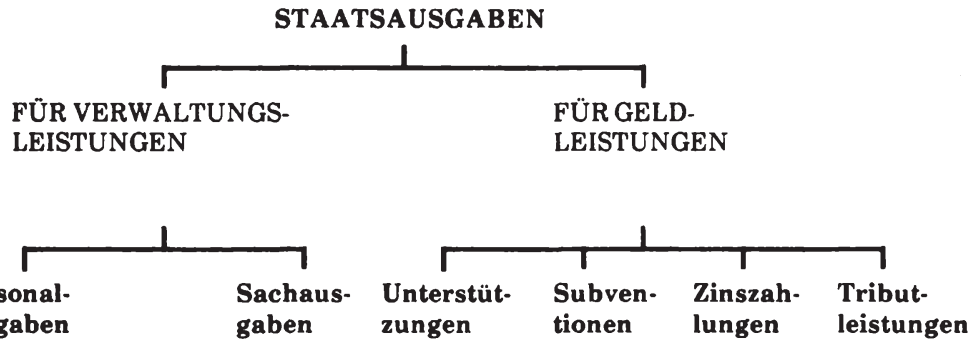

verschiedenste Personen übertragene "Ansprüche auf Leistungen der Marktwirt-

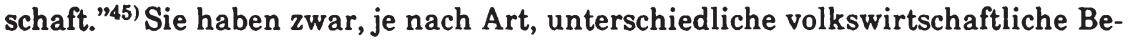
deutung, stellen aber allesamt "eine kraft der öffentlichen Hoheitsgewalt bewirkte Einkommensverschiebung"46) dar.

Sowohl bei Colm als auch bei Pigou bildet das Kriterium der Stellung im Wirtschaftskreislauf lediglich das Unterscheidungsmerkmal auf der ersten Stufe der Gliederung. Seit der Veröffentlichung ihrer Arbeiten, Ende der 20er Jahre diesen Jahrhunderts, wurden eine Vielzahl von Gliederungen entwickelt, die allesamt diesem Grundmuster folgen. ${ }^{47)}$

In seinem Artikel zum Handbuch der Finanzwissenschaft unterteilt Ehrlicher die Realausgaben in Ausgaben für den staatswirtschaftlichen Eigenbedarf, die er auch "allgemeine Staatsausgaben" nennt, und in die "ökonomischen Staatsausgaben". "8) Die "ökonomischen Staatsausgaben" charakterisiert er dabei als die Staatsleistungen, die "in einem substitutiven oder komplementären Verhältnis zu den privaten Leistungen stehen" und "die privaten Produktions- und Konsum-

45) Colm, G..: Volkswirtschaftliche Theorie ..., a.a.O., S. 40.

46) Ebenda, S. 40.

47) Vgl. Kullmer, L.: Kriterien der Abgrenzung ..., a.a.O., S. 13 ff.

48) Vgl. Ehrlicher, W.: Öffentliche Sachausgaben, a.a.O., S. 766. 


\section{Übersicht 2.3: Ausgabengliederung von Ehrlicher}
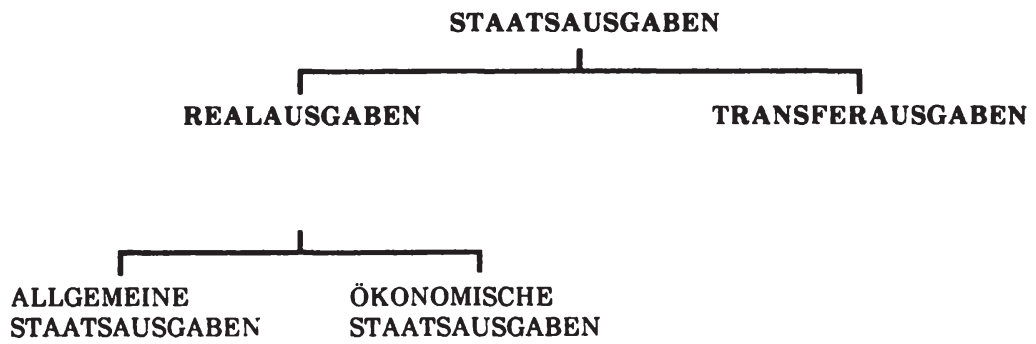

möglichkeiten" erweitern. ${ }^{491}$ Sie bilden also jene Realausgaben, die der Wirtschaft als unentgeltliche Vorleistungen wieder zur Verfügung gestellt werden. ${ }^{50)}$ Die "allgemeinen Staatsausgaben" umfassen nach Ehrlicher den Teil der Realausgaben, der zur Erfüllung der Organisations-, Verwaltungs- und Sicherheitsfunktion des Staates notwendig ist. ${ }^{51}$ Die Transferausgaben, die er den Realausgaben gegenüberstellt, definiert er als unentgeltliche Übertragungen, die "eine Umverteilung der Einkommen bewirken, ohne daß der Staat unmittelbar Ressourcen in Anspruch nimmt." ${ }^{\text {21 }}$

Auch Stephen Rose schlägt eine Dreiteilung zur Klassifizierung staatlicher Ausgaben vor, die mit der von Ehrlicher im groben Rahmen korrespondiert. ${ }^{53)}$ Die erste Gruppe bilden bei ihm die staatlichen Käufe am Markt ("State Purchases from private firms") ${ }^{54)}$, die zweite die staatlichen Dienstleistungen ("Government Services") ${ }^{55)}$ und die dritte die Transferzahlungen ("Transfer Payments") ${ }^{56}$.

49) Ehrlicher, W.: Öffentliche Sachausgaben, a.a.O., S. 766.

50) Vgl. ebenda, S. 766 .

51) Vgl. ebenda, S. 766 .

52) Ebenda, S. 766.

53) Rose, S.: On Classifying State Expenditure, in: The Review of Radical Political Economics, New York 1977, S. 31-42, insbes. S. 36 ff.

54) Ebenda, S. 36.

Hierunter zählt Rose z.B. Ausgaben für militärische Anlagen sowie Straßen und Büroausstattungen.

55) Ebenda, S. 38

Als Beispiele führt er die Ausgaben für die Polizei, für die Soziale Sicherung sowie die Ausgaben im Gesundheits- und Bildungswesen auf.

56) Ebenda, S. 39. 
Im Kontext einer detaillierteren Gliederung begründet Littmann die Unterscheidung zwischen Real- und Transferausgaben in der Tradition Colm's damit, daß erstere "mit einer Inanspruchnahme von Produktionsfaktoren seitens des öffentlichen Sektors verbunden"57) sind, während die Transferausgaben "selbst und direkt keine Verlagerung der Produktivkräfte vom privaten zum öffentlichen Sektor hervorrufen." ${ }^{58)}$ Allerdings lassen, wie auch Littmann selbst betonte, die Transferausgaben, die ja eine Einkommensumverteilung zur Folge haben, nur bei einer statischen Betrachtung die Höhe des Volkseinkommens unverändert. ${ }^{59}$ ) Bei einer dynamischen Betrachtung sind dagegen die Änderungen der Kreislaufströme, die durch die Redistributionsprozesse hervorgerufen wurden, d.h. die Auswirkungen auf die Spar- und die Investitionsquote, zu beachten. ${ }^{60)}$ Auf der zweiten Gliederungsebene unterteilt Littmann die Transferausgaben in Einkommensübertragungen an private Haushalte und Einkommensübertragungen an private Unternehmungen. ${ }^{61}$ ' Die Realausgaben wiederum gliedert er in Ausgaben für den staatswirtschaftlichen Verbrauch und für die staatswirtschaftliche Produktion. Zur Abgrenzung zieht er den Aspekt der Verwendung der Produktivkräfte heran, die durch einen hoheitlichen Akt in die Verfügungsgewalt des Staates gelangten. Zum staatswirtschaftlichen Verbrauch zählen dementsprechend Ausgaben für solche Leistungen, die von den privaten Wirtschaftssubjekten nicht verbraucht werden können ${ }^{62)}$, d.h. Ausgaben für Leistungen, die reinen Kollektivcharakter besitzen. Die staatswirtschaftliche Produktion bilden dagegen die Ausgaben, die "ihren Gegenwert in Leistungen der Staatswirtschaft zu Gunsten

57) Littmann, K.: Zunehmende Staatstätigkeit ..., a.a.O., S. 99.

58) Ebenda, S. 132.

59) Vgl. ebenda, S. 139 und $145 \mathrm{f}$.

Damit wird das Pigousche Kriterium etwas relativiert.

60) Vgl. ebenda, S. 146.

Littmann läßt allerdings offen, in welche Richtung sich Spar- und Investitionsquote bewegen.

61) Vgl. ebenda, S. 134.

Die Einkommensübertragungen an private Haushalte nennt er auch Sozialtransfers bzw. Unterstützungen. Die Einkommensübertragungen an private Unternehmungen grenzt er dagegen enumerativ ab und erwähnt in diesem Zusammenhang Subventionen und öffentliche Finanzinvestitionen. Die Zinszahlungen zählt er ebenfalls zu der letztgenannten Kategorie. Er kommt dann zur Schlußfolgerung, daß die Sozialtransfers tendenziell einkommensnivillierend sind, während die anderen Transfers die personellen Einkommensunterschiede vergrößern.

62) Vgl. ebenda, S. 103

Als Beispiele erwähnt Littmann Reparationen, den Bau von Denkmälern und Fehlinvestitionen der Staatswirtschaft. Mit Einschränkungen zählt er auch die Rüstungsausgaben zu dieser Gruppe. Vgl. ebenda, S. 128. 


\section{Übersicht 2.4: Ausgabengliederung von Littmann}

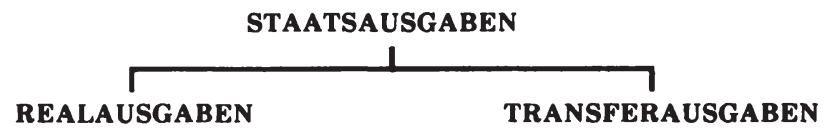

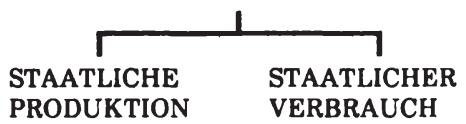

z.B. Repara-

tionen

\begin{tabular}{|c|c|}
\hline & $\perp$ \\
\hline AN PRIVATE & AN PRIVATE \\
\hline HAUSHALTE & UNTERNEHMEN \\
\hline $\begin{array}{l}\text { z.B. Unterstüt- } \\
\text { zungen }\end{array}$ & $\begin{array}{l}\text { z.B. Sub- } \\
\text { ventionen }\end{array}$ \\
\hline
\end{tabular}

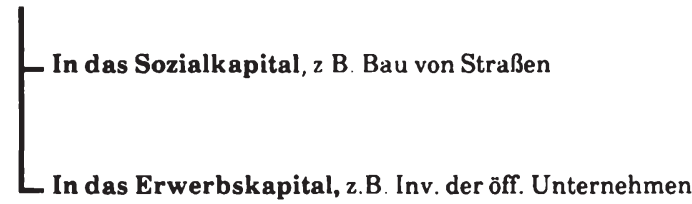

DIENSTLEISTUNGEN

z.B. Rechtspflege

Privater finden." ${ }^{\text {63) }}$ Diese staatliche Produktion bezieht sich dabei auf die Erstellung von Investitonsgütern und Dienstleistungen. ${ }^{64)}$ Deshalb unterscheidet Littmann auf der dritten Gliederungsebene Ausgaben für öffentliche Investitionen und Ausgaben für tertiäre Produktionen (Dienstleistungen). ${ }^{65)}$ Gewähren die

63) Littmann, K.: Zunehmende Staatstätigkeit ..., a.a.O., S. 103.

64) Vgl. ebenda, S. 103.

Die Konsumgüterproduktion stellt sich für Littmann nicht als ein Problem moderner Staatswirtschaft dar. Soweit Reste einer solchen Produktion vorhanden sind, die er als anachronistisch bezeichnet, vollziehe sie sich im Rahmen des kapitalistischen Rechnungssystems, weshalb er auf ihre Analyse verzichtet habe.

65) Vgl. ebenda, S. $122 \mathrm{ff}$.

Im einzelnen zählt Littmann zur tertiären Produktion die Ausgaben für die Finanzverwaltung, die Rechtspflege, die Wissenschaft und Erziehung sowie für Polizeidienste, Müllabfuhr u.a.. 
öffentlichen Investitionen den privaten Unternehmern Kostenvorteile in ihrer Produktion oder werden sie direkt von den privaten Haushalten ohne Gegenleistung verbraucht, nennt Littmann sie "Investitionen in das Sozialkapital". ${ }^{66)}$ Alle öffentlichen Investitionen, die im allgemeinen keine solchen Kostenvorteile für die privaten Unternehmen aufweisen sollen dagegen "Investitionen in das staats wirtschaftliche Erwerbskapital genannt werden".67)

Bei der Gliederung von Littmann dient die Stellung im Wirtschaftskreislauf wiederum nur auf der obersten Gliederungsebene als Unterscheidungsmerkmal. Auf der zweiten Ebene werden zur Abgrenzung zum einen die Empfängergruppen und zum anderen der Kollektivgutcharakter der Ausgaben herangezogen. Auf der dritten Stufe unterteilt Littmann dann die Ausgaben für die staatliche Produktion nach der Art der produzierten Güter. Er separiert dabei die Investitionen von den Dienstleistungen und grenzt schließlich die Investitionen zugunsten öffentlicher Unternehmungen von allen anderen ab. In dieser Gliederung bilden die Investitionen also einen Teil der Realausgaben.

Das Kriterium der Stellung im Wirtschaftskreislauf, das zu einer Unterscheidung von Realausgaben bzw. Leistungsausgaben, wie Haller sie nennt ${ }^{68)}$, und Transferausgaben bzw. Umverteilungsausgaben führt, erlaubt allerdings nicht, alle öffentlichen Ausgaben konsistent zu erfassen. Neben den Schwierigkeiten, die Zinsausgaben kriteriumsgerecht einzuordnen, taucht auch das Problem auf, die öffentliche Darlehens- und Gewährleistungsaktivität einzubeziehen. ${ }^{69}$ ' Während die staatliche Darlehensgewährung immer ausgabenwirksam ist, stellen

66) Vgl. Littmann, K.: Zunehmende Staatstätigkeit ..., a.a.O., S. 108.

$\mathrm{Zu}$ den Investitionen in das Sachkapital zählt er z.B. die Ausgaben für den Bau von Verkehrsanlagen und Anlagen zur Wasseregelung sowie Ausgaben für den Bau von Rathäusern, Schulen und Krankenhãusern.

67) Ebenda, S. 107.

68) Vgl. Haller, H.: Einige Gedanken ..., a.a.O., S. 59.

Haller nennt die erste Ausgabengruppe Leistungsausgaben, weil sich der Staat mit diesen Ausgaben "Güter und Dienstleistungen beschafft, die er in eigene Leistungen umwandelt" (ebenda, S. 59), während die zweite Gruppe Ausgaben darstellt, die "der Umverteilung der privaten Einkommen dienen" (ebenda, S. 59).

Zimmermann/Henke sprechen in diesem Zusammenhang von Leistungsentgelten. Vgl. Zimmermann, H. und Henke, K.-D.: Finanzwissenschaft ..., a.a.O., S. 13.

69) Vgl. Zimmermann, H. und Henke, K.-D.: Finanzwissenschaft ..., a.a.O., S. 13. Vgl. auch Zeitel, G.: Theoretische und technische Aspekte öffentlicher Darlehen und Gewährleistungen, in: Handbuch der Finanzwissenschaft, 3. Aufl., hrsg. v. F. Neumark, Bd. I, Tübingen 1977, S.997-1024, S. $997 \mathrm{ff}$. 
staatliche Gewährleistungen eine Haftungsübernahme dar, die das Budget im Zeitpunkt des Eintretens in die Gewährleistungsverpflichtung nicht belasten. ${ }^{701}$ Die staatlichen Darlehen bilden, so Zeitel, "eine spezielle Art von Vermögensübertragungen"71), die weder eine Einordnung in die Transferausgaben ${ }^{721}$ noch die Zurechnung zu den Realausgaben ${ }^{73)}$ rechtfertigen, zumal es sich in der Regel nicht um endgültige Zahlungen handelt. ${ }^{74)}$

Die Einteilung der Beiträge im 6. Kapitel des ersten Bandes des Handbuches der Finanzwissenschaft bietet eine Gliederung der öffentlichen Ausgaben in Realausgaben, Transferausgaben sowie Darlehen und Gewährleistungen. ${ }^{75}$ ) Sowohl die Realausgaben als auch die Transferzahlungen werden jeweils nochmals in zwei Beiträge aufgespalten. Unter den Realausgaben findet sich die Arbeit von Ehrlicher über die "Öffentlichen Sachausgaben"76) und die von Bös über die "Öffentlichen Personalausgaben". ${ }^{77 \prime}$ Die Transferausgaben umfassen die Beiträge von Albers über die "Transferzahlungen an Haushalte"78) und von Hansmeyer über die "Transferzahlungen an Unternehmen". ${ }^{79)}$ Der Artikel über "Theoretische und technische Aspekte Öffentlicher Darlehen und Gewährleistungen" von Zeitel rundet dieses Kapitel ab. ${ }^{80}$

Da die Zäsur in kreislauftheoretischer Sicht auf der ersten Ebene dieser Gliederung zwischen den Realausgaben und den beiden übrigen Ausgabenkategorien

70) Vgl. Zeitel, G.: Theoretische und technische ..., a.a.O., S. 999.

71) Ebenda, S. 1000.

72) Als Begründung für die Zuordnung zu den Transferausgaben könnte man anführen, daß diese Kreditvergabe regelmäßig Subventionselemente enthält. Da der Subventionscharakter der Kreditgewährung in quantitativer Hinsicht aber sehr stark differiert, ist diese Einordnung nicht zu rechtfertigen. Vgl. ebenda, S. 1000.

73) Die Zuordnung der staatlichen Kreditvergabe zu den Realaugaben lehnt Zeitel ebenfalls ab, obwohl durch die gewährten Darlehen "gezielt auf den Mitteleinsatz Einfluß genommen wird". Ebenda, S.1000.

74) Vgl. Ehrlicher, W.: Öffentliche Sachausgaben, a.a.O., S. 756.

75) Vgl. Neumark, F. (Hrsg.): Handbuch der Finanzwissenschaft, a.a.O., S. 723-1024.

76) Vgl. Ehrlicher, W.: Öffentliche Sachausgaben, a.a.O., S. 754 ff.

77) Vgl. Bös, D.: Öffentliche Personalausgaben, in: Handbuch der Finanzwissenschaft,3. Aufl., hrsg. v. F. Neumark, Bd. I, Tübingen 1977, S. 797-859.

78) Vgl. Albers, W.: Transferzahlungen an Haushalte, in: Handbuch der Finanzwissenschaft, 3.Aufl., hrsg. v. F. Neumark, Bd. I, Tübingen 1977, S. 861-957.

79) Vgl. Hansmeyer, K.-H.: Transferzahlungen an Unternehmen (Subventionen), in: Handbuch der Finanzwissenschaft, 3. Aufl, hrsg. v. F. Neumark, Bd. I, Tübingen 1977, S. 959-996.

80) Vgl. Zeitel, G.: Theoretische und technische ..., a.a.O., S. $997 \mathrm{ff}$. 


\section{Übersicht 2.5: Ausgabengliederung im Handbuch der Finanzwissenschaft}

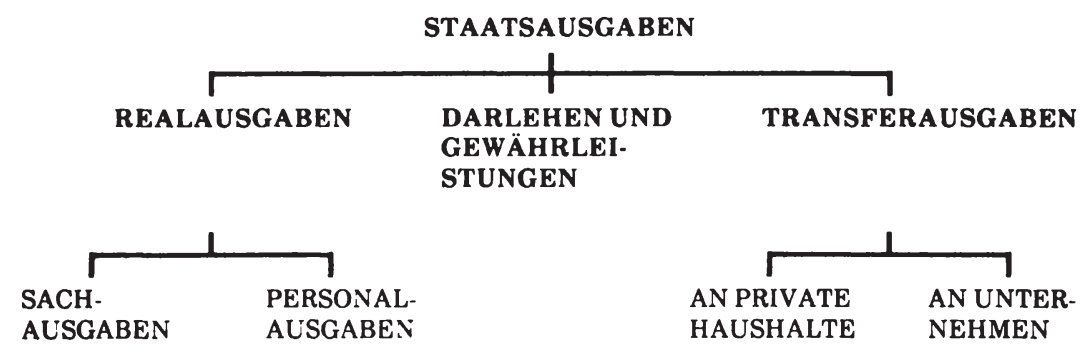

verläuft, könnte man die Transferzahlungen sowie die Darlehen und Gewährleistungen unter dem Oberbegriff Nominalausgaben zusammenfassen. ${ }^{81}$ 'Es sei auch vermerkt, daß die Einteilung der Realausgaben in Sach- und Personalaus gaben nur dann eine ökonomisch relevante Gliederung wäre, wenn sich diese Un terscheidung an den volkswirtschaftlichen Nachfrageströmen orientierte. In den Haushaltsplänen werden Sach- und Personalausgaben aber letztlich nach institutionellen Kriterien abgegrenzt, so daß "materiell gleichartige Leistungen bei institutionell divergierendem Auftragsverhältnis unterschiedlich eingestuft werden."82)

In einer recht umfassenden Gliederung versucht Shoup der Tatsache Rechnung zu tragen, daß staatliche Entscheidungsträger dieselben Aufgaben nicht nur über die staatlichen Ausgaben, sondern auch über den Verzicht von Einnahmen bzw. durch Übertragung an die privaten Wirtschaftssubjekte erfüllen können. ${ }^{83)}$ Darüber hinaus bietet sein Gliederungsvorschlag die Möglichkeit, kalkulatorische Kosten, die ja nicht ausgabenwirksam sind, zu berücksichtigen. Shoup unter-

81) Vgl. Ehrlicher, W.: Öffentliche Sachausgaben, a.a.O., S. 756.

82) Ebenda, S. 756. Vgl. auch ebenda, S. 757.

83) Shoup, C.S.: Public Finance, Chicago 1969.

In einer Rezension dieses Lehrbuches gelangt Herbert Timm zu einem überaus positiven Urteil. Vgl. Timm, H.: Ein neues amerikanisches Lehrbuch der Finanzwissenschaft, in: Finanzarchiv, hrsg. v. F. Neumark, N.F. Bd. 30 (1971/72), Tübingen 1972, S. 287-305. 
scheidet deshalb zunächst "explicit outlays" (tatsächliche Ausgaben) und "imputed outlays" (kalkulatorische Ausgaben). ${ }^{84 \prime}$ Die tatsächlichen Ausgaben entsprechen hierbei den Budgetausgaben. Die kalkulatorischen Ausgaben dagegen umfassen die staatlichen Aufwendungen, denen kein Auszahlungsstrom gegenübersteht, wie z.B. die tax expenditures ${ }^{85)}$ oder den Differenzbetrag zwischen marktmäßiger und nicht-marktmäßiger Entlohnung (z.B. für wehrpflichtige Soldaten) oder die Differenz zum Marktzins bei Zwangsanleihen und die Abschreibung auf öffentliche Gebäude. ${ }^{86)}$ Die Gliederung der tatsächlichen Ausgaben ähnelt stark den zuletzt vorgestellten Klassifikationen. So unterscheidet Shoup, entsprechend den kreislauftheoretischen Überlegungen, zunächst Transferzahlungen ("transfer payments") und Ausgaben für Güter und Dienste ("payments for goods and services"). Bei den Ausgaben für Güter und Dienste sollen dabei die Zahlungen erfaßt werden, die "commonly stimulate current production directly." ${ }^{67)}$ Die Transferzahlungen wiederum unterteilt er in die Vermögenszahlungen ("property payments") und die unentgeltlichen Transferzahlungen ("unrequited transfer payments"). ${ }^{88)}$ Die Vermögenszahlungen umfassen die Käufe von Sachvermögen ("purchases of existing real assets") ${ }^{89)}$ und die Käufe von Wertpapieren ("purchases of financial instruments"). ${ }^{90)}$ Bei den Transferzahlungen grenzt er die freiwilligen Zahlungen ("donative payments") ${ }^{91)}$ von den Zwangszahlungen ("compulsory payments") $)^{92)}$ ab.

Die Gliederung von Shoup enthält zunächst keine Aussonderung der Investitionsausgaben. Gleichwohl könnte man sie, auch in Anlehnung an die Gliederung von Littmann, derart eingrenzen, daß sie in erster Linie unter den "Vermögens-

84) Vgl. Shoup, C.S.: Public Finance, a.a.O., S. 51 ff. und S. 489. Vgl. auch Andel, N.: Finanzwissenschaft, a.a.O., S. 32.

85) Vgl. Shoup, C.S.: Public Finance, a.a.O., S. 54. Shoup selbst gebraucht nicht die Bezeichnung "tax expenditures".

86) Vgl. ebenda, S. 53.

87) Ebenda, S. 51. Als Beispiel verweist Shoup auf den Kauf von Büromaterial und Computern, sofern der Staat Erstbezieher der Güter ist.

88) Vgl. ebenda, S. $51 \mathrm{f}$.

89) Shoup führt in diesem Zusammenhang Käufe von Grundstücken und Gebäuden auf. Vgl. ebenda, S. $51 \mathrm{f}$.

90) Vgl. ebenda, S. 53.

91) Die freiwilligen Zahlungen, die den größten Teil der Transferzahlungen ausmachen, umfassen die Leistungen im Rahmen der sozialen Sicherung und der Entwicklungshilfe sowie die Finanzausgleichszahlungen. Vgl. ebenda, S. 51.

92) Als einzige Kategorie erwāhnt Shoup in diesem Fall Reparationszahlungen. Vgl. ebenda, S.51. 


\section{Übersicht 2.6: Ausgabengliederung von Shoup}
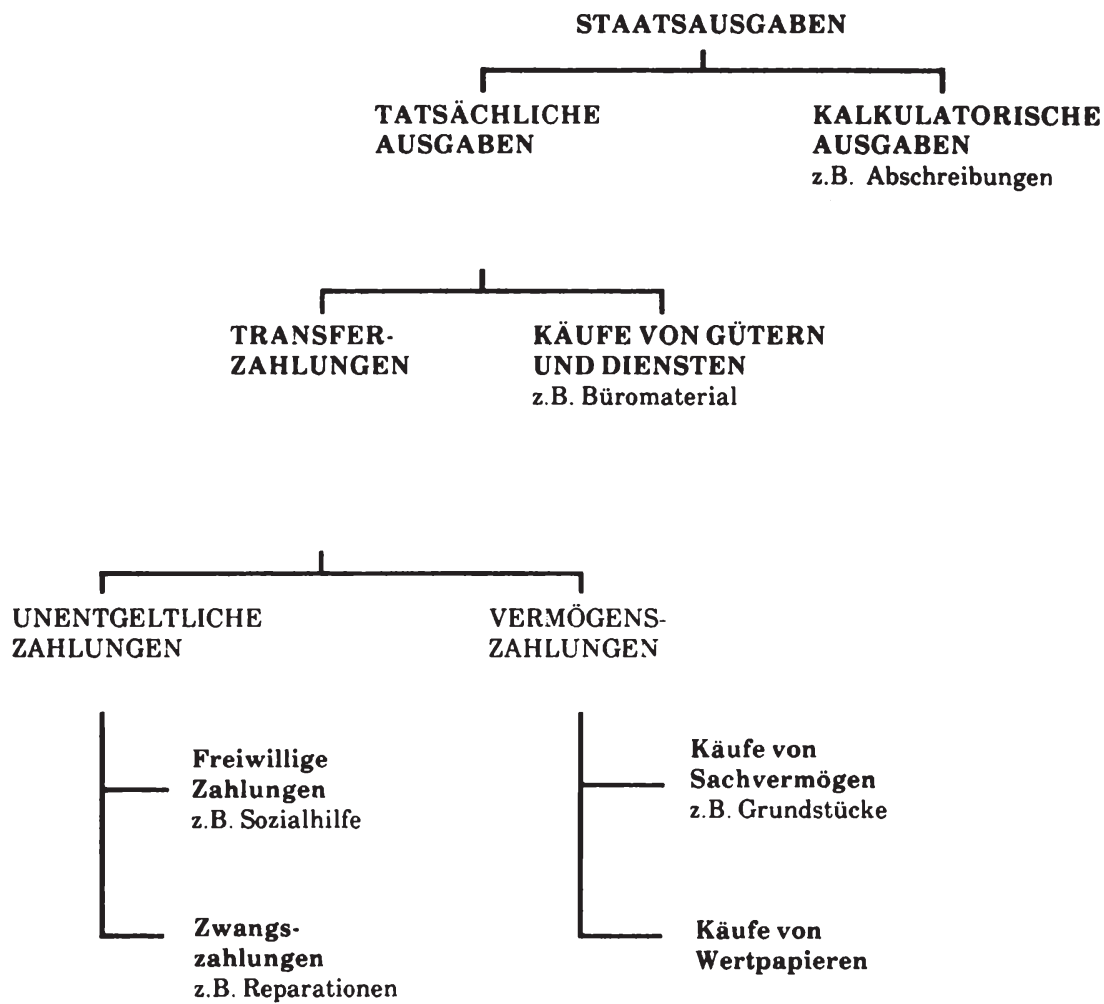

zahlungen" und den "Käufen von Gütern und Diensten" stecken. Die Klassifikation von Shoup bietet Anlaß, das Augenmerk auch auf die Einnahmenseite zu richten, denn unter Umständen kommt einem speziellen Einnahmenverzicht (z.B. Steuererleichterungen) derselbe investive Charakter zu wie einer direkten Verausgabung (z.B. Investitionszuschuß). 


\subsection{Haushaltsrechtliche Gliederungskriterien}

\subsubsection{Grundlagen des Haushaltsrechts}

Das Haushaltsrecht umfaßt "die Gesamtheit der Rechtsregeln, die sich auf die

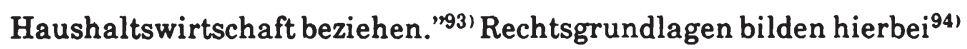

- die Verfassungsvorschriften des Grundgesetzes (Art. 109-115) und die entsprechenden landesverfassungsrechtlichen Vorschriften,

- das Haushaltsgrundsätzegesetz ( $\mathrm{HGrG}$ ),

- die Bundeshaushaltsordnung (BHO) und die entsprechenden Landeshaushaltsordnungen einschließlich der jeweils erlassenen Verwaltungsvorschrif. ten,

- die Bestimmungen des Stabilitäts- und Wachstumsgesetzes (StWG),

- die landesrechtlichen Gemeindeordnungen und Gemeindehaushaltsverordnungen sowie

- die jeweiligen Bundes- und Landesbestimmungen für andere juristische Personen des öffentlichen Rechts oder Sondervermögen.

Obwohl in Art. 109 Abs. 3 GG lediglich Bund und Länder als Adressaten gemeinsam geltender Grundsätze für das Haushaltsrecht aufgeführt werden, ist es unstrittig, daß sich die Grundsätze "auch auf das Haushaltsrecht der ... Gemeinden" beziehen. ${ }^{95)}$ Trotz dieser grundsätzlichen Gültigkeit des Haushaltsgrundsätzegesetzes auch auf der Gemeindeebene gibt es in den kommunalen Haushalten einige Besonderheiten ${ }^{96)}$, auf die in einem eigenen Abschnitt noch einzugehen sein wird. Zunächst werden aber die bundesgesetzlichen Bestimmungen betrachtet, die, mit einigen Unterschieden im Detail, auch von den Ländern übernommen wurden. ${ }^{97)}$

93) Piduch, E.A.: Bundeshaushaltsrecht, Bd. II, Loseblattsammlung, Stand 12. Lieferung, Stuttgart et al. 1977, Vorbemerkungen S. 3.

94) Vgl. Piduch,E. A.: Bundeshaushaltsrecht, Bd. I, Loseblattsammlung, Stand 12. Lieferung, Stuttgart et al: 1977, Einführung S. 36

95) Piduch, E.A.: Haushaltsreform in der Diskussion, in: Der Gemeindehaushalt, 70 Jg. (1969), S. 121-129, S. 129. Vgl. hierzu auch Rehm, H.: Analyse und Kritik der Bundeshaushaltsreform, Baden-Baden 1975, S. $21 \mathrm{f}$.

96) Vgl. Depiereux, S.: Das neue Haushaltsrecht der Gemeinden, 5. Aufl., Siegburg 1975, S.16f.

97) Vgl. Piduch,E. A.: Bundeshaushaltsrecht, Bd. II, a.a.O., Vorbemerkungen S. 8. 
Nach $\S 2$ Satz 2 HGrG ist der Haushaltsplan die Grundlage für die Haushaltsund Wirtschaftsführung. Er ermächtigt nach § 3 Abs. $1 \mathrm{HGrG}$ und gleichlautend $\S 3$ Abs. 1 BHO die Verwaltung, Ausgaben zu leisten. ${ }^{98)}$ Der Haushaltsplan selbst besteht aus den Einzelplänen und dem Gesamtplan ${ }^{99)}$, wobei der Gesamtplan als Bestandteile die Haushaltsübersicht, die Finanzierungsübersicht und den Kreditfinanzierungsplan enthält. ${ }^{100)}$ Darüber hinaus sind nach $\S 11 \mathrm{Abs} .1 \mathrm{HGrG}$ und gleichlautend § 14 Abs. 1 BHO dem Haushaltsplan als Anlagen die Gruppierungsübersicht, die Funktionenübersicht, der Haushaltsquerschnitt, die Übersicht über die durchlaufenden Posten sowie die Personalübersicht beizufügen. ${ }^{101)}$ Die haushaltsrechtlichen Bestimmungen machen demnach eine Gliederung der budgetären Ausgaben nach vorwiegend institutionellen Gesichtspunkten (Einzelpläne), nach Ausgabengruppen bzw. ökonomischen Arten (Gruppierungsübersicht) und nach Aufgabenbereichen (Funktionenübersicht) erforderlich. Damit soll den folgenden drei Grundforderungen einer Haushaltssystematik Rechnung getragen werden: ${ }^{102}$

98) Vgl. Patzig, W.: Haushaltsrecht des Bundes und der Länder, Bd. II. Kommentar zu den Rechts- und Verwaltungsvorschriften, Fortsetzungswerk in Loseblattform, Stand 6. Jg., 6.Lieferung, Baden-Baden 1987, C 3/1ff.

Zur Bedeutung des Ermächtigungscharakters vgl. auch Patzig, W.. Haushaltsrecht des Bundes und der Länder, Bd. I. Grundriß, Baden-Baden 1981, S. 294 ff.

99) Vgl. § 10 Abs. $1 \mathrm{HGrG}$ und § 13 Abs. 1 BHO. Vgl. auch Andel, N.: Finanzwissenschaft, a.a.O., S. $77 \mathrm{ff}$.

100) Vgl. § 10 Abs. 4 HGrG und § 13 Abs. 4 BHO. Vgl. auch Andel, N.: Finanzwissenschaft, a.a.O., S. $79 \mathrm{ff}$.

Die Haushaltsübersicht besteht aus der Zusammenfassung der Einnahmen, Ausgaben und Verpf iichtungsermächtigungen der Einzelpläne. In der Finanzierungsübersicht wird zunächst der Finanzierungssaldo aus der Gegenüberstellung der saldobildenden Einnahmen und Ausgaben ermittelt und anschließend die saldodeckenden Einnahmen und Ausgaben ausgewiesen. Der Kreditfinanzierungsplan schließlich enthält die Darstellung der Krediteinnahmen und Tilgungsausgaben. Vgl. Patzig, W.: Haushaltsrecht des Bundes ..., Bd. II, a.a.O., C $13 / 27 \mathrm{ff}$.

101) Die Gruppierungsübersicht faßt die im Haushaltsplan veranschlagten Einnahmen und Ausgaben auf der Grundlage des Gruppierungsplans nach ökonomischen Arten zusammen. Die Funktionenübersicht stellt eine Gliederung der Einnahmen und Ausgaben nach Aufgahenbereichen dar. Der Haushaltsquerschnitt faßt die Gruppierungs- und Funktionenübersicht in Form einer Matrix zusammen. Die Übersicht über die durchlaufenden Posten enthält im allgemeinen die Beträge, die für einen anderen vereinnahmt und in gleicher Höhe an diesen weitergeführt werden, ohne daß die Gebietskörperschaft an der Bewirtschaftung beteiligt ist bzw. bei der Verwendung der Mittel in irgendeiner Form mitwirkt. Die Personalübersicht, die im Gesetzestext "Ubbersicht über die Planstellen der Beamten und die Stellen der Angesteilten und Arbeiter" heißt, soll einen Gesamtüberblick über die Personalbewegungen vermitteln. Vgl. Patzig, W.: Haushaltsrecht des Bundes ..., Bd. II, a.a.O., C 14/13 ff. Siehe hierzu auch Piduch, E.A.: Bundeshaushaltsrecht, Bd. II, a.a.O., §14 BHO, S. $68 \mathrm{ff}$.

102) Vgl. Bundesministerium der Finanzen: Finanzbericht 1969, Bonn 1968, S. 210. 
- Beachtung der haushalts- und verwaltungsmäßigen Erfordernisse,

- Aufzeigen des wirtschaftspolitischen Gehalts des Haushalts sowie

- Auskunft über die Erfüllung einzelner öffentlicher Aufgaben.

\subsubsection{Gliederung nach institutionellen Gesichtspunkten}

Die Gliederung nach institutionellen Gesichtspunkten bildet das bestimmende Kriterium für die horizontale Einteilung des Haushalts in Einzelpläne und Gesamtplan. Häufig wird die Aufteilung in Einzelpläne mit der Ministerial- oder Ressortgliederung gleichgesetzt, was allerdings, wie unten dargelegt, nicht völlig korrekt ist. ${ }^{103)}$ Diesem Gliederungsprinzip liegt vielmehr "das alte kameralistische System der einfachen institutionellen Planung und Rechnung auf der technischen Grundlage des verwaltungsorganisatorischen Aufbaus der Behörden, Ämter und sonstigen Amtsstellen"104) zugrunde. Die Systematik, die die einzelnen Ausgaben nach der verwaltungsmäßigen Zuständigkeit ordnet, bildete sich im Laufe der Zeit "mehr als zusammengeflossene oder zusammengestoßene Kristallisation, denn als überlegt in Aufgabenzweige eingeteilte Staatsverwal. tung." ${ }^{105)}$ Obwohl bereits 1952 Weichmann und Wawrczek, im Zuge ihres Reformvorschlags zur Neuordnung der öffentlichen Haushalte, "eine Abkehr vom rein institutionellen System"106) forderten, weil es "in keiner Weise mehr den Ansprüchen" genüge, ${ }^{107)}$ wurde bei der großen Haushaltsreform Ende der 60 er Jahre ${ }^{108 \text { । }}$

103) Vgl. Kullmer, L.: Kriterien der Abgrenzung ..., a.a.O., S. 10 f.; Kolms, H.: Finanzwissenschaft, a.a.O., S. 82 f. sowie Zimmermann, H. und Henke, K.-D.: Finanzwissenschaft ..., a.a.O., S. 11.

104) Weichmann, H. und Wawrczek, C.: Neuordnung der öffentlichen Haushalte. Ein Beitrag zur volkswirtschaftlichen, staatswirtschaftlichen und betriebswirtschaftlichen Planung der öffentlichen Verwaltungs- und Finanzwirtschaft, Hamburg 1952, S. 3.

105) Heinig, K.: Das Budget, 2. Bd. Das Budgetwesen, Tübingen 1951, S. 380.

106) Weichmann, H. und Wawrczek, C.: Neuordnung der öffentlichen ..., a.a.O., S. 10. Zur Kritik an der institutionellen Systematik vgl. auch Patzig, W.: Haushaltsrecht des Bundes ..., Bd. I, a.a.O., S. 78 f. sowie Patzig, W.: Haushaltsrecht des Bundes ..., Bd. II, a.a.O., C $13 / 8 \mathrm{f}$.

Schon Karl Heinrich Rau übte zur Mitte des letzten Jahrhunderts in seinem "Lehrbuch der politischen Ökonomie" Kritik am institutionellen Gliederungsprinzip. Vgl. Abschnitt 1.3.2.

107) Weichmann, H. und Wawrczek, C.: Neuordnung der öffentlichen ..., a.a.O., S. 6. Vgl. auch Weichmann, H.: Die Neugliederung des Haushaltsplans in Hamburg. Ein Beitrag zur Haushaltsreform, in: Finanzarchiv, hrsg. v. F. Neumark, N.F. Bd. 25, Tübingen 1966, S.41-51, S. $41 \mathrm{f}$.

108) Diese Haushaltsreform bestand aus dem Haushaltsreformgesetz vom 20. 03. 1969, das die Änderungen der Artikel 109 bis 115 GG beinhaltete sowie aus dem Haushaltsgrundsātzegesetz und der Bundeshaushaltsordnung, jeweils vom 19. 08. 1969. 
weiterhin an der institutionellen Gliederung festgehalten. Dem Anliegen Weichmann's und Wawrczek's wurde insofern Rechnung getragen, als die institutionelle Systematik um einige zusätzliche Aufstellungen und Übersichten ergänzt wurde. Das Festhalten am Prinzip der institutionellen Gliederung wurde damit begründet, daß ohne dessen Beibehaltung die politische und finanzielle Verantwortung der mittelbewirtschaftenden Stellen nicht klar zu erkennen wäre. Gerade dieser formale Aufbau der Haushaltspläne stelle sicher, daß die haushaltsmäßigen Erfordernisse bei Aufstellung, Ausführung und Abschluß des Budgets genügend berücksichtigt werde. ${ }^{109}$ ) Grundsätzlich erlaubt $\S 13$ Abs. 2 BHO die Aufteilung der Einzelpläne sowohl nach institutionellen Aspekten wie auch nach Aufgabengebieten. Bei der derzeitigen Praxis wird der Bundeshaushalt ${ }^{110}$ in 27 Einzelpläne aufgegliedert ${ }^{111}$, wobei 22 davon nach institutionellen Gesichtspunkten und 5 nach Sachgebieten (Realprinzip) gebildet werden. ${ }^{112)}$ Von den institutionellen Einzelplänen sind 16 den einzelnen Ministerien zugeordnet ${ }^{113)}$ und die restlichen 6 nach anderen verwaltungsorganisatorischen Gesichtspunkten einge-

109) Vgl. Bundesministerium der Finanzen: Probleme einer Neuordnung der Haushaltssystematik von Bund und Ländern, in: Finanzbericht 1966, Bonn 1966, S. 202-205, S. 203 und Patzig, W.: Haushaltsrecht des Bundes ..., Bd. II, a.a.O., C 13/9.

Vgl. auch Ehrlicher, W.: Öffentliche Sachausgaben. a.a.O., S. 759. Ehrlicher hebt hervor, daß für den Verwaltungsvollzug diese Gliederungsart wohl die einzig sinnvolle ist.

110) Wie schon erwähnt gilt ähnliches auch für die Länderhaushalte. Vgl. Patzig, W.: Haushaltsrecht des Bundes ..., Bd. II, a.a.O., C 13/10.

Grundlage der Detailbetrachtung bildet der Haushaltsplan 1985.

111) In vertikaler Hinsicht werden die Einzelpläne in Kapitel und diese in Titel gegliedert. Die Titel bilden die unterste Stufe der Haushaltsgliederung. Sie sind Grundlage der parlamentarischen Einzelbewilligung und enthalten, soweit es sich um die Ausgaben handelt, nach der Verabschiedung des Haushaltsplans die Ermächtigung für Regierung und Verwaltung, Ausgaben zu leisten und Verpflichtungen einzugehen. Vgl. Patzig, W.: Haushaltsrecht des Bundes ..., Bd. II, a.a.O., C 13/11 ff.

112) Sowohl die Zahl als auch die Benennung der Einzelpläne haben auch heute noch sehr große Ähnlichkeiten mit dem Haushaltsgesetz 1949 und der Vorläufigen Haushaltsordnung vom 7. Juni 1950 (vgl. Heinig, K.: Das Budget, 2. Bd., a.a.O., S. 393). Die Änderungen sind im wesentlichen auf Zusammenlegungen und Neuschaffungen von Ministerien zurückzuführen. Vgl. Bundesministerium der Finanzen: Finanzbericht 1986, Bonn 1985, S. 51 sowie die Haushaltspläne früherer Jahre in den entsprechenden Finanzberichten.

113) Es sind dies Einzelplan (Epl.) 05 (Auswärtiges Amt), Epl. 06 (Inneres), Epl. 07 (Justiz), Epl. 08 (Finarizen), Epl. 09 (Wirtschaft), Epl. 10 (Ernährung, Landwirtschaft und Forsten), Epl. 11 (Arbeit und Soziales), Epl. 12 (Verkehr), Epl. 13 (Post- und Fernmeldewesen), Epl. 14 (Verteidigung), Epl. 15 (Jugerd, Familie, Gesundheit), Epl. 23 (Wirtschaftliche Zusammenarbeit), Epl. 25 (Raumordnung, Bauwesen und Städtebau), Epl. 27 (Innerdeutsche Beziehungen), Epl. 30 (Forschung und Technologie) und Epl. 31 (Bildung und Wissenschaft). 
teilt. ${ }^{114)}$ Die Einzelpläne, die dem Realprinzip folgen, betreffen mehrere oder alle Verwaltungszweige. ${ }^{115)}$ Es handelt sich hierbei z.B. um den Einzelplan 60 "Allgemeine Finanzverwaltung", in dem hauptsächlich die Steuereinnahmen veranschlagt werden. ${ }^{116)}$

Die Unzulänglichkeiten dieser Gliederung der Ausgaben liegen auf der Hand. Sie führt bei der Budgetaufstellung zu einer Überbetonung administrativer Gesichtspunkte und zu einer Vernachlässigung übergeordneter politischer Aufgaben, weil sich sehr oft Überschneidungen in der Erfüllung von Sachaufgaben durch die verschiedenen Ministerien und Behörden ergeben. ${ }^{117)}$ Die Gliederung nach institutionellen Gesichtspunkten ist vollkommen auf den Verwaltungsvollzug abgestellt und erlaubt kaum ökonomische Schlußfolgerungen.

Die vertikale Gliederung des Haushaltsplans nach § 13 Abs. 2 Satz 2 BHO sieht eine Aufgliederung der Einzelpläne in Kapitel und der Kapitel in Titel vor. ${ }^{118}$, Die Kapitel können, wie die Einzelpläne, nach institutionellen oder funktionalen Gesichtspunkten aufgestellt werden. Jedes Kapitel wird dabei mit einer zweistel ligen Ziffer versehen, die zusammen mit der ebenfalls zweistelligen Kennziffer des Einzelplans die Kapitelbezeichnung bildet. ${ }^{19)}$ Die bisherige Praxis in der Ausgestaltung des Bundeshaushalts läßt bei den Einzelplänen, die nach dem Ministerialprinzip ausgerichtet sind, ein einheitliches Schema der Einteilung der Kapitel erkennen. Danach umfaßt das Kapitel 01 den Personal- und Sachbedarf

114) Solche institutionellen Einzelpläne sind Epl. 01 (Bundespräsident und Bundespräsidial amt), Epl. 02 (Deutscher Bundestag), Epl. 03 (Bundesrat), Epl. 04 (Bundeskanzler und Bundeskanzleramt) sowie der Epl. 19 (Bundesverfassungsgericht) und Epl. 20 (Bundesrechnungshof).

115) Im einzelnen sind es Epl. 32 (Bundesschuld), Epl. 33 (Versorgung), Epl. 35 (Verteidigungskosten im Zusammenhang mit dem Aufenthalt ausländischer Streitkräfte), Epl. 36 (Zivile Verteidigung) und Epl. 60 (Allgemeine Finanzverwaltung).

Vgl. auch Piduch, E.A.: Bundeshaushaltsrecht, Bd. II, a.a.O., BHO § 13, S. 16 und Andel,N.: Finanzwissenschaft, a.a.O., S. 79.

116) Vgl. auch Piduch, E.A.: Bundeshaushaltsrecht, Bd. II, a.a.O., BHO § 13, S. 16. Heinig bezeichnet diesen Einzelplan als den "traditionelle(n) Rangierbahnhof der Finanzen". Heinig, K.: Das Budget, 2. Bd., a.a.O., S. 393.

117) Vgl. Ehrlicher, W.: Öffentliche Sachausgaben, a.a.O., S. 760 und Rehm, H.: Analyse und Kritik ..., a.a.O., S. $159 \mathrm{ff}$.

118) Vgl. Piduch, E.A.: Bundeshaushaltsrecht Bd. II, a.a.O., BHO § 13, S. 15.

119) Vgl. Patzig, W.: Haushaltsrecht des Bundes ..., Bd. II, a.a.O., C 13/12. 
des Ministeriums selbst und das Kapitel 02 die "Allgemeinen Bewilligungen" für die Zweckausgaben des Ministeriums, während die folgenden Kapitel für einzelne Behörden und Dienststellen oder ein bestimmtes Sachgebiet gebildet werden. ${ }^{120)}$

Die unterste Stufe der Haushaltsgliederung bilden die Titel. Sie "enthalten die eigentliche Entscheidung über die Zulässigkeit von Einnahmen und Ausgaben." ${ }^{21)}$ Die Zuordnung der Einnahmen und Ausgaben zu den Titeln sowie die Titelnummer richten sich gemäß $\S 10$ Abs. 2 Satz 3 HGrG und gleichlautend $\S 13$ Abs. 2 Satz 3 BHO nach dem Gruppierungsplan, der in den Verwaltungsvorschriften zur Haushaltssystematik des Bundes (VV-HB) enthalten ist. ${ }^{122)}$ Grundlage dieses Gruppierungsplans, "dessen Aufbau mit der Haushaltsgliederung der Gemeinden abgestimmt ist", bildet "die Gliederung des Staatskontos der volkswirtschaftlichen Gesamtrechnung." ${ }^{123)}$ Bei den Ausgaben werden nach dem Gruppierungsplan zunächst sechs Hauptgruppen gebildet ${ }^{124)}$, deren Kennziffer die erste Ziffer der Titelnummer bestimmen. Innerhalb der Hauptgruppen werden "Obergruppen mit gleichem ökonomischen Gehalt geschaffen"125), die

120) Vgl. Patzig, W.: Haushaltsrecht des Bundes ..., Bd. II, a.a.O., C13/12 und Piduch, E.A.: Bundeshaushaltsrecht, Bd. II, a.a.O., BHO § 13, S. 18.

Für den Epl. 08 "Geschäftsbereich des Bundesministers der Finanzen" ergab sich in 1985 die nachfolgende Kapiteleinteilung:

Kap. 0801 Bundesministerium der Finanzen

Kap. 0802 Allgemeine Bewilligungen

Kap. 0803 Bundesamt für Finanzen

Kap. 0804 Bundesfinanzverwaltung

Kap. 0805 Bundesaufsichtsamt für das Versicherungswesen in Berlin

Kap. 0806 Bundesbeteiligungen

Kap. 0807 Bundesvermögens- und Bauangelegenheiten

Kap. 0808 Bundesaufsichtsamt für das Kreditwesen in Berlin

Kap. 0809 Bundesmonopolverwaltung für Branntwein in Offenbach/Main

Kap. 0810 Oberfinanzdirektion Berlin.

Vgl. Bundeshaushaltsplan für das Haushaltsjahr 1985, Einzelplan 08 Geschäftsbereich des Bundesministers der Finanzen, S. 1.

121) Patzig, W.: Haushaltsrecht des Bundes ..., Bd. II, a.a.O., C 13/13.

122) Vgl. ebenda, D 2/24 sowie Kramp, H.: Systematik des öffentlichen Haushalts. Gruppierungsplan (mit Buchungshinweisen und Erläuterungen) und Funktionenplan, Hamburg 1972, S. $17 \mathrm{ff}$.

123) Rehm, H.: Analyse und Kritik ..., a.a.O., S. 158. Vgl. auch Patzig, W.: Haushaltsrecht des Bundes ..., Bd. II, a.a.O., C 13/14 ff.

124) Es sind dies die Hauptgruppen:

4 - Personalausgaben

5 - Sächliche Verwaltungsausgaben, militärische Beschaffung usw., Ausgaben für Schuldendienst

6 - Ausgaben für Zuweisungen und Zuschüsse mit Ausnahme für Investitionen

7 - Baumaßnahmen

8 - Sonstige Ausgaben für Investitionen und Investitionsförderungsmaßnahmen

9 - Besondere Finanzierungsvorgänge.

125) Patzig, W.: Haushaltsrecht des Bundes ..., Bd. II, a.a.O., C 13/17. 
durch das Hinzufügen einer zweiten Ziffer gekennzeichnet werden. Die in ihnen zusammengefaßten Ausgaben können, so Patzig, "einheitlich beurteilt und bei einer wirtschaftspolitischen Analyse des Haushalts zusammen behandelt werden." ${ }^{26)}$ Durch das Anfügen einer dritten Ziffer werden die Obergruppen in Gruppen untergliedert. Die Bildung der Gruppen folgt in den verschiedenen Obergruppen allerdings keinem einheitlichen Schema. ${ }^{127)}$ Der Gruppierungsplan schreibt die Einteilung der Haupt- und Obergruppen sowie der Gruppen mit den entsprechenden Gruppierungsnummern und Benennungen verbindlich vor. Die einzige Ausnahme bildet die Hauptgruppe 7 "Baumaßnahmen", bei der auf eine verbindliche Untergliederung bis zur dritten Stelle verzichtet wurde, weil sich eine "starke Auseinanderentwicklung bei Bund und Ländern ergeben hatte."128) Die weitere Aufteilung des Haushaltsplans in die Titel ist, bis auf die Festtitel ${ }^{129}$, nicht verbindlich festgelegt. Sie liegt im Ermessen des Bundes und des jeweiligen Landes. Für die Kennzeichnung dieser Untergliederung stehen die letzten beiden Stellen der insgesamt fünfstelligen Titelnummer zur Verfügung. Es obliegt den veranschlagenden Dienststellen, die Zweckbestimmung des Titels vorzunehmen.

126) Patzig, W.: Haushaltsrecht des Bundes ..., Bd. II, a.a.O., C 13/17.

Für die Hauptgruppe 8 "Sonstige Ausgaben für Investitonen und Investitionsförderungsmaßnahmen" sieht der Gruppierungsplan folgende Einteilung in Obergruppen vor:

81 - Erwerb von beweglichen Sachen

82 - Erwerb von unbeweglichen Sachen

83 - Erwerb von Beteiligungen und dgl.

85 - Darlehen an öffentlichen Bereich

86 - Darlehen an sonstige Bereiche

87 - Inanspruchnahme aus Gewährleistungen

88 - Zuweisungen für Investitionen an öffentliche Bereiche

89 - Zuschüsse für Investitionen an sonstige Bereiche

127) Vgl. ebenda, C 13/18.

Für die Obergruppe 81 "Erwerb von beweglichen Sachen" sieht diese Einteilung dann wie folgt aus:

811 - Erwerb von Fahrzeugen im Inland

812 - Erwerb von Geräten, Ausstattungs- und Ausrüstungsgegenständen im Inland

813 - Erwerb von sonstigen beweglichen Sachen im Inland

816 - Erwerb von Fahrzeugen im Ausland

817 - Erwerb von Geräten, Ausstattungs- und Ausrüstungsgegenständen im Ausland

818 - Erwerb von sonstigen beweglichen Sachen im Ausland.

Die in dieser Obergruppe nicht belegten Gruppen werden freigehalten, "bis Klarheit darüber besteht, welche Anforderungen die Bereiche Bildung und Wissenschaft künftig an die Haushaltssystematik stellen". Patzig, W.: Haushaltsrecht des Bundes ..., Bd. II, a.a.O., C $13 / 27$.

128) Ebenda, C 13/26f.

129) Festtitel sind "Titel, bei denen Nummer und Wortlaut der Zweckbestimmung für den gesamten Haushaltsplan bindend festgelegt sind." Kramp, H.: Systematik des ..., a.a.O., S. 11. Vgl. auch die Auflistung der Festtitel bei Mons, W. und Fuchs, K.W.: Gruppierungsplan des Bundeshaushaltes, Loseblattsammlung, Stand: 19. Ergänzungslieferung vom 1. Januar 1987, S. $217 \mathrm{ff}$. 
Ein Haushaltstitel weist somit drei Bestandteile auf:

1. Die fünfstellige Titelnummer, deren ersten drei Stellen durch den Gruppierungsplan vorgegeben sind.

2. Die Zweckbestimmung des Titels, die auch Dispositiv genannt wird, und

3. den Haushaltsansatz zumeist auch den Ansatz des Vorjahres und das Ist-Ergebnis des letzten abgeschlossenen Rechnungsjahres. ${ }^{130}$ )

\subsubsection{Gliederung nach Ausgabengruppen (Gruppierungsübersicht)}

Die Gliederung der Ausgaben nach Ausgabengruppen ist durch § 11 Abs. 1 HGrG und gleichlautend $\S 14$ Abs. $1 \mathrm{BHO}$ vorgeschrieben. Diese Gruppierungsübersicht wird den gesetzlichen Bestimmungen folgend als Anlage dem Haushaltsplan angefügt. ${ }^{131)}$ Sie faßt die im Haushaltsplan veranschlagten Einnahmen und Ausgaben auf der Grundlage des Gruppierungsplans zusammen. Dabei gilt für die Ausgaben, daß in der Gruppierungsübersicht alle Titel, die laut Gruppierungsplan eine Ausgabengruppe bilden - mithin die Titel, bei denen die ersten drei Stellen der Titelnummer identisch sind - zusammengefaßt und den entsprechenden Ober- und Hauptgruppen zugeordnet werden. ${ }^{132}$ In der Gruppierungs übersicht werden die Ausgaben somit entsprechend den Hauptgruppen des Grup pierungsplans eingeteilt und bis zur Gliederungstiefe der Gruppen ausgewiesen

Die Bildung der Hauptgruppen erfolgte nach ökonomischen Gesichtspunkten ${ }^{133}$, wobei man wohl davon ausging, daß den Hauptgruppen "Personalausgaben"

130) Für den Haushaltsplan 1985 sind im Einzelplan 08 "Geschäftsbereich des Bundesministers der Finanzen" für das Kapitel 0801 "Bundesministerium der Finanzen", die beiden Titel

- 81101 "Erwerb von Dienstfahrzeugen",

- 81201 "Erwerb von Geräten, Ausstattungs- und Ausrüstungsgegenständen im Inland für Verwaltungszwecke",

mit den jeweiligen Beträgen für 1985 und 1984 und dem Istergebnis aus 1983 aufgeführt. Vgl. Bundeshaushaltsplan für das Haushaltsjahr 1985, Einzelplan 08 ..., S. 22 f.

Der Titel 81101 "Erwerb von Dienstfahrzeugen" ist ein Festtitel. Vgl. Mons, W. und Fuchs, K.W.: Gruppierungsplan ..., a.a.O., S. 219.

131) Die Gruppierungsübersicht stellt eine von fünf Übersichten dar, deren Ausgestaltung im $\S 14$ Abs. 1 BHO geregelt ist. Im Gegensatz zu diesen sind die durch 113 Abs. 4 BHO vorgeschriebenen Haushalts- und Finanzierungsübersicht sowie der Kreditfinanzierungsplan Bestandteile des Haushaltsgesetzes selbst.

132) Während alle übrigen Hauptgruppen bis zur Ebene der Gruppe disaggregiert werden, werden die Baumaßnahmen in der $\mathrm{HGr} 7$ global ausgewiesen, da keine Übereinstimmung über die tiefere Gliederung dieser Hauptgruppe erzielt werden konnte.

133) Vgl. Bundesministerium der Finanzen: Finanzbericht 1969, a.a.O., S. 211. 


\section{Übersicht 2.7: Ausgabengliederung nach dem Gruppierungsplan}

\section{HAUPTGRUPPE}

\begin{tabular}{cc}
$\begin{array}{c}\text { KENN. } \\
\text { ZIFFER }\end{array}$ & BEZEICHNUNG \\
4 & Personalausgaben \\
5 & $\begin{array}{l}\text { Sächl. Verwaltungs- } \\
\text { ausgaben, militärische } \\
\text { Beschaffungen usw., } \\
\text { Ausgaben für den } \\
\text { Schuldendienst }\end{array}$ \\
\hline
\end{tabular}

6

Ausgaben für
Zuweisungen und
Zuschüsse mit
Ausnahme für
Investitionen

Baumaßnahmen

8

Sonstige Ausgaben für
Investitionen und
Investitionsförderungs.
maßnahmen

Besondere
Finanzierungs-
ausgaben

81

\section{BEZEICHNUNG}

Aufwendungen für Abgeordnete. Dienstbezüge und dgl. Versorgungsbezüge und dgl. Beihilfen, Unterstützungen und $\mathrm{dg} \mid$ Personalbezogene Sachausgaben Globale Mehr- und Minderausgaben

1-54 Sächliche Verwaltungsausgaben Militärische Beschaffungen, Anlager usu Zinsausgaben an Gebietskörperschafte' Zinsausgaben an Kreditmarkt Tilgungsausgaben an Gebietskörperschaften ... Tilgungsausgaben an Kreditmarkt

Allg. Finanzzuweisungen an öff. Bereich Schuldendiensthilfen an öff. Bereich Erstattungen von Verwaltungsausgaben ... Sonst. Erstattungen an öff. Bereich Sonst. Zuweisungen an öff. Bereich Schuldendiensthilfen an sonst. Bereiche Erstattungen an sonst. Bereiche Sonst. Zuschüsse an sonst. Bereiche Vermögensübertragungen, soweit nicht für Investitionen

Erwerb von beweglichen Sachen

Erwerb von unbeweglichen Sachen

Erwerb von Beteiligungen und dgl.

Darlehen an öff. Bereich

Darlehen an sonstige Bereiche Inanspruchnahme aus Gewährleistungen Zuweisungen für Investitionen an öff. Bereich Zuschüsse für Investitionen an sonst. Bereiche

Zuführung an Rücklagen, Fonds und Stöcke Ausgaben zur Deckung von Fehlbeträgen aus Vorjahren

Globale Mehr- und Minderausgaben Haushaltstechnische Verrechnungen

Quelle: Zusammengestellt aus: Bundesminister der Finanzen: Verwaltungsvorschriften zur Haushaltssystematik des Bundes (VV-HB), in: Ministerialblatt des Bundesministers der Finanzen und des Bundesministers für Wirtschaft (MinBIFin), 24. Jg. (1973), S. 618-655, S. $637 \mathrm{ff}$. 
(HGr 4), "Sächliche Verwaltungsausgaben, militärische Beschaffungen usw., Ausgaben für Schuldendienst" (HGr 5) sowie mit den "Zuweisungen und Zuschüssen mit Ausnahme für Investitionen" ( $\mathrm{HGr} 6$ ) die laufenden oder konsumtiven Ausgaben von denen mit investivem Charakter ( $\mathrm{HGr} 7, \mathrm{HGr} 8$ ) getrennt zu haben. Die Hauptgruppe 9 "Besondere Finanzierungsausgaben" nimmt eine Sonderstellung ein. Die Investitionsausgaben werden also, so auch die amtlichen Mitteilungen, "wegen ihrer überragenden finanz- und wirtschaftspolitischen Bedeutung ... in besonderen Hauptgruppen"134) zusammengefaßt. Sie entsprechen gemäß diesen Vorstellungen den Ausgaben, die unter der Hauptgruppe 7 "Baumaßnahmen" und der Hauptgruppe 8 "Sonstige Ausgaben für Investitionen und Investitionsförderungsmaßnahmen" ausgewiesen werden.

Neben dieser gesetzlich vorgeschriebenen Gruppierungsübersicht veröffentlicht der Bund seit 1969 als weitere Anlage zum Haushaltsplan eine leicht geänderte Version, die er "Gliederung der Ausgaben und Einnahmen nach ökonomischen Arten" nennt. ${ }^{135)}$ Diese "ökonomische Gliederung versucht die Einnahmen und Ausgaben des Bundes als Teil des gesamtwirtschaftlichen Kreislaufs darzustellen" und ist, so die weiteren Erläuterungen im Haushaltsplan. "soweit dem Staatskonto der Volkswirtschaftlichen Gesamtrechnung angeglichen, daß sie einer gesamtwirtschaftlichen Beurteilung der Bundesfinanzen zugrunde gelegt werden kann." ${ }^{136)}$ In Anlehnung an die Arbeiten von Colm und Pigou werden bei den Ausgaben ${ }^{137)}$ zunächst "Ausgaben der Laufenden Rechnung" und "Ausgaben der Kapitalrechnung" unterschieden. Die Ausgaben der Laufenden Rechnung

134) Bundesminister der Finanzen: Verwaltungsvorschriften zur Haushaltssystematik des Bundes (VV-HB), in: Ministerialblatt des Bundesministers der Finanzen und des Bundesministers für Wirtschaft (MinBlFin), 24. Jg. (1973), S. 618-655, S. 621.

135) Vgl. Bundeshaushaltsplan für das Haushaltsjahr 1985, Übersichten zum Bundeshaushaltsplan 1985, Teil I: Gruppierungsübersicht, S. 24 ff.

In den Finanzberichten wird sie auch "Gliederung nach volkswirtschaftlichen Arten" genannt. Vgl. Bundesministerium der Finanzen: Finanzbericht 1970, Bonn 1970, S. $113 \mathrm{ff}$. sowie Finanzbericht 1986, S. $129 \mathrm{ff}$.

Solche Ausgabenzusammenstellungen sind auch schon in den Finanzberichten vor 1969 enthalten und zwar aufgespaltet für Bund, LAF, ERP-Sondervermögen, Länder und Gemeinden. Sie sind in jenem Teil der Finanzberichte enthalten, der den finanzstatistischen Übersichten vorbehalten ist. Vgl. exemplarisch Bundesministerium der Finanzen: Finanzbericht 1962, Bonn 1962, S. 690 ff.

136) Bundeshaushaltsplan für das Haushaltsjahr 1985, Übersichten zum Bundeshaushaltsplan 1985, Teil I: Gruppierungsübersicht, S. 28.

137) Bei den Einnahmen wird im Grundsatz ebenso verfahren. 
Übersicht 2.8: Gliederung der Ausgaben nach ökonomischen Arten

\section{AUSGABEN DER}

LAUFENDEN RECHNUNG

1 Personalausgaben

11 Aktivitätsbezüge

12 Versorgung

2 Laufender Sachaufwand

21 Unterhaltung des unbewegl.

Vermögens

22 Militärische Beschaffung, usw.

23 Sonstiger lfd. Sachaufwand

3 Zinsausgaben

31 an Verwaltungen

32 an andere Bereiche

4 Laufende Zuweisungen und Zuschüsse

41 an Verwaltungen

42 an andere Bereiche

II AUSGABEN DER KAPITALRECHNUNG

1 Sachinvestitionen

11 Baumaßnahmen

12 Erwerb von beweglichen Sachen

13 Grunderwerb

2 Vermögensübertragungen

21 Zuweisungen und Zuschüsse für Investitionen

22 sonstige Vermögensübertragungen

3 Darlehensgewährung, Erwerb von Beteiligungen

31 Darlehensgewährung

32 Erwerb von Beteiligungen, Kapitaleinlagen

Quelle: Zusammengestellt aus: Bundeshaushaltsplan für das Haushaltsjahr 1985, Bd. 1, Übersichten zum Bundeshaushaltsplan 1985, Teil I: Gruppierungsübersicht, S. 24 f.

umfassen die Personalausgaben, den laufenden Sachaufwand, die Zinsausgaben sowie die laufenden Zuweisungen und Zuschüsse. Die Kapitalrechnung umfaßt die Sachinvestitionen, die Vermögensübertragungen an andere Bereiche und die Darlehen und Beteiligungen an andere Bereiche. Rücklagenbewegungen und Haushaltstechnische Verrechnungen werden gesondert erfaßt. 
Die sachliche Erfassung weicht in dieser Systematik gegenüber derjenigen, die aufgrund des Gruppierungsplans vorgenommen wird, nur in wenigen, kaum bedeutenden Punkten ab. Die Überführung der einzelnen Ausgabengruppen aus der Gruppierungsübersicht zur Aufstellung nach ökonomischen Arten ist, sofern sie bei den gleichen Gruppennnamen (vgl. Übersicht 2.7. ) im Detail Abweichungen aufweisen, in den Erläuterungen zu dieser Gliederung im einzelnen aufgeführt. ${ }^{138)}$

\subsubsection{Gliederung nach Aufgabenbereichen (Funktionenübersicht)}

Die funktionale Gliederung der Ausgaben soll "Auskunft darüber geben, in wel chem Umfang einzelne öffentliche Aufgaben (Funktionen) erfüllt werden."139 'Sie hat, wie Kitterer formulierte, "den Zweck, die gesellschaftspolitische Funktion des Budgets hervorzuheben"140', indem sie die "Ausgaben nach politisch relevan ten Gesichtspunkten"141' gliedert. Darüber hinaus soll die funktionale Aufschlüs selung des Budgets der Verwaltung Einblick gewähren in das, was "grundsàtz lich im politischen, wirtschaftlichen und sozialen Bereich gewollt ist und sie in die Lage versetzen, sowohl bei der Vorbereitung wie beim Vollzug des Staatshaushalts eine entsprechende gegenseitige Berücksichtigung und Abstimmung zwischen den einzelnen Aufgaben vorzunehmen."142;

In der Weimarer Republik wurden zwar schon, in gesonderten Haushaltsführern, die Einnahmen und Ausgaben nach wirtschaftlichen Zwecken getrennt, um "die historisch verknöcherte Ministerialorganisation des Budgets zu durchleuch-

138) Vgl. Bundeshaushaltsplan für das Haushaltsjahr 1985, Bd. 1, Übersichten zum Bundeshaushaltsplan 1985, Teil I: Gruppierungsübersicht, S. $28 \mathrm{f}$.

139) Bundesminister der Finanzen: Verwaltungsvorschriften zur Haushaltssystematik ..., a.a.O., S. 619.

140) Kitterer, W.: Das moderne Budget. Eine vergleichende Analyse der zentralen Staatshaushalte Frankreichs und der BRD, Frankfurt/Main, Bern 1976, S. 137.

141) Ehrlicher, W.: Öffentliche Sachausgaben, a.a.O., S. 761.

142) Hengstschläger, J.: Das Budgetrecht des Bundes. Gegenwartsprobleme und Entwicklungstendenzen, Berlin 1977, S. 128.

Vgl. auch Klaas, H.: Aufgaben der funktionalen Haushaltsgliederung im Rahmen des Funktionenplanes, in: Der öffentliche Haushalt - Archiv für Finanzkontrolle, Jg. 10 (1969/70), S. 150-158, S. 150 ff. 
ten"143), in der praktischen Ausgestaltung fand nach dem zweiten Weltkrieg allerdings zunächst eine kameralistische Rückbildung statt. ${ }^{144)}$ Diese wurde, zumindest für den Bund, ab dem Rechnungsjahr 1956 zum Teil insofern abgeschwächt, als von diesem Zeitpunkt an, in Ergänzung des Bundeshaushaltsplans, ein Funktionenplan aufgestellt wurde, "der die Finanzvorgänge nach organisch zusammengehörenden Aufgabenbereichen" ausweisen sollte. ${ }^{145)}$ Im Zuge der Haushaltsreform des Jahres 1969 fand das Prinzip der Funktionalgliederung dann endgültig Eingang in das bundesdeutsche Haushaltsrecht. Nach den damals neu geschaffenen Bestimmungen des $\S 11 \mathrm{Abs}$. $1 \mathrm{HGrG}$ und gleichlautend $\S 14$ Abs. 1 BHO ist eine Funktionenübersicht, welche die Ausgaben nach bestimmten Aufgabenbereichen ordnet, dem Haushaltsplan als Anlage anzufügen. Diese Funktionenübersicht wird nach $\S 14$ Abs. 2 BHO aufgrund des Funktionen plans zusammengestellt, der durch den Bund-Länder-Arbeitsausschuß "Haus. haltsrecht und Haushaltssystematik" erarbeitet und aktualisiert wurde. ${ }^{14 n} \mathrm{Da}$ die hierzu erlassenen Verwaltungsvorschriften im Bund und den Ländern größtenteils einheitlich sind, fördert die Funktionenübersicht auch die Vergleich barkeit der öffentlichen Haushalte. ${ }^{147)}$

Während in der Bundeshaushaltsordnung und den Länderhaushaltsordnungen die Mindestgliederung des Gruppierungsplans normiert ist, enthielten sich die Gesetzgeber im Hinblick auf den Funktionenplan jedweder gesetzlichen Festle.

143) Heinig, K.: Das Budget, 2. Bd, a.a.O., S. 389. Vgl. auch Klaas, H.: Aufgaben der funktionalen ..., a.a.O., S. 154.

144) Vgl.Heinig, K.: Das Budget, 2. Bd, a.a.O., S. 393.

145) Bundesministerium der Finanzen Finanzbericht 1966, a.a.O., S. 202.

Vgl. hierzu auch Schmölders, G.: Politische und institutionelle Probleme der Budgetgliederung, in: Probleme des öffentlichen Budgets, Schriften des Vereins für Socialpolitik, N.F. Bd. 31, hrsg. v. H. Jecht, Berlin 1964, S. 65-72, S. 68 f. und Ehrlicher, W.: Öffentliche Sachausgaben, a.a.O., S. 761. Siehe auch Brinkmann, G.: Der Funktionenplan. Anmerkungen eines Verwunderten, in: Der öffentliche Haushalt - Archiv für Finanzkontrolle, Jg. 13 (1972), S. 77 - 84, S. 77.

Wolfgang Kitterer verweist dagegen schon auf den Bundeshaushaltsplan für das Rechnungsjahr 1952, in dem er "eine Art funktionaler Gliederung des Haushaltsplans" entdeckte. Kitterer, W.: Das moderne Budget ..., a.a.O., S. 138.

146) Vgl. Patzig, W.: Haushaltsrecht des Bundes ..., Bd. II, a.a.O., C 14/10.

Die Ergebnisse der Überprüfung sind enthalten in: Bundesminister der Finanzen: Verwaltungsvorschriften zur Haushaltssystematik des Bundes (VV-HB); hier: Neufassung des Funktionenplans, in: Ministerialblatt des Bundesministers der Finanzen und des Bundesministers für Wirtschaft (MinBIFin), 25. Jg. (1974), S. 757-804.

147) Vgl. Piduch, E.A.: Bundeshaushaltsrecht, Bd. II, a.a.O., BHO § 14, S. 67. 
Übersicht 2.9: Gliederung des Funktionenplans

HAUPTFUNKTION

0

Allgemeine Dienste

1

Bildungswesen, Wissenschaft, Forschung, kulturelle Angelegenheiten

2 Soziale Sicherung, soziale Kriegsfolgeaufgaben, Wiedergutmachung

3 Gesundheit, Sport und Erholung

4

Wohnungswesen, Raumordnung und kommunale Gemeinschaftsdienste

5 Ernährung, Landwirtschaft und Forsten

\section{OBERFUNKTION}

01 Politische Führung und zentrale Verwaltung

02 Auswärtige Angelegenheiten

03 Verteidigung

04 Off. Sicherheit und Ordnung

05 Rechtsschutz

11 Verwaltung

12 Schulen und vorschulische Bildung

13 Hochschulen

14 Förderung des Bildungswesens

15 Sonstiges Bildungswesen

16/17 Wissenschaft, Forschung, Entwicklung außerhalb der Hochschulen

18 Kunst und Kulturpflege

19 Kirchliche Angelegenheiten

21 Verwaltung

22 Sozialversicherung einschl. Arbeitslosenversicherung

23 Familien-, Sozial- und Jugendhilfe

24 Soziale Leistungen für Folgen von Krieg und polit. Entscheidungen

25 Arbeitsmarktpolitik und Arbeitsschutz

26 Naturkatastrophen

27 Förderung der Vermögensbildung

28 Sonstige soziale Angelegenheiten

31 Einrichtungen und Maßnahmen des Gesundheitswesens

32 Sport und Erholung

33 Reinhaltung von Luft, Wasser und Erde, Lärmbekämpfung, Reaktorsicherheit, Strahlenschutz

41 Wohnungswesen

42 Raumordnung, Landesplanung, Vermessungswesen

43 Kommunale Gemeinschaftsdienste

44 Städtebauförderung

51 Verwaltung

52 Verbesserung der Agrarstruktur

53 Einkommensstabilisierende Maßnahmen

54 Sonstige Bereiche 


\section{HAUPTFUNKTION}

6

Energie- und Wasserwirtschaft, Gewerbe, Dienstleistungen

7 Verkehrs- und Nachrichtenwesen

8 Wirtschaftsunternehmen, allg. Grundund Kapitalvermögen, Sondervermögen

9 Allgemeine Finanzwirtschaft

\section{OBERFUNKTION}

61 Verwaltung

62 Energie- und Wasserwirtschaft, Kulturbau

63 Bergbau, verarbeitendes Gewerbe und Baugewerbe

64 Handel

65 Fremdenverkehr

66 Geld- und Versicherungswesen

67 Sonstige Dienstleistungen

68 Sonstige Bereiche

69 Regionale Förderungsmaßnahmen

71 Verwaltung

72 Straßen

73 Wasserstraßen und Häfen.

Förderung der Schiffahrt

74 Schienenverkehr

75 Luftfahrt

76 Wetterdienst

77 Nachrichtenwesen

78 Sonstige Bereiche

81 Land- und forstwirtschaftliche

Unternehmen

82 Versorgungsunternehmen

83 Verkehrsunternehmen

84 Kombinierte Versorgungs- und

Verkehrsunternehmen

85 Bergbau und Gewerbeunternehmen

86 Sonstige Wirtschaftsunternehmen

87 Allg. Grund-und Kapitalvermögen, Sondervermögen

91 Steuern und allgemeine

Finanzzuweisungen

92 Schulden

93 Versorgung

94 Beihilfen, Unterstützungen u.ä.

95 Rücklagen

96 Sonstiges

97 Abwicklung der Vorjahre

98 Globalposten

99 Haushaltstechnische

Verrechnungen

Quelle: Zusammengestellt aus: Bundesminister der Finanzen: Verwaltungsvorschriften zur Haushaltssystematik des Bundes (VV-HB); hier: Neufassung des Funktionenplans, in: Ministerialblatt des Bundesministers der Finanzen und des Bundesministers für Wirtschaft (MinBlFin),25. Jg. (1974), S. 757-804, S.757 ff. 
gung. Nach der Bund-Länder Vereinbarung sieht der Funktionenplan eine Gliederung in 10 Hauptfunktionen ${ }^{148}$ ) vor, die durch die erste Ziffer, einer in der tiefsten Gliederung dreistelligen Zahl, gekennzeichnet sind. Die zweite Ziffer der Zahl markiert die Oberfunktionen und die dritte Ziffer die Funktionen. ${ }^{149)}$ Die funktionale Kennziffer, die unabhängig von der Gruppierung des Haushaltsplans ist, stellt die Verbindung mit den Haushaltsansätzen her. Sie wird "von zentraler Stelle ... im Haushaltsplan" eingetragen und "ermöglicht es, ohne großen Verwaltungsaufwand den Inhalt des Haushaltsplans nach Funktionen zu gliedern und damit die Durchsichtigkeit des Haushalts wesentlich zu erhöhen."150)

Die hohen Erwartungen, die an die funktionale Gliederung der öffentlichen Ausgaben gestellt wurden ${ }^{151}$ ', erfüllten sich im wesentlichen nicht. So ist die Funktionenübersicht "weit davon entfernt ein Programmbudget zu sein"152), da sie zum einen auf der Ausgabenebene anknüpft und damit inputorientiert ist, und zum anderen eine rein statistische Untergliederung des Haushaltsplans darstellt, der keine eigenständige Rolle im Rahmen der Budgetvorbereitung und -planung zukommt. ${ }^{153)}$ Hengstschläger sähe "eine optimale Lösung" darin, "den institutionell gegliederten Haushalt auch noch primär funktionell-ökonomisch darzustellen

148) Piduch erwähnt in diesem Zusammenhang lediglich 9 Hauptfunktionen, offenbar, weil er die Hauptfunktion 9 "Allgemeine Finanzwirtschaft" nicht als solche anerkennt. Vgl Piduch, E.A.: Bundeshaushaltsrecht, Bd. II, a.a.O., BHO $\$ 14$, S 70

149) Zu den Haupt- und Oberfunktionen siehe Übersicht 2.9.

Als Beispiel für die weitere Aufteilung in Funktionen wird hier die Untergliederung der Oberfunktion 01 "Politische Führung und zentrale Verwaltung" vorgestellt:

011 Politische Führung

012 Innere Verwaltung

013 Informationswesen

014 Statistischer Dienst

015 Zivildienst

016 Steuer-und Zollverwaltung, Vermögensverwaltung

017 Schuldenverwaltung und sonstige Finanzverwaltung

018 Hochbauverwaltung

019 Sonstige allgemeine Staatsaufgaben

150) Bundesminister der Finanzen: MinBlFin (1973), S. $619 \mathrm{f}$.

151) Vgl. die Auflistung bei Kitterer, W.: Das moderne Budget ..., a.a.O., S. $144 \mathrm{f}$. Vgl. auch Brinkmann, G.: Der Funktionenplan ..., a.a.O., S. 77 ff., dessen kritische Anmerkungen zum Funktionenplan in den Satz münden: "Alle Aussagen, die auf dem Funktionenplan in seiner heutigen Form beruhen, sind deshalb mehr oder weniger sinnlos." Ebenda, S. 83.

152) Rehm, H.: Analyse und Kritik ..., a.a.O., S. 163

153) Vgl. hierzu Ehrlicher, W.: Öffentliche Sachausgaben, a.a.O., S. 761; Kitterer, W.: Das moderne Budget ..., a.a.O., S. 171 f. sowie Rehm, H.: Analyse und Kritik ..., a.a.O., S. 162 ff. 
und diese funktionelle Konstellation bei der Erstellung des Bundesvoranschlagsentwurfs in den Vordergrund zu rücken."154)

\subsubsection{Das Haushaltsrecht der Gemeinden}

Im Gefolge der Neugestaltung des Haushaltsrechts von Bund und Ländern wurde auch das kommunale Haushaltsrecht umgestaltet. ${ }^{155)}$ Neben dem Ziel, die vertikale Vergleichbarkeit der Haushalte zwischen Bund, Ländern und Gemeinden zu verbessern, diente die Gemeindehaushaltsreform auch der horizontalen Angleichung des Haushaltsrechts der Gemeinden. Hierzu wurden von dem Unterausschuß "Gemeindehaushaltsrecht" des Arbeitskreises III der Arbeitsgemeinschaft der Innenministerien der Bundesländer ein Musterentwurf zu den gesetzlichen Bestimmungen des neuen Gemeindehaushaltsrechts sowie ein Musterentwurf zur Gemeindehaushaltsverordnung erarbeitet. ${ }^{156)}$ Die wichtigste Besonderheit des neuen Haushaltsrechts der Gemeinden, das seit Januar 1975 in allen Bundesländern Gültigkeit besitzt ${ }^{1571}$, liegt darin, daß in ihm, im Gegensatz zu den Bestimmungen für Bund und Länder, die Trennung in einen Verwaltungs- und einen Vermögenshaushalt gefordert wird. ${ }^{158)}$

Nach $\S 3$ des Musterentwurfs zum neuen Gemeindehaushaltsrecht hat die Gemeinde für jedes Haushaltsjahr eine Haushaltssatzung zu erlassen ${ }^{159}$, die als

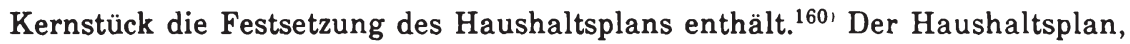

154) Hengstschläger, J.: Das Budgetrecht ..., a.a.O., S. 130.

155) Vgl. Depiereux, S.: Das neue Haushaltsrecht ..., a.a.O., S. $1 \mathrm{ff}$.

156) Vgl. ebenda, S. $8 \mathrm{ff}$. sowie S. $225 \mathrm{ff}$. und $277 \mathrm{ff}$.

157) Vgl. Deutsches Institut für Urbanistik (Hrsg.): Kommunale Entwicklungsplanung: Mittelfristige Investitions- und Finanzplanung, Berlin 1976, Kapitel 2, S. 7 und Mengert, F.; Kunert, C. und Rehm, J.: Kommunalhaushalt in Schlagworten. Systematische Darstellung der Haushaltsgliederung und -gruppierung mit einem Schlagwortkatalog und Erläuterungen zur Finanzstatistik, 4. Aufl., Köln 1983, S. V.

158) $\mathrm{Zu}$ den Gemeinsamkeiten und Abweichungen des gemeindlichen Haushaltsrechts und dem von Bund und Ländern vgl. Depiereux, S.: Das neue Haushaltsrecht ..., a.a.O., S. 16 f. Kritische Anmerkungen zur Zweiteilung des kommunalen Haushalts finden sich bei Dreissig, W.: Zur kommunalen Haushaltsreform in der Bundesrepublik Deutschland, in: Wirtschaftswissenschaft als Grundlage staatlichen Handelns. Heinz Haller zum 65. Geburtstag, hrsg. v. P. Bohley und G. Tolkemitt, Tübingen 1979, S. 413-432.

159) Vgl. Musterentwurf VI. Teil der Gemeindeordnung, veröffentlicht in Depiereux, S.: Das neue Haushaltsrecht ..., a.a.O., S. $225 \mathrm{ff}$.

160) Neben der Festsetzung des Haushaltsplans enthält die Haushaltssatzung auch die Festsetzung des Höchstbetrages der Kassenkredite sowie die Festsetzung der Steuersätze, die für jedes Haushaltsjahr neu festzusetzen sind. Darüber hinaus kann die Haushaltssatzung noch weitere Vorschriften enthalten, die sich auf die Einnahmen und Ausgaben und den Stellenplan des Haushaltsjahres beziehen. Vgl. ebenda, S. 227. 
der alle für die Erfüllung der gemeindlichen Aufgaben im Haushaltsjahr voraussichtlich eingehenden Einnahmen, die zu leistenden Ausgaben sowie die notwendigen Verpflichtungsermächtigungen enthält, bildet die Grundlage für die Haushaltswirtschaft der Gemeinden. ${ }^{161}$ Er besteht aus dem Gesamtplan ${ }^{162)}$, den Einzelplänen, den Sammelnachweisen ${ }^{163)}$ und dem Stellenplan ${ }^{164)}$ sowie einigen Anlagen. ${ }^{165)}$ Die Einzelpläne werden getrennt für den Verwaltungs- und den Vermögenshaushalt aufgestellt. ${ }^{166}$ ' Dabei sind in den Verwaltungshaushalt alle vermögensunwirksamen Ausgaben und Einnahmen einzustellen, während der Vermögenshaushalt aus den vermögenswirksamen (investiven) Positionen und ihrer Finanzierung besteht. ${ }^{167)}$ Aus Vereinfachungsgründen werden in $\S 1 \mathrm{Abs.} 1$ des $\mathrm{Mu}$ sterentwurfs zur Gemeindehaushaltsverordnung lediglich die Einnahmen und Ausgaben des Vermögenshaushalts aufgezählt und in Absatz 2 bestimmt, daß der Verwaltungshaushalt alle anderen Einnahmen und Ausgaben umfaßt. ${ }^{168)}$ Nach diesen Bestimmungen dient der Vermögenshaushalt vor allem zur Hervorhebung der gemeindlichen Investitionen. Neben der Tilgung von Krediten und ähnlichen Ausgaben, den Zuführungen in die Rücklagen und zum Verwaltungshaushalt, werden im Vermögenshaushalt die Ausgaben für die Veränderung des Anlage vermögens sowie Zuweisungen und Zuschüsse für Investitionen Dritter er

161) Zu der Einführung des Kassenwirksamkeitsprinzips, das in diesen Formulierungen deut lich wird vgl. Depiereux, S.: Das neue Haushaltsrecht ..., a.a O., S 51 f.

162) Der Gesamtplan enthält

- die Zusammenfassung der Einzelpläne,

- den Haushaltsquerschnitt,

- die Gruppierungsübersicht und

- die Finanzierungsübersicht.

163) Die "Sammelnachweise dienen dem Zweck, bestimmte zusammengehörige Einnahmen und Ausgaben für eine gemeinsame Bewirtschaftung zusammengefaßt zu veranschlagen". Depiereux, S.: Das neue Haushaltsrecht ..., a.a.O., S. 62.

164) Der Stellenplan ist die Grundlage der Personalwirtschaft der Gemeinden und ist für Beamte, Angestellte und Arbeiter aufzustellen. Vgl. ebenda, S. 62 ff.

165) Vgl. § 2 Abs. 2 des Musterentwurfs zur Gemeindehaushaltsverordnung, veröffentlicht in Depiereux, S.: Das neue Haushaltsrecht ..., a.a.O., S. 277 ff. Vgl. auch ebenda, S. 66 ff.

166) Vgl. § 2 Abs. 1 des Musterentwurfs zur Gemeindehaushaltsverordnung, veröffentlicht in Depiereux, S.: Das neue Haushaltsrecht ..., a.a.O., S. $277 \mathrm{ff}$. sowie $\S 4$ Abs. 2 des Musterentwurfs der gesetzlichen Bestimmungen des neuen Gemeindehaushaltsrechts, ebenfalls veröffentlicht in Depiereux, S.: Das neue Haushaltsrecht ..., a.a.O., S. $225 \mathrm{ff}$.

Diese Unterscheidung löste die Trennung in einen ordentlichen und außerordentlichen Haushalt ab. Vgl. ebenda, S. $53 \mathrm{f}$.

167) Vgl. Deutsches Institut für Urbanistik (Hrsg.): Kommunale Entwicklungsplanung ..., a.a.O., Kapitel 2, S. 9.

168) Vgl. Musterentwurf zur Gemeindehaushaltsverordnung, veröffentlicht in Depiereux, S.: Das neue Haushaltsrecht ..., a.a.O., S. $277 \mathrm{ff}$. 
faßt. ${ }^{169)}$ Die Einzelpläne des Verwaltungs- und Vermögenshaushaltes und ihre Abschnitte und Unterabschnitte sind nach Aufgabenbereichen gegliedert, was keine besondere Neuerung darstellt, denn die deutschen Gemeindehaushalte wurden bereits seit 1938 nach funktionalen Kriterien aufgestellt. ${ }^{170)}$ Die hierin einzustellenden Einnahmen und Ausgaben werden nach ökonomischen Arten erfaßt, deren Ordnung sich am Musterentwurf des Gruppierungsplans für die Haushalte der Gemeinden und Gemeindeverbände orientiert. Entscheidend für die Gruppierung ist die Einteilung des Haushalts in einen Verwaltungs- und einen Vermögenshaushalt. Auf der Ausgabenseite werden zum einen die Hauptgruppen "Personalausgaben" (HGr 4), "Sächlicher Verwaltungs- und Betriebsaufwand" (HGr 5/6), "Zuweisungen und Zuschüsse soweit nicht für Invesitionen" (HGr 7) sowie, "Sonstige Finanzausgaben" (HGr 8), und zum anderen die Hauptgruppe 9 "Ausgaben des Vermögenshaushalts" unterschieden. ${ }^{171)}$

169) Im Einzelnen umfaßt der Vermögenshaushalt auf der Ausgabenseite

- die Tilgung von Krediten, die Rückzahlung innerer Darlehen, die Kreditbeschaffungskosten sowie die Ablösung von Dauerlasten,

- Ausgaben für die Veränderung des Anlagevermögens, Zuweisungen und Zuschüsse für Investitionen Dritter sowie Verpflichtungsermächtigungen,

- Zuführungen zu Rücklagen und die Deckung von Fehlbeträgen aus Vorjahren und

- die Zuführung zum Verwaltungshaushalt.

Darüber hinaus sind im $\S 10$ des Musterentwurfs zur Gemeindehaushaltsverordnung zusätzliche Vorschriften zur Veranschlagung von Investitionen enthalten und in $\$ 46 \mathrm{wer}$ den die Bestandteile des Anlagevermögens konkretisiert. Vgl. Musterentwurf Gemeindehaushaltsverordnung, veröffentlicht in Depiereux, S.: Das neue Haushaltsrecht ..., a.a.O., S. $277 \mathrm{ff}$.

170) Vgl. Freund, E.: Haushaltsstatistik, in: Handbuch der Finanzwissenschaft, 3. Aufl., hrsg. v. F.Neumark, Bd. I, Tübingen 1977, S. 587 - 609, S. 596.

Der Musterentwurf des Gliederungsplans für die Haushalte der Gemeinden und Gemeindeverbände sieht eine funktionale Gliederung in 10 Einzelpläne vor:

0 Allgemeine Verwaltung

1 Öffentliche Sicherheit und Ordnung

2 Schulen

3 Wissenschaft, Forschung, Kulturpflege

4 Soziale Sicherung

5 Gesundheit, Sport, Erholung

6 Bau- und Wohnungswesen, Verkehr

7 Öffentliche Einrichtungen, Wirtschaftsförderung

8 Wirtschaftliche Unternehmen, allgemeines Grund- und Sondervermögen

9 Allgemeine Finanzwirtschaft

Vgl. Mengert, F.; Kunert, C. und Rehm, J.: Kommunalhaushalt ..., a.a.O., S. 1.

Dieser Gliederungsplan weicht doch in einigen Punkten vom Funktionenplan, der für Bund und Länder gilt, ab. Vgl. Abschnitt 2.2.4.

171) Vgl. die Musterentwürfe der Haushaltsmuster, veröffentlicht in Depiereux, S.: Das neue Haushaltsrecht ..., a.a.O., S. $344 \mathrm{ff}$. 


\section{Übersicht 2.10: Gliederung der Ausgaben nach dem kommunalen Gruppierungsplan}
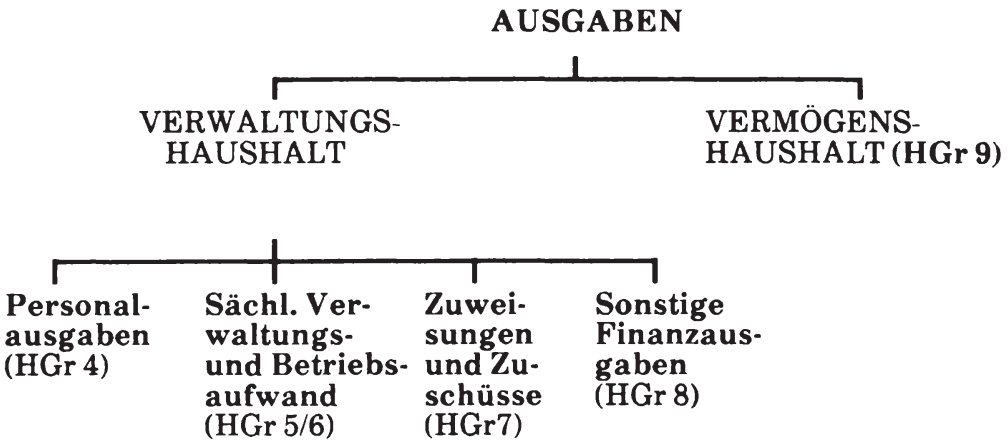

Aus dieser Gliederung der gemeindlichen Ausgaben und ihren Begründungen folgt, daß die Ausgaben des Vermögenshaushaltes im wesentlichen mit den investiven Ausgaben der Gemeinden gleichgesetzt werden. ${ }^{172)}$

\subsection{Gliederungskriterien der a mtlichen Statistik}

Die in der amtlichen Statistik ausgewiesenen öfentlichen Einnahmen und Ausgaben sind den verschiedenen Haushaltsrechnungen entnommen, gegebenenfalls auch durch Schätzungen ergänzt. Die große Palette unterschiedlicher Klassifikationen, gerade bei den Ausgaben, dokumentiert dabei die Vielzahl ökonomischer und politischer Fragestellungen, die an die statistischeAufbereitung der Daten herangetragen werden.

172) Ausnahmen bilden die Zuführungen in den Verwaltungshaushalt (91), die Rücklagenbildung (92) und die Schuldentilgung (97). 


\subsubsection{Die Beziehungen zwischen Finanzstatistik und Volkswirtschaft- lichen Gesamtrechnungen (VGR)}

Stand ursprünglich das Ziel "fundamentale Daten für die Stabilisierungspolitik zu liefern"173) im Vordergrund der Volkswirtschaftlichen Gesamtrechnungen (VGR), so wurden sie, nicht zuletzt im Zuge der Bemühungen um internationale Vergleichbarkeit, zu einem "Universalinstrument"174), mit einer "Fülle von Zielsetzungen, die sich teilweise widersprechen." ${ }^{175)}$ Die Gesamtrechnungen "sind ein auf der Basis der Kreislaufanalyse entwickeltes, in sich geschlossenes System makroökonomischer Größen, das durch zahlenmäßige Ausfüllung seiner Konten und Sektoren ein Bild der wichtigsten Vorgänge in einer Volkswirtschaft ... vermittelt." ${ }^{176)}$ Die öffentlichen Haushalte stellen in diesem System, das primär auf die Erfassung von Marktvorgängen ausgerichtet ist, in vielfacher Weise Fremdkörper dar. ${ }^{177)}$

Die Finanzstatistik dagegen erstreckt sich auf die statistische Erfassung der öffentlichen Finanzwirtschaft. ${ }^{178)}$ Als "eine aus Verwaltungsunterlagen erstellte

173) Bombach, G.: Die öffentliche Finanzwirtschaft im Wirtschaftskreislauf, in: Handbuch der Finanzwissenschaft, 3. Aufl., hrsg. v. F. Neumark, Bd. I, Tübingen 1977, S. 53-75, S. 57.

174) Ebenda, S. 55.

Zur Geschichte der VGR vgl. Stobbe, A.: Art.: Volkswirtschaftliche Gesamtrechnung, in: Handwörterbuch der Wirtschaftswissenschaft (HdWW), hrsg. v. W. Albers et al., Bd. 8, Stuttgart et al. 1980, S. 368-405, S. $396 \mathrm{ff}$.

175) Gantner, M.: Meßprobleme öffentlicher Aktivitäten, a.a.O., S. 59.

Die Volkswirtschaftlichen Gesamtrechnungen sollen Auskunft geben über die Entstehung, Verteilung und Verwendung des Sozialprodukts und dabei die Grundlage bilden für

- eine Analyse der Entwicklung der Produktivkraft,

- eine Analyse der Entwicklung des Wohlstandes,

- die kurzfristige Wirtschaftspolitik (Stabilisierungspolitik),

- die mittel- und langfristige Wirtschaftspolitik (Wachstumspolitik) und für

- Strukturanalysen verschiedenster Art.

Vgl. Bombach, G.: Die öffentliche Finanzwirtschaft ..., a.a.O., S. 55.

176) Anderson, O. et al.: Bevölkerungs- und Wirtschaftsstatistik: Aufgaben, Probleme und beschreibende Methoden, Berlin, Heidelberg, New York 1983, S. 341. Vgl. auch Stobbe, A.: Volkswirtschaftliche Gesamtrechnung, a.a.O., S. $369 \mathrm{ff}$.

177) Vgl. Bombach, G.: Die öffentliche Finanzwirtschaft ..., a.a.O., S. 56 f.; Anderson, O. et al.: Bevölkerungs- und Wirtschaftsstatistik ..., a.a.O., S. 352 f. sowie Gantner, M.: Meßprobleme öffentlicher Aktivitäten, a.a.O., S. 50 ff. und Ring, U.: Öffentliche Planungsziele ..., a.a.O., S. $114 \mathrm{ff}$.

178) Vgl. § 1 Gesetz über die Finanzstatistik, veröffentlicht in der Sammlung: Das Deutsche Bundesrecht, 526. Lieferung (Oktober 1984), VIII Z 70. 
Sekundärstatistik" ist sie "in erheblichem Maße von den rechtlichen, institutionellen, organisatorischen und sachlichen Gegebenheiten der öffentlichen Haushaltswirtschaft" 179) abhängig. Der Begriff der "Finanzstatistik" läßt sich zwar auf den gesamten Regelungsbereich des Finanzstatistikgesetzes ${ }^{1801}$ anwenden, gebräuchlicher ist jedoch die Eingrenzung auf die Statistiken über Ausgaben und Einnahmen (Haushaltsstatistik) sowie über die Schulden (Schuldenstatistik) der öffentlichen Haushalte. ${ }^{181)}$ Grundlage der Datenerfassung für die Finanzstatistik bilden die haushaltsrechtlichen Vorschriften der einzelnen öffentlichen Haushalte, so da $\beta$ als Erfassungsraster die Funktionen- und Gruppierungspläne der Haushaltssystematiken in Betracht kommen. ${ }^{182)}$ Während die Volkswirtschaftlichen Gesamtrechnungen den staatlichen Sektor vor allem in seiner Stellung zu anderen Sektoren der Wirtschaft betrachten, bezieht sich die Finanzstatistik allein auf die öffentliche Finanzwirtschaft. Die Betrachtungsweise der Finanzstatistik kann man daher auch "intrasektoral, die der Volkswirtschaftlichen Gesamtrechnungen intersektoral"183) nennen.

Die Daten der Finanzstatistik und der Volkswirtschaftlichen Gesamtrechnungen weisen hinsichtlich der Angaben über den öffentlichen Bereich bzw. Staatssektor erhebliche Abweichungen auf. Sie lassen sich durch die unterschiedlichen Zielsetzungen begründen und sind insbesondere auf die unterschiedliche sektorale Abgrenzung, auf die Unterschiede bezüglich der berücksichtigten Transaktionen sowie auf Unterschiede bei der zeitlichen Erfassung der Aktivitäten zurückzu-

179) Essig, H.: Erfassungs- und Auswertungsprogramm der Finanzstatistik, in: Wirtschaft und Statistik, Jg. 1984, S. 835-844, S. 835.

180) Vgl. § 1 Abs. 2 des Gesetzes über die Finanzstatistik.

181) Vgl. Essig, H.: Erfassungs- und Auswertungsprogramm ..., a.a.O., S. 835.

Neben der Haushalts- und Schuldenstatistik sind im Gesetz noch

- die Statistik über die Verpflichtungen,

- die Vermögensstatistik,

- die Personalstatistik und

- die Statistik der öffentlichen Unternehmen

erwähnt. Dabei ist festzuhalten, daß es bisher nicht gelungen ist, eine Vermögensstatistik aufzubauen und daß die Statistik über die konjunkturpolitisch bedeutsamen Verpflichtungen inzwischen nicht mehr aufgestellt wird. Vgl. Essig, H.: Erfassungs- und Auswertungsprogramm ..., a.a.O., S. $837 \mathrm{f}$.

182) Vgl. ebenda, S. 836.

183) Wissenschaftlicher Beirat beim Bundesministerium der Finanzen: Gutachten zum Begriff der öffentlichen Investitionen. Abgrenzungen und Folgerungen im Hinblick auf Artikel 115 Grundgesetz, Schriftenreihe des Bundesministeriums der Finanzen, Heft 29, Bonn 1980, S. 6. 
führen. ${ }^{184)} \mathrm{Da}$ das Datenmaterial der Finanzstatistik die Grundlage der in den Volkswirtschaftlichen Gesamtrechnungen ausgewiesenen Ausgaben des Staatssektors bilden, zwingen diese Unterschiede die statistischen Ämter bei der Erstellung der VGR zu mehr oder minder umfangreichen Umformungen. Zum Teil können die Daten nur aufgrund von Schätzungen in die Abgrenzungen und Definitionen der Volkswirtschaftlichen Gesamtrechnungen überführt werden. ${ }^{185)}$

\subsubsection{Finanzstatistische Gliederungen}

Die vollständige Neugestaltung des Haushaltsrechts von Bund und Ländern Ende der 60er Jahre und die sich anschließende gemeindliche Haushaltsreform hatten auch auf die Finanzstatistik in der Bundesrepublik Deutschland erhebliche Auswirkungen. ${ }^{186)}$ Neben der Regelung methodischer Fragen betrafen die wichtigsten, ab 1970 in die Finanzstatistik eingeführten, Änderungen die Präsentation der Haushaltszahlen nach Einnahmen- und Ausgabenarten sowie nach Funktionen. ${ }^{187)}$

Der Erhebungsbereich der Finanzstatistik umfaßt nach $\S 2$ Abs. 1 des Gesetzes über die Finanzstatistik den Bund und die Länder einschließlich ihrer jeweiligen Sondervermögen, die Gemeinden und Gemeindeverbände, die Zweckverbände, die Sozialversicherung einschließlich der Zusatzversorgungen, die Bundesanstalt für Arbeit, ein Teil der Organisationen ohne Erwerbscharakter sowie öffentliche Krankenhäuser. ${ }^{188)}$ Nur die Jahresrechnungsstatistik, das Kernstück der Haushaltsstatistik ${ }^{189}$, welcher die Ist-Ergebnisse der einzubeziehenden Haushalte zu-

184) Vgl. hierzuWisenschaftlicher Beirat beim Bundesministerium der Finanzen: Gutachten zum Begriff ..., a.a.O., S. 6 ff. sowie Gantner, M.: Meßprobleme öffentlicher Aktivităten, a.a.0., S. $60 \mathrm{ff}$.

185) Kopsch, G.: Der Staat in den Volkswirtschaftlichen Gesamtrechnungen 1960 bis 1982, in: Wirtschaft und Statistik, Jg. 1983, S. 749-769, S. 749.

186) Vgl. Freund, E.: Bemerkungen zu einer neuen Konzeption der Finanzstatistik, in: Allgemeines Statistisches Archiv. Organ der Deutschen Statistischen Gesellschaft, Bd. 54 (1970), S. 177-199, S. 177 sowie Freund, E.: Die Neugestaltung der Finanzstatistik ab 1970, in: Wirtschaft und Statistik, Jg. 1970, S. 543-546, S. 543.

187) Vgl. Freund, E.: Die Neugestaltung ..., a.a.O., S. 543.

188) Vgl. auch Statistisches Bundesamt: Rechnungsergebnisse des öffentlichen Gesamthaushalts 1983, Reihe 3.1 der Fachserie 14: Finanzen und Steuern, Stuttgart, Mainz 1985, S. 6.

189) Freund, E.: Haushaltsstatistik,a.a.O., S. 602. 


\section{Übersicht 2.11: Erhebungen der Finanzstatistik}

\begin{tabular}{|c|c|c|c|c|c|c|c|c|c|}
\hline \multirow[b]{2}{*}{ Statiat } & \multirow[b]{2}{*}{ Erhebungsumiang } & \multirow[b]{2}{*}{$\begin{array}{l}\text { Perlo- } \\
\text { olzittit }\end{array}$} & \multicolumn{7}{|c|}{ Ethebungaberelch } \\
\hline & & & $\begin{array}{l}\text { Bund } \\
\text { insechl. } \\
\text { Sonder- } \\
\text { vermogent? }\end{array}$ & $\begin{array}{l}\text { Linder } \\
\text { einach. } \\
\text { Sonder. } \\
\text { vermboen }\end{array}$ & $\begin{array}{l}\text { Gemeinden } \\
\text { und } \\
\text { Gemeinde- } \\
\text { verbinds }\end{array}$ & $\begin{array}{c}\text { 2woek- } \\
\text { verbinde } \\
\text { u. } 0 .\end{array}$ & $\begin{array}{l}\text { Sozlet } \\
\text { ver- } \\
\text { elechering }\end{array}$ & 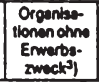 & $\begin{array}{l}\text { Oflentilehs } \\
\text { Krenker } \\
\text { huserd }\end{array}$ \\
\hline Finenzplaningsetetsotte & $\begin{array}{l}\text { Ausgaben- und Eimnohmenarten } \\
\text { nech den Finenzplenungemustern }\end{array}$ & Juhrieh & 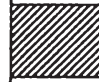 & OPOM & OMABas & & & & \\
\hline $\begin{array}{l}\text { Verteglhritiche } \\
\text { Kesesenstetistik }\end{array}$ & 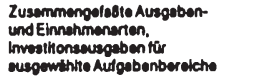 & $\begin{array}{l}\text { vertat- } \\
\text { Phrlich }\end{array}$ & OMa & 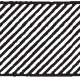 & OPIOA. OPA & & & & \\
\hline $\begin{array}{l}\text { Jehrearectinungs- } \\
\text { stotititik }\end{array}$ & 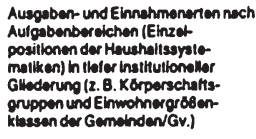 & Jhriken & 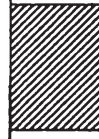 & " + & OM/OS & OM/ln & +8 & "n? & M \\
\hline \multirow[t]{2}{*}{ Schuldenstatbatlk } & 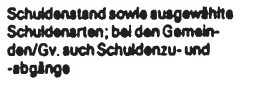 & $\begin{array}{l}\text { vertet } \\
\text { fthrileh }\end{array}$ & OPIOA & Mlle & OPIA & & & & \\
\hline & 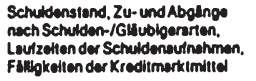 & Jhrilich & OMPOM & MIII & OIII & M & & & M \\
\hline
\end{tabular}

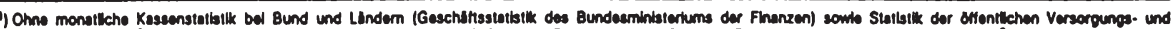

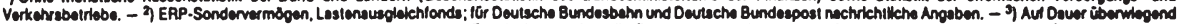
aftenilkeh finanzierte Elarichtungen lür Wlasenschaft, Forschung und Entwicklung. solern die Zuwendungen mindestens 300000 DM pro Jahr betregen. - 4 Kommunelo und steallicho Krankenhluser sowio Hochschulkiliniken mil kaulminniachem Rechnungswesen.

Quelle: Essig, H.: Erfassungs- und Auswertungsprogramm der Finanzstatistik, in: Wirtschaft und Statistik, Jg. 1984, S. 835-844, S. 837.

grunde liegen, wird für sämtliche Berichtskörperschaften der Finanzstatistik erstellt (vgl. auch Übersicht 2.11). ${ }^{190)}$ Die Gliederungen der Jahresrechnungsstatistik erfassen die Ausgaben "auf der Grundlage der Gruppierung nach Ausgabeund Einnahmearten und der Gliederung nach Aufgabengebieten oder Aufgabenbereichen."191) Desweiteren werden die Ausgaben auch noch nach Körperschaftsgruppen untergliedert. ${ }^{192)}$

190) Vgl. Essig, H.: Erfassungs- und Auswertungsprogramm ..., a.a.O., S. $840 \mathrm{ff}$.

Vgl. auch Statistisches Bundesamt: Das Arbeitsgebiet der Bundesstatistiken 1981, Stuttgart, Mainz 1981, S. 35 f. und S. $315 \mathrm{ff}$.

191) Wortlaut des $\$ 3$ Abs. 1, Punkt 1a des Gesetzes über die Finanzstatistik.

192) Vgl. Statistisches Bundesamt: Rechnungsergebnisse (1983)..., a.a.O., S. 7 und Essig, H.: Erfassungs- und Auswertungsprogramm ..., a.a.O., S. 842. 
Die aus den Jahreserhebungen der Berichtskörperschaften erfaßten Daten werden vor der finanzstatistischen Veröffentlichung einer eingehenden sachlichen Prüfung unterzogen, deren Hauptaufgabe in der Abstimmung der Zahlungsströme der einzelnen öffentlichen Haushalte untereinander liegt. ${ }^{193)}$ Darüber hinaus muß in einer Reihe von Fällen aus Gründen der "inhaltlichen Vergleichbarkeit der statistischen Ergebnisse von einer "haushaltsgetreuen" Darstellung abgewichen werden."194)

Den Ausgangspunkt für die finanzstatistischen Gliederungen nach Ausgabenarten bildet der Gruppierungsplan für Bund und Länder, der in seinen Grundzügen auch dem für die kommunalen Haushalte entspricht. Die Ergebnisse werden in einer haushaltmäßigen, einer gesamtwirtschaftlichen und einer finanzwirtschaftlichen Darstellung ausgewiesen. Die haushaltsmäßige Darstellung, die am stärksten dem Haushaltsnachweis folgt, wird hier allerdings nicht näher erläutert, da sie lediglich für den Ausweis der Gemeindehaushalte gebräuchlich ist. ${ }^{195)}$

\section{(1) Die gesamtwirtschaftliche Darstellung}

Die gesamtwirtschaftliche Darstellung der Einnahmen und Ausgaben soll "die Verflechtung der öffentlichen Haushalte mit der Gesamtwirtschaft bzw. mit den einzelnen Wirtschaftssektoren deutlich" ${ }^{196)}$ machen. Diese Gliederung der Einnahmen und Ausgaben stellt zwar "eine Übernahme der Prinzipien der Volks-

193) Vgl. Essig, H.: Erfassungs- und Auswertungsprogramm ..., a.a.O., S. 841.

Zu den bei allen Bemühungen immer noch erheblichen Abstimmungsproblemen in der Praxis siehe auch Abschnitt 3.2.1.

194) Ebenda, S. 840.

Essig verweist in diesem Zusammenhang auf die Gewerbesteuerumlage, die von den Gemeinden an Land und Bund abzuführen ist. Obwohl sie in den Gemeindehaushalten als Ausgabe veranschlagt wird, wird sie bei den empfangenden Körperschaften als direkte Steuereinnahme verbucht. Deshalb werden dann in der Finanzstatistik die kommunalen Gewerbesteuereinnahmen und die korrespondierenden Ausgaben um diesen Betrag gekürzt.

Weitere Probleme treten, vor allem bei der Gliederung nach Aufgabenbereichen da auf, wo in den Zuordnungsrichtlinien Auslegungsspielräume bestehen.

Vgl. auch die Beispiele in Statistisches Bundesamt: Rechnungsergebnisse (1983)..., a.a.O., S. $7 \mathrm{f}$.

195) Vgl. Essig, H.: Erfassung- und Auswertungsprogramm ..., a.a.O., S. $838 \mathrm{ff}$.

196) Freund, E.: Die Neugestaltung ..., a.a.O., S. $543 \mathrm{f}$. 
wirtschaftlichen Gesamtrechnungen" dar, muß aber "nach wie vor auch der Haushaltspraxis Rechnung tragen"197) und weicht deshalb in wesentlichen Punkten von Verfahren und Terminologie der VGR ab. Die Einteilung der Ausgaben in die Hauptgruppen "Ausgaben der laufenden Rechnung" und "Ausgaben der Kapitalrechnung" sowie in die "besonderen Finanzierungsvorgänge" versuchen die Ausgaben nach ihrer Stellung im Wirtschaftskreislauf zu gliedern. Zu den Ausgaben der laufenden Rechnung gehören alle Ausgaben, "die im Rahmen des Verwaltungsvollzugs sowie des Betriebs von Einrichtungen und Anstalten anfallen und nicht vermögenswirksam sind", während die Kapitalrechnung alle Ausgaben umfaßt, "die eine Vermögensveränderung herbeiführen oder zur Finanzierung von Investitionen dienen." 198) Die "besonderen Finanzierungsvorgänge" zeigen "per Saldo den Betrag, der zum Ausgleich der laufenden und der Kapitalrechnung unter Berücksichtigung von Überschüssen und Fehlbeträgen aus Vorjahren aus Kreditmarktmitteln finanziert wird." ${ }^{199)}$ Die Unterscheidung in Ausgaben der laufenden Rechnung und der Kapitalrechnung ist äquivalent mit der auf Gemeindeebene üblichen Trennung in einen Verwaltungs- und einen Vermögenshaushalt. Zu den Ausgaben der laufenden Rechnung zählen die Personalausgaben, die Ausgaben für den laufenden Sachaufwand, die Zinsausgaben sowie die Zuweisungen und Zuschüsse für laufende $Z$ wecke und Schuldendiensthilfen. In die Kapitalrechnung werden die Ausgaben für Baumaßnahmen und der Erwerb von Sachvermögen, die zusammen die Sachinvestitionen bilden sowie die Vermögensübertragungen, die Darlehensgewährung und der Erwerb von Beteiligungen eingestellt ${ }^{200)}$ (vgl. Übersicht 2.12).

Die Trennung zwischen der laufenden Rechnung und der Kapitalrechnung soll, wie auch im kommunalen Haushalt die Unterscheidung zwischen Verwaltungsund Vermögenshaushalt, die sog. konsumtiven von den investiven Ausgaben separieren. Die konsumtiven Ausgaben beinhalten jene Ausgaben für Güter und

197) Freund, E.: Haushaltsstatistik, a.a.O., S. 589. Vgl. auch Freund, E.: Die Neugestaltung ..., a.a.O., S. 544.

198) Bundesministerium der Finanzen: Erläuterungen zu den "Finanzstatistischen Übersichten", Finanzbericht 1974, Bonn 1973, S. 307-312, S. 308.

199) Ebenda, S. 308.

200) Vgl. Essig, H.: Erfassung- und Auswertungsprogramm ..., a.a.O., S. 839.

201) Vgl. Statistisches Bundesamt: Rechnungsergebnisse (1983).., a.a.O., S. 11. 
Übersicht 2.12: Gesamtwirtschaftliche Darstellung der Gliederung nach Ausgabenarten

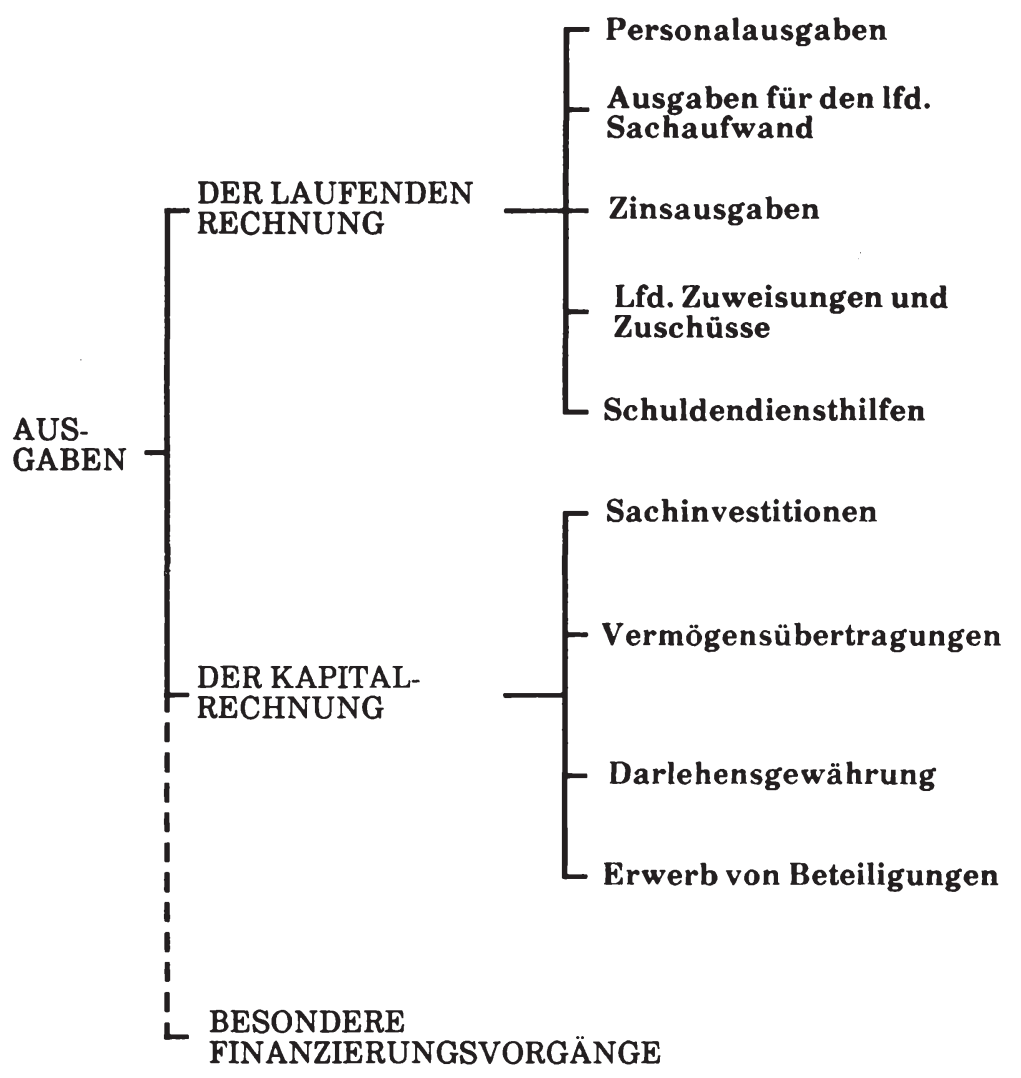

Dienstleistungen, die in aller Regel in der Haushaltsperiode ihrer Bereitstellung verbraucht werden, während bei den investiven Ausgaben eine Vermögensänderung und damit eine periodenübergreifende Wirkung unterstellt wird. 


\section{(2) Die finanzwirtschaftliche Darstellung}

Die finanzwirtschaftliche Gruppierung der Ausgaben dient vor allem zur Darstellung der Ergebnisse einzelner Körperschaften und einzelner Aufgabenbereiche. ${ }^{201)}$ Bei dieser Gliederung der Ausgaben werden die Personalausgaben und die Sachausgaben (laufender Sachaufwand + Sachinvestitionen) zusammengefaßt zu den sog. "direkten Ausgaben". Gemeinsam mit den Zahlungen an andere Bereiche bilden sie die "unmittelbaren Ausgaben". Einschließlich der Zahlungen an Verwaltungen nennt man sie dann "Bruttoausgaben". Subtrahiert man von den Bruttoausgaben die Zahlungen von Verwaltungen gleicher Ebene, erhält man die "Gesamtausgaben". Vermindert man diese wiederum um die Zahlungen von Verwaltungen anderer Ebenen, erhält man die "Nettoausgaben". ${ }^{202)}$ Die besonderen Finanzierungsvoränge sind hierbei nicht berücksichtigt.

Bei der Betrachtung des öffentlichen Gesamthaushalts sind die "Nettoausgaben" identisch mit den Gesamtausgaben und entsprechen auch den "unmittelbaren Ausgaben". Die "direkten Ausgaben" oder, wie sie in den finanzstatistischen Veröffentlichungen auch bezeichnet werden, die "unmittelbaren Ausgaben ohne Zahlungen an andere Bereiche"203) bilden den Gegenwert für "die Inanspruchnahme von Waren, Dienstleistungen und Produktionsmittel." ${ }^{204)}$ Für den öffentlichen Gesamthaushalt entsprechen sie in etwa den Verwaltungsleistungen von Colm, während die Zahlungen an andere Bereiche dem Colm'schen Begriff der Geldleistungen entspricht. Wie schon angedeutet, eignet sich diese finanzwirtschaftliche Gruppierung vorwiegend "für die Darlegung der finanziellen

201) Vgl. Freund, E.: Die Neugestaltung ..., a.a.O., S. 544 und Essig, H.: Erfassung- und Auswertungsprogramm ..., a.a.O., S. $839 \mathrm{f}$.

202) Die Bruttoausgaben zeigen alle von den Körperschaften insgesamt getätigten Ausgaben (ohne besondere Finanzierungsvorgänge) einschließlich der Doppelzählungen Die Gesamtausgaben geben an, wieviel Mittel die einzelnen Körperschaften oder Körperschaftsgruppen zur Aufgabenerfüllung einsetzen, unabhängig davon, welche anderen öffentliche Bereiche zur Ausgabenfinanzierung beigetragen haben (Erfüllungsprinzip). Sie entsprechen den Ausgaben ohne besondere Finanzierungsvorgänge der gesamtwirtschaftlichen Darstellungsweise.

Die Nettoausgaben zeigen die aus eigenen Einnahmequellen der jeweiligen Körperschaft oder Körperschaftsgruppen zu finanzierenden Ausgaben (Belastungsprinzip).

Vgl. Freund, E.: Die Neugestaltung ..., a.a.O., S. 544 sowie Statistisches Bundesamt: Rechnungsergebnisse (1983)..., a.a.O., S. 11.

203) Vgl. Statistisches Bundesamt: Rechnungsergebnisse (1983).., a.a.O., S. $116 \mathrm{ff}$.

204) Freund, E.: Die Neugestaltung ..., a.a.O., S. 544. 
Übersicht 2.13: Finanzwirtschaftliche Darstellung der Gliederung nach Ausgabenarten

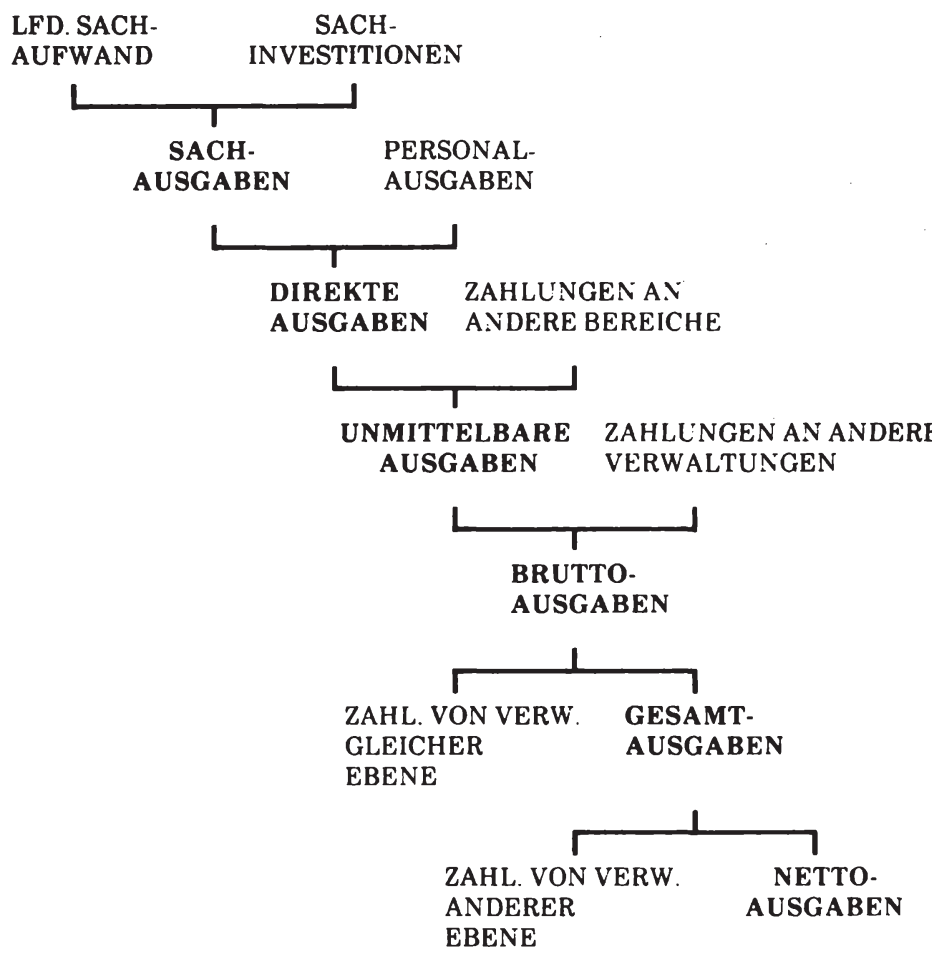

Verflechtungen innerhalb des öffentlichen Sektors oder die Einzelanalyse bestimmter Verwaltungszweige."205)

Beide Darstellungsformen, die gesamtwirtschaftliche und die finanzwirtschaftliche, weisen zwar, dem jeweiligen $Z$ weck entsprechend, Unterschiede auf, sie sind aber inhaltlich voll vergleichbar, so daß es ohne weiteres möglich ist, "die Haushaltszahlen aus dem einen in das andere Schema zu transformieren."206)

205) Freund, E.: Haushaltsstatistik, a.a.O., S. 598.

206) Freund, E.: Die Neugestaltung ..., a.a.O., S. 544. 
Die finanzstatistische Gliederung nach Aufgabenbereichen basiert zwar auf dem Funktionenplan für Bund und Länder, weist aber einige nicht unwesentliche Verănderungen auf. ${ }^{207)}$ Die Abgrenzung der Aufgabenbereiche bzw. Verwaltungszweige "folgt weitgehend pragmatischen Gesichtspunkten"208) und kann nur zum Teil funktional begründet werden. ${ }^{209}$ Die Auflistung der Übersichten und Tabellen des Statistischen Bundesamtes zeigt (vgl. Übersicht 2.14), daß in der Finanzstatistik mehr Aufgabenbereiche unterschieden werden, als im haushaltsrechtlich verbindlichen Funktionenplan. Das Statistische Bundesamt veröffentlicht allerdings einen Zuordnungsschlüssel, nach dem die einzelnen Aufgabenbereiche in die Funktionenübersicht transformiert werden können und vice versa. ${ }^{2101}$ Festzuhalten bleibt aber auch, daß die finanzstatistische Gliederung nach Aufgabenbereichen eine Vermengung von funktionalen und institutionellen Elementen darstellt.

\subsubsection{Ansatzpunkte der Volkswirtschaftlichen Gesamtrechnungen}

Die Volkswirtschaftlichen Gesamtrechnungen stellen ein System von Konten, Tabellen und Übersichten dar, das auf die statistische Erfassung der ökonomi schen Aktivitäten einer Volkswirtschaft für einen zurückliegenden Zeitraum abzielt. ${ }^{211}$ 'Sein Inhalt, Umfang und Aufbau trägt weitgehend internationalen Vereinbarungen Rechnung. ${ }^{212)}$ Die Vielzahl der Wirtschaftseinheiten und der wirtschaftlichen Vorgänge einer Volkswirtschaft werden in den Gesamtrechnungen zu Gruppen zusammengefaßt.

207) Vgl. Freund, E.: Die Neugestaltung ..., a.a.O., S. 545.

208) Freund, E.: Bemerkungen zu einer ..., a.a.O., S. 189.

209) Vgl. ebenda, S. 189 und Freund, E.: Die Neugestaltung ..., a.a.O., S. 545.

210) Vgl. Statistisches Bundesamt: Rechnungsergebnisse (1983) ..., a.a. O., S. 37 ff.

Dem Zuordnungsschlüssel sind neben den Funktionenziffern des Funktionenplans für Bund und Lånder auch die entsprechenden Gliederungsplannummern der Gemeindehaushalte beigefügt.

211) Vgl. Ring, U.: Öffentliche Planungsziele ..., a.a.O., S. 114 und Stobbe, A.: Volkswirtschaftslehre I. Volkswirtschaftliches Rechnungswesen, 5. Aufl., Berlin, Heidelberg, New York 1980, S. 372.

212) Vgl. Statistisches Bundesamt: Konten und Standardtabellen 1984, Reihe 1 der Fachserie 18: Volkswirtschaftliche Gesamtrechnungen, Stuttgart, Mainz 1985, S. 51. 
Übersicht 2.14: Auflistung der Tabellen nach Aufgabenbereichen (Finanzstatistik)

GESAMTWIRTSCHAFTLICHE UBERSICHTEN

\begin{tabular}{ll}
\hline 01 & INSGESAMT \\
02 & POLITISCHE FÜHRUNG UND \\
& ZENTRALE VERWALTUNG \\
& \\
& \\
03 & AUSWÄRTIGE \\
& ANGELEGENHEITEN \\
04 & VERTEIDIGUNG \\
05 & ÖFFENTLICHE SICHERHEIT \\
UND ORDNUNG, \\
RECHTSSCHUTZ
\end{tabular}

06 SCHULEN UND VORSCHULISCHE BILDUNG

07 HOCHSCHULEN

08 FÖRDERUNG DES BILDUNGSWESENS

09 SONST. BILDUNGSWESEN

10 WISSENSCHAFT, FORSCHUNG, ENTWICKLUNG AUSSERHALB DER HOCHSCHULEN

11 KULTURELLE ANGELEGENHEITEN

12 SOZIALE SICHERUNG, SOZIALE KRIEGSFOLGENAUFGABEN, WIEDERGUTMACHUNG

HAUPTTABELLEN"

1001 Insgesamt

1002 Politische Führung und zentrale Verwaltung

1003 Politische Führung

1004 Innere Verwaltung

1005 Hochbauverwaltung

1006 Steuer-und Finanzverwaltung

1007 Auswärtige Angelegenheiten

1008 Wirtschaftliche Zusammenarbeit

1009 Verteidigung

1010 Öff. Sicherheit und Ordnung

1011 Bundesgrenzschutz/Polizei

1012 Rechtsschutz

1013 Ordentl. Gerichte und Staatsanw.

1014 Justizvollzugsanstalten

1015 Schulen und vorsch. Bildung

1016 Kindergärten

1017 Allgemeinbildende Schulen

1018 Berufliche Schulen

1019 Hochschulen

1020 Förderung des Bildungswesens

1021 Sonstiges Bildungswesen

1022 Wissenschaft, Forschung, Entwicklung außerhalb der Hochschulen

1023 Kulturelle Angelegenheiten

1024 Theater und Musik

1025 Soziale Sicherung, ...

1026 Verwaltung

1027 Sozialversicherung

1028 Familien-, Sozial- und Jugendhilfe

1029 Sozialhilfe

1030 Jugendhilfe

1031 Soziale Kriegsfolgeleistungen

1032 Kriegsopferversorgung

1033 Wiedergutmachung

1034 Arbeitsmarktpolitik und Arbeitsschutz

1035 Förderungd. Vermögensbildung 
13 GESUNDHEIT, SPORT UND ERHOLUNG

14 WOHNUNGSWESEN, RAUMORDNUNG UND KOMMUNALE GEMEINSCHAFTSDIENSTE

15 ERNÄHRUNG, LANDWIRTSCHAFT UND FORSTEN

16 ENERGIE- UND WASSERWIRTSCHAFT, GEWERBE, DIENSTLEISTUNGEN

17 VERKEHR UND NACHRICHTENWESEN

18 WIRTSCHAFTSUNTERNEHMEN

19 ALLG. GRUND- UND KAPITALVERMÖGEN, SONDERVERMÖGEN

20 ALLG. FINANZWIRTSCHAFT
1036

1037

1038

1039

1040

1041

1042

1043

1044

1045

1046

1047

1048

1049

1050

1051

1052

1053

1054

1055

1956

1057

1058

1059

1060

1061

1062

1063

1064

1065

1066

1067

1068

1069

1070

1071

1072

1073

1974

1075

1076

1077

1078
Gesundheit, Sport und ...

Krankenhäuser und Maßnahmen des Gesund heitswesens

Sport und Erholung Reinhaltung von Luft, Wasser ...

Wohnungswesen, Raumordnung

Wohnungswesen

Raumordnung, Landesplanung,

Vermessungswesen

Städtebauförderung

Komm. Gemeinschaftsdienste

Straßenbeleuchtung

Abwasserbeseitigung

Abfallbeseitigung

Straßenreinigung

Schlacht- und Viehöfe

Sonstiges

Ernährung, Landwirtschaft u. Forsten

Verbesserung der Agrarstruktur

Einkommenstab. Maßnahmen

Energie- und Wasserwirtschaft ...

Kulturbau

Bergbau, verarb. Gewerbe

Regionale Förderungsmaßnahmen

Verkehr und Nachrichtenwesen

Straßen (1059a-1059f)

Wasserstraßen und Häfen

Schienenverkehr

Wirtschaftsunternehmen

Land-u. Forstwirtschaftl. Untern.

Versorgungsunternehmen

Verkehrsunternehmen

Kombinierte Versorgungs- und ...

Bergbau- u. Gewerbeunternehmen

Sonstige Wirtschaftsunternehmen

Allg. Grund- und Kapitalvermögen ...

Allg. Grund vermögen

Allg. Kapitalvermögen

Sondervermögen

Allg. Finanzwirtschaft

Steuern u. allg. Finanzzuw.

Schulden

Versorgung

Beihilfen, Unterstützungen ...

Sonstiges

1) Manche der Tabellen bestehen inhaltlich aus der Zusammenfassung anderer Tabellen.

Quelle: Zusammengestellt aus: Statistische Bundesamt: Rechnungsergebnisse des öffentlichen Gesamthaushalts 1983, Reihe 3.1 der Fachserie 14: Finanzen und Steuern, Stuttgart, Mainz 1985, S. $37 \mathrm{ff}$. 
Die Aggregation der Wirtschaftseinheiten zu Sektoren orientiert sich primär an institutionellen Sachverhalten, die allerdings durch funktionale Aspekte korrigiert werden. ${ }^{213)} \mathrm{Im}$ Sektor Staat werden, so zumindest die Absicht, die Institutionen zusammengefaßt, die Dienstleistungen eigener Art für die Allgemeinheit erbringen und sich hauptsächlich aus $\mathrm{Zwangsabgaben} \mathrm{finanzieren.}{ }^{214}$ Innerhalb des Staatssektors bilden die Gebietskörperschaften und die Sozialversicherung getrennte Untersektoren.

Zu den Gebietskörperschaften rechnen der Bund einschl. Lastenausgleichsfonds und ERP-Sondervermögen, die Länder einschl. Stadtstaaten und die Gemeinden einschl. der Gemeindeverbände und kommunalen Zweckverbände. Die Abgrenzung gegenüber den Unternehmen folgt der in der Finanzstatistik üblichen Trennungslinie, so daß zu den Einrichtungen der Gebietskörperschaften u.a. öffentliche Einrichtungen der Sozialhilfe (Altenheime u.ä.), Einrichtungen der Jugendhilfe (Erziehungsheime u.ä.), Einrichtungen des Gesundheitswesens (Krankenhäuser für Akutkranke usw.) und sonstige Einrichtungen wie Vieh- und Schlachthöfe, Markthallen und Feuerwehren gezählt werden. Unternehmen im Eigentum der Gebietskörperschaften zählen unabhängig von ihrer Rechtsform zum Unternehmenssektor. Dies gilt für die Deutsche Bundesbahn, die Deutsche Bundespost und andere Industriebeteiligungen des Staates, wie auch für die Mehrzahl der kommunalen Versorgungs- und Verkehrsunternehmen sowie die Hafenbetriebe. Im Gegensatz zur Finanzstatistik werden in den Volkswirtschaftlichen Gesamtrechnungen die Bruttounternehmen des Staates dem Unternehmenssektor zugeschlagen. Bei diesen Bruttobetrieben, die mit allen Einnahmen und Ausgaben im Haushalt einer Gebietskörperschaft integriert sind, handelt es sich um kleinere Wasserversorgungsbetriebe, Forstbetriebe oder vereinzelt um Stadthallen und ihre Restauration. Die Sozialversicherung, die eines der wichtigsten Instrumente öffentlicher Sozialpolitik darstellt, umfaßt die Rentenversicherung der Arbeiter und Angestellten, die knappschaftliche Rentenversicherung, die Zusatzversorgungseinrichtungen für Angestellte und Arbeiter des öffentlichen Dienstes, die Altershilfe für Landwirte, die gesetzliche Krankenversiche-

213) Vgl. auch Littmann, K.: Definition und Entwicklung der Staatsquote. Abgrenzung, Aussagekraft und Anwendungsbereiche unterschiedlicher Typen von Staatsquoten, Göttingen 1975, S. 21 sowie Bartels, H.: Das Kontensystem für die Volkswirtschaftlichen Gesamtrechnungen der Bundesrepublik Deutschland. Erster Teil: Das angestrebte Kontensystem, in: Wirtschaft und Statistik, Jg. 1960, S. 317-344, S. 318.

214) Vgl. Statistisches Bundesamt: Konten und Standardtabellen 1984, a.a.O., S. 56. 
rung, die gesetzliche Unfallversicherung und die Arbeitslosenversicherung. Unternehmen im Eigentum dieser Versicherungen zählen dagegen zum Unternehmenssektor. ${ }^{215}$ )

Die Ausgaben des Staates werden in den Volkswirtschaftlichen Gesamtrechnungen nach volkswirtschaftlichen Ausgabenarten, nach wirtschaftlichen Kategorien und nach Aufgabenbereichen gegliedert. Darüber hinaus erscheinen Gliederungen der Ausgaben nach Gebietskörperschaften und Sozialversicherung sowie nach den die staatlichen Ausgaben empfangenden Sektoren. ${ }^{216)}$ Die Aufmerksamkeit richtet sich im folgenden nicht auf die sektoralen sondern auf die zuerst genannten Gliederungen, weil sie die Ausgaben nach ökonomischen und politischen Kriterien zu ordnen suchen.

Ausgangspunkt der Zusammenfassung von Ausgabengruppen bilden die Konten 1-6 des Staatssektors der Volkswirtschaftlichen Gesamtrechnungen. ${ }^{217}$ ) Danach werden zunächst folgende Ausgaben unterschieden ${ }^{218)}$ (in Klammern die Buchungsnummern aus dem vereinfachten Kontensystem):

(1) Geleistete Subventionen (Position 2-4.10)

(2) Soziale Leistungen (Position 2-4.35)

(3) Sonstige laufende Übertragungen (Position 2-4.40)

(4) Aufwendungen für den Staatsverbrauch (Position 2-5.10)

215) Vgl. zur Abgrenzung des Staatssekiors die Ausführungen in Statistisches Bundesamt: Konten und Standardtabellen 1984, a.a.O., S. 56 f. sowie bei Ring, U.: Öffentliche Planungsziele ..., a.a.O., S. $126 \mathrm{ff}$.

216) Vgl. Kopsch, G.: Ausgaben des Staates nach Aufgabenbereichen in den Volkswirtschaftlichen Gesamtrechnungen, in: Wirtschaft und Statistik, Jg. 1980, S. 155-169, S. 155 und Kopsch, G.: Der Staat ..., a.a.O., S. 749.

Siehe auch Tabellenteil in Statistisches Bundesanit: Der Staat in den Volkswirtschaftlichen Gesamtrechungen 1960 bis 1983, Reihe S. 6 der Fachserie 18: Volkswirtschaftliche Gesamtrechnungen, Stuttgart, Mainz 1984.

217) Zum Aufbau des Kontensystems vgl. Bartels, H.: Das Kontensystem ..., a.a.O., S. $317 \mathrm{ff}$. Im einzelnen werden im Sektor Staat (Vereinfachtes Kontensystem) folgende Konten geführt:

2-1 Produktionskonto

2-2 Einkommensentstehungskonto

2-3 Einkommensverteilungskonto

2-4 Einkommensumverteilungskonto

2-5 Einkommensverwendungskonto

2-6 Vermögensveränderungskonto

2-7 Finanzierungskonto.

218) Vgl. Statistisches Bundesamt: Der Staat ..., a.a.O., S. 10. 
(5) Zinsen auf öffentliche Schulden (Position 2-3.20)

(6) Vermögensübertragungen (Position 2-6.30)

(7) Bruttoinvestitionen (Position 2-6.20)

Die geleisteten Subventionen, die sozialen Leistungen, und die sonstigen laufenden Übertragungen bilden zusammen den Posten der vom Staat geleisteten laufenden Übertragungen. ${ }^{219)}$ Die Vermögensübertragungen umfassen zum einen Investitionszuschüsse und zum anderen sonstige Vermögensübertragungen. ${ }^{2201}$ Die Bruttoinvestitionen des Staates setzen sich aus den Anlageinvestitionen und

219) Subventionen werden in den Volkswirtschaftlichen Gesamtrechnungen die Zuschüsse genannt, die der Staat an Unternehmen für laufende Produktionszwecke gewährt. Mit Ausnahme der U'msatzsteuervergünstigung in der Landwirtschaft und Berlinförderung werden nur die tatsächlichen Geldleistungen gezählt.

Soziale Leistungen sind in den Volkswirtschaftlichen Gesamtrechnungen laufende Geldleistungen an private Haushalte und die übrige Welt, für die keine spezielle Gegenleistung erbracht wird.

Die geleisteten sonstigen laufenden Übertragungen enthalten u.a. Zahlungen an die Deutsche Bundesbahn für die Versorgung ehemaliger Beamter, Beiträge an die EG und andere internationale Organisationen sowie, bei der gesonderten Darstellung einzelner staatlicher Ebenen, Zuweisungen und Zuschüsse an andere staatliche Körperschaften.

Vgl. Statistisches Bundesamt: Der Staat ..., a.a.O., S. 12 f.

220) In den Volkswirtschaftlichen Gesamtrechnungen werden als Vermögensübertragungen alle Geldleistungen angesehen, die zumindest für eine der beteiligten Wirtschaftseinheiten eine unmittelbare Vermögenszu- oder -abnahme darstellen. Im einzelnen enthalten die Vermögensübertragungen des Staates an andere Wirtschaftseinheiten:

- Unternehmen

-- Investitionszuschüsse für Bauvorhaben und andere Investitionen u.a. auch die Umwandlung von Darlehen in Zuschüsse an die Deutsche Bundesbahn und an die Deutsche Bundespost.

-- Sonstige Vermögensübertragungen wie Betriebsmittelzuweisungen an Einfuhr und Vorratsstellen, Prämien für die Schlachtung von Kühen und Nichtvermarktung von Milch u.ä. sowie fiktive Vermögensübertragungen für nicht entnommene Gewinne der Bruttounternehmen und Mittel im staatseigenen Wohnungsbau

Staat

-- Investitionszuschüsse für Infrastrukturmaßnahmen und Maßnahmen des Küstenschutzes wie auch Zuweisungen für den kommunalen Straßenbau, den Bau von Schulen und Krankenhäusern.

-. Sonstige Vermögensübertragungen in Form von einmaligen größeren Zahlungen zwischen den einzelnen Körperschaften.

- Private Haushalte erhalten (definitionsgemäß) nur sonstige Vermőgensübertragun. gen wie Spar- und Wohnungsbauprämien, Arbeitnehmersparzulagen u.ă.

- Die übrige Welt

-- Investitionszuschüsse im Rahmen der Entwicklungshilfe

-- Sonstige Vermögensübertragungen wie Wiedergutmachungsleistungen sowie die Umwandlung von Schulden der ärmsten Entwicklungsländer in Zuschüsse und die Zahlungen an den EG-Entwicklungsfonds.

Vgl. Statistisches Bundesamt: Konten und Standardtabellen 1984, a.a.O., S. 98 f. 
der Vorratsveränderung zusammen. ${ }^{221}$ Die Aufwendungen für den Staatsverbrauch schließlich entsprechen dem Produktionswert des Staates abzüglich der Verkäufe von Verwaltungsleistungen und abzüglich dem Wert der selbsterstellten Anlagen. ${ }^{2221}$

\subsubsection{Ausgabengliederungen der Volkswirtschaftlichen Gesamt- rechnungen}

Zwei Systematiken gliedern die staatlichen Ausgaben nach Arten, also kreislauforientiert, wobei die eine "Gliederung nach volkswirtschaftlichen Ausgabenarten" und die andere "Gliederung nach wirtschaftlichen Kategorien" genannt wird. Die Gliederung nach volkswirtschaftlichen Ausgabenarten unterscheidet zunächst zwei Kategorien staatlicher Ausgaben, zum einen Ausgaben, die unmittelbar oder mittelbar zur Produktion staatlicher Dienstleistungen eingesetzt werden ("Staatliche Güterbereitstellung") und zum anderen Ausgaben an andere, ohne direkte Gegenleistungen ("Übertragungen"). ${ }^{223 \prime}$ Die erste Kategorie umfaßt die Aufwendungen für den Staatsverbrauch und die Bruttoinvestitionen, die im einzelnen die Ausgaben zur Bezahlung der Beschäftigten des Staates ${ }^{241}$, zum Kauf von Verbrauchsgütern und Dienstleistungen sowie die Ausgaben zum Kauf von Investitionsgütern umfassen. Die zweite Kategorie, die staatlichen Ausgaben ohne direkte Gegenleistungen der Begünstigten, bestehen aus den laufenden und den vermögenswirksamen Übertragungen. Eine gesonderte Ausgabenart bilden die Zinsen auf öffentliche Schulden.

221) Vgl. Kopsch, G.: Der Staat ..., a.a.O., S. 752. Die Vorratsveränderungen des Staates beziehen sich auf ausgewählte Vorräte, wie Mineralöl und Kernbrennstoffe. Vgl. Statistisches Bundesamt: Konten und Standardtabellen 1984, a.a.O., S. 98.

222) Vgl. Statistisches Bundesamt: Der Staat ..., a.a.O., S. 11 f. Siehe auch die Standardtabelle 3.11 in Statistisches Bundesamt: Konten und Stardardtabellen 1984, a.a.O., S. 247.

Der Produktionswert des Staates (Position 2-1.60) entspricht den Käufen von Gütern für die laufende Produktion, die sog. Vorleistungen (Position 2-1.10) zuzüglich der Bruttowertschöpfung (Position 2-1.49 und 2-2.50). Die Bruttowertschöpfung des Staates umfaßt die Abschreibungen (Position 2-2.10), die geleisteten Produktionssteuern (Position 2-2.20) und die geleisteten Einkommen aus unselbständiger Arbeit (Position 2-3.10), welche beim Sektor Staat dem Beitrag zum Nettoinlandsprodukt zu Faktorkosten (Nettowertschöpfung) entprechen.

Gerade die Ausgabenkategorie "Staatsverbrauch" findet in der Literatur eine eingehende Behandlung. Hier spielt vor allem die Frage, inwieweit diese Ausgaben Endverbrauchsoder Vorleistungscharakter haben, eine große Rolle. Vgl. auch Kopsch, G.: Staatsverbrauch nach dem Ausgaben- und dem Verbrauchskonzept, in: Wirtschaft und Statistik, Jg. 1984, S. 297-303.

223) Vgl. Kopsch, G.: Ausgaben des Staates ..., a.a.O., S. 158.

224) Diese Ausgabengruppe ist ja nicht identisch mit den Ausgaben des Staates für personelle "inputs", denn auch in den Sachausgaben sind Personalkostenanteile enthalten. 
Übersicht 2.15: Gliederung nach Ausgabenarten (VGR)
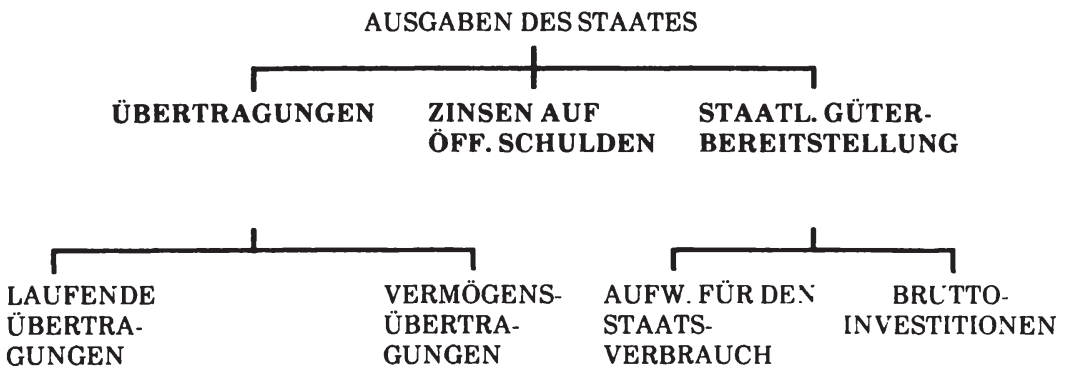

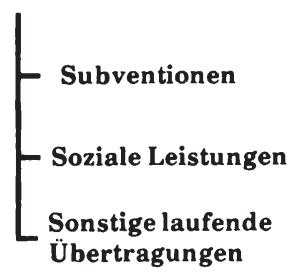

\begin{tabular}{l|l}
$\begin{array}{l}\text { Abzügl. Verkäufe } \\
\text { v. Verwaltungs- } \\
\text { leistungen } \\
\text { einschl. selbsterst. } \\
\text { Anlagen }\end{array}$ & $\begin{array}{l}\text { Sachaufwand } \\
\text { (=Vorleistungen + Abschrei- } \\
\text { bungen + Produktions- } \\
\text { steuern) }\end{array}$ \\
$\begin{array}{l}\text { Einkommen aus } \\
\text { unselbständiger Arbeit }\end{array}$
\end{tabular}

Insbesondere für den kombinierten Ausweis staatlicher Ausgaben nach Aufgabenbereichen und Ausgabenarten werden die Ausgabengruppen in anderer Weise zusammengefaßt. ${ }^{225)}$ Die Zinsen, die laufenden Übertragungen und die Aufwendungen für den Staatsverbrauch bilden dabei zusammen die Gruppe der "Laufenden Ausgaben". Vervollständigt wird diese Gliederung durch die "Bruttoinvestitionen" und die geleisteten "Vermögensübertragungen". Diese Systematik ähnelt sehr stark der in der Finanzstatistik gebräuchlichen Unterscheidung in laufende Rechnung und Kapitalrechnung (vgl. Übersicht 2.15).

Die Gliederung nach wirtschaftlichen Kategorien weicht von der Darstellung nach volkswirtschaftlichen Arten insofern ab, als die ansonsten im Staatsverbrauch enthaltenen sozialen Sachleistungen ${ }^{226)}$ wegen ihres Transfercharakters mit den

225) Vgl. Kopsch, G.: Ausgaben des Staates ..., a.a.O., S. $162 \mathrm{ff}$.

226) Diese sozialen Sachleistungen machen nur einen Teil der Realtransfers des Staates an private Haushalte aus. Der Staat stellt z.B. auch erhebliche Dienstleistungen auf dem Gebiet des Unterrichtswesens bereit, die unmittelbar und individuell zurechenbar den privaten Haushalten zugute kommen. Vgl. Statistisches Bundesamt: Der Staat ..., a.a.O., S. 35 . 


\section{Übersicht 2.16: Ausgabengliederung nach wirtschaftlichen Kategorien (VGR)}

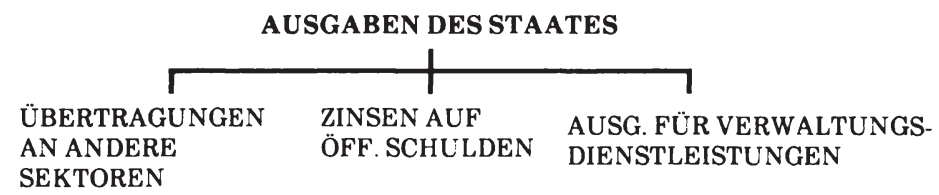

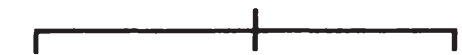

Lfd. Übertragungen
Vermögens- Soziale übertragungen
Soziale

Leistungen

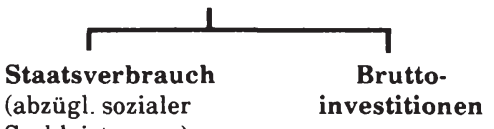

Sachleistungen)

laufenden und den Vermögensübertragungen unter der Position "Übertragungen an andere Sektoren" erscheinen. ${ }^{227}$ 'Die Bruttoinvestitionen bilden zusammen mit dem verbleibenden Teil des Staatsverbrauchs die Position "Ausgaben für Verwaltungsdienstleistungen". Die Ausgaben für Verwaltungsdienstleistungen sind mit der Inanspruchnahme sächlicher und persönlicher Produktivkräfte verbunden, während die Übertragungen Umverteilungsausgaben darstellen (vgl. Übersicht 2.16).

Die Gliederung der Staatsausgaben nach Aufgabenbereichen baut im wesentlichen auf den Empfehlungen internationaler Organisationen auf und weicht auch aus diesem Grund erheblich von den finanzstatistischen Aufgabenbereichsgliederungen ab (vgl. Übersicht 2.9). Erstmals 1980 legte das Statistische Bundesamt eine bis in das Jahr 1970 zurückreichende Darstellung staatlicher Ausgaben nach Aufgabenbereichen vor, wobei die damalige Konzeption auf der Übernahme der Systematik des Europäischen Systems Volkswirtschaftlicher Gesamt- 
rechnungen (EVSG) basierte. ${ }^{228)}$ Schon mit den Veröffentlichungen der Konten und Standardtabellen für das Jahr 1981, erschienen im November 1982, wurde die Aufgabenbereichsgliederung geändert und auf die 1980 von den Vereinten Nationen veröffentlichte Systematik "COFOG" (classification of the functions of government) umgestellt. ${ }^{229)}$ Grundlage dieser Gliederung bildet die Einordnung staatlicher Aufgaben und der dafür erforderliche Ausgaben in vier Rubriken ${ }^{230}$ ):

(1) Allgemeine Staatsleistungen ("general government services"),

(2) Gesellschaftliche und soziale Leistungen ("community and social services"),

(3) Ökonomische Leistungen ("economic services"),

(4) Sonstige Leistungen ("other functions"). ${ }^{231 \text { ) }}$

In diese Rubriken werden 14 Aufgabenbereiche ("major groups") eingeordnet (vgl. Übersicht 2.17). Zu den "allgemeinen Staatsleistungen", die für die Existenz des Staates unentbehrlich sind, aber nicht einzelnen Gruppen von Nutznießern zugerechnet werden können, zählen die Bereiche "Allgemeine staatliche Verwaltung", "Verteidigung" und "Öffentliche Sicherheit und Ordnung". Der Abschnitt "gesellschaftliche und soziale Leistungen" umfaßt solche Ausgaben, die individuell oder gruppenmäßig zugeordnet werden können, also die Aufgaben-

228) Vgl. Kopsch, G.: Ausgaben des Staates ..., a.a.O., S. 155 ff. und Statistisches Amt der Europäischen Gemeinschaften: Europäisches System Volkswirtschaftlicher Gesamtrechnungen - EVSG, Luxembourg 1970, S. $188 \mathrm{ff}$.

Siehe hierzu auch Statistisches Bundesamt: Konten und Standardtabellen 1979, Stuttgart, Mainz 1980, S. 125 u. S. 295 sowie Statistisches Bundesamt Ausgaben des Staates nach Aufgabenbereichen in den Volkswirtschaftlichen Gesamtrechnungen 1970 bis 1978, Stuttgart, Mainz 1981.

Die Systematik der EVSG unterschied neuen Aufgabenbereiche:

1. Allgemeine staatliche Verwaltung

2. Verteidigung

3. Unterrichtswesen

4. Gesundheitswesen

5. Soziale Sicherung

6. Wohnungswesen, Stadt- und Landesplanung

7. Sonstige Dienste für die Allgemeinheit

8. Wirtschaftsförderung, -ordnung und -aufsicht

9. Sonstige Ausgaben

229) Vgl. Statistisches Bundesamt: Konten und Standardtabellen 1981, Reihe 1 der Fachserie 18: Volkswirtschaftliche Gesamtrechnungen, Stuttgart, Mainz 1982, S. 115 und United Nations: Classification of the Functions of Government. Statistical Papers, Series M/70, New York 1980.

230) Vgl. United Nations: Classification of ..., a.a.O., S. 6 f. und Statistisches Bundesamt: Konten und Standardtabellen 1981, a.a.O., S. 115. Ähnlich auch bei Kopsch, G.: Ausgaben des Staates ..., a.a.O., S. 159.

231) Vgl. United Nations: Classification of ..., a.a.O., S. 6. 
Ũbersicht 2.17: Systematik der Aufgabenbereiche in der VGR

1. ALLGEMEINDE STAATLICHE VERWALTUNG

2. VERTEIDIGUNG

3. ÖFFENTLICHE SICHERHEIT UND ORDNUNG

4. UNTERRICHTSWESEN

5. GESUNDHEITSWESEN

6. SOZIALE SICHERUNG

7. WOHNUNGSWESEN, STADT. UND LANDESPLANUNG, GEMEINSCHAFTSDIENSTE

8. ERHOLUNG UND KULTUR

9. ENERGIEGEWINNUNG UND -VERSORGUNG

10. LAND- UND FORST. WIRTSCHAFT, FISCHEREI

11. WARENPRODUZIERENDES GEWERBE

12. VERKEHR UND NACHRICHTENÜBERMITTLUNG

13. SONSTIGE WIRTSCHAFTSFÖRDERUNG, - ORDNUNG UND - AUFSICHT

14. SONSTIGE AUSGABEN
1.1 Allgemeine Verwaltung

1.2 Auswärtige Angelegenheiten

1.3 Allgemeine Forschung

4.1 Schulen und schulische Erziehung

4.2 Hochschulen

4.3 Sonstiges Unterrichtswesen

5.1 Anstalten und Einrichtungen des Gesundheitswesens

5.2 Sonstiges Gesundheitswesen

6.1 Sozialversicherung und -hilfe

6.2 Soziale Hilfswerke

7.1 Wohnungswesen

7.2 Stadt- und Landesplanung

7.3 Gemeinschaftsdienste, U mweltschutz

14.1 Schuldendienste (Zinsausgaben)

14.2 Übertragungen innerhalb des Staates

Quelle: Statistisches Bundesamt: Konten und Standardtabellen 1981, Reihe 1 der Fachserie 18:Volkswirtschaftliche Gesamtrechnungen, Stuttgart, Mainz 1982,Übersicht 6,S. 380 f. 


\section{Übersicht 2.18: Ausgabengliederung nach Aufgabenbereichen (VGR)}

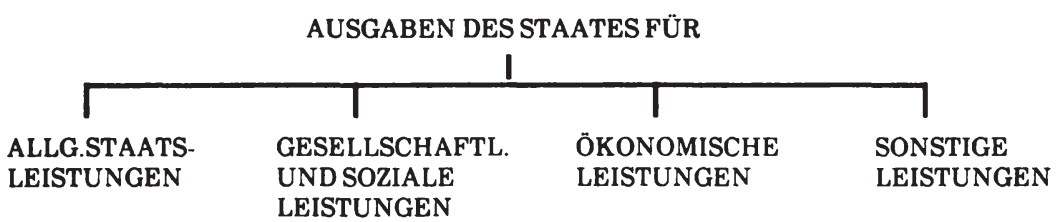

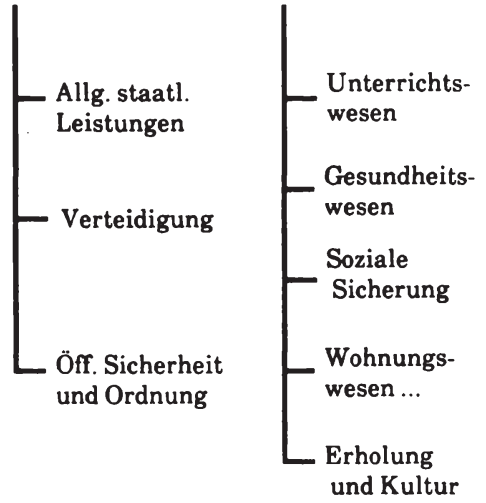

und Kultur
Energiegewinnung und-versorgung Land- und Forstwirtschaft ... Warenproduzierendes Gewerbe Verkehr und Nachrichtenübermittlung Sonstige Wirtschaftsförderung ...

bereiche "Unterrichtswesen", "Gesundheitswesen", "Soziale Sicherung", "Wohnungswesen, Stadt- und Landesplanung, Gemeinschaftsdienste" sowie "Erholung und Kultur". Unter die Rubrik "Ökonomische Leistungen fallen die Ausgaben der Bereiche "Energiegewinnung und -versorgung", "Land- und Forstwirtschaft, Fischerei", 'Warenproduzierendes Gewerbe", "Verkehr und Nachrichtenübermittlung" sowie "Sonstige Wirtschaftsförderung, -ordnung und -aufsicht". Den letzten der 14 Aufgabenbereiche bilden die "Sonstigen Ausgaben", welche aus den Zinszahlungen und Übertragungen innerhalb des Staatssektors bestehen. Die weitere Tiefengliederung der Aufgabenbereiche in Gruppen und Untergruppen erfolgt nicht nach einheitlichen Kriterien. Neben den 14 Aufgabenbereichen enthält die Klassifikation der Vereinten Nationen die weitere Aufteilung in 61 Gruppen und insgesamt 127 Untergruppen. ${ }^{2321}$ 


\section{Zur Entwicklung der Investitionsausgaben}

\subsection{Die öffentlichen Investitionen im Mittelpunkt des Interesses}

Die öffentlichen Investitionen finden im allgemeinen eine positivere Einschätzung als andere öffentlichen Ausgabenkategorien. ${ }^{1)}$ Gemeinhin verbindet man mit ihnen die Vorstellung, daß sie

- vorteilhaft auf die Produktivität der Gesamtwirtschaft einwirken,

- der Gesellschaft auch in künftigen Perioden Nutzen stiften und

- gute Instrumente der Stabilisierungspolitik darstellen.

Die öffentlichen Investitionen sollen mithin, wie auch die privaten, die Produktivität erhöhen, den Strukturwandel fördern und die Wettbewerbsfähigkeit steigern. Abgesehen von den Eigeninvestitionen des Staates (z.B. Bau von Verwaltungsgebäuden) werden die investiven staatlichen Ausgaben in erster Linie in komplementären Beziehungen zur privatwirtschaftlichen Produktion betrachtet. Zum einen wird ihnen dabei die Aufgabe zugesprochen, grundlegende innovatorische Prozesse zu unterstützen bzw. zu initiieren (z.B. großtechnologische Projekte), zum anderen sollen sie die private Produktion z.B. durch Infrastrukturinvestitionen ermöglichen bzw. erleichtern.

Das in jüngster Zeit gestiegene Interesse an den öffentlichen Investitionen läßt sich durch die entsprechende Zunahme wissenschaftlicher Abhandlungen und regierungsamtlicher Stellungnahmen belegen. Dies hängt sicherlich auch mit der

1) Vgl. hierzu u.a. Toillié, B.: Öffentliche Investitionen. Ein Begriff im Spannungsfeld von Theorie und Praxis, Berlin 1980; Wissenschaftlicher Beirat beim Bundesministerium der Finanzen: Gutachten zum Begriff ..., a.a.O.; Littmann, K.: Öffentliche Investitionen ..., a.a.O.; Wille, E.: Zum Verhältnis von investiven und konsumtiven öffentlichen Ausgaben, in: ORDO. Jahrbuch für die Ordnung von Wirtschaft und Gesellschaft, Bd. 35 (1984), S. 341-352 und Wille, E.: Öffentliche Sachausgaben ..., a.a.O., insbes. S. $11 \mathrm{ff}$.

Im Gegensatz hierzu konstatierte Vesper noch 1980, daß "das Forschungsinteresse an den offentlichen Investitionen recht gering" sei. Vesper, D.: Das Verhalten der staatlichen Investoren im Konjunkturverlauf, in: Neuere Entwicklungen in der Investitionstheorie und -politik, hrsg. v. G. Bombach, B. Gahlen und A.E. Ott, Tübingen 1980, S. 257-298, S. 257.

Im weiteren Verlauf der Arbeit ist noch zu klären, ob nur die Teile zu den öffentlichen Investitionen gezählt werden sollen, die ausgabenwirksam sind, oder ob auch andere Abgrenzungen sinnvoll und praktikabel sind. 
öffentlichen Schuldenentwicklung sowie der Haushaltspolitik in den 80er Jahren zusammen, welche die Fragen der Konsolidierung ${ }^{2)}$ und Umstrukturierung der Haushalte in den Vordergrund rückte. ${ }^{3)}$ Gleichwohl standen sie auch schon früher, z.B. im Zusammenhang mit den Galbraith'schen Thesen, im Mittelpunkt der Erörterung. ${ }^{4)}$

\subsection{1. Öffentliche Armut bei privatem Reichtum}

Galbraith konstatierte für die marktwirtschaftlich organisierten westlichen Wirtschaftssysteme eine nachhaltige Störung der sozialen Balance ${ }^{5}$, welche er seinerseits, nicht näher konkretisierend, als "a satisfactory relationship between the supply of privately produced goods and services and those of the state"6) definierte. Dabei diagnostizierte er eine Unterversorgung mit öffentlichen Leistungen, denn "the line which divides our area of wealth from our area of poverty is roughly that which divides privately produced and marketed goods and services from publicly rendered services."7) Die Beispiele, die er zur Untermauerung seiner These anführt, stammen fast allesamt aus dem Bereich des Schul- und Verkehrswesens und würden zu ihrer Beseitigung sowohl bauliche Maßnahmen als auch zusätzliche Personaleinstellungen erfordern. ${ }^{8)}$ Obwohl Galbraith behaupte-

2) Zum Begriff der Konsolidierung vgl. auch Fricke, E.: Haushaltskonsolidierung. Beobachtungen, Erfahrungen und Erkenntnisse aus zehnjähriger Praxis in einem Bundesland, in: Finanzarchiv, hrsg. v. N. Andel und F. Neumark, N.F. Bd. 43, Tübingen 1985, S. 385-420, insbesondere S. $385 \mathrm{ff}$. Der Begriff wurde vom Sachverständigenrat, der von der "qualitativen Haushaltskonsolidierung" spricht, um eine zusätzliche Dimension erweitert. Vgl. Sachverständigenrat zur Begutachtung der gesamtwirtschaftlichen Entwicklung: Jahresgutachten 1984/85, a.a.O., Ziff. 345 .

3) Vgl. Wille, E.: Zum Verhältnis ..., a.a.O., S. 341.

4) Vgl. Galbraith, J.K.: The Affluent Society, London 1958.

Siehe hierzu u.a. auch Molitor, B.: "Gesellschaft im Überfluß." Bemerkungen zu einer Studie von J. K. Galbraith, in: Hamburger Jahrbuch für Wirtschafts- und Gesellschaftspolitik, 4. Jg. (1959), S. 188-200; Schumann, J.: Gesellschaft im Überfluß, in: Finanzarchiv, hrsg. v. F. Neumark, N.F. Bd. 20 (1959/60), Tübingen 1960, S. 473-481; Preiser, E.: Probleme der Wohlstandsgesellschaft, hrsg. v. der Bayerischen Akademie der Wissenschaften. PhilosophischHistorische Klasse, Sitzungsberichte Jg. 1964, Heft 7, S. 3-25; Jürgensen, H.: Bemerkungen zu Wachstums- und Verteilungseffekten privater und öfentlicher Investitionen, in: Wirtschaftskreislauf und Wirtschaftswachstum. Carl Föhl zum 65. Geburtstag, hrsg. v. E. Schneider, Tübingen 1966, S. 75-99 und Bartel, K.: Öffentliche Infrastruktur oder privates Vermögen.Die vermögenswirksame Schuldenpolitik als Lösung eines Zielkonflikts, Berlin 1975, S.9.

5) Vgl. Galbraith, J.K.: The Affluent Society, a.a.O., S. $195 \mathrm{ff}$.

6) Ebenda, S. 198.

7) Ebenda, S. 195.

8) Vgl. ebenda, S. $195 \mathrm{ff}$. 
te, daß die von ihm propagierte Disparität bei der Versorgung mit öffentlichen und privaten Gütern keine Angelegenheit subjektiver Beurteilung sei ${ }^{9)}$ und die Werbemaßnahmen der privaten Industrie als Hauptursache für die Tendenz zur Unterversorgung mit öffentlichen Leistungen ausmachte ${ }^{10)}$, wurden seine Ausführungen gerade in diesen Punkten sehr kontrovers diskutiert. Galbraith argumentierte zwar vor dem Hintergrund der amerikanischen Verhältnisse der 50er Jahre, seine Thesen spielten aber Ende der 60er, Anfang der 70er Jahre, auch in der westdeutschen Öffentlichkeit eine große Rolle. Unter dem Stichwort von der "Öffentlichen Armut"11) wurde eine beträchtliche Ausweitung der staatlichen Investitionen gefordert, "um vornehmlich im Bereich der Infrastruktur die bisherige Unterdimensionierung" zu beseitigen. ${ }^{12)}$

Viele Politiker betonten zu dieser Zeit die Notwendigkeit einer besseren Versorgung mit Schulen, Kindergärten, Krankenhäusern u.ä. ${ }^{13)}$ Auch der Sachverständigenrat zur Begutachtung der gesamtwirtschaftlichen Entwicklung stellte in seinem Jahresgutachten 1971/72 fest, daß "das Verlangen des Staates, einen höheren Anteil des Produktionspotentials in Anspruch nehmen zu können"14), weithin Zustimmung findet. Unter den Schlagworten "Verbesserung der Lebensqualität" und "Qualitatives Wachstum" wurde deshalb "die Ausdehnung des Anteils

9) Galbraith schrieb: "This disparity between our flow of private and public goods and services is not matter of subjective judgement". Galbraith, J.K.: The Affluent Society, a.a.O., S. 195.

10) Vgl. ebenda, S. 202. Da die Werbung sich auf die privaten Güter konzentriert, hat die Bereitstellung öffentlicher Güter, so Galbraith, "an inherent tendency to lag behind".

Vgl. hierzu auch Rürup, B.: Öffentliche Armut bei privatem Reichtum? - Die falsche Frage -, in: Steuer und Wirtschaft. Zeitschrift für die gesamte Steuerwissenschaft, 50. Jg. (1973), S.250-257, S. 250 f. In seiner Fußnote 5 verweist Rürup auf eine Reihe alternativer Versuche, die Unterversorgung mit öffentlichen Gütern zu erklären.

11) Galbraith konstatierte eine "atmosphere of private opulence and public squalor" (Galbraith, J.K.: The Affluent Society, a.a.O., S. 200), welche auch in Deutschland unter dem Schlagwort "Öffentliche Armut bei privatem Reichtum" heftig diskutiert wurde. Vgl. Molitor, B.: Öffentliche Armut - Privater Reichtum, in: ORDO. Jahrbuch für die Ordnung von Wirtschaft und Gesellschaft, Bd. 24 (1973), S. 141-156, S. 141 und Rürup, B.: Öffentliche Armut ..., a.a.O., S. 250.

12) Bartel, K.: Öffentliche Infrastruktur ..., a.a.O., S. 9.

13) Vgl. Arndt, R.: Mehr öffentliche Dienstleistungen sind wichtiger als 10.000 DM auf dem Konto. Interview mit Frankfurts Oberbürgermeister Rudi Arndt (SPD), in: Wirtschaftswoche, Nr.40, 26. Jg. (1972), S. 20-24 und Vogel, H.-J.: Reale Reformen. Beiträge zu einer Gesellschaftspolkitik der neuen Mitte, München 1973, insbes. S. 15.

14) Sachverständigenrat zur Begutachtung der gesamtwirtschaftlichen Entwicklung: Währung, Geldwert, Wettbewerb. Entscheidungen für morgen. Jahresgutachten 1971/72, Stuttgart, Mainz 1971, Ziff. 327. 
der Infrastrukturinvestitionen am Bruttosozialprodukt"15) gefordert und ihre Nützlichkeit damit begründet, daß sogar der "direkte Nutzen der Infrastruktur" so hoch sei, weshalb "der Infrastrukturbedarf im Prinzip als unbegrenzt anzusehen ist."16) Konkreten Niederschlag fanden diese Gedanken einerseits in der Einführung der Gemeinschaftsaufgaben (Art. 91a, 91b GG) ${ }^{17}$ ) und der Schaffung der Investitionshilfekompetenz des Bundes zur finanziellen Förderung bestimmter Investitionen der Länder und Gemeinden (Art. 104a Abs. 4 GG) ${ }^{18}$ im Rahmen der 1969 abgeschlossenen Finanzreform sowie andererseits in dem Versuch des Bundes, Anfang der 70er Jahre, eine Aufgabenplanung aufzubauen, die die zielgerechte Versorgung mit öffentlichen Gütern auf ein stabiles Fundament stellen sollte. ${ }^{19)}$ Obwohl Downs für westliche Demokratien, wegen der geringen individuellen Merklichkeit der öffentlichen Leistungsausgaben, eine Tendenz zu einem zu

15) Gahlen, B.: Neue Wohlfahrtsmaßstäbe. Hemmnisse für eine höhere öffentliche Investitionsquote und Reform der marktwirtschaftlichen Ordnung, in: Investitionskontrolle gegen die Konzerne?, hrsg. v. M. Krüper, Reinbeck 1974, S. 45-67, S. 53. Qualitatives Wachstum bedeutet für Gahlen eine zusätzliche Versorgung mit öffentlichen Gütern und hierbei insbesondere eine relative Ausdehnung der öffentlichen Investitionen. Sie sollten, da seiner Meinung nach eine Umstrukturierung der öffentlichen Haushalte kaum möglich sei, durch das Zurückdrängen des privaten Sektors finanziert werden. Vgl. ebenda, S. $53 \mathrm{f}$.

16) Thoss, R.: Notwendigkeit und Möglichkeit öffentlicher Investitionen, in: Krise der ökonomischen Theorie - Krise der Wirtschaftspolitik, hrsg. v. Wirtschafts- und Sozialwissenschaftlichen Institut des Deutschen Gewerkschaftsbundes, WSI-Studie zur Wirtschafts- und Sozialforschung Nr. 38, Köln 1978, S. 224-246, S. 225.

$\mathrm{Zu}$ dem Problemkreis siehe auch Bombach, G.: Konsum oder Investitionen für die Zukunft?, in: Aufgabe Zukunft: Qualität des Lebens, Bd. 7. Qualitatives Wachstum, hrsg. v. d. IGMetall, Frankfurt/Main 1972, S. 38-73.

17) Gemeinschaftsaufgaben nach Art. 91 a GG sind:

- Ausbau und Neubau von Hochschulen einschließlich der Hochschulkliniken,

- Verbesserung der regionalen Wirtschaftsstruktur,

Verbesserung der Agrarstruktur und des Küstenschutzes.

18) Vgl. Patzig, W: Haushaltsrecht des Bundes ..., Bd. 1, a.a.O., S. 270.

19) Vgl. hierzu Wille, E.: Öfentlicher Haushalt ..., a.a.O., S. 591 f.

$\mathrm{Zu}$ erwähnen sind in diesem Zusammenhang auch die raumplanerischen Bemühungen der Länder und des Bundes, die in der Verabschiedung des Bundesraumordnungsprogramms (BROP) im Jahre 1975 ihren Höhepunkt fand. Unter dem Ziel, die "Disparitäten in den Lebensbedingungen abzubauen", werden im BROP bei der Verbesserung der Infrastruktur "zwei Ziele besonders hervorgehoben:

- in solchen Gebietseinheiten verstärkte Infrastrukturinvestitionen vorzunehmen, in denen die Ausstattungsdefizite besonders groß sind" und

- "die Investitionen hierfür räumlich konzentriert einzusetzen ..."

Brenken, G.: Das Bundesraumordnungsprogramm. Entstehung, Inhalt und Bedeutung, in: Raumforschung und Raumordnung, 33. Jg. (1975), S. 104-111, S. 106 f. 
kleinen Budget ausmachte ${ }^{20)}$, stieß die Ausweitung der staatlichen Ausgaben ${ }^{21)}$ bis Mitte der 70er Jahre auf keinen nennenswerten Widerstand. Die Gründe hierfür liegen vermutlich auch darin, daß die staatlichen Planträger verstärkt das Finanzierungsinstrument der Verschuldung wählten, welches zunächst die $O p$ portunitätskosten öffentlicher Güter und Dienste verschleierte. ${ }^{22)}$

Als besonders exponierter Gegner der Thesen von Galbraith gelangte Engels zu der Schlußfolgerung, daß "die öffentliche Hand ... in der Bundesrepublik nicht arm, sondern viel zu reich" sei und, daß "die Ebbe in öffentlichen Kassen ... nicht auf Armut, sondern auf Verschwendung" beruhe. ${ }^{23)}$ Die Ausführungen von Engels, wie auch die der Befürworter einer stärkeren Versorgung mit öffentlichen Gütern machen deutlich, daß es in diesem Zusammenhang keine objektiven Kriterien zur Ausfüllung der Adjektive "arm" und "reich" gibt. Deutlich wird dies auch in dem nichtoperationalen Maßstab von Rürup, wonach derjenige Staat arm sei, "in dem, gemessen an den individuellen Präferenzen seiner Bürger, eine - gedankliche - Einheit zusätzlicher öffentlicher Leistungen einen höheren 'Grenznutzen' stiftet, als der zu ihrer Finanzierung notwendige Konsumverzicht an pri-

20) Vgl. Downs, A.: Why the Government Budget Is Too Small in a Democracy, in: World Politics. A Quarterly Journal of International Relations, vol. XII (1959/60), S. 541-563.

21) Die Gesamtausgaben der öffentlichen Haushalte lagen 1962 bei 106,48 Mrd. DM. 1968 betrugen sie 158,83 Mrd. DM und stiegen dann bis 1975 um 201,68 Mrd. DM auf 360,51 Mrd. DM. Zwischen 1962 und 1968 ergibt der Durchschnitt der jährlichen Wachstumsraten den Wert von $6,9 \mathrm{vH}$. Im Zeitraum von 1968 bis 1975 schnellte dieser Wert auf $12,5 \mathrm{vH}$ hoch, um dann in der Zeit bis 1984 auf 5,5 vH zu sinken. Die Gesamtausgaben beliefen sich 1984 auf 583,04 Mrd. DM. Vgl. Sachverständigenrat zur Begutachtung der gesamtwirtschaftlichen Entwicklung: Auf dem Weg zu mehr Beschäftigung, Jahresgutachten 1985/86, Stuttgart, Mainz 1985, Tab. $35^{*}$.

22) Vgl. ebenda, Tab. $35^{*}$.

Die Steuereinnahmen der öffentlichen Haushalte beliefen sich in 1962 auf 86,66 Mrd. DM und lagen 1968 bei 122,01 Mrd.DM. Bis 1975 stiegen sie auf 242,08 Mrd. DM und betrugen 1984 insgesamt 414,96 Mrd. DM. Der Durchschnitt der jährlichen Zuwachsraten betrug im Zeitraum von 1962 bis 1968 5,9 vH, im Zeitraum von 1968 bis $197510,4 \mathrm{vH}$ und in der Zeit von 1975 bis $19846,2 \mathrm{vH}$.

Vgl. zum Problemzusammenhang des Anstiegs der Staatsausgaben und Staatsverschuldung auch Gantner, M.: Gibt es in der repräsentativen Demokratie einen systematischen Hang zur Staatsverschuldung?, in: Das öffentliche Haushaltswesen in Österreich. Zeitschrift der Gesellschaft für das offentliche Haushaltswesen, 25. Jg. (1984), S. 162-180, der auch einige Anmerkungen gegen eine allzu forsche Bejahung der im Titel enthaltenen Frage vorbringt.

23) Engels, W.: Soziale Marktwirtschaft. Verschmähte Zukunft? Streitschrift wider falsche Propheten mit Bart und Computer, Stuttgart 1972, S. 57 f. 
vaten Gütern 'Grenzleid' bedeutet."24)

Obwohl Engels, was auch seine oben zitierten Einlassungen belegen, aus grundsätzlichen Erwägungen den staatlichen Aktivitäten eher distanziert gegenübersteht, gestand er ein: 'Woran es bei uns allenfalls fehlen mag, das sind öffentliche Investitionen." ${ }^{25)}$ Sowohl die Anhänger als auch die Gegner der These von der öffentlichen Armut treffen sich also bei der Forderung nach zusätzlichen öffentlichen Investitionen. Allein schon dieser Zusammenhang macht deutlich, daß die Investitionen, sofern man in unverbindlicher Weise über sie spricht, eine hohe Wertschätzung erfahren. So begründete auch der Sachverständigenrat zur Begutachtung der gesamtwirtschaftlichen Entwicklung die Forderung nach einer Konsolidierung und Umstrukturierung der Staatsfinanzen damit, daß sie "durch Senkung der konsumtiven Staatsausgaben den Spielraum für investive Ausgaben wieder erweitern" soll. ${ }^{261}$

\subsubsection{Amtliche Stellungnahmen}

Viele regierungsamtliche Verlautbarungen zu Problemen und Aufgaben der aktuellen Haushaltspolitik betonen ebenfalls die Notwendigkeit einer Umstrukturierung der öffentlichen Ausgaben ${ }^{27)}$, von den konsumtiven hin zu den investiven Ausgaben. Anläßlich der Beratungen des Bundeshaushalts 1982 betonte der damalige Bundesfinanzminister Matthöfer die Notwendigkeit, "konsumtive Aus-

24) Rürup, B.: Öffentliche Armut ..., a.a.O., S. 253.

Vgl. auch ebenda, S. $253 \mathrm{ff}$. und Molitor, B.: Öffentliche Armut ..., a.a.O., S. $141 \mathrm{ff}$. Rürup stimmte in seinen Ausführungen der Behauptung Molitors zu, daß Armut ein relativer Begriff sei.

Sicherlich ist Armut nicht völlig ohne räumlichen und zeitlichen Bezug zu definieren. Die Armut generell als relativen Begriff auszuweisen, läuft allerdings Gefahr, diesem Terminus die Selektionsfunktion zu nehmen und ihn der vielfältigen Interpretation unterschiedlichster Interessengruppen zu überlassen. Gemessen an den unbegrenzten Wünschen wird man immer wieder Mangellagen konstatieren können. Zum Problem der Meßbarkeit vgl. auch Bartel, K.: Öffentliche Infrastruktur ..., a.a.O., S. $29 \mathrm{ff}$.

25) Engels, W.: Soziale Marktwirtschaft ..., a.a.O., S. 58.

26) Vgl. Sachverständigenrat zur Begutachtung der gesamtwirtschaftlichen Entwicklung: Ein Schritt voran. Jahresgutachten 1983/84, Stuttgart, Mainz 1983, Ziff. 333.

27) Vgl. auch Wille, E.: Zum Verhältnis ..., a.a.O., S. 341.

Ähnliches wurde allerdings auch schon bei den Konsolidierungsbemühungen, die mit dem Finanzplan 1975 bis 1979 in Angriff genommen werden sollten, verkündet. Vgl. Wille, E.: Finanzplanung am Scheideweg: Resignation oder Neubesinnung?, in: Finanzarchiv, hrsg. v. N. Andel und F. Neumark, N.F. Bd. 35 (1976/77), Tübingen 1976, S. 66-99, S. 90 ff. 
gaben zu beschneiden und den volkswirtschaftlichen Raum für Investitionen zu erweitern." ${ }^{28)}$ In der Einbringungsrede zum Haushaltsgesetz 1983 nannte Lahnstein diesen Haushaltsentwurf einen Marktstein zur Verbesserung der Rahmenbedingungen der Wirtschaft und zur Stärkung der Investitionskraft, mit dem die Investitionstätigkeit der öffentlichen Hand stabilisiert werden sollte. ${ }^{29)}$ Gleichzeitig wies er allerdings auch auf die begrenzten Möglichkeiten der Budgetpolitik hin und deutete eine differenziertere Betrachtung der öfentlichen Investitionsausgaben an, denn "nicht jede öffentliche Investition bringt uns auf einen Weg zu mehr Wachstum." 30 )

Nach der Ablösung der sozialliberalen Koalition im Herbst 1982 wurde die Konsolidierung der Staatsfinanzen fortgesetzt und die Umstrukturierung der öffentlichen Haushalte von den konsumtiven zu den investiven Ausgaben als eine Grundvoraussetzung für die Wiederbelebung der Wirtschaft hervorgehoben. Als Grundsatz künftiger Finanzpolitik wurde die Vorrangstellung zukunftsweisender und zukunftswirksamer Ausgaben mit beschäftigungs- und investitionsfordernden Effekten proklamiert. Die konsumtive Mittelverwendung, die als ausschließlich die Gegenwart begünstigend definiert wird, sollte dagegen eingeschränkt werden. ${ }^{31}$ Im Finanzbericht 1983 findet sich die Absichtserklärung, "konsumtive Leistungen zugunsten wachstumsfördernder Ausgaben zurückzudrängen"32) und auch der Finanzplanungsrat empfahl als Beitrag "der Finanzpolitik zur Verbesserung der Beschäftigungslage" in den Haushalten 1982 bis 1985 "bei den konsumtiven Ausgaben des Staates zurückhaltend zu sein, um Raum für mehr öffentliche Investitionen zu gewinnen." ${ }^{33)}$ In seiner 47. Sitzung am 18. 3. 1982 bemerkte er zu diesem Problemkreis: "Das Niveau der investiven Ausgaben sollte im Hinblick auf die struktur- und beschäftigungspolitischen Ziele erhalten

28) Matthöfer, H.: Bundesfinanzminister Hans Matthöfer zu den Beratungen über den Bundeshaushalt 1982, BMF-Dokumentation 9/81, Bonn 1981, S. 6.

29) Vgl. Lahnstein, M.: Haushaltsgesetz 1983 vor dem Deutschen Bundestag. Einbringungsrede des Bundesministers der Finanzen, in: Bulletin, hrsg. v. Presse- und Informationsamt der Bundesregierung, Nr. 85, Bonn 16. September 1982, S. 773-784, S. 777.

30) Ebenda, S. 777.

31) Vgl. Stoltenberg, G.: Haushaltsrede des Bundesministers der Finanzen Dr. Gerhard Stoltenberg am 10. November 1982 im Deutschen Bundestag, in: Bundeshaushalt 1983. Erste Schritte zur Gesundung von Wirtschaft und Finanzen, hrsg. v. Presse- und Informationsamt der Bundesregierung, Reihe: Berichte und Dokumentationen, Bonn, November 1982, S. 5-27, S.21.

32) Bundesministerium der Finanzen: Finanzbericht 1983, Bonn 1982, S. 16.

33) Ebenda, S. 91. 
bleiben. Deshalb müsse der Zuwachs der konsumtiven Ausgaben deutlich begrenzt werden." ${ }^{34)}$ In der darauffolgenden Sitzung bekräftigte er als einen Grundsatz finanzpolitischer Entscheidungen, daß die "konsumtiven Ausgaben ... zugunsten zukunftsorientierter Ausgaben mit beschäftigungs- und investitionsfördernden Wirkungen" ${ }^{35)}$ eingeschränkt werden müßten, was er in den folgenden Sitzungen jeweils wiederholte. ${ }^{36)}$ Im Finanzbericht 1985 kündigte die Bundesregierung an, für den Planungszeitraum der mittelfristigen Finanzplanung 1984 bis 1988 die begonnene Umschichtung zugunsten investiver Ausgaben fortsetzen zu wollen. Gleichzeitig schränkte sie aber ein, daß aufgrund sich abzeichnender Sättigungstendenzen und der Tatsache, daß "wichtige technologiefördernde und langfristig die internationale Wettbewerbsfähigkeit der deutschen Wirtschaft sichernde Maßnahmen ... von den investiven Ausgaben nicht erfaßt" ${ }^{37)}$ werden, die Zuwachsraten geringer sein werden als in der Vergangenheit. Es deutete sich also eine vorsichtigere Betrachtungsweise an, die auch im Finanzbericht 1986 ihre Fortsetzung erfährt, in dem bedauert wird, daß "der Bundeshaushalt trotz aller Bemühungen um eine Verbesserung der Ausgabenstruktur vorwiegend ein 'konsumtiver' Haushalt" bleibe. ${ }^{38}$ Im Finanzbericht 1987 findet sich wieder eine optimistischere Einschätzung der staatlichen Investitionstätigkeit, die in der Prognose eines kräftigen Anstiegs der Investitionsausgaben bei den Ländern und $\mathrm{Ge}$ meinden gipfelt. Gleichzeitig wird darauf verwiesen, daß eine Verlagerung der Investitionstätigkeit "von den klassischen 'Infrastrukturbereichen' wie z.B. Schulen, in denen eine hohe Bedarfsfüllung vorliegt, zu neuen Bedarfsfeldern im Bereich des Umweltschutzes, der Ver- und Entsorgung, der Stadterneuerung und Wohnumfeldverbesserung" stattfände. ${ }^{39)}$

Die etwas differenziertere Betrachtungsweise der ausgewiesenen öffentlichen Investitionsausgaben entstand nicht zuletzt durch die wissenschaftliche Beschäfti-

34) Bundesministerium der Finanzen: Finanzbericht 1983, Bonn 1982, S. 92.

35) Bundesministerium der Finanzen: Finanzbericht 1984, Bonn 1983, S. 111.

36) Vgl. ebenda, S: 112.

37) Bundesministerium der Finanzen: Finanzbericht 1985, Bonn 1984, S. 30.

38) Bundesministerium der Finanzen: Finanzbericht 1986, a.a.O., S. 27. Vgl. auch Wille, E.: Öffentliche Sachausgaben ..., a.a.O., S. 13.

39) Bundesministerium der Finanzen: Finanzbericht 1987, Bonn 1986, S. 71. Vgl. auch die Ausführungen ebenda, S. $29 \mathrm{f}$. 
gung mit diesem Themenkomplex. ${ }^{40)}$ Bei der allseits befürwortete Umstrukturierung der öffentlichen Haushalte bleibt schließlich zu beachten, daß es sich bei den Ausgaben mit investivem Charakter "nicht in jedem Fall um die statistisch ausgewiesenen öffentlichen Investitionsausgaben handelt."41) Daneben ist die vorsichtigere amtliche Beurteilung der staatlichen Investitionen möglicherweise aber auch Ausfluß der Tatsache, daß das finanzpolitische Ziel, die Ausgabenstruktur zugunsten eines höheren Anteils der investiven Ausgaben zu verändern, weitgehend verfehlt wurde. ${ }^{42}$

\subsection{Zur empirischen Entwicklung in der Finanzstatistik}

\subsubsection{Der Investitionsbegriff}

Die Veröffentlichungen der Finanzstatistik werden aus den Haushaltsrechnungen der Berichtskörperschaften entwickelt und folgen somit weitgehend den haushaltsrechtlichen Abgrenzungen. Sie bieten daher "den Vorzug, jenes Datenmaterial zu liefern, das die Entscheidungsprozesse der verschiedenen öffentlichen Instanzen am besten widerspiegelt." ${ }^{43)}$ Die Veröffentlichungen der Finanzstatistik weisen sehr verschiedene Ausgabengruppierungen aus, ${ }^{44)}$ von denen die Glie-

40) Allerdings wurde auch schon im Finanzbericht 1970 darauf verwiesen, daß die Aussagefähigkeit der Unterscheidung zwischen konsumtiven und investiven Ausgaben gering sei (vgl. Bundesministerium der Finanzen: Finanzbericht 1970, a.a.O., S. 148). Im Finanzbericht 1975 wurde diese Aussage, wohl auch vor dem Hintergrund der tatsächlichen Entwicklung der investiven Ausgaben, die den verkündeten Zielvorstellungen nicht entsprach (vgl. hierzu Wille, E.: Finanzplanung am Scheideweg ..., a.a.O., S. 93 ff.), präzisiert und um die Folgekostenkomponente ergänzt (vgl. Bundesministerium der Finanzen: Finanzbericht 1975, Bonn 1974, S.98).

$\mathrm{Zu}$ der veränderten Betrachtungsweise in den Finanzberichten siehe auch Patzig, W.: Haushaltsrecht des Bundes ..., Bd. 1, a.a.O., S. $183 \mathrm{f}$.

41) Wille, E.: Öffentliche Sachausgaben ..., a.a.O., S. 13.

42) Vgl. Sachverständigenrat zur Begutachtung der gesamtwirtschaftlichen Entwicklung: Jahresgutachten 1983/84, a.a.O., Ziff. 221.

43) Wille, E.: Öffentliche Sachausgaben ..., a.a.O., S. 17.

44) Das Gesetz über die Finanzsatatistik regelt in seiner Fassung vom 11. Juni 1980

- die Statistiken über Ausgaben und Einnahmen (§3)

- die Statistiken über das Steueraufkommen (\$ 4)

- die Vermögensstatistik ( $\$ 5$ )

- die Statistiken über die Schulden (\$ 6)

- die Personalstatistiken ( $\$ 7$ )

- die Statistik der öffentlichen Unternehmen, die sog. Bilanzstatistik ( $\$ 8)$.

Der Erhebungsumfang des Finanzstatistikgesetzes, der gegenüber der ursprünglichen Fassung vom 23.6. 1960 schon reduziert ist(vgl Reimann,B.: Erstes Gesetz zur Änderung statistischer Rechtsvorschriften in Kraft getreten, in: Wirtschaft und Statistik, Jg. 1980, S. 433-436) 
derung nach Ausgabenarten, welcher die Einteilung der haushaltsrechtlich vorgeschriebenen Gruppierungsübersicht zugrunde liegt, eine Aussonderung der Investitionsausgaben erlaubt. Nach dieser Systematik werden zunächst Ausgaben der laufenden Rechnung und solche der Kapitalrechnung unterschieden. ${ }^{45)} \mathrm{Zu}$ den Ausgaben der laufenden Rechnung zählen dabei die Personalausgaben, der laufende Sachaufwand, die Zinsausgaben die laufenden Zuweisungen und Zuschüsse. Die Ausgaben der Kapitalrechnung umfassen die Sachinvestitionen, die Vermögensübertragungen sowie die Darlehensgewährung und den Erwerb von Beteiligungen.

Die Verwaltungsvorschriften zur Haushaltssystematik betonen die besondere Stellung der Investitionsausgaben. ${ }^{46)}$ So schreibt der für den Bund und die Länder gültige Gruppierungsplan vor, sie, wegen ihrer finanz- und wirtschaftspolitischen Bedeutung, in zwei gesonderten Hauptgruppen zu erfassen, nämlich der Gruppe 7 "Baumaßnahmen" und der Gruppe 8 "Sonstige Ausgaben für Investitionen und Investitionsforderungsmaßnahmen". Die finanzstatistischen Veröffentlichungen nehmen ebenfalls eine Zweiteilung der Investitionsausgaben vor. Sie unterscheiden zwischen den Sachinvestitionen und den Investitionsförderungsmaßnahmen ${ }^{47)}$, wobei allerdings diese Unterscheidung nicht völlig mit der Trennung des Gruppierungsplans korrespondiert. Die Sachinvestitionen umfassen "diejenigen Produktionsmittel, derer sich der Staat und die Kommunen zur Erfüllung ihrer Aufgaben bedienen müssen ... oder anderen Wirtschaftsbereichen als Produktionsmittel zur Verfügung stellen", während die Investitionsförderungsmaßnahmen, wie schon der Name andeutet, Zuschüssse beinhalten, die "unmittelbar der Investitionsförderung zugute kommen." ${ }^{\text {"18) }}$

wurde durch die Verordnung zur Änderung statistischer Rechtsvorsschriften (Statistikbereinigungsverordnung) vom 14. September 1984 weiter eingeschränkt.

Vgl. hierzu auch Essig, H.: Erfassungs- und Auswertungsprogramm ..., a.a.O., S. 835.

45) Zur "Laufenden Rechnung" rechnen alle Ausgaben, die im Rahmen des Verwaltungsvollzugs sowie des Betriebs von Einrichtungen und Anstalten meistens regelmäßig anfallen und nicht vermögenswirksam sind. Die "Kapitalrechnung" umfaßt dagegen alle Ausgaben, die eine Vermögensveränderung herbeiführen oder der Finanzierung von Investitionen anderer Träger dienen und keine besonderen Finanzierungsvorgänge darstellen. Vgl. Statistisches Bundesamt: Rechnungsergebnisse (1983) ..., a.a.O., S. 11.

46) Vgl. Mons, W. und Fuchs, K.W.: Gruppierungsplan ..., a.a.O., S. 55.

47) Vgl. Statistisches Bundesamt: Rechnungsergebnisse (1983) ..., a.a.O., S. 72 ff.

In den Finanzberichten des Bundesfinanzministeriums wird zwische: "Sachinvestitionen" und "Finanzierungshilfen für Investitionsausgaben Dritter" unterschieden. Vgl. Bundesministerium der Finanzen: Finanzbericht 1987, a.a.O., S. 29 ff.

48) Freund, E.: Haushaltsstatistik, a.a.O., S. 596. 
Die Buchungstafel, die auf der Grundlage des Gruppierungsplans erstellt wird, charakterisiert die Invesititonen als "Ausgaben, die nach ihrer Zweckbindung zur Finanzierung folgender Investitionsausgaben bestimmt sind: Bauten, Erwerb von beweglichen und sonstigem unbeweglichem Vermögen und andere Investitionsausgaben im Sinne der Hauptgruppen 7 und 8." ${ }^{\text {49) }}$ Im folgenden werden in der Finanzstatistik die Sachinvestitionen unterteilt in die Aufwendungen

(1) für Baumaßnahmen,

(2) für den Erwerb von beweglichen Sachen und

(3) für den Erwerb von unbeweglichen Sachen.

Ad (1): In den entsprechenden Verordnungen wird eine Baumaßnahme als "die Herstellung von mit dem Boden festverbundenen Anlagen durch die baugewerbliche Produktion" definiert. ${ }^{50}$ Unter die Ausgaben für Baumaßnahmen fallen alle Neu-, Um- und Erweiterungsbauten sowie der Erwerb von unbebauten Grundstücken, sofern diese mit dem Ziel erworben werden, auf ihnen Gebäude oder bauliche Anlagen zu errichten. ${ }^{51)}$ Die Baukosten enthalten dabei im einzelnen ${ }^{52}$ )

- den Roh- und Ausbau (z.B. auch Innen- und Außenanstrich und Glaserarbeiten),

- alle dauerhaften Einbauten und Ausstattungen, die normalerweise vor dem Bezug oder der Ingebrauchnahme installiert werden (z.B. Zentralheizung),

- alle dauerhaften und unbeweglichen Ausstattungen, die ein wesentlicher Bestandteil dieser Bauten sind sowie

- alle Baunebenkosten (z.B. Kosten für Leistungen von Architekten und Richtfeste).

Was die Veranschlagung der Baumaßnahmen angeht, so bestimmen die "Vorläufigen Verwaltungsvorschriften zur Bundeshaushaltsordnung (BHO)" und sinngemäß, wenn auch mit unterschiedlichen Wertgrenzen, die Verwaltungsvorschriften der Länder, daß grundsätzlich die Ausgaben mit einem Mittelbedarf von

49) Mons, W. und Fuchs, K.W.: Gruppierungsplan ..., a.a.O., S. 549.

50) Ebenda, S. 562.

Die Verwaltungsvorschriften zum Gruppierungsplan listen dabei im einzelnen Baumaßnahmen des Hochbaues, des Bauingenieurwesens, des Wasserwesens, des Eisenbahnwesens, des Straßenbauwesens, des Stadtbauwesens und der Landespflege auf. Vgl. hierzu ebenda, S. 159.

51) Vgl. ebenda, S. 544.

Diese Vorschrift gilt allerdings nicht für den Bund, bei dem der Grundstückserwerb grundsätzlich als Erwerb von unbeweglichen Sachen behandelt wird. Vgl. ebenda, S. 582.

52) Vgi. Patzig, W.: Haushaltsrecht des Bundes ..., Bd. II, a.a.O., C 24 S. 8. 
mehr als 500.000,- DM einzeln zu veranschlagen sind. ${ }^{53)}$ Die Ausgaben für die Unterhaltung der Grundstücke und baulichen Anlagen rechnen zum laufenden Sachaufwand, auch wenn es sich um kleine Veränderungen oder Ergänzungen handelt, sofern sie die Kosten von 10.000,- DM im Einzelfall nicht überschreiten. ${ }^{54)}$ Ebenfalls zum laufenden Sachaufwand zählen die Ausgaben für militärische Anlagen, die "in Übereinstimmung mit den verschiedenen nationalen, supra- und internationalen ökonomischen Systemen nicht zu den Ausgaben für Investitionen" gerechnet werden. ${ }^{55}$

Ad (2): Die Aufwendungen für den Erwerb beweglicher Sachen werden den Sachinvestitionen zugeordnet, falls "die Nutzungsdauer dieser Anlagegüter mehr als ein Jahr beträgt und ihr Preise eine bestimmte Wertgrenze übersteigt." ${ }^{\text {"5) }}$ Diese Wertgrenze ist bei Bund, Ländern und Gemeinden sehr verschieden bemessen. ${ }^{57)}$ Im Detail zählen die Aufwendungen für den Erwerb folgender beweglicher Sachen zu den Sachinvestitionen ${ }^{58)}$ :

1. Ausgaben für die Beschaffung von Fahrzeugen. ${ }^{591}$

2. Ausgaben für den Erwerb von Geräten, Ausstattungs- und Ausrüstungsgegenständen, sofern sie im Einzelfall eine Wertgrenze (beim Bund 10.000,- DM) überschreiten. ${ }^{601}$

53) Vgl. Patzig, W.: Haushaltsrecht des Bundes ..., Bd. II, a.a.O., C 24 S. 9.

54) Vgl. Mons, W. und Fuchs, K.W.: Gruppierungsplan ..., a.a.O., S. 508 f.

55) Bundesminister der Finanzen: MinBIFin 1973, S. 621. Vgl. auch Wille, E. Öffentliche Sachausgaben ..., a.a.O., S. $19 \mathrm{f}$.

Wagner weist in diesem Zusammenhang auf die willkürlich anmutende Regelung hin, daß der Bau von Truppenunterkünften für Stationierungsstreitkräfte in haushaltsrechtlichem Sinne eine Investitionsausgabe darstellt, während der Bau von Truppenunterkünften für die Bundeswehr als Sachaufwand gebucht wird. Vgl. Wagner, K.-D.: Möglichkeiten und Grenzen der Finanzierung öffentlicher Investitionen in der Zukunft, in: ifo-schnelldienst, 16/1978, S.11-17, S. 11.

56) Wille, E.: Zum Verhältnis ..., a.a.O., S. 344. Vgl. auch die Ausführungen in den Allgemeinen Hinweisen des BMF zum Gruppierungsplan. Siehe hierzu Mons, W. und Fuchs K.W.: Gruppierungsplan ..., a.a.O., S. 160.

57) Vgl. auch die Zusammenstellung bei Toillié, B.: Öffentliche Investitionen ..., a.a.O., S. 23 ff.

58) Vgl. Mons, W. und Fuchs, K.W.: Gruppierungsplan ..., a.a.O., S. 160 und S. 538 f.

59) Beim Erwerb von Fahrzeugen besteht keine Wertgrenze. Den allgemeinen Hinweisen des Bundesfinanzministeriums zum Gruppierungsplan ist zu entnehmen, daß neben Wasser- und Luftfahrzeugen auch alle Land- und Schienenfahrzeuge einschließlich der Kraft- und Fahrräder als Teil der Sachinvestitionen erfaßt werden. Vgl. ebenda, S. 160.

60) Hierunter fallen Ausgaben für die Beschäftigung, die Unterhaltung, den Ersatz und die Ergänzung von Zimmerausstattungen für Räume in Dienstgebäuden, Wohnungen, Anstalten und Einrichtungen sowie Büromaschinen, Arbeitsgeräte und Maschinen, ärztliche Instrumente, Operations-, Untersuchungs- und Meßgeräte, Geschirr, Eßgeräte, Wäsche und Kleidung in Anstalten und dgl., Werkzeuge, Verkehrzeichen, Waffen usw.Vgl. ebenda, S. 536. 
3. Ausgaben für den Erwerb sonstiger beweglicher Sachen, wie Kunst- und wissenschaftliche Sammlungen, sofern der Anschaffungswert eine bestimmte Grenze (beim Bund 10.000,- DM) übersteigt. ${ }^{61 \text { ) }}$

Der Erwerb von beweglichen Sachen, die im Einzelfall die jeweilige Wertgrenze nicht erreichen, sowie die Unterhaltung von Geräten und sonstigen Gegenständen werden in der Kategorie "Laufender Sachaufwand" erfaßt. Dasselbe gilt für alle Rüstungskäufe ungeachtet ihres Anschaffungswertes.

Ad (3): Unter den Aufwendungen für den Erwerb unbeweglicher Sachen werden neben dem Ankauf von bebauten und unbebauten Grundstücken und dem Kauf von sonstigen Anlagen (z.B. Obstgärten u.ä.) auch die Ausgaben für Entschädigungen bei der Landbeschaffung sowie alle Kosten, die im Zusammenhang mit dem Grunderwerb stehen, erfaßt. ${ }^{62)}$

Zu den Ausgaben für Investitionsförderungsmaßnahmen rechnet die Finanzstatistik

(1) den Erwerb von Beteiligungen und dgl. ${ }^{63)}$,

(2) Darlehen an den öffentlichen Bereich und an sonstige Bereiche ${ }^{64}$,

(3) die Inanspruchnahme aus Gewährleistungen ${ }^{65)}$,

(4) Zuweisungen für Investitionen an den öffentlichen Bereich und

(5) Zuschüsse für Investitionen an sonstige Bereiche. ${ }^{66)}$

61) Neben den Ausgaben für Kunst- und wissenschaftliche Sammlungen werden unter den sonstigen beweglichen Sachen auch die Anschaffung von Dienstkleidung, Zuchttieren und Reitpferden, sofern sie die Wertgrenze übersteigen, erfaßt. Vgl.Mons, W. und Fuchs, K.W.: Gruppierungsplan ..., a.a.O., S. 161.

62) Vgl. ebenda, S. 161 und S. 544.

63) Neben den Ausgaben für den Erwerb von Beteiligungen und sonstigem Kapitalvermögen, von Forderungen und Anteilsrechten an Unternehmen werden hierunter auch die Ausgaben für die Heraufsetzung des Kapitals von Unternehmen sowie der Erwerb von Aktien, Pfandbriefen und sonstigen Wertpapieren veranschlagt. Vgl. ebenda, S. 513.

64) Zum öffentlichen Bereich im Sinne des Gruppierungsplans, der hier Anwendung findet, gehören die Gebietskörperschaften, das Sondervermögen Lastenausgleichsfonds und das ERP-Sondervermögen, die Sozialversicherungsträger und die Zweckverbände. Die sonstigen Bereiche bilden die öffentlichen Unternehmen, hier z.B. auch die Darlehen des Bundes an die Kreditanstalt für Wiederaufbau als Entwicklungshilfe, die privaten Unternehmen sowie sonstige inländische Wirtschaftssubjekte und das Ausland. Vgl. ebenda, S. 56 ff., S. 162 und S.521.

65) Hierunter werden die Ausgaben für die Inanspruchnahme aus Bürgschafts- und Gewährverträgen und anderen ähnlichen Zwecken dienenden Verträgen erfaßt. Vgl. ebenda, S. 162.

66) Zuweisungen bzw. Zuschüsse für Investitionen sind Ausgaben, die nach ihrer $Z$ weckbindung zur Finanzierung von Sachinvestitionen und anderen Investitionsausgaben im Sinne des Gruppierungsplans bestimmt sind, wobei z.B. die Wohnungsbauprämien unter der Rubrik "Zuschüsse für Investitionen an Sonstige im Inland" erfaßt werden. Vgl. ebenda, S. 162 f. 
Das Gemeindehaushaltsrecht sieht, wie auch schon im 2. Kapitel dargelegt, die Zweiteilung in einen Verwaltungs- und einen Vermögenshaushalt vor, wobei die Investitionen als vermögenswirksame Ausgaben in den Vermögenshaushalt eingestellt werden. Der Musterentwurf Gemeindehaushaltsverordnung (GHVO) ${ }^{67}$ ), unterscheidet im § 10, unter der Überschrift "Investitionen", zunächst Investitionen und Investitionsförderungsmaßnahmen und zählt dann zusätzlich die Ausgaben für Bauten auf. ${ }^{68)}$ Aus den Begriffsbestimmungen, so die Überschrift des $\$ 46$ GHVO, folgt weiter, daß unter den Investitionen die Ausgaben für die Veränderung des Anlagevermögens zu verstehen sind, und daß die Investitionsförderungsmaßnahmen aus den Zuweisungen, Zuschüssen und Darlehen für Investitionen Dritter und für Investitionen der Sondervermögen mit Sonderrechnungen bestehen. Welche Ausgaben eine Veränderung des Anlagevermögens herbeiführen, kann man dem kommunalen Gruppierungsplan und dem entsprechenden $\mathrm{Zu}$ ordnungskatalog entnehmen, die eine detaillierte Untergliederung des Vermögenshaushalts beinhalten. ${ }^{69)}$ Hierin werden als Vermögenserwerb ${ }^{701}$ der Erwerb von Beteiligungen sowie Kapitaleinlagen, der Erwerb von Grundstücken und der Erwerb von beweglichen Sachen des Anlagevermögens aufgelistet. Zu den kommunalen Sachinvestitionen im Sinne der finanzstatistischen Veröffentlichungen $^{71)}$ gehören demnach:

(1) Die Ausgaben für Baumaßnahmen, also die Aufwendungen für Erweiterungs-, Neu-, Um- und Ausbauten, in ähnlicher Abgrenzung wie bei Bund und Ländern ${ }^{72}$;

(2) die Ausgaben für den Erwerb beweglicher Sachen des Anlagevermögens, sofern dieser Erwerb im Vermögenshaushalt nachzuweisen ist; dies bedeutet, daß die erworbenen Güter keine geringwertigen Wirtschaftsgüter im Sinne

67) Der Inhalt des Musterentwurfs wurde im wesentlichen von allen Bundesländern übernommen. Vgl. hierzu auch Littmann, K.: Öffentliche Investitionen, a.a.O., S. 816.

68) Vgl. Musterentwurf Gemeindehaushaltsverordnung, veröffentlicht in: Depiereux, S.: Das neue Haushaltsrecht ..., a.a.O., S. 290.

69) Vgl. Mengert, F.; Kunert, C. und Rehm, J.: Kommunalhaushalt ..., a.a.O., S. 7 ff. und S. $61 \mathrm{ff}$.

70) Die "Ausgaben des Vermögenshaushalts" bilden die Hauptgruppe 9 des kommunalen Gruppierungsplans. Der "Vermögenserwerb" wiederum stellt die Gruppe 93 mit den im Text aufgeführten Untergruppen dar. Vgl. Mengert, F.; Kunert, C. und Rehm, J.: Kommunalhaushalt ..., a.a.O., S. 104.

71) Vgl. auch Deutsches Institut für Urbanistik: Kommunaler Investitionsbedarf bis 1990, Berlin 1980, S. 32 f. und Reidenbach, M.: Zur Investitionstätigkeit der kommunalen Gebietskörperschaften, Zweckverbände und Unternehmen, in: Archiv für Kommunalwissenschaften, 19. Jg. (1980), S. 217-231, S. 218.

72) Vgl Mengert, F.; Kunert, C. und Rehm, J.: Kommunalhaushalt ..., a.a.O., S. 105 f. und S.125ff. Die Ausgaben für Baumaßnahmen werden in den Gruppen 94, 95 und 96 des kommunalen Gruppierungsplans erfaßt. 
des Einkommensteuergesetzes sein dürfen, d.h. ihre Anschaffungs- und Herstellungskosten müssen u.a. mehr als $800,-\mathrm{DM}_{\text {betragen }}{ }^{73)}$;

(3) die Ausgaben für den Erwerb von Grundstücken.

Zu den kommunalen Investitionsförderungsmaßnahmen im Sinne der Finanzstatistik rechnen zum einen die Ausgaben für die Finanzierung von Sachinvestitionen und sonstigen Investitionsausgaben anderer öffentlicher Körperschaften und zum anderen Investitionshilfen an Dritte. ${ }^{74)} \mathrm{Im}$ Detail umfassen die Investitionsförderungsmaßnahmen ${ }^{751}$

(1) die Gewährung von Darlehen einschl. der Inanspruchnahme aus Bürgschaften und ähnlichen Verträgen ${ }^{76}$,

(2) den Erwerb von Beteiligungen und Kapitaleinlagen ${ }^{77)}$ sowie

(3) Zuweisungen und Zuschüsse für Investitionen. ${ }^{781}$

Eine besondere Bedeutung erhalten die kommunalen Investitionen auch durch die gesetzlichen Bestimmungen über die fünfjährige Finanzplanung der Gemeinden. ${ }^{79}$ Sie schreiben die Erstellung eines Finanzplans und eines Investitionsprogramms vor, die spätestens mit dem Entwurf der Haushaltssatzung dem Gemeinderat vorzulegen sind. Das besondere Gewicht der Investitionen verdeutlicht die gleichlautende Bestimmung in allen Gemeindeordnungen, wonach das Investitionsprogramm als Grundlage der Finanzplanung dient. Mehrere Gemeindeord-

73) Vgl. Mengert, F.; Kunert, C. und Rehm, J.: Kommunalhaushalt ..., a.a.O., S. 125.

74) Vgl. ebenda, S. 124.

75) In manchen Publikationen über die kommunale Investitionstätigkeit werden die Investitionsförderungsmaßnahmen auch Finanzinvestitionen genannt (so in Deutsches Institut für Urbanistik: Kommunaler Investitionsbedarf ..., a.a.O., S. 33 und bei Reidenbach, M.: Zur Investitionstätigkeit ..., a.a.O., S. 218), was sich zumindest in Teilen als eine unzutreffende Charakterisierung erweisen kann.

Im Musterentwurf zum kommunalen Haushaltsquerschnitt (veröffentlicht in: Depiereux, S.: Das neue Haushaltsrecht ..., a.a.O., S. 339) werden die Investitionen in die Baumaßnahmen und die sonstigen Investitionsausgaben untergliedert.

76) Sie werden in der Gruppe 92 des kommunalen Gruppierungsplans erfaßt.

77) Der Erwerb von Beteiligungen und Kapitaleinlagen werden in die Untergruppe 930 eingestellt.

78) Sie bilden die Gruppe 98 des Gruppierungsplans.

79) Vgl. \& 9 Musterentwurf der Gemeindeordnung, veröffentlicht in: Depiereux, S.: Das Haushaltsrecht ..., a.a.O., S. $225 \mathrm{ff}$. 


\section{Übersicht 3.1: Der Investitionsbegriff der Finanzstatistik}

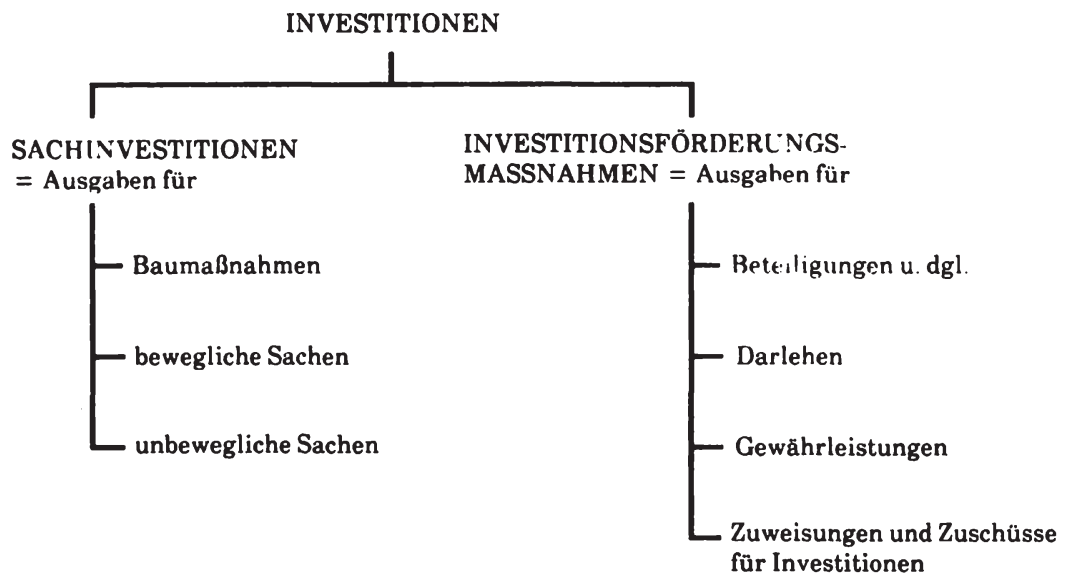

nungen schreiben darüber hinaus eine Beschlußfassung über das Investitionsprogramm ausdrücklich vor. ${ }^{801}$

In den Veröffentlichungen der Finanzstatistik werden die Investitionen auf der obersten Stufe in die Sachinvestitionen und die Investitionsforderungsmaßnahmen bzw. Finanzierungshilfen unterteilt (vgl. Übersicht 3.1). Die Sachinvestitionen sollen dabei die Ausgaben für die staatliche Sachkapitalbildung erfassen und die Investitionsförderungsmaßnahmen die mittels staatlicher Ausgaben initiierte Investitionstätigkeit Dritter aufzeigen. ${ }^{811}$

80) Vgl. § 101, Abs. 3, Satz 2 Gemeindeordnung (GO) Hessen; § 70, Satz 2 GO Nordrhein-Westfalen; $\S 101$, Abs. 2, Satz 2 GO Rheinland-Pfalz; $\S 88$, Abs. 3, Satz 2 Kommunalselbstverwaltungsgesetz Saarland.

Vgl. auch Depiereux, S.: Das neue Haushaltsrecht ..., a.a.O., S. 151 ff. und Thiem, H.: Kommunale Finanzwirtschaft, Köln 1984, S. 13 f.

81) Vgl. auch Deutsche Bundesbank: Sachinvestitionen, Darlehen und sonstige Finanzierungshilfen der Gebietskörperschaften seit Mitte der siebziger Jahre, in: Monatsberichte der Deutschen Bundesbank, 36. Jg. (1984), Nr. 11 (November), S. 26-34, S. 27 f. 


\subsubsection{Die Investitionsquote im Öffentlichen Gesamthaushalt}

Bei der Erstellung und Beurteilung von Zahlenreihen taucht immer das Problem der Vergleichbarkeit der Daten auf. Insbesondere bei der Aufbereitung für die Finanzstatistik sind, wegen der Änderungen des Haushaltsrechts und der statistischen Nachweise, mehr oder minder umfangreiche Umrechnungen erforderlich, um ein einheitliches, für Periodenvergleiche geeignetes Zahlenwerk entstehen zu lassen. ${ }^{82}$ Neben der Haushaltsrechtsreform ${ }^{83)}$ verursachten hier vor allem die ab 1974 gültige Erweiterung des Erhebungsbereiches, mit der Einbeziehung der Zweckverbände, der Sozialversicherung und der Organisationen ohne Erwerbscharakter sowie die von 1975 an erfolgte Ausgliederung der kommunalen Krankenhäuser mit kaufmännischem Rechnungswesen erhebliche Probleme. Bei der Erfassung der Organisationen ohne Erwerbscharakter machte man inzwischen wieder deutliche Abstriche ${ }^{84)}$ Für die Berichtskörperschaften der Sozialversiche rung wurden in der Finanzstatistik von 1974 bis 1981 lediglich die laufenden Ausgaben erfaßt, da nicht alle Rechnungsunterlagen eine Ausgliederung der $\mathrm{Ka}$ pitalrechnung erlaubten ${ }^{85)}$ Dieser Umstand ist allerdings wenig gravierend, weil im Bereich der Sozialversicherungen ${ }^{86)}$ die Ausgaben der Kapitalrechnung nur einen geringen Anteil besitzen. Mit der Umstellung auf ein kaufmännisches Buchführungssystem schieden die Krankenhäuser zwischen 1976 und 1980 aus dem finanzstatistischen Nachweis aus, ohne daß eine Erfassung in einer anderen Statistik vorgesehen war. Für diesen Zeitraum enthielten die Haushalte der Krankenhausträger als Ausweis lediglich die Zuweisungen an Sondervermögen.

82) Vgl. Dietz, O.: Finanzen von Bund und Ländern 1950 bis 1981, in: Wirtschaft und Statistik, Jg. 1983, S. 132-140, S. 132. Siehe auch Wille, E.: Öffentliche Sachausgaben ..., a.a.O., S. 17f.

83) Auf der kommunalen Ebene war die Reform schließlich 1975 überall abgeschlossen. Vgl. Essig, H.: Kommunalfinanzen 1950 bis 1980, in: Wirtschaft und Statistik, Jg. 1982, S. 29-37, S. 29.

84) Vgl. Essig, H.: Erfassungs- und Auswertungsprogramm ..., a.a.O., S. 836 und Statistisches Bundesamt: Rechnungsergebnisse (1983) ..., a.a.O., S. 5.

Im einzelnen werden sie durch Bestimmungen des 1. Statistikbereinigungsgesetzes vom 14.03. 1980 und die Statistikbereinigungsverordnung vom 14. 09. 1984 geregelt.

85) Vgl. Dietz, O.: Darstellung der Sozialversicherung in der Finanzstatistik, in: Wirtschaft und Statistik, Jg. 1984, S. 185-193, S. 185 ff.

86) Zum Bereich der Sozialversicherung rechnen

- die Sozialversicherungsträger (Gesetzliche Krankenversicherung, Gesetzliche U'nfallversicherung, Gesetzliche Rentenversicherung, Altershilfe für Landwirte), die Bundesanstalt für Arbeit, die Zusatzversorgungskassen

Vgl. hierzu Dietz, O.: Darstellung der Sozialversicherung ..., a.a.O., S. 185. 
Eine Regelung des 1 . Statistikbereinigungsgesetzes bestimmte, daß die kaufmännisch buchenden Krankenhäuser seit 1979 wieder in die Jahresrechnungsstatistik einbezogen werden ${ }^{87)}$ Für die $\mathrm{Zwischenzeit} \mathrm{begnügte} \mathrm{man} \mathrm{sich,} \mathrm{mittels}$ Schätzungen und Hilfsrechnungen das Zahlenmaterial aufzuarbeiten. ${ }^{88}$

Neben dem Statistischen Bundesamt veröffentlicht auch das Bundesministerium der Finanzen in den jährlich erscheinenden Finanzberichten und in anderen Publikationen Daten der einzelnen öffentlichen Haushalte bzw. Verwaltungen. Die Zahlenangaben des Bundesministeriums lehnen sich dabei stärker an die Haushaltsrechnungen an, weshalb sie von den finanzstatistischen Daten des Statistischen Bundesamtes abweichen. ${ }^{89)}$ Die Differenz beim Ausweis der Ausgaben für den Öffentlichen Geesamthaushalt lassen sich für den Zeitraum ab 1974 zum überwiegenden Teil durch die unterschiedliche Abgrenzung des Berichtskreises erklären. So rechnet das Bundesfinanzministerium die Zweckverbände und den Bereich der Sozialversicherung nicht zum öffentlichen Bereich, weswegen diese in den Budgetdaten lediglich über die eingestellten Zuschüsse erscheinen. Andere Unterschiede, auch beim Ausweis einzelner Gebietskörperschaften, entstehen als Folge von Bruttostellungen, die das Statistische Bundesamt bei bestimmten Positionen vornimmt. ${ }^{90)}$ Bei der Analyse der Investitionsförderungsmaßnahmen

87) Vgl. Essig, H. und Müller, W.: Darstellung des öffentlichen Krankenhausbereichs in der Finanzstatistik, in: Wirtschaft und Statistik, Jg. 1980, S. 14-20, S. 15 ff. und Reidenbach, M.: Zur Investitionstätigkeit ..., a.a.O., S. 220.

88) Vgl. Essig, H. und Müller, W.: Darstellung des öffentlichen ..., a.a.O., S. 15.

Gleiches gilt heute noch für die Veröffentlichungen im Rahmen der Vierteljahresstatistik. Vgl. ebenda, S. 20.

89) Da das Bundesfinanzministerium in den Finanzberichten sowohl Daten des Statistischen Bundesamtes als auch hausinterne Daten verwendet, präsentieren die Finanzberichte "in ihren Zusammenstellungen, Tabellen und Übersichten dem äußeren Beobachter leider kein durchgehend einheitliches Zahlenwerk" (Wille, E.: Öffentliche Sachausgaben ..., a.a.O., S.18).,

Die Zusammenstellungen und Tabellen der Finanzberichte enthalte ${ }_{\perp}$ die Daten des Finanzministeriums, z.B. 7,12 Mrd. DM Sachinvestitionen bzw. 246,75 Mrd. DM an Gesamtausgaben des Bundes für 1983, während die Übersichten, die im Statistischen Bundesamt bearbeitet wurden, andere Zahlen für 1983 ausweisen, nämlich 7,25 Mrd. DM für die Sachinvestitionen und 248,72 Mrd. DM für die Gesamtausgaben des Bundes. Vgl. Bundesministerium der Finanzen: Finanzbericht 1987, a.a.O., S. 72, S. 152 ff. und S. $229 \mathrm{ff}$.

90) Die in der obigen Fußnote angesprochene Differenz beim Ausweis der Sachinvestitionen des Bundes von 0,13 Mrd.DM sind das Resultat von Bruttostellungen des Statistischen Bundesamtes bei Baumaßnahmen im Verkehrsbereich.

Für das Jahr 1983 gibt das Statistische Bundesamt die Höhe der Sachinvestitionen für den Öffentlichen Gesamthaushalt mit 51,71 Mrd. DM an, das Bundesfinanzministerium weist lediglich 48,50 Mrd.DM aus.Die Differenz von 3,21 Mrd.DM schlüsselt sich auf in 1,30 Mrd.DM Sachinvestitionen im Bereich der Sozialversicherung und 1,78 Mrd.DM Sachinvestitionen bei den Zweckverbänden sowie 0,13 Mrd.DM durch die Bruttostellungen beim Bund. Der Ausweis der Sachinvestitionen bei den Ländern (9,87 Mrd.DM) und den Gemeinden (31,51 Mrd.DM) differiert nicht. Vgl. Bundesministerium der Finanzen: Finanzbericht 1987, a.a.O., S. 70 ff. und Statistisches Bundesamt: Rechnungsergebnisse (1983).., a.a.O., S. 72. 
ist darüber hinaus Vorsicht geboten, weil die Angaben des Statistischen Bundesamtes zumeist auf dem Konzept der unmittelbaren Ausgaben beruhen. Dies bedeutet, daß der Teil der Investitionsförderungsmaßnahmen, der an andere öffentliche Verwaltungen fließt, also die Investitionszuweisungen und die Darlehen an andere öffentliche Bereiche im Ansatz keine Berücksichtigung finden und zumeist lediglich nachrichtlich ausgewiesen werden. ${ }^{911}$ Die Zahlenangaben des Bundesfinanzministers enthalten dagegen in jedem Fall die Zahlungen an andere öffentliche Bereiche, da gerade sie bei den Ausgaben des Bundes, insbesondere auch bei den Investitionsförderungsmaßnahmen einen beträchtlichen Anteil besitzen. ${ }^{92)}$ Das Statistische Bundesamt sieht sich leider, wegen des hierfür erforderlichen unverhältnismäßig hohen Aufwandes, nicht in der Lage, sein Zahlenmaterial derart aufzuarbeiten, daß auch für den Zeitraum vor 1974 eine Ermittlung der Investitionsförderungsmaßnahmen an andere öffentliche Bereiche möglich wäre. ${ }^{93)}$ Die Vergleichbarkeit der Zahlenangaben gegenüber denen des Bundesministeriums der Finanzen ist damit bei der Betrachtung der gesamten Investitionsförderungsmaßnahmen zumindest unterhalb der Ebene des Öffentlichen

91) Vgl. Statistisches Bundesamt: Rechnungsergebnisse (1983) .., a.a.O., S. 72.

Diese zusammenfassende Übersicht zu den "Ausgaben der öffentlichen Haushalte für Investitionen und Investitionsförderungsmaßnahmen..." ist in der neugefaßten Veröffentlichungsreihe über die Jahresrechnungsergebnisse des Öffentlichen Gesamthaushalts ab dem Rechnungsjahr 1984 leider nicht mehr enthalten. Vgl. Statistisches Bundesamt: Rechnungsergebnisse des öffentlichen Gesamthaushalts 1984, Reihe 3.1 der Fachserie 14: Finanzen und Steuern, Stuttgart, Mainz 1986.

92) Die gesamten Investitionsförderungsmaßnahmen des Bundes betragen für 1983 nach Berechnungen aus Unterlagen des Statistischen Bundesamtes 23,69 Mrd. DM, davon stellen 8,54 Mrd.DM Investitionszuweisungen und Darlehen an andere öffentliche Bereiche dar, was einem Anteil von 36,0 vH entspricht. Der Anteil der Investitionsförderungsmaßnahmen des Bundes für andere öffentliche Bereiche an den gesamten investiven Ausgaben, also Sachinvestitionen plus Investitionsförderungsmaßnahmen, beträgt immerhin noch $27,4 \mathrm{vH}$.

93) Vgl. Tabelle 1*a-c im Anhang. Auf einen Ausweis der Investitionsförderungsmaßnahmen wurde in diesen Tabellen deshalb verzichtet.

Das Bundesministerium der Finanzen stellte zwar die entsprechenden Daten zur Verfügung, betonte allerdings ausdrücklich, daß sie in großen Bereichen nur auf Grundlagen von Schätzungen ermittelt werden konnten. 
Gesamthaushalts ${ }^{94)}$ und für diesen Zeitraum, sehr stark eingeschränkt. ${ }^{951}$ Ein Problem, allerdings geringeren Ausmaßes, das mit dem zuletzt beschriebenen Sachverhalt in enger Verbindung steht, bildet die in vielen Veröffentlichungen zu geringe Disaggregation, insbesondere der Vermögensübertragungen an andere öffentliche Bereiche. ${ }^{96}$ Die intensive Durchforstung des Zahlenmaterials ergab, daß fast ausschließlich Zahlungsverkehr zwischen den einzelnen öffentlichen Verwaltungen hier das Hauptproblem der Datenerfassung darstellt. Dies gilt hinsichtlich der Aufbereitung in den einzelnen Ämtern und erklärt auch einen Großteil der Unterschiede bei den Angaben des Bundesfinanzministeriums und des Statistischen Bundesamtes.

Trotz größter Bemühungen des Statistischen Bundesamtes durch Umrechnungen und Angleichungen die finanzstatistischen Zeitreihen vergleichbar zu machen, ist 1974 durch die Erweiterung des Berichtskreises ein Sprung eingetreten, "der nicht ausgeglichen werden kann." ${ }^{\text {97) }}$ Die Zahlenreihen des Bundesministeriums der Finanzen weisen demgegenüber keinen Bruch auf ${ }^{98}$ ), da weder die Zweckverbände, noch der Bereich der Sozialversicherung in der Abgrenzung des Ministeriums zum Öffentlichen Gesamthaushalt rechnen.

94) Auf der Ebene des Öffentlichen Gesamthaushalts sind, sofern es sich um bereinigte Ausgaben handelt, die Zahlungen innerhalb des öffentlichen Bereichs eliminiert, um Doppelzählungen zu vermeiden. Dies bedeutet, daß theoretisch für den Öffentlichen Gesamthaushalt die unmittelbaren Ausgaben den Netto- und den Gesamtausgaben entsprechen (vgl die Ausführungen in 2.3.2.). Die Tatsache, daß die Angaben über die unmittelbaren Ausgaben mit denen für die Netto- und die Gesamtausgaben beim Öffentlichen Gesamthaushalt nicht übereinstimmen, resultiert aus den Problemen bei der Erfassung des Zahlungsverkehrs zwischen den öfentlichen Verwaltungen. Die Einnahmen der öffentlichen Verwaltungen aus den Zahlungen anderer Verwaltungen differiert mit den Angaben über die Ausgaben für andere Verwaltungen.

95) Die Zuweisungen für Investitionen und Darlehen an andere öffentliche Bereiche beliefen sich, nach finanzstatistischen Angaben, beim Bund für 1974 immerhin auf 8,9 Mrd.DM, was einen Anteil von $57,3 \mathrm{vH}$ an den gesamten Investitionsförderungsmaßnahmen des Bundes entspricht.

96) Vgl. Bundesministerium der Finanzen: Finanzbericht 1987, a.a.O., S. 70 ff. und S. 229 ff. Die sonstigen Vermögensübertragungen soweit nicht für Investitionen an andere öffentliche $\mathrm{Be}-$ reiche spielen nur beim Bund eine gewisse Rolle und bewegen sich hier seit 1974 in der Grōßenordnung zwischen 196 Mill. DM und 308 Mill. DM.

97) Dietz, O.: Finanzen von Bund ..., a.a.O., S. 132.

98) Wille verweist auf einen Bruch in der Systematik der Erfassung bei dem Laufenden Sachaufwand. Vgl. Wille, E.: Öffentliche Sachausgaben ..., a.a.O., S. 18 (Fußnote 32) und S. 28 f. (Fußnote 57). 
Tabelle 1: Die Gesamtausgaben und investiven Ausgaben der öffentlichen IIaushalte (Öffentlicher Gesamthaushalt) - Vergleich der finanzstatistischen Zahlen des Statistischen Bundesamtes und des BMF

\begin{tabular}{|c|c|c|c|c|c|c|c|c|c|c|}
\hline \multirow{3}{*}{ Jahr } & \multicolumn{4}{|c|}{ GESAM'TAUSGABEN } & \multicolumn{6}{|c|}{ INVES'TIVE $\triangle U S G \wedge B E N$} \\
\hline & \multicolumn{2}{|c|}{ Stat. Bundesamt" } & \multicolumn{2}{|c|}{$\mathrm{BMF}^{2)}$} & \multicolumn{3}{|c|}{ Stat. Bundesam "" } & \multicolumn{3}{|c|}{$\mathrm{BMF}^{2)}$} \\
\hline & Mrd. DM & $\begin{array}{l}\text { Wachstums- } \\
\text { rates" }\end{array}$ & Mrd. DM & $\begin{array}{l}\text { Wachstums- } \\
\text { rate" }\end{array}$ & Mrd. DM & $\begin{array}{l}\text { Wachstums- } \\
\text { rate }\end{array}$ & $\begin{array}{c}\text { Investitions- } \\
\text { quote }\end{array}$ & Mrd.DM & $\begin{array}{c}\text { Wachstums- } \\
\text { rate }^{31}\end{array}$ & $\begin{array}{c}\text { Investitions- } \\
\text { quote }^{4}\end{array}$ \\
\hline 1962 & 107,23 & - & 106,48 & - & 27,04 & $\cdot$ & 25,2 & 28,44 & $\cdot$ & 26,7 \\
\hline 1963 & 116,77 & 8,9 & 116,34 & 9,3 & 31,02 & 14,7 & 26,6 & 32,12 & 12,9 & 27,6 \\
\hline 1964 & 128,11 & 9,7 & 127,15 & 9,3 & 34,07 & 9,8 & 26,6 & 35,72 & 11,2 & 28,1 \\
\hline 1965 & 140,58 & 9,7 & 139,30 & 9,6 & 36,79 & 8,0 & 26,2 & 37,98 & 6,3 & 27,3 \\
\hline 1966 & 146,72 & 4,4 & 145,02 & 4,1 & 35,86 & $-2,5$ & 24,4 & 36,87 & $-2,9$ & 25,4 \\
\hline 1967 & 155,94 & 6,3 & 153,79 & 6,0 & 36,76 & 2,5 & 23,6 & 37,42 & 1,5 & 24,3 \\
\hline 1968 & 159,19 & 2,1 & 158,83 & 3,3 & 35,82 & $-2,6$ & 22,5 & 36,69 & $-2,0$ & 23,1 \\
\hline 1969 & 174,72 & 9,8 & 174,55 & 9,9 & 40,04 & 11,8 & 22,9 & 40,76 & 11,1 & 23,4 \\
\hline 1970 & 196,33 & 12,4 & 196,32 & 12,5 & 47,57 & 18,8 & 24,2 & 48,11 & 18,0 & 24,5 \\
\hline 1971 & 225,18 & 14,7 & 226,48 & 15,4 & 55,42 & 16,5 & 24,6 & 56,08 & 16,6 & 24,8 \\
\hline 1972 & 251,27 & 11,6 & 252,13 & 11,3 & 58,70 & 5,9 & 23,4 & 60,17 & 7,3 & 23,9 \\
\hline 1973 & 277,67 & 10,5 & 280,49 & 11,2 & 62,99 & 7,3 & 22,7 & 64,31 & 6,9 & 22,9 \\
\hline 1974 & 316,50 & 14,0 & 318,26 & 13,5 & 69,85 & 10,9 & 22,1 & 69,76 & 8,5 & 21,9 \\
\hline 1974 & 458,12 & $\cdot$ & 318,26 & - & 69,80 & - & 15,2 & 69,76 & $\cdot$ & 21,9 \\
\hline 1975 & 526,80 & 15,0 & 360,51 & 13,3 & 70,42 & 0,9 & 13,4 & 72,22 & 3,5 & 20,0 \\
\hline 1976 & 559,48 & 6,2 & 376,76 & 4,5 & 69,92 & $-0,7$ & 12,5 & 69,69 & $-3,5$ & 18,5 \\
\hline 1977 & 592,62 & 5,9 & 395,17 & 4,9 & 68,36 & $-2,2$ & 11,5 & 68,50 & $-1,7$ & 17,3 \\
\hline 1978 & 636,74 & 7,4 & 433,40 & 9,7 & 78,50 & 14,8 & 12,3 & 78,70 & 14,9 & 18,2 \\
\hline 1979 & 688,66 & 8,2 & 469,85 & 8,4 & 89,54 & 14,1 & 13,0 & 90,45 & 14,9 & 19,3 \\
\hline 1980 & 741,34 & 7,6 & 509,24 & 8,4 & 97,80 & 9,2 & 13,2 & 98,26 & 8,6 & 19,3 \\
\hline 1981 & 790,88 & 6,7 & 541,76 & 6,4 & 95,58 & $-2,3$ & 12,1 & 95,68 & $-2,6$ & 17,7 \\
\hline 1982 & 827,96 & 4,7 & 561,61 & 3,7 & 95,61 & 0,0 & 11,5 & 92,26 & $-3,6$ & 16,4 \\
\hline 1983 & 848,55 & 2,5 & 570,08 & 1,5 & 91,39 & $-4,4$ & 10,8 & 88,46 & $-4,1$ & 15,5 \\
\hline 1984 & 875,58 & 3,2 & 583,58 & 2,4 & 93,67 & 2,5 & 10,7 & 90,75 & 2,6 & 15,6 \\
\hline
\end{tabular}

1) Rechnungsergebnisse des Statistischen Bundesamtes. $\Lambda b 1974$ bei den Gesamtausgaben einschl. der Zweckverbande und Sozialversicherung sowie bei den investiven Ausgaben einschl. der Zweckverbånde. Ab 1982 auch bei den investiven Ausgaben einschl. Sozialversicherung.

2) Rechnungsergebnisse des Bundesministeriums der Finanzen (Bund, LAF, EIRP-Sondervermbgen, EG-Anleile, Lander, Gemeinden).

3) Veränderung gegenüber dem Vorjahr in vill.

4) Anteil der investiven Ausgaben an den jeweiligen Gesamtausgaben in vill.

Quelle: Zusammengestellt und errechnet nus Unterlagen, dic uns das Bundesminislerium der Finanzen und dns Slatistische Bundesaml freundlicherweise zur Verfügung stellten. 
Nach diesen Ausführungen über die beiden Zahlenwerke für die öffentlichen Haushalte taucht natürlich die Frage auf, welche Angaben einer empirischen Analyse zugrunde gelegt werden sollen. Die Antwort hängt zum einen sehr wesentlich vom Untersuchungsgegenstand ab und unterliegt zum anderen auch den Restriktionen bezüglich des vorhandenen Zahlenmaterials. Die Analyse der Tabelle 1, in der für den Öffentlichen Gesamthaushalt die finanzstatistischen Daten des Statistischen Bundesamtes mit den Zahlen des Bundesfinanzministeriums konfrontiert werden, verdeutlicht einige Problembereiche:

1. Die Entwicklung der Gesamtausgaben verläuft nahezu parallel. Während für den Zeitraum von 1962 bis 1974 diese Parallelität auch in etwa für das Niveau zutrifft ${ }^{99}$, bewirkt die Ausweitung des Berichtskreises im Ausweis des Statistischen Bundesamtes 1974 eine Niveauverschiebung um 141,62 Mrd. DM. Der Durchschnitt der jährlichen Wachstumsraten beträgt bei den finanzstatistischen Angaben für 1962 bis 1974 ungefähr 9,5 vH und für die Zahlen des Finanzministeriums 9,6 vH. Für den Zeitraum seit 1974 sinkt diese Kennziffer bei den Daten des Statistischen Bundesamtes auf 6,7 vH und bei den Zahlen des Bundesministeriums der Finanzen auf 6,3 vH. Die Tatsache, daß dieser Durchschnittswert bei den Daten des Statistischen Bundesamtes trotz der höheren Basis größer ist, deutet auf eine überproportionale Ausdehnung der Ausgaben im Bereich der Sozialversicherung und bei den Zweckverbänden hin.

2. Die Zahlen für die investiven Ausgaben ergeben ein ähnliches Bild, wobei die Angaben des Statistischen Bundesamtes von 1962 bis 1974 permanent leicht unterhalb der Werte des Bundesfinanzministeriums liegen. ${ }^{100}$ Die Erweite-

99) Von 1962 bis 1969 weist das Statistische Bundesamt durchweg leicht höhere Gesamtausgaben aus, während von 1971 bis 1974 die Ausgaben des Bundesfinanzministeriums über denen des Bundesamtes liegen. Eine Ursache hierfür könnte in der Neugestaltung der Finanzstatistik und der Einführung einer neuen Haushaltssystematik in 1970 liegen.

100) Eine Erklärung für diesen Umstand liefert die Tatsache, daß die Angaben des Statistischen Bundesamtes auf dem Konzept der unmittelbaren Ausgaben beruhen. Obwohl die "unmittelbaren Ausgaben" mit den "Gesamtausgaben" übereinstimmen müßten, wenn der Öffentliche Gesamthaushalt betrachtet wird, führt das Konzept der "unmittelbaren Ausgaben" in praxi zu leicht niedrigeren Ausgabenansätzen (vgl. auch Fußnote 94 auf S.156). Einen weiteren Beleg für diese Erklärung bilden die Werte für die Sachinvestitionen bei den einzelnen Gebietskörperschaften, die lediglich beim Bund minimal differieren - wegen Bruttostellungen -, bei den Ländern und Gemeinden aber völlig übereinstimmen (vgl. Tabellen 1*a-c im Anhang). Die Abweichungen bei den Angaben für die gesamten investiven Ausgaben zwischen BMF und Statistischem Bundesamt resultieren also vorwiegend aus den Unterschieden bei der Erfassung der Investitionsförderungsmaßnahmen. 
rung des Berichtskreises durch das Statistisches Bundesamt beeinflußt die Höhe der gesamten investiven Ausgaben für den Öffentlichen Gesamthaushalt allerdings nur dann, wenn die betreffenden Investitionsausgaben mit Eigenmittel finanziert werden, ansonsten findet lediglich ein Austausch zwischen den Ausgabenkategorien statt. Dies bedeutet natürlich auch, daß von dieser Seite her beide Varianten finanzstatistischer Zahlenangaben kaum Unterschiede aufweisen, sofern die Eigenmittelfinanzierung gegen Null geht. Für die Investitionsausgaben der Zweckverbände trifft genau dies zu. Die Einbeziehung der Kapitalrechnungen im Bereich der Sozialversicherung dagegen bildet die Ursache für den ab 1982 deutlich höheren Ansatz der investiven Ausgaben beim Statistischen Bundesamt, da diese Körperschaften den überwiegenden Teil ihrer Investitionen selbst finanzieren. Inwieweit weitere methodische Umstellungen Auswirkungen auf die Zahlenangaben der Investitionen in 1974 hatte, läßt sich im einzelnen nicht mehr nachvollziehen.

Zwei Sachverhalte bedürfen allerdings noch der näheren Erläuterung. Zunächst betrifft dies die unterschiedliche Behandlung von Konjunktur- und Sonderprogrammen. In den Zahlenreihen des Statistischen Bundesamtes sind die investiven Bestandteile einiger Programme der Jahre 1974 und 1975 nicht enthalten ${ }^{101)}$, da sie zum Teil außerhalb des Bundeshaushalts abgewickelt wurden $^{102)}$, während sie in dem vorliegenden Zahlenmaterial des Bundesfi-

101) Bei den betroffenen Programmen handelt es sich um

- das zweite Sonderprogramm zur "Abstützung der Beschäftigung" vom 25. September 1974,

- das "Programm zur Förderung von Beschäftigung und Wachstum bei Stabilität" vom 12. Dezember 1974 und

- das "Programm zur Stärkung von Bau- und anderen Investitionen" vom August 1975.

Vgl. Bundesministerium der Finanzen: Finanzbericht 1984, a.a.O., S. 166 ff. (Fußnote 8) sowie Ehrlicher W. und Hagemann, R.: Die öffentlichen Finanzen der Bundesrepublik im Jahre 1974, in: Finanzarchiv, hrsg. v. N. Andel und F. Neumark, N.F. Bd. 35 (1976/77), Tübingen 1977, S. 322-346, S. 326 f. und Ehrlicher W. und Rohwer, B.: Die öffentlichen Finanzen der Bundesrepublik im Jahre 1975, in: Finanzarchiv, hrsg. v. N. Andel und F. Neumark, N.F. Bd. 36 (1977/78), Tübingen 1978, S. 485-512, S. 489.

102) Die Finanzierung dieser Programme erfolgte größtenteils durch die Freigabe der Konjunkturausgleichsrücklage. Vgl. Ehrlicher, W. und Hagemann, R.: Die öffentlichen Finanzen ..., a.a.O., S. 326 sowie Ehrlicher, W. und Rohwer, B.: Die öffentlichen Finanzen ..., a.a.O., S. 489. 
nanzministeriums Berücksichtigung fanden. ${ }^{103)}$ Die Größenordnung der hierdurch bedingten Differenzen beläuft sich, was den Öffentlichen Gesamthaushalt angeht ${ }^{104}$, auf wenige Hundert Millionen Deutsche Mark in den Jahren 1975 und 1976 mit sinkender Tendenz für die Folgejahre. Der zweite Sachverhalt, der nach einer zusätzlichen Erklärung verlangt, ist der sehr große Unterschied im Ausweis des Jahres 1975. Ursache hierfür ist die Tatsache, daß der Bund in diesem Jahr "im Rahmen der Liquiditätshilfe an die Bundesanstalt für Arbeit ... ein Darlehen von rund. $2 \frac{1}{2}$ Mrd. DM gewährt hatte"105), während in den Vor- und in den Folgejahren lediglich Zuschüsse gegeben wurden. Insoweit, als diese Zuschüsse für laufende Zwecke geleistet wurden, erhöhte die Darlehensgewährung die Investitionsausgaben des Bundes. Da die Bundesanstalt für Arbeit zum Bereich der Sozialversicherung gerechnet wird, weitet sich dieser Höherausweis der Investitionsausgaben bei der Betrachtung des Öffentlichen Gesamthaushalts ${ }^{106)}$ nur bei den Zahlen des Finanzministeriums aus, denn bei den Angaben des Statistischen Bundesamtes handelt es sich um Darlehen an andere öffentliche Verwaltungen, welche beim Konzept der unmittelbaren Ausgaben nicht berücksichtigt werden.

3. Die Entwicklung der Investitionsquote ${ }^{107)}$, die hier als Anteil der investiven Ausgaben an den jeweiligen Gesamtausgaben definiert wurde, unterliegt

103) Der überwiegende Teil der Sonderprogramme, die zumeist auf eine Verbesserung der Beschäftigungssituation abzielten, wird in den Zahlen beider Statistiken berücksichtigt. So auch das sehr umfangreiche "Programm für Zukunftsinvestitionen (ZIP)" vom März 1977. Vgl. hierzu Ehrlicher W. und Leibinger, H.-B.: Die öffentlichen Finanzen der Bundesrepublik Deutschland im Jahre 1978, in: Finanzarchiv, hrsg. v. N. Andel und F. Neumark, N.F. Bd. 39, Tübingen 1981, S. 462-494, S. 466 f. sowie Presse- und Informationsamt der Bundesregierung (Hrsg.): Abwicklung des Programms für Zukunftsinvestitionen (ZIP), in: Aktuelle Beiträge zur Wirtschafts- und Finanzpolitik, Nr. 55/1980, Bonn, den 25. August 1980.

Was die Berücksichtigung bzw. Nichtberücksichtigung bestimmter Ausgabenprogramme der Jahre 1974 und 1975 angeht, verfährt das Bundesfinanzministerium selbst in den von ihm bearbeiteten Tabellen und Zusammenstellungen nicht einheitlich. Vgl. Bundesministerium der Finanzen: Finanzbericht 1984, a.a.O., S. 18 (Zusammenstellung 3) und S.166ff. (Tabellenteil).

104) Bei der Betrachtung einzelner Gebietskörperschaften könnte die Differenz anders aussehen.

105) Bundesministerium der Finanzen: Finanzbericht 1977, Bonn 1977, S. 27 und S. 30.

106) Bei der Betrachtung des Bundeshaushalts wirkt sich diese Darlehensgewährung nicht auf die Höhe der Investitionsausgaben aus, sondern lediglich auf die Struktur. In einem Fall stellen sie Darlehen an andere Bereiche und im anderen Fall Darlehen an andere öffentliche Verwaltungen dar.

107) Vgl. hierzu Littmann, K.: Definition und Entwicklung ..., a.a.O., S. $88 \mathrm{ff}$. 
selbstverständlich allen oben aufgezeigten Störgrößen. Im Zeitraum von 1962 bis 1974 bewegen sich beide Varianten der Quote nahezu im Gleichschritt. Bedingt durch den enormen Anstieg der Gesamtausgaben im Jahre 1974, dem kein entsprechender Anstieg der investiven Ausgaben gegenübersteht, erfolgt in diesem Jahr eine Niveauverschiebung der Investitionsquote des Statistischen Bundesamtes von 22,1 vH auf 15,2 vH (vgl. Tabelle 1). Die Einbeziehung der Investitionen des Bereichs der Sozialversicherung läßt diese Investitionsquote in 1982 gegenüber 1981 um lediglich 0,6 Prozentpunkte sinken, während die Berechnung nach den Zahlen des Bundesfinanzministeriums einen Rückgang um 1,3 Prozentpunkte ergeben. Die übrigen oben schon dargelegten Unterschiede, wie bestimmte Bruttostellungen oder die Berücksichtigung bzw. Nichtberücksichtigung von Konjunkturprogrammen sowie die Abstimmungsschwierigkeiten im Zahlungsverkehr zwischen den öffentlichen Verwaltungen und die vielen kleinen, letztlich nicht immer erkennbaren Differenzen in der Methodik und Systematik beeinflussen ebenfalls die Aussagekraft der Investitionsquote.

Die Gegenüberstellung der Daten des Statistischen Bundesamtes und des Finanzministeriums demonstriert die z.T. erhebliche Diskrepanz der Zahlenwerte für den Öffentlichen Gesamthaushalt, insbesondere seit 1974. Die Zahlenangaben für die einzelnen Gebietskörperschaften weisen dagegen entweder nur geringe Differenzen auf, wie beim Burd ${ }^{108}$, oder sind, wie bei Ländern und Gemeinden $^{109)}$, fast identisch. Bei einer Analyse der öffentlichen Investitionen stehen die Haushalte der Gebietskörperschaften zwangsläufig im Vordergrund, weshalb die Verwendung der finanzstatistischen Daten des Bundesfinanzministeriums ge-

108) Vgl. Tabelle 1*a im Anhang.

Die Angaben des Bundesfinanzministeriums bezüglich des Bundes basieren auf den IstErgebnissen der Haushaltsstatistik, die das Statistische Bundesamt bei seinen Veröffentlichungen in die Abgrenzungen der Finanzstatistik überführt. Der unterschiedliche Ausweis der Sachinvestitionen, für 1984 etwa 140 Mill. DM, ist das Ergebnis von Bruttostellungen des Statistischen Bundesamtes bei bestimmten Baumaßnahmen im Verkehrsbereich. Die Unterschiede bei den Investitionsförderungsmaßnahmen resultieren größtenteils aus der unterschiedlichen Behandlung von Teilen des Zahlungsverkehrs an andere öffentliche Verwaltungen.

109) Vgl. hierzu die Tabellen $1^{*}$ b und $1^{*} \mathrm{c}$ im Anhang.

Die Unterschiede beim Ausweis der Investitionsförderungsmaßnahmen sind, wie auch schon an anderer Stelle vermerkt, auf die Behandlung des innerstaatlichen Zahlungsverkehrs zurückzuführen. Die zum Teil doch erheblichen Differenzen beim Ausweis der Länder ab 1979 (z.B. 1984 eine Differenz von 620 Mill. D.M) entstehen durch die abweichende Verbuchung von Zahlungen an die staatlichen Krankenhäuser. 
Tabelle 2: Die Investitionsausgaben der öffentliche Haushalte (Öff. Gesamthaushalt)" - Finanzstatistische Daten des BMF

\begin{tabular}{|c|c|c|c|c|c|c|c|c|c|c|c|c|}
\hline \multirow{3}{*}{ Jahr } & \multirow{2}{*}{\multicolumn{2}{|c|}{ GESAMTAUSGABEN }} & \multicolumn{8}{|c|}{ INVESTITIONSAUSGABEN } & \multirow{2}{*}{\multicolumn{2}{|c|}{$\begin{array}{c}\text { INVESTITIONS- } \\
\text { QUO'TEN }\end{array}$}} \\
\hline & & & \multicolumn{2}{|c|}{ insgesamt } & \multicolumn{3}{|c|}{ Sachinvestitionen } & \multicolumn{3}{|c|}{ Investitionsförderungsmaßnahmen } & & \\
\hline & Mrd. DM & $\begin{array}{l}\text { Wachs- } \\
\text { tumsrate }\end{array}$ & Mrd. DM & $\begin{array}{l}\text { Wachs- } \\
\text { tumsrate }\end{array}$ & Mrd.DM & $\begin{array}{l}\text { Wachs- } \\
\text { tumsrate }^{2)}\end{array}$ & Anteil $^{31}$ & Mrd.DM & $\begin{array}{l}\text { Wachs- } \\
\text { tumsrate }\end{array}$ & Anteil' & insgesamt" & $\begin{array}{l}\text { Sachinve- } \\
\text { stitionen }^{31}\end{array}$ \\
\hline 1962 & 106,48 & - & 28,44 & - & 16,55 & - & 58,2 & 11,89 & - & 41,8 & 26,7 & 15,5 \\
\hline 1963 & 116,34 & 9,3 & 32,12 & 12,9 & 19,09 & 15,3 & 59,4 & 13,03 & 9,6 & 40,6 & 27,6 & 16,4 \\
\hline 1964 & 127,15 & 9,3 & 35,72 & 11,2 & 22,44 & 17,5 & 62,8 & 13,28 & 1,9 & 37,2 & 28,1 & 17,6 \\
\hline 1965 & 139,30 & 9,6 & 37,98 & 6,3 & 23,47 & 4,6 & 61,8 & 14,51 & 9,3 & 38,2 & 27,3 & 16,8 \\
\hline 1966 & 145,02 & 4,1 & 36,87 & $-2,9$ & 23,36 & $-0,5$ & 63,4 & 13,51 & $-6,9$ & 36,6 & 25,4 & 16.1 \\
\hline 1967 & 153,79 & 6,0 & 37,42 & 1,5 & 22,78 & $-2,5$ & 60,9 & 14,64 & 8,4 & 39,1 & 24,3 & 14,8 \\
\hline 1968 & 158,83 & 3,3 & 36,69 & $-2,0$ & 23,04 & 1,1 & 62,8 & 13,65 & $-6,8$ & 37,2 & 23,1 & 14,5 \\
\hline 1969 & 174,55 & 9,9 & 40,76 & 11,1 & 26,39 & 14,5 & 64,7 & 14,37 & 5,3 & 35,3 & 23,4 & 15,1 \\
\hline 1970 & 196,32 & 12,5 & 48,11 & 18,0 & 32,24 & 22,2 & 67,0 & 15,87 & 10,4 & 33,0 & 24,5 & 16,4 \\
\hline 1971 & 226,48 & 15,4 & 56,08 & 16,6 & 37,57 & 16,5 & 67,0 & 18,51 & 16,6 & 33,0 & 24,8 & 16,6 \\
\hline 1972 & 252,13 & 11,3 & 60,17 & 7,3 & 39,13 & 4,2 & 65,0 & 21,04 & 13,7 & 35,0 & 23,9 & 15,5 \\
\hline 1973 & 280,49 & 11,2 & 64,31 & 6,9 & 41,35 & 5,7 & 64,3 & 22,96 & 9.1 & 35,7 & 22,9 & 14.7 \\
\hline 1974 & 318,26 & 13,5 & 69,76 & 8,5 & 46,13 & 11,6 & 66,1 & 23,63 & 2,9 & 33,9 & 21,9 & 14,5 \\
\hline 1975 & 360,51 & 13,3 & 72,22 & 3,5 & 46,03 & $-0,2$ & 63,7 & 26,19 & 10,8 & 36,3 & 20,0 & 12,8 \\
\hline 1976 & 376,76 & 4,5 & 69,69 & $-3,5$ & 43,63 & $-5,2$ & 62,6 & 26,06 & $.0,5$ & 37,4 & 18,5 & 11,6 \\
\hline 1977 & 395,17 & 4,9 & 68,50 & $-1,7$ & 43,21 & $-1,0$ & 63,1 & 25,29 & $-3,0$ & 36,9 & 17,3 & 10,9 \\
\hline 1978 & 433,40 & 9,7 & 78,70 & 14,9 & 47,56 & 10,1 & 60,4 & 31,14 & 23,1 & 39,6 & 18,2 & 11,0 \\
\hline 1979 & 469,85 & 8,4 & 90,45 & 14,9 & 53,32 & 12,1 & 58,9 & 37,13 & 19,2 & 41,1 & 19,3 & 11,3 \\
\hline 1980 & 509,24 & 8,4 & 98,26 & 8,6 & 60,00 & 12,5 & 61,1 & 38,26 & 3,0 & 38,9 & 19,3 & 11,8 \\
\hline 1981 & 541,76 & 6.4 & 95,68 & $-2,6$ & 56,99 & $-5,0$ & 59,6 & 38,69 & 1,1 & 40.4 & 17,7 & 10,5 \\
\hline 1982 & 561,61 & 3,7 & 92,26 & $-3,6$ & 52,01 & $-8,7$ & 56,4 & 40,25 & 4,0 & 43,6 & 16,4 & 9,3 \\
\hline 1983 & 570,08 & 1,5 & 88,46 & $-4,1$ & 48,50 & $-6,7$ & 54,8 & 39,96 & $-0,7$ & 45,2 & 15,5 & 8,5 \\
\hline 1984 & 583,58 & 2,4 & 90.75 & 2,6 & 47,62 & $-1,8$ & 52,5 & 43,13 & 7,9 & 47,5 & 15,6 & 8.2 \\
\hline 1985 & 604,03 & 3,5 & 91,80 & 1,2 & 49,98 & 5,0 & 54,4 & 41,82 & $-3,0$ & 45,6 & 15,2 & 8,3 \\
\hline 1986 & 627,35 & 3,9 & 94,72 & 3,2 & 53,00 & 6,0 & 56,0 & 41,72 & $-0,2$ & 44,0 & 15,1 & 8.4 \\
\hline
\end{tabular}

1) Rechnungsergebnisse für Bund, I,AF, F.RP-Sonderverm., E.G-Anteile, Länder sowie Gemeinden (Gv), zuz.ügl. Krankenhäuser der I,änder und Gemeinden. Für 1985 bei l.ändern und Gemeinden (Gv) Ergebnisse der Vierteljahresstatistik zuzügl. der Krankenhäuser; mit den Vorjahren nur bedingt vergleichbar.

2) VerAnderung gegenüber dem Vorjahr in vH.

3) Jeweilige Ausgaben in vll der gesumten Investitionsausgaben.

4) Gesamle Investitionsausgaben in vll der Gesamtausgahen.

5) Suchinvestitionen in vll der Gesamtnusgaten.

Quelle: Zusammengestellt und crrechnet aus Unterlagen, dic uns das Bundesministerium der Finanzen freundlicherweise zur Verfügung stellte. 
rechtfertigt ist, zumal sie in der gleichen Systematik auch für den Zeitraum vor 1974 vorliegen.

Der empirische Befund zeigt für den Öffentlichen Gesamthaushalt einen kontinuierlichen Anstieg der Gesamtausgaben an, wobei die Zuwachsraten ab 1976, insbesondere aber seit 1982 deutlich niedriger ausfallen. ${ }^{10)}$ Die Investitionsausgaben sanken dagegen teilweise sogar dem absoluten Betrag nach und weisen insgesamt einen sehr viel geringeren Anstieg auf, weshalb sich ihr Anteil an den Gesamtausgaben von 26,7 vH im Jahre 1962 auf 15,1 vH in 1986 (vgl. Tabelle 2)

Schaubild 3.1: Die Entwicklung der Investitionsquote für den Öffentlichen Gesamthaushalt ${ }^{11}$

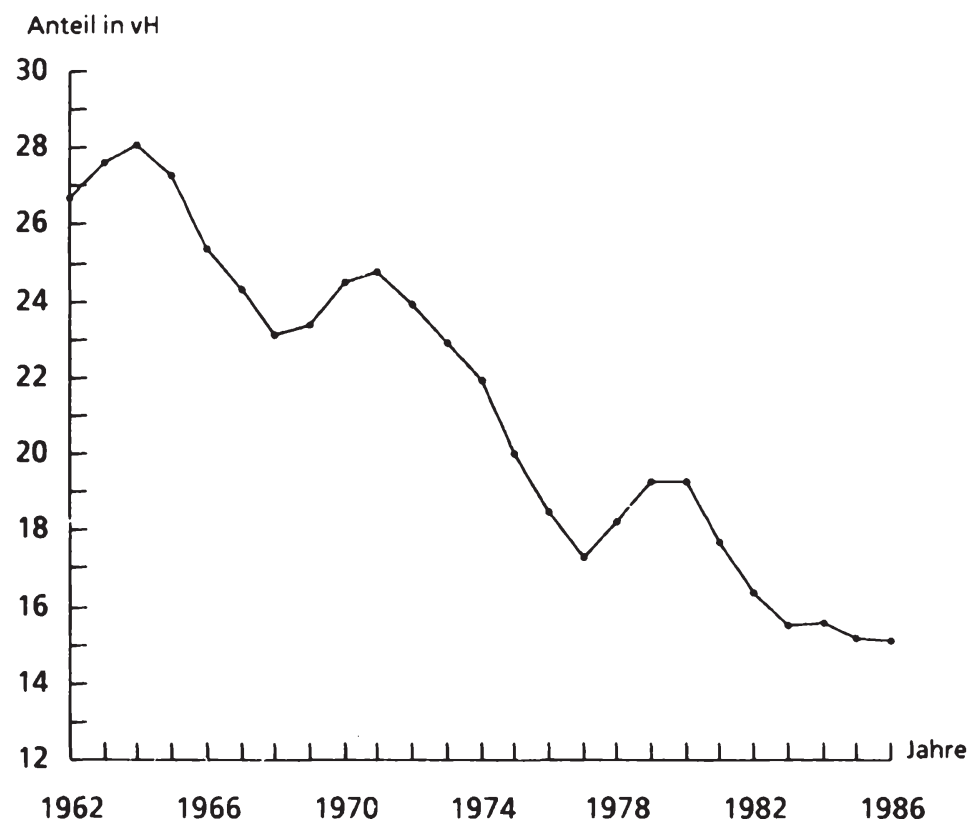

1) Vgl. Tabelle 2.

110) Vgl. Tabelle 2. Der Durchschnitt der Wachstumsraten beträgt für den Zeitraum von 1962 bis 1975 etwa $9,9 \mathrm{vH}$, während er in den Folgejahren auf 5,3 vH sank. 
verringerte. Dieser Rückgang des Anteils der Investitionen an den Gesamtausgaben ist durchgängig bei allen Gebietsköperschaften zu beobachten ${ }^{111}$, wobei er bei den Gemeinden besonders drastisch, von 45,6 vH (1964) auf 22,7 vH (1985), erfolgte. ${ }^{112)}$ Die rückläufige Entwicklung vollzog sich, wie Schaubild 3.1 verdeutlicht, in mehreren Schüben. Den vergleichsweise kurzen Perioden des Anstiegs folgen jeweils längere Abschnitte der Abwärtsentwicklung. So sank die Investitionsquote für den Öffentlichen Gesamthaushalt zwischen 1964 und 1968 von $28,1 \mathrm{vH}$ auf $23,1 \mathrm{vH}$ und von 1971 bis 1977 von $24,8 \mathrm{vH}$ auf $17,3 \mathrm{vH}$. Sie ging schließlich seit 1980 nochmals von $19,3 \mathrm{vH}$ auf $15,1 \mathrm{vH}$ zurück, wobei die Rückwärtsentwicklung ab 1983 zum Stillstand kam und die Investitionsquote wohl auch zumindest kurzfristig auf diesem Niveau verharren dürfte. ${ }^{113)}$ Der Anteil der Investitionsausgaben an den Gesamtausgaben hat damit einen Wert erreicht, der weit unter dem der 50er Jahre liegt. ${ }^{114)}$

\subsubsection{Differenzierung nach Gebietskörperschaften}

Die Entwicklung bei den Gebietskörperschaften weisen zwar in der Tendenz ebenfalls einen Rückgang der Investitionsquote aus, die Stärke des Rückgangs verläuft jedoch auf den einzelnen Ebenen sehr unterschiedlich (vgl. Schaubild 3.2). Die größten Ausschläge, aber auch das stärkste Absinken der Investitionsquote verzeichnen die Gemeinden, deren Quote von etwa $45 \mathrm{vH}$, Anfang der 60er Jahre, auf unter $25 \mathrm{vH}$, Mitte der $80 \mathrm{er}$ Jahre, fiel. ${ }^{115)}$ Dieser Niedergang der kommunalen Investitionen beeinflußte die öffentliche Investitionsquote nachhaltig, weil der größte Teil der öffentlichen Investitionsausgaben über die Haushalte der Gemeinden verausgabt wird. So werden rund zwei Drittel der Sachinvestitonen über die Kommunalhaushalte abgewickelt, während beim Bund ungefähr $15 \mathrm{vH}$

111) Vgl. Tabellen 2*a-c im Anhang.

112) Vgl. Tabelle 2*c im Anhang.

113) Vgl. Tabelle 2. Siehe auch die Prognosen in Bundesministerium der Finanzen: Finanzbericht 1987, a.a.O., S. 71.

114) Vgl. Hoffmann, U.: Begriffe, Struktur und Wachstum der öffentlichen Investitionen, Heft 5 der Studien zur Finanzpolitik, hrsg. v. Ifo-Institut für Wirtschaftsforschung, München 1967, S. $22 \mathrm{ff}$.

115) Vgl. Tabelle 2* $\mathrm{im}$ Anhang. 
Schaubild 3.2: Die Entwicklung der Investitionsquoten der Gebietskörperschaften $^{11}$

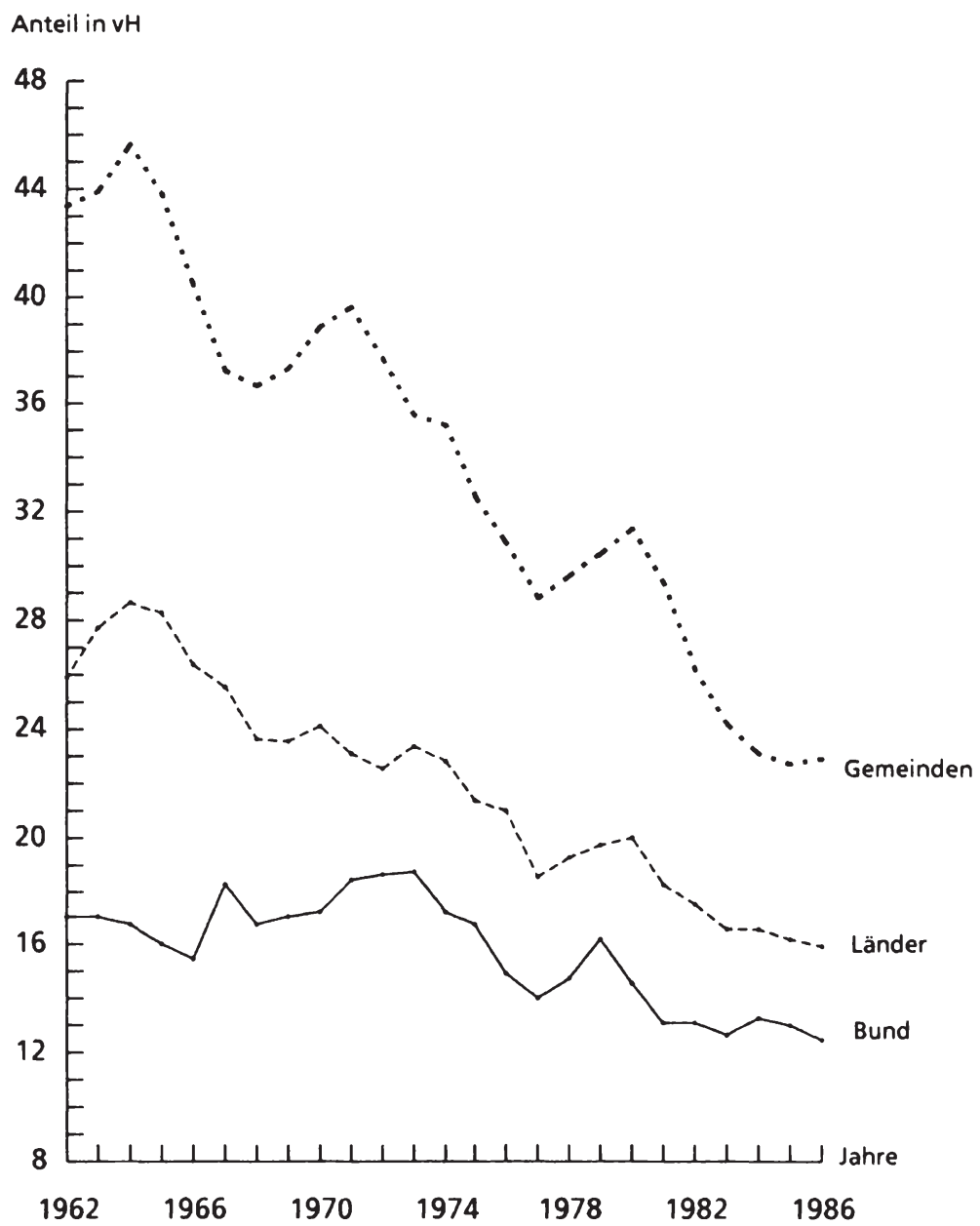

1) Vgl. Tabellen 2*a - c im Anhang. 
und bei den Ländern etwa $20 \mathrm{vH}$ anfallen. ${ }^{116)}$

Die Untersuchung der Investitionen auf der Basis verschiedener finanzwirtschaftlicher Ausgabenkonzepte ${ }^{117)}$ und unter Einbeziehung der Investitionsförderungsmaßnahmen relativiert allerdings diese herausragende Bedeutung der Kommunen. Die unmittelbaren investiven Ausgaben, die die gesamten Investitionen abzüglich der Zuweisungen und Darlehen an andere öffentliche Verwaltungen umfassen, geben Auskunft über die "direkte Investitionsfinanzierung"118) der Haushaltsebenen an Dritte. ${ }^{119}$ ) Für das Jahr 1984 besitzen die Gemeinden hieran einen Anteil von 40,4 vH, die Länder einen von 31,5 vH und der Bund einen von 28,2 $\mathrm{vH}^{120}$ Die Entwicklung der Anteilswerte weist im Beobachtungszeitraum erhebliche Schwankungen und Verschiebungen auf (vgl. Schaubild 3.3). Der Anteil der Länder bewegte sich mit kleineren Ausschlägen bis 1971 nach unten und ist seitdem, allerdings mit größeren Auf- und Abwärtsbewegungen, trendmäßig wieder angestiegen. Die Kurven, die die Veränderungen der Anteile des Bundes und der Gemeinden abbilden, zeigen, trotz ihrer extremen Verläufe, eine trendmäßige Gewichtsverlagerung zu Lasten der Gemeinden. Lag der Anteil der Gemeinden bis 1981 - mit Ausnahme des Jahres $1967^{121}$ - ständig, z.T. sogar sehr erheblich, über $45 \mathrm{vH}$, so sank er seit 1982 recht drastisch. Der Anteil des Bundes an den unmittelbaren investiven Ausgaben erreichte dagegen in 1984 mit 28,2 vH seinen bisherigen Höchststand. Die Verlagerung dieser Gewichte zeigt die

116) Vgl. Tabelle $3^{*}$ a im Anhang. Vgl. auch die Ausführungen bei Leibfritz, W.: Der Staat als Investor. Ein Überblick über die öffentliche Investitionstätigkeit und die Entwicklung des Infrastrukturbestandes in der Bundesrepublik, in: Ifo-Studien. Zeitschrift für empirische Wirtschaftsforschung, 26. Jg. (1980), S. 123-171, S. 138ff. Siehe auch Fuest, W. und Kroker, R.: Quantitative und qualitative Konsolidierung, Nr. 141 der Beiträge zur Wirtschafts- und Sozialpolitik, hrsg. v. Institut der deutschen Wirtschaft, Köln 1986, S. 33 ff.

117) Vgl. Abschnitt 2.3.2.

118) Leibfritz, W.: Der Staat ..., a.a.O., S. 139.

119) Die unmittelbaren investiven Ausgaben bestehen aus den Sachinvestitionen und den Investitionszuschüssen sowie den Darlehen an andere (nicht-öffentliche) Stellen und den Beteiligungen.

120) Vgl. Tabelle $3^{*}$ b im Anhang.

121) Für das Jahr 1967 weisen die Daten einen sprunghaften Anstieg des Anteilswertes beim Bund auf, dem ein abrupter Fall bei den Gemeinden gegenübersteht (vgl. Tabelle $3^{*} \mathrm{~b}$ im Anhang). Ursache hierfür ist der enorme Anstieg der Investitionsausgaben des Bundes, als Folge der Durchführung zweier Konjunkturförderungsprogramme, während die Gemeinden in diesem Jahr sogar Kürzungen ihrer Investitionsausgaben vornehmen. Vgl. Tabelle 2*a - c im Anhang sowie Deutsche Bundesbank: Die Entwicklung der öffentlichen Investitionsausgaben seit 1961, in: Monatsberichte der Deutschen Bundesbank, 24. Jg. (1972), Nr. 4 (April), S. 12-20, S. 14. 
Schaubild 3.3: Die Entwicklung der Anteile der unmittelbaren investiven Ausgaben der Gebietskörperschaften ${ }^{1)}$

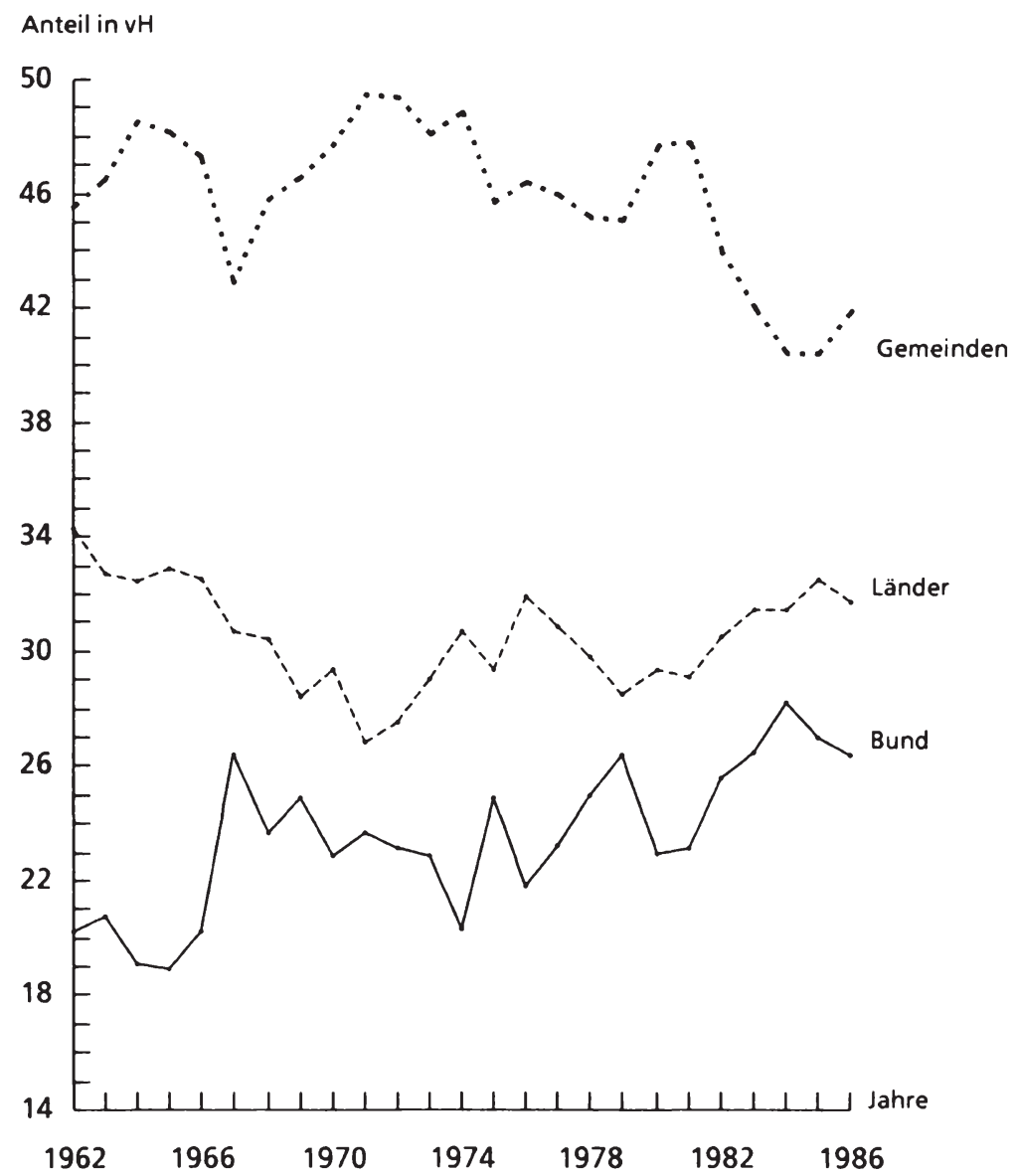

1) Vgl. Tabelle 3*b im Anhang. 
vergleichsweise stärkere Einbindung des Bundes in die öffentliche Investitionstätigkeit, die allerdings fast ausschließlich von der relativen Zunahme der $\mathrm{Zu}$ schüsse sowie der Darlehen und Beteiligungen verursacht wurde. ${ }^{122}$

Legt man der Analyse der Investitionen das Konzept der Nettoausgaben zugrunde, wird die Zunahme der Bedeutung des Bundes noch deutlicher. Die investiven Nettoausgaben kennzeichnen die aus eigenen Einnahmequellen finanzierten Investitionen. ${ }^{123)}$ Der Bund besaß 1984 hieran einen Anteil von $38,7 \mathrm{vH}$, die Länder einen von 33,3 vH und die Gemeinden einen Anteil von 28,0 vH (vgl. Tabelle 3). Die Entwicklung der Anteile der Gebietskörperschaften an den investiven Nettoausgaben, die auf den ersten Blick sehr verwirrend anmuten, läßt sich in drei aussagefähigere Zeitabschnitte zerlegen. Der erste umfaßt die Jahre bis 1966, der zweite erstreckt sich von 1966 bis 1974 und der dritte markiert die Zeitspanne seit 1974. In der ersten Phase bewegt sich der Anteil der Gemeinden an den investiven Nettoausgaben über $36,0 \mathrm{vH}$, während der Anteil der Länder steigende (von 31,9 auf 34,8 vH) und der des Bundes sinkende Tendenz (von 31,2 über 28,2 $\mathrm{vH}$ auf $29,1 \mathrm{vH}$ ) aufweist. In diesem Zeitabschnitt liegen somit die Anteilswerte der Gemeinden an den gesamten investiven Nettoausgaben der Gebietskörperschaften weit über denen des Bundes. Der Anteil der Länder bewegt sich ständig zwischen beiden Größen. Das Bild der folgenden Periode wird von kräftigen Ausschlägen der Werte für den Bund und die Gemeinden bestimmt, während der Anteil der Länder bis 1972 eine ziemlich stetige Abwärtsentwicklung aufweist (von $34,8 \mathrm{vH}$ auf 27,5 vH), die im weiteren Verlauf jedoch fast wieder ausgeglichen wird. Der Bundesanteil stieg zunächst von $29,1 \mathrm{vH}$ (1966) auf 37,5 vH (1967), fiel dann auf 30,6 vH (1970), erhöhte sich wieder auf 36,3 vH (1973), um schließlich 1974 abermals leicht auf den Wert 33,8 vH zu sinken. Die Entwicklung bei den Gemeinden verlief gleichermaßen sprunghaft; so folgte dem abrupten Absinken von 36,2 vH (1966) auf 31,1 vH (1967) eine kontinuierliche Aufwärtsbewegung, die 1971 bei 38,4 vH endete, was den höchsten Stand im gesamten Beobachtungszeitpunktbedeutete und fiel bis 1974 wiederum auf $34,5 \mathrm{vH}$. Die Werte des Anteils der Länder liegen in dieser Phase fast ständig unterhalb derjenigen der bei-

122) Vgl. Tabellen $3^{*}$ a und $5 * a$ im Anhang.

123) Die investiven Nettoausgaben werden aus den gesamten Investitionsausgaben durch Abzug der von anderen öffentlichen Stellen erhaltenen Investitionsförderungsmaßnahmen ermittelt. 
Tabelle 3: Die investiven Nettoausgaben der Gebietskörperschaften - Finanzstatistische Daten des BMF .

\begin{tabular}{|c|c|c|c|c|c|c|c|c|}
\hline \multirow{2}{*}{ Jahr } & \multicolumn{2}{|c|}{ zusammen $^{11}$} & \multicolumn{2}{|c|}{ Bund $^{21}$} & \multicolumn{2}{|c|}{ Lănder $^{3)}$} & \multicolumn{2}{|c|}{ Gemeinden $(\mathrm{Gv})^{4)}$} \\
\hline & Mrd.DM & $\begin{array}{l}\text { Wachstums- } \\
\text { rate }^{51}\end{array}$ & Mrd.DM & Anteil $^{(6)}$ & Mrd.DM & Anteil $^{b_{1}}$ & Mrd.DM & Anteil $^{6}$ \\
\hline 1962 & 27,15 & - & 8,47 & 31,2 & 8,67 & 31,9 & 10,01 & 36,9 \\
\hline 1963 & 30,57 & 12,6 & 9,29 & 30,4 & 10,26 & 33,6 & 11,02 & 36,0 \\
\hline 1964 & 34,50 & 12,9 & 9,75 & 28,3 & 11,73 & 34,0 & 13,02 & 37,7 \\
\hline 1965 & 36,36 & 5,4 & 10,27 & 28,2 & 12,56 & 34,5 & 13,53 & 37,2 \\
\hline 1966 & 35,68 & $-1,9$ & 10,38 & 29,1 & 12,40 & 34,8 & 12,90 & 36,2 \\
\hline 1967 & 36,13 & 1,3 & 13,55 & 37,5 & 11,36 & 31,4 & 11,22 & 31,1 \\
\hline 1968 & 35,23 & $-2,5$ & 12,71 & 36,1 & 10,76 & 30,5 & 11,76 & 33,4 \\
\hline 1969 & 39,31 & 11,6 & 14,01 & 35,6 & 12,14 & 30,9 & 13,16 & 33,5 \\
\hline 1970 & 49,51 & 25,9 & 15,16 & 30,6 & 14,39 & 29,1 & 16,96 & 34,3 \\
\hline 1971 & 54,57 & 10,2 & 18,11 & 33,2 & 15,48 & 28,4 & 20,98 & 38,4 \\
\hline 1972 & 58,58 & 7,3 & 20,64 & 35,2 & 16,13 & 27,5 & 21,81 & 37,2 \\
\hline 1973 & 62,97 & 7,5 & 22,88 & 36,3 & 18,27 & 29,0 & 21,82 & 34,7 \\
\hline 1974 & 67,99 & 8,0 & 23,01 & 33,8 & 21,50 & 31,6 & 23,48 & 34,5 \\
\hline 1975 & 70,17 & 3,2 & 26,71 & 38,1 & 21,77 & 31,0 & 21,69 & 30,9 \\
\hline 1976 & 67,53 & $-3,8$ & 24,63 & 36,5 & 22,54 & 33,4 & 20,36 & 30,1 \\
\hline 1977 & 66,60 & $-1,4$ & 24,13 & 36,2 & 21,20 & 31,8 & 21,27 & 31,9 \\
\hline 1978 & 76,40 & 14,7 & 28,11 & 36,8 & 24,36 & 31,9 & 23,93 & 31,3 \\
\hline 1979 & 87,71 & 14,8 & 32,94 & 37,6 & 27,83 & 31,7 & 26,94 & 30,7 \\
\hline 1980 & 94,91 & 8,2 & 31,47 & 33,2 & 31,86 & 33,6 & 31,58 & 33,3 \\
\hline 1981 & 92,03 & $-3,0$ & 30,50 & 33,1 & 29,77 & 32,3 & 31,76 & 34,5 \\
\hline 1982 & 89,19 & $-3,1$ & 32,02 & 35,9 & 29,63 & 33,2 & 27,54 & 30,9 \\
\hline 1983 & 84,65 & $-5,1$ & 31,30 & 37,0 & 28,48 & 33,6 & 24,87 & 29,4 \\
\hline 1984 & 86,74 & 2,5 & 33,57 & 38,7 & 28,87 & 33,3 & 24,30 & 28,0 \\
\hline 1985 & 87,95 & 1,4 & 33,40 & 38,0 & 30,00 & 34,1 & 24,55 & 27,9 \\
\hline 1986 & 90,82 & 3,3 & 32,82 & 36,1 & 31,13 & 34,3 & 26,87 & 29,6 \\
\hline
\end{tabular}

1) Die Summe der investiven Nettoausgaben der Gebietskörperschaften ist geringer als die investiven Gesamtausgaben für den Öffentlichen Gesamthaushalt, weil die Investitionsausgaben der Sonderrechnungen des Bundes (LAF und ERP) nicht berücksichtigt sind.

2) Ist-Ergebnisse der Haushaltsstatistik, ohne LAF, ERP-Sondervermögen und EG-Anteile.

3) Rechnungsergebnisse, zuzüglich der staatlichen Krankenhäuser. Für 1985 Ergebnisse der Vierteljahresstatistik, einschl. Sonderrechnungen und Krankenhāuser; mit den Vorjahren nur bedingt vergleichbar.

4) Rechnungsergebnisse, zuzüglich der kommunalen Krankenhäuser. Für 1985 Ergebnisse der Vierteljahresstatistik, einschl. der kommunalen Krankenhāuser; mit den Vorjahren nur bedingt vergleichbar.

5) Veränderung gegenüber dem Vorjahr in vH.

6) Jeweilige Ausgaben in vH der Ausgaben insgesamt.

Quelle: Zusammengestellt und errechnet aus Unterlagen, die uns das Bundesministerium der Finanzen freundlicherweise zur Verfügung stellte. 
Schaubild 3.4: Die Entwicklung der Anteile der investiven Nettoausgaben der Gebietskörperschaften ${ }^{1}$

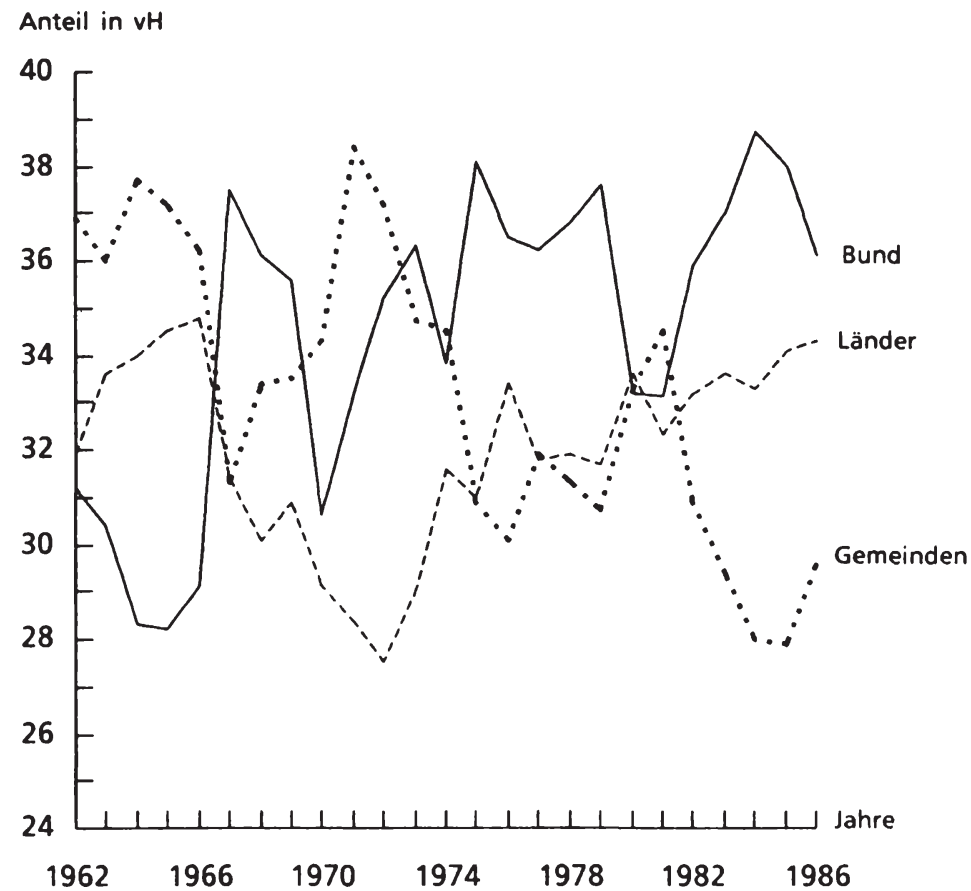

1) Vgl. Tabelle 3.

den anderen Gebietskörperschaften. ${ }^{124)}$ Der Bund und die Gemeinden wechseln sich, was die Spitzenstellung angeht, ab, wobei für die Werte des Bundes gilt, daß sie mit Ausnahme des Jahres 1970 ständig oberhalb der Werte des ersten Abschnitts liegen und für die Gemeinden mit Ausnahme der Jahre 1971 und 1972 das umgekehrte zutrifft. Kennzeichen des letzten Zeitabschnitts ist die überwie-

124) Eine Ausnahme bildet lediglich das erste Jahr, 1967, in dem der Gemeindeanteil $31,1 \mathrm{vH}$ und der Länderanteil $31,4 \mathrm{vH}$ beträgt. 
gende Dominanz des Bundesanteils. Bei den Ländern setzt sich die ansteigende Tendenz, die schon 1972 beginnt, fort, wenngleich mit schwächerer Ausprägung und einigen gegenläufigen Ausschlägen. Im Verlauf der 80er Jahre entfällt auf die Länder ziemlich gleichmäßig etwa ein Drittel der investiven Nettoausgaben der Gebietsköperschaften. Die Werte des Bundes liegen mit Ausnahme der Jahre 1980 und 1981 sehr deutlich über denen der Gemeinden. Die Auseinanderentwicklung der beiden Anteilswerte, die für die zweiten Hälfte der 70er Jahre zu beobachten ist und 1980 sowie 1981 kurzzeitig rückgängig gemacht wurde, setzte, sehr viel stärker sogar, seit 1982 wieder ein. Insgesamt läßt sich aus der Entwicklung der Verteilung der investiven Nettoausgaben die Schlußfolgerung ziehen, daß mittlerweile der Bund innerhalb der Gebietskörperschaften zum größten Finanzier öffentlicher Investitionen avancierte.

Die Ausweitung seines Einflusses auf die Investitionstätigkeit der öffentlichen Haushalte erfolgte allerdings in erster Linie durch die Zunahme des Gewichts der Investitionsförderungsmaßnahmen. Ihr Anteil an den gesamten Investitionsausgaben des Bundes stieg von rund $65 \mathrm{vH}$, in den 60er Jahren, auf weit über $75 \mathrm{vH}$, in den 80er Jahren, während der Anteil der Sachinvestitionen die umgekehrte Entwicklung durchlief. Bei den Ländern und Gemeinden blieb dieses Verhältnis trotz größerer Schwankungen bei den Ländern im Beobachtungszeitraum in etwa gleich, wobei die Investitionsförderungsmaßnahmen bei den Gemeinden eine untergeordnete Rolle spielen. ${ }^{125)}$

Die Sachinvestitionen der öffentlichen Haushalte, die den "materiellen Kern" der Investitionsausgaben bilden ${ }^{126}$ ), sind seit 1962 insgesamt erheblich geringer angestiegen als die Gesamtausgaben. Sie sanken sogar zwischen 1980 und 1984, wie auch schon in den Krisenjahren 1966/67 und 1974 bis 1977 absolut ab. Mit 47,62 Mrd.DM erreichten sie 1984 nominal gerade etwa den Stand von 1978 (vgl. Tabelle 4). Die durchschnittliche jährliche Wachstumsrate, die für die Gesamtausgaben bei 7,8 vH liegt, beträgt bei den Sachinvestitionen lediglich 4,9 vH. Die Investitionsförderungsmaßnahmen weisen demgegenüber einen Durchschnittswert von $5,6 \mathrm{vH}$ auf, obgleich sie gemessen an den Gesamtausgaben ebenfalls weniger

125) Vgl. Tabellen $2^{*}$ a-c im Anhang.

126) Vgl. Wille, E.: Öffentliche Sachausgaben ..., a.a.O., S. 309. Siehe auch die ähnliche Bezeichnung in: Deutsche Bundesbank: Sachinvestitionen, Darlehen ..., a.a.O., S. 32. 
kräftig anstiegen. Der Anteil der Sachinvestitionen an den Gesamtausgaben der öffentlichen Haushalte fiel entsprechend stärker als die Quote der gesamten Investitionen. Er erreicht inzwischen mit 8,4 vH weniger als die Hälfte seines bisherigen Höchststandes von 17,6 vH im Jahr 1964 (vgl. Tabelle 2). Was die Verteilung der Sachinvestitionen auf die Gebietsköperschaften angeht, so ist der Anteil des Bundes insgesamt leicht gesunken und der der Länder und Gemeinden leicht gestiegen. ${ }^{127}$

\subsubsection{Sachinvestitionen versus Investitionsförderungsmaßnahmen}

Den größten Teil der Sachinvestitionen bilden die Ausgaben für Baumaßnahmen. Beim Öffentlichen Gesamthaushalt nehmen sie 1984 rund drei Viertel der Sachinvestitionen ein, was in etwa auch das Größenverhältnis bei den Gemeinden widerspiegelt, während der Bund einen etwas höheren und die Länder einen etwas niedrigeren Wert aufweisen. Die dominante Stellung der Ausgaben für Baumaßnahmen, deren Anteil an den Sachinvestitionen bis Mitte der 70er Jahre um den Wert $80 \mathrm{vH}$ schwankte, wurde seitdem etwas abgebaut (vgl. Tabelle 4), was vor allem auf ein entsprechend starkes Absinken bei den Gemeinden und Ländern zurückgeht. ${ }^{128)}$ Beanspruchten die Baumaßnahmen 1964 knapp über einem Drittel der gesamten Ausgaben der Gemeinden, so lag ihr Anteil 1984 noch bei 15,2vH. Der Rückgang der Investitionsquote wurde also zu einem beträchtlichen Teil durch das relative Sinken der Sachinvestitionen und hier insbesondere im Bereich der Bautätigkeit verursacht.

Zum Abbau des Anteils der investiven Ausgaben an den Gesamtausgaben der öffentlichen Haushalte kommt somit eine Strukturverschiebung innerhalb der Investitionen zugunsten der Investitionsförderungsmaßnahmen hinzu. Diese strukturelle Verlagerung der Gewichte von den direkten zu den indirekten Investitionen vollzog sich, nachdem der Anteil der Sachinvestitionen Anfang der 70er Jahre seinen Höchststand mit 67,0 vH erreicht hatte, vor allem im Verlauf der achtziger Jahre. Als Folge dieser Entwicklung entfielen 1984 nur noch etwas über $50 \mathrm{vH}$ der gesamten Investitionen der öffentlichen Haushalte auf die Sachinvesti-

127) Vgl. Tabelle $3 * a$ im Anhang.

128) Vgl. Tabellen $4^{*}$ a-c im Anhang. 
Tabelle 4: Aufgliederung der Sachinvestitionen der öffentlichen Haushalte (Öff. Gesamthaushalt) ${ }^{1}$ - Finanzstatistische Daten des BMF

\begin{tabular}{|c|c|c|r|r|r|r|r|r|}
\hline & \multicolumn{2}{|c|}{ Sachinvestitionen } & \multicolumn{2}{c|}{ Baumaßnahmen } & \multicolumn{2}{c|}{ bewegl. Sachen } & \multicolumn{2}{c|}{ unbewegl. Sachen } \\
\cline { 2 - 8 } Jahr & & $\begin{array}{c}\text { Wachstums- } \\
\text { rate }\end{array}$ & Mrd.DM & Anteil ${ }^{21}$ & Mrd.DM & Anteil ${ }^{21}$ & Mrd.DM & Anteil $^{21}$ \\
\hline 1962 & 16,55 & - & 13,06 & 78,9 & 1,49 & 9,0 & 2,00 & 12,1 \\
1963 & 19,09 & 15,3 & 15,36 & 80,5 & 1,69 & 8,9 & 2,04 & 10,7 \\
1964 & 22,44 & 17,5 & 18,29 & 81,5 & 1,73 & 7,7 & 2,42 & 10,8 \\
1965 & 23,47 & 4,6 & 18,88 & 80,4 & 1,91 & 8,1 & 2,69 & 11,5 \\
1966 & 23,36 & $-0,5$ & 19,04 & 81,5 & 1,91 & 8,2 & 2,42 & 10,4 \\
1967 & 22,78 & $-2,5$ & 18,42 & 80,9 & 1,78 & 7,8 & 2,58 & 11,3 \\
1968 & 23,04 & 1,1 & 18,57 & 80,6 & 1,69 & 7,3 & 2,79 & 12,1 \\
1969 & 26,39 & 14,5 & 21,23 & 80,4 & 1,91 & 7,2 & 3,25 & 12,3 \\
1970 & 32,24 & 22,2 & 25,73 & 79,8 & 2,59 & 8,0 & 3,92 & 12,2 \\
1971 & 37,57 & 16,5 & 30,35 & 80,8 & 3,09 & 8,2 & 4,14 & 11,0 \\
1972 & 39,13 & 4,2 & 31,81 & 81,3 & 3,13 & 8,0 & 4,18 & 10,7 \\
1973 & 41,35 & 5,7 & 32,91 & 79,6 & 3,47 & 8,4 & 4,97 & 12,0 \\
1974 & 46,13 & 11,6 & 36,38 & 78,9 & 4,02 & 8,7 & 5,74 & 12,4 \\
1975 & 46,03 & $-0,2$ & 36,39 & 79,1 & 4,50 & 9,8 & 5,14 & 11,2 \\
1976 & 43,63 & $-5,2$ & 34,91 & 80,0 & 3,99 & 9,1 & 4,73 & 10,8 \\
1977 & 43,21 & $-1,0$ & 33,55 & 77,6 & 4,46 & 10,3 & 5,20 & 12,0 \\
1978 & 47,56 & 10,1 & 36,98 & 77,8 & 4,71 & 9,9 & 5,88 & 12,4 \\
1979 & 53,32 & 12,1 & 41,21 & 77,3 & 5,20 & 9,8 & 6,92 & 13,0 \\
1980 & 60,00 & 12,5 & 46,48 & 77,5 & 6,10 & 10,2 & 7,43 & 12,4 \\
1981 & 56,99 & $-5,0$ & 44,44 & 78,0 & 5,49 & 9,6 & 7,05 & 12,4 \\
1982 & 52,01 & $-8,7$ & 40,81 & 78,5 & 4,83 & 9,3 & 6,37 & 12,2 \\
1983 & 48,50 & $-6,7$ & 37,60 & 77,5 & 4,82 & 9,9 & 6,08 & 12,5 \\
1984 & 47,62 & $-1,8$ & 36,13 & 75,9 & 5,24 & 11,0 & 6,25 & 13,1 \\
1985 & 49,98 & 5,0 & 37,28 & 74,6 & 6,25 & 12,5 & 6,45 & 12,9 \\
1986 & 53,00 & 6,0 & 39,04 & 73,7 & 7,10 & 13,4 & 6,86 & 12,9 \\
\hline
\end{tabular}

1) Rechnungsergebnisse für Bund, LAF, ERP-Sondervermögen, EG-Anteile, Länder sowie Gemeinden und Gemeindeverbände, zuzūglich der Krankenhäuser der Lānder und Gemeinden. Für 1985 teilweise Ergebnisse der Vierteljahresstatistik, zuzüglich der Krankenhäuser; mit den Vorjahren nur bedingt vergleichbar.

2) Veränderung gegenüber dem Vorjahr in $v H$.

3) Jeweilige Ausgaben in $\mathrm{vH}$ der gesamten Sachinvestitionen.

Quelle: Zusammengestellt und errechnet aus Unterlagen, die uns das Bundesministerium der Finanzen freundlicherweise zur Verfügung stellte. 
tionen (vgl. Tabelle 2). Die Investitionsförderungsmaßnahmen spielen quantitativ insbesondere beim Bund und den Ländern eine bedeutende Rolle, bei den $\mathrm{Ge}-$ meinden erreichen sie dagegen lediglich einen Anteil von etwa $12-14 \mathrm{vH} .{ }^{129)} \mathrm{Be}-$ standen die Investitionsförderungsmaßnahmen der Gemeinden ursprünglich fast ausschließlich aus "Darlehen an andere Bereiche", so gewähren die Kommunen mittlerweile auch Investitionszuschüsse in derselben Größenordnung und Zuweisungen in Höhe von ca. 1 Mrd.DM. ${ }^{130)}$ Beim Bund und den Ländern nehmen die Investitionsförderungsmaßnahmen etwa drei Viertel der jeweiligen Investitionsausgaben in Anspruch, wobei der Anteilswert der Länder, trotz größerer Schwankungen, keine trendmäßige Veränderung aufweist, während beim Bund eine merkliche Steigerung zu konstatieren ist. ${ }^{131}$ )

Die Investitionsförderungsmaßnahmen der Länder bestehen im wesentlichen aus den Zuschüssen und Zuweisungen für Investitionen sowie den Darlehen und Beteiligungen an andere Bereiche. Die Darlehen an andere öffentliche Verwaltungen, die fast ausnahmslos den Gemeinden zugute kommen, sind von ihrer Größenordnung her bedeutlungslos. Die Gewichtung der übrigen drei Bestandteile verändert sich im Beobachtungszeitraum recht deutlich. Bis Mitte der 70er Jahre stiegen die Anteile der Zuschüsse und der Zuweisungen sehr stark an, in ihrem Gipfelpunkt erreichten die Investitionszuschüsse einen Wert von 43,3 vH (1974) und die Investitionszuweisungen einen von 45,2 vH (1975). Die Darlehen und Beteiligungen an andere Bereiche sanken dagegen sogar absolut und erzielten 1972 mit 11,4 vH ihren niedrigsten Anteilswert. Mittlerweile haben sich die Gewichte wieder leicht zurückverlagert. Im Jahre 1984 besaßen die Zuschüsse einen Anteil von 34,6 vH, die Zuweisungen einen von 40,1vH und die Darlehen und Beteiligungen an andere Bereiche einen von $24,7 \mathrm{vH} .{ }^{132}$ Die Investitionszuweisungen der Länder bestehen zu beinahe 100 Prozent aus den Zuweisungen an die Gemeinden. Sie stiegen mit einer Ausnahme bis 1980 in jedem

129) Vgl. Tabellen $2 *$ a-c im Anhang.

130) Vgl. Tabelle $5^{*} c$ im Anhang.

Die Position "Darlehen und Beteiligungen an andere Bereiche" teilt sich zur Hälfte in die Darlehen, vor allem für Unternehmen und Sonstige im Inland und die Beteiligungen auf. Die Investitionszuschüsse gehen in erster Linie an Zweckverbände und Sonstige (Unternehmen und Privatpersonen) im Inland. Die Zuweisungen für Investitionen sind zum überwiegenden Teil an die Länder adressiert und bestehen hauptsächlich aus Beteiligungen an Baumaßnahmen der Länder.

131) Vgl. Tabellen 2*a und $b$ im Anhang.

132) Vgl. Tabelle 5*b im Anhang. 
Jahr an ${ }^{133)}$ und gingen danach stark zurück. ${ }^{134)}$ Inwieweit das Jahr 1984 hier wieder eine Trendwende markiert, bleibt unklar, denn eine tiefere Durchleuchtung der Daten offenbart bei den Zahlenangaben dieses Jahres besonders große Probleme im Verrechnungsverkehr der öffentlichen Haushalte. Die Investitionszuschüsse nahmen bis Mitte der 70er Jahre in etwa dieselbe Entwicklung wie die Zuweisungen. Sie sanken allerdings dann im absoluten Betrag von 1975 bis 1977 und stiegen anschließend bis auf das Niveau von ca. $11 \mathrm{Mrd}$. DM an, welches sie im Verlauf der 80er Jahre in etwa behaupteten. ${ }^{135 \prime}$ Die Zuschüsse der Länder für Investitionen gehen zu etwa 10 Prozent an die Zweckverbände und zu 90 Prozent an Unternehmen und Sonstige im Inland. Sie enthalten u.a. die Investitionszuschüsse für Krankenhäuser sowie die Zuschüsse im Rahmen des Wohnungsbauprämiengesetzes. ${ }^{136)}$ Der größte Teil der Darlehen und Beteiligungen, etwa 75vH, fließt an Sonstige im Inland, wobei hiervon wiederum ungefähr drei Viertel für die Förderung des Wohnungsbaues bestimmt ist. ${ }^{137)}$

Der Anteil der Investitionsförderungsmaßnahmen an den investiven Ausgaben ist beim Bund seit 1970 sehr stark angestiegen. Besonders ausgeprägt verlief diese Entwicklung in den ersten drei Jahren der 70er Jahre sowie in 1977 und 1978, in denen diese indirekten Investitionen extrem hohe Zuwachsraten zu verzeichnen hatten. Mit Ausnahme von 1980 besitzen sie seit 1979 einen Anteil von über $75 \mathrm{vH}^{138)}$ Was die Gewichtung der einzelnen Komponenten der Investitionsförderungsmaßnahmen angeht, so sind im Beobachtungszeitraum erhebliche Verschiebungen zu beobachten (vgl. Tabelle 5). Dabei läßt sich ein Anwachsen des Gewichts der Investitionszuschüsse verzeichnen, während die Zuweisungen und die Darlehen an andere öffentliche Verwaltungen an Bedeutung verloren. Die Darlehen und Beteiligungen an andere Bereiche erreichten Mitte der 80er Jahre in etwa wieder den Anteil, den sie Anfang der 60er Jahre besaßen, nachdem die Werte zwischenzeitlich sowohl erheblich darüber als auch deutlich darunter lagen.

133) Von 1976 auf 1977 sanken sie um 1,4 Mrd. DM, von 10,59 Mrd. DM auf 9,19 Mrd. DM.

134) Vgl. auch die Ausführungen in: Institut "Finanzen und Steuern" (Hrsg.): Die Haushalte der Flächenländer unter Konsolidierungszwang, Nr. 262, Bonn 1986, S. 36.

135) Für das Jahr 1984 gilt die gleiche Einschränkung wie schon oben bei den Investitionszuweisungen.

136) Vgl. Institut "Finanzen und Steuern" (Hrsg.): Die Haushalte ..., a.a.O., S. 36.

137) Vgl. ebenda, S. 37.

138) Vgl. Tabelle $2 * a$. 
Tabelle 5: Aufgliederung der Investitionsförderungsmaßnahmen des Bundes ${ }^{11}$ - Finanzstatistische Daten des BMF -

\begin{tabular}{|c|c|c|c|c|c|c|c|c|c|}
\hline \multirow{2}{*}{ Jahr } & \multirow{2}{*}{\begin{tabular}{|l|} 
Insgesamt \\
Mrd.DM
\end{tabular}} & \multicolumn{2}{|c|}{ Zuschüsse } & \multicolumn{2}{|c|}{$\begin{array}{l}\text { Darlehen und } \\
\text { Beteiligungen }\end{array}$} & \multicolumn{2}{|c|}{ Zuweisungen } & \multicolumn{2}{|c|}{$\begin{array}{l}\text { Darlehen an öff. } \\
\text { Verwaltungen }\end{array}$} \\
\hline & & Mrd.DM & Anteil $^{2)}$ & Mrd.DM & Anteil $^{2 \prime}$ & Mrd.DM & Anteil $^{2 \prime}$ & Mrd.DM & Anteil $^{2}$ \\
\hline 1962 & 5,53 & 0,80 & 14,5 & 1,66 & 30,0 & 1,77 & 32,0 & 1,30 & 23,5 \\
\hline 1963 & 5,86 & 0,83 & 14,2 & 1,89 & 32,3 & 1,93 & 32,9 & 1,21 & 20,7 \\
\hline 1964 & 6,07 & 0,91 & 15,0 & 1,81 & 29,8 & 2,18 & 35,9 & 1,17 & 19,3 \\
\hline 1965 & 6,51 & 0,66 & 10,1 & 2,26 & 34,7 & 2,55 & 39,2 & 1,04 & 16,0 \\
\hline 1966 & 6,51 & 0,59 & 9,1 & 2,59 & 39,8 & 2,47 & 37,9 & 0,86 & 13,2 \\
\hline 1967 & 8,90 & 0,89 & 10,0 & 3,84 & 43,2 & 3,34 & 37,5 & 0,83 & 9,3 \\
\hline 1968 & 8,56 & 0,96 & 11,2 & 3,10 & 36,2 & 3,52 & 41,1 & 0,98 & 11,5 \\
\hline 1969 & 9,01 & 1,50 & 16,7 & 3,14 & 34,9 & 3,74 & 41,5 & 0,63 & 7,0 \\
\hline 1970 & 9,53 & 2,30 & 24,1 & 2,63 & 27,6 & 4,05 & 42,5 & 0,55 & 5,8 \\
\hline 1971 & 11,70 & 3,07 & 26,2 & 3,22 & 27,5 & 4,73 & 40,4 & 0,58 & 5,0 \\
\hline 1972 & 14,00 & 3,48 & 24,9 & 3,09 & 22,1 & 6,41 & 45,8 & 1,02 & 7,3 \\
\hline 1973 & 16,40 & 2,88 & 17,6 & 4,89 & 29,8 & 7,60 & 46,3 & 1,03 & 6,3 \\
\hline 1974 & 15,91 & 3,15 & 19,8 & 3,58 & 22,5 & 8,09 & 50,9 & 1,09 & 6,9 \\
\hline 1975 & 18,91 & 3,71 & 19,6 & 6,08 & 32,2 & 7,95 & 42,0 & 1,17 & 6,2 \\
\hline 1976 & 17,62 & 4,47 & 25,4 & 3,29 & 18,7 & 8,61 & 48,9 & 1,25 & 7,1 \\
\hline 1977 & 16,92 & 5,15 & 30,4 & 2,99 & 17,7 & 7,46 & 44,1 & 1,32 & 7,8 \\
\hline 1978 & 20,45 & 7,20 & 35,2 & 4,11 & 20,1 & 7,71 & 37,7 & 1,43 & 7,0 \\
\hline 1979 & 24,96 & 9,64 & 38,6 & 5,52 & 22,1 & 8,15 & 32,7 & 1,65 & 6,6 \\
\hline 1980 & 23,27 & 8,61 & 37,0 & 5,05 & 21,7 & 7,87 & 33,8 & 1,74 & 7,5 \\
\hline 1981 & 23,24 & 8,82 & 38,0 & 5,14 & 22,1 & 7,28 & 31,3 & 2,00 & 8,6 \\
\hline 1982 & 25,06 & 10,12 & 40,4 & 5,93 & 23,7 & 7,08 & 28,3 & 1,93 & 7,7 \\
\hline 1983 & 24,18 & 8,76 & 36,2 & 6,66 & 27,5 & 6,77 & 28,0 & 1,99 & 8,2 \\
\hline 1984 & 26,47 & 8,86 & 33,5 & 8,31 & 31,4 & 6,65 & 25,1 & 2,65 & 10,0 \\
\hline 1985 & 26,02 & 9,12 & 35,1 & 7,62 & 29,3 & 6,37 & 24,5 & 2,91 & 11,2 \\
\hline 1986 & 25,30 & 10,16 & 40,2 & 6,64 & 26,3 & 5,67 & 22,4 & 2,83 & 11,2 \\
\hline
\end{tabular}

1) Ist-Ergebnisse in der Systematik des Haushalts 1986, ohne LAF, ERP-Sondervermögen und EG-Anteile.

2) Jeweilige Ausgaben in $\mathrm{vH}$ der gesamten Investitionsförderungsmaßnahmen.

Quelle: Zusammengestellt und errechnet aus Unterlagen, die uns das Bundesministerium der Finanzen freundlicherweise zur Verfügung stellte. 
Schaubild 3.5: Die Entwicklung der Investitionsförderungsmaßnahmen des Bundes ${ }^{1)}$

Anteil in vH

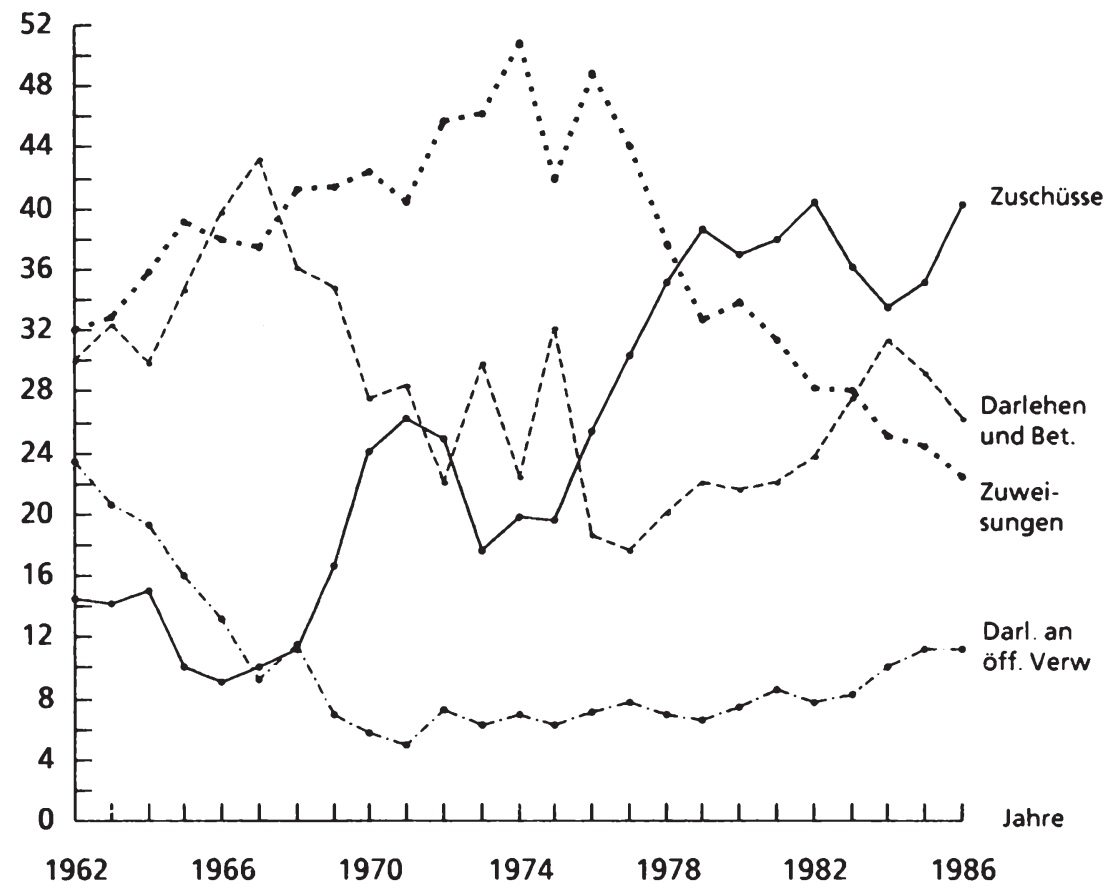

1) Vgl. Tabe!le 5.

Zerlegt man den gesamten Beobachtungsbereich in drei Zeitabschnitte, lassen sich einige detailliertere Entwicklungstendenzen ablesen (vgl. Schaubild 3.5). In der Phase von 1962 bis 1967 beanspruchen die Investitionszuweisungen und die Darlehen und Beteiligungen an andere Bereiche rund zwei Drittel der Investitionsförderungsmaßnahmen. Die Investitionszuschüsse besitzen in diesen Jahren mit einem Anteil von unter $15 \mathrm{vH}$ einen ebenso geringen Stellenwert wie die Darlehen an öffentliche Verwaltungen, deren Anteil überdies drastisch sank. 
Im zweiten Unterabschnitt, von 1967 bis 1976 dominieren die Zuweisungen, die sich von 3,34 Mrd. DM (1967) auf 8,61 Mrd. DM (1976) erhöhten und in dieser Zeit ständig einen Anteil von weit über $40 \mathrm{vH}$ realisierten. In dieser Zunahme manifestieren sich veränderte Rahmenbedingungen wie die Regelungen über die Gemeinschaftsaufgaben und die Bestimmungen in Zusammenhang mit dem Artikel 104a Abs. 4 GG, der die Finanzhilfen des Bundes bei bedeutenden Investitionen der Länder und Gemeinden sowie die Beteiligung des Bundes an der Krankenhausfinanzierung regelt. ${ }^{139)}$ Die Darlehen und Beteiligungen an andere Bereiche verlieren in dieser Periode an Gewicht, wobei die Zahlenwerte für die Jahre 1973 und 1975 völlig gegen diesen Trend ausschlagen. Die Ursache hierfür liegt 1973 in der sehr starken Zunahme der Darlehen an inländische Unternehmen und den hohen Ausgaben für den Erwerb neuer Beteiligungen ${ }^{140)}$ und in 1975 an der einmaligen Darlehensgewährung an die Bundesanstalt für Arbeit, in Höhe von 2,45 Mrd.DM. ${ }^{141)}$ Mit einem Anteil von 18,7 vH verzeichneten die Darlehen und Beteiligungen an andere Bereiche 1976 den bis dahin tiefsten Stand ihrer Entwicklung. Die Darlehen an andere öffentliche Verwaltungen sanken gegen Ende der 60er Jahre auf ein Anteilsniveau von unter $10 \mathrm{vH}$, auf dem sie mit nur geringen Schwankungen bis heute verharren.

Der letzte Zeitabschnitt umfaßt die Entwicklung seit 1976. Sie ist gekennzeichnet durch das Anwachsen der Investitionszuschüsse und der Darlehen und Beteiligungen sowie das Absinken des Anteils der Investitionszuweisungen. Von den gesamten Investitionsförderungsmaßnahmen des Bundes entfielen 1986 40,2 vH auf die Zuschüsse, 26,3 vH auf die Darlehen und Beteiligungen, 22,4 vH auf die Zuweisungen und 11,2 vH auf die Darlehen an andere öffentliche Verwaltungen. Besonders auffällig ist die Ende der 70er Jahre erfolgte deutliche Steigerung der Investitionszuschüsse, die auf mehreren, sich teilweise überlappenden Einflußfaktoren beruht. Zum einen zeigen sich hierin die Auswirkungen besonderer konjunktureller Bemühungen des Bundes, die in verschiedenen Konjunkturprogrammen wie dem "Programm für Zukunftsinvestitionen" mündeten, zum anderen

139) Vgl. Bundesministerium der Finanzen: Finanzbericht 1974, a.a.O., S. $163 \mathrm{ff}$. Vgl. hierzu auch die Ausführungen in Abschnitt 3.1.1.

140) Vgl. Bundesministerium der Finanzen: Finanzbericht 1975, a.a.O., S. 196 ff. Bei dem Erwerb neuer Beteiligungen handelte es sich um die Gelsenberg AG und die Flughafen München GmbH.

141) Vgl. Bundesministerium der Finanzen: Finanzbericht 1977, a.a.O., S. 30. Vgl. auch die Ausführungen oben S. 159 insbesondere die Fußnote 106. 
sind sie aber auch auf die erhöhten Abführungen von Investitionszuschüssen an die Deutsche Bundesbahn zurückzuführen ${ }^{142)}$, welche zumindest teilweise den Charakter einer versteckten Verlustabdeckung besitzen. ${ }^{143)}$ Schließlich ist eine weitere Ursache in der sprunghaften Erhöhung der Investitionszuschüsse an das Ausland im Jahre 1979 zu sehen. Letztere besitzen seitdem durchgängig einen Anteil von rund $18 \mathrm{vH}$ der gesamten Investitionszuschüsse des Bundes. ${ }^{144)}$ Bei den Darlehen und Beteiligungen an andere Bereiche sind ebenfalls sehr beträchtliche Teile für das Ausland eingestellt. So vergab der Bund Ende der 70er, Anfang der 80er Jahre etwa 50 Prozent dieser Ausgaben als Darlehen an das Ausland, in absoluten Größen mittlerweile etwa 3 Mrd. DM. ${ }^{145)}$ In der Entwicklung dieser Position kommt sicher auch eine verstärkte Inanspruchnahme von Gewährleistungen zum Ausdruck. Desweiteren stieg im Verlauf der 80er Jahre der Anteil der Ausgaben für den Erwerb von Beteiligungen im Ausland. ${ }^{146)}$ Hierbei handelt es sich in aller Regel um die Erhöhungen der bundesdeutschen Beteiligungen an internationalen Organisationen. ${ }^{147)}$ Zusammen mit den Darlehen an das Ausland beanspruchen sie seit Ende der 70er Jahre über 50 vH der Darlehen und Beteiligungen an andere Bereiche. Die Darlehen an andere öffentliche Verwaltungen enthalten seit 1984 die Darlehen des Bundes im Rahmen des Bundesausbildungsförderungsgesetzes, die an die Länder abgeführt werden. Zuvor waren diese $\mathrm{Be}$ träge unter die laufenden Zuweisungen eingestelit, weshalb diese geänderte Veranschlagungspraxis zu einer sprunghaften Erhöhung der Darlehen an die Länder führte. Der Bund leistet im Rahmen des BAföG immerhin Darlehen in Höhe von rund 1,3 Mrd.DM. ${ }^{148 \text { ) }}$

142) Vgl. Bundesministerium der Finanzen: Finanzbericht 1977, a.a.O., S. 30; ders.: Finanzbericht 1978, a.a.O., S. 22 und ders.: Finanzbericht 1981, a.a.O., S. 20.

143) Vgl. Deutsche Bundesbank: Sachinvestitionen, Darlehen und ..., a.a.O., S. 31.

144) Der Anteil der Zuschüsse für Investitionen an das Ausland an den gesamten Investitionszuschüssen des Bundes betrug 1978 11,5 vH, 1979 18,3 vH, 1980 19,2 vH, 1981 19,7 vH, $198217,9 \mathrm{vH}, 198318,6 \mathrm{vH}, 198418,8 \mathrm{vH}, 198516,6 \mathrm{vH}$ und $198615,8 \mathrm{vH}$.

145) Im einzelnen betrug dieser Anteil $197848,4 \mathrm{vH}, 197946,5 \mathrm{vH}, 198051,9 \mathrm{vH}, 1981$ 56,2vH, $198248,6 \mathrm{vH}, 198339,9 \mathrm{vH}, 198440,0 \mathrm{vH}, 198536,6 \mathrm{vH}$ und $198639,5 \mathrm{vH}$.

146) Für die einzelnen Jahre ergaben sich folgende Werte: $19786,9 \mathrm{vH}, 19798,7 \mathrm{vH}, 1980$ 11,0vH, $198111,0 \mathrm{vH}, 1982$ 10,9 vH, 1983 16,0 vH, 1984 13,2 vH, 1985 15,7 vH und 1986 $17,0 \mathrm{vH}$.

147) Vgl. Bundesministerium der Finanzen: Finanzbericht 1987, a.a.O., S. $203 \mathrm{ff}$.

148) Vgl. Bundeshaushaltsplan für das Haushaltsjahr 1985, Einzelplan 31: Geschäftsbereich des Bundesministers für Bildung und Wissenschaft, S. 34 .

Diese 1,3 Mrd. DM stellen den 65-prozentigen Anteil des Bundes an der Förderung nach dem Bundesausbildungsförderungsgesetz dar. Bei den Ländern fallen zusätzlich noch etwa 700 Mill. DM für diesen Zweck an. Hinzukommen bei Bund und Ländern eine Vielzahl anderer Ausbildungsbeihilfen, die ebenfalls z.T. auf Darlehensbasis gewährt werden. 
Das Fazit der empirischen Analyse der finanzstatistischen Daten lautet resümierend:

1. Der Anteil der investiven Ausgaben an den Gesamtausgaben ist auf allen Ebenen der Gebietskörperschaften gesunken, wobei sich die wellenartige Abwärtsbewegung besonders stark bei den Gemeinden vollzog.

2. Die Anteile der Sachinvestition sind relativ stärker gefallen als die der Investitionsförderungsmaßnahmen, weshalb ihr Anteil an den Gesamtausgaben der öffentlichen Haushalte nurmehr noch $8,4 \mathrm{vH}$ beträgt. In diesem Sachverhalt, der vor allem von Seiten der Gemeinden auf den Öffentlichen Gesamthaushalt durchschlägt, spiegelt sich auch der relative Rückgang der Bautätigkeit wider.

3. Die Steigerung des Anteils der Investitionsförderungsmaßnahmen (an den gesamten Investitionsausgaben), welche zum überwiegenden Teil beim Bund und den Ländern anfallen, bewirkte, daß der Bund etwa seit Mitte der 70er Jahre, den größten Anteil an den gesamten investiven Nettoausgaben besitzt und damit den größten Teil der Investitionen finanziert. Die Gemeinden sind in dieser Hinsicht sogar von den Ländern überholt worden.

4. Die Ausweitung der Investitionsförderungsmaßnahmen, insbesondere beim Bund beruht auf der Zunahme gerade jener "Komponenten dieser Ausgabenkategorie ..., deren 'Investitionscharakter' stärker in Frage zu stellen ist"149), so daß neben der Niveauabsenkung der öffentlichen Investitionsquote auch eine Strukturverschiebung innerhalb der als investiv ausgewiesenen Förderungsmaßnahmen konstatiert werden kann.

\subsection{Empirischer Befund der Volkswirtschaftlichen Gesamtrechnungen}

\subsubsection{Konzeptionelle Unterschiede zur Finanzstatistik}

Die Ergebnisse der Volkswirtschaftlichen Gesamtrechnungen werden in mehrjährigen Abständen überarbeitet, um die Daten zu aktualisieren und gegebenen-

149) Deutsche Bundesbank: Sachinvestitionen, Darlehen und ..., a.a.O., S. 31. 
falls notwendige methodische Änderungen durchzuführen ${ }^{150)}$, gleichwohl sind diese Anpassungen für die Erstellung langer Reihen weniger problematisch, als die Änderungen bei der Finanzstatistik. ${ }^{151}$ ' Die zuletzt erfolgte Revision im Jahre 1985 beschränkte sich im wesentlichen auf die Einführung des neuen Preisbasisjahres 1980, hatte aber auch bei den Bauinvestitionen des Staates geringfügige Korrekturen zur Folge. ${ }^{152)}$

Die primär an institutionellen Sachverhalten ausgerichtete Aggregation der Wirtschaftseinheiten führt zur Unterscheidung der drei inländischen Hauptsektoren "Unternehmen", "Staat" und "Private Haushalte und private Organisationen ohne Erwerbscharakter". ${ }^{153)}$ Die Institutionen des Staatssektors werden im allgemeinen durch ihre spezielle Aufgabenstellung und ihre besondere Finanzierungsmöglichkeit charakterisiert. Sie erbringen Dienstleistungen eigener Art

150) Vgl. Lützel, H.: Ansätze zur Weiterentwicklung der Volkswirtschaftlichen Gesamtrechnungen, 5. Abschnitt des Artikels: Weiterentwicklung und Revision der Volkswirtschaftlichen Gesamtrechnungen, in: Wirtschaft und Statistik, Jg. 1985, S. 107-109, S. 107 f. Siehe auch Stobbe, A.: Volkswirtschaftliche Gesamtrechnung, a.a.O., S. 393 f.

151) Vgl. Abschnitt 3.2.

152) Vgl. Lützel, H.: Revision der Volkswirtschaftlichen Gesamtrechnungen 1960 bis 1984, in: Wirtschaft und Statistik, Jg. 1985, S. 603-617, S. 603 und S. 615.

153) Zur Erweiterung der vereinfachten Sektorengliederung vgl. Hamer, G.: Revidierte Konten der Volkswirtschaftlichen Gesamtrechungen, in: Wirtschaft und Statistik, Jg. 1970, S.281-288.

Zum Sektor "Unternehmen" rechnen die Wirtschaftseinheiten, die vorwiegend Waren und Dienstleistungen produzieren bzw. erbringen und diese gegen spezielles Entgelt verkaufen. Hierzu gehören auch die landwirtschaftlichen Betriebe und Praxen der Freien Berufe sowie Bundesbahn, Bundespost und andere staatliche Unternehmen unabhängig von ihrer Rechtsform. Im Unternehmenssektor werden ferner solche Organisationen ohne Erwerbszweck erfaßt, die ihre Leistungen vorwiegend für die Unternehmen ohne spezielles Entgelt erbringen und von diesen finanziert werden. Darüber hinaus wird auch die nicht gewerbliche Wohnungsvermietung privater Haushalte sowie der staatliche Wohnungsbau im Unternehmenssektor erfaßt. Im Sektor Unternehmen werden die Teilsektoren "Produktionsunternehmen", "Kreditinstitute" und "Versicherungsunternehmen" unterschieden.

Der Sektor "Private Haushalte und private Organisationen ohne Erwerbszweck" besteht aus den Teilsektoren "Private Haushalte" und "Private Organisationen ohne Erwerbszweck". Zum Sektor "Private Haushalte" rechnen alle Ein- und Mehrpersonenhaushalte (einschi. der Anstaltsbevölkerung). Er umfaßt somit die Institutionen, die auf dem Markt in erster Linie als Anbieter von Arbeitskraft, als letzter Käufer von Ver- und Gebrauchsgütern und als Anleger von Ersparnissen auftreten. Zu den "Privaten Organisationen ohne Erwerbszweck" zählen alle Organisationen, Verbände, Vereine, Institute usw., deren Leistungen vorwiegend privaten Haushalten dienen und die sich zu einem wesentlichen Teil aus freiwilligen Zahlungen von privaten Haushalten und Vermögensträgern finanzieren. Hierzu gehören u.a. Kirchen, politische Parteien, Gewerkschaften, Sportvereine und gesellige Vereine. Aus statistischen Gründen werden hier auch Organisationen ohne Erwerbszweck einbezogen, die überwiegend vom Staat finanziert werden. Vgl. hierzu auch Ring, U.: Öffentliche Planungsziele ..., a.a.O., S. $122 \mathrm{ff}$.

Zu den grundsätzlichen Problemen des "3-Sektoren-Modells" der VGR siehe Franz, A.: Grundfragen der Statistik des öffentlichen Sektors, in: Wirtschaftspolitische Blätter, hrsg. v. der Bundeskammer der gewerblichen Wirtschaft (Wien), 27. Jg. (1980), H. 2, S.91108 , S. $92 \mathrm{ff}$. 
für die Allgemeinheit und finanzieren sich hauptsächlich aus Zwangsabgaben. Innerhalb des Staatssektors bilden die Gebietsköperschaften und die Sozialversicherung getrennte Untersektoren. ${ }^{154)}$

Die Einteilung der Ausgabenarten in "Übertragungen", "Aufwendungen für den Staatsverbrauch", "Zinsen auf offentliche Schulden" und "Bruttoinvestitionen" nimmt eine zentrale Stellung in den Veröfentlichungen der Volkswirtschaftlichen Gesamtrechnungen über die Staatsausgaben ein. ${ }^{155)}$ Die Übertragungen werden dabei in die "Laufenden Übertragungen" und die "Vermögensübertragungen" unterteilt, wobei bei den vom Staat geleisteten Vermögensübertragungen nochmals "Investitionszuschüsse" und "Sonstige Vermögensübertragungen" unterschieden werden. ${ }^{156}$

Auf den ersten Blick stehen somit den Sachinvestitionen und Investitionsförderungsmaßnahmen der Finanzstatistik als korrespondierende Termini der Volkswirtschaftlichen Gesamtrechnungen die Bruttoinvestitionen bzw. die Investitionszuschüsse des Staates gegenüber. Was die Gegenüberstellung der Sach- und Bruttoinvestitionen angeht, besteht hierüber auch kein Dissens. In den meisten Veröffentlichungen, die sich mit den inhaltlichen Analogien der ausgewiesenen

154) Vgl. Statistisches Bundesamt: Konten und Standardtabellen 1984, a.a.O., S. 56. Zur detaillierten Abgrenzung siehe Abschnitt 2.3.3.

155) Vgl. auch Abschnitt 2.3.3.

156) Die vom Staat geleisteten sonstigen Vermögensübertragungen umfassen, dargestellt nach den empfangenden Sektoren:

- Unternehmen: Entschädigungen nach dem Allgemeinen Kriegsfolgengesetz und nach dem Altsparergesetz; Betriebsmittelzuweisungen an Einfuhr und Vorratsstellen, Prämien für die Schlachtung von Kühen und Nichtvermarktung von Milch, Prämien und Zuschüsse für die Stillegung von Kohlebergwerken, Abwrackprämien für Schiffe u.ä., sowie fiktive Vermögensübertragungen (nichtentnommene Gewinne der Bruttounternehmen und Mittel für den staatseigenen Wohnungsbau).

- Staat: einmalige größere Zahlungen zwischen den einzelnen Körperschaften des Staatssektors.

- private Haushalte: Spar- und Wohnungsbauprämien, Arbeitnehmersparzulage, Entschädigungen nach dem Allgemeinen Kriegsfolgengesetz und nach dem Altsparergesetz, Hauptentschädigungen ihm Rahmen des Lastenausgleichs, Wiedergutmachungsleistungen nach dem Bundesentschädigungsgesetz und dem Bundesrückerstattungsgesetz.

- an die übrige Welt: Hauptentschädigungen im Rahmen des Lastenausgleichs, Wiedergutmachungsleistungen nach dem Bundesentschädigungsgesetz und dem Bundesrückerstattungsgesetz, die Umwandlung von Schulden der ärmsten Entwicklungsländer in Zuschüsse sowie Zahlungen an den EG-Entwicklungsfonds.

Die privaten Haushalte empfangen per definitionem nur sonstige Vermögensübertragungen. Vgl. Statistisches Bundesamt: Konten und Standardtabellen 1984, a.a.O., S. 98 f. 
Investitionsausgaben der amtlichen Statistik beschäftigen, werden allerdings die "Vermögensübertragungen an Unternehmen" zum Vergleich mit den Investitionsförderungsmaßnahmen herangezogen. ${ }^{157)}$ Der Hauptgrund für diese Verfahrensweise liegt wohl darin, daß unter der Position "Sonstige Vermögensübertragungen an Unternehmen" fiktive Vermögensübertragungen eingestellt werden, die den staatseigenen Wohnungsbau und die Einlagen in Bruttounternehmen betreffen. ${ }^{158)}$ Die Bruttounternehmen und der Wohnungsbau des Staates werden in den Volkswirtschaftlichen Gesamtrechnungen nicht dem Sektor Staat zugeordnet, so daß die Einbeziehung dieser fiktiven Bestandteile einen Versuch darstellen, die direkten staatlichen Investitionen sachgerechter zu erfassen. Zu den Vermögensübertragungen an Unternehmen rechnen allerdings auch Zahlungen wie Schlacht- und Stillegungsprämien, deren Ähnlichkeit mit anderen investiven Ausgaben kaum gegeben ist. Zusätzlich bedeutet diese Gegenüberstellung, daß alle mittelbaren Investitionen, deren Adressat ein ausländisches Wirtschaftssubjekt ist, bei den Investitionen der Volkswirtschaftlichen Gesamtrechnungen im Gegensatz zur Finanzstatistik unberücksichtigt bleiben.

Die Bruttoinvestitionen setzen sich aus den Bruttoanlageinvestitionen und den Vorratsveränderungen zusammen, wobei die Anlageinvestitionen dauerhafte, reproduzierbare Produktionsmittel darstellen, deren Nutzungsdauer mehr als ein Jahr beträgt. Im einzelnen umfassen die Bruttoanlageinvestitionen ${ }^{159}$

- die Käufe neuer Anlagen,

- die von den Investoren selbst erstellten Anlagen sowie

- die Käufe von gebrauchten Anlagen und Land, abzüglich der Verkäufe von gebrauchten Anlagen und Land.

In den Tabellen zur Verwendungsrechnung des Sozialprodukts werden die Anlageinvestitionen hauptsächlich in Ausrüstungs- und Bauinvestitionen unterteilt, wobei sich die Ausrüstungsinvestitionen auf Maschinen und maschinelle Anlagen, Fahrzeuge-, Betriebs- und Geschäftsausstattungen sowie ähnliche Anlage-

157) Vgl. Wissenschaftlicher Beirat beim Bundesministerium der Finanzen: Gutachten zum Begriff ..., a.a.O., S. 5 ff.; Toillié, B.: Öffentliche Investitionen ..., a.a.O., S. 40 ff. sowie Littmann, K.: Öffentliche Investitionen, a.a.O., S. 817 f.

158) Vgl. Statistisches Bundesamt: Konten und Standardtabellen 1984, a.a.O., S. 99. Die fiktiven Vermögensübertragungen besitzen immerhin einen Anteil von etwa 10 bis $15 \mathrm{vH}$ an den gesamten Vermögensübertragungen, während die Investitionszuschüsse rund 70 Prozent ausmachen. Vgl. Statistisches Bundesamt: Der Staat ..., a.a.O., S. 90.

159) Vgl. Kupka, G.: Methoden der Berechnung der Anlageinvestitionen in den Volkswirtschaftlichen Gesamtrechnungen, in: Wirtschaft und Statistik, Jg. 1977, S. 757-763, S. 757. 
güter, die nicht fest mit Bauten verbunden sind, beziehen, während die Bauinvestitionen Gebäude und sonstige Bauten, wie Straßen, Brücken, Tunnels, Eisenbahnstrecken, Flugplätze, Kanäle, Staudämme, Stahl- und Holzkonstruktionen (Montagebauten), Versorgungs- und Rohrfernleitungen, Parks u.ä. betreffen. Zu den Bauinvestitionen rechnen auch die mit den Bauten fest verbundenen Einrichtungen wie Aufzüge, Heizungs-, Lüftungs- und Klimaanlagen, außerdem gärtnerische Anlagen, die Umzäunungen von Grundstücken u.ä. ${ }^{160)}$

Im allgemeinen werden geringwertige Wirtschaftsgüter nicht zu den Bruttoinvestitionen gerechnet, wobei deren Wertgrenze in den Volkswirtschaftlichen Gesamtrechnungen unterhalb der Grenze der steuerlichen Regelung in der Bundesrepublik Deutschland liegt, weshalb der größte Teil der im steuerlichen Sinne geringwertigen Wirtschaftsgüter in den Anlageinvestitionen erfaßt werden. ${ }^{161}$ ' Diese Zuordnung gilt sowohl für die privaten als auch staatlichen Investitionen, so daß die finanzstatistischen Haushaltszahlen, die ja auf erheblich größeren Wertgrenzen basieren, für die Veröffentlichungen der Volkswirtschaftlichen Gesamtrechnungen entsprechend ergänzt werden müssen. ${ }^{162}$ ) $\mathrm{Zu}$ den Anlageinvestitionen zählen desweiteren auch werterhöhende Reparaturen und Umbauten, allerdings nicht die Aufwendungen für die Instandhaltung und für die Beschaffung immaterieller Güter, wie Lizenzen und Patente. Ebenfalls nicht als Investitionen

160) Vgl. Statistisches Bundesamt: Konten und Standardtabellen 1984, a.a.O., S. 80 f. Als dritte Komponente der Anlageinvestitionen werden die Käufe abzüglich der Verkäufe von gebrauchten Anlagen und Land ausgewiesen, die allerdings zunehmend an Bedeutung verlieren. Vgl. Statistisches Bundesamt: Konten und Standardtabellen 1984, a.a.O., Tabelle $3.39, \mathrm{~S} .300$.

161) Vgl. Kupka, G.: Methoden der Berechnungen ..., a.a.O., S. 757.

Entsprechend den steuerrechtlichen Vorschriften müssen alle Anlagegüter deren Anschaffungs- oder Herstellungkosten 100,- DM überschreiten, in ein besonderes Verzeichnis aufgenommen werden (vgl. Nr. 40 Abs. 4 der EStR zu § 6 EStG), während sie erst ab der Grenze von 800,- DM zum Anlagevermögen zählen (vgl. § 6 Abs. 2 EStG) und mehrjährig abgeschrieben werden müssen. "Das EVSG sieht ... als Grenze für die Zuordnung von Gütern zu den Investitionen einen Betrag von 100 Rechnungseinheiten vor. ... In der Praxis stellt dieser Wert nur eine Richtgröße dar, da die statistischen Unterlagen eine exakte Einhaltung einer Wertgrenze nicht erlauben." Engelmann, M. und Mohr, D.: Anlageinvestitionen nach Wirtschaftsbereichen, in: Wirtschaft und Statistik, Jg. 1978, S. 755771, S. 758.

162) Vgl. Engelmann, M. und Mohr, D.: Anlageinvestitionen ..., a.a.O., S. 759.

Die Aussage von Toillié, daß die VGR zum Nachweis der Käufe von dauerhaften Gütern die Angaben der Finanzstatistik und damit deren höhere Wertgrenzen übernähme (vgl. Toillié, B.: Öffentliche Investitionen ..., a.a.O., S. 42) findet keine Bestätigung in der Literatur und ist auch von Herrn Mohr (Mitarbeiter des Statistischen Bundesamtes) als unzutreffend charakterisiert worden. 
gelten die Käufe dauerhafter Ausrüstungsgüter und Bauten für Verteidigungszwecke, die gemäß internationaler Regelungen, dem Staatsverbrauch zugeordnet werden. ${ }^{163)}$ "Die Bewertung der Anlageinvestitionen geht von den Kosten aus, die der Investor insgesamt aufzubringen hat." Sie "werden, soweit es sich um Käufe handelt, grundsätzlich zum Zeitpunkt des Entstehens von Forderungen und Verbindlichkeiten nachgewiesen." ${ }^{64)}$ Angefangene Bauten werden unabhängig hiervon bereits zum Zeitpunkt der Produktion zu den Anlageinvestitionen gerechnet. Halbfertige Ausrüstungen zählen dagegen stets zu den Vorratsveränderungen. Dies erfordert, sofern Haushaltszahlen verwendet werden, entsprechende Umrechnungen, da sich die Angaben der Haushaltsstatistik auf den Zahlungszeitpunkt beziehen. ${ }^{165 \text { ) }}$

Abschreibungen sind sowohl im einzel- wie im gesamtwirtschaftlichen Rechnungswesen von großer Bedeutung. Sie markieren den Übergang von den Bruttozu den Nettoinvestitionen und sollen damit die Wertminderung des Anlagevermögens messen. Ihr wertmäßiger Ansatz ist abhängig von der Bewertungsmethode, der unterstellten Nutzungsdauer, dem Abschreibungsverfahren und bei der Analyse von Gütergesamtheiten vom Kreis der abschreibbaren Tatbestände. Im allgemeinen beziehen sich die Abschreibungen der Volkswirtschaftlichen Gesamtrechnungen auf das reproduzierbare Anlagevermögen. Die Tiefbauten des Staates sind, internationalem Brauch folgend, hiervon allerdings ausgenommen $^{166)}$, weil bei Straßen, Brücken, Wasserwegen und ähnlichen Gütern des Staates davon auszugehen sei, "daß ihr Nutzwert durch entsprechende Reparaturen erhalten bleibt." ${ }^{167)}$ Nach Littmann stößt die Ermittlung der Abschreibungen im Staatssektor auf derart große Schwierigkeiten, "daß die Unterscheidung zwischen offentlichen Brutto- und Nettoinvestitionen in ihren quantitativen Dimensionen fragwürdig wird." ${ }^{\text {68) }}$

163) Vgl. Kupka, G.: Methoden der Berechnung ..., a.a.O., S. 757.

164) Ebenda, S. 758.

165) Vgl. Kopsch, G.: Der Staat ..., a.a.O., S. 752.

166) Vgl. auch Schäfer, D. und Schmidt, L.: Abschreibungen nach verschiedenen Bewertungsund Berechnungsmethoden, in: Wirtschaft und Statistik, Jg. 1983, S. 919-931, S. 920.

167) Statistisches Bundesamt: Konten und Standardtabellen 1984, a.a.O., S. 84.

168) Littmann, K.: Öffentliche Investitionen ..., a.a.O., S. 820. Vgl. auch Littmann, K.: Definition und Entwicklung ..., a.a.O., S. $91 \mathrm{ff}$. 
Die Abweichungen im Ausweis der Bruttoinvestitionen und der Sachinvestitionen resultieren hauptsächlich aus der unterschiedlichen Behandlung folgender Sachverhalte ${ }^{169)}$ :

1. Die Ausgaben der Bruttounternehmen und die für den staatlichen Wohnungsbau, die in der Finanzstatistik Berücksichtigung finden, werden in den Volkswirtschaftlichen Gesamtrechnungen nicht beim Staat, sondern im Unternehmenssektor erfaßt.

2. Die Kosten für den Um- und Ausbau bestehender Verkehrswege werden in den Volkswirtschaftlichen Gesamtrechnungen dem Staatsverbrauch zugerechnet, während sie bei Überschreiten der vorgegebenen Wertgrenze in der Finanzstatistik als Teil der Sachinvestitionen behandelt werden.

3. In der Finanzstatistik werden die Ausgaben für Bauten und Ausrüstungen der ausländischen Streitkräfte als Investitionen verbucht, in den Volkswirtschaftlichen Gesamtrechnungen werden sie dagegen wie die Ausgaben für inländische Streitkräfte behandelt.

4. Die Investitionsausgaben der Volkswirtschaftlichen Gesamtrechnungen sind um die Verkäufe von gebrauchten Anlagen und Land gekürzt, während dies in der Finanzstatistik nicht der Fall ist.

$\mathrm{Zu}$ diesen Sachverhalten kommt noch der Unterschied im Buchungszeitpunkt hinzu. Die Finanzstatistik, die vom Kassenprinzip ausgeht, weist den entsprechenden Tatbestand nach erfolgter Zahlung aus. Die Volkswirtschaftlichen Gesamtrechnungen basieren auf dem Produktionsprinzip, weshalb z.B. die angefangenen Bauten bereits im Verlauf ihrer Erstellung anteilsmäßig den Investitionen zugerechnet werden.

Die Vorratsveränderungen, die neben den Bruttoanlageinvestitionen die zweite Katẹrie der Bruttoinvestitionen bilden, betreffen beim Staat ausgewählte Rohstoffe wie Mineralöl und Kernbrennstoffe. In der Finanzstatistik werden sie als Erwerb beweglicher Sachen erfaßt und somit in analoger Weise als Sachinvestitionen registriert. ${ }^{170)}$

169) Vgl. auch Wissenschaftlicher Beirat beim Bundesministerium der Finanzen: Gutachten zum Begriff ..., a.a.O., S. $8 \mathrm{ff}$.

170) Vgl. ebenda, S. 10. 
Wenn man die mittelbaren Investitionen in die Analyse staatlicher Investitionstätigkeit einbeziehen will ${ }^{171)}$, entsteht, wie auch schon oben angedeutet, die Frage, welche Ausgabenkategorien sie im Ausweis der Volkswirtschaftlichen Gesamtrechnungen umfassen sollen. Eine Möglichkeit, die unmittelbar ins Auge fällt, wäre alle vom Staat geleisteten Investitionszuschüssse hierzu heranzuziehen. Diese bilden einen Teil der vom Staat geleisteten Vermögensübertragungen. Sie umfassen staatliche Investitionszuschüsse an Unternehmen, an die übrige Welt und, sofern intrastaatliche Verflechtungen betrachtet werden, auch Investitionszuschüsse an andere staatliche Körperschaften. Zu den Investitionszuschüssen an die Unternehmen zählen Zuschüsse für Bauvorhaben und andere Investitionen sowie die Umwandlung von Darlehen in Zuschüsse an die Deutsche Bundesbahn und die Deutsche Bundespost. Die Investitionszuschüsse in Form von Zuweisungen für Infrastrukturmaßnahmen, für Maßnahmen des Küstenschutzes sowie für den Bau von Schulen, Krankenhäusern u.ä. Den privaten Haushalten kommen ex definitione nur sonstige Vermögensübertragungen $\mathrm{zu}^{172)}$

Die Einengung auf die Investitionszuschüsse hätte zur Folge, daß einerseits die oben erwähnten fiktiven Vermögensübertragungen, die zumindest partiell ein Äquivalent zu Teilen der finanzstatistischen Sachinvestitionen darstellen ${ }^{173)}$, keine Berücksichtigung fänden, andererseits würden die Investitionszusschüsse an das Ausland einbezogen, die ja primär aus Leistungen im Rahmen der Entwicklungshilfe bestehen. Eine zweite Möglichkeit besteht darin, die Verfahrensweise des Wissenschaftlichen Beirats beim Bundesministerium der Finanzen zu übernehmen, der die gesamten "Vermögensübertragungen an Unternehmen" als Pendant zu den Investitionsförderungsmaßnahmen der Finanzstatistik betrachtet. Für diese Vorgehensweise, die allerdings bei intrastaatlichen Betrachtungen

171) Bartholmai lehnt die Einbeziehung der mittelbaren Investitionen ab, da u.a. "vom ökonomischen Inhalt her die Abgrenzung zum Subventionsbereich willkürlich" bleibe. Bartholmai, B.: Entwicklung und Struktur der Staatsinvestitionen seit 1960 und der Stand der längerfristigen Investitionsplanung, Sonderheft 95, hrsg. v. Deutschen Institut für Wirtschaftsforschung, Berlin 1973, S. 7.

172) Vgl. Statistisches Bundesamt: Konten und Standardtabellen 1984, a.a.O., S. 98 f.

173) Vgl. Wissenschaftlicher Beirat beim Bundesministerium der Finanzen: Gutachten zum Begriff ..., a.a.O., S. $11 \mathrm{f}$. 
unzweckmäßig ist ${ }^{174)}$, spricht neben der vergleichsweise leichten Aussonderung des statistischen Materials auch die Tatsache, daß sie fast ausschließlich aus den Investitionszuschüssen und fiktiven Vermögensübertragungen bestehen. Die restlichen Teile der sonstigen Vermögensübertragungen an Unternehmen spielen eine nur sehr unbedeutende Rolle (vgl. Tabelle 6). ${ }^{175)}$

\begin{abstract}
Abgesehen von dieser Abgrenzungsproblematik fassen die Volkswirtschaftlichen Gesamtrechnungen die mittelbaren öffentlichen Investitionen in einem von der Größenordnung her, sehr viel bedeutenderen Punkt enger als die Finanzstatistik. Die Vergabe staatlicher Darlehen, die, unabhängig von ihrer Verwendung und ihren Adressaten, ebenso wie der Erwerb von Beteiligungen zu den Investitionsförderungsmaßnahmen rechnen, werden in den Volkswirtschaftlichen Gesamtrechnungen als Finanzierungsvorgänge betrachtet und lediglich "im Finanzierungskonto, d.h. als Erhöhung der Forderungen, berücksichtigt."176) Die hieraus resultierende Differenz im Ausweis der Investitionen ist sehr beträchtlich, belief sich doch der Umfang dieser Position in der Finanzstatistik 1984 für den Öffentlichen Gesamthaushalt auf immerhin 20,97 Mrd. DM. ${ }^{177}$ )
\end{abstract}

Die Entscheidung für die "Vermögensübertragungen an Unternehmen" als Gegenstück zu den Investitionsförderungsmaßnahmen hat noch einige andere gravierende Abweichungen gegenüber dem finanzstatistischen Ausweis zur Folge: ${ }^{178)}$

174) In diesem Falle sollten wohl auch die Investitionszuschüsse an andere staatliche Körperschaften berücksichtigt werden.

175) Vgl. auch Tabelle $6^{*} \mathrm{a}$ und $6^{*} \mathrm{~b}$ im Anhang. Sie zeigen darüber hinaus, daß der weitaus größte Teil der mittelbaren Investitionen unabhängig von ihrer konkreten Abgrenzung im Bereich der Gebietskörperschaften anfällt.

Die Ursache für den außergewöhnlich hohen Ausweis der "sonstigen Vermögensübertragungen" im Jahre 1962 konnte nicht geklärt werden.

176) Wissenschaftlicher Beirat beim Bundesministerium der Finanzen: Gutachten zum Begriff ,.., a.a.O., S. 13.

177) Vgl. Tabelle 5*a im Anhang.

178) Vgl. auch Wissenschaftlicher Beirat beim Bundesministerium der Finanzen: Gutachten zum Begriff ..., a.a.O., S. $11 \mathrm{ff}$. 
Tabelle 6: Die mittelbaren Investitionen des Staates in der VGR ${ }^{11}$

\begin{tabular}{|c|c|c|c|c|c|c|c|}
\hline \multicolumn{7}{|c|}{} & \multicolumn{3}{|c|}{ INVESTITIONSZUSCHÜSSE } & \multicolumn{3}{c|}{ VERMÖGENSÜBERTRAGUNGEN (Vü) } \\
Jahr UNTERNEHMEN \\
\cline { 2 - 8 } & an Unter- & an übrige & & Sonstige & fiktive & Investi- & \\
& nehmen & Welt & insgesamt & Vü & Vü & tionszusch. & insgesamt \\
\cline { 2 - 8 } & Mrd.DM & Mrd.DM & Mrd.DM & Mrd.DM & Mrd.DM & Mrd.DM & Mrd.DM \\
\hline 1962 & 1,71 & 0,03 & 1,74 & 2,64 & 1,32 & 1,71 & 5,67 \\
1963 & 1,88 & 0,07 & 1,95 & 0,55 & 1,42 & 1,88 & 3,85 \\
1964 & 2,16 & 0,09 & 2,25 & 0,30 & 1,67 & 2,16 & 4,13 \\
1965 & 2,37 & 0,08 & 2,45 & 0,21 & 1,83 & 2,37 & 4,41 \\
1966 & 2,19 & 0,14 & 2,33 & 0,64 & 1,47 & 2,19 & 4,30 \\
1967 & 2,44 & 0,15 & 2,59 & 0,55 & 1,32 & 2,44 & 4,31 \\
1968 & 2,68 & 0,16 & 2,84 & 0,19 & 1,37 & 2,68 & 4,24 \\
1969 & 3,82 & 0,18 & 4,00 & 1,28 & 1,53 & 3,82 & 6,63 \\
1970 & 4,95 & 0,20 & 5,15 & 0,95 & 2,16 & 4,95 & 8,06 \\
1971 & 6,67 & 0,17 & 6,84 & 0,23 & 1,93 & 6,67 & 8,83 \\
1972 & 7,92 & 0,17 & 8,09 & 0,11 & 1,78 & 7,92 & 9,81 \\
1973 & 8,75 & 0,17 & 8,92 & 0,23 & 2,25 & 8,75 & 11,23 \\
1974 & 10,44 & 0,26 & 10,70 & 0,46 & 2,36 & 10,44 & 13,26 \\
1975 & 10,98 & 0,32 & 11,30 & 0,45 & 1,98 & 10,98 & 13,41 \\
1976 & 15,90 & 0,36 & 16,26 & 0,65 & 1,36 & 15,90 & 17,91 \\
1977 & 16,15 & 0,39 & 16,54 & 0,67 & 1,91 & 16,15 & 18,73 \\
1978 & 15,71 & 0,42 & 16,13 & 1,04 & 2,09 & 15,71 & 18,84 \\
1979 & 18,32 & 1,15 & 19,47 & 1,03 & 2,46 & 18,32 & 21,81 \\
1980 & 18,58 & 1,41 & 19,99 & 1,19 & 3,01 & 18,58 & 22,78 \\
1981 & 18,91 & 1,82 & 20,73 & 0,54 & 2,62 & 18,91 & 22,07 \\
1982 & 20,58 & 1,83 & 22,41 & 0,47 & 1,98 & 20,58 & 23,03 \\
1983 & 21,38 & 1,72 & 23,10 & 0,89 & 0,93 & 21,38 & 23,20 \\
1984 & 24,74 & 1,66 & 26,40 & 0,49 & 1,88 & 24,74 & 27,11 \\
1985 & 23,51 & 1,74 & 25,25 & 0,95 & 2,48 & 23,51 & 26,94 \\
\hline
\end{tabular}

1) Ergebnisse in der Abgrenzung der Volkswirtschaftlichen Gesamtrechnungen in jeweiligen Preisen; ab 1984 vorläufige Ergebnisse.

Quelle: Zusammengestellt und errechnet aus: Statistisches Bundesamt: Revidierte Ergebnisse 1960 bis 1984, Reihe S.8 der Fachserie 18: Volkswirtschaftliche Gesamtrechnungen, Stuttgart, Mainz 1985, Tabelle 3.34 S. 185 ff. und Statistisches Bundesamt: Konten und Standardtabellen 1985, Reihe 1 der Fachserie 18: Volkswirtschaftliche Gesamtrechnungen, Stuttgart, Mainz 1986, Tabelle 3.34 S. 294. 
1. Die Vermögensübertragungen an Unternehmen enthalten fiktive Bestandteile $\mathrm{e}^{179)}$, die als Äquivalente zu den Einlagen in Bruttounternehmen und für den staatlichen Wohnungsbau anzusehen sind. In der Finanzstatistik werden die investiven Ausgaben der Bruttounternehmen und die Ausgaben für den staatlichen Wohnungsbau unmittelbar den Sachinvestitionen zugeordnet.

2. Die Wohnungsbauprämien an private Haushalte, die finanzstatistisch als Investitionszuschüsse behandelt werden, zählen in den Volkswirtschaftlichen Gesamtrechnungen als Vermögensübertragungen an private Haushalte.

3. Die mittelbaren Investitionen der Volkswirtschaftlichen Gesamtrechnungen enthalten in dieser Abgrenzung keine Investitionszuschüsse ans Ausland.

\section{Übersicht 3.2: Der Investitionsbegriff der Volkswirtschaftlichen Gesamt- rechnungen}

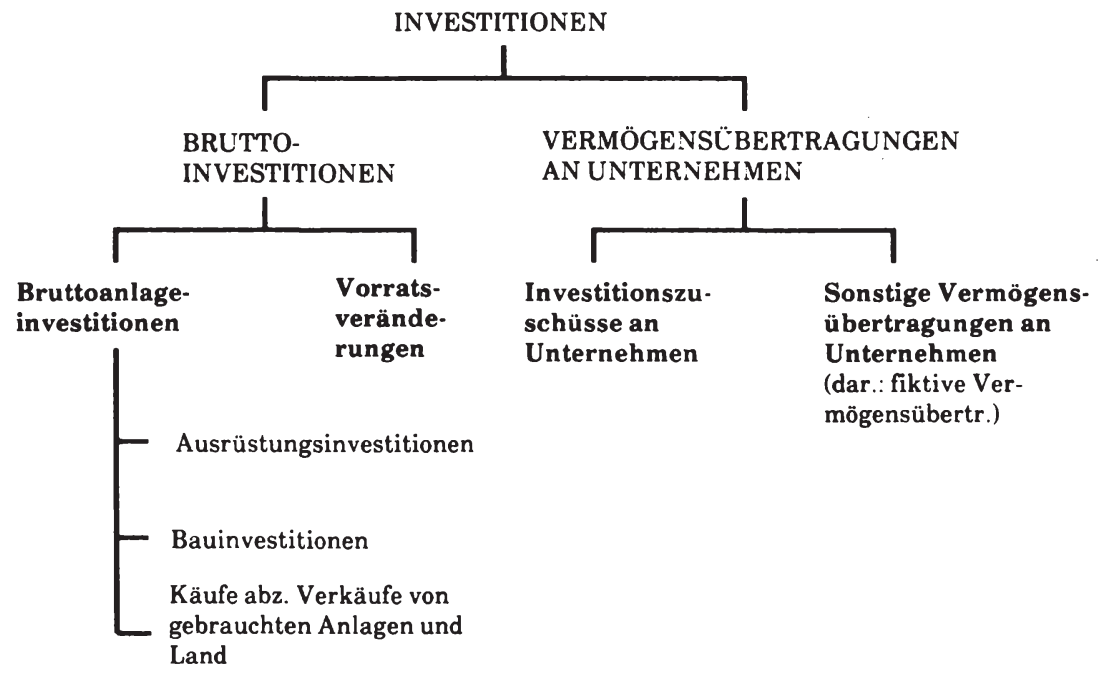

179) Vgl. hierzu die Ausführungen in Statistisches Bundesamt: Konten und Standardtabellen 1984, a.a.O., S. $98 \mathrm{ff}$. 


\subsubsection{Vergleich verschiedener Investitionsquoten}

Die Investitionen des Staates, wie sie in den Volkswirtschaftlichen Gesamtrechnungen ausgewiesen werden, liegen in absoluten Zahlen immer unterhalb der Werte der Finanzstatistik. Dies gilt unabhängig davon, ob der gesamte Staatssektor betrachtet wird und welche finanzstatistischen Daten zum Vergleich herangezogen werden. ${ }^{180)}$ Der Tatbestand gilt ebenfalls für die vergleichende Betrachtung der Brutto- und Sachinvestitionen. ${ }^{181}$ ' Die investiven öffentlichen Ausgaben sind also, besonders deutlich bei Einbeziehung der mittelbaren Investitionen, in den Volkswirtschaftlichen Gesamtrechnungen per Saldo inhaltlich enger gefaßt als in der Finanzstatistik.

Die Investitionsquoten der Volkswirtschaftlichen Gesamtrechnungen liegen ebenfalls z.T. deutlich unterhalb der Werte der Finanzstatistik, wobei, wie auch schon die Analyse der finanzstatistischen Daten zeigte, die staatlichen Investitionen zum weitaus überwiegenden Teil bei den Gebietskörperschaften anfallen. ${ }^{182)}$ Dieser Sachverhalt läßt die Beschränkung des Vergleichs der Quoten auf den Untersektor Gebietskörperschaften bzw. die Angaben des Bundesministeriums der Finanzen zulässig erscheinen. Dies um so mehr, als die finanzstatistischen Zahlenreihen des Statistischen Bundesamtes, wegen der Anpassung an Abgrenzungen der Volkswirtschaftlichen Gesamtrechnungen, 1974 einen Bruch aufweisen, und somit einen sinnvollen Vergleich dieser Zahlen lediglich bis zu diesem Jahr zurück zulassen. Der Anteil der gesamten Investitionen an den Gesamtausgaben liegt für den Bereich der Gebietskörperschaften stellenweise bis zu acht Prozentpunkten unter den finanzstatistischen Angaben des Bundesfinanzministeriums, gleichwohl verläuft die Entwicklung der Quoten, zumindest seit Beginn der 70er Jahre nahezu parallel. Die Abfolge der Investitionsquoten, bezogen auf

180) Vgl. Tabelle 1 und Tabelle $7^{*}$ a im Anhang.

Die vergleichende Betrachtung der Investitionsquote des gesamten Staatssektors mit der finanzstatistischen Quote des Statistischen Bundesamtes kann sinnvollerweise erst mit dem Jahr 1974 beginnen, weil in diesem Jahr der Berichtskreis der Finanzstatistik angepaßt wurde.

Vgl. auch Tabelle 2 und Tabelle 7.

181) Vgl. ebenda.

182) Vgl. Abschnitt 3.2.2. und Tabellen 7 sowie 7*a im Anhang 
Schaubild 3.6: Die Entwicklung der verschiedenen Investitionsquoten für die Gebietskörperschaften

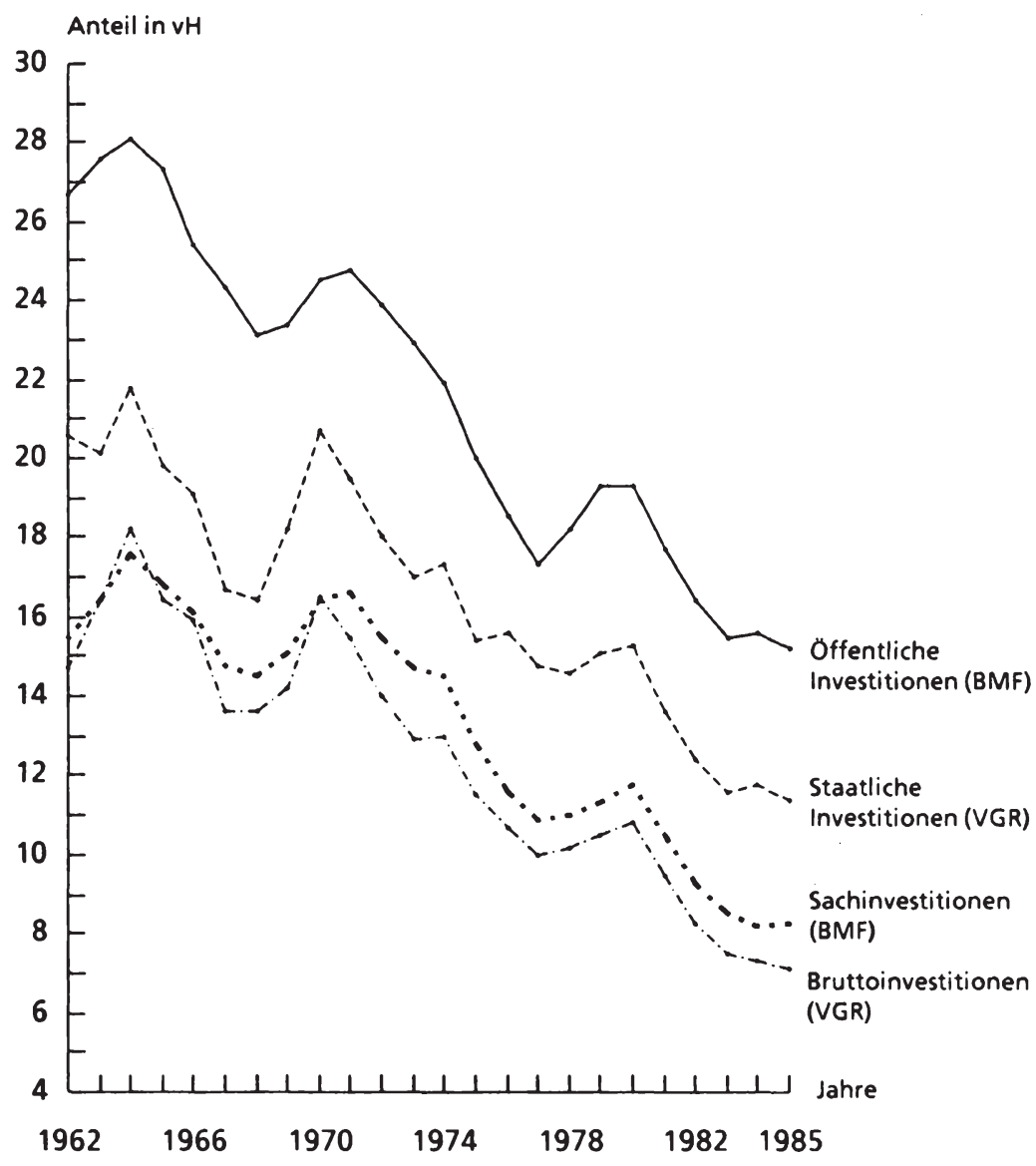

1) Vgl. Tabellen 2 und 7.

die Sach- bzw. Bruttoinvestitionen, vollzieht sich in einem sehr viel engeren Differenzbereich ${ }^{183)}$ (vgl. Schaubild 3.6). Das auch hier zu beobachtende fast parallele Nebeneinander der Quoten, seit 1970, deutet auf eine methodische und inhaltliche Angleichung beider statistischer Systeme hin.

183) Vgl. Tabellen 2 und 7. 
Tabelle 7: Die Gesamtausgaben und Investitionen der Gebietskörperschaften (VGR)"

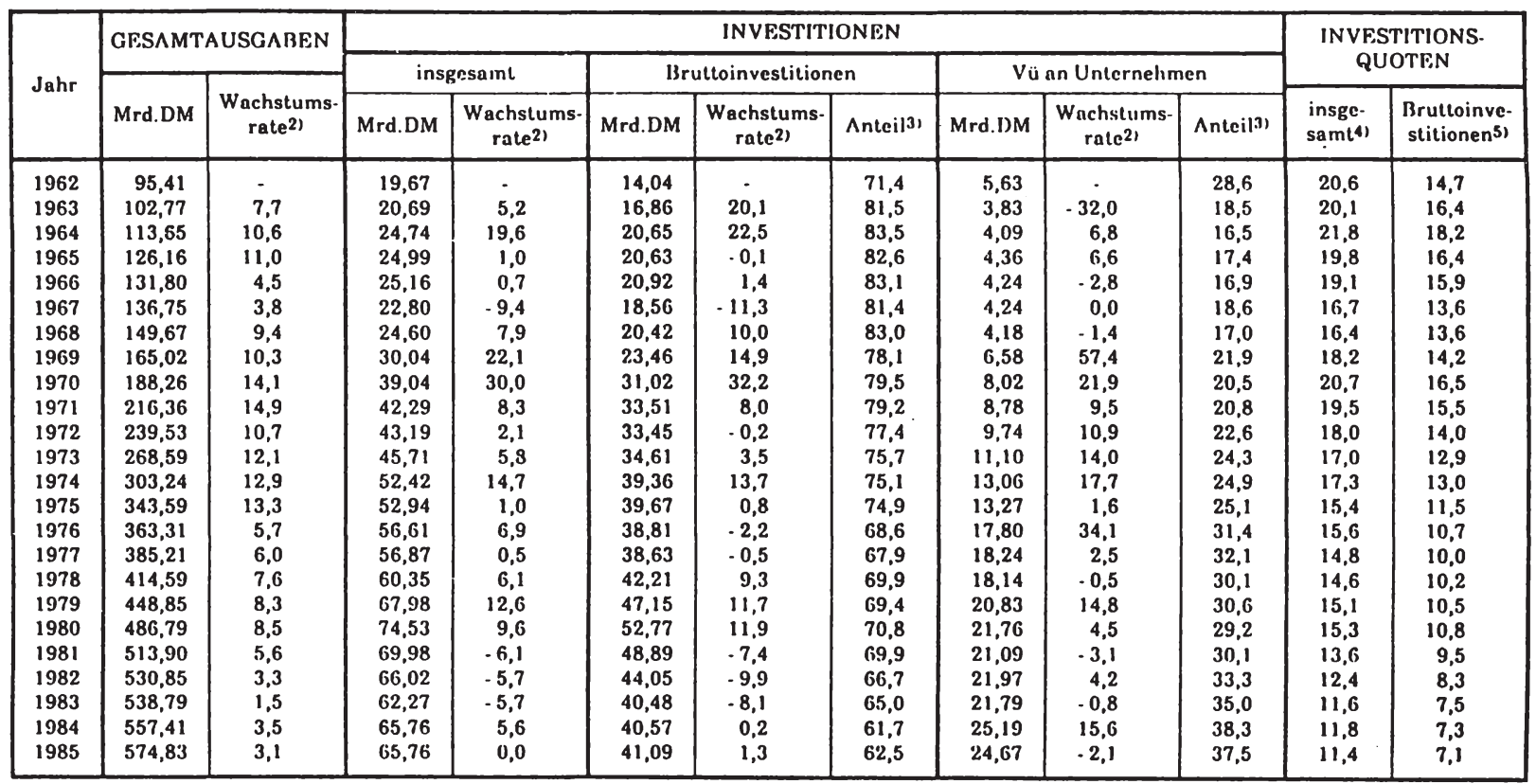

1) Ergebnisse in der Abgrenzung der Volkswirtschaftlichen Gesumtrechnungen in jeweiligen Preisen; ab 1984 vorläufige Ergebnisse.

2) Veränderung gegenüber dem Vorjahır in vll.

3) Jeweilige Ausgaben in vll der gesumten Investitionen.

4) Gesumte Investitionen in vll der Gesamlausgaben.

5) Brultoinvestitionen in vll der Gesamtausgaben.

Quelle: \%usammengestellt und errechnet aus: Slatistisches Bundesamt: Revidierte Lirgebnisse 1960 bis 1984, Reihe S. 8 der Ruchseric 18: Volkswirtschan. liche Gesumtrechnungen, Stultgart, Mainz. 1985, 'Tabelle 3.34, S. 188 rr. und Statistisches Bundesumt: Konten und Stundardtabellen 1985, Reihe I der Piuchserie 18: Volkswirtschaftliche Gesamtrechnungen, Stutlgart, Mainz 1986, Tubelle 3.34. S. 295. 
Die engere Abgrenzung der mittelbaren Investitionen bedingt eine ungleich dominierendere Stellung der Bruttoinvestitionen innerhalb der gesamten staatlichen Investitionen der Volkswirtschaftlichen Gesamtrechnungen, als sie die Sachinvestitionen beim finanzstatistischen Ausweis innehaben (vgl.Tab. 7). ${ }^{184 \text { ) }}$ Die relative Bedeutung der "Vermögensübertragungen an Unternehmen" nahm allerdings, insbesondere seit Beginn der 70er Jahre, deutlich zu. Besonders bemerkenswert ist hierbei der Zuwachs von 1975 auf 1976, der in erster Linie aufgrund außerordentlicher Steigerungen der Investitionszuschüsse der einzelnen Gebietskörperschaften erfolgte. ${ }^{185)}$ Dieser Trend, hin zur indirekten Investitionsfinanzierung, setzte sich auch im Laufe der 80er Jahre fort, so daß mittlerweile die "Vermögensübertragungen an Unternehmen" einen Anteil von über $35 \mathrm{vH}$ an den gesamten Investitionen der Gebietskörperschaften besitzen (vgl. Tab. 7). ${ }^{186}$

\subsubsection{Die Struktur der Bruttoinvestitionen}

Die Bruttoinvestitionen selbst bestehen fast ausnahmslos aus den Bruttoanlageinvestitionen. Die Vorratsveränderungen als zweiter Bestandteil bilden von ihrem Umfang her eine vernachlässigbare Größe und fallen überdies lediglich beim Bund an (vgl. Tabelle 8). ${ }^{187)}$ Von den Anlageinvestitionen wiederum nehmen die Bauinvestitionen mit über $80 \mathrm{vH}$ den weitaus größten Teil ein, während die Ausrüstungsinvestitionen einen Anteil von etwas über $10 \mathrm{vH}$ und die saldierte Größe der Käufe abzüglich Verkäufe von gebrauchten Anlagen und Land einen Anteil von etwa $5 \mathrm{vH}$ besitzen. Der Anteil der Bauinvestitionen an den gesamten Bruttoanlageinvestitionen des Staates hat allerdings seit Beginn der 70er Jahre merklich abgenommen (vgl. Tabelle 8). ${ }^{188)}$

184) Vgl. auch Tabelle 2.

185) Die Investitionszuschüsse an Unternehmen erhöhten sich beim Bund von 4,51 auf 6,72 Mrd.DM ( = 49,0 vH), bei den Ländern von 5,28 auf 7,72 Mrd.DM ( = 46,2 vH) und bei den Gemeinden von 1,05 auf $1,35 \mathrm{Mrd} . \mathrm{DM}(=28,6 \mathrm{vH})$. Vgl. Statistisches Bundesamt: Revidierte Ergebnisse 1960 bis 1984, a.a.O., Tabelle 3.34, S. 189.

186) Die relative Verschiebung erfolgte für den Gesamtsektor "Staat" noch deutlicher (vgl. Tabelle 7*a im Anhang), weil sich hierin auch die extremen Veränderungen der Anteile im Bereich der Sozialversicherung niederschlagen (vgl. Tabelle 7*b im Anhang).

187) Siehe hierzu auch Statistisches Bundesamt: Revidierte Ergebnisse 1960 bis 1984, a.a.O., Tabelle 3.39, S. $227 \mathrm{ff}$.

188) Vgl. auch die gleiche Entwicklung bei den Gebietskörperschaften. Siehe hierzu Tabelle $8^{*}$ im Anhang. 
Tabelle 8: Die Bruttoinvestitionen des Staates (VGR)"

\begin{tabular}{|c|c|c|c|c|c|c|c|c|c|c|c|c|}
\hline \multirow{3}{*}{ Jahr } & \multicolumn{2}{|c|}{ INSGESAMT } & \multicolumn{8}{|c|}{ BRU'ITOANLAGEIN VESIIITIONLN } & \multirow{2}{*}{\multicolumn{2}{|c|}{$\begin{array}{c}\text { VORRATS- } \\
\text { VERÄNIDERUNGEN }\end{array}$}} \\
\hline & \multirow{2}{*}{ Mrd.DM } & \multirow{2}{*}{$\begin{array}{c}\text { Wachstums- } \\
\text { rate?) }\end{array}$} & \multicolumn{2}{|c|}{ insgesamt } & \multicolumn{2}{|c|}{ Bauinvestitionen } & \multicolumn{2}{|c|}{$\begin{array}{l}\text { Ausrüstungs- } \\
\text { investitionen }\end{array}$} & \multicolumn{2}{|c|}{$\begin{array}{l}\text { sonstige Anlage- } \\
\text { investitionen2l }\end{array}$} & & \\
\hline & & & Mrd.DM & Antcil(4) & Mrd.DM & Anteil5) & Mrd.DM & Antcil51 & Mrd.DM & Antcil51 & Mrd.DM & Anteil4) \\
\hline 1962 & 14,28 & - & 14,28 & 100 & 12,37 & 86,6 & 1,23 & 8,6 & 0,68 & 4,8 & - & 0,0 \\
\hline 1963 & 17,11 & 19,8 & 17,11 & 100 & 14,96 & 87,4 & 1,41 & 8,2 & 0,74 & 4,3 & - & 0,0 \\
\hline 1964 & 20,88 & 22,0 & 20,88 & 100 & 18,53 & 89,8 & 1,50 & 7,2 & 0,85 & 4,1 & - & 0,0 \\
\hline 1965 & 20,86 & $-0,1$ & 20,86 & 100 & 18,20 & 87,3 & 1,67 & 8,0 & 0,99 & 4,8 & - & 0,0 \\
\hline 1966 & 21,20 & 1,6 & 21,20 & 100 & 18,70 & 88,2 & 1,65 & 7,8 & 0,85 & 4,0 & - & 0,0 \\
\hline 1967 & 18,87 & $-11,0$ & 18,87 & 100 & 16,17 & 85,7 & 1,60 & 8,5 & 1,10 & 5,8 & - & 0,0 \\
\hline 1968 & 20,68 & 9,6 & 20,68 & 100 & 18,08 & 87,4 & 1,54 & 7,5 & 1,06 & 5,1 & . & 0,0 \\
\hline 1969 & 23,73 & 14,7 & 23,73 & 100 & 20,78 & 87,6 & 1,76 & 7,4 & 1,19 & 5,0 & - & 0,0 \\
\hline 1970 & 31,29 & 31,9 & 31,09 & 99,4 & 27,52 & 88,5 & 2,26 & 7,3 & 1,31 & 4,2 & 0,20 & 0,6 \\
\hline 1971 & 33,87 & 8,2 & 33,67 & 99,4 & 29,36 & 87,2 & 2,75 & 8,2 & 1,56 & 4,6 & 0,20 & 0,6 \\
\hline 1972 & 33,85 & $-0,1$ & 33,85 & 100 & 29,24 & 86,4 & 2,97 & 8,8 & 1,64 & 4,8 & - & 0,0 \\
\hline 1973 & 35,13 & 3,8 & 35,13 & 100 & 29,91 & 85,1 & 3,36 & 9,6 & 1,86 & 5,3 & - & 0,0 \\
\hline 1974 & 40,13 & 14,2 & 40,03 & 99,7 & 33,85 & 84,6 & 3,81 & 9,5 & 2,37 & 5,9 & 0,10 & 0,3 \\
\hline 1975 & 40,33 & 0,5 & 39,73 & 98,5 & 33,70 & 84,8 & 3,77 & 9,5 & 2,26 & 5,7 & 0,60 & 1,5 \\
\hline 1976 & 39,49 & $-2,1$ & 39,29 & 99,5 & 33,42 & 85,1 & 3,64 & 9,3 & 2,23 & 5,7 & 0,20 & 0,5 \\
\hline 1977 & 39,34 & $-0,4$ & 39,04 & 99,2 & 32,95 & 84,4 & 4,06 & 10,4 & 2,03 & 5,2 & 0,30 & 0,8 \\
\hline 1978 & 42,78 & 8,7 & 42,58 & 99,5 & 35,85 & 84,2 & 4,52 & 10,6 & 2,21 & 5,2 & 0,20 & 0,5 \\
\hline 1979 & 47,81 & 11,8 & 47,81 & 100 & 40,17 & 84,0 & 5,08 & 10,6 & 2,56 & 5,4 & - & 0,0 \\
\hline 1980 & 53,59 & 12,1 & 53,09 & 99,1 & 44,87 & 84,5 & 5,58 & 10,5 & 2,64 & 5,0 & 0,50 & 0,9 \\
\hline 1981 & 50,02 & $-6,7$ & 49,82 & 99,6 & 42,37 & 85,1 & 5,22 & 10,5 & 2,23 & 4,5 & 0,20 & 0,4 \\
\hline 1982 & 45,26 & $-9,5$ & 45,26 & 100 & 38,55 & 85,2 & 4,80 & 10,6 & 1,91 & 4,2 & - & 0,0 \\
\hline 1983 & 41,77 & $-7,7$ & 41,77 & 100 & 35,37 & 84,7 & 4,82 & 11,5 & 1,58 & 3,8 & - & 0,0 \\
\hline 1984 & 41,74 & $-0,1$ & 41,74 & 100 & 35,02 & 83,9 & 5,27 & 12,6 & 1,45 & 3,5 & - & 0,0 \\
\hline 1985 & 42,13 & 0,9 & 42,13 & 100 & 34,53 & 82,0 & 5,88 & 14,0 & 1,72 & 4,1 & - & 0,0 \\
\hline
\end{tabular}

1) Ergebnisse in der Abgrenzung der Volkswirtschaftlichen Gesamtrechnungen in jeweiligen Preisen; ab 1984 vorläufige Ergebnisse

2) Käufe von gebrauchten Anlagen und l,and abzüglich Verkaufe von gebrauchten Anlagen und l.and.

3) Verănderung gegenüber dem Vorjahr in vill.

4) Jeweilige Ausgaben in vll der gesamten Bruttoinvestitionen.

5) Jeweilige Ausgaben in vll der gesumten Bruttoanlageinvestitionen.

Quelle: Zusummengestellt und errechnet uus: Statistisches Bundesamt: Revidierte Brgebnisse 1960 bis 1984 , Reihe S. 8 der Fuchserie 18: Volkswirtschaftliche Gesamtrechnungen, Stuttgart, Mainz. 1985, Tabelle 3.39, S. 227 ก. und Stalistisches Bundesamt: Konten und Standardtulellen 1985, Reihe 1 der Pachseric 18: Volkswirtschaftliche Gesamtrechnungen, Stuttgart, Mainz. 1986, 'Tabelle 3.39, S. 310. 
Schaubild 3.7: Die Entwicklung der Anteile der Bruttoinvestitionen für ausgewählte Aufgabenbereiche ${ }^{1)}$

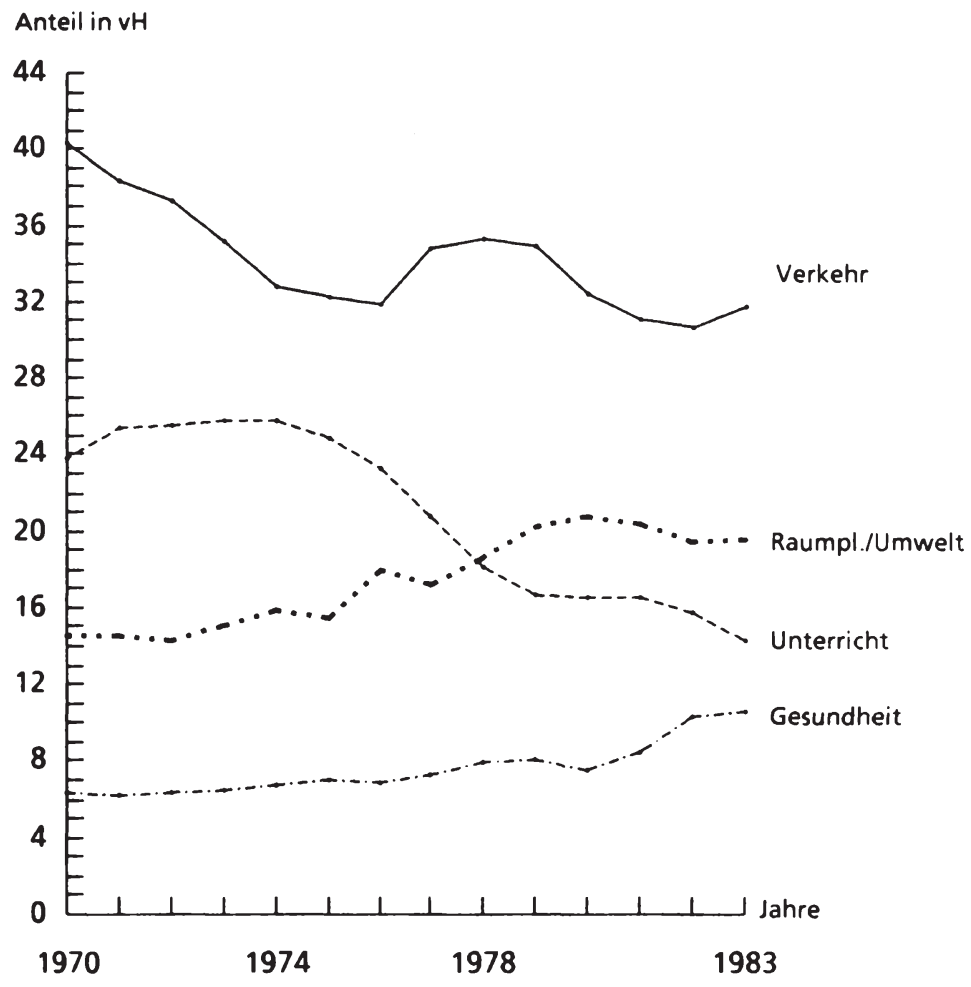

1) Tabelle 9

Die funktionale Verteilung der Bruttoinvestitionen, vor allem aber deren Veränderung in der Zeit, gibt auch Aufschluß über den jeweiligen politischen Stellenwert der einzelnen Aufgabenbereiche. ${ }^{189)}$ Wenngleich der Investitionsbedarf in den verschiedenen Funktionszweigen aufgrund spezifischer Sonderheiten unterschiedlich ist, spiegeln der Rückgang der Anteile in den Bereichen "Unterrichts-

189) Zu den Aufgabenbereichen der VGR vgl. die Ausführungen in Abschnitt 2.3.4. 
wesen" und "Verkehr und Nachrichtenübermittlung" sowie die Steigerungen im "Gesundheitswesen" und dem Bereich "Wohnungswesen, Stadt- und Landesplanung, Gemeinschaftsdienste (Umweltschutz)" geänderte politische Einschätzungen wider (vgl. Schaubild 3.7). Auf diese vier Aufgabenbereiche entfallen rund drei Viertel der gesamten Bruttoinvestitionen (vgl. Tabelle 9). Von den anderen Bereichen besitzen lediglich noch die Aufgabenzweige "Erholung und Kultur" mit etwa $7 \mathrm{vH}$ und "Allgemeine staatliche Verwaltung" mit etwa $6 \mathrm{vH}$ einen nennenswerten Anteil.

Im Rückgang des Anteils für den Bereich "Verkehr und Nachrichtenübermittlung", der 1970 noch einen Wert von 40,3 vH einnahm und 1983 lediglich 31,7 vH erreichte, manifestiert sich der geringere Stellenwert der klassischen Infrastruk. turmaßnahmen. Gleichzeitig deutet sich hier, in erster Linie im Verkehrsbereich, eine gewisse Sättigungstendenz an. ${ }^{190)}$ Ein Großteil der hier angesprochenen Aufgabe wird allerdings über die Haushalte öffentlicher Unternehmen, z.B. der Deutschen Bundespost abgewickelt, deren Ausgaben aber nicht berücksichtigt sind. Der Rückgang des Anteils dieses Aufgabenbereichs deutet auch auf die Abnahme der staatlichen Bautätigkeit, insbesondere im Bereich des Straßenbaus hin. Mit etwas über 13 Mrd.DM erreichen die Bruttoinvestitionen heute in diesem Bereich gerade in etwa den Stand von 1970. Das kurzzeitige Hochschnellen dieser Investitionsausgaben Ende der 70er Jahre wurde durch verschiedene Konjunkturprogramme bedingt. ${ }^{191)}$ Ebenfalls rückläufig ist die Entwicklung des Anteilswertes im Bereich "Unterrichtswesen". Bis zur Mitte der 70er Jahre verharrte der Anteil, bei insgesamt steigenden Investitionsausgaben, bei etwa $25 \mathrm{vH}$. Danach gingen die Bruttoinvestitionen für diesen Bereich sowohl absolut als auch relativ gesehen drastisch zurück, wobei dies gleichermaßen die Untergruppen "Schulen und vorschulische Erziehung", wie auch "Hochschulen" betrifft. ${ }^{192)}$

Im Gegensatz hierzu stiegen die Bruttoinvestitionen im Bereich "Wohnungswesen, Stadt- und Landesplanung, Gemeinschaftsdienste (Umweltschutz)" bis 1980

190) Vgl. hierzu auch Vesper, D.: Staatliche Einflußnahme auf die Baunachfrage. Eine Analyse für die Jahre 1965 bis 1980, Heft 69 der Beiträge zur Strukturforschung, hrsg. v. Deutschen Institut für Wirtschaftsforschung, Berlin 1981, S. 238.

191) Vgl. ebenda, S. 141. Vgl. auch Tabelle 9*a im Anhang.

192) Vgl. Statistisches Bundesamt: Revidierte Ergebnisse 1960 bis 1984, a.a.O., S. $230 \mathrm{ff}$. 
Tabelle 9: Die Bruttoinvestitionen des Staates nach Aufgabenbereichen in vH"

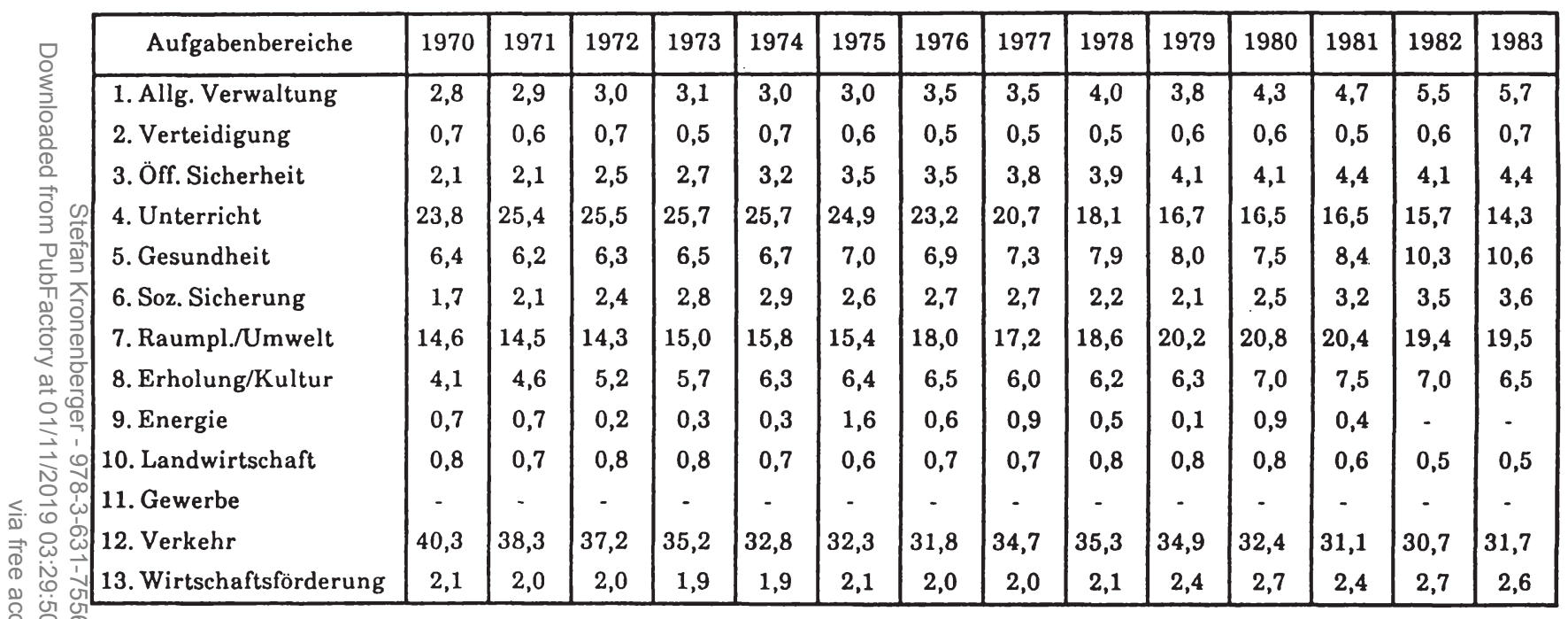

1) Bruttoinvestitionen der jeweiligen Aufgabenbereiche in vH der gesamten Bruttoinvestitionen. Vgl. Tabelle 9* im Anhang.

Quelle: Zusammengestellt und errechnet aus: Statistisches 13undesamt: Revidierte Ergebnisse 1960 bis 1984, Reihe S.8 der Fachserie 18: Volkswirtschaft. liche Gesamtrechnungen, Stuttgart, Mainz 1985, Tabelle 3.40, S. 230 ff. 
sehr stark an. Besondere Bedeutung kommt hierbei der Untergruppe "Gemeinschaftsdienste, Umweltschutz" zu, auf die etwa 85 Prozent der gesamten Investitionen dieses Bereichs entfallen. Bis 1980 hatten sich die investiven Ausgaben hierfür mehr als verdoppelt und der Anteil stieg von 14,6 vH auf 20,8 vH. Anfang der 80er Jahre zeichnete sich eine merkliche Abschwächung ab, die wegen des insgesamt rückläufigen Investitionsvolumens, nur geringe Auswirkungen auf den Anteilswert hatte. Auch für den Bereich "Gesundheitswesen" kann eine deutliche Steigerung der investiven Ausgaben konstatiert werden, die vor allem in den letzten Jahren zu einem beträchtlichen Anstieg des Anteils führte. Diese auf die funktionale Verteilung der Bruttoinvestitionen gerichtete Analyse muß immer auch das insgesamt rückläufige Investitionsvolumen berücksichtigen, was bei der Beurteilung, gerade von Anteilen, zur Vorsicht mahnt.

\subsubsection{Die Entwicklung in konstanten Preisen}

Die einzelnen Wertgrößen der Volkswirtschaftlichen Gesamtrechnungen werden nicht nur in jeweiligen Preisen (vgl. Tabelle 10) ausgewiesen, sondern auch auf der Grundlage der Preise eines Basisjahres (vgl. Tabelle 11). ${ }^{193)}$ Unabhängig von den methodischen Problemen der Deflationierung und der konkreten Vorgehensweise im Rahmen der Gesamtrechnungen ${ }^{194)}$ zeigt die Analyse auf der Basis konstanter Preise, daß der Wert der staatlichen Bruttoanlageinvestitionen, dem realen ${ }^{195)}$ Volumen nach, 1985 unter dem Stand von 1964 liegt (vgl. Tabelle 11). Die bis Mitte der 70er Jahre expansive staatliche Investitionstätigkeit - der Durchschnitt der jährlichen Wachstumsrate der realen staatlichen Anlageinvestitionen lag bei $4,7 \mathrm{vH}$, der des realen Bruttosozialprodukts bei $4,0 \mathrm{vH}$ und

193) Das Preisbasisjahr wird in den Revisionen der Volkswirtschaftlichen Gesamtrechnungen, die in mehrjährigen Abständen stattfinden, angepaßt. Vgl. Lützel, H.: Revision der ..., a.a.O., S. 603.

Siehe hierzu auch Angermann, O.: Zur Neuberechnung der Preisindizes auf Basis 1980, in: Wirtschaft und Statistik, Jg. 1983, S. 204-206.

194) Zu den allgemeinen Problemen der Deflationierung im Rahmen der Volkswirtschaftlichen Gesamtrechnungen sowie dem Aussagewert spezieller Preisindizes vgl. Angermann, O. und Stahmer, C.: Preisindices und Geldwertmessung im Rahmen der Volkswirtschaftlichen Gesamtrechnungen, in: Messung der Kaufkraft des Geldes, Heft 10 der Sonderhefte zum Allgemeinen Statistischen Archiv, hrsg. v. G. Fürst, Göttingen 1976, S.101-127.

195) Zur hier verwendeten Bedeutung des Begriffes "real" vgl. Gantner, M.: Meßprobleme ..., a.a.0., S. $113 \mathrm{ff}$. 
Tabelle 10: Bruttosozialprodukt und Bruttoanlageinvestitionen in jeweiligen Preisen (VGR) ${ }^{\prime \prime}$

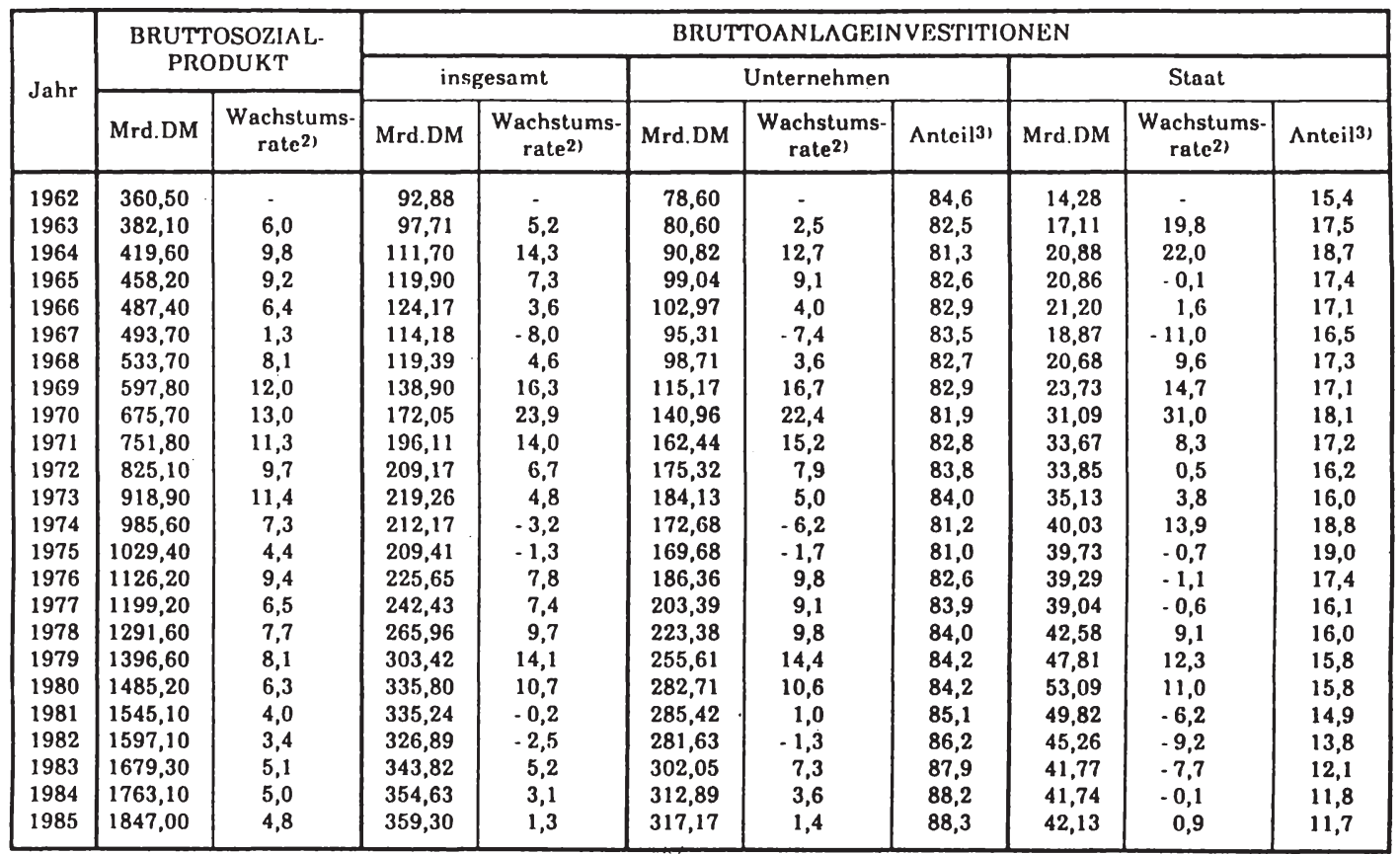

1) Ergebnisse in der $\Lambda$ bgrenzung der Volkswirtschaftlichen Gesamtrechnungen; ab 1984 vorläufige Ergebnisse.

2) Veränderung gegenüber dem Vorjahr in vH.

3) Jeweilige Ausgaben in vll der gesamten Bruttoanlageinvestitionen.

Quelle: 7usammengestellt und errechnet aus: Statistisches Bundesaml: Revidierte Ergebnisse 1960 bis 1984, Reihe S. 8 der Fachserie 18: Volkswirtschafliche Gesamtrechnungen, Stuttgart, Mainz 1985, Tabelle 3.1, S. 29 爪r. sowie Tabelle 3.17, S. 102 爪T. und Statistisches Bundesamt: Konten und Standardlabellen 1985, Reihe 1 der Pachserie 18: Volkswirtschaftliche Gesamtrechnungen, Stuttgart, Mainz 1986, Tabelle 3.1, S. 228 sowic Tubelle 3.17, S. 265. 
Tabelle 11: Bruttosozialprodukt und Bruttoanlageinvestitionen in Preisen von 1980 (VGR)"

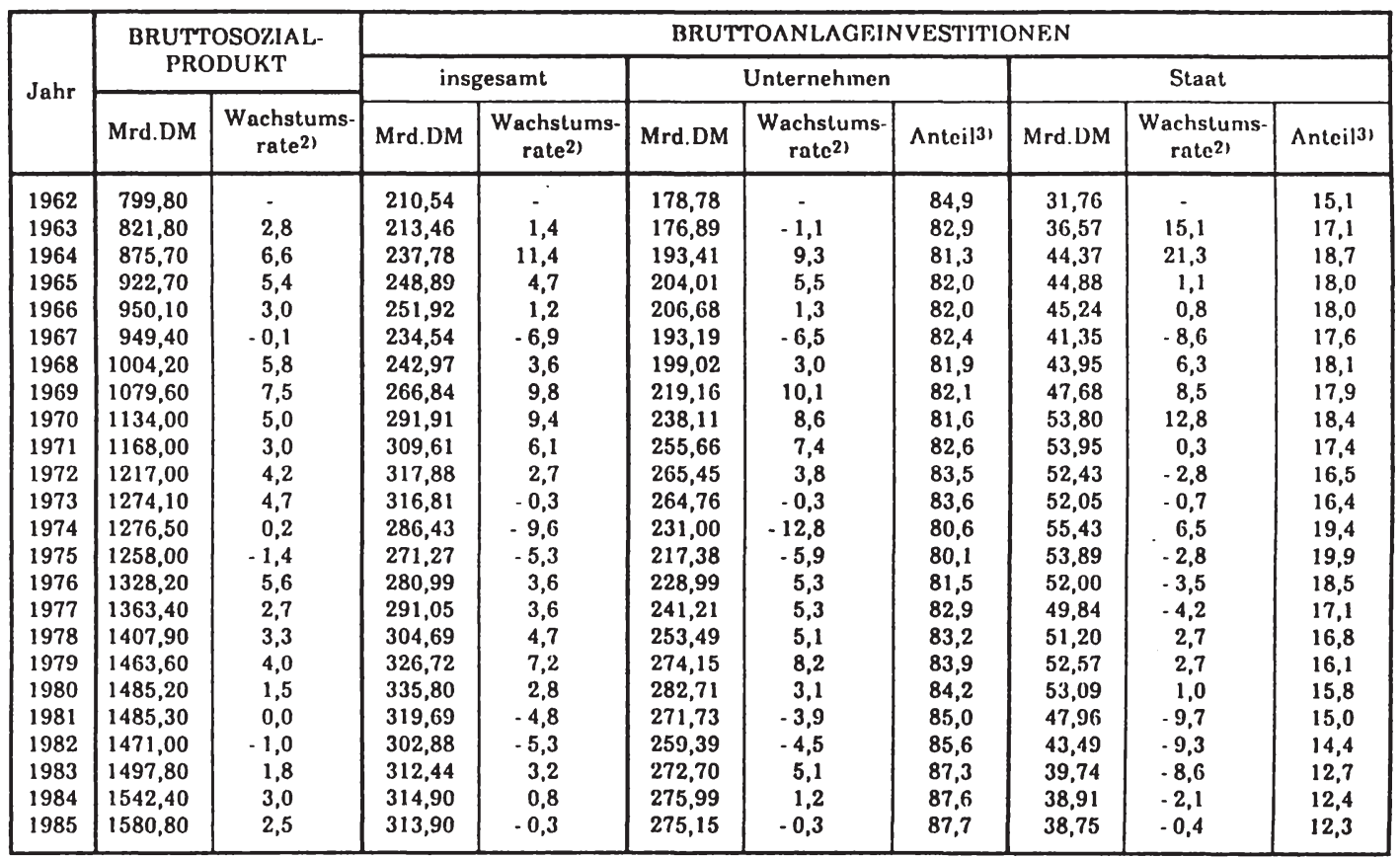

1) Ergebnisse in der $\Lambda$ bgrenzung der Volkswirtschaftlichen Gesamtrechnungen; ab 1984 vorläufige Ergebnisse.

2) Vertinderung gegenüber dem Vorjahr in vll.

3) Jeweilige Ausgaben in vll der gesamten Bruttoantageinvestitionen .

Quelle: Zusammengestellt und errechnet aus: Statistisches Bundesamt: Revidierte Frgebnisse 1960 his 1984 , Reihe S. 8 der Fachseric 18: Volkswirtschaftliche Gesamtrechnungen, Stuttgart, Muinz. 1985, 'T'abelle 3.1, S. 29 IT sowic 'Tabelle 3.17 S. $102 \pi$ und Statistisches Bundesamt: Konten und Standardtabellen 1985, Reihe I der Fuchseric 18: Volkswirtschaflliche Gesamtrechnungen, Stutlgart, Mainz. 1986, Tabelle 3.1, S. 228 sowic T'abelle 3.17, S. 265. 
Schaubild 3.8: Die Entwicklung der Wachstumsraten des Bruttosozialprodukts und der staatlichen Anlageinvestitionen in Preisen von $1980^{11}$

Veränderung in $\mathrm{vH}$

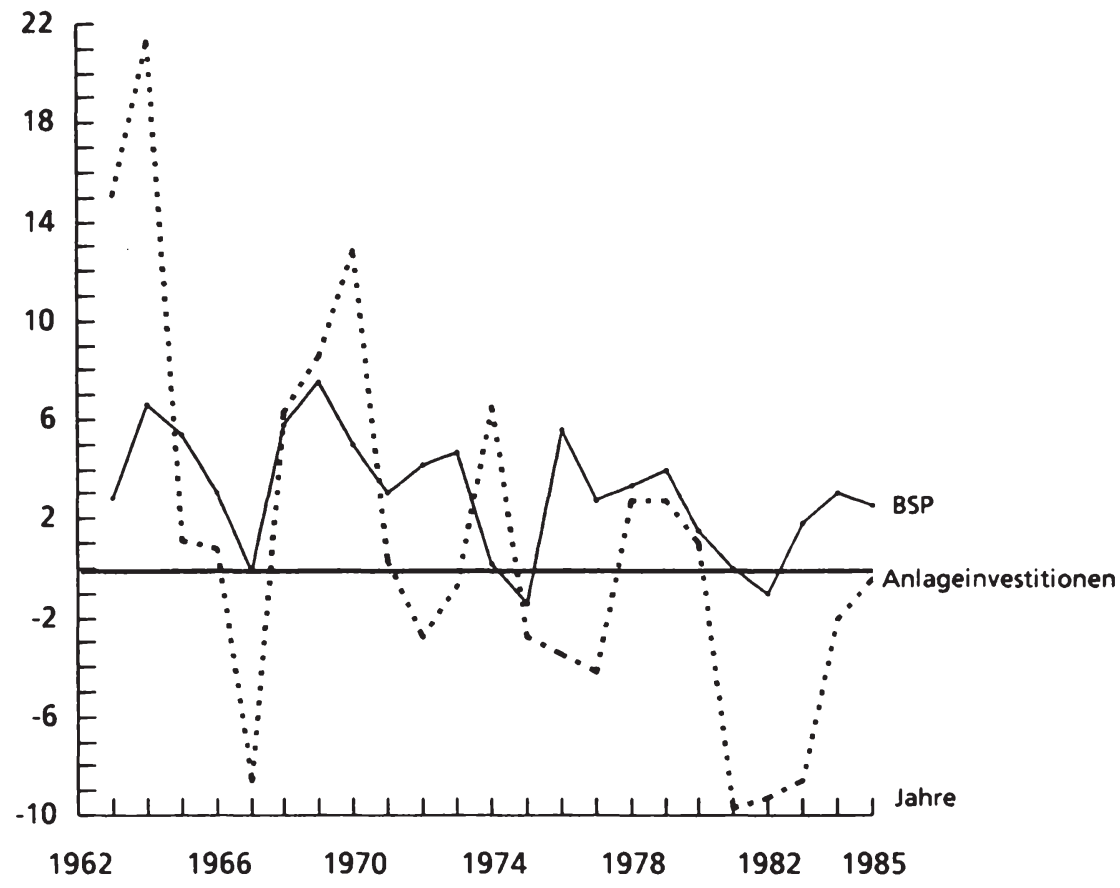

1) Vgl. Tabelle 11.

der der realen Unternehmensinvestitionen bei $2,2 \mathrm{vH}$ (vgl. Übersicht 3.3) - ließ zwischenzeitlich merklich nach und sank im Verlauf der 80er Jahre mit z.T. sehr großen negativen Veränderungsraten ${ }^{196)}$ (siehe auch Schaubild 3.8). Die durchschnittliche jährliche Wachstumsrate der realen Bruttoanlageinvestitionen des

196) Für den Durchschnitt der siebziger Jahre ermittelte Leibfritz eine Stagnation der realen öffentlichen Investitionen. Vgl. Leibfritz, W.: Der Staat ..., a.a.O., S. 125. 
Staates ist im Zeitraum von 1974 bis 1985 negativ und beträgt $-3,1$ vH. Die privaten Anlageinvestitionen wuchsen in ihrem realen Wert um 1,6 vH pro Jahr und das reale Bruttosozialprodukt um 1,9 vH pro Jahr (vgl. Übersicht 3.3 und Schaubild 3.9). Wie bei der nominalen Betrachtung, d.h. der Analyse der Größen auf der Basis ihrer jeweiligen Preise, schlägt die Entwicklung der staatlichen Bauinvestitionen auch bei der realen Betrachtungsweise sehr stark auf die gesamte Bruttoanlageinvestitionen des Staates durch. ${ }^{197)}$

Die Gegenüberstellung der Ausgabenwerte zu jeweiligen und zu konstanten Preisen gibt auch Aufschluß über die Steigerungsraten der verwendeten Preisindizes. ${ }^{198)}$ Schon der absolute Unterschied in Prozentpunkten zwischen den realen und nominalen Wachstumsraten ergibt eine recht gute Approximation der Steigerungsrate des zugrundeliegenden Preisindexes ${ }^{199)}$ (vgl. Schaubild 3.10). Nach der genauen Berechnung ${ }^{200)}$ stieg der Preisindex für das Bruttosozialprodukt im Zeitraum von 1962 bis 1974 durchschnittlich pro Jahr um 4,6 vH und von 1974 bis 1985 um 3,8 vH pro Jahr. Die Veränderungsraten des Preisindexes für die gesamten Bruttoanlageinvestitionen lag mit einem durchschnittlichen jährlichen Wert von 4,4 vH im ersten Zeitabschnitt, von 1962 bis 1974, unterhalb und im zweiten Zeitabschnitt, von 1974 bis 1985 , mit 4,0 vH oberhalb des entsprechenden Wertes des Bruttosozialprodukts. Die durchschnittlichen jährlichen Wachstumsraten der Preisindizes für die privaten Investitionen übertreffen für die betrachteten Zeitabschnitte immer diejenigen der staatlichen. Besonders deutlich ist dies bei den Bauinvestitionen ${ }^{201)}$, deren Preisindex bei den privaten Investitionen von 1962 bis 1974 um durchschnittlich 5,4 vH pro Jahr und für den Zeitraum von

197) Vgl. Tabelle $11^{*} \mathrm{a}-\mathrm{b}$ im Anhang.

198) Hinsichtlich der speziellen Problematik der Deflationierung staatlicher Leistungen und zu empirischen Ergebnissen der Preisentwicklung öfentlicher Ausgaben vgl. auch Klein, M.: Deflationierung der staatlichen Leistungen und Preisentwicklungen im öffentlichen Sektor, in: Konzeptionelle Probleme öffentlicher Planung, hrsg. v. E. Wille, Frankfurt/ Main et al. 1983, S. 85-126

Die Preisindizes für verschiedene Ausgabenkategorien setzen sich selbst wiederum aus einer Vielzahl von Preisindizes für die unterschiedlichen Gütergruppen der Kategorie zusammen.

199) Der korrekte Zusammenhang der drei Größen wird bei diskreter Betrachtung durch folgende Sachverhalte beschrieben: $w^{\text {nom }}=w^{\text {real }}+w_{P}+w^{r e a l} \cdot w_{P}$, mit: $w^{\text {nom: }}$ Wachstumsrate der nominalen Ausgaben; wreal: Wachstumsrate der realen Ausgaben; wp: Wachstumsrate des Preisindexes für diese Ausgabengruppe.

200) Vgl. Übersicht 3.3 und Schaubild 3.10.

201) Vgl. hierzu auch Vesper, D.: Staatliche Einflußnahme ..., a.a.O., S. 151. 
Übersicht 3.3: Die durchschnittlichen jährlichen Wachstumsraten für das Bruttosozialprodukt, die Bruttoanlageinvestitionen und deren Preisindizes

\begin{tabular}{|c|c|c|}
\hline & $1962-1974$ & $1974-1985$ \\
\hline $\begin{array}{l}\text { BRUTTOSOZIALPRODUKT } \\
\text { - nominal } \\
\text { - real } \\
\text { - Preisindex }\end{array}$ & $\begin{array}{l}w^{n}=8,7 v H \\
w^{r}=4,0 v H \\
w_{p}=4,6 v H\end{array}$ & $\begin{array}{l}w^{n}=5,8 v H \\
w^{r}=1,9 v H \\
w_{p}=3,8 v H\end{array}$ \\
\hline $\begin{array}{l}\text { BRUTTOANLAGEINVESTITIONEN } \\
\begin{array}{l}\text { (insgesamt) } \\
\\
\\
\text { - nominal } \\
\text { - real } \\
\text { - Preisindex }\end{array}\end{array}$ & $\begin{array}{l}w^{n}=7,1 v H \\
w^{r}=2,6 v H \\
w_{p}=4,4 v H\end{array}$ & $\begin{array}{l}\mathrm{w}^{\mathrm{n}}=4,9 \mathrm{vH} \\
\mathrm{w}^{\mathrm{r}}=0,8 \mathrm{vH} \\
\mathrm{w}_{\mathrm{p}}=4,0 \mathrm{vH}\end{array}$ \\
\hline $\begin{array}{l}\text { BRUTTOANLAGEINVESTITIONEN } \\
\text { (Unternehmen) } \\
\\
\text { - nominal } \\
\text { - real } \\
\text { - Preisindex }\end{array}$ & $\begin{array}{l}\mathrm{w}^{\mathrm{n}}=6,8 \mathrm{vH} \\
\mathrm{wr}^{\mathrm{r}}=2,2 \mathrm{vH} \\
\mathrm{w}_{\mathrm{p}}=4,5 \mathrm{vH}\end{array}$ & $\begin{array}{l}\mathrm{w}^{\mathrm{n}}=5,7 \mathrm{vH} \\
\mathrm{w}^{\mathrm{r}}=1,6 \mathrm{vH} \\
\mathrm{w}_{\mathrm{p}}=4,0 \mathrm{vH}\end{array}$ \\
\hline $\begin{array}{l}\text { BRUTTOANLAGEINVESTITIONEN } \\
\begin{array}{l}\text { (Staat) } \\
\\
\\
\text { - nominal } \\
\text { - real } \\
\text { - Preisindex }\end{array}\end{array}$ & $\begin{array}{l}w^{n}=9,0 v H \\
w^{r}=4,7 v H \\
w_{p}=4,0 v H\end{array}$ & $\begin{array}{l}\mathrm{w}^{\mathrm{n}}=0,5 \mathrm{vH} \\
\mathrm{w}^{\mathrm{r}}=-3,1 \mathrm{vH} \\
\mathrm{w}_{\mathrm{p}}=3,8 \mathrm{vH}\end{array}$ \\
\hline $\begin{aligned} \text { BAUINVESTITIONEN (Unternehmen) } & \text { - nominal } \\
& \text { - real } \\
& \text { - Preisindex }\end{aligned}$ & $\begin{array}{l}w^{n}=7,3 v H \\
w^{r}=1,7 v H \\
w_{p}=5,4 v H\end{array}$ & $\begin{array}{l}\mathrm{w}^{\mathrm{n}}=4,5 \mathrm{vH} \\
\mathrm{w}^{\mathrm{r}}=0,3 \mathrm{vH} \\
\mathrm{w}_{\mathrm{p}}=4,1 \mathrm{vH}\end{array}$ \\
\hline $\begin{aligned} \text { BAUINVESTITIONEN (Staat) } \\
\text { - nominal } \\
\text { - real } \\
\text { - Preisindex }\end{aligned}$ & $\begin{array}{l}w^{n}=8,9 v H \\
w^{r}=4,6 v H \\
w_{p}=4,1 v H\end{array}$ & $\begin{array}{l}w^{n}=0,1 v H \\
w^{r}=-3,5 v H \\
w_{p}=3,8 v H\end{array}$ \\
\hline $\begin{array}{l}\text { AUSRÜSTUNGSINVESTITIONEN } \\
\text { (Unternehmen) } \\
\\
\text { - nominal } \\
\text { - real } \\
\text { - Preisindex }\end{array}$ & $\begin{array}{l}w^{n}=6,1 v H \\
w^{r}=2,9 v H \\
w_{p}=3,1 v H\end{array}$ & $\begin{array}{l}\mathrm{w}^{\mathrm{n}}=7,3 \mathrm{vH} \\
\mathrm{w}^{\mathrm{r}}=3,3 \mathrm{vH} \\
\mathrm{w}_{\mathrm{p}}=3,8 \mathrm{vH}\end{array}$ \\
\hline $\begin{array}{l}\text { AUSRÜSTUNGSINVESTITIONEN } \\
\text { (Staat) } \\
\\
\\
\text { - nominal } \\
\\
\text { - real } \\
\text { - Preisindex }\end{array}$ & $\begin{array}{l}w^{n}=9,8 v H \\
w^{r}=6,8 v H \\
w_{p}=2,8 v H\end{array}$ & $\begin{array}{l}w^{n}=3,8 v H \\
w^{r}=0,1 v H \\
w_{p}=3,7 v H\end{array}$ \\
\hline
\end{tabular}

Quelle: Zusammengestellt und errechnet aus den Zahlenangaben der Tabellen 10, 10*a-b im Anhang sowie 11 und $11^{*} a-b$ im Anhang. 


\section{Schaubild 3.9: Die durchschnittlichen jāhrlichen Wachstumsraten für das Bruttosozialprodukt und die Anlageinvestitionen}

\section{Veränderung in vH}

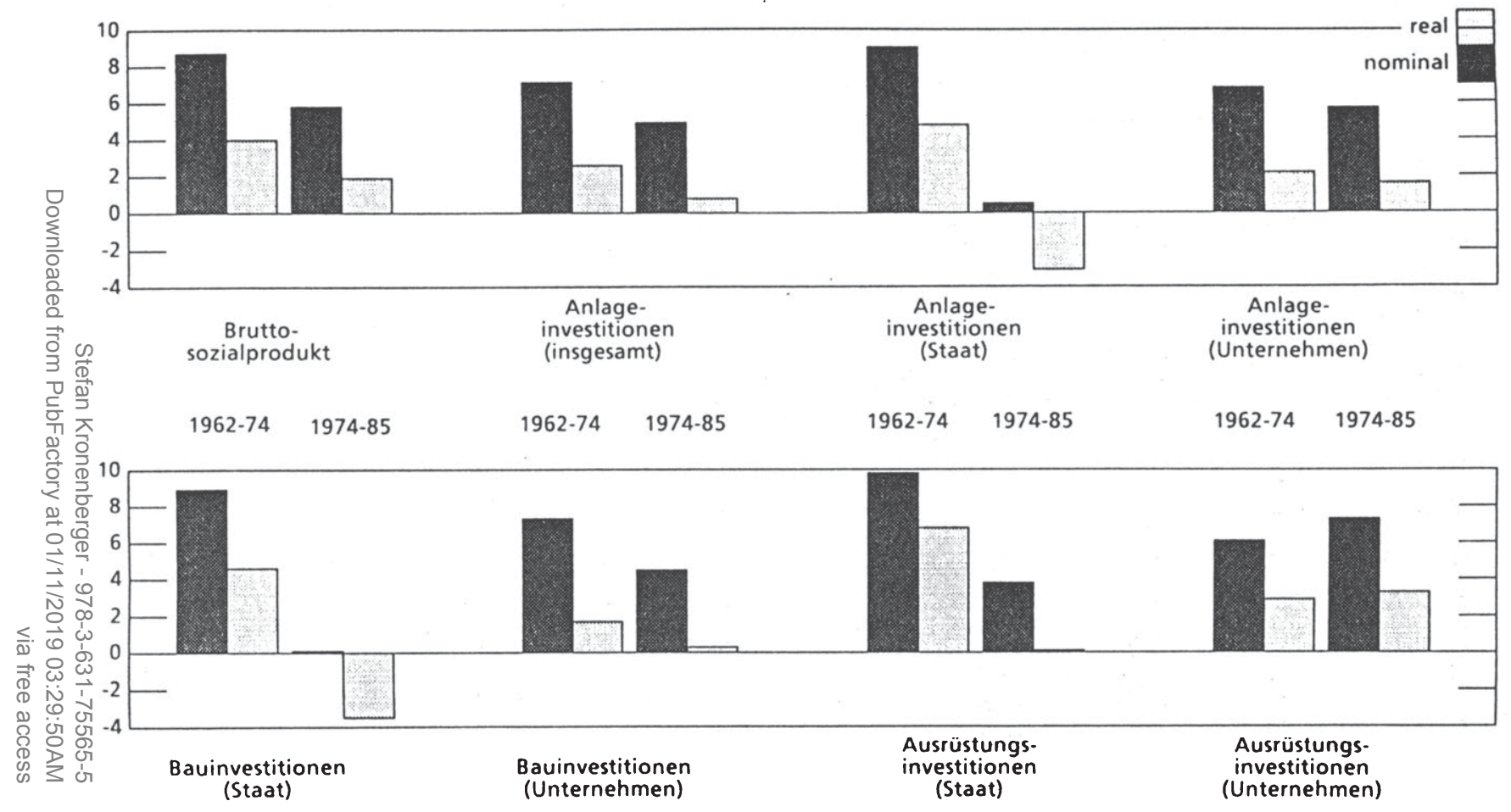


1974 bis 1985 mit einer jährlichen Durchschnittsrate von 4,1 vH anwuchs. Der Preisindex der staatlichen Bauinvestitionen stieg demgegenüber von 1962 bis 1974 mit einer Rate von 4,1 vH pro Jahr bzw. für 1974 bis 1985 mit 3,8 vH pro Jahr. Die Differenzen in der Preisentwicklung ergeben sich aus Unterschieden in der Zusammensetzung der Bauinvestitionen. Die Preiserhöhungen für Leistungen im Straßenbau, welche hauptsächlich beim Staat anfallen und dort einen Großteil der Bauinvestitionen ausmachen ${ }^{202)}$, sind deutlich niedriger als die Preissteigerungen für Wohnbauten. ${ }^{203)}$ Dies hängt mit der eher industriellen Fertigungsweise im Straßenbau zusammen, die die Voraussetzungen zu einer kapitalintensiveren Produktion bietet und die Möglichkeiten zur Einführung technischer Neuerungen sowie für Rationalisierungsmaßnahmen erleichtern. ${ }^{244}$ ) Die Preisindizes der Ausrüstungsinvestitionen sind gegenüber denen der Bauinvestitionen weniger stark gestiegen ${ }^{205}$, aber auch bei ihnen liegen die Indizes für die staatlichen Ausgaben unterhab derjenigen der privaten, wobei die Unterschiede vergleichsweise gering sind, was aus der größeren Ähnlichkeit der betreffenden Investitionsgüter resultiert.

\subsection{Einige kritische Anmerkungen}

Gesamtwirtschaftliche Untersuchungen über die konjunkturpolitischen Verwendungsmöglichkeiten staatlicher Investitionsausgaben und deren längerfristigen Implikationen gelangen zu teilweise konträren Urteilen. So kommen die Mitarbeiter der Deutschen Bundesbank auf der Grundlage ihres ökonometrischen Modells zum Schluß, daß, nach einem anfänglichen Strohfeuer, einer Erhöhung öffentlicher Investitionen am Ende der Entwicklung "ein fast gleich

202) Sie verkörpern ca. 40 Prozent der Bauinvestitionen der Gebietskörperschaften. Vgl. Statistisches Bundesamt: Konten und Standardtabellen 1985, a.a.O., Tabelle 3.39, S. 103.

203) Vgl. Statistisches Bundesamt: Meßzahlen für Bauleistungspreise und Preisindizes für Bauwerke August 1986, Reihe 4 der Fachserie 17: Preise, Stuttgart, Mainz 1986, S. 36 ff.

204) Vgl. Vesper, D.: Staatliche Einflußnahme ..., a.a.O., S. 152.

205) Vgl. auch Stahmer, C. und Mayer, H.: Input-Output-Rechnung in konstanten Preisen, in: Wirtschaft und Statistik, Jg. 1985, S. 270-281, S. 281. 
Tabelle 12: Bruttosozialprodukt und Bruttoanlageinvestitionen in jeweiligen Preisen (VGR) ${ }^{\prime \prime}$

\begin{tabular}{|c|c|c|c|c|c|c|c|c|c|c|c|}
\hline \multirow{3}{*}{ Jahr } & \multirow{2}{*}{\multicolumn{2}{|c|}{$\begin{array}{l}\text { BRUTTOSOZIAL- } \\
\text { PRODUKT }\end{array}$}} & \multicolumn{9}{|c|}{ BRUTTOANLAGEINVESTITIONEN } \\
\hline & & & \multicolumn{3}{|c|}{ insgesamt } & \multicolumn{3}{|c|}{ Unternehmen } & \multicolumn{3}{|c|}{ Staat } \\
\hline & Mrd.DM & $\begin{array}{c}\text { Wachstums- } \\
\text { rate }\end{array}$ & Mrd.DM & $\begin{array}{l}\text { Wachstums- } \\
\text { rate }\end{array}$ & Quote3) & Mrd.DM & $\begin{array}{c}\text { Wachstums- } \\
\text { rate }\end{array}$ & Quote 31 & Mrd.DM & $\begin{array}{c}\text { Wachstums- } \\
\text { rate }^{2)}\end{array}$ & Quote ${ }^{31}$ \\
\hline 1962 & 360,50 & - & 92,88 & - & 25,8 & 78,60 & - & 21,8 & 14,28 & - & 4,0 \\
\hline 1963 & 382,10 & 6,0 & 97,71 & 5,2 & 25,6 & 80,60 & 2,5 & 21,1 & 17,11 & 19,8 & 4,5 \\
\hline 1964 & 419,60 & 9,8 & 111,70 & 14,3 & 26,6 & 90,82 & 12,7 & 21,6 & 20,88 & 22,0 & 5,0 \\
\hline 1965 & 458,20 & 9,2 & 119,90 & 7,3 & 26,2 & 99,04 & 9,1 & 21,6 & 20,86 & $-0,1$ & 4,6 \\
\hline 1966 & 487,40 & 6,4 & 124,17 & 3,6 & 25,5 & 102,97 & 4,0 & 21,1 & 21,20 & 1,6 & 4,4 \\
\hline 1967 & 493,70 & 1,3 & 114,18 & $-8,0$ & 23,1 & 95,31 & $-7,4$ & 19,3 & 18,87 & $-11,0$ & 3,8 \\
\hline 1968 & 533,70 & 8,1 & 119,39 & 4,6 & 22,4 & 98,71 & 3,6 & 18,5 & 20,68 & 9,6 & 3,9 \\
\hline 1969 & 597,80 & 12,0 & 138,90 & 16,3 & 23,2 & 115,17 & 16,7 & 19,3 & 23,73 & 14,7 & 4,0 \\
\hline 1970 & 675,70 & 13,0 & 172,05 & 23,9 & 25,5 & 140,96 & 22,4 & 20,9 & 31,09 & 31,0 & 4,6 \\
\hline 1971 & 751,80 & 11,3 & 196,11 & 14,0 & 26,1 & 162,44 & $15 ; 2$ & 21,6 & 33,67 & 8,3 & 4,5 \\
\hline 1972 & 825,10 & 9,7 & 209,17 & 6,7 & 25,4 & 175,32 & 7,9 & 21,3 & 33,85 & 0,5 & 4,1 \\
\hline 1973 & 918,90 & 11,4 & 219,26 & 4,8 & 23,9 & 184,13 & 5,0 & 20,0 & 35,13 & 3,8 & 3,8 \\
\hline 1974 & 985,60 & 7,3 & 212,17 & $-3,2$ & 21,5 & 172,68 & $-6,2$ & 17,5 & 40,03 & 13,9 & 4,1 \\
\hline 1975 & 1029,40 & 4,4 & 209,41 & $-1,3$ & 20,3 & 169,68 & $-1,7$ & 16,5 & 39,73 & $-0,7$ & 3,9 \\
\hline 1976 & 1126,20 & 9,4 & 225,65 & 7,8 & 20,0 & 186,36 & 9,8 & 16,6 & 39,29 & $-1,1$ & 3,5 \\
\hline 1977 & 1199,20 & 6,5 & 242,43 & 7,4 & 20,2 & 203,39 & 9,1 & 17,0 & 39,04 & $-0,6$ & 3,3 \\
\hline 1978 & 1291,60 & 7,7 & 265,96 & 9,7 & 20,6 & 223,38 & 9,8 & 17,3 & 42,58 & 9,1 & 3,3 \\
\hline 1979 & 1396,60 & 8,1 & 303,42 & 14,1 & 21,7 & 255,61 & 14,4 & 18,3 & 47,81 & 12,3 & 3,4 \\
\hline 1980 & 1485,20 & 6,3 & 335,80 & 10,7 & 22,6 & 282,71 & 10,6 & 19,0 & 53,09 & 11,0 & 3,6 \\
\hline 1981 & 1545,10 & 4,0 & 335,24 & $-0,2$ & 21,7 & 285,42 & 1,0 & 18,5 & 49,82 & $-6,2$ & 3,2 \\
\hline 1982 & 1597,10 & 3,4 & 326,89 & $-2,5$ & 20,5 & 281,63 & $-1,3$ & 17,6 & 45,26 & $-9,2$ & 2,8 \\
\hline 1983 & 1679,30 & 5,1 & 343,82 & 5,2 & 20,5 & 302,05 & 7,3 & 18,0 & 41,77 & $-7,7$ & 2,5 \\
\hline 1984 & 1763,10 & 5,0 & 354,63 & 3,1 & 20,1 & 312,89 & 3,6 & 17,7 & 41,74 & $-0,1$ & 2,4 \\
\hline 1985 & 1847,00 & 4,8 & 359,30 & 1,3 & 19,5 & 317,17 & 1,4 & 17,2 & 42,13 & 0,9 & 2,3 \\
\hline
\end{tabular}

1) Ergebnisse in der Abgrenzung der Volkswirtschaftlichen Gesamtrechnungen; ab 1984 vorläufige Ergebnisse.

2) Veränderung gegenüber dem Vorjahr in vIl.

3) Jeweilige Ausgaben in vH des Bruttosozialprodukts.

Quelle: Zusammengestellt und errechnet aus: Statistisches Bundesamt: Revidierte Ergebnisse 1960 bis 1984, Reihe S. 8 der Fachserie 18 Volkswirtschaftliche Gesamtrechnungen, Stuttgart, Mainz 1985, Tabelle 3.1, S. 29 爪f. sowic Tabelle 3.17, S. 102 If. und Statistisches Bundesamt: Konten und Standardtabellen 1985, Reihe 1 der Fachserie 18: Volkswirtschaftliche Gesamtrechnungen, Stutlgart, Mainz 1986, 'Tabcllc 3.1, S. 2289 sowic Tabcllc 3.17, S. 265. 
großer Ausfall an privater Investitionsnachfrage" gegenübersteht. ${ }^{206)}$ Zwiener diagnostiziert demgegenüber, in einer kritischen Würdigung des BundesbankModells stark expansive gesamtwirtschaftliche Effekte, die in einer normalen konjunkturellen Situation von den öffentlichen Investitionen ausgehen. ${ }^{207)}$ Ungeachtet dieses Dissenses über die längerfristige Wirkung einer Erhöhung staatlicher Investitionsausgaben, deutet deren Umfang insgesamt "auf einen vergleichsweise geringen Beitrag zur Entwicklung der gesamtwirtschaftlichen Nachfrage in der Bundesrepublik hin."208) Die staatliche Investitionsquote, verstanden als Quotient der Bruttoanlageinvestitionen des Staates und des Bruttosozialprodukts ${ }^{209)}$, die zwischen 1962 und 1974 mehr oder minder stark um den Wert $4 \mathrm{vH}$ schwankte und 1964 mit 5,0 vH den bisherigen Höchststand einnahm $^{210)}$, ging seither sogar auf einen Wert von 2,3 vH im Jahre 1985 zurück

206) Deutsche Bundesbank: Struktur und Eigenschaften einer neuen Version des ökonometrischen Modells der Deutschen Bundesbank, in: Monatsberichte der Deutschen Bundesbank, 34. Jg. (1982), Nr. 8 (August), S. 32-41, S. 39.

Die Autoren des Bundesbankberichts schränken allerdings selbst ein, ihre Untersuchungsergebnisse seien in starkem Maße zeitgebunden und stellten keinesfalls ein grundsätzliches Verdikt über die Wirksamkeit öffentlicher Ausgabenprogramme dar. Vgl. ebenda, S. 40.

207) Zwiener, R.: "Crowding-out" durch öffentliche Investitionen? Eine Diskussion der Modellergebnisse der Deutschen Bundesbank und eine Gegenüberstellung mit den Ergebnissen der DIW-Version des ökonometrischen Konjunkturmodells der Wirtschaftsforschungsinstitute, in: Konjunkturpolitik. Zeitschrift für angewandte Wirtschaftsforschung, 29. Jg. (1983), S. 121-140, S. 139.

Vgl. auch Heilemann, U.: Kritische Anmerkungen zu einer Simulationsstudie der Deutschen Bundesbank, in: Vierteljahreshefte zur Wirtschaftsforschung, hrsg. v. Deutschen Institut für Wirtschaftsforschung, Jg. 1983, S. 59-67. Ungeachtet der Frage, ob mit solchen prinzipiell kurzfristig ausgerichteten Modellen langfristige Wirkungsanalysen sinnvoll ableitbar sind, hält Heilemann die von der Bundesbank festgestellten Wirkungen kaum für repräsentativ. Vgl. ebenda, S. 67.

Vgl. auch die sehr hohen Erwartungen bei Höhnen, W.: Das DGB-Investitionsprogramm zur Sicherung der Beschäftigung durch qualitatives Wachstum: Ansätze zur Konkretisierung seiner Schwerpunktbereiche, in: WSI-Mitteilungen. Zeitschrift des Wirtschaftsund Sozialwissenschaftlichen Institut des Deutschen Gewerkschaftsbundes, 35. Jg. (1982), S.597-606, S. 598 f.

208) Leibfritz, W.: Mehr staatliche Investitionen zum Abbau der Arbeitslosigkeit? Ein Beitrag zu der aktuellen Diskussion vor dem Hintergrund einer längerfristigen Analyse der staatlichen Investitionstätigkeit, in: Ifo-Schnelldienst, 36. Jg. (1983), Nr. 3, S. 3-14, S. 4.

209) Leibfritz zieht das Bruttoinlandsprodukt zum Vergleich heran (vgl. Leibfritz, W.: Der Staat ..., a.a.O., S. 125 ff.), was allerdings keine nennenswerte Differenz hervorruft, da der Unterschied zwischen dem Inlands- und Inländerkonzept lediglich aus dem Saldo der Erwerbs- und Vermögenseinkommen zwischen Inländern und der übrigen Welt besteht.

210) Die länger zurückgehende Analyse von Leibfritz zeigt, daß der Anteil in den $50 e r$ Jahren bis in die 60er hinein, angestiegen ist. Vgl. Leibfritz, W.: Der Staat ..., a.a.O., S. 126. 
Schaubild 3.10: Die Entwicklung der Wachstumsraten der privaten und staatlichen Anlageinvestitionen1)

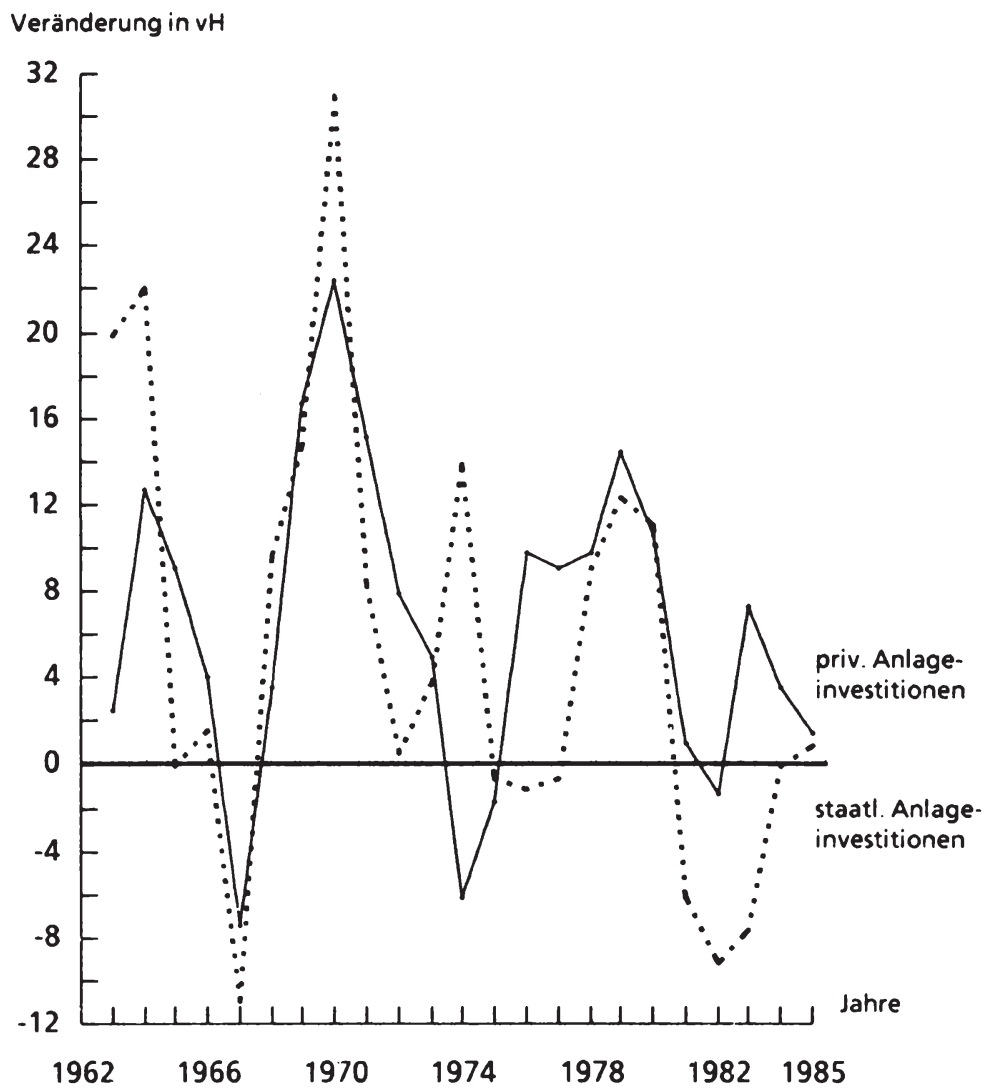

1) Vgl. Tabelle 10

(vgl. Tabelle 12). Die privaten Anlageinvestitionen besitzen demgegenüber ein ungleich größeres Gewicht. Ihre Quote beläuft sich auf 17,2 vH (1985), wobei sie für den Zeitraum von 1974 bis 1985 leicht stieg, während sie im ersten Abschnitt des Beobachtungszeitraumes, von 1962 bis 1974, sank. Neben den privaten Investitionen bestimmen, einer Untersuchung des Ifo-Instituts zu Folge, vor allem 
der private Verbrauch und die Exporte das gesamtwirtschaftliche Nachfragewachstum. Auch der Beitrag des Staatsverbrauchs zur Entwicklung der Gesamtnach frage ist danach größer als der der staatlichen Investitionen. ${ }^{2111}$

Als weiteres Ergebnis zeigen die Daten, daß die staatlichen Investitionen in ihren Veränderungen sehr viel größeren Schwankungen unterworfen waren als die privaten (vgl. Schaubild 3.10). Auf die durchschnittliche jährliche Wachstumsrate bezogen ergab dies für den Zeitraum von 1962 bis 1974 eine Zuwachsrate der staatlichen Anlageinvestitionen von 9,0 vH, die damit nicht nur 2,2 Prozentpunkte über der entsprechenden Rate der privaten Investitionen lag, sondern auch die durchschnittliche jährliche Steigerungsrate des Bruttosozialprodukts übertraf. Im darauf folgenden Zeitabschnitt, von 1974 bis 1985, stiegen die staatlichen Ausgaben für Anlageinvestitionen lediglich noch mit einer jährlichen Durchschnittsrate von $\mathbf{0 , 5} \mathrm{vH}$, während das Bruttosozialprodukt im Durchschnitt um 5,8 vH pro Jahr und die privaten Anlageinvestitionen um 5,7 vH anwuchsen (vgl. auch Schaubild 3.9). Folglich verschob sich die sektorale Verteilung der Bruttoanlageinvestitionen im ersten Zeitabschnitt leicht zugunsten des Staates. Im zweiten Abschnitt, von 1974 bis 1985, stieg dann der Anteil der Unternehmensinvestitionen an den gesamten Bruttoanlageinvestitionen sehr stark an. Die staatlichen Anlageinvestitionen nahmen damit 1985 nur noch einen Anteil von 11,8 vH an den gesamten Anlageinvestitionen der Wirtschaft ein (vgl. Tabelle 10). Die oben dargelegte Entwicklung für die Anlageinvestitionen des Staates stimmt weitgehend mit der der staatlichen Bauinvestitionen überein, die ja den überwiegenden Teil der staatlichen Investitionen ausmachen. Die sektorale Verteilung der Bauinvestitionen, die in ihrer zeitlichen Veränderung dem obigen Grundmuster folgt, weist dementsprechend auch einen höheren Anteil des Staates auf. ${ }^{212}$ Der relative Rückgang der staatlichen Anlage- und Bauinve-

211) Vgl. Leibfritz, W.: Mehr staatliche Investitionen ..., a.a.O., S. 3 f.

Vgl. auch Vesper, D.: Das Verhalten ..., a.a.O., S. $257 \mathrm{ff}$. Im Bericht über die Diskussion zu diesem Vortrag, der auf dem 9. Ottobeurer Wirtschaftswissenschaftlichen Seminar gehalten wurde, finden sich einige relativierende Anmerkungen zum Gewicht staatlicher Investitionen, die die Bedeutung der vom Staat zu verantwortenden Investitionen gewichtiger erscheinen läßt. Vgl. Blum, R.: Bericht über die Diskussion zum Referat D. Vesper, in: Neuere Entwicklungen in der Investitionstheorie und -politik, hrsg. v. G. Bombach, B. Gahlen und A.E. Ott, Tübingen 1980, S. 293-298.

212) Vgl. hierzu auch Tabelle $10^{*} a-b$ im Anhang. 


\section{Schaubild 3.11: Die Entwicklung der Wachstumsraten der staatlichen} Anlageinvestitionen und des Bruttosozialprodukts ${ }^{1}{ }^{1}$

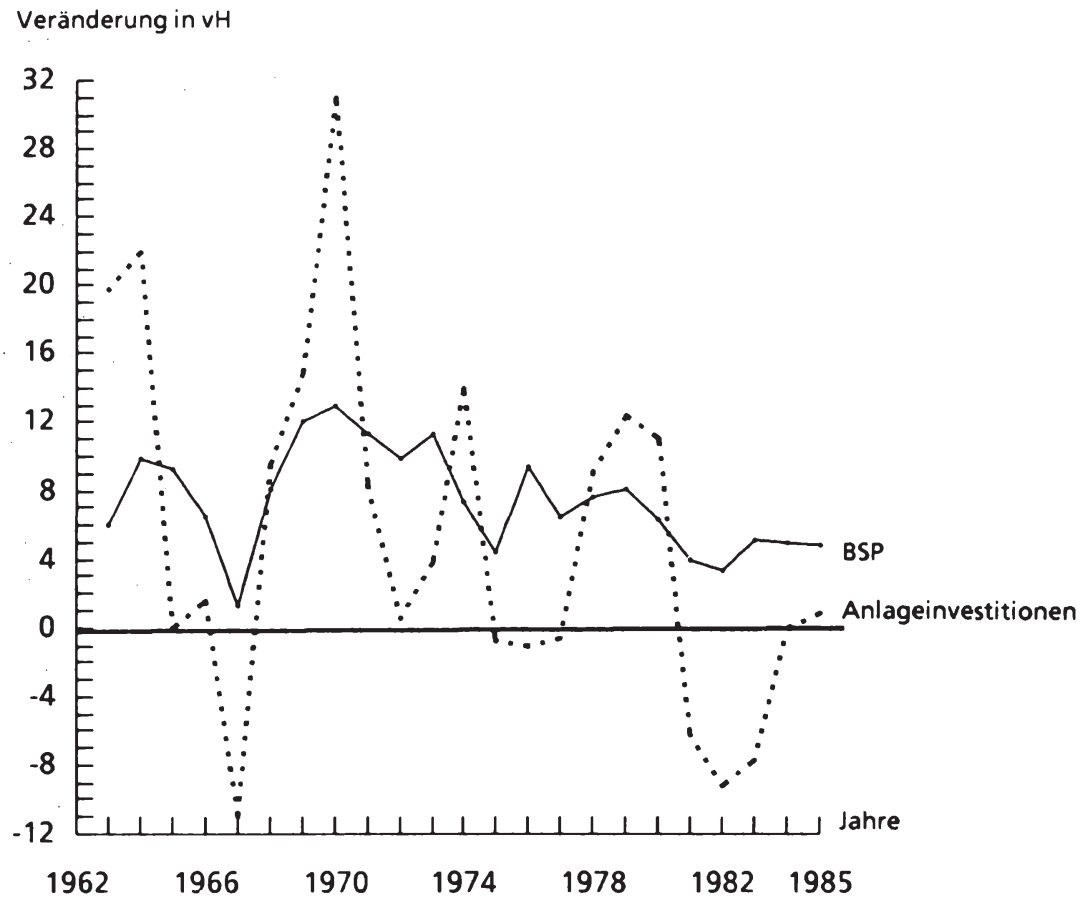

1) Vgl. Tahelle 10

stitionen $^{213)}$ gegenüber den jeweiligen Gesamtgrößen, d.h. die Abnahme des sektoralen Anteils gegenüber dem privaten Sektor, vollzog sich vor dem Hintergrund einer gesunkenen gesamitwirtschaftlichen Investitionsquote ${ }^{214)}$ (vgl. Tabelle 12).

213) Die Ausrüstungsinvestitionen des Staates spielen eine nur sehr unbedeutende Rolle. Vgl. Tabelle 10*b im Anhang.

214) Anteil der gesamten Bruttoanlageinvestitionen am Bruttosozialprodukt. 
Ungeachtet der instrumentellen Stabilisierungsfähigkeit der staatlichen Investitionsausgaben liefert die Gegenüberstellung ihrer Veränderungen mit den Wachstumsraten des Bruttosozialprodukts Anhaltspunkte über ihre Entwicklung im Konjunkturverlauf. ${ }^{215)}$ Der Vergleich zeigt, bis auf wenige Ausnahmen, ziemlich gleichgerichtete Veränderungen der Anlageinvestitionen des Staates und des Bruttosozialprodukts (vgl. Schaubild 3.11). Der empirische Befund deutet damit nicht auf ein antizyklisch ausgerichtetes Investitionsverhalten des Staates hin ${ }^{216)}$, sondern spricht im Gegenteil "für die These, daß die öffentlichen Investitionen überwiegend als abhängige Variablen des zyklisch vermittelten Wirtschaftswachstums zu werten sind."217) Dies erklärt auch, warum die kommunalen Investitionsausgaben vergleichsweise stark prozyklisch sind. ${ }^{218)}$ Gerade bei den Gemeinden sind die Investitionen sehr stark von der Differenz der laufenden Einnahmen und Ausgaben abhängig ${ }^{219}$, die ihrerseits stark vom wirtschaftlichen Verlauf bestimmt werden. Zusätzlich werden die Gemeindeinvestitionen positiv von der Höhe der Zweckzuweisungen des Bundes und der Länder beeinflußt ${ }^{2201}$, die selbst wiederum "normalerweise ... prozyklischen Einfluß aufweisen."221)

Die empirischen Analysen der Investitionsausgaben offentlicher Haushalte belegen einen deutlichen Bruch in deren Entwicklung zur Mitte der 70er Jahre. Die bis dahin expansive staatliche Investitionstätigkeit schwächte sich seither merklich ab. Die Bedarfsschätzungen der Infrastrukturinvestitionen, welche noch zu Beginn des letzten Jahrzehnts, wohl auch unter dem Eindruck der Thesen von

215) Vesper mißt die Form und Intensität der zyklischen Bewegungen mit Hilfe des "Wirkungsquotienten", den er als Verhältnis der Veränderungsraten der Investitionsausgaben und der Wachstumsrate des gesamtwirtschaftlichen Produktionspotentials definiert. Vgl. Vesper, D.: Das Verhalten ..., a.a.O., S. 271 insbes. Fußn. 1.

216) Vgl. hierzu auch Bartholmai, B. et al.: Gesamtwirtschaftliche und strukturelle Auswirkungen von Veränderungen der Struktur des öffentlichen Sektors, Heft 81 der Beiträge zur Strukturforschung, hrsg. v. Deutschen Institut für Wirtschaftsforschung, Berlin 1984, S. 83 f. sowie Littmann, K.: Öffentliche Investitionen, a.a.O., S. 822 f. und Leibfritz, W.: Mehr staatliche Investitionen ..., a.a.O., S. 5 ff.

217) Vesper, D.: Das Verhalten ..., a.a.O., S. 278.

Ähnlich auch bei Leibfritz, W.: Der Staat ..., a.a.O., S. 162, der allerdings Anfang der 80er Jahre Ansätze für eine antizyklische Ausrichtung der staatlichen Investitionen zu sehen glaubte.

218) Bartholmai, B. et al.: Gesamtwirtschaftliche und strukturelle ..., a.a.O., S. 83.

219) Vgl. Schwarting, G.: Kommunale Investitionen. Theoretische und empirische Untersuchungen der Bestimmungsgründe kommunaler Investitionstätigkeit in Nordrhein-Westfalen 1965-1972, Frankfurt/Main 1979, S. $175 \mathrm{ff}$.

220) Vgl. ebenda, S. 172.

221) Vgl. Bartholmai, B. et al.: Gesamtwirtschaftliche und strukturelle ..., a.a.O., S. 83. 
Galbraith, "Zuwachsraten für erforderlich hielten, die über dem gesamtwirtschaftlichen Wachstumspfad liegen sollten"222), wurden seither deutlich nach unten korrigiert. ${ }^{223)}$ Vor dem Hintergrund der demographischen Entwicklung wurden für weite Bereiche staatlicher Aufgabenfelder Bedarfssättigungen prognostiziert, die ein Schrumpfen oder Stagnieren der öffentlichen Investitionen erwarten ließen. ${ }^{224)}$

Gleichzeitig tauchte die Folgelastenhypothese auf, die den sich abzeichnenden Rückgang der Investitionsquoten mit den Folgelasten der Investitionsprojekte erklärte. ${ }^{2251}$ Sie erfreute sich rasch sehr großer Beliebtheit und führte zu einer fast unüberschaubaren Menge von einschlägigen Veröffentlichungen, die sich zumeist auf die kommunalen Investitionen beziehen und neben definitorischen Bemühungen auch konkrete empirische Untersuchungen enthalten. ${ }^{2261}$ Unabhängig von der Nützlichkeit praktischer Folgelastenuntersuchungen als Pla-

222) Bartholmai, B. et al.: Gesamtwirtschaftliche und strukturelle ..., a.a.O., S. 80.

Vgl. hierzu auch Krumsieck, R.; Lenz, D. und Wimmer, S.: Kommunaler Investitionsbedarf 1971 bis 1980, Köln 1967, S. 9 ff. sowie Aberle, G.: Verkehrsinfrastrukturinvestitionen im Wachstumsprozeß entwickelter Volkswirtschaften, Düsseldorf 1972, S. $21 \mathrm{ff}$. und Bartholmai, B.: Entwicklung und Struktur ..., a.a.O., S. $47 \mathrm{ff}$. Vgl. auch Leibfritz, W.: Mehr staatliche Investitionen ..., a.a.O., S. 13.

223) Vgl. die Ausführungen hierzu bei Leibfritz, W.: Der Staat ..., a.a.O., S. 164 ff., sowie Bartholmai, B. et al.: Gesamtwirtschaftliche und strukturelle ..., a.a.O., S. 80 f. Als Ausnahme hierzu siehe Höhnen, W.: Das DGB-Investitionsprogramm ..., a.a.O., S. 597, der von einem "längst nicht gedeckten personellen und investiven gesellschaftlichen" Bedarf ausgeht, welcher sich auch auf den Ausbau der Infrastruktur erstrecke.

224) Vgl. Gaddum, J.W.: Bevölkerungsentwicklung und öffentliche Investitionen, in: An den Grenzen der Belastbarkeit. Festschrift für Günter Schmölders zum 75. Geburtstag, hrsg. v. W. Haubrichs, Frankfurt/Main 1978, S. 137-155, S. $137 \mathrm{ff}$.

Die Mitarbeiter des Deutschen Instituts für Urbanistik beurteilen die Entwicklung etwas anders und erwarten für die Zukunft eine beträchtliche Zunahme des Ersatzbedarfs, sowie der Verlagerung der staatlichen Investitionen auf Bereiche wie die Stadterneuerung. Vgl. Deutsches Institut für Urbanistik: Kommunaler Investitionsbedarf ..., a.a.O., S. 9 ff. Vgl. auch Sachverständigenrat zur Begutachtung der gesamtwirtschaftlichen Entwicklung: Jahresgutachten 1984/85, a.a.O., Ziff. 230.

225) Vgl. Bundesministerium der Finanzen: Finanzbericht 1975, a.a.O., S. 98 sowie Ministerium der Finanzen Rheinland-Pfalz: Folgekosten öffentlicher Investitionen, Bad Ems 1975, S. $7 \mathrm{ff}$.

226) Vgl. die keineswegs vollständige Auflistung bei Schwarting, G.: Folgelasten und öffentliche Investitionsprogramme. Zum Einsatz von Folgelastendarstellungen als Planungsinstrument, in: Konkrete Probleme öffentlicher Planung. Grundlegende Aspekte der Zielbildung, Effizienz und Kontrolle, hrsg. v. E. Wille, Frankfurt/Main et al. 1986, S. 181-201, S. $182 \mathrm{ff}$. 
nungshilfen ${ }^{227)}$ und "unbeschadet ihrer möglichen grundsätzlichen Berechtigung diente die Folgelastenhypothese den öffentlichen Entscheidungseinheiten ... allzu häufig als pauschale Schutzbehauptung für die Sachnotwendigkeit"228) einer sinkenden Investitionsquote. Diese Diskussion über die Folgelasten der öffentlichen Investitionen, deren Anstöße in erster Linie aus der Praxis kamen ${ }^{229)}$, steht in einem gewissen Gegensatz zu den regierungsamtlichen Verlautbarungen, die zu Beginn des Kapitels erörtert wurden. Die Investitionen, auch die öffentlichen, stellen allgemein einen Begriff mit positivem Sinngehalt dar, weil die investive Verausgabung das Schaffen bzw. Erhalten von Vermögenswerten und weitsichtiges Handeln suggeriert. Von daher ist die sehr wohlwollende Beurteilung zwar verständlich, allerdings sprechen die Daten der empirischen Entwicklung eine andere Sprache. Im Gefolge der Bemühungen um Konsolidierung der öffentlichen Haushalte, die den Ausgabenspielraum auf längere Sicht erweitern sollten, bildeten die öffentlichen Investitionen - in erster Linie die Sachinvestitionen - ein bevorzugtes Opfer, da sie die "kurzfristig disponibelste Ausgabenkategorie"230) dar-

227) Vgl. Schwarting, G.: Folgelasten und öffentliche ..., a.a.O., S. 183 f.

Je nachdem, ob die Folgelastenüberlegungen im Rahmen einer Kosten-Nutzen-Analyse zur Beurteilung des geamtwirtschaftlichen Nutzens herangezogen werden oder ob im Rahmen einer haushaltsmäßigen Finanzplanung der zukünftige Ausgabenspielraum untersucht werden soll, empfiehlt es sich, die Folgelastenuntersuchungen auf dem Kostenbzw. dem Ausgabenkonzept aufzubauen. Vgl. Lenk, P. und Lang, E.: Herstellungskosten und Folgelasten öffentlicher Investitionen. Gutachten im Auftrag des Finanzministeriums des Landes Nordrhein-Westfalen, München 1981, S. $18 \mathrm{ff}$. und S. $39 \mathrm{ff}$.

Es versteht sich fast von selbst, daß auch andere staatliche Maßnahmen, die zunächst nicht direkt ausgabenwirksam sind (gesetzgeberische Versprechen) bzw. deren Ausgaben nicht zu den Investitionen zählen (Besoldungszusagen, Erweiterung der Rentenbasis) Folgeausgaben verursachen können, deren Beachtung im Sinne einer rationalen Entscheidungsfindung geboten ist.

228) Wille, E.: Öffentliche Sachausgaben ..., a.a.O., S. 79. Ähnlich beurteilt dies auch Schwarting in Schwarting, G.: Folgelasten und öffentliche ..., a.a.O., S. 183. Das Verdikt gegen die staatlichen Ausgaben, welche auf ein Niveau gebracht werden müssen, "das der Privatwirtschaft genügend Freiraum für Investitionen einräumt; denn private Investitionen erwirtschaften Erträge, während öffentliche Investitionen häufig nur Folgekosten verursachen" (Meyer, A.: Die öffentlichen Haushalte zwischen Konsum und Investition, in: Folgekosten öffentlicher Investitionen - Eine Last für die Zukunft?, hrsg. v. H. G. Stockinger, München 1982, S. 11-18) ist eine ganz offensichtlich maßlose und einseitige Betrachtung.

229) Vgl. Schwarting, G.: Folgelasten und öffentliche ..., a.a.O., S. $183 \mathrm{f}$.

Vgl. hierzu Bundesministerium der Finanzen: Finanzbericht 1975, a.a.O., S. 98; Ministerium der Finanzen Rheinland-Pfalz: Folgelasten öffentlicher Investition, a.a.O., S. 7 ff. sowie Meyer, A.: Die öffentlichen Haushalte ..., a.a.O., S. $11 \mathrm{ff}$.

230) Bundesministerium der Finanzen: Finanzbericht 1982, a.a.O., S. 20.

Vgl. hierzu auch die Ausführungen bei Vesper, D.: Das Verhalten ..., a.a.O., S. 277, der die öffentlichen Investitionen als die "flexibelste Ausgabenart" bezeichnete. 
stellen. Der Sachverständigenrat zur Begutachtung der gesamtwirtschaftlichen Entwicklung spricht in diesem Zusammenhang von "Konsolidierungsschäden"231) und fordert mittlerweile eine "qualitative Konsolidierung der öffentlichen Haushalte."232)

Die Beschränkung auf den Sektor Staat in der Abgrenzung der Volkswirtschaftlichen Gesamtrechnungen bzw. auf den Öffentlichen Gesamthaushalt der Finanzstatistik wird gerade bei der Analyse staatlicher Investitionsausgaben vielfach als nicht sachgerecht angesehen, weil damit die Investitionen öfentlicher Unternehmen unberücksichtigt blieben. ${ }^{233)}$ Dieses Problem ist umso dringlicher, als in den vergangenen Jahren eine Flucht aus dem Budget ${ }^{234}$ konstatiert wurde, hinter der strategische Absicht vermutet werden kann ${ }^{235)}$ und, weil im Bereich der öffentlichen Unternehmen in jüngster Zeit ein starker Anstieg der Investitionen festzustellen ist. ${ }^{236)}$ Mit dem Begriff "öffentliche Unternehmen" werden nun allerdings eine Vielzahl von Unternehmensformen belegt, so daß eine differenziertere Betrachtung notwendig ist. ${ }^{237)}$

Die Investitionen der Bruttobetriebe, welche mit ihren Einnahmen und Ausgaben voll in den Trägerhaushalt eingestellt werden, sind sowohl im Ausweis der Finanzstatistik als auch dem der Volkswirtschaftlichen Gesamtrechnungen ${ }^{238}$ ) enthalten. Die Nettobetriebe, bei denen es sich in aller Regel um öffentliche Unternehmen mit eigenverantwortlicher Werkleitung und einem kaufmännischen

231) Sachverständigenrat zur Begutachtung der gesamtwirtschaftlichen Entwicklung: Zur wirtschaftlichen Lage im Oktober 1982, Sondergutachten, BT-Drucksache 9/2027, Bonn 12. 10. 1982, Tz. 57.

232) Sachverständigenrat zur Begutachtung der gesamtwirtschaftlichen Entwicklung: Jahresgutachten 1984/85, Ziff. 345.

233) Vgl. Blum, R.: Bericht über ..., a.a.O., S. 293. Siehe hierzu auch die Ausführungen bei Bartholmai, B. et al.: Gesamtwirtschaftliche und strukturelle ..., a.a.O., S. $23 \mathrm{ff}$.

234) Siehe hierzu Smekal, C.: Die Flucht aus dem Budget, Wien 1977.

235) Vgl. auch Ring, U.: Öffentliche Planungsziele ..., a.a.O., S. $55 \mathrm{ff}$.

236) Vgl. Leetz, W.: Imposanter Anstieg der Investitionen, in: Öffentliche Wirtschaft und Gemeinwirtschaft (ÖWG), JG. XXXIII (1984), H. 3, S. 76-78, S. 76 ff.

237) Vgl. Rheinisch-Westfälisches Institut für Wirtschaftsforschung (RWI): Analyse der strukturellen Entwicklung der deutschen Wirtschaft (Strukturberichterstattung 1987), Bd. 3 (Schwerpunktthema): Die Auswirkungen staatlicher Marktregulierungen auf die sektorale Strukturbildung und Faktorallokation - Möglichkeiten und Auswirkungen von Deregulierungen in einzelnen Wirtschaftszweigen, Essen 1986, S. $30 \mathrm{ff}$.

238) In den VGR sind sie als fiktive Vermögensübertragungen an Unternehmen eingestellt. Vgl. die Ausführungen in Abschnitt 3.2.2. 
Rechnungswesen handelt, erscheinen lediglich mit dem Differenzbetrag zwischen ihren Ausgaben und Einnahmen im Trägerhaushalt. ${ }^{239)}$ Inwieweit Ausgaben für diese Unternehmen, die hauptsächlich die kommunalen Sondervermögen im Bereich der Versorgung und des Verkehrs betreffen, in den Investitionen der öffentlichen Haushalte bzw. des Staates enthalten sind, hängt von der finanziellen Verflechtung beider ab. Sind in den öffentlichen Haushalten Zuschüsse für Investitionen dieser Unternehmen eingestellt, so sind zumindest in diesem Umfang die Investitionsausgaben im Ausweis enthalten. Gleiches gilt für die Bundesbahn und Bundespost als Sondervermögen des Bundes, wobei die Bundesbahn Investitionszuschüsse von ca. $4 \mathrm{Mrd}$. DM erhält, die in etwa auch ihrem Investitionsvolumen entsprechen. ${ }^{240}$ ) Die Investitionen der Bundespost dagegen, die mit einem Volumen von über $18 \mathrm{Mrd}$. DM in $1986^{241)}$ dieses Unternehmen als den "bei weitem größten Investor in der Bundesrepublik Deutschland"242) ausweisen, erscheinen nicht in den öffentlichen Haushalten. Zusammen mit den Elektrizitätsversorgungsunternehmen tätigt die Bundespost den überwiegenden Teil der Investitionen der öffentlichen Unternehmen. ${ }^{243}$ ) Die Ausgaben der öffentlich-rechtlichen Unternehmen mit eigener Rechtspersönlichkeit im Bereich der Kreditinstitute sowie Versicherungs- und Wohnungswirtschaft ${ }^{244)}$ erscheinen ebenfalls nicht in den staatlichen Budgets, es sei denn, es würden entsprechende Zuschüsse gewährt. Daneben steht es der öffentlichen Hand frei, Unternehmen in privatrechtlicher Form zu gründen oder sich an solchen Unternehmen zu beteiligen. Unbeschadet der Probleme, die eine statistische Aussonderung der Ausgaben der "öffentlichen Unternehmen" bereitet ${ }^{245}$, bleiben auch die Fragen, ob sie "öffentlichen Interesse" dienen und, wie dieses Kriterium überhaupt ausgefültt werden

239) Vgl. Ring, U.: Öffentliche Planungsziele ..., a.a.O., S. 52 f.

240) Vgl. die entsprechenden Ausführungen in Abschnitt 3.2.

241) Vgl. den Bericht über die Sitzung des Verwaltungsrates der Deutschen Bundespost vom 5. Dezember 1986, in: Bulletin, hrsg. v. Presse- und Informationsamt der Bundesregierung, Nr. 156, 11. Dezember 1986, S. 1275.

242) Emmerich, V.: Anmerkungen zu den Postfinanzen, in: ORDO. Jahrbuch für die Ordnung von Wirtschaft und Gesellschaft, Bd. 35 (1984), S. 43 - 69, S. 47. Vgl. hierzu auch Zurhorst, B.: Bundespost als größter Investor, in: Öffentliche Wirtschaft und Gemeinwirtschaft (ÖWG), Jahrgang XXXIII (1984), H. 4, S. 100-103.

243) Vgl. Leetz, W.: Imposanter Anstieg ..., a.a.O., S. 77.

244) Vgl. Bartholmai, B. et al.: Gesamtwirtschaftliche und strukturelle ..., a.a.O., S. 24 f.

245) Vgl. Rheinisch-Westfälisches Institut für Wirtschaftsforschung (RWI): Analyse der strukturellen ..., a.a.O., S. $32 \mathrm{f}$. 
könnte, weitgehend unbestimmt. ${ }^{246)}$

Die Prognosen des Deutschen Instituts für Urbanistik hinsichtlich des kommunalen Investitionsbedarfs bis 1990 gehen von einem kräftigen Zuwachs der Investitionen bei den kommunalen Versorgungs- und Verkehrsunternehmen aus, während in den klassischen Infrastrukturbereichen Sättigungstendenzen bemerkbar seien. ${ }^{247)}$ Mit dieser Verlagerung des öffentlichen Investitionsbedarfs hin zu den öffentlichen Unternehmen verändern sich auch die Faktoren, die eine Investitionsentscheidung beeinflussen und die Möglichkeiten ihrer Finanzierung. ${ }^{248}$ ) Gleichzeitig gewinnen damit unter Umständen die mittelbaren Investitionen in Form von Zuschüssen an Bedeutung.

Die empirischen Untersuchungen der öffentlichen Invesitionen legen eine Fülle von Detailproblemen offen, die zum größten Teil aus den Fragen ihrer sachgerechten Abgrenzungen resultieren. Die Analyse der Ausgaben läßt dabei auch unberücksichtigt, daß staatliche Entscheidungsträger denselben Sachverhalt auch mit Einnahmenverzicht anstreben können. ${ }^{249)}$ Apodiktischen Schlußfolgerungen ist deshalb, gerade wenn sie die staatlichen Investitionsausgaben betreffen, mit größter Zurückhaltung zu begegnen. Die positive Wertschätzung, die die öffentlichen Investitionsausgaben im Gegensatz zu anderen Ausgabenkategorien erfahren, ist darüber hinaus unter allokativen Gesichtspunkten nicht zu rechtfertigen, weil die Investitionen ja vielfach in einem limitationalen Verhältnis zu den anderen Ausgaben stehen und erst mit diesen zusammen das öffentliche Angebot bilden. ${ }^{250}$

246) Vgl. Rheinisch-Westfälisches Institut für Wirtschaftsforschung (RWI): Analyse der strukturellen ..., a.a.O., S. $30 \mathrm{f}$. Vgl. auch Kitterer, W.: Öffentlicher Haushalt und öffentliche Unternehmen: Planungs- und Organisationsaspekte der intermediären Erfüllung offentlicher Ausgaben, in: Konkrete Probleme öffentlicher Planung. Grundlegende Aspekte der Zielbildung, Effizienz und Kontrolle, hrsg. v. E. Wille, Frankfurt/ Main et al. 1986, S. $143-179$, S. $143 \mathrm{ff}$.

247) Vgl. hierzu Deutsches Institut für Urbanistik: Kommunaler Investitionsbedarf ..., a.a.O., S. $52 \mathrm{ff}$. und S. $106 \mathrm{ff}$.

248) Vgl. Leibfritz, W.: Mehr staatliche Investitionen ..., a.a.O., S. 12.

249) Es dürfte für einen privaten Investor ziemlich egal sein, sofern er Steuern zahlt, ob er vom Staat eine Investitionsprämie erhält oder ob der Staat auf einen entsprechenden Betrag der Steuerschuld verzichtet.

250) Vgl. Wille, E.: Öffentliche Sachausgaben ..., a.a.O., S. $30 \mathrm{ff}$. 


\section{Die öffentlichen Investitionen in finaler Sicht}

\subsection{Der Investitionsbegriff im allgemeinen}

Die vorstehenden Ausführungen zur empirischen Entwicklung der Investitionsausgaben bedürfen schließlich noch einer ergänzenden Analyse der besonderen Eigenschaften und Merkmale, welche die Investitionen gegenüber anderen Ausgabenkategorien "auszeichnen", um so die empirischen Ergebnisse bewerten zu können.

Obwohl der Begriff der Investition "voll und ganz zum Kanon der Lehrbuchliteratur ... zu gehören scheint"1), gibt es keinen einheitlichen Investitionsbegriff. ${ }^{2)}$ Gleichwohl verdeutlichen die verschiedenen Abgrenzungen und Definitionsversuche einige grundlegende Elemente der Investitionen. Nach Stobbe liegt dann ein Investitionsproblem vor, "wenn Entscheidungen über die Festlegung von Mitteln oder den Verzicht auf Erträge mit Wirkung für mehrere ... Planperioden zu treffen sind."3) Arrow beschreibt den Investitionsvorgang als "the allocation of current resources which have alternative productive uses, to an activity whose benefits will accrue over the future."4) Eine ähnliche Beschreibung geben Palm und Quayum, für die eine Investition "a commitment to some costs in exchange for an anticipated flow of benefits" bedeutet. ${ }^{5)}$ Rürup wiederum bezeichnet "den Teil der in einer Volkswirtschaft erstellten Güter ..., der nicht in der laufenden Periode verbraucht wird, sondern auch noch in kommenden Perioden Leistungen abgibt" als Investition. ${ }^{6)}$

1) Ott, A.E.: Investitionseffekte, in: Neuere Entwicklungen in der Investitionstheorie und -politik, hrsg. v. G. Bombach, B. Gahlen und A.E. Ott, Tübingen 1980, S. 299-316, S. 299.

2) Vgl. hierzu auch Schörry, O.: Art.: Investitionsstatistik, in: Handwörterbuch der Sozialwissenschaften (HdSW), hrsg. v. E. von Beckerath et al., 5. Bd., Stuttgart et al. 1956, S. 347-354, S.347 und Uhlmann, L.: Konsum- und Investitionsverhalten in der Bundesrepublik Deutschland seit den fünfziger Jahren, Bd. II: Das Investitionsverhalten der Industrie im Spiegel von Investorenbefragungen, Berlin 1981, S. 7 f.

3) Stobbe, A.: Volkswirtschaftslehre II. Mikroökonomik, Berlin et al. 1983, S. 255.

4) Arrow, K. J.: Criteria for Social Investment, in: Economics of the Environment. Selected Readings, ed. by R. Dorfmann and N.S. Dorfmann, 2nd ed., New York 1977, S. 409-417, S. 410.

5) Palm, T. and Quayum, A.: Private and public investment analysis, Cicinnati (USA) et al. 1985, S. 2.

6) Rürup, B.: Methoden und Kriterien der Investitionsentscheidungen in der öffentlichen Verwaltung, in: Investition. Erklärung und Planung durch Simulation, hrsg. v. F.X. Bea, A. Bohnet und H. Klimesch, München, Wien 1981, S. 137-154, S. 138. 
Die vorstehenden Beschreibungen und Definitionsversuche belegen allesamt gleichsam als ein konstitutives Element der Investitionen, das Erfordernis, über einen längeren Zeitraum hinweg wirtschaftlich zu disponieren. ${ }^{71}$ Investitionen stellen damit Ausgaben und/oder Einnahmenverzichte für die Anschaffung von Gütern dar, deren Nutzungsdauer sich über mehr als eine Periode erstreckt. ${ }^{8}{ }^{8}$ Sie nehmen damit Einfluß auf Bestandsgrößen der Wirtschaftssubjekte ${ }^{9)}$, z.B. deren Vermögensposition.

Aus volkswirtschaftlicher Sicht bedeutet eine Investition Konsumverzicht in der Erstellungsphase, um künftig Güter verbrauchen zu können. Eine Investition vornehmen heißt daher in diesem Sinne, "Güter zur Erhaltung, Erweiterung oder Verbesserung des Produktionsapparates einer Volkswirtschaft" zu verwenden. ${ }^{10)}$ Aus betriebswirtschaftlicher Sicht bedeutet die Investition "eine Anlage finanzieller Mittel in Objekte materieller und immaterieller Art, die im Hinblick auf die Zielsetzung des Investors längerfristig von Nutzen zu sein versprechen." ${ }^{11)}$ Sie umfaßt demgemäß "die Beschaffung von Produktionsfaktoren, insbesondere Betriebsmitteln (Sachinvestitionen), von Wertpapieren und Forderungen (Finanzinvestitionen), die mit einer Bindung von Kapital verbunden ist, wobei sich diese über mehrere Perioden erstreckt."12)

7) Vgl. Helmstädter, E.: Die Investitionstheorie und der Zeitaspekt, in: Neuere Entwicklungen in der Investitionstheorie und der Zeitaspekt, in: Neuere Entwicklungen in der Investitionstheorie und -politik, hrsg. v. G. Bombach, B. Gahlen und A.E Ott, Tübingen 1980, S. 181 204, S. $184 \mathrm{ff}$.

8) Es ist sicher richtig, daß, wie Toillié anmerkt, "jede Periodenabgrenzung auf Konvention beruht" (Toillié, B.: Offentliche Investitionen ..., a.a.O., S. 64). Definitionen sind aber immer aus $\mathrm{Zweckmäßigkeitsüberlegungen} \mathrm{heraus} \mathrm{zu} \mathrm{bilden} \mathrm{und} \mathrm{von} \mathrm{daher} \mathrm{bietet} \mathrm{sich} \mathrm{in} \mathrm{diesem}$ Fall ein Jahr als Periodenabgrenzung geradezu an. Die privaten Unternehmen sind aus Publizitätsgründen und durch steuerrechtliche Bestimmungen gehalten, Jahresabschlüsse vorzulegen. Für den Bund und die Länder bestimmen $\S 8 \mathrm{Abs}$. $1 \mathrm{HGrG}$ und $\S 11 \mathrm{Abs}$. $1 \mathrm{BHO}$ gleichlautend: "Für jedes Haushaltsjahr ist ein Haushaltsplan aufzustellen." Dies wird auch nicht dadurch verändert, daß manche Länder in der Bundesrepublik Haushaltspläne verabschieden, die zwei Jahre umfassen. Für diesen Fall sehen § 9 Abs. 1 HGrG und $\S 12$ Abs. 1 BHO vor: "Der Haushaltsplan kann für zwei Haushaltsjahre, nach Jahren getrennt, aufgestellt werden."

9) Vgl. Helmstädter, E.: Die Investitionstheorie ..., a.a.O., S. 186.

10) Kromphardt, J.: Art.: Investitionen I: volkswirtschaftliche, in: Handwörterbuch der Wirtschaftswissenschaft (HdWW), hrsg. v. W. Albers et al., Bd. 4, Stuttgart et al. 1978, S. 246 254, S. 246 f.

11) Jacob, H.: Art.: Investitionen II: betriebswirtschaftliche, in: Handwörterbuch der Wirtschaftswissenschaft (HdWW), hrsg. v. W. Albers et al., Bd. 4, Stuttgart et al. 1978, S. 254275 , S. 255.

12) Seelbach, H.: Investition, in: Allgemeine Betriebswirtschaftslehre, hrsg. v. F.X. Bea, E. Dichtl und M. Schweitzer, Bd. 3: Leistungsprozeß, Stuttgart, New York 1985, 4. Kapitel, S.151-211, S. 151. 
Nach Littmann ist die Aufteilung in konsumtive und investive öffentliche Ausgaben "mehr oder weniger auf die Neigung zurückzuführen, Tätigkeiten des öffentlichen Bereichs mit der marktwirtschaftlichen Elle zu messen."13) Es erscheint daher sinnvoll, private und öffentliche Investitionen einander gegenüberzustellen.

Bei privatwirtschaftlich organisierten Unternehmen verlangt die Ermittlung des Periodenerfolges die Ausgaben für Güter, die eine längerfristige Leistungsabgabe besitzen, systematisch zu erfassen, um damit "das Erfolgskriterium des Wirtschaftens, den Gewinn, genauer zu periodisieren."14) Für den öffentlichen Bereich gilt aber, daß die periodische Anrechnung zum Zwecke der Gewinnermittlung nicht erforderlich ist, "da der Gewinn allein ein marktwirtschaftliches und kein staatswirtschaftliches Erfolgskriterium bildet." ${ }^{15)}$ Die Unterscheidung in Investition und Konsum ${ }^{16)}$ ist deshalb aus diesem, in der Privatwirtschaft berechtigten Grund, beim Staat nicht nötig. Die zeitgerechte Anrechnung der Investitionsgüter erfolgt in den privatwirtschaftlich organisierten Unternehmen mit Hilfe der Abschreibungen. Die Haushaltspläne von Bund, Ländern und Gemeinden enthalten dagegen keine Abschreibungen, da sie keine Jahresabschlüsse zur Ermittlung einer Erfolgsposition, sondern Ausgaben- bzw. Einnahmenermächtigungen darstellen. In den Produktions- und Vermögensänderungskonten der Volkswirtschaftlichen Gesamtrechnungen sind auch beim Staat Abschreibungen eingestellt, was auf eine Übereinstimmung zur privatwirtschaftlichen Vorgehensweise hinzudeuten scheint. Diese Analogie besteht in Wirklichkeit jedoch nicht, weil sich diese Abschreibungen nur auf ein sehr kleines Segment des öffentlichen Sachvermögens beziehen. ${ }^{17)}$

Einzelwirtschaftlich bedeutet "Investition die Festlegung von Mitteln über einen längeren Zeitraum in der Erwartung, Erträge zu erzielen."18) Öffentliche

13) Littmann, K.: Öffentliche Investitionen, a.a.O., S. 813.

14) Ebenda, S. 814.

15) Ebenda, S. 814.

16) Vgl. hierzu auch Meinhold, H.: Art.: Investitionen, in: Handwörterbuch der Sozialwissenschaften (HdSW), hrsg. v. E. von Beckerath et al., 5. Bd., Stuttgart et al. 1956, S. 333-346, S.334.

17) Vgl. Bombach, G.: Die öffentliche Finanzwirtschaft ..., a.a.O., S. 66.

18) Stobbe, A.: Volkswirtschaftslehre II ..., a.a.O., S. 255. 
Investitionen entziehen sich aber in aller Regel solchen Rentabilitätsüberlegungen, denn die erwarteten Erträge öffentlicher Investitionen sind quantitativ kaum zu erfassen. ${ }^{19}$ ) Selbst "ex-post gibt es teilweise keine genauen Kriterien, die über den Erfolg oder Nichterfolg einer staatswirtschaftlichen Investition Aufschluß geben." ${ }^{201}$ Die Ursachen liegen u.a. darin, daß die Ziele bzw. Zielfunktionen staatlicher Entscheidungsträger weit mehrdimensionaler und heterogener sind als die einer Unternehmung. ${ }^{21}$ 'Sie schließen zumeist eine aggregierte Bewertung öffentlicher Investitionen aus, die darüber hinaus vielfach durch das Fehlen von Marktpreisen erschwert wird. Die Nichtanwendbarkeit privatwirtschaftlicher Rentabilitätskalküle bei der Bewertung öffentlicher Projekte gründet nicht zuletzt aber auch darin, daß die Vorteile öffentlicher Investitionsprojekte in aller Regel "nicht im öffentlichen Bereich, sondern bei den privaten Wirtschaftseinheiten anfallen, ohne daß mit ihnen Markterlöse verbunden wären." ${ }^{22)}$ Private Investitionen beziehen sich zum größten Teil auf Vorgänge innerhalb eines Unternehmens. Ihre Leistungsabgaben lassen sich somit mit den internen, d.h. im Kalkül des Investors sichtbaren, Wirkungen messen. ${ }^{23)}$ Öffentliche Investitionen dagegen umfassen neben solchen Ausgaben für Produktionsmittel (z.B. EDV-Anlage für die Verwaltung) "auch einzelne produzierte Leistungen, also Teile des Outputs selbst"24) (z.B. öffentliche Straßen). Private Investitionen knüpfen immer an Prozessen innerhalb des Unternehmens an, während sich die öffentlichen Investitionen sowohl auf innengerichtete wie auch außengerichtete Vorgänge erstrecken können. ${ }^{25)}$ Wegen dieser Außenorientierung stehen viele staatliche Investitionen in einer komplementären Beziehung zur privaten Investitionstätigkeit, insoweit als diese Investitionen Vorleistungscharakter für die private Produktion besitzen. ${ }^{26)}$

19) Vgl. Vesper, D.: Das Verhalten ..., a.a.O., S. 257.

$\mathrm{Zu}$ den verschiedenen Bewertungsmethoden öffentlicher Investitionen siehe Rürup, B.: Methoden und Kriterien ..., a.a.O., S. $139 \mathrm{ff}$.

20) Littmann, K.: Zunehmende Staatstätigkeit ..., a.a.O., S. 106.

21) $\mathrm{Vgl}$. auch die diesbezüglichen Ausführungen bei Rürup, B.: Methoden und Kriterien ..., a.a.O., S. 138.

22) Wissenschaftlicher Beirat beim Bundesministerium der Finanzen: Gutachten zum Begriff ..., a.a.O., S. 42.

23) Vgl. Rürup, B.: Methoden und Kriterien ..., a.a.O., S. 139.

24) Toillié, B.: Öffentliche Investitionen ..., a.a.O., S. 15.

25) Vgl. . Toillié, B.: Öffentliche Investitionen ..., a.a.O., S. 15 f. und Wille, E.: Zum Verhältnis ..., a.a.O., S. 334 .

26) Vgl. Wille, E.: Zum Verhältnis ..., a.a.O., S. 344. Siehe auch Vesper, D.: Das Verhalten ..., a.a.O., S. $257 \mathrm{f}$., der darauf hinweist, daß offentliche Investitionen eine umso wohlwollendere Beurteilung erfahren, je unmittelbarer ihr komplementärer Charakter zur privaten Investitionstätigkeit ersichtlich ist. 
Schließlich nehmen staatliche Entscheidungsträger sehr direkten Einfluß auf die privaten Investitionen, indem sie Finanzierungshilfen in Form von Zuschüssen oder Steuernachlässen gewähren, wobei in diesen Fällen die Frage auftaucht, ob und in welchem Umfang diese Hilfen zu den privaten oder öffentlichen Investitionen rechnen sollen. ${ }^{27)}$

\subsection{Wirkungstheoretische A bgrenzungsversuche}

Die Investitionen, die, wie die vorstehenden Ausführungen verdeutlichen, selbst "unmittelbar keine Bedürfnisse decken" können ${ }^{28}$, gewinnen ihre volkswirtschaftliche Bedeutung und ihren Reiz aus den ihnen unterstellten Wirkungen. In der Literatur finden sich hierzu mehr oder minder umfangreiche Listen verschiedenster Effekte ${ }^{29}$ ), wobei Uhlmann darauf hinweist, daß eine "umfassende und empirisch überprüfte Theorie der Investitionseffekte noch aussteht." ${ }^{30)}$

Die Darstellung der Versuche, die Investitionen wirkungstheoretisch zu begründen, geschieht vor dem Hintergrund der Zweifel, "ob die Wirkungen öffentlicher Ausgaben praeter propter bekannt oder zumindest in Umrissen abzuschätzen" sind. ${ }^{31)}$ Wie auch schon Fecher in diesem Kontext feststellte, können wirkungstheoretische Begriffe "schwerlich a priori gelten"32), da sie am Ergebnis einer

27) Staatliche Entscheidungsträger können die privaten Investitionen auch auf andere Weise beeinflussen. So kann das allgemeine politische Klima und die sog. Rahmenbedingungen (Steuersystem) ebenso einen Einfluß auf die Investitionsbereitschaft besitzen wie auch die staatliche Kreditaufnahme, die u.U. auf die Zinsentwicklung einwirkt. Die Einflußnahme kann auch über staatliche Normsetzungen erfolgen. Vgl. die Ausführungen bei Zimmermann, H. und Henke, K.-D.: Finanzwissenschaft ..., a.a.O., S. $337 \mathrm{ff}$.

28) Uhlmann, L.: Konsum- und Investitionsverhalten ..., a.a.O., S. 2

Bombach spricht in diesem Kontext davon, daß "der Investitionsprozeß nicht Selbstzweck, sondern nur Umweg zu höherem Konsum ist". Bombach, G.: Konsum oder Investitionen ..., a.a.O., S. 55 .

29) Vgl. Meinhold, H.: Investitionen, a.a.O., S. 337; Kromphardt, J.: Investitionen I: volkswirtschaftliche, a.a.O., S. 250 ff.; Rall, L. und Wied-Nebbeling, S.: Ausmaß, Ursachen und Wirkungen der Investitionslücke in der Bundesrepublik Deutschland. Gutachten im Auftrag des Bundesministers für Wirtschaft, Tübingen 1980, S. 173 ff.; Uhlmann, L.: Konsum- und Investitionsverhalten ..., a.a.O., S. $2 \mathrm{ff}$. und Ott, A.E.: Investitionseffekte, a.a.O., S. $30 \mathrm{ff}$.

30) Uhlmann, L.: Konsum- und Investitionsverhalten ..., a.a.O., S. 4.

31) Littmann, K.: Über einige Probleme einer Wirkungslehre öffentlicher Ausgaben, in: Beiträge zur Theorie der öffentlichen Ausgaben, hrsg. v. H. Timm und H. Haller, Schriften des Vereins für Socialpolitik, N.F. Bd. 47, Berlin 1967, S. 277-298, S. 278.

32) Fecher, H.: Ausgaben, öffentliche ..., a.a.O., S. 336. 
Wirkungsanalyse ansetzen und somit lediglich teleologisch zu deuten sind..$^{33)}$ Gleichwohl demonstrieren diese Bemühungen die Bandbreite des Investitionsbegriffes und zeigen gleichzeitig die Kluft zwischen den praktischen Abgrenzungen und den theoretischen Ansprüchen auf.

\section{In diesem Kontext bilden}

- der positive Zukunftsnutzen

- die wachstumsfördernde Wirkung und

- der Einfluß auf die Vermögenssituation

die Grundlage der wirkungstheoretisch orientierten Abgrenzungsversuche öffentlicher Investitionen. ${ }^{34}$ ' Toillié verweist in diesem Zusammenhang auch auf die stabilisierungspolitische Funktion der Investitionen des Staates ${ }^{35}$, wobei sie allerdings diese Zweckbestimmung, die auf den Einkommens- und Beschäftigungseffekt abstellt ${ }^{36}$, selbst als wenig taugliches Abgrenzungskriterium betrachtet. ${ }^{371}$

\subsection{1. Öffentliche Investitionen und positiver Zukunftsnutzen}

Wie schon oben angedeutet betreffen die Wirkungen öffentlicher Ausgaben in aller Regel nicht nur den öffentlichen Sektor, sondern auch den privaten Bereich, entsprechend erstrecken sich die einzubeziehenden Nutzenwirkungen auf alle Wirtschaftssubjekte der Volkswirtschaft. ${ }^{38)}$ Nach diesem Abgrenzungskriterium

33) Vgl. Fecher, H.: Ausgaben, öffentliche ..., a.a.O., S. 336. Siehe auch Wille, E.: Zum Verhältnis ,.., a.a.O., S. 348 .

34) Vgl. Toillié, B.: Öffentliche Investitionen, a.a.O., S. 11 f; Wissenschaftlicher Beirat beim Bundesministerium der Finanzen: Gutachten zum Begriff ..., a.a.O., S. 29 ff. sowie Littmann, K.: Öffentliche Investitionen, a.a.O., S. $815 \mathrm{f}$.

35) Vgl. Toillié, B.: Öffentliche Investitionen, a.a.O., S. 11. Siehe hierzu auch Kromphardt, J.: Investitionen I: volkswirtschaftliche ..., a.a.O., S. 252 und Brümmerhoff, D.: Finanzwissenschaft, München, Wien 1986, S. 17.

36) Vgl. hierzu Rall, L. und Wied-Nebbeling, S.: Ausmaß, Ursachen ..., a.a.O., S. $173 \mathrm{ff}$.

37) Vgl. Toillié, B.: Öffentliche Investitionen, a.a.O., S. 11.

Der stabilisierungspolitische Effekt öffentlicher Ausgaben, sofern man einen solchen überhaupt anerkennt, hängt u.a. von der konkreten Ausgangssituation, der Dosierung und dem zeitgerechten Einsatz und auch vom Finanzierungsaspekt ab. Es ist deshalb unmöglich, mit Hilfe dieses Kriteriums investive Ausgaben, also solche mit positiver stabilisierungspolitischer Wirkung, von anderen zu trennen, zumal positive konjunkturelle Einflüsse von jeder Ausgabenkategorie ausgehen können.

38) Vgl. Wissenschaftlicher Beirat beim Bundesministerium der Finanzen: Gutachten zum Begriff ..., a.a.O., S. 32 .

Es ist sogar sehr leicht vorstellbar, daß der Nutzen öffentlicher Leistungen, z.B. im Bereich der Entwicklungshilfe, bei ausländischen Wirtschaftseinheiten anfällt. 
sollten also alle öffentlichen Ausgaben, die bei einem einzelnen oder einer Gruppe von Individuen zukünftig positiven Nutzen stiften, zu den öffentlichen Investitionen zählen.

Der Aspekt der positiven Zukunftsnutzen resultiert teilweise aus der mehrjährigen Lebensdauer öffentlicher Anlagen, sofern diese Ausgaben den Präferenzen der Bürger entsprechen. Die mehrjährige Lebensdauer öffentlicher Anlagen bildet allerdings keine notwendige Voraussetzung für die künftige positive Nutzenwirkung der öffentlichen Aktivität. So ist das ganze Bildungssystem darauf abgestellt, den Staatsbürgern zukünftigen Nutzen zu bringen. ${ }^{39)}$ Dementsprechend müßten alle Ausgaben für die allgemeine und berufliche Ausbildung als Investitionen gelten ${ }^{40}$, zumal es nach dem Kriterium gleichgültig ist, ob der Nutzen der Bildungsleistung rein privater Natur bleibt. Ähnlich verhält es sich mit dem überwiegenden Teil der Ausgaben im Gesundheitsbereich. Darüber hinaus erzeugen die meisten staatlichen Sachausgaben, z.B. Baumaßnahmen oder Kauf maschineller Anlagen, außer ihrer Beschäftigungswirkung in der Erstellungsphase, erst dann Nutzen wenn mit ihnen eine öffentliche Leistung angeboten werden kann, d.h. wenn die entsprechenden komplementären Personal- und Unterhaltungsleistungen aufgebracht werden.

Die Investitionsbegriffe des Haushaltsrechts und der amtlichen Statistik sind somit unter Zugrundelegung dieser Betrachtungsweise viel zu eng gefaßt. Gleichzeitig wird aber auch deutlich, daß das Unterscheidungsmerkmal keine "materielle Funktion" mehr besitzt ${ }^{41}$, da letztlich alle öffentlichen Ausgaben nur durch ihren positiven Nutzen legitimiert sind "und nahezu jede öffentliche Aktivität auch für die Entwicklung zukünftiger Perioden von Bedeutung ist." ${ }^{\text {2) }}$ Hinzu kommt, daß der Nutzenansatz von vornherein eine Aufrechnung positiver und negativer Ausprägungen kaum zuläßt. ${ }^{43)}$

39) Vgl. Littmann, K.: Öffentliche Investitionen, a.a.O., S. 815.

40) Littmann sieht hierin die "unangebrachte Neigung, auch die Bedeutung von Bildungsausgaben durch ihre Deklaration als Investitionen in das 'human-capital' herauszustellen", die sich in erster Linie aus politischen Vorurteilen erklärt. Littmann, K.: Öffentliche Investitionen, a.a.O., S. 815.

41) Ebenda, S. 815 .

42) Wissenschaftlicher Beirat beim Bundesministerium der Finanzen: Gutachten zum Begriff ..., a.a.O., S. 32.

43) Eine Ursache hierfür liegt in der sehr individualistischen Ausrichtung des Nutzenansatzes. Vgl. auch Krelle, W.: Dynamisierung der Nutzenfunktion, in: Zeitschrift für Nationalökonomie (Journal of Economics), Bd. 32 (1972), S. 59-70, S. 60. 


\subsection{2. Öffentliche Investitionen und Wirtschaftswachstum}

Wirtschaftliches Wachstum bildet zwar schon seit jeher ein Grundproblem der Nationalökonomie ${ }^{44}$ ), trotzdem fand das Wachstumsziel erst vergleichsweise spät Eingang in den wirtschaftspolitischen Zielkatalog. ${ }^{45}$ Die Veränderung des realen Sozialprodukts galt lange Zeit als alleiniger Maßstab für das Wirtschaftswachstum, bis etwa Anfang der 70er Jahre eine umfassende wissenschaftliche und politische Diskussion einsetzte, in deren Verlauf die Forderung nach einer qualitativen Ergänzung dieses eindimensionalen monetären Wachstumsindikators auftauchte. ${ }^{461}$ Entsprechend vielschichtig ist mittlerweile der Begriff des Wirtschaftswachstums. ${ }^{471}$

Ausgangspunkt der modernen Wachstumstheorie bildete die Erweiterung der kurzfristigen Keynesschen Analyse. ${ }^{48)}$ Domar ergänzte diese Sichtweise, die lediglich den Einkommenseffekt der Investitionen betrachtete, durch die explizite Berücksichtigung des Kapazitätseffektes und zeigte die duale Natur des Investi-

44) Vgl. Neumann, M.: Art.: Wachstumspolitik, in: Handwörterbuch der Wirtschaftswissenschaft (HdWW), hrsg. v. W. Albers et al., Bd. 8, Stuttgart et al. 1980, S. 462-475, S. 462 und Helmstädter, E.: Art.: Wachstumstheorie I: Überblick, in: Handwörterbuch der Wirtschaftswissenschaft (HdWW), hrsg. v. W. Albers et al., Bd. 8, Stuttgart et al. 1980, S. 475-492, S. 478 ff.

Vgl. auch Domar, E.D.: A Theoretical Analysis of Economic Growth, in: Essays in the Theory of Economic Growth, ed. by E.D. Domar, New York 1957, S. 16-34, der es als absurd bezeichnete zu behaupten "that economic growth is a new subject" (ebenda, S. 16) und einen kurzen dogmenhistorischen Überblick gibt (ebenda, S. 16 ff.).

45) Vgl. Walter, H.: Theoretische Probleme und Ansatzpunkte der Wachstumspolitik, in: Das Wirtschaftsstudium (Wisu), 13. Jg. (1984), S. 36-42, S. 36 f. und Schlecht, O.: Wirtschaftswachstum wozu, wie, womit?, Nr. 79 der Reihe: Vorträge und Aufsätze des Walter Eucken Instituts, Tübingen i 980, S. 5 ff.

Schlecht schildert nicht nur die Einwände gegen die Aufnahme des Wachstumsziels in den wirtschaftspolitischen Zielkatalog, sondern belegt ebenso wie Walter die enge Verbindung zwischen wirtschaftlichem Wachstum und "nahezu allen sonstigen wirtschaftspolitischen Problemen". Walter, H.: Theoretische Probleme ..., a.a.O., S. 38.

46) Vgl. Frey, R.L.: Wachstumspolitik, Stuttgart, New York 1979, S. 1 und S. 11 ff.; Herdzina, K.: Wirtschaftliches Wachstum, Strukturwandel und Wettbewerb, Berlin 1981, S. $21 \mathrm{ff}$. sowie Zimmermann, H. und Henke, K.-D.: Die Finanzwissenschaft ..., a.a.O., S. 332.

47) Vgl. Hohmann, R.: Wachstum und Reallokation. Ansatzpunkte zur Wachstumssteigerung durch Reallokation, Diss., Wuppertal 1984, S. $19 \mathrm{ff}$.

Nach Herdzina bedeutet "Wachstum eine Durchbrechung des stationären Zustandes im Sinne einer Aufwärtsentwicklung", wobei die Frage besteht, "welche ökonomischen Variablen den stationären Zustand durchbrechen". Herdzina, K.: Wirtschaftliches Wachstum ..., a.a.O., S.21.

48) Vgl. Jürgensen, H.: Wachstums- und Verteilungseffekte ..., a.a.O., S. 80 sowie Heiduk, G.: Gewährleistet die Zunahme der Investitionen eine Erhöhung des gesamtwirtschaftlichen Wachstums?, in: Das Wirtschaftsstudium (Wisu), 8. Jg. (1979), S. 81-87, S. 81. 
tionsprozesses auf ${ }^{49)}$ : "On the left side it generates income via multiplier effect; and on the right side it increases productive capacity." ${ }^{50 \prime}$ Er legte damit den Grundstock für eine Fülle von Arbeiten ${ }^{51}$, bei denen zunächst fast ausschließlich die Höhe der privaten Investitionen die Hauptdeterminante des Wachstums bildete. Empirische Untersuchungen bestätigen allerdings diesen strikten allgemeinen Zusammenhang zwischen Investitionsquote und Wirtschaftswachstum nicht ${ }^{52}$, denn den weitaus größten Teil der Wachstumsraten erklärt in diesen statistischen Modellen die Residualgröße "technischer Fortschritt". ${ }^{53}$ Sie beinhaltet Faktoren wie den Wissensstand der Bevölkerung, die Möglichkeiten technischer Innovationen sowie die gegebene Wettbewerbssituation, die ihrerseits wiederum nicht unabhängig von der Investitionstätigkeit sind. ${ }^{54)}$ Der hohe Abstraktionsgrad der modernen Wachstumstheorie bildet den Hintergrund der weit verbreiteten Klage, daß die "Wachstumspolitik von der Wachstumstheorie bisher kaum verwertbare, praxisrelevante und operational handhabbare Anregungen erhalten" habe. ${ }^{551}$

49) Domar bezeichnet diejenigen, die den Kapazitätseffekt der Investitionen ignorierten, als besonders "zealous Keynesians". Domar, E.D.: A Theoretical Analysis ..., a.a.O., S. 19.

50) Domar, E.D.: Expansion and Employment, in: Essays in the Theory of Economic Growth, ed. by E.D. Domar, New York 1957, S. 83-108, S. 98.

51) Die verschiedenen Arbeiten werden dabei in aller Regel in bestimmte Modellklassen eingeteilt. So besteht neben der "postkeynesianischen Wachstumstheorie" auch eine "neokeynesianische Wachstumstheorie" und neben der "neoklassischen einsektoralen Wachstumstheorie" die Variante eines "neoklassischen Zwei-Sektoren-Modells". Darüber hinaus finden sich Modelle, die neben der Berücksichtigung von Arbeit und Kapital auch die natürlichen Ressourcen einbeziehen. Vgl. Müller, K.-W. und Ströbele, W.: Wachstumstheorie, München, Wien 1985, Inhaltsverzeichnis.

52) Vgl. Heiduk, G.: Gewährleistet die Zunahme ..., a.a.O., S. 81 f. sowie Zimmermann, H. und Henke, K.-D.: Finanzwissenschaft ..., a.a.O., S. 334.

53) Vgl. Dürr, E.: Wachstumspolitisch relevante Ergebnisse der Wachstumstheorie, in: Beiträge zur Wachstumspolitik, hrsg. v. H.K. Schneider, Schriften des Vereins für Socialpolitik, N.F. Bd. 55, Berlin 1970, S. 1-31, S. 3 ff.; Schneider, H.K.: Wirtschaftpolitisch relevante Ergebnisse der Wachstumstheorie, in: Beiträge zur Wachstumspolitik, hrsg. v. H.K. Schneider, Schriften des Vereins für Socialpolitik, N.F. Bd. 55, Berlin 1970, S. 32-49, S. 38 ff. und Frey, R. L.: Wachstumspolitik, a.a.O., S. $68 \mathrm{ff}$.

54) Vgl. auch Neumann, M.: Wachstumspolitik, a.a.O., S. 466.

Davies und Hughes bemerken hierzu in einer Studie über die britische Wirtschaft: "The causes of economic growth are extremely complex. Nevertheless, it is the authors' belief that investment is a fundamental contribution to high rates of economic growth although the relationship between investment and growth is uncertain" (S. 8). An anderer Stelle ihrer Lntersuchung schreiben sie: "It would appear that investment does have a role to play in growth, although a high level of investment is a necessary condition rather than a sufficient condition for a high rate of economic growth" (S. 16). Davies, J.R. and Hughes, S.: Investment in the British Economy, London et al. 1981.

55) Walter, H.: Theoretische Probleme ..., a.a.O., S. 37.

Nach Frey bezeichnen selbst führende Wachstumstheoretiker "die Brauchbarkeit der Wachstumstheorie für die Wachstumspolitik als gering". Frey, R.L.: Wachstumspolitik, a.a.O., S. 8. 
Neben den privaten Investitionen rückten vor allem die Ausstattung mit materieller und immaterieller Infrastruktur als Wachstumsfaktoren in den Vordergrund ${ }^{56}$, wobei sich allerdings ihre Operationalisierung als problematisch erweist. ${ }^{57)}$ Soll nun die wachstumsfördernde Wirkung als Abgrenzungskriterium herangezogen werden, müßten wohl alle Ausgaben bzw. Einnahmenverzichte, die

- die private Investitionstätigkeit anregen,

- die Ausstattung mit materieller und immaterieller Infrastruktur erhöhen sowie

- den technischen Fortschritt begünstigen

zu den öffentlichen Investitionen zählen.

Die Berücksichtigung der staatlichen Einflußnahme auf die private Investitionstätigkeit gestaltet sich, wegen der "Komplexität des privaten Investorenverhaltens" ${ }^{\text {"5) }}$ besonders schwierig. Läßt man die rahmenpolitischen Maßnahmen des Staates wie den Abbau rechtlicher und administrativer Investitionshemmnisse beiseite, deren Erfassung hinsichtlich ihres konkreten Wachstumsbeitrages ebenso unmöglich erscheint wie der geldpolitischer Regelungen, verbleiben die finanzpolitischen Instrumente zur Förderung der privaten Investitionstätigkeit. Sie umfassen neben der Gestaltung eines investitionsfreundlichen Steuersystems, spezielle Investitionszuschüsse und allgemeine Investitionsprämien sowie Finanzierungserleichterungen durch Bürgschaftsübernahmen, Sonderabschreibungen und andere steuerliche Begünstigungen für Investitionen. ${ }^{59)}$

56) Vgl. Frey, R.L.: Artikel: Infrastruktur, in: Handwörterbuch der Wirtschaftswissenschaft (HdWW), hrsg. v. W. Albers et al., Bd. 4, Stluttgart et al. 1978, S. 200-215, S. 212.

57) Vgl. Frey, R.L.: Infrastruktur und Wirtschaftswachstum, in: Konjunkturpolitik, 15. Jg. (1969), S. 103-126, S. 103 ff.; Frey, R.L.: Infrastruktur, a.a.O., S. 212; Littmann, K.: Wirtschaftswachstum, Konjunktur und öffentliche Finanzen, in: Finanzpolitik im Umbruch: Zur Konsolidierung öffentlicher Haushalte, hrsg. v. H.H. von Arnim und K. Littmann, Berlin 1984, S. 31-50, S. 38 f. sowie Zimmermann, H. und Henke, K.-D.: Finanzwissenschaft ..., a.a.O., S. 337 .

Schon 1952 stellie Domar hierzu fest: "As usual, the government is the most troublesome ... because we have no theory of government expenditure whatsoever".Domar, E.D.: A Theoretical Analysis ..., a.a. O., S. 20.

58) Leibfritz, W.: Staatliche Investitionsförderung - Ansatzpunkte der verschiedenen Instrumente und Möglichkeiten der Beurteilung, in: Neuere Entwicklungen in der Investitionstheorie und -politik, hrsg. v. G. Bombach, B. Gahlen und A.E. Ott, Tübingen 1980, S. 477-517, S. 477. Vgl. hierzu auch Neldner, M.: Investitionsorientierte Wachstumspolitik, in: Das Wirtschaftsstudium (Wisu), 9. Jg. (1980), S. 84-90, S. 86 ff.

59) Vgl. Neldner, M.: Investitionsorientierte Wachstumspolitik, a.a.O., S. $87 \mathrm{ff}$. 
Die genaue mengenmäßige Erfassung ist allerdings auch bei den Finanzierungserleichterungen kaum möglich. Bürgschaften können quantitativ erst dann berücksichtigt werden, wenn die teilweise oder völlige Übernahmeverpflichtung eingetreten ist, wobei dieser Fall nicht gerade ein Qualitätsbeweis für die betroffenen Investitionsprojekte darstellt. Der Umfang der Steuererleichterungen ist nur näherungsweise zu ermitteln, weil die Höhe der Referenzbasis, nämlich die Steuereinnahmen ohne diese Erleichterung, in aller Regel prognostischen Charakter besitzt.

Die staatlichen Ausgaben in Form von Zuschüssen für spezielle Investitionsvorhaben Dritter sowie die allgemeinen Investitionsprämien sind in ihrer zahlenmäßigen Größenordnung vergleichsweise leicht zu erfassen. Fraglich bleibt allerdings, ob sie die private Investitionstätigkeit in ihrem vollen Umfang erhöhen, oder ob sie lediglich, zumindest teilweise, an die Stelle privater Finanzierung treten. Darüber hinaus besteht der Verdacht, daß die privaten Investitionen, die staatliche Finanzierungshilfen benötigen, eher die schlechten Risiken repräsentieren, deren effiziente Nutzung ${ }^{60}$ ' noch nachgewiesen werden müßte. Schließlich gelten für alle staatlichen Maßnahmen zur Förderung der privaten Investitionen in diesem Kontext auch die oben angesprochenen Vorbehalte hinsichtlich des $\mathrm{Zu}$ sammenhangs zwischen Investitionsquote und Wachstum.

Die Erfassung der Zuschüsse für Investitionsvorhaben im Ausland und die generelle Einbeziehung der staatlichen Darlehen, wie dies bei den Investitionsförderungsmaßnahmen der Finanzstatistik geschieht, ist unter dem Wachstumsaspekt kaum zu rechtfertigen. Die Volkswirtschaftlichen Gesamtrechnungen weisen in dieser Hinsicht die Unzulänglichkeit auf, daß sie, sofern die "Vermögensübertragungen an Unternehmen" als Investitionsförderungsmaßnahmen angesehen werden, etliche Bestandteile, wie Schlachtprämien und Zuschüsse für Betriebsstillegungen enthalten ${ }^{61}$, die keine positive Wachstumswirkung besitzen.

60) Vgl. hierzu Heiduk, G.: Gewährleistet die Zunahme ..., a.a.O., S. 87.

61) Vgl. Statistisches Bundesamt: Konten und Standardtabellen 1985, a.a.O., S. 110. Siehe auch Ausführungen in Abschnitt 3.3.1. 
Die Infrastruktur stellt denjenigen Teil einer Volkswirtschaft dar, "der das Fundament für die eigentliche wirtschaftliche Aktivität bildet." ${ }^{22}$ Sie umfaßt eine materielle und immaterielle Komponente, wobei das Sachkapital in Form von Anlagen und Ausrüstungen den materiellen Infrastrukturbestand bildet und der Ausbildungs-, Gesundheits- und Wissensstand der Bevölkerung den Bestand an immaterieller Infrastruktur verkörpert. ${ }^{63)}$ Nach Frey rechnet man zur Infrastruktur "die Verkehrsanlagen (inkl. Nachrichtenübermittlung), die Wasser-, Gas-, Elektrizitäts-, Fernwärmeversorgung usw., den Umweltschutz, den Schutz vor Elementarschäden, das Bildungswesen, das Gesundheitswesen, die Forschung sowie Anlagen für die Freizeitgestaltung (Sport, Kultur, Erholung usw.)".64)

Die öffentlichen Infrastrukturausgaben werden "als besonders wachstumswirksam angesehen, weil sie häufig erst die Voraussetzung für private Investitionen schaffen"65) bzw. die Produktivität des privaten Kapitals verbessern. ${ }^{66)}$ Dabei ist allerdings der Zusammenhang zwischen Infrastruktur und Produktivität des privaten Kapitals nicht linear, sondern hängt vom relativen Ausbaugrad der Infrastruktur ab. ${ }^{67)}$ Die wachstumsfördernde Wirkung betrifft jedoch, wenn man den sehr weiten Infrastrukturbegriff von Frey zugrundelegt, lediglich einen Teil der öffentlichen Infrastrukturausgaben, nämlich die zur Erhöhung des Produktivkapitals. Die Ausgaben für die Erhöhung des "Infrastruktur-Konsumtivkapitals" haben demgegenüber keinen oder nur sehr geringen Einfluß auf das Wirtschaftswachstum. ${ }^{68}$

62) Frey, R.L.: Infrastruktur, a.a.O., S. 201.

Die weiteste Definition der Infrastruktur stammt von Jochimsen, der mit Infrastruktur "die Gesamtheit aller materiellen, institutionellen und personalen Anlagen, Einrichtungen und Gegebenheiten bezeichnet, die den Wirtschaftseinheiten im Rahmen einer arbeitsteiligen Wirtschaft zur Verfügung stehen und die mit dazu beitragen,

1. die Entgelte für gleiche Leistungen der Produktivkräfte auszugleichen und

2. zugleich die größte Zuwachsrate der Gesamtwirtschaft herbeizuführen".

Jochimsen, R.: Theorie der Infrastruktur. Grundlagen der marktwirtschaftlichen Entwicklung, Tübingen 1966, S. 145.

63) Vgl. Zimmermann, H. und Henke, K.-D.: Finanzwissenschaft ..., a.a.O., S. 345.

64) Frey, R.L.: Wachstumspolitik, a.a.O., S. 77 f.

65) Zimmermann, H. und Henke, K.-D.: Finanzwissenschaft ..., a.a.O., S. 343.

66) Vgl. Frey, R.L.: Wachstumspolitik, a.a.O., S. 78.

67) Vgl. ebenda, S. 78 sowie Frey, R.L.: Infrastruktur und Wirtschaftswachstum, a.a.O., S. 123ff.

68) Vgl. Frey, R.L.: Infrastruktur. Grundlagen der Planung öffentlicher Investitionen, 2. Aufl., Tübingen 1972, S. $19 \mathrm{ff}$. 
Dienen die Wachstumswirkungen der Infrastrukturausgaben als Charakteristikum für die öffentlichen Investitionen wird deutlich, daß sowohl die Finanzstatistik als auch die Volkswirtschaftlichen Gesamtrechnungen die öffentlichen Investitionsausgaben auf der einen Seite zu eng und auf der anderen zu weit auslegen. Beide beinhalten alle öffentlichen Baumaßnahmen, soweit sie eine bestimmte Wertgrenze überschreiten, unabhängig davon, ob sie intermediären bzw. Vorleistungs-Charakter für die private Produktion besitzen oder ob ihnen weitgehend Endproduktcharakter zukommt. Stellen sie Endprodukte dar, wie Parks, Theater, Schwimmbäder und ähnliche Einrichtungen, so enthalten sie die Eigenschaften langlebiger Konsumgüter, die zwar positive Zukunftswirkungen aufweisen können, aber keine Steigerung der Produktionsmöglichkeiten bewirken. Diese langlebigen Konsumgüter dürften unter Wachstumsaspekten nicht zu den Investitionen zählen. Selbst die öffentlichen Straßen haben teilweise konsumtiven Charakter, da sie auch zu Ausflugsfahrten benutzt werden.

Beide Systeme der amtlichen Statistik fassen die Investitionen unter dem obigen Aspekt allerdings auch zu eng, weil sie die Ausgaben für die immaterielle Infrastruktur nur teilweise erfassen, nämlich lediglich insofern als es sich um Sachbzw. Bruttoinvestitionen im Ausbildungs-, Forschungs- und Gesundheitswesen handelt. Die Bereitstellung der Sachkapazitäten besitzt in diesen Bereichen allein noch keine Wachstumswirkung. Sie kann erst durch die Komplettierung mit anderen laufenden Ausgaben erreicht werden, die dann zusammen das öffentliche Leistungsangebot bilden. Der Vorschlag, alle Ausgaben für Bildung, Gesundheit und Forschung als Investitionen anzusehen, geht über das vorgegebene Abgrenzungskriterium hinaus. Unter Wachstumsaspekten müßte nämlich unterschieden werden, ob z.B. die Bildungsleistung lediglich zu einer persönlichen Bedürfnisbefriedigung dient oder ob die erlernten Fähigkeiten im Produktionsprozeß eingesetzt werden. Ebenso differenziert sind die Ausgaben im Gesundheitsbereich zu beurteilen, deren Wachstumsbeitrag davon abhängt, ob sie Menschen gelten, die voll im Erwerbsleben stehen oder nicht, ob sie jüngere oder ältere Menschen betreffen.

Selbst bei den öffentlichen Ausgaben, die normalerweise unstrittig zu den produktiven Infrastrukturausgaben zählen, wie z.B. im Verkehrsbereich, ist die positive Wachstumswirkung nicht a priori gegeben bzw. die Wirkung kann bei der 
gleichen Maßnahme Unterschiede aufweisen. Ihr Produktivitätsbeitrag wird dann fragwürdig, wenn der Vorleistungscharakter für die private Produktion verlorengeht, weil z.B. die Standortwahl falsch war, keine Nachfrage besteht oder, wenn sie lediglich andere Infrastruktureinrichtungen substituieren. ${ }^{69)} \mathrm{Wie}$ schon oben angedeutet ist der Wachstumsbeitrag von Infrastrukturmaßnahmen auch vom Ausbaugrad der Infrastruktur abhängig.

Die Ansatzpunkte zur Beeinflussung des technischen Fortschritts sind recht schwierig zu bestimmen und wegen Abgrenzungs- und Erfassungsproblemen auch empirisch kaum zu überprüfen. ${ }^{70)}$ In aller Regel wird ein positiver Zusammenhang zwischen dem technischen Fortschritt auf der einen Seite und der Höhe der gesamtwirtschaftlichen Investitionen, der Ausgaben für Forschung und Entwicklung sowie dem reibungslosen Strukturwandel einer Volkswirtschaft auf der anderen Seite vermutet. Dies alles weist, wie auch Walter anmerkt, "auf die Bedeutung einer Wachstumspolitik hin, die sich zunehmend auch als Strukturpolitik zu verstehen hat."71' Eine solche Politik wird sich in einem marktwirtschaftlichen System im wesentlichen auf die Sicherung wirtschaftlicher Rahmenbedingungen konzentrieren und auf den dynamischen und innovationsorientierten Unternehmer im Sinne Schumpeters vertrauen. ${ }^{72}$

Der Versuch, die öffentlichen Ausgaben anhand ihrer Wachstumswirkung abzugrenzen, erscheint nicht nur praktisch unmöglich, weil konsumtive und investive Bestandteile vielfach nicht zu trennen sind, sondern kann auch theoretisch nicht befriedigen, da die in diesem Sinne investive Wirkung oft erst im nachhinein bestätigt oder verworfen werden kann. Sowohl die öffentlichen Investitionen der Finanzstatistik als auch die der Volkswirtschaftlichen Gesamtrechnungen enthalten einerseits Ausgaben für Güter, deren Wachstumsbeitrag gegen Null tendiert, andererseits finden Ausgaben keine Berücksichtigung, deren positiver Einfluß auf das Wirtschaftswachstum naheliegt.

69) Vgl. auch Littmann, K.: Wirtschaftswachstum, Konjunktur und ..., a.a.O., S. 38.

70) Vgl. Frey, R.L.: Wachstumspolitik, a.a.O., S. $80 \mathrm{ff}$.

71) Walter, H.: Theoretische Probleme ..., a.a.O., S. 42.

72) Vgl. Frey, R.L.: Wachstumspolitik, a.a.O., S. $82 \mathrm{ff}$. 


\subsection{3. Öffentliche Investitionen und Vermögenszugang}

Die Charakterisierung der öffentlichen Investitionen als Vermögenszugang setzt die Festlegung dessen voraus, was unter Vermögen verstanden werden soll, wobei sehr schnell klar wird, daß allerdings ein generell akzeptierter Vermögensbegriff nicht existiert. ${ }^{73)}$ Weitgehende Einigkeit besteht nur darüber, daß "Vermögen" eine Bestandsgröße darstellt, die Objekte umfaßt, über die die Wirtschaftssubjekte verfügen können und die ökonomisch bewertbar sind. ${ }^{74)}$ Eine Investition bedeutet in diesem Sinne die Veränderung des Vermögensbestandes in der Zeit. ${ }^{751}$

Die vielfältigen ökonomischen Phänomene, die in ihrer Gesamtheit das Vermögen verkörpern, werden im allgemeinen in die Teilgesamtheiten immaterielles Vermögen sowie Human-, Sach- und Geldvermögen eingeteilt, wobei das Humanvermögen häufig auch als Bestandteil des immateriellen Vermögens aufgefaßt wird. ${ }^{76)}$ Das Sachvermögen umfaßt den gesamten Sachgüterbestand, der in aller Regel aus einem nichtreproduzierbaren und einem reproduzierbaren Teil besteht. Der wertmäßige Saldo aus Forderungen und Verbindlichkeiten bildet das Geldvermögen und als Objekte des immateriellen Vermögens gelten handelbare Rechte zur Ausbeutung von Lagerstätten oder zur Nutzung bestimmter Güter, wie Patente oder Lizenzen. ${ }^{77)}$ Das Human-oder Arbeitsvermögen schließlich

73) Vgl. Folkers, C.: Art.: Vermögen I: Struktur und Verteilung, in: Handwörterbuch der Wirtschaftswissenschaft (HdWW), hrsg. v. W. Albers et al., Bd. 8, Stuttgart et al. 1980, S. 265282, S. 266 und Siebke, J.: Stichwort: Verteilung, in: Vahlens Kompendium der Wirtschaftstheorie und Wirtschaftspolitik, Bd. 1, hrsg. v. D. Bender et al., München 1984, S. 366-399, S.379.

74) Vgl. Paulsen, A. und Schilcher, R.: Allgemeine Volkswirtschaftslehre I. Grundlegung, Wirtschaftskreislauf, 10. Aufl., Berlin, New York 1974, S. 201 und Folkers, C.: Vermögen I ..., a.a.O., S. 266. Der Verfasser ist sich bewußt, daß es auch einen hedonistischen Vermögensbegriff gibt, der "schlechthin alles, was in irgendeiner Weise zur Vermehrung des Wohlstandes einer Person oder eines Volkes beiträgt", einschließt. Schmidt, K.-D.: Was ist Vermögen?, in: Allgemeines Statistisches Archiv. Organ der Deutschen Statistischen Gesellschaft, 56. Bd., Göttingen 1972.

75) Vgl. auch Toillié, B.: Öffentliche Investitionen ..., a.a.O., S. 72.

76) Vgl. Paulsen, A. und Schilcher, R.: Allgemeine Volkswirtschaftslehre I ..., a.a.O., S. 202 und Stobbe, A.: Volkswirtschaftslehre I ..., a.a.O., S. 46 ff.

77) Vgl. Stobbe, A.: Volkswirtschaftslehre I ..., a.a. O., S. 78 und S. 384.

Internationales Ansehen, Attraktivität eines Landes oder auch das gute Arbeitsklima stellen durchaus Vermögenswerte im hedonistischen Sinne dar, sind monetär aber kaum zu fassen und bleiben deshalb in aller Regel außerhalb der Betrachtung. 
umfaßt "die Gesamtheit der durch Ausbildung, Erziehung, Gesundheitsfürsorge usw. erworbenen Kenntnisse und Fähigkeiten der Menschen". ${ }^{78)}$ In Anlehnung an die Wirtschaftstheorie, in der das Vermögen als Quelle zukünftiger Einkommensströme definiert wird, ${ }^{79)}$ unterscheidet man häufig auch Konsumtiv- und Produktivermögen. ${ }^{80)}$ Obgleich das Konsumtivvermögen keine wiederkehrenden Erträge abwirft, besitzt es doch einen Tauschwert, der durchaus in zukünftiges Einkommen umgewandelt werden kann. ${ }^{811}$

Schließlich ist in diesem Kontext ebenfalls zu beachten, daß "sich der Vermögenszugang, den öffentliche Ausgaben bewirken, nicht zwangsläufig auf den öffentlichen Sektor" beschränkt, sondern auch "privaten Entscheidungseinheiten zufließen" kann ${ }^{821}$, so daß die Beschränkung auf ein irgendwie abgegrenztes öffentliches Vermögen nicht zulässig erscheint. Bildet die Gesamtheit des privaten und öffentlichen Vermögens den Anknüpfungspunkt, verliert der Begriff der öffentlichen Investitionen ähnlich wie auch schon das Kriterium des positiven $\mathrm{Zu}$ kunftsnutzens, fast gänzlich seine inhaltliche Abgrenzungsfunktion. Beinahe jede öffentliche Ausgabe berührt die Vermögenssituation von Wirtschaftssubjekten. Bildungs- und Gesundheitsausgaben verändern in aller Regel die Kenntnisse und Fähigkeiten der Menschen und somit das Humanvermögen, das zumindest ein potentielles Arbeitsvermögen darstellt. Die Vermögensänderung ist zu-

78) Paulsen, A. und Schilcher, R.: Allgemeine Volkswirtschaftslehre I .., a.a.O., S. 202. Vgl. auch Stobbe, A.: Volkswirtschaftslehre I ..., a.a.O., S. $80 \mathrm{f}$.

79) Vgl. Hübl, L.: Stichwort: Wirtschaftskreislauf und Gesamtwirtschaftliches Rechnungswesen, in: Vahlens Kompendium der Wirtschaftstheorie und Wirtschaftspolitik, Bd. 1, hrsg. v. D. Bender et al., 2. Aufl., München 1984, S. 48-83, S. 75

Nach Engels, Sablotny und Zickler ist die Zahl Vermögen "nichts anderes, als ein zusammengefaßter Ausdruck für zukünftige Einkommensströme, die die Besitzer dieses Vermögens aus zukünftigen Volkseinkommen erwarten oder auf die sie Anspruch haben." Engels, W.; Sablotny, H. und Zickler, D.: Das Volksvermögen. Seine verteilungs- und wohlstandspolitische Bedeutung, Frankfurt/Main 1974, S. 32.

80) Vgl. Folkers, C.: Vermögen I ..., a.a.O., S. 266.

Andere nennen diese Vermögensteile Gebrauchs- und Erwerbsvermögen. Vgl. Paulsen, A. und Schilcher, R.: Volkswirtschaftslehre I ..., a.a.O., S. 201.

Sowohl bei Folkers als auch in der Veröffentlichung von Paulsen und Schilcher werden lediglich das Sachvermögen in konsumtive und produktive Vermögensteile bzw. in Gebrauchsund Erwerbsvermögen getrennt. Wie aber schon bei der Diskussion des Wachstumsaspektes gesehen, ist die Unterscheidung in konsumtive und produktive Teile auch beim Humanvermögen denkbar.

81) Vgl. auch Schmidt, K.-D.: Was ist Vermögen?, a.a.O., S. 40.

82) Wille, E.: Zum Verhältnis ..., a.a.O., S. 343. 
nächst unabhängig davon, ob die Individuen dies nur als Steigerung ihrer unmittelbaren persönlichen Wohlfahrt betrachten oder ob sie ihre diesbezügliche Vermögensänderung im Sinne eines Produktivitätsbeitrages einsetzen. Bei einem derart weit gefaßten Vermögensbegriff müßten außerdem die öffentlichen Ausgaben für die Sparförderung genauso wie die öffentlichen Zuschüsse zur Rentenversicherung, die ja den Rentenanspruch sichern helfen, zu den Investitionen zählen. Unbeschadet der enormen Bewertungsprobleme, die sich vor allem beim Humanvermögen einstellen ${ }^{831}$, besitzt ein derart weit gefaßter Vermögensbegriff und entsprechend der hieraus abgeleitete Begriff der öffentlichen Investitionen keinen Aussagegehalt.

Die Beschränkung auf das Produktivvermögen beinhaltet dieselben Probleme, die schon im Zusammenhang mit dem Wachstumsaspekt diskutiert wurden. Sie führt dazu, daß dasselbe Gut je nach Verwendung unterschiedlich klassifiziert wird. Die Verbindung des Vermögensbegriffes mit der zukünftigen Einkommenserzielung bringt in diesem Kontext ebenfalls keine weitere Klärung, zumal ein Gut, das heute zum Konsumtivvermögen zählt, z.B. ein Wohnhaus oder ein brachliegendes Grundstück, auch zukünftig gewerblich genutzt werden kann. Eine Begrenzung auf das Produktivvermögen würde vielen öffentlichen Ausgaben, die in der Finanzstatistik und den Volkswirtschaftlichen Gesamtrechnungen zu den Investitionen zählen, den investiven Charakter absprechen, z.B. den Ausgaben für Theater, Parks u.ä., "bei denen es sich materiell um langlebige Konsumgüter handelt." "84)

Als Ausweg bietet sich die Eingrenzung auf das Sachvermögen an. Öffentliche Investitionen im Vermögenssinne wären dann alle öffentlichen Ausgaben, die die private oder öffentliche Sachvermögensposition beeinflussen. Diese Überlegung markiert gleichzeitig den Übergang zu einer an formalen Kriterien orientiertొn "Zuordnung öffentlicher Aktivitäten zu den Investitionen." ${ }^{85)}$ Die Sachbzw. Bruttoinvestitionen der amtlichen Statistik erfüllen dieses Abgrenzungskriterium, lediglich die mittelbaren Investitionen enthalten Bestandteile, bei

83) Vgl. hierzu auch Mitschke, J.: Über die Eignung von Einkommen, Konsum und Vermögen als Bemessungsgrundlagen der direkten Besteuerung. Eine meßtechnische Analyse, Berlin 1976, S. $117 \mathrm{f}$.

84) Wille, E.: Zum Verhältnis ..., a.a.O., S. 343.

85) Vgl. auch Engels, W.; Sablotny, H. und Zickler, D.: Das Volksvermögen ..., a.a.O., S. 29 
denen kein Einfluß auf die Sachvermögensposition privater Wirtschaftssubjekte existiert, wie z.B. bei den Darlehen im Rahmen der Ausbildungsförderung. Daneben gibt es aber auch öffentliche Ausgaben, die in diesem Sinne Investitionen darstellen und nicht als solche erfaßt werden, z.B. bestimmte Ausgaben im militärischen Bereich.

Wirkungstheoretische Abgrenzungen öffentlicher Investitionen werden entweder inhaltsleer, weil sie fast nichts ausschließen, oder verlagern das Definitionsund Meßproblem auf Effekte, die sich empirisch weder quantitativ noch qualitativ eindeutig abgrenzen und ermitteln lassen.

\subsection{Formale A bgrenzung öffentlicher Investitionen}

Die Auswahlmöglichkeiten formaler, objektivierbarer Kriterien zur Abgrenzung der Investitionen unterliegen a priori keinen generellen Beschränkungen. So könnte man grundsätzlich alle öffentlichen Ausgaben für genau festgelegte Aufgabenbereiche Investitionen nennen. Letzten Endes ist jede Definition eine Frage der Zweckmäßigkeit. Entsprechend der betriebswirtschaftlichen Ausrichtung ${ }^{86)}$ erscheint eine vermögensorientierte Abgrenzung der Investitionen als zweckmäßiger und praktikabler Weg. Jede öffentliche Ausgabe, die den Vermögensbestand verändert, heißt dann Investition, wobei Ersatzinvestition, eine entsprechende Wertminderung ausgleicht.

Im Gegensatz zur Volkseinkommensrechnung existieren allerdings keine wissenschaftlich akzeptierten Verfahren, keine Normen und keine Konventionen für die Aufstellung einer Volksvermögensrechnung. ${ }^{87)}$ Nach den oben angestellten Überlegungen zu den Vermögenswirkungen öffentlicher Ausgaben bietet sich die Eingrenzung auf das private Betriebsvermögen ergänzt um die Wohnhäuser privater Haushalte und ein ähnlich abgegrenztes öffentliches Vermögen an. Die Einbeziehung staatlicher Zuschüsse an private Wirtschaftssubjekte

86) Vgl. Wöhe, G.: Einführung in die Allgemeine Betriebswirtschaftslehre, 11. Aufl., München 1975, S. 487 ff. Wöhe schreibt: "Mit dem Begriff 'Investition' verbindet sich dagegen die Vorstellung der Verwendung finanzieller Mittel zur Beschaffung von Sachvermögen, immateriellem Vermögen oder Finanzvermögen". Ebenda, S. 487.

87) Vgl. Engels, W.; Sablotny, H. und Zickler, D.: Das Volksvermögen ..., a.a.O., S. 87 sowie Paulsen, A. und Schilcher, R.: Allgemeine Volkswirtschaftslehre I .., a.a.O., S. 201 ff. 
könnte sich dabei an den Vorschriften zur Vermögensaufstellung für das Betriebsvermögen orientieren ${ }^{88)}$ und um die staatliche Förderung des privaten Wohnungsbaus ergänzt werden. Obgleich ökonomisch kein Unterschied besteht zwischen einer Zuschußgewährung und einem Einnahmenverzicht, ist die Beschränkung auf die Erfassung der Zuschüsse, wegen der Schwierigkeiten die Steuerausfälle zu bestimmen, unter Aspekten der Praktikabilität naheliegend.

Es ist sicher nicht weiter verwunderlich, daß "Aussagen über den Umfang des öffentlichen Vermögens" kaum möglich sind, ${ }^{89)}$ da zum einen trotz früher eingegangener gesetzlicher Verpflichtungen keine umfassende Vermögensstatistik der öffentlichen Haushalte existiert ${ }^{901}$ und zum anderen die Bewertung der $\mathrm{Be}$ stände anerkanntermaßen schwierig ist. ${ }^{91}$ Einen ersten Ansatzpunkt liefert die Gliederung des "Allgemeinen Bundesvermögens", die der Vermögensaufstellung des Bundes zugrundelag. ${ }^{92)}$ Sie erlaubt unbeschadet der Schwierigkeit, einzelne Teile des Vermögensbestandes zu bewerten ${ }^{93)}$, eine Zuordnung der hierfür verausgabten Mittel zu den Investitionen. Danach zählen die Ausgaben für Grundstücke und Gebäude einschließlich militärischer Anlagen sowie die Baumaßnahmen im Verkehrsbereich zu den investiven Ausgaben. Die Darlehen und Beteiligungen bilden ebenfalls Bestandteile der Vermögensaufstellung, so daß ihre Erhöhung eine in diesem Sinne investive Verausgabung darstellt, es sei denn, man entschließt sich, alle oder Teile von ihnen per Konvention, z.B. wegen ihres Transferscharakters, aus der Vermögensaufstellung herauszunehmen bzw. sie

88) Vgl. hierzu Wagner, F.E.: Stichwort: Besteuerung, in: Vahlens Kompendium der Betriebswirtschaftslehre, Bd. 2, hrsg. v. J. Baetge et al., München 1984, S. 407-451, S. 423.

89) Maier, A.: Art.: Öffentliches Vermögen II: Umfang und Struktur, in: Handwörterbuch der Wirtschaftswissenschaft (HdWW), hrsg. v. W. Albers et al., Bd. 5, Stuttgart et al., 1980, S.623-633, S. 626.

90) Vgl. Essig, H.: Erfassungs- und Auswertungsprogramm ..., a.a.O., S. 837. Vgl. auch die $\S \S 73$, 80 und $86 \mathrm{BHO}$.

91) Vgl. Meier, A.: Öffentliches Vermögen II ..., a.a.O., S. 626.

92) Diese Gliederung lag bis zum Finanzbericht 1980 der Aufstellung über das "Allgemeine Bundesvermögen" zugrunde. In den nachfolgenden Finanzberichten findet sich diese Aufstellung nicht.

93) Vgl. Übersicht 10.1 in Bundesministerium der Finanzen: Finanzbericht 1980, Bonn 1979, S.225 f. Bei den "Sachen im Gemeingebrauch", die die Bundesautobahnen, Bundesstraßen und Schiffahrtswege umfassen, verzichtet das Finanzministerium "mangels finanzieller Verwertbarkeit" auf den Bestandsausweis, da jährliche Haushaltsmittel in diesem Bereich "sogleich wieder abgeschrieben" werden. Ebenda, S. 257. Die Unterscheidung in Verwaltungs-, Finanz- und Sondervermögen, wie Meier vorschlägt, ist wenig hilfreich. Vgl. Meier, A.: Öffentliches Vermögen II ..., a.a.O., S. 627. 
nicht zu den Investitionen zu zählen. Die Vermögensaufstellung des Bundes enthält allerdings keine beweglichen Sachgüter, die, sofern sie langlebige Güter darstellen, z.B. EDV-Anlagen, jedoch unzweifelhaft zum Vermögen rechnen.

Neben dem vermögensorientierten Hauptmerkmal verlangt eine an formalen Kriterien ausgerichtete Bestimmung öffentlicher Investitionen zusätzliche Vorschriften über den Berechnungszeitpunkt, die Periodenlänge und Bewertungsnormen sowie die Festlegung von Wertgrenzen, um Bagatellfälle auszuschließen, und gegebenenfalls die Regelung von Ausnahmefällen. Wie schon zu Beginn der Analyse angedeutet erweist sich "die Zuordnung öffentlicher Aktivitäten zu den Investitionen nach formalen Kriterien logisch als überlegen." bildeten nicht ganz zu Unrecht auch schon bisher die Grundlagen der statistischen und haushaltsrechtlichen Nachweise, wobei freilich sehr verschiedene Abgrenzungen möglich sind, die zu quantitativ erheblichen Unterschieden im Investitionsvolumen führen können. ${ }^{95)}$ "Der Abschied von wirkungstheoretischen Kriterien" läuft allerdings auch auf "die Konklusion hinaus, daß die Investitionsausgaben per se keinen höheren wirtschaftspolitischen Stellenwert besitzen als andere öffentliche Ausgabenarten."96)

94) Vgl. Littmann, K.: Öffentliche Investitionen, a.a.O., S. 816.

95) Vgl. Wissenschaftlicher Beirat beim Bundesministerium der Finanzen: Gutachten zum Begriff ..., a.a.O., S. 49.

Letztlich stellt die Klassifizierung als öffentliche Investitionen ein politisches Entscheidungsproblem dar, dessen gesetzgeberisches Offenhalten durchaus Rückschlüsse auf die zugrundeliegenden Schwierigkeiten erlaubt.

96) Wille, E.: Zum Verhältnis ..., a.a.O., S. 348. 


\section{Zusammenfassung}

Die Staatsausgaben fanden in der Finanzwissenschaft lange Zeit vergleichsweise wenig Beachtung. Im Vordergrund des Interesses stand eindeutig die Finanzbedarfsdeckung, während die Ausgaben selbst als durch die staatlichen Aufgaben determiniert galten und damit dem Problembereich anderer Wissenschaftszweige zugewiesen wurden. Gleichwohl zeigt der dogmenhistorische Rückblick, daß die Auf- und Ausgaben des Staates auch schon früher Gegenstand ökonomischer Erörterungen waren.

Im Zeitalter des Merkantilismus dienten die staatlichen Ausgaben nicht nur als Mittel höfischer Prachtentfaltung, sondern auch als probate Instrumente einer aktiven Wirtschaftsförderungspolitik, in deren Gefolge u.a. die verkehrsmäßige Erschließung weiter Landstriche vorangetrieben und ein System staatlicher Manufakturen aufgebaut wurde. Den Übergang zu den Auffassungen des klassischen Liberalismus, die an die Stelle merkantilistischer Anschauungen mit ihrer staatlichen Reglementierung traten, markierten die Physiokraten. Während in der Literatur der Liberalismus häufig allzu einseitig als Zeitalter staatlicher Enthaltsamkeit und ungezügelter Entfaltung privater Eigeninteressen und wirtschaftlicher Macht charakterisiert wird, zeigt die Analyse, daß auch die Klassiker dem Staat Verantwortung für bestimmte Aufgabenbereiche zusprachen. Adam Smith wies den staatlichen Entscheidungsträgern außer der Zuständigkeit in den Bereichen Verteidigungs- und Justizwesen auch die Verpflichtung für die Aufgaben zu, die zwar von gesellschaftlichem Interesse sind, aber von privaten Wirtschaftssubjekten nicht erledigt werden, weil ihr Nutzen nicht oder nur schwer internalisiert werden kann. Gleichwohl bleibt unbestritten, daß er der staatlichen Lenkung eher mißtrauisch gegenüberstand und eine Wirtschaftsverfassung präferierte, welche dem individuellen Streben Vorrang einräumt, weil eine solche Ordnung letztlich dem Wohl der Gesamtheit am meisten dient.

Aufgrund der sozialen Probleme, die im Gefolge der Industrialisierung auftraten, wurde der Liberalismus - vornehmlich im deutschsprachigen Raum, wo er ohnehin erst vergleichsweise spät Fuß fassen konnte - zum Gegenstand von Angriffen. Neben dem sog. "Methodenstreit" waren deshalb die letzten Jahrzehnte 
des 19. Jahrhunderts vor allem geprägt durch die Forderungen nach einem sozialpolitischen Engagement des Staates. Im Anschluß an die starke Betonung historisch-deskriptiver Analysemethoden, die insbesondere in Deutschland im Hinblick auf analytische Aspekte zu einer Lethargie in der Nationalökonomie führten, machte sich in den zwanziger Jahren dieses Jahrhunderts wieder eine Belebung finanzwissenschaftlichen Denkens bemerkbar. In den Arbeiten von Colm und Pigou werden die staatlichen Aktivitäten, hauptsächlich die öffentlichen Ausgaben, unter ökonomisch theoretischen Aspekten behandelt und so auch der Boden der "fiscal theory" bereitet.

Angeregt durch die große Depression der 30er Jahre wurde dem Staat auch eine Verantwortung für die Beschäftigungssituation zugewiesen, denn die staatlichen Ausgaben sollten den Nachfrageausfall kompensieren, die Wirtschaft ankurbeln und damit die Beschäftigung sichern helfen. Die Ideen der "fiscal theory" besaßen großen Einfluß auf die Gestaltung der praktischen Wirtschaftspolitik der westlichen Industrienationen. Heute existiert über die allokative, distributive und stabilisierungspolitische Aufgabe des Staates kaum Dissens, wenngleich differenzierte Auffassungen über ihren Umfang und über die jeweiligen Einsatzmöglichkeiten der Ausgaben bestehen.

Der dogmenhistorische Rückblick zeigt, daß die Aufgaben und Ausgaben des Staates schon recht früh, wenn auch in unterschiedlichem Maße den Gegenstand wissenschaftlicher Betätigung bildeten. Ihre stiefmütterliche Behandlung in der deutschsprachen Finanzwissenschaft gründet u.a. in der tief verwurzelten kameralistischen Lehrtradition, welche einseitig den Finanzierungsaspekt staatlicher Budgets hervorhob. In den letzten Jahren nahm aber auch die Zahl der Arbeiten zu, die einzelnen Ausgabenkategorien stärkere Aufmerksamkeit schenkten. Insbesondere die Investitionen finden dabei in aller Regel eine günstige Beurteilung, weshalb uns ihre Einordnung in die verschiedenen Klassifikationen öffentlicher Ausgaben von besonderem Interesse erschien. Übergeordnete Gesichtspunkte der Einteilung der Staatsausgaben bilden hierbei allgemeine Gliederungskriterien sowie die Gliederungen des Haushaltsrechts und der amtlichen Statistik.

Die allgemeinen Gliederungskriterien, die die Ausgaben nach den Aspekten 
- Abhängigkeit von der wirtschaftlichen Entwicklung,

- Grad des privaten und öffentlichen Nutzens und

- Stellung im Wirtschaftskreislauf

gruppieren, bieten kaum Ansatzpunkte zur Aussonderung der Investitionen. Das Haushaltsrecht schreibt neben institutionellen und funk tionalen Gliederungen auch solche nach Ausgabenarten (Gruppierungsübersicht) vor, welche die Investitionsausgaben wegen ihrer finanz- und wirtschaftspolitischen Bedeutung in zwei Gruppen zusammenfaßt. Die Gliederung nach ökonomischen Arten, die sehr starke Ähnlichkeit mit der kommunalen Ausgabengliederung aufweist, trennt vermögenswirksame, und damit investive, von vermögensunwirksamen Ausgaben. Die amtliche Statistik, repräsentiert durch die Finanzstatistik und die Volkswirtschaftlichen Gesamtrechnungen, stützt sich im wesentlichen auf die Haushaltsrechnungen. Die Finanzstatistik ist dabei in starkem Maße von den rechtlichen, institutionellen und sachlichen Gegebenheiten der staatlichen Haushaltswirtschaft abhängig und bildet selbst die Grundlage für den Ausweis großer Teile des Staatssektors der Volkswirtschaftlichen Gesamtrechnungen. Beide Systeme der amtlichen Statistik enthalten in ihrem Veröffentlichungsprogramm eine Vielzahl verschiedenster Ausgabengliederungen, die, sofern sie nach Ausgabenarten differenzieren, die Investitionen von anderen Ausgaben trennen.

Der Investitionsbegriff der Finanzstatistik unterscheidet zunächst zwischen Sachinvestitionen und Investitionsförderungsmaßnahmen. Die Sachinvestitionen setzen sich zusammen aus den Ausgaben für Baumaßnahmen sowie den Ausgaben für den Erwerb beweglicher und unbeweglicher Sachen, falls diese eine bestimmte Wertgrenze überschreiten. Die Investitionsforderungsmaßnahmen umfassen neben den Zuweisungen und Zuschüssen für Investitionsvorhaben Dritter auch die Ausgaben für Beteiligungen, Darlehen und Gewährleistungen. Der Investitionsbegriff der Volkswirtschaftlichen Gesamtrechnungen umspannt die Bruttoinvestitionen und als Pendant zu den Investitionsförderungsmaßnahmen in aller Regel die Vermögensübertragungen an Unternehmen. Die Bruttoinvestitionen werden in die Bruttoanlageinvestitionen und die Vorratsveränderungen unterteilt, wobei letztere beim Staat quantitativ eine nur geringe Rolle spielen. Die Bruttoanlageinvestitionen wiederum setzen sich aus den 
Ausrüstungs- und Bauinvestitionen sowie dem Saldo aus den Käufen abzüglich Verkäufen von gebrauchten Anlagen und Land zusammen. Während die Sachbzw. Bruttoinvestitionen inhaltlich im wesentlichen ähnliche Tatbestände erfassen, weisen die Investitionsförderungsmaßnahmen und die Vermögensübertragungen an Unternehmen auch in dieser Hinsicht quantitativ bedeutende Unterschiede auf. In den Volkswirtschaftlichen Gesamtrechnungen wird im Gegensatz zur Finanzstatistik die staatliche Darlehensvergabe nicht zu den öffentlichen Investitionen gezählt, sondern als Finanzierungsvorgang betrachtet.

Die Entwicklung der Investitionsausgaben verdient insofern besondere Aufmerksamkeit als die Investitionen in den letzten Jahren zunehmend in den Mittelpunkt des Interesses rückten und sie auch in amtlichen Verlautbarungen besondere Wertschätzung erfahren. Bei der empirischen Analyse gelten die Zahlenan gaben der Finanzstatistik als besonders geeignet, den intrastaatlichen Stellenwert der Investitionsausgaben aufzuzeigen, während die Daten der Volkswirtschaftlichen Gesamtrechnungen in erster Linie über ihren gesamtwirtschaftlichen Aspekt Auskunft geben. Bilden finanzstatistische Veröffentlichungen die Grundlage längerfristiger, empirischer Untersuchungen, taucht das Problem auf, daß neben einigen rechtlichen und methodischen Änderungen die Erweiterung des Berichtskreises im Jahre 1974 die Vergleichbarkeit der Daten über diesen Zeitpunkt hinaus beeinträchtigt. Sofern sich der Untersuchungsgegenstand auf die öffentlichen Haushalte ohne die Sozialversicherungshaushalte beschränkt, was bei den Investitionen durchaus angezeigt ist, können die finanzstatistischen Zahlen des Bundesministeriums der Finanzen verwendet werden, die diese Zäsur nicht aufweisen.

Die Investitionsquote, verstanden als Anteil der gesamten Investitionsausgaben an den Gesamtausgaben der öffentlichen Haushalte, sank im Beobachtungszeitraum von 28,1 vH (1964) auf 15,1 vH (1986), wobei sich der Rückgang in mehreren Schüben vollzog. Besonders drastisch verlief die Entwicklung bei den Gemeinden, deren Investitionsquote von 45,6 vH (1964) auf 22,7 vH (1985) zurückging. Der Niedergang der kommunalen Investitionen beeinflußte die öffentlichen Investitionsausgaben sehr nachhaltig, weil der größte Teil der Investitionsausgaben, nämlich rund zwei Drittel der Sachinvestitionen, über die Kommunalhaushalte verausgabt wird. Die Haushalte der Gemeinden enthalten aller- 
dings lediglich knapp 40 Prozent der investiven Ausgaben, wenn die Investitionen der Gebietskörperschaften auf der Basis des Konzepts der unmittelbaren Ausgaben analysiert werden. Die entsprechend stärkere Einbindung des Bundes in die öffentliche Investitionstätigkeit erfolgte freilich fast ausschließlich über die relative Zunahme der Zuschüsse sowie Darlehen und Beteiligungen.

Der Anteil der Gemeinden an den investiven Nettoausgaben der öffentlichen Haushalte, welche die aus eigenen Einnahmenquellen finanzierten Investitionen belegen, beträgt mittlerweile nur noch etwa 28 Prozent, während er 1971 38,4 vH betrug. Obwohl die Schwankungen dieser Anteilswerte im Zeitablauf recht beträchtlich sind, zeigt die Entwicklung, daß der Bund inzwischen innerhalb der Gebietskörperschaften zum größten Finanzier der Investitionen avancierte. Die Ausweitung seines Einflusses erfolgte dabei allerdings in erster Linie durch die Zunahme der Ausgaben für die Investitionsförderungsmaßnahmen.

Die Sachinvestitionen, die den "materiellen Kern" der Investitionsausgaben bilden, stiegen seit 1962 insgesamt erheblich geringer an als die Gesamtausgaben der öffentlichen Haushalte. Teilweise sanken sie sogar absolut und erreichen inzwischen mit einem Anteilswert von 8,4 vH an den Gesamtausgaben der öffentlichen Haushalte weniger als die Hälfte des bisherigen Höchststandes. Der Rückgang der Investitionsquote wurde somit zum größeren Teil vom relativen Sinken der Sachinvestitionen und hier insbesondere im Bereich der Bautätigkeit verursacht. Zum Abbau des Anteils der investiven Ausgaben an den Gesamtausgaben der öffentlichen Haushalte kommt folglich noch eine Strukturverschiebung zuungunsten der Sachinvestitionen hinzu.

Die Investitionsförderungsmaßnahmen spielen quantitativ lediglich beim Bund und den Ländern eine bedeutende Rolle. Beim Bund besitzen sie einen Anteil von etwa drei Viertel der gesamten Invesititionsausgaben, wobei die Gewichtung ihrer einzelnen Komponenten im Beobachtungszeitraum erheblichen Schwankungen unterlag. Von den gesamten Investitionsförderungsmaßnahmen des Bundes entfielen 1986 40,2 vH auf die Zuschüsse, 26,3 vH auf die Darlehen und Beteiligungen, 22,4 vH auf die Zuweisungen und 11,2 vH auf die Darlehen an andere öffentliche Verwaltungen. Die Ausweitung der Investitionsförderungsmaßnahmen beruht allerdings insbesondere beim Bund auf der Zunahme 
jener Komponenten, wie z.B. BAFöG-Darlehen oder Darlehen an ausländische Wirtschaftssubjekte, deren Investitionscharakter stärker in Frage zu stellen ist. Neben der Niveauabsenkung der öffentlichen Investitionsquote sowie der Verschiebung hin zu den Investitionsförderungsmaßnahmen fand damit auch eine Strukturverlagerung innerhalb der als investiv ausgewiesenen Förderungsmaßnahmen statt.

Die Investitionsausgaben des Staates, wie sie in den Volkswirtschaftlichen Gesamtrechnungen ausgewiesen werden, liegen in absoluten Zahlen immer unterhalb der Werte der Finanzstatistik. Die engere Abgrenzung, insbesondere der mittelbaren Investitionen, bedingt eine ungleich dominierendere Stellung der Bruttoinvestitionen innerhalb der gesamten staatlichen Investitionen. Die Veränderung der funktionalen Verteilung der Bruttoinvestitionen in der Zeit spiegelt den jeweiligen politischen Stellenwert der Aufgabenbereiche wider. So nahm der Anteil der Investitionen für den Verkehrsbereich und seit Mitte der 70er Jahre auch der für das Unterrichtswesen ab, während die Aufgabenzweige Umwelt und Gesundheit ihren Anteil an den gesamten Irıvestitionen vergrößern konnten. Die Analyse auf der Basis konstanter Preise zeigt, daß der reale Wert der Bruttoanlageinvestitionen 1985 noch erheblich unterhalb des Standes von 1964 liegt. Die bis Mitte der 70er Jahre expansive staatliche Investitionstätigkeit ließ zwischenzeitlich merklich nach und sank im Verlauf der 80er Jahre mit z.T. sehr großen negativen Veränderungsraten. Die Gegenüberstellung der Ausgabenwerte zu jeweiligen und konstanten Preisen gibt darüber hinaus Auskunft über die Steigerungsraten der verwendeten Preisindizes. Dabei übertreffen die durchschnittlichen jährlichen Wachstumsraten der Preisindizes für die privaten diejenigen der staatlichen Investitionen. Besonders deutlich ist dies bei den Bauinvestitionen, weil die Preiserhöhungen für Leistungen im Straßenbau, die einen Großteil der staatlichen Investitionen verkörpern, merklich niedriger ausfallen als die Preissteigerungen für Wohnbauten.

Die Urteile über die konjunkturpolitischen Verwendungsmöglichkeiten staatlicher Investitionsausgaben fallen zum Teil sehr konträr aus. Ungeachtet des Dissenses über die längerfristigen Wirkungen einer Erhöhung der staatlichen Investitionsausgaben deutet auch ihr Umfang auf einen vergleichsweise geringen Beitrag zur gesamtwirtschaftlichen Nachfrage hin. Die staatliche Investitions- 
quote, verstanden als Quotient der Bruttoanlageinvestitionen des Staates und des Bruttosozialprodukts, ging im Beobachtungszeitraum stark zurück und beträgt 1985 noch 2,3 vH, während die privaten Anlageinvestitionen immerhin einen Anteil von 17,2 vH besitzen. Unbeschadet der instrumentellen Stabilisierungsfähigkeit staatlicher Investitionsausgaben signalisiert der empirische Befund ebenfalls kein antizyklisch ausgerichtetes Investitionsverhalten des Staates, sondern spricht im Gegenteil, vor allem bei den Kommunen, für die These, daß die Investitionsausgaben in hohem Maße von der Wirtschaftsentwicklung und damit den Einnahmen bestimmt werden.

Neben der Folgelastenhypothese diente insbesondere die demographische Entwicklung als Erklärungsmuster für den Rückgang der Investitionsquote. Mit ihr werden in erster Linie die Sättigungstendenzen in den sog. klassischen Infrastrukturbereichen begründet. Dementsprechend unterstellen die Prognosen über den Investitionsbedarf für die 2. Hälfte der 80er Jahre eine Verlagerung der Investitionen hin zu den kommunalen Versorgungs- und Verkehrsunternehmen. Die Investitionen dieser Unternehmen werden allerdings in der amtlichen Statistik nur zu einem geringen Teil oder wie die der Deutschen Bundespost überhaupt nicht zu den staatlichen Investitionen gerechnet. Mit der Verlagerung der Investitionen zu den öffentlichen Unternehmen verändern sich auch die Faktoren, die eine Investitionsentscheidung beeinflussen sowie die Möglichkeiten ihrer Finanzierung.

Eine Würdigung der Entwicklung der Investitionsausgaben kann nur vor dem Hintergrund der besonderen Eigenschaften und Merkmale erfolgen, welche die Investitionen gegenüber anderen Ausgabenkategorien "auszeichnen". Trotz seiner häufigen und wie selbstverständlich gebrauchten Verwendung gibt es in der Literatur keinen einheitlichen Investitionsbegriff. Gleichsam als konstitutives Element gilt das Erfordernis, bei investiven Ausgaben über einen längeren Zeitraum hinweg wirtschaftlich zu disponieren. Investitionen, die Verzicht auf Gegenwartskonsum in Erwartung zukünftiger Nutzen bedeuten, nehmen dementsprechend auch Einfluß auf Bestandgrößen der Wirtschaftssubjekte, z.B. deren Vermögensposition. 
Während die betriebswirtschaftliche Unterscheidung zwischen Investitionen und anderen Ausgaben nötig ist, um den Erfolg eines Unternehmens periodisieren zu können, besteht dieser Grund für die öffentlichen Haushalte nicht. Zudem stellen private Investitionsentscheidungen das Ergebnis eines einzelwirtschaftlichen Rentabilitätskalküls dar. Diese betriebswirtschaftlichen Investitionsrechnungen sind für öffentliche Investitionsprojekte kaum durchzuführen, da der Nutzen dieser Projekte in den meisten Fällen nicht nur im öffentlichen, sondern auch im privaten Bereich anfällt und sich auch dort einer präzisen marktmäßigen Bewertung entzieht.

Ihre volkswirtschaftliche Bedeutung und ihren wirtschaftspolitischen Reiz gewinnen die öffentlichen Investitionen aus den ihnen unterstellten Wirkungen. Der Versuch, die Investitionen mit Hilfe ihrer Wirkungen von anderen Ausgaben abzugrenzen, scheitert zwar, weil wirkungstheoretische Begriffe schwerlich a priori gelten können, gleichwohl demonstrieren diese Bemühungen die Bandbreite des Investitionsbegriffs und zeigen gleichzeitig die Kluft zwischen den praktischen Abgrenzungen und den theoretischen Ansprüchen auf. Die Grundlage der wirkungstheoretisch orientierten Abgrenzungen bilden in aller Regel die Kriterien

- positiver Zukunftsnutzen

- wachstumsfördernde Wirkung und

- Einfluß auf die Vermögenssituation.

Bei Anlegen des Kriteriums positiver Zukunftsnutzen rechnen alle öffentlichen Ausgaben, die bei einem einzelnen oder einer Gruppe von Individuen zukünftigen Nutzen stiften, zu den öffentlichen Investitionen. Da letztlich grundsätzlich nur ein positiver Nutzen die Legitimation öffentlicher Ausgaben bildet und nahezu jede öffentliche Aktivität für die zukünftige Entwicklung von Bedeutung sein kann bzw. sollte, verliert ein solchermaßen abgegrenzter Investitionsbegriff seine materielle Selektionsfunktion.

Die wachstumsfördernde Wirkung öffentlicher Ausgaben hängt eng mit dem Kapazitätseffekt der Investitionen zusammen, der in einer Erweiterung zukünftiger Produktionsmöglichkeiten besteht. Gilt die Wachstumswirkung als Abgrenzungskriterium, müßten alle Ausgaben, welche die private Investitionstätigkeit 
anregen sowie die Ausstattung mit materieller und immaterieller Infrastruktur erhöhen oder den technischen Fortschritt begünstigen, zu den öffentlichen Investitionen zählen. Eine besondere Bedeutung kommt in diesem Zusammenhang den öffentlichen Infrastrukturausgaben zu, weil sie häufig die Voraussetzungen für private Investitionen schaffen bzw. die Produktivität des privaten Kapitals verbessern. Aber keineswegs alle in der amtlichen Statistik ausgewiesenen Sach- bzw. Bruttoinvestitionen können diese wachstumsfördernde Wirkung beanspruchen, denn Parks, Theater und ähnliche Einrichtungen besitzen die Eigenschaften langlebiger Konsumgüter, die zwar positiven Zukunftsnutzen aufweisen können, aber keine Steigerung der Produktionsmöglichkeiten bewirken. Diese langlebigen Konsumgüter dürften unter Wachstumsaspekten nicht zu den Investitionen zählen. Selbst öffentliche Straßen weisen teilweise konsumtiven Charakter auf, da sie auch für private Ausflugsfahren benutzt werden. Auf der anderen Seite müßten die Teile der Bildungs-, Forschungs- und Gesundheitsausgaben, die Auswirkungen auf die Produktionsmöglichkeiten besitzen, unter diesem Aspekt zu den Investitionen zählen. Der Versuch, die öffentlichen Ausgaben anhand ihrer Wachstumswirkungen abzugrenzen, erscheint nicht nur praktisch unmöglich, weil konsumtive und investive Bestandteile vielfach nicht $\mathrm{zu}$ trennen sind, sondern kann auch theoretisch nicht überzeugen, da die in diesem Sinne investiven Wirkung oft erst ex post bestätigt oder verworfen werden kann.

Die Charakterisierung der öffentlichen Investitionen als Vermögenszugang setzt die Festlegung dessen voraus, was unter Vermögen verstanden werden soll. Ein weitgefaßter Vermögensbegriff, der auch das Humanvermögen einbezieht, besitzt ähnlich wie das Nutzenkriterium, abgesehen von den enormen Bewertungsproblemen, keinen Aussagegehalt mehr hinsichtlich der Abgrenzung öffentlicher Investitionen. Die Eingrenzung auf das Sachvermögen bietet sich als Ausweg an und markiert gleichzeitig den Übergang zu einer Zuordnung, die sich beim Investitionsbegriff an formalen Kriterien orientiert.

Formale Kriterien bildeten nicht ganz zu Unrecht auch schon bisher die Grundlagen statistischer und haushaltsrechtlicher Nachweise. Entsprechend der betriebswirtschaftlichen Ausrichtung erscheint die formale vermögensorientierte Abgrenzung der Investitionen als zweckmäßiger und praktikabler Weg. Bislang existieren allerdings noch keine wissenschaftlich akzeptierten Verfahren, keine 
Normen und keine Konventionen für die Aufstellung einer Volksvermögensrechnung, die die Basis der Abgrenzung bilden könnte. Der Abschied von den wirkungstheoretischen Abgrenzungskriterien bedeutet allerdings auch, daß die Investitionsausgaben per se keinen höheren wirtschaftspolitischen Stellenwert besitzen als andere öffentliche Ausgabenarten, zumal sie erst in Kombination mit diesen das öffentliche Leistungsangebot erzeugen. 


\section{Tabellenanhang}


Tabelle 1*a: Die Gesamtausgaben und investiven Ausgaben des Bundes ${ }^{1}$ - Vergleich der finanzstatistischen Zahlen des Statistischen Bundesamtes und des BMF

\begin{tabular}{|c|c|c|c|c|c|c|c|c|c|c|c|c|c|}
\hline & \multirow{4}{*}{ Jahr } & \multicolumn{4}{|c|}{ GESAMTAUSGABEN } & \multicolumn{4}{|c|}{ INVESTIVE AUSGABEN } & \multicolumn{2}{|c|}{$\begin{array}{c}\text { SACHI. } \\
\text { INVISS'I'TIONEN }\end{array}$} & \multicolumn{2}{|c|}{$\begin{array}{l}\text { INVESTITIONS- } \\
\text { FÖRD.MASSN. }\end{array}$} \\
\hline & & \multicolumn{2}{|c|}{ Stat. Bundesamt ${ }^{2}$} & \multicolumn{2}{|c|}{$\mathrm{BMF}^{31}$} & \multicolumn{2}{|c|}{ Stat. Bundesamt ${ }^{21}$} & \multicolumn{2}{|c|}{ BMF" } & \multirow{2}{*}{$\begin{array}{c}\text { Stut. Bun- } \\
\text { desamt }\end{array}$} & \multirow{2}{*}{$B M F^{3 \prime}$} & \multirow{2}{*}{$\begin{array}{l}\text { Stat.Bun- } \\
\text { desamt }\end{array}$} & \multirow{2}{*}{$\mathrm{BMF}^{3 \mathrm{3}}$} \\
\hline & & & Wachstums- & & Wachstums- & & Wachstums- & & Wachstums- & & & & \\
\hline & & Mrd. DM & rate & Mrd. DM & rate" & Mrd. DM & rate & Mrd.DM & rate & Mrd.DM & Mrd.DM & Mrd.DM & Mrd.DM \\
\hline & 1962 & 50,74 & - & 49,87 & - & & & 8,48 & - & 2,55 & 2,95 & & 5,53 \\
\hline & 1963 & 55,23 & 8,8 & 54,76 & 9,8 & & & 9,29 & 9,6 & 2,92 & 3,43 & & 5,86 \\
\hline 뭉 & 1964 & 59,15 & 7,1 & 58,15 & 6,2 & & & 9,75 & 5,0 & 3,28 & 3,68 & & 6,07 \\
\hline$\sum$ & 1965 & 63,46 & 7,3 & 64,19 & 10,4 & & & 10,27 & 5,3 & 3,51 & 3,77 & & 6,50 \\
\hline 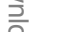 & 1966 & 68,51 & 8,0 & 66,88 & 4,2 & & & 10,39 & 1,2 & 3,64 & 3,88 & & 6,51 \\
\hline ఏి & 1967 & 76,72 & 12,0 & 74,64 & 11,6 & & & 13,56 & 30,5 & 4,53 & 4,67 & & 8,89 \\
\hline$\frac{0}{1}$ & 1968 & 76,07 & $-0,8$ & 75,77 & 1,5 & & & 12,71 & $-6,3$ & 4,25 & 4,15 & & 8,56 \\
\hline 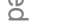 & 1969 & 82,42 & 8,3 & 82,26 & 8,6 & & & 14,01 & 10,2 & 5,03 & 5,01 & & 9,00 \\
\hline & 1970 & 88,21 & 7,0 & 87,99 & 7,0 & & & 15,16 & 8,2 & 5,72 & 5,64 & & 9,52 \\
\hline 윽 웅 & 1971 & 98,77 & 12,0 & 98,48 & 11,9 & & & 18,11 & 19,5 & 6,46 & 6,41 & & 11,70 \\
\hline $3 \overrightarrow{\mathbb{D}}$ & 1972 & 112,57 & 14,0 & 111,10 & 12,8 & & & 20,64 & 14,0 & 6,75 & 6,63 & & 14,01 \\
\hline$\subseteq \stackrel{0}{丂}$ & 1973 & 122,57 & 8,9 & 122,56 & 10,3 & & & 22,88 & 10,9 & 6,56 & 6,49 & & 16,39 \\
\hline б & 1974 & 134,91 & 10,1 & 134,04 & 9,4 & & & 23,01 & 0,6 & 7,23 & 7,10 & & 15,91 \\
\hline ه & 1974 & 135,19 & $\cdot$ & - & - & 22,77 & - & - & - & 7,23 & - & 15,54 & - \\
\hline 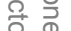 & 1975 & 160,15 & 18,5 & 158,80 & 18,5 & 26,57 & 16,7 & 26,71 & 16,1 & 7,96 & 7,81 & 18,61 & 18,90 \\
\hline$\frac{0}{2}$ & 1976 & 166,71 & 4,1 & 165,20 & 4,0 & 24,39 & $-8,2$ & 24,63 & $-7,8$ & 7,11 & 7,01 & 17,28 & 17,62 \\
\hline வ & 1977 & 174,20 & 4,5 & 172,39 & 4,4 & 24,06 & $-1,4$ & 24,14 & $-2,0$ & 7,40 & 7,21 & 16,66 & 16,93 \\
\hline$\stackrel{\oplus}{\rightleftharpoons}$ & 1978 & 191,22 & 9,8 & 189,66 & 10,0 & 28,01 & 16,4 & 28,11 & 16,4 & 7,79 & 7,66 & 20,22 & 20,45 \\
\hline$\stackrel{\circ}{\rightleftharpoons} \stackrel{0}{\mathbb{D}}$ & 1979 & 205,06 & 7,2 & 203,41 & 7,2 & 32,80 & 17,1 & 32,94 & 17,2 & 8,09 & 7,98 & 24,71 & 24,96 \\
\hline 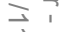 & 1980 & 217,58 & 6,1 & 215,72 & 6,1 & 31,49 & $-4,0$ & 31,47 & $-4,5$ & 8,37 & 8,21 & 23,12 & 23,26 \\
\hline$\vec{\nabla}$ & 1981 & 234,87 & 7,9 & 232,99 & 8,0 & 30,45 & $-3,3$ & 30,50 & $-3,1$ & 7,40 & 7,28 & 23,05 & 23,22 \\
\hline N & 1982 & 246,62 & 5,0 & 244,65 & 5,0 & 31,93 & 4,9 & 32,02 & 5,0 & 7,10 & 6,96 & 24,83 & 25,06 \\
\hline$\vec{\omega} \stackrel{1}{\omega}$ & 1983 & 248,72 & 0,9 & 246,75 & 0,9 & 31,25 & $-2,1$ & 31,30 & $-2,2$ & 7,25 & 7,12 & 24,00 & 24,18 \\
\hline ○ के & 1984 & 253,85 & 2,1 & 251,78 & 2,0 & 33,50 & 7,2 & 33,58 & 7,3 & 7,26 & 7,12 & 26,24 & 26,46 \\
\hline
\end{tabular}

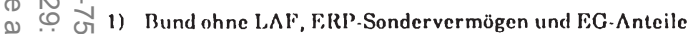

疒 $G(2)$ Rechnungsergebnisse des Statistischen Bundesamtes.

D $O$ 3) Ist-lirgebnisse des Bundesministeriums der Finanzen.

\& 3 or 4) Veránderung gegenüber dem Vorjahr in vll.

Quelle: Zusammengestellt und errechnet aus Unterlagen, die uns das Bundesministerium der Finanzen und das Statistische Bundesamt freundlicherweise zur Verfügung stellicn. 
Tabelle 1*b: Die Gesamtal @gaben und investiven Ausgaben der Länder - Vergleich der finanzstatistischen Zahlen des Statistischen Bundesamtes und des BMF

\begin{tabular}{|c|c|c|c|c|c|c|c|c|c|c|c|c|c|}
\hline & \multirow{4}{*}{ Jahr } & \multicolumn{4}{|c|}{ GESAMTAUSGABEN } & \multicolumn{4}{|c|}{ INVESTIVE AUSGABEN } & \multicolumn{2}{|c|}{$\begin{array}{l}\text { SACHI- } \\
\text { INVESTITIONEN }\end{array}$} & \multicolumn{2}{|c|}{$\begin{array}{l}\text { INVESTITIONS- } \\
\text { FÖRD.MASSN. }\end{array}$} \\
\hline & & \multicolumn{2}{|c|}{ Stat. Bundesamt" } & \multicolumn{2}{|c|}{$\mathrm{BMF}^{21}$} & \multicolumn{2}{|c|}{ Stat. Bundesam l" $^{\prime \prime}$} & \multicolumn{2}{|c|}{$\mathrm{BMF}^{21}$} & \multirow{2}{*}{$\begin{array}{c}\text { Stal. Bun- } \\
\text { desamt }\end{array}$} & \multirow{2}{*}{$\mathrm{BMF}^{21}$} & \multirow{2}{*}{$\begin{array}{c}\text { Slat. Bun- } \\
\text { desamt" }\end{array}$} & \multirow{2}{*}{$\mathrm{BMF}^{21}$} \\
\hline & & & Wachstums- & & Wachstums- & & Wachstums- & & Wachstums- & & & & \\
\hline \multirow{7}{*}{ 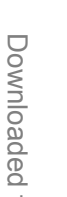 } & & Mrd. DM & rate" & Mrd. DM & rate $^{3 \prime}$ & Mrd. DM & rate $^{3 \prime}$ & Mrd.DM & rate $^{31}$ & Mrd.DM & Mrd.DM & Mrd.DM & Mrd.DM \\
\hline & 1962 & 42,54 & - & 43,51 & - & & & 11,26 & - & 3,09 & 3,09 & & 8,17 \\
\hline & 1963 & 45,96 & 8,0 & 45,96 & 5,6 & & & 12,72 & 13,0 & 3,57 & 3,57 & & 9,15 \\
\hline & 1964 & 50,18 & 9,2 & 50,18 & 9,2 & & & 14,37 & 13,0 & 4,28 & 4,28 & & 10,09 \\
\hline & 1965 & 54,55 & 8,7 & 54,55 & 8,7 & & & 15,42 & 7,3 & 4,68 & 4,68 & & 10,74 \\
\hline & 1966 & 57,88 & 6,1 & 57,88 & 6,1 & & & 15,28 & $-0,9$ & 4,66 & 4,66 & & 10,62 \\
\hline & 1967 & 59,80 & 3,3 & 60,15 & 3,9 & & & 15,32 & 0,3 & 4,52 & 4,52 & & 10,80 \\
\hline \multirow{8}{*}{ 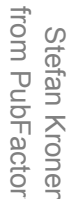 } & 1968 & 62,82 & 5,1 & 63,38 & 5,4 & & & 14,96 & $-2,3$ & 4,53 & 4,53 & & 10,43 \\
\hline & 1969 & 67,13 & 6,9 & 67,78 & 6,9 & & & 15,93 & 6,5 & 4,94 & 4,94 & & 10,99 \\
\hline & 1970 & 77,09 & 14,8 & 77,65 & 14,6 & & & 18,73 & 17,6 & 6,40 & 6,40 & & 12,33 \\
\hline & 1971 & 89,05 & 15,5 & 89,53 & 15,3 & & & 20,66 & 10,3 & 6,96 & 6.96 & & 13,70 \\
\hline & 1972 & 100,38 & 12,7 & 100,38 & 12,1 & & & 22,54 & 9,1 & 6,73 & 6,73 & & 15,81 \\
\hline & 1973 & 115,85 & 15,4 & 115,85 & 15,4 & & & 26,95 & 19,6 & 7,37 & 7,37 & & 19,58 \\
\hline & 1974 & 134,05 & 15,7 & 134,05 & 15,7 & & & 30,54 & 13,3 & 8,66 & 8,66 & & 21,88 \\
\hline & $19 \overline{44}$ & 134,05 & - & - & $\cdot$ & 30,58 & - & - & - & 8,66 & - & 21,92 & - \\
\hline$\overline{0}$ & 1975 & 146,27 & 9,1 & 146,28 & 9,1 & 31.27 & 2,3 & 31,23 & 2,3 & 8,59 & 8,59 & 22,68 & 22,64 \\
\hline $\overrightarrow{0}$ & 1976 & 154,39 & 5,6 & 154,39 & 5,5 & 32,49 & 3,9 & 32,43 & 3,8 & 8,12 & 8,12 & 24,37 & 24,31 \\
\hline$\stackrel{0}{\rightarrow}$ & 1977 & 161,59 & 4,7 & 161,60 & 4,7 & 29,95 & $-7,8$ & 29,91 & $-7,8$ & 8,38 & 8,38 & 21,57 & 21,53 \\
\hline $\bar{\rightrightarrows}$ & 1978 & 176,52 & 9,2 & 176,52 & 9,2 & 34,00 & 13,5 & 33,85 & 13,2 & 8,75 & 8,75 & 25,25 & 25,10 \\
\hline$\geqslant \varphi$ & 1979 & 191,83 & 8,7 & 191,83 & 8,7 & 38,03 & 11,9 & 37,77 & 11,6 & 9,35 & 9,35 & 28,68 & 28,42 \\
\hline N & 1980 & 208,65 & 8,8 & 208,61 & 8,7 & 42,20 & 11,0 & 41,78 & 10,6 & 10,56 & 10,56 & 31,64 & 31,22 \\
\hline$\vec{\omega} \omega$ & 1981 & 216,63 & 3,8 & 216,63 & 3,8 & 39,99 & $-5,2$ & 39,50 & $-5,5$ & 10,02 & 10,02 & 29,97 & 29,48 \\
\hline ó & 1982 & 224,21 & 3,5 & 224,21 & 3,5 & 39,89 & $-0,3$ & 39,24 & $-0,7$ & 9,94 & 9,94 & 29,95 & 29,30 \\
\hline ب & 1983 & 228,29 & 1,8 & 228,29 & 1,8 & 38,50 & $-3,5$ & 37,88 & $-3,5$ & 9,87 & 9,87 & 28,63 & 28,01 \\
\hline Nं ज & 1984 & 234,30 & 2,6 & 234,29 & 2,6 & 39,53 & 2,7 & 38,90 & 2,7 & 9,97 & 9,96 & 29,56 & 28,94 \\
\hline
\end{tabular}

(

(s) ó $\left._{2}\right)$ Rechnungsergebnisse des Bundesministeriums der Finanzen.

3) Verănderung gegenüher dem Vorjahr in vil.

Quelle: Zusammengestellt und errechnet aus Unterlagen, die uns das Bundesminislerium der Finanzen und das Statistische Bundesamt freundlicherweise zur Verfügung stellten. 
Tabelle 1*c: Die Gesamtausgaben und investiven Ausgaben der Gemeinden und Gemeindeverbände - Vergleich der finanzstatistischen Zahlen des Statistischen Bundesamtes und des BMF

\begin{tabular}{|c|c|c|c|c|c|c|c|c|c|c|c|c|c|}
\hline & \multirow{4}{*}{ Jahr } & \multicolumn{4}{|c|}{ GESAMTAUSGABEN } & \multicolumn{4}{|c|}{ INVESTIVE $\triangle$ USG $\triangle B E N$} & \multicolumn{2}{|c|}{$\begin{array}{l}\text { SACII- } \\
\text { INVESTITIONEN }\end{array}$} & \multicolumn{2}{|c|}{$\begin{array}{l}\text { INVESTITIONS- } \\
\text { FÖRD.MASSN. }\end{array}$} \\
\hline & & \multicolumn{2}{|c|}{ Stat. Bundesamt ${ }^{11}$} & \multicolumn{2}{|c|}{$\mathrm{BMF}^{21}$} & \multicolumn{2}{|c|}{ Stat. Bundesamt" } & \multicolumn{2}{|c|}{ BMF" } & \multirow{2}{*}{$\begin{array}{l}\text { Stat. Bun- } \\
\text { desamt" }\end{array}$} & \multirow{2}{*}{$B M F^{21}$} & \multirow{2}{*}{$\begin{array}{l}\text { Stat.Bun- } \\
\text { desamt }\end{array}$} & \multirow{2}{*}{$\mathrm{BMF}^{21}$} \\
\hline & & & Wachstums- & & Wachstums- & & Wachstums- & & Wachstums- & & & & \\
\hline & & Mrd. DM & rate" & Mrd. DM & rate $^{3}$ & Mrd. DM & rates" & Mra.DM & rate" & Mrd.DM & Mrd.DM & Mrd.DM & Mrd.DM \\
\hline & 1962 & 28,04 & - & 28,04 & - & & & 12,15 & - & 10,51 & 10,51 & & 1,64 \\
\hline & 1963 & 31,49 & 12,3 & 31,48 & 12,3 & & & 13,80 & 13,6 & 12,09 & 12,09 & & 1,71 \\
\hline 우 & 1964 & 35,81 & 13,7 & 35,81 & 13,8 & & & 16,32 & 18,3 & 14,47 & 14,47 & & 1,85 \\
\hline$\leqq$ & 1965 & 39,02 & 9,0 & 39,02 & 9,0 & & & 17,11 & 4,8 & 15,02 & 15,02 & & 2,09 \\
\hline$\overline{0}$ & 1966 & 41,03 & 5,2 & 41,03 & 5,2 & & & 16,57 & $-3,2$ & 14,81 & 14,81 & & 1,76 \\
\hline व & 1967 & 41,02 & 0,0 & 41,02 & 0,0 & & & 15,24 & $-8,0$ & 13,59 & 13,59 & & 1,65 \\
\hline 요 & 1968 & 43,19 & 5,3 & 43,19 & 5,3 & & & 15,85 & 4,0 & 14,36 & 14,36 & & 1,49 \\
\hline 2 & 1969 & 48,42 & 12,1 & 48,42 & 12,1 & & & 18,04 & 13,8 & 16,44 & 16,44 & & 1.60 \\
\hline & 1970 & 56,49 & 16,7 & 56,49 & 16,7 & & & 21,98 & 21,8 & 20,20 & 20,20 & & 1,78 \\
\hline $3 \frac{0}{3}$ & 1971 & 67,42 & 19,3 & 67,42 & 19,3 & & & 26,72 & 21,6 & 24,20 & 24,20 & & 2,52 \\
\hline 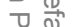 & 1972 & 74,72 & 10,8 & 74,72 & 10,8 & & & 28,20 & 5,5 & 25,77 & 25,77 & & 2,43 \\
\hline & 1973 & 84,08 & 12,5 & 84,08 & 12,5 & & & 29,95 & 6,2 & 27,50 & 27,50 & & 2,45 \\
\hline 宁 즈 & 1974 & 97,17 & 15,6 & 95,85 & 14,0 & & & 33,73 & 12,6 & 30,37 & 30,37 & & 3,36 \\
\hline$\stackrel{0}{0}$ & 1974 & 95,86 & $\cdot$ & $\cdot$ & 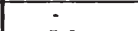 & 33,78 & $\cdot$ & $\cdot$ & $\cdot$ & 30,37 & - & 3,41 & - \\
\hline$\stackrel{\overbrace{}}{0}$ & 1975 & 101,40 & 5,8 & 101,23 & 5,6 & 32,94 & $-2,5$ & 32,96 & $-2,3$ & 29,64 & 29,64 & 3,30 & 3,32 \\
\hline 를 & 1976 & 104,32 & 2,9 & 104,08 & 2,8 & 31,98 & $-2,9$ & 32,01 & $-2,9$ & 28,51 & 28,51 & 3,47 & 3,50 \\
\hline$₫ 8$ & 1977 & 108,41 & 3,9 & 107,65 & 3,4 & 31,07 & $-2,8$ & 30,98 & $-3,2$ & 27,62 & 27,62 & 3,45 & 3,36 \\
\hline $\overrightarrow{0}$ & 1978 & 118,20 & 9,0 & 118,92 & 10,5 & 35,24 & 13,4 & 35,02 & 13,0 & 31,16 & 31,16 & 4,08 & 3,86 \\
\hline$\stackrel{\mathbb{D}}{\rightarrow}$ & 1979 & 130,36 & 10,3 & 130,35 & 9,6 & 39,79 & 12,9 & 39,69 & 13,3 & 35,99 & 35,99 & 3,80 & 3,70 \\
\hline$\vec{\prime}$ i & 1980 & 145,58 & 11,7 & 145,47 & 11,6 & 45,61 & 14,6 & 45,70 & 15,1 & 41,23 & 41,23 & 4,38 & 4,47 \\
\hline $\overrightarrow{\vec{N}} \varphi$ & 1981 & 152,12 & 4,5 & 152,13 & 4,6 & 44,69 & $-2,0$ & 44,71 & $-2,2$ & 39,69 & 39,69 & 5,00 & 5,02 \\
\hline ర & 1982 & 153,05 & 0,6 & 153,06 & 0,6 & 40,23 & $-10,0$ & 40,07 & $-10,4$ & 35,12 & 35,12 & 5,11 & 4,95 \\
\hline$\vec{\omega} \underset{1}{\omega}$ & 1983 & 151,65 & $-0,9$ & 151,66 & $-0,9$ & 36,76 & $-8,6$ & 36,67 & $-8,5$ & 31,51 & 31,51 & 5,25 & 5,16 \\
\hline 0 ఏ & 1984 & 154,71 & 2,0 & 154,70 & 2,0 & 36,15 & $-1,7$ & 35,76 & $-2,5$ & 30,54 & 30,54 & 5,61 & 5,22 \\
\hline
\end{tabular}

() $(\mathcal{i l l})$ Rechnungsergebnisse des Statistischen Bundesamtes einschl. der kommunalen Krankenhăuser.

( 2 ) Rechnungsergebnisse des Bundesminisleriuıns der Pinanzen.

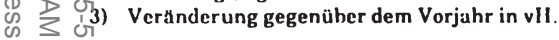

Quelle: 7,usammengestellt und errechnet aus Unterlagen, die uns das Bundesministerium der Finanzen und das Statistische Bundesaml freundlicherweise zur Verfügung stellten. 
Tabelle 2*a: Die Investitionsausgaben des Bundes" - Finanzstatistische Daten des BMF

\begin{tabular}{|c|c|c|c|c|c|c|c|c|c|c|c|}
\hline \multirow{3}{*}{ Jahr } & \multirow{2}{*}{\multicolumn{2}{|c|}{ GESAMTAUSGABEN }} & \multicolumn{9}{|c|}{ INVESTITIONSAUSGABLN } \\
\hline & & & \multicolumn{3}{|c|}{ insgesamt } & \multicolumn{3}{|c|}{ Sachinvestitionen } & \multicolumn{3}{|c|}{ Investitionsförderungsmaßnahmen } \\
\hline & Mrd. DM & $\begin{array}{l}\text { Wachs- } \\
\text { tumsrate }\end{array}$ & Mrd. DM & $\begin{array}{l}\text { Wachs- } \\
\text { tumsrate }^{2)}\end{array}$ & Anteil ${ }^{3}$ & Mrd.DM & $\begin{array}{l}\text { Wachs- } \\
\text { tumsrate }\end{array}$ & Antcil" & Mrd.DM & $\begin{array}{c}\text { Wachs- } \\
\text { tumsrate }\end{array}$ & Anteil") \\
\hline 1962 & 49,87 & - & 8,48 & - & 17,0 & 2,95 & - & 34,8 & 5,53 & - & 65,2 \\
\hline 1963 & 54,76 & 9,8 & 9,29 & 9,6 & 17,0 & 3,43 & 16,3 & 36,9 & 5,86 & 6,0 & 63,1 \\
\hline 1964 & 58,15 & 6,2 & 9,75 & 5,0 & 16,8 & 3,68 & 7,3 & 37,7 & 6,07 & 3,6 & 62,3 \\
\hline 1965 & 64,19 & 10,4 & 10,27 & 5,3 & 16,0 & 3,77 & 2,4 & 36,7 & 6,50 & 7,1 & 63,3 \\
\hline 1966 & 66,88 & 4,2 & 10,39 & 1,2 & 15,5 & 3,88 & 2,9 & 37,3 & 6,51 & 0,2 & 62,7 \\
\hline 1967 & 74,64 & 11,6 & 13,56 & 30,5 & 18,2 & 4,67 & 20,4 & 34,4 & 8,89 & 36,6 & 65,6 \\
\hline 1968 & 75,77 & 1,5 & 12,71 & $-6,3$ & 16,8 & 4,15 & $-11,1$ & 32,7 & 8,56 & $-3,7$ & 67,3 \\
\hline 1969 & 82,26 & 8,6 & 14,01 & 10,2 & 17,0 & 5,01 & 20,7 & 35,8 & 9,00 & 5,1 & 64,2 \\
\hline 1970 & 87,99 & 7,0 & 15,16 & 8,2 & 17,2 & 5,64 & 12,6 & 37,2 & 9,52 & 5,8 & 62,8 \\
\hline 1971 & 98,48 & 11,9 & 18,11 & 19,5 & 18,4 & 6,41 & 13,7 & 35,4 & 11,70 & 22,9 & 64,6 \\
\hline 1972 & 111,10 & 12,8 & 20,64 & 14,0 & 18,6 & 6,63 & 3,4 & 32,1 & 14,01 & 19,7 & 67,9 \\
\hline 1973 & 122,56 & 10,3 & 22,88 & 10,9 & 18,7 & 6,49 & $-2,1$ & 28,4 & 16,39 & 17,0 & 71,6 \\
\hline 1974 & 134,04 & 9,4 & 23,01 & 0,6 & 17,2 & 7,10 & 9,4 & 30,9 & 15,91 & $-2,9$ & 69,1 \\
\hline 1975 & 158,80 & 18,5 & 26,71 & 16,1 & 16,8 & 7,81 & 10,0 & 29,2 & 18,90 & 18,8 & 70,8 \\
\hline 1976 & 165,20 & 4,0 & 24,63 & $-7,8$ & 14,9 & 7,01 & $-10,2$ & 28,5 & 17,62 & $.6,8$ & 71,5 \\
\hline 1977 & 172,39 & 4,4 & 24,13 & $-2,0$ & 14,0 & 7,21 & 2,9 & 29,9 & 16,92 & $-4,0$ & 70,1 \\
\hline 1978 & 189,66 & 10,0 & 28,11 & 16,5 & 14,8 & 7,66 & 6,2 & 27,3 & 20,45 & 20.9 & 72,7 \\
\hline 1979 & 203,41 & 7,2 & 32,94 & 17,2 & 16,2 & 7,98 & 4,2 & 24,2 & 24,96 & 22,1 & 75,8 \\
\hline 1980 & 215,72 & 6,1 & 31,47 & $-4,5$ & 14,6 & 8,21 & 2,9 & 26,1 & 23,26 & $-6,8$ & 73,9 \\
\hline 1981 & 232,99 & 8,0 & 30,50 & $-3,1$ & 13,1 & 7,28 & $-11,3$ & 23,9 & 23,22 & $-0,2$ & 76,1 \\
\hline 1982 & 244,65 & 5,0 & 32,02 & 5,0 & 13,1 & 6,96 & $.4,4$ & 21,7 & 25,06 & 7,9 & 78,3 \\
\hline 1983 & 246,75 & 0,9 & 31,30 & $-2,2$ & 12,7 & 7,12 & 2,3 & 22,7 & 24,18 & $-3,5$ & 77,3 \\
\hline 1984 & 251,78 & 2,0 & 33,57 & 7,3 & 13,3 & 7,12 & 0,0 & 21,2 & 26,46 & 9,4 & 78,8 \\
\hline 1985 & 257,11 & 2,1 & 33,40 & $-0,5$ & 13,0 & 7,39 & 3,8 & 22,1 & 26,01 & $\begin{array}{r}0,4 \\
-1,7\end{array}$ & 77,9 \\
\hline 1986 & 261,53 & 1,7 & 32,82 & -1.7 & 12,5 & 7,52 & 1,8 & 22,9 & 25,30 & $-2,7$ & 77,1 \\
\hline
\end{tabular}

1) Ist-Ergebnisse in der Systematik des Haushalts 1986, ohne LAF, ERP-Sondervermögen und EG-Anteile.

2) Veränderung gegenüber dem Vorjahr in vll.

3) Gesamle Investitionsausgaben in vll der Gesamtausgaben.

4) Jeweilige Ausgaben in vll der gesamten Investitionsausgaben.

Quelle: Zusammengestellt und errechnet aus Unterlagen, die uns das Bundesministerium der Finanzen freundlicherwcise zur Verfügung stellte. 
'Tabelle 2*b: Die Investitionsausgaben der Länder") - Finanzstatistische Daten des BMF

\begin{tabular}{|c|c|c|c|c|c|c|c|c|c|c|c|}
\hline \multirow{3}{*}{ Jahr } & \multirow{2}{*}{\multicolumn{2}{|c|}{ GESAMTAUSGABEN }} & \multicolumn{9}{|c|}{ INVESTITIONSAUSGABEN } \\
\hline & & & \multicolumn{3}{|c|}{ insgesamt } & \multicolumn{3}{|c|}{ Sachinvestitionen } & \multicolumn{3}{|c|}{ Investitionsförderungsmaßnahmen } \\
\hline & Mrd. DM & $\begin{array}{l}\text { Wachs- } \\
\text { tumsrate }^{21}\end{array}$ & Mrd. DM & $\begin{array}{l}\text { Wachs- } \\
\text { tumsrate }\end{array}$ & Anteil' & Mrd.DM & $\begin{array}{l}\text { Wachs- } \\
\text { tumsratc }^{21}\end{array}$ & Anteil" & Mrd.DM & $\begin{array}{l}\text { Wachs- } \\
\text { tumsrate }^{2)}\end{array}$ & Anteil" \\
\hline 1962 & 43,51 & - & 11,26 & $\cdot$ & 25,9 & 3,09 & - & 27,4 & 8,17 & - & 72,6 \\
\hline 1963 & 45,96 & 5,6 & 12,72 & 13,0 & 27,7 & 3,57 & 15,5 & 28,1 & 9,15 & 12,0 & 71,9 \\
\hline 1964 & 50,18 & 9,2 & 14,37 & 13,0 & 28,6 & 4,28 & 19,9 & 29,8 & 10,09 & 10,3 & 70,2 \\
\hline 1965 & 54,55 & 8,7 & 15,42 & 7,3 & 28,3 & 4,68 & 9,3 & 30,4 & 10,74 & 6,4 & 69,6 \\
\hline 1966 & 57,88 & 6,1 & 15,28 & $-0,9$ & 26,4 & 4,66 & $-0,4$ & 30,5 & 10,62 & $-1,1$ & 69,5 \\
\hline 1967 & 60,15 & 3,9 & 15,32 & 0,3 & 25,5 & 4,52 & $-3,0$ & 29,5 & 10,80 & 1,7 & 70,5 \\
\hline 1968 & 63,38 & 5,4 & 14,96 & $-2,3$ & 23,6 & 4,53 & 0,2 & 30,3 & 10,43 & $-3,4$ & 69,7 \\
\hline 1969 & 67,78 & 6,9 & 15,93 & 6,5 & 23,5 & 4,94 & 9,1 & 31,0 & 10,99 & 5,4 & 69,0 \\
\hline 1970 & 77,65 & 14,6 & 18,73 & 17,6 & 24,1 & 6,40 & 29,6 & 34,2 & 12,33 & 12,2 & 65,8 \\
\hline 1971 & 89,53 & 15,3 & 20,66 & 10,3 & 23,1 & 6,96 & 8,8 & 33,7 & 13,70 & 11,1 & 66,3 \\
\hline 1972 & 100,38 & 12.1 & 22,54 & 9,1 & 22,5 & 6,73 & $-3,3$ & 29,9 & 15,81 & 15,4 & 70,1 \\
\hline 1973 & 115,85 & 15,4 & 26,94 & 19,5 & 23,3 & 7,37 & 9,5 & 27,4 & 19,58 & 23,8 & 72,7 \\
\hline 1974 & 134,05 & 15,7 & 30,54 & 13,4 & 22,8 & 8,66 & 17,5 & 28,4 & 21,88 & 11,7 & 71,6 \\
\hline 1975 & 146,28 & 9,1 & 31,23 & 2,3 & 21,3 & 8,59 & $-0,8$ & 27,5 & 22,64 & 3,5 & 72,5 \\
\hline 1976 & 154,39 & 5,5 & 32,44 & 3,9 & 21,0 & 8,12 & $-5,5$ & 25,0 & 24,32 & 7,4 & 75,0 \\
\hline 1977 & 161,60 & 4,7 & 29,92 & $-7,8$ & 18,5 & 8,38 & 3,2 & 31,4 & 21,54 & $-11,4$ & 72,0 \\
\hline 1978 & 176,52 & 9,2 & 33,84 & 13,1 & 19,2 & 8,75 & 4,4 & 25,9 & 25,09 & 16,5 & 74,1 \\
\hline 1979 & 191,83 & 8,7 & 37,77 & 11,6 & 19,7 & 9,35 & 6,9 & 24,8 & 28,42 & 13,3 & 75,2 \\
\hline 1980 & 208,61 & 8.7 & 41,78 & 10,6 & 20,0 & 10,56 & 12,9 & 25,3 & 31,22 & 9,9 & 74,7 \\
\hline 1981 & 216,63 & 3,8 & 39,50 & $-5,5$ & 18,2 & 10,02 & $-5,1$ & 25,4 & 29,48 & $-5,6$ & 74,6 \\
\hline 1982 & 224,21 & 3,5 & 39,24 & $-0,7$ & 17,5 & 9,94 & $-0,8$ & 25,3 & 29,30 & $-0,6$ & 74,7 \\
\hline 1983 & 228,29 & 1,8 & 37,87 & $-3,5$ & 16,6 & 9,87 & $-0,7$ & 26,1 & 28,00 & $-4,4$ & 73,9 \\
\hline 1984 & 234,29 & 2,6 & 38,90 & 2,7 & 16,6 & 9,96 & 0,9 & 25,6 & 28,94 & 3,4 & 74,4 \\
\hline 1985 & 243,94 & 4,1 & 39,62 & 1,9 & 16,2 & 10,61 & 6,5 & 26,8 & 29,01 & 0,2 & 73,2 \\
\hline 1986 & 253,13 & 3,8 & 40,37 & 1,9 & 15,9 & 10,86 & 2,4 & 26,9 & 29,51 & 1,7 & 73,1 \\
\hline
\end{tabular}

1) Rechnungsergebnisse, zuzüglich der slautlichen Krankenhaluser. Für 1985 Ergebnisse der Vierleljahresstutistik, einschl. Sonderrechnungen und Krankenhäuser der Lånder; mil den Vorjahren nur bedingt vergleichbar.

2) Veränderung gegenüber dem Vorjahr in vII

3) Investitionsausgaben (insgesamt) in vil der Gesamlausgaben.

4) Jeweilige Ausguben in vll der gesumlen Investitionsuusguben.

Quelle: Zusammengestellt und errechnet uus Unterlagen, dic uns das Bundesministerium der Finanzen freundlicherweise zur Verfügung stellte. 
Tabelle $2^{*}$ c: Die Investitionsausgaben der Gemeinden und Gemeindeverbände ${ }^{\prime \prime}$ - Finanzstatistische Daten des BMF -

\begin{tabular}{|c|c|c|c|c|c|c|c|c|c|c|c|}
\hline \multirow{3}{*}{ Jahr } & \multirow{2}{*}{\multicolumn{2}{|c|}{ GESAMTAUSGABEN }} & \multicolumn{9}{|c|}{ INVESTITIONSAUSGABIEN } \\
\hline & & & \multicolumn{3}{|c|}{ insgesumt } & \multicolumn{3}{|c|}{ Suchinvestitionen } & \multicolumn{3}{|c|}{ Investitionsförderungsmaßnahmen } \\
\hline & Mrd. DM & $\begin{array}{c}\text { Wachs- } \\
\text { tumsrate }^{21}\end{array}$ & Mrd. DM & $\begin{array}{l}\text { Wachs- } \\
\text { tumsrate }\end{array}$ & Anteil ${ }^{3 \prime}$ & Mrd.DM & $\begin{array}{l}\text { Wachs- } \\
\text { tumsrate }\end{array}$ & Antcil" & Mrd.I)M & $\begin{array}{c}\text { Wachs- } \\
\text { tumsrate }\end{array}$ & Anteil" \\
\hline 1962 & 28,04 & - & 12,15 & - & 43,3 & 10,51 & - & 86,5 & 1.64 & - & 13,5 \\
\hline 1963 & 31,48 & 12,3 & 13,81 & 13,7 & 43,9 & 12,09 & 15,0 & 87,5 & 1,72 & 4,9 & 12,5 \\
\hline 1964 & 35,81 & 13,8 & 16,32 & 18,2 & 45,6 & 14,47 & 19,7 & 88,7 & 1,85 & 7,6 & 11,3 \\
\hline 1965 & 39,02 & 9,0 & 17,11 & 4,8 & 43,8 & 15,02 & 3,8 & 87,8 & 2,09 & 13,0 & 12,2 \\
\hline 1966 & 41,03 & 5,2 & 16,57 & $-3,2$ & 40,4 & 14,81 & $-1,4$ & 89,4 & 1,76 & $-15,8$ & 10,6 \\
\hline 1967 & 41,02 & 0,0 & 15,24 & $-8,0$ & 37,2 & 13,59 & $-8,2$ & 89,2 & 1,65 & $-6,3$ & 10,8 \\
\hline 1968 & 43,19 & 5,3 & 15,85 & 4,0 & 36,7 & 14,36 & 5,7 & 90,6 & 1,49 & $-9,7$ & 9,4 \\
\hline 1969 & 48,42 & 12,1 & 18,04 & 13,8 & 37,3 & 16,44 & 14,5 & 91,1 & 1,60 & 7,4 & 8,9 \\
\hline 1970 & 56,49 & 16,7 & 21,98 & 21,8 & 38,9 & 20,20 & 22,9 & 91,9 & 1,78 & 11,3 & 8,1 \\
\hline 1971 & 67,42 & 19,3 & 26,72 & 21,6 & 39,6 & 24,20 & 19,8 & 90,6 & 2,52 & 41,6 & 9,4 \\
\hline 1972 & 74,72 & 10,8 & 28,20 & 5,5 & 37,7 & 25,77 & 6,5 & 91,4 & 2,43 & 3,6 & 8,6 \\
\hline 1973 & 84,08 & 12,5 & 29,95 & 6,2 & 35,6 & 27,50 & 6,7 & 91,8 & 2,45 & 0,8 & 8,2 \\
\hline 1974 & 95,85 & 14,0 & 33,73 & 12,6 & 35,2 & 30,37 & 10,4 & 90,0 & 3,36 & 37,1 & 10,0 \\
\hline 1975 & 101,23 & 5,6 & 32,96 & $-2,3$ & 32,6 & 29,64 & $-2,4$ & 89,9 & 3,32 & $-1,2$ & 10,1 \\
\hline 1976 & 104,08 & 2,8 & 32,01 & $-2,9$ & 30,8 & 28,51 & $-3,8$ & 89,1 & 3,50 & 5,4 & 10,9 \\
\hline 1977 & 107,65 & 3,4 & 30,99 & $-3,2$ & 28,8 & 27,62 & $-3,1$ & 89,1 & 3,37 & $-3,7$ & 10,9 \\
\hline 1978 & 118,19 & 9,8 & 35,01 & 13,0 & 29,6 & 31,16 & 12,8 & 89,0 & 3,86 & 14,5 & 11,0 \\
\hline 1979 & 130,35 & 10,3 & 39,70 & 13,4 & 30,5 & 35,99 & 15,5 & 90,7 & 3,70 & $-4,1$ & 9,3 \\
\hline 1980 & 145,47 & 11,6 & 45,70 & 15,1 & 31,4 & 41,23 & 14,6 & 90,2 & 4,47 & 20,8 & 9.8 \\
\hline 1981 & 152,13 & 4,6 & 44,71 & $-2,2$ & 29,4 & 39,69 & $-3,7$ & 88,8 & 5,02 & 12,3 & 11,2 \\
\hline 1982 & 153,06 & 0,6 & 40,06 & $-10,4$ & 26,2 & 35,12 & $-11,5$ & 87,7 & 4,95 & $-1,4$ & 12,4 \\
\hline 1983 & 151,66 & $-0,9$ & 36,67 & $-8,5$ & 24,2 & 31,51 & $-10,3$ & 85,9 & 5,16 & 4,2 & 14,1 \\
\hline 1984 & 154,70 & 2,0 & 35,76 & $-2,5$ & 23,1 & 30,54 & $-3,1$ & 85,4 & 5,22 & 1,2 & 14,6 \\
\hline 1985 & 162,59 & 5,1 & 36,95 & 3,3 & 22,7 & 31,98 & 4,7 & 86,5 & 4,97 & $-4,8$ & 13,5 \\
\hline 1986 & 171,69 & 5,6 & 39,37 & 6,5 & 22,9 & 34,63 & 8,3 & 88,0 & 4,74 & $-4,6$ & 12,0 \\
\hline
\end{tabular}

1) Rechnungsergebnisse, zuzüglich der kommunaler Krankenhåuser. Für 1985 Ergebnisse der Vierleljahresstatistik, cinschl. kommunaler Krankenhäuser; mit den Ergebnissen der Vorjahre nur bedingt verglcichbar.

2) Veränderung gegenüber dem Vorjahr in vH.

3) Investitionsausgaben (insgesamt) in vH der Gesamtausgaben.

4) Jeweilige Ausgaben in vll der gesamten Investitionsausgaben.

Quelle: Zusammengestellt und errechnet aus Unterlagen, die uns das Bundesministerium der Finanzen freundlicherweise жur Verfügung stellte 
Tabelle 3*a: Die Sachinvestitionen der Gebietskörperschaften - Finanzstatistische Daten des BMF -

\begin{tabular}{|c|c|c|c|c|c|c|c|c|}
\hline \multirow[b]{2}{*}{ Jahr } & \multicolumn{2}{|c|}{ zusammen } & \multicolumn{2}{|c|}{ Bund ${ }^{\prime \prime}$} & \multicolumn{2}{|c|}{ Länder ${ }^{21}$} & \multicolumn{2}{|c|}{ Gemeinden $(\mathrm{Gv})^{3)}$} \\
\hline & Mrd. D.M & $\begin{array}{c}\text { Wachs- } \\
\text { tumsrate }^{4}\end{array}$ & Mrd. DM & Anteil $^{51}$ & Mrd. DM & Anteil $^{5}$ & Mrd. DM & Anteil $^{5)}$ \\
\hline 1962 & 16,55 & - & 2,95 & 17,8 & 3,09 & 18,7 & 10,51 & 63,5 \\
\hline 1963 & 19,09 & 15,3 & 3,43 & 18,0 & 3,57 & 18,7 & 12,09 & 63,3 \\
\hline 1964 & 22,43 & 17,5 & 3,68 & 16,4 & 4,28 & 19,1 & 14,47 & 64,5 \\
\hline 1965 & 23,47 & 4,6 & 3,77 & 16,1 & 4,68 & 19,9 & 15,02 & 64,0 \\
\hline 1966 & 23,35 & $-0,5$ & 3,88 & 16,6 & 4,66 & 20,0 & 14,81 & 63,4 \\
\hline 1967 & 22,78 & $-2,4$ & 4,67 & 20,5 & 4,52 & 19,8 & 13,59 & 59,7 \\
\hline 1968 & 23,04 & 1,1 & 4,15 & 18,0 & 4,53 & 19,7 & 14,36 & 62,3 \\
\hline 1969 & 26,39 & 14,5 & 5,01 & 19,0 & 4,94 & 18,7 & 16,44 & 62,3 \\
\hline 1970 & 32,24 & 22,2 & 5,64 & 17,5 & 6,40 & 19,9 & 20,20 & 62,7 \\
\hline 1971 & 37,57 & 16,5 & 6,41 & 17,1 & 6,96 & 18,5 & 24,20 & 64,4 \\
\hline 1972 & 39,13 & 4,2 & 6,63 & 16,9 & 6,73 & 17,2 & 25,77 & 65,9 \\
\hline 1973 & 41,36 & 5,7 & 6,49 & 15,7 & 7,37 & 17,8 & 27,50 & 66,5 \\
\hline 1974 & 46,13 & 11,5 & 7,10 & 15,4 & 8,66 & 18,8 & 30,37 & 65,8 \\
\hline 1975 & 46,04 & $-0,2$ & 7,81 & 17,0 & 8,59 & 18,7 & 29,64 & 64,4 \\
\hline 1976 & 43,64 & $-5,2$ & 7,01 & 16,1 & 8,12 & 18,6 & 28,51 & 65,3 \\
\hline 1977 & 43,21 & $-1,0$ & 7,21 & 16,7 & 8,38 & 19,4 & 27,62 & 63,9 \\
\hline 1978 & 47,57 & 10,1 & 7,66 & 16,1 & 8,75 & 18,4 & 31,16 & 65,5 \\
\hline 1979 & 53,32 & 12,1 & 7,98 & 15,0 & 9,35 & 17,5 & 35,99 & 67,5 \\
\hline 1980 & 60,00 & 12,5 & 8,21 & 13,7 & 10,56 & 17,6 & 41,23 & 68,7 \\
\hline 1981 & 56,99 & $-5,0$ & 7,28 & 12,8 & 10,02 & 17,6 & 39,69 & 69,6 \\
\hline 1982 & 52,02 & $-8,7$ & 6,96 & 13,4 & 9,94 & 19,1 & 35,12 & 67,5 \\
\hline 1983 & 48,50 & $-6,8$ & 7,12 & 14,7 & 9,87 & 20,4 & 31,51 & 65,0 \\
\hline 1984 & 47,62 & $-1,8$ & 7,12 & 15,0 & 9,96 & 20,9 & 30,54 & 64,1 \\
\hline 1985 & 49,98 & 5,0 & 7,39 & 14,8 & 10,61 & 21,2 & 31,98 & 64,0 \\
\hline 1986 & 53,01 & 6,1 & 7,52 & 14,2 & 10,86 & 20,5 & 34,63 & 65,3 \\
\hline
\end{tabular}

1) Ist-Ergebnisse der Haushaltsstatistik, ohne LAF, ERP-Sondervermögen und EG-Anteile.

2) Rechnungsergebnisse zuzüglich der staatlichen Krankenhäuser. Für 1985 Ergebnisse der Vierteljahresstatistik, einschl. Sonderrechnungen und Krankenhäuser; mit den Vorjahren nur bedingt vergleichbar.

3) Rechnungsergebnisse, zuzüglich kommunaler Krankenhäuser. Für 1985 Ergebnisse der Vierteljahresstatistik, einschl. der kommunalen Krankenhäuser; mit den Vorjahren nur bedingt vergleichbar.

4) Veränderung gegenüber dem Vorjahr in vH.

5) Jeweilige Ausgaben in $\mathrm{vH}$ der gesamten Sachinvestitionen.

Quelle: Zusammengestellt und errechnet aus Unterlagen, die uns das Bundesministerium der Finanzen freundlicherweise zur Verfügung stellte. 
Tabelle 3*b: Die unmittelbaren investiven Ausgaben der Gebietskörperschaften - Finanzstatistische Daten des BMF

\begin{tabular}{|c|c|c|c|c|c|c|c|c|}
\hline \multirow[b]{2}{*}{ Jahr } & \multicolumn{2}{|c|}{ insgesamt $^{11}$} & \multicolumn{2}{|c|}{ Bund $^{21}$} & \multicolumn{2}{|c|}{ Länder ${ }^{31}$} & \multicolumn{2}{|c|}{ Gemeinden $(\mathrm{Gv})^{41}$} \\
\hline & Mrd.DM & $\begin{array}{c}\text { Wachstums- } \\
\text { rate }^{5 !}\end{array}$ & Mrd.DM & Anteil $^{6)}$ & Mrd.DM & Anteil $^{61}$ & Mrd.DM & Anteil $^{6 !}$ \\
\hline 1962 & 26,72 & - & 5,41 & 20,2 & 9,16 & 34,3 & 12,15 & 45,5 \\
\hline 1963 & 29,67 & 11,0 & 6,16 & 20,8 & 9,70 & 32,7 & 13,81 & 46,5 \\
\hline 1964 & 33,63 & 13,3 & 6,41 & 19,1 & 10,90 & 32,4 & 16,32 & 48,5 \\
\hline 1965 & 35,47 & 5,5 & 6,69 & 18,9 & 11,67 & 32,9 & 17,11 & 48,2 \\
\hline 1966 & 35,03 & $-1,2$ & 7,07 & 20,2 & 11,39 & 32,5 & 16,57 & 47,3 \\
\hline 1967 & 35,55 & 1,5 & 9,40 & 26,4 & 10,91 & 30,7 & 15,24 & 42,9 \\
\hline 1968 & 34,59 & $-2,7$ & 8,21 & 23,7 & 10,53 & 30,4 & 15,85 & 45,8 \\
\hline 1969 & 38,70 & 11,9 & 9,65 & 24,9 & 11,01 & 28,4 & 18,04 & 46,6 \\
\hline 1970 & 46,05 & 19,0 & 10,56 & 22,9 & 13,53 & 29,4 & 21,96 & 47,7 \\
\hline 1971 & 53,99 & 17,2 & 12,80 & 23,7 & 14,49 & 26,8 & 26,70 & 49,5 \\
\hline 1972 & 57,07 & 5,7 & 13,21 & 23,1 & 15,68 & 27,5 & 28,18 & 49,4 \\
\hline 1973 & 62,24 & 9,1 & 14,25 & 22,9 & 18,06 & 29,0 & 29,93 & 48,1 \\
\hline 1974 & 68,05 & 9,3 & 13,83 & 20,3 & 20,91 & 30,7 & 33,31 & 48,9 \\
\hline 1975 & 70,78 & 4,0 & 17,60 & 24,9 & 20,83 & 29,4 & 32,35 & 45,7 \\
\hline 1976 & 67,80 & $-4,2$ & 14,77 & 21,8 & 21,60 & 31,9 & 31,43 & 46,4 \\
\hline 1977 & 66,27 & $-2,3$ & 15,35 & 23,2 & 20,46 & 30,9 & 30,46 & 46,0 \\
\hline 1978 & 76,00 & 14,7 & 18,97 & 25,0 & 22,67 & 29,8 & 34,36 & 45,2 \\
\hline 1979 & 87,56 & 15,2 & 23,14 & 26,4 & 24,95 & 28,5 & 39,47 & 45,1 \\
\hline 1980 & 95,26 & 8,8 & 21,87 & 23,0 & 27,97 & 29,4 & 45,42 & 47,7 \\
\hline 1981 & 91,82 & $-3,6$ & 21,23 & 23,1 & 26,69 & 29,1 & 43,90 & 47,8 \\
\hline 1982 & 89,71 & $-2,3$ & 23,00 & 25,6 & 27,35 & 30,5 & 39,36 & 43,9 \\
\hline 1983 & 84,97 & $-5,3$ & 22,54 & 26,5 & 26,73 & 31,5 & 35,70 & 42,0 \\
\hline 1984 & 86,23 & 1,5 & 24,28 & 28,2 & 27,14 & 31,5 & 34,81 & 40,4 \\
\hline 1985 & 89,24 & 3,5 & 24,12 & 27,0 & 29,04 & 32,5 & 36,08 & 40,4 \\
\hline 1986 & 92,24 & 3,4 & 24,32 & 26,4 & 29,22 & 31,7 & 38,69 & 41,9 \\
\hline
\end{tabular}

1) Die Summe der unmittelbaren investiven Ausgaben der Gebietskörperschaften ist geringer als die gesamten investiven Ausgaben der Öffentlichen Haushalte (Öffentlicher Gesamthaushalt), weil die Investitionsausgaben der Sonderrechnungen des Bundes (LAF und ERP) nicht berücksichtigt sind.

2) Ist-Ergebnisse der Haushaltsstatistik, ohne LAF, ERP-Sondervermögen und EG-Anteile.

3) Rechnungsergebnisse, zuzüglich der staatlichen Krankenhäuser. Für 1985 Ergebnisse der Vierteljahresstatistik, einschl. Sonderrechnungen und Krankenhäuser; mit den Vorjahren nur bedingt vergleichbar.

4) Rechnungsergebnisse, zuzüglich der kommunalen Krankenhäuser. Für 1985 Ergebnisse der Vierteljahresstatistik, einschl. der kommunalen Krankenhäuser; mit den Vorjahren nur bedingt vergleichbar.

5) Veränderung gegenūber dem Vorjahr in vH.

6) Jeweilige Ausgaben in $\mathrm{vH}$ der Ausgaben insgesamt.

Quelle: Zusammengestellt und errechnet aus Unterlagen, die uns das Bundesministerium der Finanzen freundlicherweise zur Verfügung stellte. 
Tabelle 4*a: Aufgliederung der Sachinvestitionen des Bundes ${ }^{11}$ - Finanzstatistische Daten des BMF .

\begin{tabular}{|c|c|r|r|r|r|r|r|}
\hline \multirow{2}{*}{ Jahr } & $\begin{array}{c}\text { Sachinvesti- } \\
\text { tionen }\end{array}$ & \multicolumn{2}{|c|}{ Baumaßnahmen } & \multicolumn{2}{c|}{ bewegl. Sachen } & \multicolumn{2}{c|}{ unbewegl. Sachen } \\
\cline { 2 - 8 } & Mrd.DM & Mrd.DM & Anteil $^{21}$ & Mrd.DM & Anteil ${ }^{2}$ & Mrd.DM & Anteil $^{2}$ \\
\hline 1962 & 2,95 & 2,24 & 75,9 & 0,47 & 15,9 & 0,24 & 8,1 \\
1963 & 3,43 & 2,71 & 79,0 & 0,53 & 15,5 & 0,19 & 5,5 \\
1964 & 3,68 & 2,94 & 79,9 & 0,45 & 12,2 & 0,29 & 7,9 \\
1965 & 3,77 & 3,02 & 80,1 & 0,46 & 12,2 & 0,29 & 7,7 \\
1966 & 3,88 & 3,13 & 80,7 & 0,46 & 11,9 & 0,29 & 7,5 \\
1967 & 4,67 & 3,72 & 79,7 & 0,41 & 8,8 & 0,54 & 11,6 \\
1968 & 4,15 & 3,39 & 81,7 & 0,31 & 7,5 & 0,45 & 10,8 \\
1969 & 5,01 & 4,22 & 84,2 & 0,33 & 6,6 & 0,46 & 9,2 \\
1970 & 5,64 & 4,59 & 81,4 & 0,54 & 9,6 & 0,51 & 9,0 \\
1971 & 6,41 & 5,07 & 79,1 & 0,63 & 9,8 & 0,71 & 11,1 \\
1972 & 6,63 & 5,35 & 80,7 & 0,48 & 7,2 & 0,80 & 12,1 \\
1973 & 6,49 & 5,23 & 80,6 & 0,51 & 7,9 & 0,75 & 11,6 \\
1974 & 7,10 & 5,62 & 79,2 & 0,73 & 10,3 & 0,75 & 10,6 \\
1975 & 7,81 & 5,85 & 74,9 & 1,26 & 16,1 & 0,70 & 9,0 \\
1976 & 7,01 & 5,45 & 77,7 & 0,85 & 12,1 & 0,71 & 10,1 \\
1977 & 7,21 & 5,64 & 78,2 & 0,96 & 13,3 & 0,61 & 8,5 \\
1978 & 7,66 & 6,13 & 80,0 & 0,94 & 12,3 & 0,59 & 7,7 \\
1979 & 7,98 & 6,55 & 82,1 & 0,81 & 10,2 & 0,62 & 7,8 \\
1980 & 8,21 & 6,41 & 78,1 & 1,26 & 15,3 & 0,54 & 6,6 \\
1981 & 7,28 & 5,77 & 79,3 & 0,98 & 13,5 & 0,53 & 7,3 \\
1982 & 6,96 & 5,52 & 79,3 & 0,82 & 11,8 & 0,62 & 8,9 \\
1983 & 7,12 & 5,68 & 79,8 & 0,84 & 11,8 & 0,60 & 8,4 \\
1984 & 7,12 & 5,70 & 80,1 & 0,85 & 11,9 & 0,57 & 8,0 \\
1985 & 7,39 & 5,80 & 78,5 & 0,94 & 12,7 & 0,65 & 8,8 \\
1986 & 7,52 & 5,81 & 77,3 & 1,08 & 14,3 & 0,63 & 8,4 \\
\hline
\end{tabular}

1) Ist-Ergebnisse in der Systematik des Haushalts 1986, ohne LAF, ERP-Sondervermögen und EG-Anteile.

2) Jeweilige Ausgaben in vH der gesamten Investitionen.

Quelle: Zusammengestellt und errechnet aus Unterlagen, die uns das Bundesministerium der Finanzen freundlicherweise zur Verfügung stellte. 
Tabelle 4*b: Aufgliederung der Sachinvestitionen der Länder ${ }^{1)}$ - Finanzstatistische Daten des BMF -

\begin{tabular}{|c|c|r|r|r|r|r|r|}
\hline \multirow{2}{*}{ Jahr } & $\begin{array}{c}\text { Sachinvesti- } \\
\text { tionen }\end{array}$ & \multicolumn{2}{|c|}{ Baumaßnahmen } & \multicolumn{2}{|c|}{ bewegl. Sachen } & \multicolumn{2}{|c|}{ unbewegl. Sachen } \\
\cline { 2 - 8 } & Mrd.DM & Mrd.DM & Anteil $^{2)}$ & Mrd.DM $^{2}$ & Anteil $^{2}$ & Mrd.DM $^{\text {Anteil }}{ }^{21}$ \\
\hline 1962 & 3,09 & 2,34 & 75,7 & 0,36 & 11,7 & 0,39 & 12,6 \\
1963 & 3,57 & 2,76 & 77,3 & 0,42 & 11,8 & 0,39 & 10,9 \\
1964 & 4,28 & 3,28 & 76,6 & 0,49 & 11,4 & 0,51 & 11,9 \\
1965 & 4,68 & 3,49 & 74,6 & 0,58 & 12,4 & 0,61 & 13,0 \\
1966 & 4,66 & 3,57 & 76,6 & 0,59 & 12,7 & 0,50 & 10,7 \\
1967 & 4,52 & 3,37 & 74,6 & 0,59 & 13,1 & 0,56 & 12,4 \\
1968 & 4,53 & 3,42 & 75,5 & 0,60 & 13,2 & 0,51 & 11,3 \\
1969 & 4,94 & 3,76 & 76,1 & 0,63 & 12,8 & 0,55 & 11,1 \\
1970 & 6,40 & 4,93 & 77,0 & 0,88 & 13,8 & 0,59 & 9,2 \\
1971 & 6,96 & 5,27 & 75,7 & 1,07 & 15,4 & 0,62 & 8,9 \\
1972 & 6,73 & 5,06 & 75,2 & 1,13 & 16,8 & 0,54 & 8,0 \\
1973 & 7,37 & 5,30 & 71,9 & 1,26 & 17,1 & 0,81 & 11,0 \\
1974 & 8,66 & 6,18 & 71,4 & 1,49 & 17,2 & 0,99 & 11,4 \\
1975 & 8,59 & 6,36 & 74,0 & 1,50 & 17,5 & 0,73 & 8,5 \\
1976 & 8,12 & 5,98 & 73,6 & 1,42 & 17,5 & 0,72 & 8,9 \\
1977 & 8,38 & 6,13 & 73,2 & 1,55 & 18,5 & 0,70 & 8,4 \\
1978 & 8,75 & 6,40 & 73,1 & 1,62 & 18,5 & 0,73 & 8,3 \\
1979 & 9,35 & 6,73 & 72,0 & 1,74 & 18,6 & 0,88 & 9,4 \\
1980 & 10,56 & 7,62 & 72,2 & 1,97 & 18,7 & 0,97 & 9,2 \\
1981 & 10,02 & 7,29 & 72,8 & 1,83 & 18,3 & 0,90 & 9,0 \\
1982 & 9,94 & 7,38 & 74,2 & 1,68 & 16,9 & 0,88 & 8,9 \\
1983 & 9,87 & 7,22 & 73,2 & 1,78 & 18,0 & 0,87 & 8,8 \\
1984 & 9,96 & 6,97 & 70,0 & 2,05 & 20,6 & 0,94 & 9,4 \\
1985 & 10,61 & 7,24 & 68,2 & 2,38 & 22,4 & 0,99 & 9,3 \\
1986 & 10,86 & 6,93 & 63,8 & 2,96 & 27,3 & 0,96 & 8,8 \\
\hline
\end{tabular}

1) Rechnungsergebnisse, zuzüglich der staatlichen Krankenhäuser. Für 1985 Ergebnisse der Vierteljahresstatistik, einschl. Sonderrechnungen und Krankenhäuser der Länder; mit den Vorjahren nur bedingt vergleichbar.

2) Jeweilige Ausgaben in $\mathrm{vH}$ der gesamten Sachinvestitionen.

Quelle: Zusammengestellt und errechnet aus Unterlagen, die uns das Bundesministerium der Finanzen freundlicherweise zur Verfügung stellte. 
Tabelle 4*c: Aufgliederung der Sachinvestitionen der Gemein-

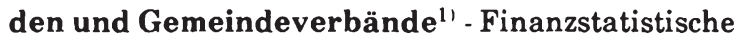
Daten des BMF

\begin{tabular}{|c|c|r|r|r|r|r|r|}
\hline \multirow{2}{*}{ Jahr } & $\begin{array}{c}\text { Sachinvesti- } \\
\text { tionen }\end{array}$ & \multicolumn{2}{|c|}{ Baumaßnahmen } & \multicolumn{2}{c|}{ bewegl. Sachen } & \multicolumn{2}{c|}{ unbewegl. Sachen } \\
\cline { 2 - 8 } & Mrd.DM & Mrd.DM & Anteil $^{21}$ & Mrd.DM & Anteil ${ }^{21}$ & Mrd.DM & Anteil $^{2}$ \\
\hline 1962 & 10,51 & 8,47 & 80,6 & 0,67 & 6,4 & 1,37 & 13,0 \\
1963 & 12,09 & 9,89 & 81,8 & 0,74 & 6,1 & 1,46 & 12,1 \\
1964 & 14,47 & 12,05 & 83,3 & 0,80 & 5,5 & 1,62 & 11,2 \\
1965 & 15,02 & 12,35 & 82,2 & 0,88 & 5,9 & 1,79 & 11,9 \\
1966 & 14,81 & 12,33 & 83,3 & 0,86 & 5,8 & 1,62 & 10,9 \\
1967 & 13,59 & 11,31 & 83,2 & 0,79 & 5,8 & 1,49 & 11,0 \\
1968 & 14,36 & 11,75 & 81,8 & 0,78 & 5,4 & 1,83 & 12,7 \\
1969 & 16,44 & 13,24 & 80,5 & 0,96 & 5,8 & 2,24 & 13,6 \\
1970 & 20,20 & 16,20 & 80,2 & 1,18 & 5,8 & 2,82 & 14,0 \\
1971 & 24,20 & 20,00 & 82,6 & 1,39 & 5,7 & 2,81 & 11,6 \\
1972 & 25,77 & 21,41 & 83,1 & 1,52 & 5,9 & 2,84 & 11,0 \\
1973 & 27,50 & 22,38 & 81,4 & 1,71 & 6,3 & 3,41 & 12,4 \\
1974 & 30,37 & 24,57 & 80,9 & 1,80 & 5,9 & 4,00 & 13,2 \\
1975 & 29,64 & 24,18 & 81,6 & 1,75 & 5,9 & 3,71 & 12,5 \\
1976 & 28,51 & 23,47 & 82,3 & 1,73 & 6,1 & 3,31 & 11,6 \\
1977 & 27,62 & 21,78 & 78,9 & 1,95 & 7,1 & 3,89 & 14,1 \\
1978 & 31,16 & 24,44 & 78,4 & 2,15 & 6,9 & 4,57 & 14,7 \\
1979 & 35,99 & 27,93 & 77,6 & 2,64 & 7,3 & 5,42 & 15,1 \\
1980 & 41,23 & 32,45 & 78,7 & 2,86 & 6,9 & 5,92 & 14,4 \\
1981 & 39,69 & 31,38 & 79,1 & 2,69 & 6,8 & 5,62 & 14,2 \\
1982 & 35,12 & 27,92 & 79,5 & 2,33 & 6,6 & 4,87 & 13,9 \\
1983 & 31,51 & 24,69 & 78,4 & 2,20 & 7,0 & 4,62 & 14,7 \\
1984 & 30,54 & 23,45 & 76,7 & 2,35 & 7,7 & 4,74 & 15,5 \\
1985 & 31,98 & 24,23 & 75,8 & 2,93 & 9,2 & 4,81 & 15,0 \\
1986 & 34,63 & 26,30 & 75,9 & 3,06 & 8,8 & 5,27 & 15,2 \\
\hline
\end{tabular}

1) Rechnungsergebnisse, zuzüglich kommunaler Krankenhäuser. Für 1985 Ergebnisse dei Vierteljahresstatistik, einschl. kommunaler Krankenhäuser; mit den Ergebnissen der Vorjahre nur bedingt vergleichbar.

2) Jeweilige Ausgaben in vH der gesamten Sachinvestitionen.

Quelle: Zusammengestellt und errechnet aus Unterlagen, die uns das Bundesministerium der Finanzen freundlicherweise zur Verfügung stellte. 
Tabelle 5*a: Aufgliederung der Investitionsförderungsmaßnahmen der öffentlichen Haushalte (Öffentlicher Gesamthaushalt) ${ }^{1}$ '

- Finanzstatistische Daten des BMF -

\begin{tabular}{|c|c|c|c|c|c|c|c|c|}
\hline \multirow[b]{2}{*}{ Jahr } & \multirow{2}{*}{\begin{tabular}{|c|} 
Insgesamt \\
Mrd.DM
\end{tabular}} & \multicolumn{3}{|c|}{ Zuschüsse } & \multicolumn{3}{|c|}{ Darlehen und Beteiligungen } & \multirow{2}{*}{$\frac{\text { Rest }^{21}}{\text { Mrd.DM }}$} \\
\hline & & Mrd.DM & $\begin{array}{c}\text { Wachstums- } \\
\text { rate }^{3)}\end{array}$ & Anteil $^{4}$ & Mrd.DM & $\begin{array}{c}\text { Wachstums- } \\
\text { rate }^{31}\end{array}$ & Anteil $^{4}$ & \\
\hline 1962 & 11,89 & 2,24 & - & 18,8 & 9,05 & - & 76,1 & 0,60 \\
\hline 1963 & 13,03 & 2,66 & 18,8 & 20,4 & 9,38 & 3,6 & 72,0 & 0,99 \\
\hline 1964 & 13,28 & 2,90 & 9,0 & 21,8 & 9,47 & 1,0 & 71,3 & 0,91 \\
\hline 1965 & 14,51 & 3,25 & 12,1 & 22,4 & 10,33 & 9,1 & 71,2 & 0,93 \\
\hline 1966 & 13,51 & 3,40 & 4,6 & 25,2 & 9,42 & $-8,8$ & 69,7 & 0,69 \\
\hline 1967 & 14,64 & 3,81 & 12,1 & 26,0 & 10,12 & 7,4 & 69,1 & 0,71 \\
\hline 1968 & 13,65 & 4,13 & 8,4 & 30,3 & 8,52 & $-15,8$ & 62,4 & 1,00 \\
\hline 1969 & 14,37 & 5,26 & 27,4 & 36,6 & 8,28 & $-2,8$ & 57,6 & 0,83 \\
\hline 1970 & 15,87 & 7,26 & 38,0 & 45,8 & 7,99 & $-3,5$ & 50,4 & 0,62 \\
\hline 1971 & 18,51 & 8,70 & 19,8 & 47,0 & 9,15 & 14,5 & 49,3 & 0,66 \\
\hline 1972 & 21,04 & 10,28 & 18,2 & 48,9 & 9,11 & $-0,4$ & 43,3 & 1,65 \\
\hline 1973 & 22,96 & 11,82 & 15,0 & 51,5 & 10,28 & 12,8 & 44,8 & 0,86 \\
\hline 1974 & 23,63 & 14,05 & 18,9 & 59,5 & 9,50 & $-7,6$ & 40,2 & 0,08 \\
\hline 1975 & 26,19 & 14,27 & 1,6 & 54,5 & 12,26 & 29,1 & 46,8 & $-0,34$ \\
\hline 1976 & 26,06 & 14,66 & 2,7 & 56,3 & 11,11 & $-9,4$ & 42,6 & 0,29 \\
\hline 1977 & 25,29 & 14,49 & $-1,2$ & 57,3 & 10,21 & $-8,1$ & 40,4 & 0,59 \\
\hline 1978 & 31,14 & 18,79 & 29,7 & 60,3 & 11,77 & 15,3 & 37,8 & 0,58 \\
\hline 1979 & 37,13 & 22,47 & 19,6 & 60,5 & 14,19 & 20,6 & 38,2 & 0,47 \\
\hline 1980 & 38,26 & 22,86 & 1,7 & 59,8 & 15,30 & 7,8 & 40,0 & 0,10 \\
\hline 1981 & 38,69 & 22,38 & $-2,1$ & 57,8 & 15,59 & 1,9 & 40,3 & 0,72 \\
\hline 1982 & 40,25 & 23,52 & 5,1 & 58,4 & 16,73 & 7,3 & 41,6 & 0,00 \\
\hline 1983 & 39,96 & 21,63 & $-8,0$ & 54,1 & 18,10 & 8,2 & 45,3 & 0,23 \\
\hline 1984 & 43,13 & 20,91 & $-3,3$ & 48,5 & 20,97 & 15,9 & 48,6 & 1,25 \\
\hline 1985 & 41,82 & 22,11 & 5,7 & 52,9 & 20,29 & $-3,2$ & 48,5 & $-0,58$ \\
\hline 1986 & 41,72 & 23,09 & 4,4 & 55,3 & 19,49 & $-3,9$ & 46,7 & $-0,86$ \\
\hline
\end{tabular}

1) Rechnungsergebnisse für Bund, LAF, ERP-Sondervermögen, EG-Anteile, Länder sowie Gemeinden und Gemeindeverbände, zuzüglich der Krankenhäuser der Lānder und Gemeinden. Für 1985 teilweise Ergebnisse der Vierteljahresstatistik, zuzüglich der Krankenhäuser; mit den Ergebnissen der Vorjahre nur bedingt vergleichbar.

2) Die Restgröße ergibt sich als Saldo des öffentlichen Verrechnungsverkehrs. Eine positive Größe bedeutet, daß insgesamt mehr an Zuweisungen und Darlehen an andere Verwaltungen ausgewiesen wird, als auf der Gegenseite gleichnamige Einnahmen eingestellt werden.

3) Veränderung gegenüber dem Vorjahr in vH.

4) Jeweilige Ausgaben in vH der gesamten Investitionsförderungsmaßnahmen.

Quelle: Zusammengestellt und errechnet aus Unterlagen, die uns das Bundesministerium der Finanzen freundlicherweise zur Verfügung stellte. 
Tabelle 5*b: Aufgliederung der Investitionsförderungsmaßnahmen der Länder " - Finanzstatistische Daten des BMF

\begin{tabular}{|c|c|c|c|c|c|c|c|c|c|}
\hline \multirow{2}{*}{ Jahr } & \multirow{2}{*}{\begin{tabular}{|l|} 
Insgesamt \\
Mrd.DM
\end{tabular}} & \multicolumn{2}{|c|}{ Zuschūsse } & \multicolumn{2}{|c|}{$\begin{array}{l}\text { Darlehen und } \\
\text { Beteiligungen }\end{array}$} & \multicolumn{2}{|c|}{ Zuweisungen } & \multicolumn{2}{|c|}{$\begin{array}{l}\text { Darlehen an off. } \\
\text { Verwaltungen }\end{array}$} \\
\hline & & Mrd.DM & Anteil $^{21}$ & Mrd.DM & Anteil $^{2 \prime}$ & Mrd.DM & Anteil $^{21}$ & Mrd.DM & Anteil $^{21}$ \\
\hline 1962 & 8,18 & 1,39 & 17,0 & 4,68 & 57,2 & 1,92 & 23,5 & 0,19 & 2,3 \\
\hline 1963 & 9,13 & 1,76 & 19,3 & 4,37 & 47,9 & 2,76 & 30,2 & 0,24 & 2,6 \\
\hline 1964 & 10,09 & 1,90 & 18,8 & 4,72 & 46,8 & 3,25 & 32,2 & 0,22 & 2,2 \\
\hline 1965 & 10,74 & 2,45 & 22,8 & 4,54 & 42,3 & 3,53 & 32,9 & 0,22 & 2,1 \\
\hline 1966 & 10,62 & 2,67 & 25,1 & 4,06 & 38,2 & 3,69 & 34,8 & 0,20 & 1,9 \\
\hline 1967 & 10,80 & 2,78 & 25,7 & 3,60 & 33,3 & 4,18 & 38,7 & 0,24 & 2,2 \\
\hline 1968 & 10,42 & 2,98 & 28,6 & 3,01 & 28,9 & 4,20 & 40,3 & 0,23 & 2,2 \\
\hline 1969 & 10,99 & 3,47 & 31,6 & 2,60 & 23,7 & 4,47 & 40,7 & 0,45 & 4,1 \\
\hline 1970 & 12,34 & 4,65 & 37,7 & 2,49 & 20,2 & 5,02 & 40,7 & 0,18 & 1,5 \\
\hline 1971 & 13,69 & 5,19 & 37,9 & 2,34 & 17,1 & 5,97 & 43,6 & 0,19 & 1,4 \\
\hline 1972 & 15,81 & 6,37 & 40,3 & 2,58 & 16,3 & 6,78 & 42,9 & 0,08 & 0,5 \\
\hline 1973 & 19,58 & 8,46 & 43,2 & 2,23 & 11,4 & 8,76 & 44,7 & 0,13 & 0,7 \\
\hline 1974 & 21,89 & 9,48 & 43,3 & 2,78 & 12,7 & 9,50 & 43,4 & 0,13 & 0,6 \\
\hline 1975 & 22,64 & 9,05 & 40,0 & 3,20 & 14,1 & 10,23 & 45,2 & 0,16 & 0,7 \\
\hline 1976 & 24,31 & 8,75 & 36,0 & 4,73 & 19,5 & 10,59 & 43,6 & 0,24 & 1,0 \\
\hline 1977 & 21,54 & 7,92 & 36,8 & 4,16 & 19,3 & 9,19 & 42,7 & 0,27 & 1,3 \\
\hline 1978 & 25,09 & 9,86 & 39,3 & 4,06 & 16,2 & 10,93 & 43,6 & 0,24 & 1,0 \\
\hline 1979 & 28,42 & 10,79 & 38,0 & 4,81 & 16,9 & 12,58 & 44,3 & 0,24 & 0,9 \\
\hline 1980 & 31,22 & 11,94 & 38,2 & 5,47 & 17,5 & 13,54 & 43,4 & 0,27 & 0,9 \\
\hline 1981 & 29,48 & 11,28 & 38,3 & 5,39 & 18,3 & 12,48 & 42,3 & 0,33 & 1,1 \\
\hline 1982 & 29,30 & 10,98 & 37,5 & 6,43 & 22,0 & 11,65 & 39,8 & 0,24 & 0,8 \\
\hline 1983 & 28,00 & 10,84 & 38,7 & 6,02 & 21,5 & 10,94 & 39,1 & 0,20 & 0,7 \\
\hline 1984 & 28,94 & 10,02 & 34,6 & 7,16 & 24,7 & 11,59 & 40,1 & 0,17 & 0,6 \\
\hline 1985 & 29,01 & 11,27 & 38,8 & 7,15 & 24,6 & 10,30 & 35,5 & 0,28 & 1,0 \\
\hline 1986 & 29,51 & 11,09 & 37,6 & 7,28 & 24,7 & 10,72 & 36,3 & 0,43 & 1,5 \\
\hline
\end{tabular}

1) Rechnungsergebnisse, zuzüglich der staatlichen Krankenhäuser. Für 1985 Ergebnịsse der Vierteljahresstatistik, einschl. Sonderrechnungen und Krankenhäuser der Länder; mit den Vorjahren nur bedingt vergleichbar.

2) Jeweilige Ausgaben in vH der gesamten Investitionsförderungsmaßnahmen.

Quelle: Zusammengestellt und errechnet aus Unterlagen, die uns das Bundesministerium der Finanzen freundlicherweise zur Verfügung stellte. 
Tabelle 5* ${ }^{*}$ : Aufgliederung der Investitionsförderungsmaßnahmen der Gemeinden und Gemeindeverbānde ${ }^{11}$

- Finanzstatistische Daten des BMF -

\begin{tabular}{|c|c|c|c|c|c|c|c|c|c|}
\hline \multirow{2}{*}{ Jahr } & \multirow{2}{*}{$\begin{array}{l}\text { Insgesamt } \\
\text { Mrd.D.M }\end{array}$} & \multicolumn{2}{|c|}{ Zuschūsse } & \multicolumn{2}{|c|}{$\begin{array}{l}\text { Darlehen und } \\
\text { Beteiligungen }\end{array}$} & \multicolumn{2}{|c|}{ Zuweisungen } & \multicolumn{2}{|c|}{$\begin{array}{l}\text { Darlehen an öff. } \\
\text { Verwaltungen }\end{array}$} \\
\hline & & Mrd.D.M & Anteil $^{2 \prime}$ & Mrd.DM & Anteil $^{21}$ & Mrd.DM & Anteil $^{21}$ & Mrd.DM & Anteil $^{2)}$ \\
\hline 1962 & 1,64 & 0,05 & 3,1 & 1,59 & 96,9 & - & - & - & - \\
\hline 1963 & 1,72 & 0,07 & 4,1 & 1,65 & 95,9 & - & - & - & - \\
\hline 1964 & 1,85 & 0,09 & 4,9 & 1,76 & 95,1 & - & - & - & - \\
\hline 1965 & 2,09 & 0,14 & 6,7 & 1,95 & 93,3 & - & - & - & - \\
\hline 1966 & 1,76 & 0,14 & 8,0 & 1,62 & 92,0 & - & - & - & - \\
\hline 1967 & 1,65 & 0,14 & 8,5 & 1,51 & 91,5 & - & - & - & - \\
\hline 1968 & 1,49 & 0,19 & 12,8 & 1,30 & 87,2 & - & - & - & - \\
\hline 1969 & 1,60 & 0,29 & 18,1 & 1,31 & 81,9 & - & - & - & - \\
\hline 1970 & 1,78 & 0,32 & 18,0 & 1,44 & 80,9 & 0,02 & 1,1 & 0,00 & 0,0 \\
\hline 1971 & 2,52 & 0,44 & 17,5 & 2,06 & 81,8 & 0,02 & 0,8 & 0,00 & 0,0 \\
\hline 1972 & 2,43 & 0,42 & 17,3 & 1,99 & 81,9 & 0,02 & 0,8 & 0,00 & 0,0 \\
\hline 1973 & 2,46 & 0,48 & 19,5 & 1,96 & 79,7 & 0,02 & 0,8 & 0,00 & 0,0 \\
\hline 1974 & 3,36 & 1,43 & 42,6 & 1,51 & 44,9 & 0,42 & 12,5 & 0,00 & 0,0 \\
\hline 1975 & 3,33 & 1,52 & 45,7 & 1,20 & 36,0 & 0,57 & 17,1 & 0,04 & 1,2 \\
\hline 1976 & 3,50 & 1,44 & 41,1 & 1,48 & 42,3 & 0,54 & 15,4 & 0,04 & 1,1 \\
\hline 1977 & 3,35 & 1,42 & 42,4 & 1,41 & 42,1 & 0,52 & 15,5 & 0,00 & 0,0 \\
\hline 1978 & 3,87 & 1,73 & 44,7 & 1,48 & 38,2 & 0,64 & 16,5 & 0,02 & 0,5 \\
\hline 1979 & 3,70 & 2,03 & 54,9 & 1,45 & 39,2 & 0,22 & 6,0 & 0,00 & 0,0 \\
\hline 1980 & 4,47 & 2,31 & 51,7 & 1,88 & 42,1 & 0,27 & 6,0 & 0,01 & 0,2 \\
\hline 1981 & 5,02 & 2,29 & 45,6 & 1,92 & 38,3 & 0,79 & 15,7 & 0,02 & 0,4 \\
\hline 1982 & 4,95 & 2,42 & 48,9 & 1,82 & 36,8 & 0,70 & 14,1 & 0,01 & 0,2 \\
\hline 1983 & 5,16 & 2,02 & 39,2 & 2,17 & 42,1 & 0,97 & 18,8 & 0,00 & 0,0 \\
\hline 1984 & 5,22 & 2,03 & 38,9 & 2,24 & 42,9 & 0,95 & 18,2 & 0,00 & 0,0 \\
\hline 1985 & 4,97 & 1,72 & 34,6 & 2,38 & 47,9 & 0,87 & 17,5 & 0,00 & 0,0 \\
\hline 1986 & 4,74 & 1,84 & 38,8 & 2,23 & 47,0 & 0,67 & 14,1 & 0,00 & 0,0 \\
\hline
\end{tabular}

1) Rechnungsergebnisse, zuzüglich kommunaler Krankenhäuser. Für 1985 Ergebnisse der Vierteljahresstatistik, einschl. kommunaler Krankenhāuser; mit den Ergebnissen der Vorjahre nur bedingt vergleichbar.

2) Jeweilige Ausgaben in vH der gesamten Investitionsförderungsmaßnahmen.

Quelle: Zusammengestellt und errechnet aus Unterlagen, die uns das Bundesministerium der Finanzen freundlicherweise zur Verfügung stellte. 
Tabelle 6*a: Die mittelbaren Investitionen der Gebietskörperschaften $(\text { VGR })^{1)}$

\begin{tabular}{|c|c|c|c|c|c|c|c|}
\hline \multirow{2}{*}{ Jahr } & \multicolumn{3}{|c|}{ INVESTITIONSZUSCHÜSSE } & \multicolumn{3}{c|}{ VERMÖGENSÜBERTRAGUNGEN (Vü) } \\
\cline { 2 - 8 } & $\begin{array}{c}\text { an Unter- } \\
\text { nehmen }\end{array}$ & $\begin{array}{c}\text { an übrige } \\
\text { Welt }\end{array}$ & insgesamt & $\begin{array}{c}\text { sonstige } \\
\text { Vü }\end{array}$ & $\begin{array}{c}\text { fiktive } \\
\text { Vü }\end{array}$ & $\begin{array}{c}\text { Investi- } \\
\text { tionszusch. }\end{array}$ & insgesamt \\
\cline { 2 - 8 } & Mrd.DM & Mrd.DM & Mrd.DM & Mrd.DM & Mrd.DM & Mrd.DM & Mrd.DM \\
\hline 1962 & 1,67 & 0,03 & 1,70 & 2,64 & 1,32 & 1,67 & 5,63 \\
1963 & 1,86 & 0,07 & 1,93 & 0,55 & 1,42 & 1,86 & 3,83 \\
1964 & 2,12 & 0,09 & 2,21 & 0,30 & 1,67 & 2,12 & 4,09 \\
1965 & 2,32 & 0,08 & 2,40 & 0,21 & 1,83 & 2,32 & 4,36 \\
1966 & 2,13 & 0,14 & 2,27 & 0,64 & 1,47 & 2,13 & 4,24 \\
1967 & 2,37 & 0,15 & 2,52 & 0,55 & 1,32 & 2,37 & 4,24 \\
1968 & 2,62 & 0,16 & 2,88 & 0,19 & 1,37 & 2,62 & 4,18 \\
1969 & 3,77 & 0,18 & 3,95 & 1,28 & 1,53 & 3,77 & 6,58 \\
1970 & 4,91 & 0,20 & 5,11 & 0,95 & 2,16 & 4,91 & 8,02 \\
1971 & 6,62 & 0,17 & 6,79 & 0,23 & 1,93 & 6,62 & 8,78 \\
1972 & 7,85 & 0,17 & 8,02 & 0,11 & 1,78 & 7,85 & 9,74 \\
1973 & 8,62 & 0,17 & 8,79 & 0,23 & 2,25 & 8,62 & 11,10 \\
1974 & 10,24 & 0,26 & 10,50 & 0,46 & 2,36 & 10,24 & 13,06 \\
1975 & 10,84 & 0,32 & 11,16 & 0,45 & 1,98 & 10,84 & 13,27 \\
1976 & 15,79 & 0,36 & 16,15 & 0,65 & 1,36 & 15,79 & 17,80 \\
1977 & 15,66 & 0,39 & 16,05 & 0,67 & 1,91 & 15,66 & 18,24 \\
1978 & 15,01 & 0,42 & 15,43 & 1,04 & 2,09 & 15,01 & 18,14 \\
1979 & 17,34 & 1,15 & 18,49 & 1,03 & 2,46 & 17,34 & 20,83 \\
1980 & 17,56 & 1,41 & 18,97 & 1,19 & 3,01 & 17,56 & 21,76 \\
1981 & 17,93 & 1,82 & 19,75 & 0,54 & 2,62 & 17,93 & 21,09 \\
1982 & 19,52 & 1,83 & 21,35 & 0,47 & 1,98 & 19,52 & 21,97 \\
1983 & 19,97 & 1,72 & 21,69 & 0,89 & 0,93 & 19,97 & 21,79 \\
1984 & 22,82 & 1,66 & 24,48 & 0,49 & 1,88 & 22,82 & 25,19 \\
1985 & 21,24 & 1,74 & 22,98 & 0,95 & 2,48 & 21,24 & 24,67 \\
\hline
\end{tabular}

1) Ergebnisse in der Abgrenzung der Volkswirtschaftlichen Gesamtrechnungen in jeweiligen Preisen; ab 1984 vorläufige Ergebnisse.

Quelle: Zusammengestellt und errechnet aus: Statistisches Bundesamt: Revidierte Ergebnisse 1960 bis 1984, Reihe S.8 der Fachserie 18: Volkswirtschaftliche Gesamtrechnungen, Stuttgart, Mainz 1985, Tabelle 3.34, S. $188 \mathrm{ff}$. und Statistisches Bundesamt: Konten und Standardtabellen 1985, Reihe 1 der Fachserie 18: Volkswirtschaftliche Gesamtrechnungen, Stuttgart, Mainz 1986, Tabelle 3.34, S. 295. 
Tabelle 6*b: Die mittelbaren Investitionen der Sozialversicherungen (VGR) ${ }^{11}$

\begin{tabular}{|c|c|c|c|c|c|c|c|c|}
\hline \multirow{4}{*}{ Jahr- } & \multicolumn{3}{|c|}{ INVESTITIONSZLSCHÜSSE } & \multicolumn{3}{c|}{ VERMÖGENSC̈BERTRAGUNGEN (Vü) } \\
\cline { 2 - 9 } & $\begin{array}{c}\text { an Unter- } \\
\text { nehmen }\end{array}$ & $\begin{array}{c}\text { an den } \\
\text { Staat2) }\end{array}$ & $\begin{array}{c}\text { an übrige } \\
\text { Welt }\end{array}$ & insgesamt & $\begin{array}{c}\text { sonstige } \\
\text { Vü }\end{array}$ & $\begin{array}{c}\text { fiktive } \\
\text { Vü }\end{array}$ & $\begin{array}{c}\text { Investi- } \\
\text { tionszusch. }\end{array}$ & insgesamt \\
\cline { 2 - 9 } & Mrd.DM & Mrd.DM & Mrd.DM & Mrd.DM & Mrd.DM & Mrd.DM & Mrd.DM & Mrd.DM \\
\hline 1962 & 0,04 & - & - & 0,04 & - & - & 0,04 & 0,04 \\
1963 & 0,02 & - & - & 0,02 & - & - & 0,02 & 0,02 \\
1964 & 0,04 & - & - & 0,04 & - & - & 0,04 & 0,04 \\
1965 & 0,05 & - & - & 0,05 & - & - & 0,05 & 0,05 \\
1966 & 0,06 & - & - & 0,06 & - & - & 0,06 & 0,06 \\
1967 & 0,07 & - & - & 0,07 & - & - & 0,07 & 0,07 \\
1968 & 0,06 & - & - & 0,06 & - & - & 0,06 & 0,06 \\
1969 & 0,05 & - & - & 0,05 & - & - & 0,05 & 0,05 \\
1970 & 0,04 & - & - & 0,04 & - & - & 0,04 & 0,04 \\
1971 & 0,05 & - & - & 0,05 & - & - & 0,05 & 0,05 \\
1972 & 0,07 & - & - & 0,07 & - & - & 0,07 & 0,07 \\
1973 & 0,13 & - & - & 0,13 & - & - & 0,13 & 0,13 \\
1974 & 0,20 & 0,04 & - & 0,24 & - & - & 0,20 & 0,20 \\
1975 & 0,14 & 0,08 & - & 0,22 & - & - & 0,14 & 0,14 \\
1976 & 0,11 & 0,13 & - & 0,24 & - & - & 0,11 & 0,11 \\
1977 & 0,49 & 0,11 & - & 0,60 & - & - & 0,49 & 0,49 \\
1978 & 0,70 & 0,12 & - & 0,82 & - & - & 0,70 & 0,70 \\
1979 & 0,98 & 0,11 & - & 1,09 & - & - & 0,98 & 0,98 \\
1980 & 1,02 & 0,10 & - & 1,12 & - & - & 1,02 & 1,02 \\
1981 & 0,98 & 0,08 & - & 1,06 & - & - & 0,98 & 0,98 \\
1982 & 1,06 & 0,08 & - & 1,14 & - & - & 1,06 & 1,06 \\
1983 & 1,41 & 0,10 & - & 1,51 & - & - & 1,41 & 1,41 \\
1984 & 1,92 & 0,11 & - & 2,03 & - & - & 1,92 & 1,92 \\
1985 & 2,27 & 0,11 & - & 2,38 & - & - & 2,27 & 2,27 \\
\hline
\end{tabular}

1) Ergebnisse in der Abgrenzung der Volkswirtschaftlichen Gesamtrechnungen in jeweiligen Preisen; ab 1984 vorläufige Ergebnisse.

2) Investitionszuschüsse der Sozialversicherungen an die Gemeinden.

Quelle: Zusammengestellt und errechnet aus: Statistisches Bundesamt: Revidierte Ergebnisse 1960 bis 1984, Reihe S.8 der Fachserie 18: Volkswirtschaftliche Gesamtrechnungen, Stuttgart, Mainz 1985, Tabelle 3.34, S. $200 \mathrm{ff}$. und Statistisches Bundesamt: Konten und Standardtabellen 1985, Reihe 1 der Fachserie 18: Volkswirtschaftliche Gesamtrechnungen, Stuttgart, Mainz 1986, Tabelle 3.34, S.299. 
Tabelle 7*a: Die Gesamtausgaben und Investitionen des Staates (VGR)"

\begin{tabular}{|c|c|c|c|c|c|c|c|c|c|c|c|c|}
\hline \multirow{3}{*}{ Jahr } & \multirow{2}{*}{\multicolumn{2}{|c|}{ GESAMTAUSG $\triangle B E N$}} & \multicolumn{8}{|c|}{ INVESTIIIIONEN } & \multirow{2}{*}{\multicolumn{2}{|c|}{$\begin{array}{l}\text { INVESTITIONS- } \\
\text { QUOTEN }\end{array}$}} \\
\hline & & & \multicolumn{2}{|c|}{ insgesamt } & \multicolumn{3}{|c|}{ Bruttoinvestitionen } & \multicolumn{3}{|c|}{ Vü an Unternehmen } & & \\
\hline & Mrd.DM & $\begin{array}{l}\text { Wachstums- } \\
\text { rate } 2)\end{array}$ & Mrd.DM & $\begin{array}{c}\text { Wachstums- } \\
\text { rate }^{21}\end{array}$ & Mrd.DM & $\begin{array}{c}\text { Wachstums- } \\
\text { rate } 21\end{array}$ & Anleil31 & Mrd.IDM & $\begin{array}{c}\text { Wachstums- } \\
\text { rate } 21\end{array}$ & Anteil3) & $\begin{array}{l}\text { insge- } \\
\text { saml4) }\end{array}$ & $\begin{array}{l}\text { Brultoinve- } \\
\text { stitionen } 5 \text { ) }\end{array}$ \\
\hline 1962 & 129,58 & - & 19,95 & - & 14,28 & - & 71,6 & 5,67 & - & 28,4 & 15,4 & 11,0 \\
\hline 1963 & 140,38 & 8,3 & 20,96 & 5,1 & 17,11 & 19,8 & 81,6 & 3,85 & $-32,1$ & 18,4 & 14,9 & 12,2 \\
\hline 1964 & 153,17 & 9,1 & 25,01 & 19,3 & 20,88 & 22,0 & 83,5 & 4,13 & 7,3 & 16,5 & 16,3 & 13,6 \\
\hline 1965 & 170,23 & 11,1 & 25,27 & 1,0 & 20,86 & $-0,1$ & 82,5 & 4,41 & 6,8 & 17,5 & 14,8 & 12,3 \\
\hline 1966 & 181,59 & 6,7 & 25,50 & 0,9 & 21,20 & 1,6 & 83,1 & 4,30 & $-2,5$ & 16,9 & 14,0 & 11,7 \\
\hline 1967 & 193,56 & 6,6 & 23,18 & $-9,1$ & 18,87 & $-11,0$ & 81,4 & 4,31 & 0,2 & 18,6 & 12,0 & 9,7 \\
\hline 1968 & 211,08 & 9,1 & 24,92 & 7,5 & 20,68 & 9,6 & 83,0 & 4,24 & $-1,6$ & 17,0 & 11,8 & 9,8 \\
\hline 1969 & 233,33 & 10,5 & 30,36 & 21,8 & 23,73 & 14,7 & 78,2 & 6,63 & 56,4 & 21,8 & 13,0 & 10,2 \\
\hline 1970 & 264,13 & 13,2 & 39,35 & 29,6 & 31,29 & 31,9 & 79,5 & 8,06 & 21,6 & 20,5 & 14,9 & 11,8 \\
\hline 1971 & 304,30 & 15,2 & 42,70 & 8,5 & 33,87 & 8,2 & 79,3 & 8,83 & 9,6 & 20,7 & 14,0 & 11,1 \\
\hline 1972 & 340,99 & 12,1 & 43,66 & 2,2 & 33,85 & $-0,1$ & 77,5 & 9,81 & 11,1 & 22,5 & 12,8 & 9,9 \\
\hline 1973 & 386,45 & 13,3 & 46,36 & 6,2 & 35,13 & 3,8 & 75,8 & 11,23 & 14,5 & 24,2 & 12,0 & 9,1 \\
\hline 1974 & 444,84 & 15,1 & 53,39 & 15,2 & 40,13 & 14,2 & 75,2 & 13,26 & 18,1 & 24,8 & 12,0 & 9,0 \\
\hline 1975 & 509,09 & 14,4 & 53,74 & 0,7 & 40,33 & 0,5 & 75,0 & 13,41 & 1,1 & 25,0 & 10,6 & 7,9 \\
\hline 1976 & 546,20 & 7,3 & 57,40 & 6,8 & 39,49 & $-2,1$ & 68,8 & 17,91 & 33,6 & 31,2 & 10,5 & 7,2 \\
\hline 1977 & 582,68 & 6,7 & 58,07 & 1,2 & 39,34 & $-0,4$ & 67,7 & 18,73 & 4,6 & 32,3 & 10,0 & 6,8 \\
\hline 1978 & 620,76 & 6,5 & 61,62 & 6,1 & 42,78 & 8,7 & 69,4 & 18,84 & 0,6 & 30,6 & 9,9 & 6,9 \\
\hline 1979 & 669,75 & 7,9 & 69,62 & 13,0 & 47,81 & 11,8 & 68,7 & 21,81 & 15,8 & 31,3 & 10,4 & 7,1 \\
\hline 1980 & 722,36 & 7,9 & 76,37 & 9,7 & 53,59 & 12,1 & 70,2 & 22,78 & 4,4 & 29,8 & 10,6 & 7,4 \\
\hline 1981 & 766,17 & 6,1 & 72,09 & $-5,6$ & 50,02 & $-6,7$ & 69,4 & 22,07 & $-3,1$ & 30,6 & 9,4 & 6.5 \\
\hline 1982 & 795,98 & 3,9 & 68,29 & $-5,3$ & 45,26 & $-9,5$ & 66,3 & 23,03 & 4,3 & 33,7 & 8,6 & 5,7 \\
\hline 1983 & 816,44 & 2,6 & 64,97 & $-4,9$ & 41,77 & $-7,7$ & 64,3 & 23,20 & 0.7 & 35,7 & 8,0 & 5,1 \\
\hline 1984 & 849,01 & 4,0 & 68,85 & 6,0 & 41,74 & 0,1 & 60,6 & 27,11 & 16,9 & 39,4 & 8,1 & 4,9 \\
\hline 1985 & 874,79 & 3,0 & 69,07 & 0,3 & 42,13 & 0,9 & 61,0 & 26,94 & $-0,6$ & 39,0 & 7,9 & 4,8 \\
\hline
\end{tabular}

1) Ergebnisse in der Abgrenzung der Volkswirtschaftlichen Gesamtrechnungen in jeweiligen Preisen; ab 1984 vorläufige Ergebnisse.

2) Veränderung gegenüber dem Vorjahr in vH.

3) Jeweilige Ausgaben in vll der gesamten Investitionen.

4) Gesamle Investitionen in vll der Gesamtausgaben.

5) Brultoinvestitionen in vll der Gesamtausgaben.

Quelle: Zusammengestellt und errechncl aus: Statistisches Bundesamt: Revidicrte Ergebnisse 1960 bis 1984 , Reihe S. 8 der Fachseric 18: Volkswirtschaftliche Gesamtrechnungen, Stuttgart, Mainz 1985, 'labelle 3.34, S. $185 \mathrm{Ir}$. und Statistisches Bundesamt: Konten und Standardtabellen 1985, Reihe 1 der Fachseric 18: Volkswirtschuftliche Gesamtrechnungen, Stultgart, Muinz. 1986, Tabelle 3.34, S. 294. 
Tabelle 7*b: Die Gesamtausgaben und Investitionen der Sozialversicherungen (VGIR)"

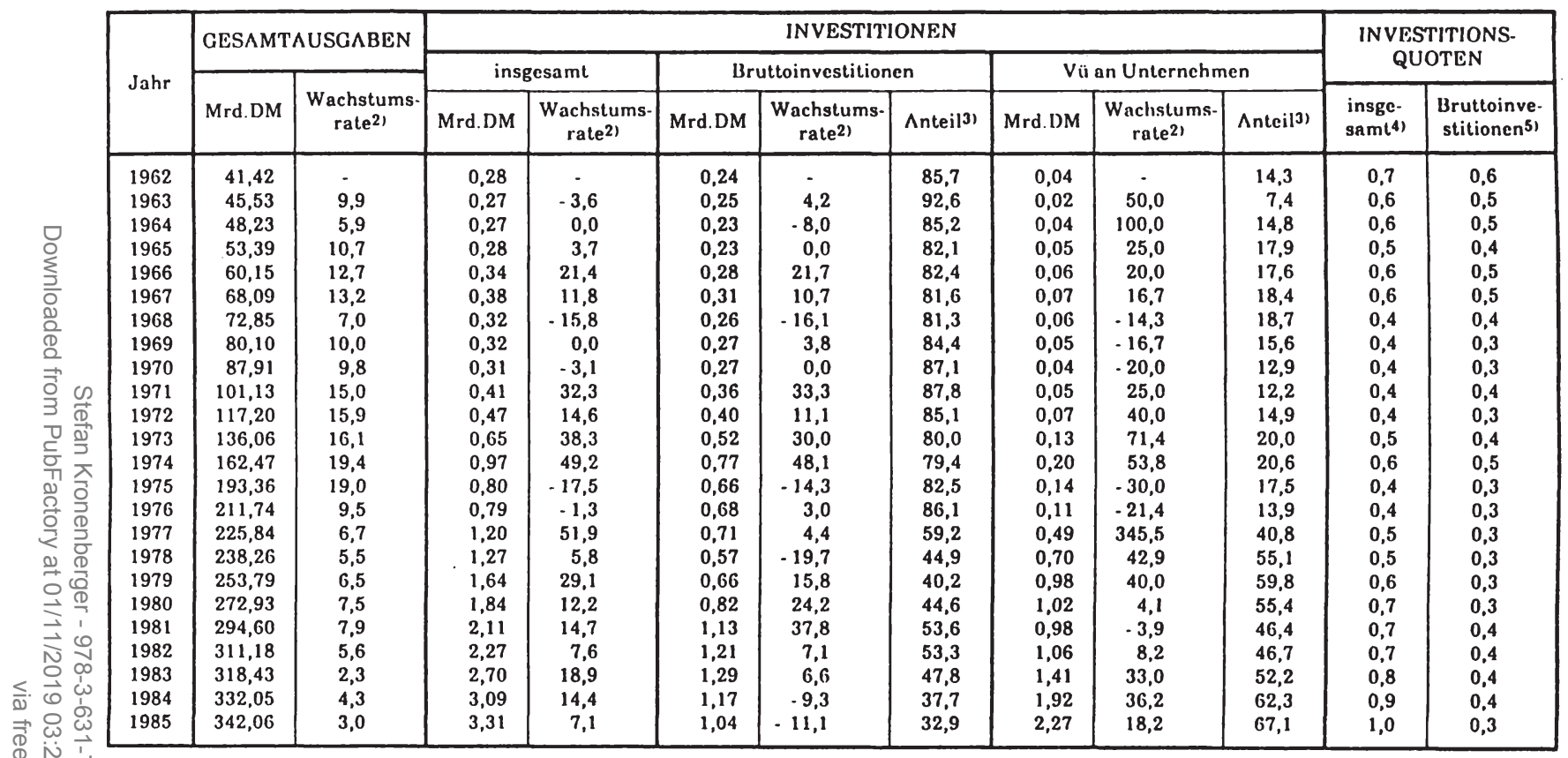

1) Ergebnisse in der Ahgrenzung der Volkswirtschaftlichen Gesamtrechnungen in jewciligen Preisen; ab 1984 vorlăulige Ergebnisse.

3) Jeweilige Ausgaben in vll der gesamten Investitionen.

4) Gesamte Investitionen in vH der Gesamtausgaben.

5) Bruttoinvestitionen in vH der Gesamtausgaben.

Quelle: 7usummengestellt und errechnel aus: Statistisches Bundesamt: Revidierte Ergelsnisse 1960 bis 1984, Reihe S. 8 der Fachserie 18: Volkswirtschufliche Gesumtrechnungen, Stultgurt, Mainz 1985, Tubelle 3.34, S. 200 Ir. und Statistisches Bundesamt: Konten und Standurdtubellen 1985, Reihe 1 der Fuchserie 18: Volkswirtschuftliche Gesumtrechnungen, Stutlgart, Mainz. 1986, Tubelle 3.34, S. 299. 
Tabelle 8*: Die Bruttoinvestitionen der Gebietskörperschaften (VGR)"

\begin{tabular}{|c|c|c|c|c|c|c|c|c|c|c|c|c|}
\hline \multirow{4}{*}{ Jahr } & \multicolumn{2}{|c|}{ INSGESAMT } & \multicolumn{8}{|c|}{ BRUTTOANIAAGEINVESTITIONEN } & \multirow{2}{*}{\multicolumn{2}{|c|}{$\begin{array}{c}\text { VORRATS- } \\
\text { VERÄNDERUNGEN }\end{array}$}} \\
\hline & \multirow{3}{*}{ Mrd.DM } & \multirow{3}{*}{$\begin{array}{l}\text { Wachstums- } \\
\text { rate }\end{array}$} & \multirow{2}{*}{\multicolumn{2}{|c|}{ insgesamt }} & \multicolumn{2}{|c|}{ Bauinvestitionen } & \multicolumn{2}{|c|}{$\begin{array}{l}\text { Ausrüstungs- } \\
\text { investitionen }\end{array}$} & \multirow{2}{*}{\multicolumn{2}{|c|}{$\begin{array}{l}\text { sonstige Anlage- } \\
\text { investitionen2l }\end{array}$}} & & \\
\hline & & & & & & & & & & & \multirow{2}{*}{ Mrd.DM } & \multirow{2}{*}{ Anteil4) } \\
\hline & & & Mrd.DM & Anteil4) & Mrd.DM & Anteil5) & Mrd.DM & Anteil5I & Mrd.I)M & Anteil5) & & \\
\hline 1962 & 14,04 & - & 14,04 & 100 & 12,15 & 86,5 & 1,21 & 8,6 & 0,68 & 4,8 & - & 0,0 \\
\hline 1963 & 16,86 & 20,1 & 16,86 & 100 & 14,73 & 87,4 & 1,39 & 8,2 & 0,74 & 4,4 & - & 0,0 \\
\hline 1964 & 20,65 & 22,5 & 20,65 & 100 & 18,31 & 88,7 & 1,49 & 7,2 & 0,85 & 4,1 & - & 0,0 \\
\hline 1965 & 20,63 & $-0,1$ & 20,63 & 100 & 17,98 & 87,2 & 1,66 & 8,0 & 0,99 & 4,8 & - & 0,0 \\
\hline 1966 & 20,92 & 1,4 & 20,92 & 100 & 18,43 & 88,1 & 1,64 & 7,8 & 0,85 & 4,1 & - & 0,0 \\
\hline 1967 & 18,56 & $-11,3$ & 18,56 & 100 & 15,88 & 85,6 & 1,58 & 8,5 & 1,10 & 5,9 & - & 0,0 \\
\hline 1968 & 20,42 & 10,0 & 20,42 & 100 & 17,83 & 87,3 & 1,53 & 7,5 & 1,06 & 5,2 & - & 0,0 \\
\hline 1969 & 23,46 & 14,9 & 23,46 & 100 & 20,51 & 87,4 & 1,76 & 7,5 & 1,19 & 5,1 & - & 0,0 \\
\hline 1970 & 31,02 & 32,2 & 30,82 & 99,4 & 27,26 & 88,4 & 2,25 & 7,3 & 1,31 & 4,3 & 0,20 & 0,6 \\
\hline 1971 & 33,51 & 8,0 & 33,31 & 99,4 & 29,02 & 87,1 & 2,73 & 8,2 & 1,56 & 4,7 & 0,20 & 0,6 \\
\hline 1972 & 33,45 & $.0,2$ & 33,45 & 100 & 28,87 & 86,3 & 2,94 & 8,8 & 1,64 & 4,9 & . & 0,0 \\
\hline 1973 & 34,61 & 3,5 & 34,61 & 100 & 29,44 & 85,1 & 3,31 & 9,6 & 1,86 & 5,4 & - & 0,0 \\
\hline 1974 & 39,36 & 13,7 & 39,26 & 99,7 & 33,25 & 84,7 & 3,69 & 9,4 & 2,32 & 5,9 & 0,10 & 0,3 \\
\hline 1975 & 39,67 & 0,8 & 39,07 & 98,5 & 33,15 & 84,8 & 3,67 & 9,4 & 2,25 & 5,8 & 0,60 & 1,5 \\
\hline 1976 & 38,81 & $-2,2$ & 38,61 & 99,5 & 32,83 & 85,0 & 3,57 & 9,2 & 2,21 & 5,7 & 0,20 & 0,5 \\
\hline 1977 & 38,63 & $-0,5$ & 38,33 & 99,2 & 32,37 & 84,5 & 3,98 & 10,4 & 1,98 & 5,2 & 0,30 & 0,8 \\
\hline 1978 & 42,21 & 9,3 & 42,01 & 99,5 & 35,38 & 84,2 & 4,45 & 10,6 & 2,18 & 5,2 & 0,20 & 0,5 \\
\hline 1979 & 47,15 & 11,7 & 47,15 & 100 & 39,69 & 84,2 & 5,00 & 10,6 & 2,46 & 5,2 & - & 0,0 \\
\hline 1980 & 52,77 & 11,9 & 52,27 & 99,1 & 44,21 & 84,6 & 5,49 & 10,5 & 2,57 & 4,9 & 0,50 & 0,9 \\
\hline 1981 & 48,89 & $-7,4$ & 48,69 & 99,6 & 41,39 & 85,0 & 5,12 & 10,5 & 2,16 & 4,4 & $0 ; 20$ & 0,4 \\
\hline 1982 & 44,05 & $-9,9$ & 44,05 & 100 & 37,49 & 85,1 & 4,69 & 10,6 & 1,87 & 4,2 & - & 0,0 \\
\hline 1983 & 40,48 & $-8,1$ & 40,48 & 100 & 34,19 & 84,5 & 4,69 & 11,6 & 1,60 & 4,0 & . & 0,0 \\
\hline 1984 & 40,57 & 0,2 & 40,57 & 100 & 34,09 & 84,0 & 5,07 & 12,5 & 1,41 & 3,5 & . & 0,0 \\
\hline 1985 & 41,09 & 1,3 & 41,09 & 100 & 33,63 & 81,8 & 5,76 & 14,0 & 1,70 & 4,1 & - & 0,0 \\
\hline
\end{tabular}

1) Prgebnisse in der Abgrenzung der Volkswirtschaftlichen Gesamtrechnungen in jeweiligen Preisen ; ab 1984 vorläufige Ergebnisse.

2) Käufe von gebrauchten Anlagen und I,and abzüglich Verkäufe von gebrauchten Anlagen und Iand.

3) Veränderung gegenüber dem Vorjahr in vII.

4) Jeweilige Ausgaben in vHI der gesamlen Bruttoinvestitionen.

5) Jeweilige Ausgaben in vHI der gesamten Bruttoanlageinvestitionen.

Quelle: \%usammengestellt und crrechnet aus: Statistisches Bundesamt: Revidierte Ergebnisse 1960 bis 1984 , Reihe S. 8 der Fachseric 18: Volkswirtschaftliche Gesamtrechnungen, Stuttgart, Mainz. 1985, Tabelle 3.39, S. 227 If. und Statistisches Bundesamt: Konten und Standardtabellen 1985, Reihe 1 der l'achseric 18: Volkswirtschaftliche Gesamtrechnungen, Stuttgart, Mainz. 1986, 'Tabelle 3.39, S. 310. 
Tabelle 9*: Die Bruttoinvestitionen des Staates nach Aufgabenbereichen in Mrd. DM (VGR) ${ }^{11}$

\begin{tabular}{|c|c|c|c|c|c|c|c|c|c|c|c|c|c|c|}
\hline Aufgabenbereiche ${ }^{2)}$ & 1970 & 1971 & 1972 & 1973 & 1974 & 1975 & 1976 & 1977 & 1978 & 1979 & 1980 & 1981 & 1982 & 1983 \\
\hline 1. Allg. Verwal & 0,86 & $0 ; 97$ & 1,02 & 1,09 & 1,22 & 1,21 & 1,39 & 1,37 & 1,69 & 1,81 & 2,30 & 2,36 & 2,50 & 2,38 \\
\hline 2. Verteidigung & 0,22 & 0,20 & 0,22 & 0,18 & 0,26 & 0,22 & 0,21 & 0,18 & 0,20 & 0,30 & 0,30 & 0,25 & 0,25 & 0,31 \\
\hline 3. Öff. Sicherheit & 0,65 & 0,72 & 0,84 & 0,93 & 1,28 & 1,42 & 1,37 & 1,48 & 1,67 & 1,94 & 2,22 & 2,19 & 1,86 & 1,82 \\
\hline 4. Unterricht & 7,45 & 8,59 & 8,64 & 9,03 & 10,31 & 10,05 & 9,17 & 8,16 & 7,74 & 8,00 & 8,82 & 8,24 & 7,09 & 5,96 \\
\hline 5. Gesundheit & 1,99 & 2,10 & 2,13 & 2,28 & 2,68 & 2,84 & 2,73 & 2,88 & 3,38 & 3,81 & 4,04 & 4,19 & 4,66 & 4,41 \\
\hline 6. Soz. Sicherung & 0,53 & 0,71 & 0,81 & 0,97 & 1,17 & 1,06 & 1,08 & 1,07 & 0,94 & 1,02 & 1,34 & 1,61 & 1,59 & 1,52 \\
\hline 7. Raumpl./Umwelt & 4,57 & 4,92 & 4,84 & 5,27 & 6,35 & 6,21 & 7,10 & 6,78 & 7,95 & 9,67 & 11,12 & 10,20 & 8,79 & 8,14 \\
\hline 8. Erholung/Kultur & 1,29 & 1,55 & 1,77 & 1,99 & 2,52 & 2,58 & 2,57 & 2,34 & 2,66 & 3,02 & 3,74 & 3,73 & 3,18 & 2,70 \\
\hline 9. Energie & 0,21 & 0,25 & 0,08 & 0,11 & 0,12 & 0,63 & 0,25 & 0,36 & 0,21 & 0,04 & 0,50 & 0,20 & - & - \\
\hline 10. Landwirtschaft & 0,24 & 0,24 & 0,26 & 0,27 & 0,27 & 0,25 & 0,26 & 0,27 & 0,32 & 0,36 & 0,40 & 0,31 & 0,23 & 0,21 \\
\hline 11. Gewerbe & - & - & - & - & -. & - & - & - & - & - & - & - & - & - \\
\hline 12. Verkehr & 12,62 & 12,96 & 12,58 & 12,36 & 13,17 & 13,02 & 12,56 & 13,66 & 15,12 & 16,70 & 17,37 & 15,54 & 13,88 & 13,26 \\
\hline 13. Wirtschaftsförderung & 0,66 & 0,66 & 0,66 & 0,65 & 0,78 & 0,84 & 0,80 & 0,79 & 0,90 & 1,14 & 1,44 & 1,20 & 1,23 & 1,08 \\
\hline Insgesamt & 1,29 & 33,87 & 33,85 & 35,13 & 40,13 & 40,33 & 39,49 & 39,34 & 42,78 & 47,81 & 53,59 & 50,02 & 45,26 & 41,79 \\
\hline
\end{tabular}

1) Ergebnisse in der Abgrenzung der Volkswirtschaftichen Gesamtrechnungen in jeweiligen Preisen; ab 1983 vorlïufige Ergebnisse.

2) Zur vollständigen Benennung siehe Übersicht 2.17.

Quelle: Zusammengestellt aus: Statistisches Bundesamt: Revidierte Ergebnisse 1960 bis 1984, Reihe S.8 der Fachseric 18: Volkswirtschaftliche Gesamtrechnungen, Stuttgart, Mainz 1985, Tabelle 3.40, S. $230 \mathrm{fr}$. 
Tabelle 10*a: Die Bauinvestitionen in jeweiligen Preisen nach Sektoren (VGR)"

\begin{tabular}{|c|c|c|c|c|c|c|c|c|}
\hline \multirow[b]{2}{*}{ Jahr } & \multicolumn{2}{|c|}{ insgesamt } & \multicolumn{3}{|c|}{ Unternehmen } & \multicolumn{3}{|c|}{ Staat } \\
\hline & Mrd.D.M & $\begin{array}{l}\text { Wachstums- } \\
\text { rate }^{2)}\end{array}$ & Mrd.DM & $\begin{array}{l}\text { Wachstums- } \\
\text { rate }^{21}\end{array}$ & Anteil3' & Mrd.DM & $\begin{array}{c}\text { Wachstums- } \\
\text { rate }^{21}\end{array}$ & Anteil3) \\
\hline 1962 & 57,90 & - & 44,84 & - & 77,4 & 13,06 & - & 22,6 \\
\hline 1963 & 62,07 & 7,2 & 46,36 & 3,4 & 74,7 & 15,71 & 20,3 & 25,3 \\
\hline 1964 & 72,49 & 16,8 & 53,08 & 14,5 & 73,2 & 19,41 & 23,6 & 26,8 \\
\hline 1965 & 76,55 & 5,6 & 57,34 & 8,0 & 74,9 & 19,21 & $-1,0$ & 25,1 \\
\hline 1966 & 80,19 & 4,8 & 60,62 & 5,7 & 75,6 & 19,57 & 1,9 & 24,4 \\
\hline 1967 & 73,11 & 8,8 & 55,81 & $-7,9$ & 76,3 & 17,30 & $-11,6$ & 23,7 \\
\hline 1968 & 76,25 & 4,3 & 57,08 & 2,3 & 74,9 & 19,17 & 10,8 & 25,1 \\
\hline 1969 & 85,31 & 11,9 & 63,30 & 10,9 & 74,2 & 22,01 & 14,8 & 25,8 \\
\hline 1970 & 106,17 & 24,5 & 77,27 & 22,1 & 72,8 & 28,90 & 31,3 & 27,2 \\
\hline 1971 & 123,45 & 16,3 & 92,45 & 19,6 & 74,9 & 31,00 & 7,3 & 25,1 \\
\hline 1972 & 136,43 & 10,5 & 105,47 & 14,1 & 77,3 & 30,96 & $-0,1$ & 22,7 \\
\hline 1973 & 143,99 & 5,5 & 112,13 & 6,3 & 77,9 & 31,86 & 2,9 & 22,1 \\
\hline 1974 & 140,35 & $-2,5$ & 104,05 & $-7,2$ & 74,1 & 36,30 & 13,9 & 25,9 \\
\hline 1975 & 131,36 & $-6,4$ & 95,33 & $-8,4$ & 72,6 & 36,03 & $-0,7$ & 27,4 \\
\hline 1976 & 139,57 & 6,3 & 103,85 & 8,9 & 74,4 & 35,72 & $-0,9$ & 25,6 \\
\hline 1977 & 147,11 & 5,4 & 112,04 & 7,9 & 76,2 & 35,07 & $-1,8$ & 23,8 \\
\hline 1978 & 160,21 & 8,9 & 122,05 & 8,9 & 76,2 & 38,16 & 8,8 & 23,8 \\
\hline 1979 & 184,45 & 15,1 & 141,60 & 16,0 & 76,8 & 42,85 & 12,3 & 23,2 \\
\hline 1980 & 208,46 & 13,0 & 160,83 & 13,6 & 77,2 & 47,63 & 11,2 & 22,8 \\
\hline 1981 & 207,59 & $-0,4$ & 162,87 & 1,3 & 78,5 & 44,72 & $-6,1$ & 21,5 \\
\hline 1982 & 201,99 & $-2,7$ & 161,40 & $-0,9$ & 79,9 & 40,59 & $-9,2$ & 20,1 \\
\hline 1983 & 208,22 & 3,1 & 171,11 & 6,0 & 82,2 & 37,11 & $-8,6$ & 17,8 \\
\hline 1984 & 217,05 & 4,2 & 180,42 & 5,4 & 83,1 & 36,63 & $-1,3$ & 16,9 \\
\hline 1985 & 205,45 & $-5,3$ & 169,04 & $-6,3$ & 82,3 & 36,41 & $-0,6$ & 17,7 \\
\hline
\end{tabular}

1) Ergebnisse in der Abgrenzung der Volkswirtschaftlichen Gesamtrechnungen einschl. der Kăufe abzũgl. der Verkäufe von Land; ab 1984 vorläufige Ergebnisse.

2) Veränderung gegenüber dem Vorjahr in vH.

3) Jeweilige Ausgaben in $\mathrm{vH}$ der gesamten Bauinvestitionen.

Quelle: Zusammengestellt und errechnet aus: Statistisches Bundesamt: Revidierte Ergebnisse 1960 bis 1984 , Reihe S.8 der Fachserie 18: Volkswirtschaftliche Gesamtrechnungen, Stuttgart, Mainz 1985, Tab. 3.17,S. 102 ff. und Statistisches Bundesamt: Konten und Standardtabellen 1985, Reihe 1 der Fachserie 18: Volkswirtschaftliche Gesamtrechnungen, Stuttgart, Mainz 1986, Tab.3.17, S. 265. 
Tabelle 10*b: Die Ausrüstungsinvestitionen in jeweiligen Preisen nach Sektoren $(\text { VGR })^{11}$

\begin{tabular}{|c|c|c|c|c|c|c|c|c|}
\hline \multirow[b]{2}{*}{ Jahr } & \multicolumn{2}{|c|}{ insgesamt } & \multicolumn{3}{|c|}{ Unternehmen } & \multicolumn{3}{|c|}{ Staat } \\
\hline & Mrd.DM & $\begin{array}{c}\text { Wachstums- } \\
\text { rate }^{21}\end{array}$ & Mrd.DM & $\begin{array}{l}\text { Wachstums- } \\
\left.\text { rate }^{2}\right)\end{array}$ & Anteil31 & Mrd.DM & $\begin{array}{l}\text { Wachstums- } \\
\text { rate }^{2)}\end{array}$ & Anteil3) \\
\hline 1962 & 34,98 & . & 33,76 & - & 96,5 & 1,22 & - & 3,5 \\
\hline 1963 & 35,64 & 1,9 & 34,24 & 1,4 & 96,1 & 1,40 & 14,8 & 3,9 \\
\hline 1964 & 39,21 & 10,0 & 37,74 & 10,2 & 96,2 & 1,47 & 5,0 & 3,8 \\
\hline 1965 & 43,35 & 10,6 & 41,70 & 10,5 & 96,2 & 1,65 & 12,2 & 3,8 \\
\hline 1966 & 43,98 & 1,5 & 42,35 & 1,6 & 96,3 & 1,63 & $-1,2$ & 3,7 \\
\hline 1967 & 41,07 & $-6,6$ & 39,50 & $-6,7$ & 96,2 & 1,57 & $-3,7$ & 3,8 \\
\hline 1968 & 43,14 & 5,0 & 41,63 & 5,4 & 96,5 & 1,51 & $-3,8$ & 3,5 \\
\hline 1969 & 53,59 & 24,2 & 51,87 & 24,6 & 96,8 & 1,72 & 13,9 & 3,2 \\
\hline 1970 & 65,88 & 22,9 & 63,69 & 22,8 & 96,7 & 2,19 & 27,3 & 3,3 \\
\hline 1971 & 72,66 & 10,3 & 69,99 & 9,9 & 96,3 & 2,67 & 21,9 & 3,7 \\
\hline 1972 & 72,74 & 0,1 & 69,85 & $-0,2$ & 96,0 & 2,89 & 8,2 & 4,0 \\
\hline 1973 & 75,27 & 3,5 & 72,00 & 3,1 & 95,7 & 3,27 & 13,1 & 4,3 \\
\hline 1974 & 72,36 & $-3,9$ & 68,63 & $-4,7$ & 94,8 & 3,73 & 14,1 & 5,2 \\
\hline 1975 & 78,05 & 7,9 & 74,35 & 8,3 & 95,3 & 3,70 & $-0,8$ & 4,7 \\
\hline 1976 & 86,08 & 10,3 & 82,51 & 11,0 & 95,8 & 3,57 & $-3,5$ & 4,2 \\
\hline 1977 & 95,32 & 10,7 & 91,35 & 10,7 & 95,8 & 3,97 & 11,2 & 4,2 \\
\hline 1978 & 105,75 & 10,9 & 101,33 & 10,9 & 95,8 & 4,42 & 11,3 & 4,2 \\
\hline 1979 & 118,97 & 12,5 & 114,01 & 12,5 & 95,8 & 4,96 & 12,2 & 4,2 \\
\hline 1980 & 127,34 & 7,0 & 121,88 & 6,9 & 95,7 & 5,46 & 10,1 & 4,3 \\
\hline 1981 & 127,65 & 0,2 & 122,55 & 0,5 & 96,0 & 5,10 & $-6,6$ & 4,0 \\
\hline 1982 & 124,90 & $-2,2$ & 120,23 & $-1,9$ & 96,3 & 4,67 & $-8,4$ & 3,7 \\
\hline 1983 & 135,60 & 8,6 & 130,94 & 8,9 & 96,6 & 4,66 & $-0,2$ & 3,4 \\
\hline 1984 & 137,58 & 1,5 & 132,47 & 1,2 & 96,3 & 5,11 & 9,7 & 3,7 \\
\hline 1985 & 153,85 & 11,8 & 148,13 & 11,8 & 96,3 & 5,72 & 11,9 & 3,7 \\
\hline
\end{tabular}

1) Ergebnisse in der Abgrenzung der Volkswirtschaftlichen Gesamtrechnungen; ab 1984 vorläufige Ergebnisse.

2) Veränderung gegenüber dem Vorjahr in $v \mathrm{H}$.

3) Jeweilige Ausgaben in vH der gesamten Ausrüstungsinvestitionen.

Quelle: Zusammengestellt und errechnet aus: Statistisches Bundesamt: Revidierte Ergebnisse 1960 bis 1984 , Reihe S.8 der Fachserie 18: Volkswirtschaftliche Gesamtrechnungen, Stuttgart, Mainz 1985, Tab. 3.17, S. $102 \mathrm{ff}$. und Statistisches Bundesamt: Konten und Standardtabellen 1985, Reihe 1 der Fachserie 18: Volkswirtschaftliche Gesamtrechnungen, Stuttgart, Mainz 1986, Tab. 3.17, S. 265. 
Tabelle 11*a: Die Bauinvestitionen in Preisen von 1980 nach Sektoren (VGR) ${ }^{1}$

\begin{tabular}{|c|c|c|c|c|c|c|c|c|}
\hline \multirow{3}{*}{ Jahr } & \multicolumn{2}{|c|}{ insgesamt } & \multicolumn{3}{c|}{ Unternehmen } & \multicolumn{3}{c|}{ Staat } \\
\cline { 2 - 8 } & Mrd.DM & $\begin{array}{c}\text { Wachstums- } \\
\text { rate2) }\end{array}$ & Mrd.DM & $\begin{array}{c}\text { Wachstums- } \\
\text { rate } 2 \text { ) }\end{array}$ & Anteil3) & Mrd.DM & $\begin{array}{c}\text { Wachstums- } \\
\text { rate }{ }^{2)}\end{array}$ & Anteil3) \\
\hline 1962 & 146,32 & & 116,70 & - & 79,8 & 29,62 & - & 20,2 \\
1963 & 149,01 & 1,8 & 114,87 & $-1,6$ & 77,1 & 34,14 & 15,3 & 22,9 \\
1964 & 168,30 & 12,9 & 126,46 & 10,1 & 75,1 & 41,84 & 22,6 & 24,9 \\
1965 & 174,05 & 3,4 & 131,99 & 4,4 & 75,8 & 42,06 & 0,5 & 24,2 \\
1966 & 178,42 & 2,5 & 135,91 & 3,0 & 76,2 & 42,51 & 1,1 & 23,8 \\
1967 & 167,12 & $-6,3$ & 128,34 & $-5,6$ & 76,8 & 38,78 & $-8,8$ & 23,2 \\
1968 & 170,85 & 2,2 & 129,38 & 0,8 & 75,7 & 41,47 & 6,9 & 24,3 \\
1969 & 179,09 & 4,8 & 134,13 & 3,7 & 74,9 & 44,96 & 8,4 & 25,1 \\
1970 & 189,93 & 6,1 & 139,39 & 3,9 & 73,4 & 50,54 & 12,4 & 26,6 \\
1971 & 202,87 & 6,8 & 152,69 & 9,5 & 75,3 & 50,18 & $-0,7$ & 24,7 \\
1972 & 213,63 & 5,3 & 165,19 & 8,2 & 77,3 & 48,44 & $-3,5$ & 22,7 \\
1973 & 213,10 & $-0,2$ & 165,41 & 0,1 & 77,6 & 47,69 & $-1,5$ & 22,4 \\
1974 & 194,19 & $-8,9$ & 143,45 & $-13,3$ & 73,9 & 50,74 & 6,4 & 26,1 \\
1975 & 179,39 & $-7,6$ & 129,90 & $-9,4$ & 72,4 & 49,49 & $-2,5$ & 27,6 \\
1976 & 183,67 & 2,4 & 135,80 & 4,5 & 73,9 & 47,87 & $-3,3$ & 26,1 \\
1977 & 186,13 & 1,3 & 140,73 & 3,6 & 75,6 & 45,40 & $-5,2$ & 24,4 \\
1978 & 191,41 & 2,8 & 144,99 & 3,0 & 75,8 & 46,42 & 2,2 & 24,2 \\
1979 & 202,57 & 5,8 & 155,20 & 7,0 & 76,6 & 47,37 & 2,0 & 23,4 \\
1980 & 208,46 & 2,9 & 160,83 & 3,6 & 77,2 & 47,63 & 0,5 & 22,8 \\
1981 & 197,88 & $-5,1$ & 154,81 & $-3,7$ & 78,2 & 43,07 & $-9,6$ & 21,8 \\
1982 & 189,29 & $-4,3$ & 150,10 & $-3,0$ & 79,3 & 39,19 & $-9,0$ & 20,7 \\
1983 & 192,54 & 1,7 & 156,96 & 4,6 & 81,5 & 35,58 & $-9,2$ & 18,5 \\
1984 & 195,54 & 1,6 & 161,07 & 2,6 & 82,4 & 34,47 & $-3,1$ & 17,6 \\
1985 & 183,37 & $-6,2$ & 149,46 & $-7,2$ & 81,5 & 33,91 & $-1,6$ & 18,5 \\
\hline
\end{tabular}

1) Ergebnisse in der Abgrenzung der Volkswirtschaftlichen Gesamtrechnungen einschl. Käufe abzügl. Verkäufe von Land; ab 1984 vorläufige Ergebnisse.

2) Veränderung gegenüber dem Vorjahr in vH.

3) Jeweilige Ausgaben in $\mathrm{vH}$ der gesamten Bauinvestitionen.

Quelle: Zusammengestellt und errechnet aus: Statistisches Bundesamt: Revidierte Ergebnisse 1960 bis 1984, Reihe S.8 der Fachserie 18: Volkswirtschaftliche Gesamtrechnungen, Stuttgart, Mainz 1985, Tabelle 3.17, S. 102 ff. und Statistisches Bundesamt: Konten und Standardtabellen 1985, Reihe 1 der Fachserie 18: Volkswirtschaftliche Gesamtrechnungen, Stuttgart, Mainz 1986, Tabelle 3.17, S. 265 . 
Tabelle 11*b: Die Ausrüstungsinvestitionen in Preisen von 1980 nach Sektoren $(\text { VGR })^{1 \prime}$

\begin{tabular}{|c|c|c|r|c|c|c|c|c|}
\hline \multirow{3}{*}{ Jahr } & \multicolumn{2}{|c|}{ insgesamt } & \multicolumn{3}{c|}{ Unternehmen } & \multicolumn{3}{c|}{ Staat } \\
\cline { 2 - 8 } & Mrd.DM & $\begin{array}{c}\text { Wachstums- } \\
\text { rate }^{2}\end{array}$ & Mrd.DM & $\begin{array}{c}\text { Wachstums- } \\
\text { rate2) }\end{array}$ & Anteil3) & Mrd.DM & $\begin{array}{c}\text { Wachstums- } \\
\text { rate2) }\end{array}$ & Anteil3) \\
\hline 1962 & 64,22 & - & 62,08 & - & 96,7 & 2,14 & - & 3,3 \\
1963 & 64,45 & 0,4 & 62,02 & $-0,1$ & 96,2 & 2,43 & 13,6 & 3,8 \\
1964 & 69,48 & 7,8 & 66,95 & 7,9 & 96,4 & 2,53 & 4,1 & 3,6 \\
1965 & 74,84 & 7,7 & 72,02 & 7,6 & 96,2 & 2,82 & 11,5 & 3,8 \\
1966 & 73,50 & $-1,8$ & 70,77 & $-1,7$ & 96,3 & 2,73 & $-3,2$ & 3,7 \\
1967 & 67,42 & $-8,3$ & 64,85 & $-8,4$ & 96,2 & 2,57 & $-5,9$ & 3,8 \\
1968 & 72,12 & 7,0 & 69,64 & 7,4 & 96,6 & 2,48 & $-3,5$ & 3,4 \\
1969 & 87,75 & 21,7 & 85,03 & 22,1 & 96,9 & 2,72 & 9,7 & 3,1 \\
1970 & 101,98 & 16,2 & 98,72 & 16,1 & 96,8 & 3,26 & 19,9 & 3,2 \\
1971 & 106,74 & 4,7 & 102,97 & 4,3 & 96,5 & 3,77 & 15,6 & 3,5 \\
1972 & 104,25 & 2,3 & 100,26 & $-2,6$ & 96,2 & 3,99 & 5,8 & 3,8 \\
1973 & 103,71 & $-0,5$ & 99,35 & $-0,9$ & 95,8 & 4,36 & 9,3 & 4,2 \\
1974 & 92,24 & $-11,1$ & 87,55 & $-11,9$ & 94,9 & 4,69 & 7,6 & 5,1 \\
1975 & 91,88 & $-0,4$ & 87,48 & $-0,1$ & 95,2 & 4,40 & $-6,2$ & 4,8 \\
1976 & 97,32 & 5,9 & 93,19 & 6,5 & 95,8 & 4,13 & $-6,1$ & 4,2 \\
1977 & 104,92 & 7,8 & 100,48 & 7,8 & 95,8 & 4,44 & 7,5 & 4,2 \\
1978 & 113,28 & 8,0 & 108,50 & 8,0 & 95,8 & 4,78 & 7,7 & 4,2 \\
1979 & 124,15 & 9,6 & 118,95 & 9,6 & 95,8 & 5,20 & 8,8 & 4,2 \\
1980 & 127,34 & 2,6 & 121,88 & 2,5 & 95,7 & 5,46 & 5,0 & 4,3 \\
1981 & 121,81 & $-4,3$ & 116,92 & $-4,1$ & 96,0 & 4,89 & $-10,4$ & 4,0 \\
1982 & 113,59 & $-6,7$ & 109,29 & $-6,5$ & 96,2 & 4,30 & $-12,1$ & 3,8 \\
1983 & 119,90 & 5,6 & 115,74 & 5,9 & 96,5 & 4,16 & $-3,3$ & 3,5 \\
1984 & 119,36 & $-0,5$ & 114,92 & $-0,7$ & 96,3 & 4,44 & 6,7 & 3,7 \\
1985 & 130,53 & 9,4 & 125,69 & 9,4 & 96,3 & 4,84 & 9,0 & 3,7 \\
\hline
\end{tabular}

1) Ergebnisse in der Abgrenzung der Volkswirtschaftlichen Gesamtrechnungen; ab 1984 vorläufige Ergebnisse.

2) Veränderung gegenüber dem Vorjahr in vH.

3) Jeweilige Ausgaben in vH der gesamten Ausrüstungsinvestitionen.

Quelle: Zusammengestellt und errechnet aus: Statistisches Bundesamt: Revidierte Ergebnisse 1960 bis 1984 , Reihe S.8 der Fachserie 18: Volkswirtschaftliche Gesamtrechnungen, Stuttgart, Mainz 1985, Tab. 3.17, S. 102 ff. und Statistisches Bundesamt: Konten und Standardtabellen 1985, Reihe 1 der Fachserie 18: Volkswirtschaftliche Gesamtrechnungen, Stuttgart, Mainz 1986, Tab. 3.17, S. 265. 


\section{LITERATURVERZEICHNIS}

Aberle, Gerd: Verkehrsinfrastrukturinvestitionen im Wachstumsprozeß entwickelter Volkswirtschaften, Düsseldorf 1972.

Akerman, Johan: Preise und Produktion. Rezension des gleichnamigen Buches von F.A. Hayek, in: Zeitschrift für Nationalökonomie, Bd. V (1934), S. 372-379.

Albers, Willi: Transferzahlungen an Haushalte, in: Handbuch der Finanzwissenschaft, 3. Aufl., hrsg. v. Fritz Neumark, Bd. I, Tübingen 1977, S. 861-957.

Albrecht, Gerhard: Das Problem der öffentlichen Ausgaben in der älteren Finanzwissenschaft, in: Jahrbücher für Nationalökonomie und Statistik, Bd. 148, Jena 1938, S. 171-201.

Albrecht, Gerhard: Artikel: Verein für Socialpolitik, in: Handwörterbuch der Sozialwissenschaften, hrsg. v. Erwin von Beckerath et al., 11. Bd., Stuttgart et al. 1961, S. 10-16.

Andel, Norbert: Nutzen-Kosten-Analysen, in: Handbuch der Finanzwissenschaft, 3. Aufl., hrsg. v. Fritz Neumark, Bd. I, Tübingen 1977, S. 475-518.

Andel, Norbert: Finanzwissenschaft, Tübingen 1983.

Anderson, Oskar et al.: Bevölkerungs- und Wirtschaftsstatistik: Aufgaben, Probleme und beschreibende Methoden, Berlin, Heidelberg, New York 1983.

Andic, Suphan and Veverka, Jindrich: The Growth of Government Expenditure in Germany since the Unification, in: Finanzarchiv, hrsg. v. Fritz Neumark, N.F. Bd. 23, Tübingen 1964, S. 169-278.

Angermann, Oswald und Stahmer, Carsten: Preisindices und Geldwertmessung im Rahmen der Volkswirtschaftlichen Gesamtrechnungen, in: Messung der Kaufkraft des Geldes, Heft 10 der Sonderhefte zum Allgemeinen Statistischen Archiv, hrsg. v. Gerhard Fürst, Göttingen 1976, S. 101-127.

Angermann, Oswald: Zur Neuberechnung der Preisindizes auf Basis 1980, in: Wirtschaft und Statistik, Jg. 1983, S. 204-206.

Arndt, Rudi: Mehr öffentliche Dienstleistungen sind wichtiger als $10.000 \mathrm{DM}$ auf dem Konto. Interview mit Oberbürgermeister Rudi Arndt (SPD), in: Wirtschaftswoche, Nr. 40, 26. Jg. (1972), S. 20-24.

Arnim, Hans Herbert v.: Staatslehre der Bundesrepublik Deutschland, München 1984.

Arrow, Kenneth J.: Criteria for Social Investment, in: Economics of the Environment. Selected Readings, ed. by Robert Dorfmann and Nancy S. Dorfmann, 2nd ed., New York 1977, S. 409-417.

Avineri, Shlomo: Hegel's Theory of the Modern State, Cambridge 1972. 
Backhaus, Juergen and Wagner, Richard E.: The cameralists: A public choice perspective, in: Public Choice, vol. 53 (1987), S. 3-20.

Bartel, Karl: Öffentliche Infrastruktur oder privates Vermögen. Die vermögenswirksame Schuldenpolitik als Lösung eines Zielkonflikts, Berlin 1975.

Bartels, Hildegard: Das Kontensystem für die Volkswirtschaftlichen Gesamtrechnungen der Bundesrepublik Deutschland. Erster Teil: Das angestrebte Kontensystem, in: Wirtschaft und Statistik, Jg. 1960, S. 317-344.

Bartholmai, Bernd: Entwicklung und Struktur der Staatsinvestitionen seit 1960 und der Stand der längerfristigen Investitionsplanung, Sonderheft 95, hrsg. v. Deutschen Institut für Wirtschaftsforschung, Berlin 1973.

Bartholmai, Bernd et al.: Gesamtwirtschaftliche und strukturelle Auswirkungen von Veränderungen der Struktur des öffentlichen Sektors, Heft 81 der Beiträge zur Strukturforschung, hrsg. v. Deutschen Institut für Wirtschaftsforschung, Berlin 1984.

Beckerath, Erwin von: Die neuere Geschichte der deutschen Finanzwissenschaft, in: Handbuch der Finanzwissenschaft, 2. Aufl., hrsg. v. Wilhelm Gerloff und Fritz Neumark, Bd. I, Tübingen 1952, S. 416-468.

Bentham, Jeremy: Manual of Political Economy (1793-1795), in: Jeremy Bentham's Economic Writings, ed. by W. Stark, vol. I, London 1952, S. 221-273.

Bieri, Stephan: Zur Stellung der frühen deutschen Finanzwissenschaft. Unter besonderer Berücksichtigung von Jakob, Soden, Lotz und Malchus, Zürich 1968.

Birnbacher, Dieter: John Stuart Mill, in: Klassiker der Philosophie, hrsg. v. Otfried Höffe, Bd. 2. Von Immanuel Kant bis Jean Paul Satre, München 1981, S.132-152.

Blaich, Fritz: Artikel: Merkantilismus, in: Handwörterbuch der Wirtschaftswissenschaft (HdWW), hrsg. v. Willi Albers et al., Bd. 5, Stuttgart et al. 1980, S. 240-251.

Blaich, Fritz: Merkantilismus, Kameralismus, Physiokratie, in: Geschichte der Nationalökonomie, hrsg. v. Otmar Issing, München 1984, S. 35-47.

Blankart, Charles B.: Das Handbuch der Finanzwissenschaft, eine Selbstdarstellung der deutschen Finanzwissenschaft?, in: Kyklos, vol. 39 (1986), S. 448-455.

Blaug, Mark: Systematische Theoriengeschichte der Ökonomie, Bd. I, München 1971 .

Blümel, Wolfgang; Pethig, Rüdiger und von dem Hagen, Oskar: The Theory of Public Goods: A Survey of Recent Issues, in: Journal of Institutional and Theoretical Economics, vol. 142 (1986), S. 241-309.

Blum, Reinhard: Bericht über die Diuskussion zum Referat D. Vesper, in: Neuere Entwicklungen in der Investitionstheorie und -politik, hrsg. v. Gottfried Bombach, Bernhard Gahlen und Alfred E. Ott, Tübingen 1980, S. 293-298. 
Boeckle, Willi Alfred: Artikel: Liberalismus, in: Handwörterbuch der Wirtschaftswissenschaft (HdWW), hrsg. v. Willi Albers et al., Bd. 5, Stuttgart et al 1980, S. 32-47.

Böhler, Eugen: Die Erneuerung der deutschen Finanzwissenschaft, in: Zeitschrift für die Schweizerische Statistik und Volkswirtschaft, 63. Jg. (1927), S. 583-597.

Bös, Dieter: Öffentliche Personalausgaben, in: Handbuch der Finanzwissenschaft, 3. Aufl., hrsg. v. Fritz Neumark, Bd. I, Tübingen 1977, S. 797-859.

Boese, Franz: Geschichte des Vereins für Socialpolitik 1872-1932, Berlin 1939.

Bombach, Gottfried: Konsum oder Investitionen für die Zukunft?, in: Aufgabe Zukunft: Qualität des Lebens, Bd. 7. Qualitatives Wachstum, hrsg. v. der IG-Metall, Frankfurt/Main 1972, S. 38-73.

Bombach, Gottfried: Die öffentliche Finanzwirtschaft im Wirtschaftskreislauf, in: Handbuch der Finanzwissenschaft, 3. Aufl., hrsg. v. Fritz Neumark, Bd. I, Tübingen 1977, S. 53-75.

Born, Karl Erich: Artikel: Wirtschaftskrisen, in: Handwörterbuch der Wirtschaftswissenschaft (HdWW), hrsg. v. Willi Albers et al., Bd. 9, Stuttgart et al 1982 , S. 130-141.

Boulding, Kenneth: A New Look at Institutionalism, in: The American Economic Review, vl. XLVII, Number 2, 1957, S. 1-12.

Bowden, Elbert V.: Economic Evolution. Principles, Issues, Ideas. Through the Loobing Class of Time, 2nd ed., Cincinnati (USA) 1985.

Brenken, Günter: Das Bundesraumordnungsprogramm. Entstehung, Inhalt und Bedeutung, in: Raumforschung und Raumordnung, 33. Jg. (1975), S. 104-111.

Brinkmann, Gerhard: Der Funktionenplan. Anmerkungen eines Verwunderten, in: Der öffentliche Haushalt - Archiv für Finanzkontrolle, Jg. 13 (1972), S. 77-84.

Brümmerhoff, Dieter: Finanzwissenschaft, München, Wien 1986.

Buchanan, Jarnes $M$. and Wagner, Richard E.: Democracy in Deficit. The Political Legacy of Lord Keynes, New York et al. 1977.

Bull, Hans Peter: Die Staatsaufgaben nach dem Grundgesetz, 2. Aufl., Kronberg/Ts. 1977.

Bundesminister der Finanzen: Verwaltungsvorschriften zur Haushaltssystematik des Bundes (VV-HB); hier: Neufassung 1. der Allgemeinen Hinweise zum Gruppierungsplan und zum Funktionenplan, 2. des Gruppierungsplans, in: Ministerialblatt des Bundesministers der Finanzen und des Bundesministers für Wirtschaft (MinBlFin), 24. Jg. (1973), S. 618-655. 
Bundesminister der Finanzen: Verwaltungsvorschriften zur Haushaltssystematik des Bundes (VV-HB); hier: Neufassung des Funktionenplans (FPl), in: Ministerialblatt des Bundesministers der Finanzen und des Bundesministers für Wirtschaft (MinBlFin), 25. Jg. (1974), S. 757-804.

Bundesministerium der Finanzen: Finanzbericht 1962, Bonn 1962.

Bundesministerium der Finanzen: Probleme einer Neuordnung der Haushaltssystematik von Bund und Ländern, in: Finanzbericht 1966, Bonn 1966, S. 202-205.

Bundesministerium der Finanzen: Finanzbericht 1969, Bonn 1968.

Bundesministerium der Finanzen: Finanzbericht 1970, Bonn 1970.

Bundesministerium der Finanzen: Erläuterungen zu den "Finanzstatistischen Übersichten", in: Finanzbericht 1974, Bonn 1973, S. 307-312.

Bundesministerium der Finanzen: Finanzbericht 1975, Bonn 1974.

Bundesministerium der Finanzen: Finanzbericht 1977, Bonn 1977.

Bundesministerium der Finanzen: Finanzbericht 1980, Bonn 1979.

Bundesministerium der Finanzen: Finanzbericht 1983, Bonn 1982.

Bundesministerium der Finanzen: Finanzbericht 1984, Bonn 1983.

Bundesministerium der Finanzen: Finanzbericht 1985, Bonn 1984.

Bundesministerium der Finanzen: Finanzbericht 1986, Bonn 1985.

Bundesministerium der Finanzen: Finanzbericht 1987, Bonn 1986.

Buschor, Ernst: Theorie der Allokation der Staatsausgaben. Darstellung und kritische Würdigung der Theorie der Staatsausgaben unter dem Aspekt der Allokationsproblematik. Heerbrugg 1970.

Clower, Robert: The Keynesian Counterrevolution: A Theoretical Appraisal, in: The Theory of Interest Rates. Proceedings of a Conference held by the International Economic Association, ed. by Frank H. Hahn and Frank P.R. Brechling, New York 1965, S. 103-125.

Colm, Gerhard: Volkswirtschaftliche Theorie der Staatsausgaben. Ein Beitrag zur Finanztheorie, Tübingen 1927.

Colm, Gerhard: Comments on Richard A . Musgrave's "A Multiple Theory of Budget Determination", in: Finanzarchiv, N.F. Bd. 18 (1957/58), Tübingen 1958, S. 52-55.

Colm, Gerhard: On Goals Research, in: Neue Perspektiven aus Wirtschaft und Recht. Festschrift für Hans Schäffer, hrsg. v. Carsten Peter Claussen, Berlin 1966, S. 67-78.

Damaschke, Adolf: Geschichte der Nationalökonomie, 13. Aufl., Bd. 2, Jena 1922. 
Davies, Jeffrey Rowe and Hughes, Steward: Investment in the British Economy, London et al. 1981.

Davis, Elynor G.: Mill, Socialism and the English Romantics: An Interpretation, in: Economica, vol. 52 (1985), S. 345-358.

Depiereux, Stefan: Das neue Haushaltsrecht der Gemeinden, 5. Aufl., Siegburg 1975.

Deutsche Bundesbank: Die Entwicklung der öffentlichen Investitionsausgaben seit 1961, in: Monatsberichte der Deutschen Bundesbank, 24. Jg. (1972), Nr. 4 (April), S. 12-20.

Deutsche Bundesbank: Struktur und Eigenschaften einer neuen Version des ökonometrischen Modells der Deutschen Bundesbank, in: Monatsberichte der Deutschen Bundesbank, 34. Jg. (1982), Nr. 8 (August), S. 32-41.

Deutsche Bundesbank: Sachinvestitionen, Darlehen und sonstige Finanzierungshilfen der Gebietskörperschaften seit Mitte der siebziger Jahre, in: Monatsberichte der Deutschen Bundesbank, 36. Jg. (1984), Nr. 11 (November), S. 26-34.

Deutsches Institut für Urbanistik: Kommunale Entwicklungsplanung. Mittelfristige Investitions- und Finanzplanung, Berlin 1976.

Deutsches Institut für Urbanistik: Kommunaler Investitionsbedarf bis 1990, Berlin 1980.

Dietz, Otto: Finanzen von Bund und Ländern 1950 bis 1981, in: Wirtschaft und Statistik, Jg. 1983, S. 132-140.

Dietz, Otto: Darstellung der Sozialversicherung in der Finanzstatistik, in: Wirtschaft und Statistik, Jg. 1984, S. 185-193.

Domar, Eusey D.: A Theoretical Analysis of Economic Growth, in: Essays in the Theory of Economic Growth, ed. by Evsey D. Domar, New York 1957, S. 16-34.

Domar, Eusey D.: Expansion and Employment, in: Essays in the Theory of Economic Growth, ed. by Evsey D. Domar, New York 1957, S. 83-108.

Downs, Anthony: Why the Government Budget Is Too Small in a Democracy, in: World Politics. A Quarterly Journal of International Relations, vol. XII (1959/60), S. 541-563.

Dreissig, Wilhelmine: Zur Entwicklung der öffentlichen Finanzwirtschaft seit dem Jahre 1950, in: Währung und Wirtschaft in Deutschland 1876-1975, hrsg. v. der Deutschen Bundesbank, Frankfurt/Main 1976, S. 691-744.

Dreissig, Wilhelmine: Zur kommunalen Haushaltsreform in der Bundesrepublik Deutschland, in: Wirtschaftswissenschaft als Grundlage staatlichen Handelns. Heinz Haller zum 65. Geburtstag, hrsg. v. Peter Bohley und Georg Tolkemitt, Tübingen 1979, S. 413-432. 
Dürr, Ernst: Wachstumspolitisch relevante Ergebnisse der Wachstumstheorie, in: Beiträge zur Wachstumspolitik, hrsg. v. Hans Karl Schneider, Schriften des Vereins für Socialpolitik, N.F. Bd. 55, Berlin 1970, S. 1-31.

Engels, Wolfram: Soziale Marktwirtschaft. Verschmähte Zukunft? Streitschrift wider falsche Propheten mit Bart und Computer, Stuttgart 1972.

Engels, Wolfram, Sablotny, Herbert und Zickler, Dieter: Das Volksvermögen. Seine verteilungs- und wohlstandspolitische Bedeutung, Frankfurt/Main 1974.

Ehrlicher, Werner: Öffentliche Sachausgaben, in: Handbuch der Finanzwissenschaft, 3. Aufl., hrsg. v. Fritz Neumark, Bd. I, Tübingen 1977, S. 753-795.

Ehrlicher, Werner und Hagemann, Reiner: Die öffentlichen Finanzen der Bundesrepublik im Jahre 1974, in: Finanzarchiv, hrsg. v. Norbert Andel und Fritz Neumark, N.F. Bd. 35 (1976/77), Tübingen 1977, S. 322-346.

Ehrlicher, Werner und Rohwer, Bernd: Die öffentlichen Finanzen der Bundesrepublik im Jahre 1975, in: Finanzarchiv, hrsg. v. Norbert Andel und Fritz Neumark, N.F. Bd. 36 (1977/78), Tübingen 1978, S. 485-512.

Ehrlicher, Werner und Leibinger, Hans-Bodo: Die öffentlichen Finanzen der Bundesrepublik im Jahre 1978, in: Finanzarchiv, hrsg. v. Norbert Andel und Fritz Neumark, N.F. Bd. 39, Tübingen 1981, S. 462-494.

Emmerich, Volker: Anmerkungen zu den Postfinanzen, in: ORDO. Jahrbuch für die Ordnung von Wirtschaft und Gesellschaft, Bd. 35 (1984), S. 43-69.

Engelmann, Margot und Mohr, Dietrich: Anlageinvestitionen nach Wirtschaftsbereichen, in: Wirtschaft und Statistik, Jg. 1978, S. 755-771.

Essig, Hartmut: Kommunalfinanzen 1950 bis 1980, in: Wirtschaft und Statistik, Jg. 1982, S. 29-37.

Essig, Hartmut: Erfassungs- und Auswertungsprogramm der Finanzstatistik, in: Wirtschaft und Statistik, Jg. 1984, S. 835-844.

Essig, Hartmut und Müller, Wolfgang: Darstellung des öffentlichen Krankenhausbereichs in der Finanzstatistik, in: Wirtschaft und Statistik, Jg. 1980, S.1420.

Fecher, Hans: Artikel: Ausgaben, öffentliche I: Ansätze zu ihrer Analyse, in: Handwörterbuch der Wirtschaftswissenschaft (HdWW), hrsg. v. Willi Albers et al., Bd. 1, Stuttgart et al. 1977, S. 334-349.

Fellmuth, Rainer: Staatsaufgaben im Spiegel politischer Ökonomie. Zum Verhältnis von Wirtschaft und Staatstätigkeit in Werken von Adam Smith und Adolph Wagner, München 1981.

Folkers, Cay: Artikel: Vermögen I: Struktur und Verteilung, in: Handwörterbuch der Wirtschaftswissenschaft (HdWW), hrsg. v. Willi Albers et al., Bd. 8, Stuttgart et al. 1980, S. 265-282. 
Franz, Alfred: Grundfragen der Statistik des öffentlichen Sektors, in: Wirtschaftspolitische Blätter, hrsg. v. der Bundeskammer der gewerblichen Wirtschaft(Wien), 27. Jg. (1980), H. 2, S. 91-108.

Freund, Elmar: Bemerkungen zu einer neuen Konzeption der Finanzstatistik, in: Allgemeines Statistisches Archiv. Organ der Deutschen Statistischen Gesellschaft, Bd. 54 (1970), S. 177-199.

Freund, Elmar: Die Neugestaltung der Finanzstatistik ab 1970, in: Wirtschaft und Statistik, Jg. 1970, S. 543-546.

Freund, Elmar: Haushaltsstatistik, in: Handbuch der Finanzwissenschaft, 3. Aufl., hrsg. v. Fritz Neumark, Bd. I, Tübingen 1977, S. 587-609.

Frey, René L.: Infrastruktur und Wirtschaftswachstum, in: Konjunkturpolitik, 15. Jg. (1969), S. 103 - 126.

Frey, René L.: Infrastruktur. Grundlagen der Planung öffentlicher Investitionen, 2. Aufl., Tübingen 1972.

Frey, René L.: Artikel: Infrastruktur, in: Handwörterbuch der Wirtschaftswissenschaft (HdWW), hrsg. v. Willi Albers et al., Bd. 4, Stuttgart et al. 1978, S. 200215.

Frey, René L.: Wachstumspolitik, Stuttgart, New York 1979.

Fricke, Eberhard: Haushaltskonsolidierung. Beobachtungen, Erfahrungen und Erkenntnisse aus zehnjähriger Praxis in einem Bundesland, in: Finanzarchiv, hrsg. v. Norbert Andel und Fritz Neumark, N.F. Bd. 43, Tübingen 1985, S. 385420 .

Friedman, Milton: Adam Smith's Relevance to Today, in: Challenge. The Magazine of Economic Affairs, vol. 20 (1977), S. 6-12.

Fuest, Winfried und Kroker, Rolf: Quantitative und qualitative Konsolidierung, Nr. 141 der Beiträge zur Wirtschafts- und Sozialpolitik, hrsg. v. Institut der deutschen Wirtschaft, Köln 1986.

Gaddum, Johann Wilhelm: Bevölkerungsentwicklung und öffentliche Investitionen, in: An den Grenzen der Belastbarkeit. Festschrift für Günter Schmölders zum 75. Geburtstag, hrsg. v. Willy Haubrichs, Frankfurt/Main 1978, S. 137-155.

Gahlen, Bernhard: Neue Wohlfahrtsmaßstäbe. Hemmnisse für eine höhere öffentliche Investitionsquote und Reform der marktwirtschaftlichen Ordnung, in: Investitionskontrolle gegen die Konzerne?, hrsg. v. M. Krüper, Reinbeck 1974, S.45-67.

Galbraith, John Kenneth: The Affluent Society, London 1958.

Gantner, Manfried: Meßprobleme öffentlicher Aktivitäten. Staatsquoten, Preissteigerungen, Outputkonzepte, Baden-Baden 1984. 
Gantner, Manfried: Gibt es in der repräsentativen Demokratie einen systematischen Hang zur Staatsverschuldung?, in: Das öffentliche Haushaltswesen, 25. Jg. (1984), S. 162-180.

Garvy, George: Keynes and the Economic Activists of Pre-Hitler Germany, in: Journal of Political Economy, vol. 83 (2), Chicago 1975, S. 391-405.

George, Henry: Progress and Poverty. An Inquiry into the Cause of Industrial Depressions and of Increase of Want with Increase of Wealth. The Remedy, New York 1904.

Gerloff, Wilhelm: Grundlegung der Finanzwissenschaft, in: Handbuch der Fi nanzwissenschaft, (2. Aufl.) hrsg. v. Wilhelm Gerloff und Fritz Neumark, Bd. I, Tübingen 1952, S. 1-65.

Gerloff Wilhelm und Meisel, Franz (Hrsg.): Handbuch der Finanzwissenschaft, 1. Aufl., jeweils erschienen in Tübingen, Bd. I, 1926; Bd. Il, 1927; Bd. III, 1929.

Gerloff, Wilhelm und Neumark, Fritz (Hrsg.): Handbuch der Finanzwissenschaft, 2. Aufl., jeweils erschienen in Tübingen, Bd. I, 1952; Bd. II, 1956; Bd. III, 1958; Bd. IV, 1965.

Graf, Gerhard: Artikel: Beschäftigungstheorie, in: Handwörterbuch der Wirtschaftswissenschaft (HdWW), hrsg. v. Willi Albers et al., Bd. 1, Stuttgart et al. 1977, S. 531-543.

Grossman, Herschel I.: Was Keynes a "Keynesian"? A Review Article, in: Journal of Economic Literature, vol. X (1972), S. 26-30.

Häuser, Karl: Abriß der geschichtlichen Entwicklung der öffentlichen Finanzwirtschaft, in: Handbuch der Finanzwissenschaft, 3. Aufl., hrsg. v. Fritz Neumark, Bd. I, Tübingen 1977, S. 3-51.

Hahn, Albert: Ewige Hochkonjunktur und kommandiertes Wachstum, Nr. 17 der Reihe: Vorträge und Aufsätze des Walter Eucken Instituts, Tübingen 1967.

Haller, Heinz: Einige Gedanken zum Thema: Öffentliche Finanzen im Wirtschaftswachstum, in: Wirtschaftskreislauf und Wirtschaftswachstum. Carl Föhl zum 65. Geburtstag, hrsg. v. Erich Schneider, Tübingen 1966, S. 57-74.

Hamer, Günter: Revidierte Konten der Volkswirtschaftlichen Gesamtrechnungen, in: Wirtschaft und Statistik, Jg. 1970, S. 281-288.

Hansmeyer, Karl-Heinrich: Transferzahlungen an Unternehmen (Subventionen), in: Handbuch der Finanzwissenschaft, 3. Aufl., hrsg. v. Fritz Neumark, Bd. I, Tübingen 1977, S. 959-996.

Hansmeyer, Karl-Heinrich: Ursachen des Wandels der Budgetpolitik, in: Budgetpolitik im Wandel, N.F. Bd. 149 der Schriften des Vereins für Socialpolitik, hrsg. v. Karl Häuser, Berlin 1986, S. 11-32.

Harrod, Roy Forbes: Artikel: Keynes, John Maynard, in: Handwörterbuch der Sozialwissenschaften (HdSW), hrsg. v. Erwin von Beckerath et al., 5. Bd., Stuttgart et al. 1956, S. 606-614. 
Harrod, Roy Forbes: The Life of John Maynard Keynes, New York 1966.

Hayek, Friedrich August: Full Employment at Any Price?, published by The Institute of Economic Affairs, London 1975.

Heckscher, Eli Filip: Der Merkantilismus. Autorisierte Übersetzung aus dem Schwedischen von Gerhard Mackenroth, Bd. I, Jena 1932.

Heiduk, Günter: Gewährleistet die Zunahme der Investitionen eine Erhöhung des gesamtwirtschaftlichen Wachstums?, in: Das Wirtschaftsstudium (Wisu), 8. Jg. (1979), S. 81-87.

Heilemann, Ullrich: Kritische Anmerkungen zu einer Simulationsstudie der Deutschen Bundesbank, in: Vierteljahreshefte zur Wirtschaftsforschung, hrsg. v. Deutschen Institut für Wirtschaftsforschung, Jg. 1983, S. 59-67.

Heinig, Kurt: Das Budget, 2. Bd. Das Budgetwesen, Tübingen 1951.

Heinig, Kurt: Die Sachausgaben im öffentlichen Haushalt, in: Handbuch der Finanzwissenschaft, 2. Aufl., hrsg. v. Wilhelm Gerloff und Fritz Neumark, Bd. II, Tübingen 1956, S. 143-160.

Heller, Walter et al.: Finanzpolitik im Dienste des Wirtschaftlichen Gleichgewichts, Veröffentlichung der OECD, Dezember 1968.

Helmstädter, Ernst: Artikel: Wachstumstheorie I: Überblick, in: Handwörterbuch der Wirtschaftswissenschaft (HdWW), hrsg. v. Willi Albers et al., Bd. 8, Stuttgart 1980, S. 475-492.

Helmstädter, Ernst: Die Investitionstheorie und der Zeitaspekt, in: Neuere Entwicklungen in der Investitionstheorie und -politik, hrsg. v. Gottfried Bombach, Bernhard Gahlen und Alfred E. Ott, Tübingen 1980, S. 181-204.

Helmstädter, Ernst: Die Geschichte der Nationalökonomie als Geschichte ihres Fortschritts, in: Geschichte der Nationalökonomie, hrsg. v. Otmar Issing, München 1984, S. 1-13.

Hengstschläger, Johannes: Das Budgetrecht des Bundes. Gegenwartsprobleme und Entwicklungstendenzen, Berlin 1977.

Herdzina, Klaus: Wirtschaftliches Wachstum, Strukturwandel und Wettbewerb, Berlin 1981.

Hesse, Günter: Staatsaufgaben. Zur Theorie der Legitimation und Identifikation staatlicher Aufgaben, Baden-Baden 1979.

Hicks, John R.: Mr. Keynes' Theory of Employment, in: The Economic Journal, vol. XLVI (1936), S. 238-253.

Hicks, John R.: Mr. Keynes and the "Classics": A Suggested Interpretation, in: Econometrica, vol. 5 (1937), S. 147-159. 
Höhnen, Wilfried: Das DGB-Investitionsprogramm zur Sicherung der Beschäftigung durch qualitatives Wachstum: Ansätze zur Konkretisierung seiner Schwerpunktbereiche, in: WSI-Mitteilungen. Zeitschrift des Wirtschafts- und Sozialwissenschaftlichen Instituts des Deutschen Gewerkschaftsbundes, 35. Jg. (1982), S.597-606.

Hohmann, Rainer: Wachstum und Reallokation. Ansatzpunkte zur Wachstumssteigerung durch Reallokation, Diss., Wuppertal 1984.

Hoffmann, Ulrich: Begriffe, Struktur und Wachstum der öffentlichen Investitionen, Heft 5 der Studien zur Finanzpolitik, hrsg. v. Ifo-Institut für Wirtschaftsforschung, München 1967.

Hübl, Lothar: Stichwort: Wirtschaftskreislauf und Gesamtwirtschaftliches Rechnungswesen, in: Vahlens Kompendium der Wirtschaftstheorie und Wirtschaftspolitik, Bd. 1, hrsg. v. Dieter Bender et al., 2. Aufl., München 1984, S. 48-83.

Humboldt, Wilhelm von: Ideen zu einem Versuch, die Grenzen der Wirksamkeit des Staates zur bestimmen, Stuttgart 1962

Hutchison, Terence W.: Economics and Economic Policy in Britain, 1946-1966. Some Aspects of Their Interrelations, London 1968.

Institut "Finanzen und Steuern" (Hrsg.): Entwicklung wesentlicher Daten der öffentlichen Finanzwirtschaft in der Bundesrepublik Deutschland von 1972-1982, Nr. 224, Bonn 1983.

Institut "Finanzen und Steuern" (Hrsg.): Die Haushalte der Flächenländer unter Konsolidierungszwang, Nr. 262, Bonn 1986.

Jacob, Herbert: Artikel: InvestitionenII: betriebswirtschaftliche, in: Handwörterbuch der Wirtschaftswissenschaft (HdWW), hrsg. v. Willi Albers et al., Bd. 4, Stuttgart et al. 1978, S. 254-275.

Jarchow, Hans-Joachim: Der Keynesianismus, in: Geschichte der Nationalökonomie, hrsg. v. Otmar Issing, München 1984, S. 147-163.

Jecht, Horst: Artikel: Finanzwissenschaft, in: Handwörterbuch der Sozialwissenschaft, hrsg. v. Erwin von Beckerath et al., 3. Bd., Stuttgart et al. 1961, S.707-722.

Jochimsen, Reimut: Theorie der Infrastruktur. Grundlagen der marktwirtschaftlichen Entwicklung, Tübingen 1966.

Johnson, Harry G.: The Keynesian Revolution and the Monetarist Counter-Revolution, in: The American Economic Review, vol. LXI (1971), S. 1-14.

Jürgensen, Harald: Bemerkungen zu Wachstums- und Verteilungseffekten privater und öffentlicher Investitionen, in: Wirtschaftskreislauf und Wirtschaftswachstum. Carl Föhl zum 65. Geburtstag, hrsg. v. Erich Schneider, Tübingen 1966, S. 75-99.

Keynes, John Maynard: The Balance of Payments of the United States, in: The Economic Journal, vol. LVI (1946), S. 172-187. 
Keynes, John Maynard: An Open Letter, in: Readings in Fiscal Policy, ed. by A Smithies and J.K. Butters, London 1955, S. 31-37.

Keynes, John Maynard: A Tract on Monetary Reform, in: The Collected Writings of John Maynard Keynes, vol. IV, ed. by The Royal Economic Society, London 1971.

Keynes, John Maynard: A Treatise on Money, in: The Collected Writings of John Maynard Keynes, vol. V and VI, ed. by The Royal Economic Society, London 1971.

Keynes, John Maynard: The Great Slump of 1930, in: The Collected Writings of John Maynard Keynes, vol. IX. Essays in Persuasion, ed. by The Royal Economic Society, London 1972, S. 126-134.

Keynes, John Maynard: The End of Laissez Faire, in: The Collected Writings of John Maynard Keynes, vol. IX. Essays in Persuasion, ed. by The Royal Economic Society, London 1972, S. 272-294.

Keynes, John Maynard: Am I A Liberal? in: The Collected Writings of John Maynard Keynes, vol. IX. Essays in Persuasion, ed. by The Royal Economic Society, London 1972, S. 295-306.

Keynes, John Maynard: Economic Possibilities for our Grandchildren, in: The Collected Writings of John Maynard Keynes, vol. IX. Essays in Persuasion, ed. by The Royal Economic Society, London 1972, S. 321-332.

Keynes, John Maynard: The Means to Prosperity, in: The Collected Writings of John Maynard Keynes, vol. IX. Essays in Persuasion, ed. by The Royal Economic Society, London 1972, S. 335-366

Keynes, John Maynard: The General Theory of Employment, Interest and Money, in: The Collected Writings of John Maynard Keynes, vol. VII, ed. by The Royal Economic Society, London 1973.

Keynes, John Maynard: The Macmillan Committee, in: The Collected Writings of John Maynard Keynes, vol. XX. Activities 1929-1931. Rethinking Employment and Unemployment Policies, ed. by The Royal Economic Society, London 1981, S. 38-311.

Kirchgässner, Gebhard: Causality testing of the popularity function: An empirical investigation of the Federal Republic of Germany, 1971-1982, in: Public Choice, vol. 45 (1985), S. 155-173.

Kitterer, Wolfgang: Das moderne Budget. Eine vergleichende Analyse der zentralen Staatshaushalte Frankreichs und der BRD, Frankfurt/Main, Bern 1976.

Kitterer, Wolfgang: Öffentlicher Haushalt und öffentliche Unternehmen: Planungs- und Organisationsaspekte der intermediären Erfüllung öffentlicher Aufgaben, in: Konkrete Probleme öffentlicher Planung. Grundlegende Aspekte der Zielbildung, Effizienz und Kontrolle, hrsg. v. Eberhard Wille, Frankfurt/Main et al. 1986, S. 143-179. 
Klaas, Hermann: Aufgaben der funktionalen Haushaltsgliederung im Rahmen des Funktionenplanes, in: Der öffentliche Haushalt - Archiv für Finanzkontrolle, Jg. $10(1969 / 70)$, S. 150-158.

Klein, Ernst: Die englischen Wirtschaftstheoretiker des 17. Jahrhunderts, Darmstadt 1973.

Klein, Marianne: Deflationierung der staatlichen Leistungen und Preisentwicklungen im öffentlichen Sektor, in: Konzeptionelle Probleme öffentlicher Planung, hrsg. v. Eberhard Wille, Frankfurt/Main et al. 1983, S. 85-126.

Koch, Woldemar: Artikel: Finanzwissenschaft I: Geschichte, in: Handwörterbuch der Wirtschaftswissenschaft (HdWW), hrsg. v. Willi Albers et al., Bd. 3, Stuttgart et al. 1981, S. 212-234.

Kohl, Horst (Hrsg.): Die Reden des Fürsten Bismarck, 12. Bd. 1886-1890, Stuttgart 1894.

Kolms, Heinz: Finanzwissenschaft, Bd. 1, 4. Aufl , Berlin, New York 1974.

Kolms, Heinz: Artikel: Finanzwirtschaft, öffentliche IV: Geschichte, in: Handwörterbuch der Wirtschaftswissenschaft (HdWW), hrsg. v. Willi Albers et al., Bd. 9, Stuttgart et al. 1982, S. 764-782.

Kopsch, Günter: Ausgaben des Staates nach Aufgabenbereichen in den Volkswirtschaftlichen Gesamtrechnungen, in: Wirtschaft und Statistik, Jg. 1980, S.155-169.

Kopsch, Günter: Der Staat in den Volkswirtschaftlichen Gesamtrechnungen von 1960 bis 1982, in: Wirtschaft und Statistik, Jg. 1983, S. 749-769.

Kopsch, Günter: Staatsverbrauch nach dem Ausgaben- und dem Verbrauchskonzept, in: Wirtschaft und Statistik, Jg. 1984, S. 297-303.

Koulis, Johannes: Die öffentlichen Ausgaben als volkswirtschaftliche Erscheinung, Frankfurt/Main 1948.

Kramp, Hellmuth: Systematik des öffentlichen Haushalts. Gruppierungsplan (mit Buchungshinweisen und Erläuterungen) und Funktionenplan, Hamburg 1972.

Krelle, Wilhelm: Dynamisierung der Nutzenfunktion, in: Zeitschrift für Nationalökonomie (Journal of Economics), Bd. 32 (1972), S. 59-70.

Kromphardt, Jürgen: Artikel: Investitionen I: volkswirtschaftliche, in: Handwörterbuch der Wirtschaftswissenschaft (HdWW), hrsg. v. Willi Albers et al., Bd. 4, Stuttgart et al 1978, S. 246-254.

Krüsselberg, Hans-Günter: Property Rights-Theorie und Wohlfahrtsökonomik, in: Property Rights und ökonomische Theorie, hrsg. v. Alfred Schüller, München 1983, S. 45-77.

Krumsieck, Rolf; Lenz, Dieter und Wimmer, Siegmund: Kommunaler Investitionsbedarf 1971 bis 1980 , Köln 1967. 
Kullmer, Lore: Kriterien der Abgrenzung öffentlicher Ausgaben, in: Beiträge zur Theorie der öffentlichen Ausgaben, hrsg. v. Herbert Timm und Heinz Haller, Schriften des Vereins für Socialpolitik, N.F. Bd. 47, Berlin 1967, S. 9-35.

Kupka, Günter: Methoden der Berechnung der Anlageinvestitionen in den Volkswirtschaftlichen Gesamtrechnungen, in: Wirtschaft und Statistik, Jg. 1977, S.757-763.

Láhnstein, Manfred:Haushaltsgesetz 1983 vor dem Deutschen Bundestag. Einbringungsrede des Bundesministers der Finanzen: in: Bulletin, hrsg. v. Presseund Informationsamt der Bundesregierung, Nr. 85, Bonn 16. September 1982, S.773-784.

Landmann, Oliver: Keynes in der heutigen Wirtschaftstheorie, in: Der Keynesianismus, Bd. I. Theorie und Praxis keynesianischer Wirtschaftspolitik, hrsg. v. Gottfried Bombach et al., Berlin, Heidelberg, New York 1976, S. 133-210.

Lasalle, Ferdinand: Das Arbeiterprogramm. Über den besonderen Zusammenhang der gegenwärtigen Geschichtsperiode mit der Idee des Arbeiterstandes, in: Ferdinand Lasalle. Gesammelte Reden und Schriften, hrsg. v. E. Bernstein, 2. Bd., Berlin 1919, S. 131-202.

Lauener, Henri: Französische Aufklärer, in: Klassiker der Philosophie, hrsg. v. Ottfried Höffe, Bd. 1. Von den Vorsoleratikern bis David Hume, München 1981, S. 405-433.

Leetz, Wolf: Imposanter Anstieg der Investitionen, in: Öffentliche Wirtschaft und Gemeinwirtschaft (ÖWG), Jg. XXXIII (1984), H. 3, S. 76-78.

Leibfritz, Willi: Der Staat als Investor. Ein Überblick über die öffentliche Investitionstätigkeit und die Entwicklung des Infrastrukturbestandes in der Bundesrepublik, in: Ifo-Studien. Zeitschrift für empirische Wirtschaftsforschung, 26. Jg. (1980), S. 123-171.

Leibfritz, Willi: Staatliche Investitionsförderung - Ansatzpunkte der verschiede nen Instrumente und Möglichkeiten der Beurteilung, in: Neuere Entwicklungen in der Investitionstheorie und -politik, hrsg. v. Gottfried Bombach, Bernhard Gahlen und Alfred E. Ott, Tübingen 1980, S. 477-517.

Leibfritz, Willi: Mehr staatliche Investitionen zum Abbau der Arbeitslosigkeit? Ein Beitrag zu der aktuellen Diskussion vor dem Hintergrund einer längerfristigen Analyse der staatlichen Investitionstätigkeit, in: Ifo-Schnelldienst, 36. Jg. (1983), Nr. 3, S. 3-14.

Leijonhufuud, Axel: On Keynesian Economics and the Economics of Keynes. A Study in Monetary Theory, New York 1968.

Leipold, Helmut: Theorie der Property Rights: Forschungsziele und Anwendungsbereiche, in: Wirtschaftswissenschaftliches Studium (WiSt), 7. Jg. (1978), S. 518 525. 
Lenk, Reinhard und Lang, Eva: Herstellungskosten und Folgelasten öffentlicher Investitionen. Gutachten im Auftrag des Finanzministeriumns des Landes Nordrhein-Westfalen, München 1981.

Lerner, Abba P.: The Economics of Control. Principles of Welfare Economics, New York 1949.

Lerner, Abba P.: Functional Finance and the Federal Debt, in: Readings in Macroeconomics, ed. by M.G. Mueller, 2nd ed., London et al. 1971, S. 353-360.

Liefmann-Keil, Elisabeth: Zur Entwicklung der Theorie der Bewilligung öffentlicher Einnahmen und Ausgaben, in: Finanzarchiv, N.F. Bd. 19 (1958/59), Tübingen 1959 , S. 219-239.

Littmann, Konrad: Zunehmende Staatstätigkeit und wirtschaftliche Entwicklung. Versuche über die Wirkungen staatswirtschaftlicher Prozesse in der spätkapitalistischen Periode, Köln, Opladen 1957.

Littmann, Konrad: Über einige Probleme einer Wirkungslehre öffentlicher Aus gaben, in: Beiträge zur Theorie der öffentlichen Ausgaben, hrsg. v. Herbert Timm und Heinz Haller, Schriften des Vereins for Socialpolitik, N.F. Bd. 47, Berlin 1967, S. 277-298.

Littmann, Konrad: Definition und Entwicklung der Staatsquote. Abgrenzung, Aussagekraft und Anwendungsbereiche unterschiedlicher Typen von Staatsquoten, Göttingen 1975.

Littmann, Konrad: Artikel: Ausgaben, öffentliche II: Die "Gesetze" ihrer langfristigen Entwicklung, in: Handwörterbuch der Wirtschaftswissenschaft (HdWW), hrsg. v. Willi Albers et al., Bd. 1, Stuttgart et al. 1977, S. 349-363.

Littmann, Konrad: Problemstellung und Methoden der heutigen Finanzwissenschaft, in: Handbuch der Finanzwissenschaft, 3. Aufl., hrsg. v. Fritz Neumark, Bd. I, Tübingen 1977, S. 99-120.

Littmann, Konrad: Artikel: Öffentliche Investitionen, in: Handwörterbuch der Wirtschaftswissenschaft (HdWW), hrsg. v. Willi Albers et al., Bd. 9, Stuttgart et al. 1982, S. 812-825.

Littmann, Konrad: Wirtschaftswachstum, Konjunktur und öffentliche Finanzen, in: Finanzpolitik im Umbruch: Zur Konsolidierung öffentlicher Haushalte, hrsg. v. Hans Herbert v. Arnim und Konrad Littmann, Berlin 1984, S. 31-50.

Lützel, Heinrich: Ansätze zur Weiterentwicklung der Volkswirtschaftlichen Gesamtrechnungen, 5. Abschnitt des Artikels: Weiterentwicklung und Revision der Volkswirtschaftlichen Gesamtrechnungen, in: Wirtschaft und Statistik, Jg. 1985, S. 107-109.

Lützel, Heinrich: Revision der Volkswirtschaftlichen Gesamtrechnungen, in: Wirtschaft und Statistik, Jg. 1985, S. 603-617.

Mäding, Erhard: Aufgaben der öffentlichen Verwaltung, in: Die Verwaltung. Zeitschrift für Verwaltungswissenschaft, hrsg., v. Ernst Forsthoff, Bd. 6, Berlin 1973, S. 257-282. 
Mann, Fritz Karl: Die Staatswirtschaft unserer Zeit. Eine Einführung, Jena 1930.

Mann, Fritz Karl: Geschichte der angelsächsischen Finanzwissenschaft, in: Handbuch der Finanzwissenschaft, 2. Aufl., hrsg. v. Wilhelm Gerloff und Fritz Neumark, Bd. I, Tübingen 1952, S. 469-488.

Mann, Fritz Karl: Volkswirtschaftliche Analyse und Institutionalismus in der Finanzwissenschaft, in: Finanzarchiv, hrsg. v. Fritz Neumark, N.F. Bd. 17 (1956/57), Tübingen 1957, S. 451-467.

Mann, Fritz Karl: Abriß einer Geschichte der Finanzwissenschaft, in: Handbuch der Finanzwissenschaft, 3. Aufl., hrsg. v. Fritz Neumark, Bd. I, Tübingen 1977, S. 77-98.

Matthöfer, Hans: Bundesfinanzminister Hans Matthöfer zu den Beratungen über den Bundeshaushalt 1982, BMF-Dokumentation 9/81, Bonn 1981.

Meier, Alfred: Artikel: Öffentliches Vermögen II: Umfang und Struktur, in: Handwörterbuch der Wirtschaftswissenschaft (HdWW), hrsg. v. Willi Albers et al., Bd. 5, Stuttgart et al. 1980, S. 623-633.

Meinhold, Helmut: Artikel: Investitionen, in: Handwörterbuch der Sozialwissenschaften (HdSW), hrsg. v. Erwin von Beckerath et al., 5. Bd., Stuttgart et al. 1956, S. 333-346.

Meisel, Franz: Stand und Wert der deutschen Finanzwissenschaft, in: Schmollers Jahrbuch für Gesetzgebung, Verwaltung und Volkswirtschaft im Deutschen Reich, hrsg. v. Hermann Schumacher und Artur Spiethoff, 42. Jg., München 1918, S. 1147-1194.

Meisel, Franz: Wo steht die deutsche Finanzwissenschaft?, in: Zeitschrift für die gesamte Staatswissenschaft, hrsg. v. Karl Bücher, 75. Jg. (1920), Tübingen 1921, S. 54-131.

Mengert, Friedrich; Kunert, Christa und Rehm, Johann: Kommunalhaushalt in Schlagworten. Systematische Darstellung der Haushaltsgliederung und -gruppierung mit einem Schlagwortkatalog und Erläuterungen zur Finanzstatistik, 4. Aufl., Köln 1983.

Meyer, Albert: Die öffentlichen Haushalte zwischen Konsum und Investition, in: Folgekosten öffentlicher Investitionen - Eine Last für die Zukunft?, hrsg. v. Hans Gerhard Stockinger, München 1982, S. 11-18.

Meyer, Fritz W.: Glanz und Elend der Vollbeschäftigungspolitik, in: Grundtexte zur Sozialen Marktwirtschaft. Zeugnisse aus zweihundert Jahren ordnungspolitischer Diskussion, hrsg. v. Wolfgang Stützel et al., Stuttgart, New York 1981, S. 233-246.

Mill, John Stuart: Grundsätze der politischen Ökonomie mit einigen ihrer Anwendungen auf die Sozialphilosophie. Nach der Ausgabe letzter Hand (7. Auflage 1871) übersetzt von Wilhelm Gehrig, Bd. 2, Jena 1921. 
Mill, John Stuart: Grundsätze der politischen Ökonomie mit einigen ihrer Anwendungen auf die Sozialphilosophie. Nach der Ausgabe letzter Hand (7. Auflage 1871) übersetzt von Wilhelm Gehrig, Bd. 1, 2. Aufl., Jena 1924.

Mill, John Stuart: Autobiographie. With an Appendix of hitherto unpublished Speeches and a Preface by Harold J. Lasky, London 1924.

Ministerium der Finanzen Rheinland-Pfalz: Folgekosten öffentlicher Investitionen, Bad Ems 1975.

Mitschke, Joachim: Über die Eignung von Einkommmen, Konsum und Vermögen als Bemessungsgrundlagen der direkten Besteuerung. Eine meßtechnische Analyse, Berlin 1976.

Molitor, Bruno: "Gesellschaft im Überfluß". Bemerkungen zu einer Studie von J.K. Galbraith, in: Hamburger Jahrbuch für Wirtschafts- und Gesellschaftspolitik, 4. Jg. (1959), S. 188-200.

Molitor, Bruno: Öffentliche Armut - Privater Reichtum, in: ORDO. Jahrbuch für die Ordnung von Wirtschaft und Gesellschaft, Bd. 24 (1973), S. 141-156.

Mons, Wilhelm und Fuchs, Karl Wilhelm: Gruppierungsplan des Bundeshaushaltes, Loseblattsammlung, Stand: 19. Ergänzungslieferung vom 1. Januar 1987.

Montaner, Antonio: Der Institutionalismus als Epoche amerikanischer Geistesgeschichte, Tübingen 1948.

Münch, Ingo von: Grundgesetz-Kommentar, 2. Aufl., Bd. 2: Artikel 21 bis Artikel 69 sowie Bd. 3: Artikel 70 bis Artikel 146 und Gesamtregister, München 1983.

Müller, Karl-Wilhelm und Ströbele, Wolfgang: Wachstumstheorie, München, Wien 1985.

Müssiggang, Albert: Die soziale Frage in der historischen Schule der deutschen Nationalökonomie, Tübingen 1968.

Musgrave, Richard A.: A Multiple Theory of Budget Determination, in: Finanzarchiv, N.F. Bd. 17 (1956/57), Tübingen 1957, S. 333-343.

Musgrave, Richard A.: The Theory of Public Finance. A Study in Public Economy, New York et al. 1959.

Musgrave, Richard A.: Finanztheorie. Studienausgabe, Tübingen 1974.

Musgrave, Richard A.; Musgrave, Peggy B. und Kullmer, Lore: Die öffentlichen Finanzen in Theorie und Praxis, Bd. 3, Tübingen 1977.

Musgrave, Richard A.: Public Finance, now and then, in: Finanzarchiv, N.F. Bd.41, Tübingen 1983, S. 1-13.

Musgrave, Richard A.: Public Finance in Theory and Practice. 4th ed., New York et al. 1984. 
Neldner, Manfred: Investitionsorientierte Wachstumspolitik, in: Das Wirtschaftsstudium (Wisu), 9. Jg. (1980), S. 84-90.

Neumann, Manfred: Artikel: Wachstumspolitik, in: Handwörterbuch der Wirtschaftswissenschaft (HdWW), hrsg. v. Willi Albers et al., Bd. 8, Stuttgart et al. 1980, S. $462-475$.

Neumark, Fritz: Grundsätze und Arten der Haushaltsführung und Finanzbedarfsdeckung, in: Handbuch der Finanzwissenschaft, 2. Aufl., hrsg. v. Wilhelm Gerloff und Fritz Neumark, Bd. I, Tübingen 1952, S. 606-669.

Neumark, Fritz (Hrsg.): Handbuch der Finanzwissenschaft, 3. Aufl., jeweils erschienen in Tübingen, Bd. I, 1977; Bd. II, 1980; Bd. III, 1981; Bd. IV, 1983.

Neumark, Fritz: Hundert Jahre "Finanzarchiv", in: Finanzarchiv, hrsg. v. Norbert Andel und Fritz Neumark, N.F. Bd. 42, Tübingen 1984, S. 385-406.

Ott, Alfred, $E .$. Investitionseffekte, in: Neuere Entwicklungen in der Investitionstheorie und -politik, hrsg. v. Gottfried Bombach, Bernhard Gahlen und Alfred E. Ott, Tübingen 1980, S. 299-316.

Ottmann, Henning: Individuum und Gemeinschaft bei Hegel, Bd. 1. Hegel im Spiegel der Interpretationen, Berlin, New York 1977.

Palm, Thomas and Quayum, Abdul: Private und public investment analysis, Cicinnati (USA) et al. 1985.

Patzig, Werner: Haushaltsrecht des Bundes und der Länder, Bd. I. Grundriß, Ba den-Baden 1981.

Patzig, Werner: Haushaltsrecht des Bundes und der Länder, Bd. II. Kommentar zu den Rechts- und Verwaltungsvorschriften, Fortsetzungswerk in Loseblattform, Stand 6. Jg., 6. Lieferung, Baden-Baden 1987.

Paulsen, Andreas und Schilcher, Rudolf: Allgemeine Volkswirtschaftslehre I. Grundlegung, Wirtschaftskreislauf, 10. Aufl., Berlin, New York 1974.

Peacock, Alan Turner and Wiseman, Jack: The Growth of Public Expenditure in the United Kingdom, London 1961.

Peters, Albert: Ökonomische Kriterien für eine Aufgabenverteilung in der Marktwirtschaft. Eine deskriptive und normative Betrachtung für den Allokationsbereich, Frankfurt/Main 1985.

Piduch, Erwin Adolf: Haushaltsreform in der Diskussion, in: Der Gemeindehaushalt, 70. Jg. (1969), S. 121-129.

Piduch, Erwin Adolf: Bundeshaushaltsrecht, Bd. I, Loseblattsammlung, Stand 12. Lieferung, Stuttgart et al. 1977.

Piduch, Erwin Adolf: Bundeshaushaltsrecht, Bd. II, Loseblattsammlung, Stand 12. Lieferung, Stuttgart et al. 1977.

Pigou, Arthur Cecil: A Study in Public Finance, London 1928. 
Pigou, Arthur Cecil: A Study in Public Finance, 3rd ed., London 1947, reprinted London 1951.

Preiser, Erich: Probleme der Wohlstandsgesellschaft, hrsg. v. der Bayerischen Akademie der Wissenschaften. Philosophisch-Historische Klasse, Sitzungsberichte Jg. 1964, Heft 7, S. 3-25.

Presse- und Informationsamt der Bundesregierung (Hrsg.): Abwicklung des Programms für Zukunftsinvestitionen (ZIP), in: Aktuelle Beiträge zur Wirtschaftsund Finanzpolitik, Nr. 55/1980, Bonn, den 25. August 1980.

Presse- und Informationsamt der Bundesregierung (Hrsg.): Bericht über die Sitzung des Verwaltungsrates der Deutschen Bundespost vom 5. Dezember 1986, Bulletin Nr. 156, 11. Dezember 1986.

Rall, Lothar und Wied-Nebbeling, Sabine: Ausmaß, Ursachen und Wirkungen der Investitionslücke in der Bundesrepublik Deutschland. Gutachten im Auftrag des Bundesministers für Wirtschaft, Tübingen 1980.

Rau, Karl-Heinrich: Lehrbuch der politischen Ökonomie, Bd. III, 1. Abtheilung. Grundsätze der Finanzwissenschaft, 3. Aufl., Leipzig, Heidelberg 1855.

Recktenwald, Horst Claus: Umfang und Struktur der öffentlichen Ausgaben in säkularer Entwicklung, in: Handbuch der Finanzwissenschaft, 3. Aufl., hrsg. v. Fritz Neumark, Bd. I, Tübingen 1977, S. 713-752.

Recktenwald, Horst Claus: Die Klassik der ökonomischen Wissenschaft, in: Geschichte der Nationalökonomie, hrsg. v. Otmar Issing, München 1984, S. 49-71.

Recktenwald, Horst Claus (Hrsg.): Ethik, Wirtschaft und Staat. Adam Smiths Politische Ökonomie heute, Darmstadt 1985.

Recktenwald, Horst Claus: Eine Adam-Smith-Renaissance anno 1976? Eine Neubeurteilung seiner Originalität und Gelehrsamkeit, in: Ethik, Wirtschaft und Staat. Adam Smiths Politische Ökonomie heute, hrsg. v. Horst Claus Recktenwald, Darmstadt 1985, S. 345-390.

Rehm, Hannes: Analyse und Kritik der Bundeshaushaltsreform, Baden-Baden 1975.

Reidenbach, Michael: Zur Investitionstätigkeit der kommunalen Gebietskörperschaften, Zweckverbände und Unternehmen, in: Archiv für Kommunalwissenschaften, 19. Jg. (1980), S. 217-231.

Reimann, Brigitte: Erstes Gesetz zur Änderung statistischer Rechtsvorschriften in Kraft getreten, in: Wirtschaft und Statistik, Jg. 1980, S. 433-436.

Reinermann, Heinrich: Programmbudgets in Regierung und Verwaltung. Möglichkeiten und Grenzen von Planungs- und Entscheidungssystemen, Baden-Baden 1975. 
Rheinisch-Westfälisches Institut für Wirtschaftsforschung (RWI): Analyse der strukturellen Entwicklung der deutschen Wirtschaft (Strukturberichterstattung 1987), Bd. 3 (Schwerpunktthema): Die Auswirkungen staatlicher Marktregulierungen auf die sektorale Strukturbildung und Faktorallokation - Möglichkeiten und Auswirkungen von Deregulierungen in einzelnen Wirtschaftszweigen, Essen 1986.

Ricardo, David: Grundsätze der Volkswirtschaftslehre und Besteuerung, aus dem englischen Original (3. Aufl. 1821) ins Deutsche übertragen von O. Thiele, Jena 1905.

Richter, Rudolf, Schlieper, Ulrich und Friedmann, Willy: Makroökonomik. Eine Einführung, 4. Aufl., Berlin, Heidelberg, New York 1981.

Riha, Thomas: German Political Economy: The History of an Alternative Economics, Bradford 1985.

Ring, Ulrich: Öffentliche Planungsziele und Staatliche Budgets. Zur Erfüllung öffentlicher Aufgaben durch nicht-staatliche Entscheidungseinheiten, Frankfurt/Main 1985.

Rittig, Gisbert: Öffentliche Güter, öffentliche Unternehmungen und die oeconomia publica, in: Öffentliche Güter und öffentliche Unternehmen. Beiträge zur Relevanz der Theorie der öffentlichen Güter für die öffentlichen Unternehmen, hrsg. v. Karl Oettle, Baden-Baden 1984, S. 15-57.

Röpke, Wilhelm: Was lehrt uns Keynes? Die Revolution in der Nationalökonomie, in: Universitas, 7. Jg. (1952), S. 1285-1295.

Röpke, Wilhelm: Gegen die Brandung. Zeugnisse eines Gelehrtenlebens unserer Zeit, hrsg. v. A. Hunold, Zürich 1959.

Rose, Stephen: On Classifying State Expenditure, in: The Review of Radical Political Economics, New York 1977, S. 31-42.

Rürup, Bert: Öffentliche Armut bei privatem Reichtum? - Die falsche Frage-, in: Steuer und Wirtschaft. Zeitschrift für die gesamte Steuerwissenschaft, 50 . Jg. (1973), S. 250-257.

Rürup, Bert: Methoden und Kriterien der Investitionsentscheidungen in der öffentlichen Verwaltung,in: Investition. Erklärung und Planung durch Simulation, hrsg. v. Franz Xaver Bea, Armin Bohnet und Herbert Klimesch, München, Wien 1981, S. 137-154.

Sachverständigenrat zur Begutachtung der Gesamtwirtschaftlichen Entwicklung: Währung, Geldwert, Wettbewerb. Entscheidung für morgen. Jahresgutachten 1971/72, Stuttgart, Mainz 1971.

Sachverständigenrat zur Begutachtung der Gesamtwirtschaftlichen Entwicklung: Zur wirtschaftlichen Lage im Oktober 1982, Sondergutachten, BT-Drucksache 9/2027, Bonn 12. 10.1982.

Sachverständigenrat zur Begutachtung der Gesamtwirtschaftlichen Entwicklung: Ein Schritt voraus. Jahresgutachten 1983/84, Stuttgart, Mainz 1983. 
Sachverständigenrat zur Begutachtung der Gesamtwirtschaftlichen Entwicklung: Chancen für einen langen Aufschwung. Jahresgutachten 1984/85, Stuttgart, Mainz 1984.

Sachverständigenrat zur Begutachtung der Gesamtwirtschaftlichen Entwicklung: Auf dem Weg zu mehr Beschäftigung. Jahresgutachten 1985/86, Stuttgart, Mainz 1985.

Samuelson, Paul Anthony: Economics, 11th ed., New York 1980.

Say, Jean Baptiste: A Treatise on Political Economy, translated from the fourth Edition of French by C.R. Prinsep, reproduction of 1880 printing, New York 1964.

Schäfer, Claus: Beschäftigungssichernde Finanzpolitik. Was sie ist und was sie kann. Eine Einführung und Zusammenfassung, in: Beschäftigungssichernde Finanzpolitik. Eine Chance für Vollbeschäftigung, hrsg. v. Claus Schäfer und Hartmut Tofaute, Frankfurt/Main, New York 1981, S. 11-34.

Schäfer, Dieter und Schmidt, Liane: Abschreibungen nach verschiedenen Bewertungs- und Berechnungsmethoden, in: Wirtschaft und Statistik, Jg. 1983, S. 919931.

Schiller, Karl: Konjunkturpolitik auf dem Wege zu einer Affluent Society. Vortrag im Institut für Weltwirtschaft an der Universität Kiel am 26. Januar 1968, Kieler Vorträge, N.F. Nr. 54, Kiel 1968.

Schlecht, Otto: Wirtschaftswachstum wozu, wie, womit?, Nr. 79 der Reihe: Vorträge und Aufsätze des Walter Eucken Instituts, Tübingen 1980.

Schlecht, Otto: "Konjunkturpolitik in der Krise", Nr. 94 der Reihe: Vorträge und Aufsätze des Walter Eucken Instituts, Tübingen 1983.

Schlecht, Otto: Ethische Betrachtungen zur Sozialen Marktwirtschaft, Nr. 97 der Reihe: Vorträge und Aufsätze des Walter Eucken Instituts, Tübingen 1983.

Schlieper, Ulrich: Der Keynesianismus als wirtschaftspolitische Doktrin, in: Perspektiven der deutschen Wirtschaftspolitik, hrsg. v. Horst Siebert, Stuttgart 1983, S. 79-84.

Schmidt, Klaus-Dieter: Was ist Vermögen?, in: Allgemeines Statistisches Archiv. Organ der Deutschen Statistischen Gesellschaft, 56. Bd., Göttingen 1972.

Schmidt, Klaus-Dieter et al.: Im Anpassungsprozeß zurückgeworfen. Die deutsche Wirtschaft vor neuen Herausforderungen. Tübingen 1984.

Schmidt, Kurt: Kollektivbedürfnisse und Staatstätigkeit, in: Theorie und Praxis des finanzpolitischen Interventionismus. Fritz Neumark zum 70. Geburtstag, hrsg. v. Heinz Haller et al., Tübingen 1970, S. 3-27.

Schmidt, Kurt: Vorbemerkungen zum Stichwort Finanzwissenschaft, in: Handwörterbuch der Wirtschaftswissenschaft (HdWW), hrsg. v. Willi Albers et al., Bd. 3, Stuttgart et al. 1981, S. 211-212.

Schmölders, Günter: Geschichte der Volkswirtschaftslehre, Wiesbaden 1961. 
Schmölders, Günter: Politische und institutionelle Probleme der Budgetgliederung, in: Probleme des öffentlichen Budgets, hrsg. v. Horst Jecht, Schriften des Vereins für Socialpolitik, N.F. Bd. 31, Berlin 1964, S. 65-72.

Schmölders, Günter: Artikel: Wirtschaftswissenschaft III: Theorienbildung in der Volkswirtschaftslehre, Geschichte, in: Handwörterbuch der Wirtschaftswissenschaft (HdWW), hrsg. v. Willi Albers et al., Bd. 9, Stuttgart et al. 1982, S.425-446.

Schmölders, Günter: Historische Schule, in: Geschichte der Nationalökonomie, hrsg. v. Otmar Issing, München 1984, S. 107-119.

Schneider, Erich: Der Streit um Keynes. Dichtung und Wahrheit in der neueren Keynes-Diskussion, in: Jahrbücher für Nationalökonomie und Statistik, Bd. 165 (1953), S. 89-122.

Schneider, Hans Karl: Wirtschaftspolitisch relevante Ergebnisse der Wachstumstheorie, in: Beiträge zur Wachstumspolitik, hrsg. v. Hans Karl Schneider, Schriften des Vereins für Socialpolitik, N.F. Bd. 55, Berlin 1970, S. 32-49.

Schneider, Hans Karl: Ist der Keynesianismus ein taugliches Konzept zur Überwindung der Arbeitslosigkeit?, in: Perspektiven der deutschen Wirtschaftspolitik, hrsg. v. Horst Siebert, Stuttgart 1983, S. 67-78.

Schörry, Otto: Artikel: Investitionsstatistik, in: Handwörterbuch der Sozialwissenschaften (HdSW), hrsg. v. Erwin von Beckerath et al., 5. Bd., Stuttgart et al. 1956, S. 347-354.

Schulz, Frank: Die Vorschläge von Georg von Schanz zur antizyklischen Finanzpolitik in der Tradition der öffentlichen Arbeitsbeschaffung. Ein Beitrag zur Dog mengeschichte der "functional finance", in: Finanzarchiv, hrsg. v. Norbert Andel und Fritz Neumark, N.F. Bd. 42, Tübingen 1984, S. 542-552.

Schumann, Jochen: Gesellschaft im Überfluß, in: Finanzarchiv, hrsg. v. Fritz Neumark, N.F. Bd. 20 (1959/60), Tübingen 1960, S. 473-481.

Schumann, Jochen: Der Wegbereiter der modernen Preis- und Kostentheorie, in: Geschichte der Nationalökonomie, hrsg. v. Otmar Issing, München 1984, S.121146.

Schumpeter, Joseph Alois: Geschichte der ökonomischen Analyse, 2 Bände, Göttingen 1965.

Schwarting, Gunnar: Kommunale Investitionen. Theoretische und empirische Untersuchung der Bestimmungsgründe kommunaler Investitionstätigkeit in Nordrhein-Westfalen 1965-1972, Frankfurt/Main 1979.

Schwarting, Gunnar: Positive Theorien der Staatsausgaben: Ein kritischer Überblick, in: Schweizerische Zeitschrift für Volkswirtschaft und Statistik, 116. Jg. (1980), S. 67-92.

Schwarting, Gunnar: Folgelasten und öffentliche Investitionsprogramme. Zum Einsatz von Folgelastendarstellungen als Planungsinstrument, in: Konkrete Pro- 
bleme öffentlicher Planung. Grundlegende Aspekte der Zielbildung, Effizienz und Kontrolle, hrsg. v. Eberhard Wille, Frankfurt/Main et al. 1986, S. 181-201.

Seelbach, Horst: Investition, in: Allgemeine Betriebswirtschaftslehre, hrsg. v. Franz Xaver Bea, Erwin Dichtl und Marcell Schweitzer, Bd. 3: Leistungsprozeß, Stuttgart, New York 1985, 4. Kapitel, S. 151-211.

Shoup, Carl S.: Public Finance, Chicago 1969.

Siebert, Horst (Hrsg.): Perspektiven der deutschen Wirtschaftspolitik, Stuttgart 1983.

Siebke, Jürgen: Stichwort: Verteilung, in: Vahlens Kompendium der Wirtschaftstheorie und Wirtschaftspolitik, Bd. 1, hrsg. v. Dieter Bender et al., 2. Aufl., München 1984, S. 366-399.

Skinner, Andrew: Adam Smith: Some Functions and Limitations of Government, in: Staat und Politische Ökonomie heute. Horst Claus Recktenwald zum 65 . Geburtstag, hrsg. v. Horst Hanusch, Karl W. Roskamp und Jack Wiseman, Stuttgart, New York 1985, S. 3-11.

Smekal, Christian: Die Flucht aus dem Budget, Wien 1977.

Smith, Adam: An Inquiry into the Nature and Causes of the Wealth of Nations, ed. by R.H. Campbell and A.S. Skinner, Textual Editor W.B. Todd, Oxford 1976. Diese Ausgabe erschien als Band II der "Glasgow Edition of the Works and Correspondence of Adam Smith".

Socher, Karl und Lehner, Gerhard: Einführung, in: Ausgabenintensität öffentlicher Aufgaben, hrsg. v. Institut für Angewandte Sozial- und Wirtschaftsforschung, Wien 1982, S. 1-7.

Spiethoff, Arthur: Artikel: Krisen, in: Handwörterbuch der Staatswissenschaften, 4. Aufl., Bd. VI, Jena 1925, S. 8-91.

Stahmer, Carsten und Mayer, Helmut: Input-Output-Rechnung in konstanten Preisen, in: Wirtschaft und Statistik, Jg. 1985, S. 270-281.

Starbatty, Joachim: Marx, Keynes und Schumpeter zu aktuellen und grundsätzlichen Fragen. Ein fiktives Interview, in: Wirtschaftswissenschaftliches Studium (WiSt), 13.Jg. (1984), S. 33-39.

Statistisches Amt der Europäischen Gemeinschaften: Europäisches System Volkswirtschaftlicher Gesamtrechnungen - EVSG, Luxembourg 1970.

Statistisches Bundesamt: Ausgaben des Staates nach Aufgabenbereichen in den Volkswirtschaftlichen Gesamtrechnungen 1970 bis 1978, Stuttgart, Mainz 1981.

Statistisches Bundesamt: Das Arbeitsgebiet der Bundesstatistik 1981, Stuttgart, Mainz 1981.

Statistisches Bundesamt: Der Staat in den Volkswirtschaftlichen Gesamtrechnungen 1960 bis 1983, Reihe S. 6 der Fachserie 18: Volkswirtschaftliche Gesamtrechnungen, Stuttgart, Mainz 1984. 
Statistisches Bundesamt: Konten und Standardtabellen 1979, Reihe 1 der Fachserie 18: Volkswirtschaftliche Gesamtrechnungen, Stuttgart, Mainz 1980.

Statistisches Bundesamt: Konten und Standardtabellen 1981, Reihe 1 der Fachserie 18: Volkswirtschaftliche Gesamtrechnungen, Stuttgart, Mainz 1982.

Statistisches Bundesamt: Konten und Standardtabellen 1984, Reihe 1 der Fachserie 18: Volkswirtschaftliche Gesamtrechnungen, Stuttgart, Mainz 1985.

Statistisches Bundesamt: Konten und Standardtabellen 1985, Reihe 1 der Fachserie 18: Volkswirtschaftliche Gesamtrechnungen, Stuttgart, Mainz 1986.

Statistisches Bundesamt: Meßzahlen für Bauleistungspreise und Preisindizes für Bauwerke August 1986, Reihe 4 der Fachserie 17: Preise, Stuttgart, Mainz 1986.

Statistisches Bundesamt: Rechnungsergebnisse des öfentlichen Gesamthaus halts 1983, Reihe 3.1 der Fachserie 14: Finanzen und Steuern, Stuttgart, Mainz 1985.

Statistisches Bundesamt: Rechnungsergebnisse des öffentlichen Gesamthaushalts 1984, Reihe 3.1 der Fachserie 14: Finanzen und Steuern, Stuttgart, Mainz 1986.

Statistisches Bundesamt: Revidierte Ergebnisse 1960 bis 1984, Reihe S.8 der Fachserie 18: Volkswirtschaftliche Gesamtrechnungen, Stuttgart, Mainz 1985.

Stein, Lorenz von: Lehrbuch der Finanzwissenschaft, 3. Aufl., Leipzig 1875.

Stein, Lorenz von: Geschichte der sozialen Bewegung in Frankreich von 1789 bis auf unsere Tage, Bd. 3. Das Königtum, die Republik und die Souveränität der französischen Gesellschaft seit der Februarrevolution 1848, Hildesheim 1959.

Stigler, George John: The Economist and the State, in: The American Economic Review, vol. LV (1965), S. 1-18.

Stigler, George John: The Economist as Preacher, Oxford 1982.

Stobbe, Alfred: Artikel: Volkswirtschaftliche Gesamtrechnung, in: Handwörterbuch der Wirtschaftswissenschaft (HdWW), hrsg. v. Willi Albers et al., Bd. 8, Stuttgart et al. 1980, S. 368-405.

Stobbe, Alfred: Volkswirtschaftslehre I. Volkswirtschaftliches Rechnungswesen, 5. Aufl., Berlin et al., 1980.

Stobbe, Alfred: Volkswirtschaftslehre II. Mikroökonomik, Berlin et al. 1983.

Stoltenberg, Gerhard: Haushaltsrede des Bundesministers der Finanzen Dr. Gerhard Stoltenberg am 10. November 1982 im Deutschen Bundestag, in: Bundeshaushalt 1983. Erste Schritte zur Gesundung von Wirtschaft und Finanzen, hrsg. v. Presse-. und Informationsamt der Bundesregierung, Reihe: Berichte und Dokumentationen, Bonn, November 1982, S. 5-27. 
Tautscher, Anton: Geschichte der deutschen Finanzwissenschaft bis zum Ausgang des 18. Jahrunderts, in: Handbuch der Finanzwissenschaft, 2. Aufl., hrsg. v. Wilhelm Gerloff und Fritz Neumark, Bd. I, Tübingen 1952, S. 382-415.

Thiem, Hans: Kommunale Finanzwirtschaft, Köln 1984.

Thiemeyer, Theo: Theorie der öffentlichen Güter als ökonom(ist)ische Staatstheorie, in: Offentliche Güter und öffentliche Unternehmen. Beiträge zur Relevanz der Theorie der öffentlichen Güter für die öffentlichen Unternehmen, hrsg. v. Karl Oettle, Baden-Baden 1984, S. 73-89.

Thoma, Matthias: Theorie der öffentlichen Güter, in: Wirtschaftswisssenschaftliches Studium (WiSt), 14. Jg. (1985), S. 125-130.

Thoss, Rainer: Notwendigkeit und Möglichkeit öffentlicher Investitionen, in: Krise der ökonomischen Theorie - Krise der Wirtschaftspolitik, hrsg. v. Wirtschafts- und Sozialwissenschaftlichen Institut des Deutschen Gewerkschaftsbundes, WSI-Studie zur Wirtschafts- und Sozialforschung Nr. 38, Köln 1978, S. 224246.

Timm, Albrecht: Von der Kameralistik zur Nationalökonomie, in: Festschrift Herrmann Aubin zum 80. Geburtstag, hrsg. v. Otto Brunner et al., Bd. I, Wiesbaden 1965, S. 358-374.

Timm, Herbert: Das Gesetz der wachsenden Staatsausgaben, in: Finanzarchiv, N.F. Bd. 21, Tübingen 1961, S. 201-247.

Timm, Herbert: Ein neues amerikanisches Lehrbuch der Finanzwissenschaft, in: Finanzarchiv, hrsg. v. Fritz Neumark, N.F. Bd. 30 (1971/72), Tübingen 1972.

Timm, Herbert: Zur Finanzierung staatlicher Investitionen unter dem Aspekt der gerechten zeitlichen Lastverteilung, in: Staat und Politische Ökonomie heute. Horst Claus Recktenwald zum 65. Geburtstag, hrsg. v. Horst Hanusch, Karl W. Roskamp und Jack Wiseman, Stuttgart, New York 1985, S. 319-331.

Toillié, Barbara: Öffentliche Investitionen. Ein Begriff im Spannungsfeld von Theorie und Praxis, Berlin 1980.

Uhlmann, Luitpold: Konsum- und Investitionsverhalten in der Bundesrepublik Deutschland seit den fünfziger Jahren, Bd. II: Das Investitionsverhalten der Industrie im Spiegel von Investorenbefragungen, Berlin 1981.

United Nations: Classification of the Functions of Government. Statistical Papers, Series M/70, New York 1980.

Vesper, Dieter: Das Verhalten der staatlichen Investoren im Konjunkturverlauf, in: Neuere Entwicklungen in der Investitionstheorie und -politik, hrsg. v. Gottfried Bombach, Bernhard Gahlen und Alfred E. Ott, Tübingen 1980, S. 257-298.

Vesper, Dieter: Staatliche Einflußnahme auf die Baunachfrage. Eine Analyse für die Jahre 1965 bis 1985, Heft 69 der Beiträge zur Strukturforschung, hrsg. v. Deutschen Institut für Wirtschaftsforschung, Berlin 1981. 
Vogel, Hans-Jochen: Reale Reformen. Beiträge zu einer Gesellschaftspolitik der neuen Mitte, München 1973.

Wagner, Adolph: Finanzwissenschaft, 2. Aufl., erster Theil, Leipzig, Heidelberg 1877.

Wagner, Adolph: Grundlegung der politischen Ökonomie, 3. Aufl., erster Theil. Grundlagen der Volkswirtschaft, zweiter Halbband, Buch 4-6, Leipzig 1893.

Wagner, Adolph: Theoretische Sozialökonomik oder Allgemeine und theoretische Volkswirtschaftslehre, erste Abteilung, Leipzig 1907.

Wagner, Franz E.: Stichwort: Besteuerung, in: Vahlens Kompendium der Betriebswirtschaftslehre, Bd. 2, hrsg. v. Jörg Baetge et al., München 1984, S. 407451.

Wagner, Kurt-Dieter: Möglichkeiten und Grenzen der Finanzierung öffentlicher Investitionen in der Zukunft, in: Ifo-Schnelldienst, 16/1978, S. 11-17.

Walter, Helmut: Theoretische Probleme und Ansatzpunkte der Wachstumspolitik, in: Das Wirtschaftsstudium (Wisu), 13. Jg. (1984), S. 36-42.

Weichmann, Herbert und Wawrczek, Curt: Neuordnung der öffentlichen Haushalte. Ein Beitrag zur volkswirtschaftlichen, staatswirtschaftlichen und betriebswirtschaftlichen Planung der offentlichen Verwaltungs- und Finanzwirtschaft, Hamburg 1952.

Weichmann, Herbert: Die Neugliederung des Haushaltsplans in Hamburg. Ein Beitrag zur Haushaltsreform, in: Finanzarchiv, hrsg. v. Fritz Neumark, N.F. Bd. 25, Tübingen 1966, S. 41-51.

Wille, Eberhard: Finanzplanung am Scheideweg: Resignation oder Neubesinnung?, in: Finanzarchiv, hrsg. v. Norbert Andel und Fritz Neumark, N.F. Bd. 35 (1976/77), Tübingen 1976, S.66-99.

Wille, Eberhard: Artikel: Öffentlicher Haushalt IV: Finanz- und Aufgabenplanung, in: Handwörterbuch der Wirtschaftswissenschaft (HdWW), hrsg. v. Willi Albers et al., Bd. 5, Stuttgart et al. 1980, S. 591-620.

Wille, Eberhard: Soziale Indikatoren als Ansatzpunkte wirtschaftspolitischer Zielbildung und Kontrolle - Verbesserung oder Verschleierung politischer Entscheidungsgrundlagen?, in: ORDO. Jahrbuch für die Ordnung von Wirtschaft und Gesellschaft, Bd. 31 (1980), S. 127-151.

Wille, Eberhard: Die öffentlichen Ausgaben und die Entwicklung der Staatsquote. Zu den entsprechenden Beiträgen im neuen Handwörterbuch der Wirtschaftswissenschaft (HdWW), in: ORDO. Jahrbuch für die Ordnung von Wirtschaft und Gesellschaft, Bd. 32 (1981), S. 297-311.

Wille, Eberhard: Gesamtwirtschaftliche Allokation zwischen "Markt- und Staatsversagen" - ein ordnungspolitischer Überblick, in: Beiträge zur gesamtwirtschaftlichen Allokation, hrsg. v. Eberhard Wille, Frankfurt/Main et al., 1983, S. 1-28. 
Wille, Eberhard: Zum Verhältnis von investiven und konsumtiven öffentlichen Ausgaben, in: ORDO. Jahrbuch für die Ordnung von Wirtschaft und Gesellschaft, Bd. 35 (1984), S. 341-352.

Wille, Eberhard: Öffentliche Sachausgaben versus öffentliche Personalausgaben, in: Produktivitätsentwicklung staatlicher Leistungen, hrsg. v. Karl Häuser, Schriften des Vereins für Socialpolitik N.F. Bd. 145 , Berlin 1985, S. 11-122.

Wille, Eberhard: Rationalität, Effizienz und Effektivität aus der Sicht des Ökonomen, in: Effizienz und Effektivität medizinischer Diagnostik. Bericht über ein Symposion der Internationalen Gesellschaft für Gesundheitsökonomie, Mainz, hrsg. v. Hans Rüdiger Vogel, Stuttgart 1985, S. 15-37.

Wille, Eberhard und Gläser, Martin: Staatsaufgaben bei Adam Smith - eine Würdigung unter Allokationsaspekten, in: ORDO. Jahrbuch für die Ordnung von Wirtschaft und Gesellschaft, Bd. 28 (1977), S. 34-77.

Wille, Eberhard und Kronenberger, Stefan: Zielkonflikte im Kontext der Staatsverschuldung. Einige Anmerkungen mit empirischem Bezug, in: Intertemporale Allokation, hrsg. v. Horst Siebert, Frankfurt/Main et al. 1984, S. 607-647.

Williamson, Oliver $E$.: Reflections on the New Institutionalism, in: Zeitschrift für die gesamte Staatswissenschaft (Journal of Institutional and Theoretical Economics), Bd. 141 (1985), S. 187-195.

Wilson, Thomas: Invisible Hands: Public and Private, in: Staat und Politische Ökonomie heute. Horst Claus Recktenwald zum 65. Geburtstag, hrsg. v. Horst Hanusch, Karl W. Roskamp und Jack Wiseman, Stuttgart, New York 1985, S.13-21.

Winkel, Harald: Die deutsche Nationalökonomie im 19. Jahrhundert, Darmstadt 1977.

Winkel, Harald: Artikel: Wirtschaftswissenschaft I: Geschichte, in: Handwörterbuch der Wirtschaftswissenschaft (HdWW), hrsg. v. Willi Albers et al., Bd. 9, Stuttgart et al. 1982, S. 413-425.

Wissenschaftlicher Beirat beim Bundesministerium der Finanzen: Gutachten zum Begriff der öffentlichen Investitionen. Abgrenzungen und Folgerungen im Hinblick auf Artikel 115 Grundgesetz, Schriftenreihe des Bundesministeriums der Finanzen, Heft 29, Bonn 1980.

Wöhe, Günter: Einführung in die Allgemeine Betriebswirtschaftslehre, 11. Aufl., München 1975.

Wolfslast, Jürgen Christian: Bestimmungsfaktoren wachsender Staatsausgaben. Dargestellt am Beispiel des Deutschen Reiches, 1871 bis 1913, Hamburg 1967.

Woll, Arthur: Das Ende der Stabilitätspolitik, Nr. 93 der Reihe: Vorträge und Aufsätze des Walter Eucken Instituts, Tübingen 1983.

Zeitel, Gerhard: Theoretische und technische Aspekte öffentlicher Darlehen und Gewährleistungen, in: Handbuch der Finanzwissenschaft, 3. Auf1., hrsg. v. Fritz Neumark, Bd. I, Tübingen 1977, S. 997-1024. 
Zimmermann, Horst: Die Ausgabenintensität der öffentlichen Aufgabenerfüllung, in: Finanzarchiv, hrsg. v. Fritz Neumark, N.F. Bd. 32 (1973/74), Tübingen 1974, S. 1-20.

Zimmermann, Horst und Henke, Klaus-Dirk: Finanzwissenschaft. Eine Einführung in die Lehre von der öffentlichen Finanzwirtschaft, 4. Aufl., München 1985.

Zurhorst, Bernhard: Bundespost als größter Investor, in: Öffentliche Wirtschaft und Gemein wirtschaft (ÖWG), Jahrgang XXXIII (1984), H. 4, S. 100-103.

Zwiener, Rudolf: "Crowding-out" durch öffentliche Investitionen? Eine Diskussion der Modellergebnisse der Deutschen Bundesbank und eine Gegenüberstellung mit den Ergebnissen der DIW-Version des ökonometrischen Konjunkturmodells der Wirtschaftsforschungsinstitute, in: Konjunkturpolitik. Zeitschrift für angewandte Wirtschaftsforschung, 29. Jg. (1983), S. 121-140. 


\section{STAATLICHE ALLOKATIONSPOLITIK IM MARKTWIRTSCHAFTLICHEN SYSTEM}

Band 1 Horst Siebert (Hrsg.): Umweltallokation im Raum. 1982.

Band 2 Horst Siebert (Hrsg.): Global Environmental Resouces. The Ozone Problem. 1982.

Band 3 Hans-Joachim Schulz: Steverwirkungen in einem dynamischen Unternehmensmodell. Ein Beitrag zur Dynamisierung der Steuerüberwälzungsanalyse. 1981.

Band 4 Eberhard Wille (Hrsg.): Beiträge zur gesamtwirtschaftlichen Allokation. Allokationsprobleme im intermediären Bereich zwischen öffentlichem und privatem Wirtschaftssektor. 1983.

Band 5 Heinz König (Hrsg.): Ausbildung und Arbeitsmarkt. 1983.

Band 6 Horst Siebert (Hrsg.): Reaktionen auf Energiepreissteigerungen. 1982.

Band 7 Eberhard Wille (Hrsg.): Konzeptionelle Probleme öffentlicher Planung. 1983.

Band 8 Ingeborg Kiesewetter-Wrana: Exporterlösinstabilität. Kritische Analyse eines entwicklungspolitischen Problems. 1982.

Band 9 Ferdinand Dudenhöfer: Mehrheitswahl-Entscheidungen über Umweltnutzungen. Eine Untersuchung von Gleichgewichtszuständen in einem mikroökonomischen Markt- und Abstimmungsmodell. 1983.

Band 10 Horst Siebert (Hrsg.): Intertemporale Allokation. 1984.

Band 11 Helmut Meder: Die intertemporale Allokation erschöpfbarer Naturressourcen bei fehlenden Zukunftsmärkten und institutionalisierten Marktsubstituten. 1984.

Band 12 Ulrich Ring: Öffentliche Planungsziele und staatliche Budgets. Zur Erfüllung offentlicher Aufgaben durch nicht-staatliche Entscheidungseinheiten. 1985.

Band 13 Ehrentraud Graw: Informationseffizienz von Terminkontraktmärkten für Währungen. Eine empirische Untersuchung. 1984.

Band 14 Rüdiger Pethig (Ed.): Public Goods and Public Allocation Policy. 1985.

Band 15 Eberhard Wille (Hrsg.): Offentliche Planung auf Landesebene. Eine Analyse von Planungskonzepten in Deutschland, Osterreich und der Schweiz. 1986.

Band 16 Heiga Gebauer: Regionale Umweltnutzungen in der Zeit. Eine intertemporale Zwei-Regionen-Analyse. 1985.

Band 17 Christine Pfitzer: Integrierte Entwicklungsplanung als Allokationsinstrument auf Landesebene. Eine Analyse der öffentlichen Planung der Länder Hessen, Bayern und Niedersachsen. 1985.

Band 18 Heinz König (Hrsg.): Kontroltheoretische Ansätze in makroökonometrischen Modellen. 1985.

Band 19 Theo Kempt: Theorie und Empirie betrieblicher Ausbildungsplatzangebote. 1985.

Band 20 Eberhard Wille (Hrsg.): Konkrete Probleme öffentlicher Planung. Grundlegende Aspekte der Zielbildung, Effizienz und Kontrolle. 1986.

Band 21 Eberhard Wille (Hrsg.): Informations- und Planungsprobleme in öffentlichen Aufgabenbereichen. Aspekte der Zielbildung und Outputmessung unter besonderer Berücksichtigung des Gesundheitswesens. 1986.

Band 22 Bernd Gutting: Der Einfluß der Besteuerung auf die Entwicklung der Wohnungs- und Baulandmärkte. Eine intertemporale Analyse der bundesdeutschen Stevergesetze. 1986.

Band 23 Heiner Kuhl: Umweltressourcen als Gegenstand internationaler Verhandlungen. Eine theoretische Transaktionskostenanalyse. 1987.

Band 24 Hubert Hornbach: Besteuerung, Inflation und Kapitalallokation. Intersektorale und internationale Aspekte. 1987.

Band 25 Peter Müller: Intertemporale Wirkungen der Staatsverschuldung. 1987.

Band 26 Stefan Kronenberger: Die Investitionen im Rahmen der Staatsausgaben. 1988. 
Stefan Kronenberger - 978-3-631-75565-5

Downloaded from PubFactory at 01/11/2019 03:29:50AM

via free access 
Stefan Kronenberger - 978-3-631-75565-5

Downloaded from PubFactory at 01/11/2019 03:29:50AM

via free access 
Stefan Kronenberger - 978-3-631-75565-5

Downloaded from PubFactory at 01/11/2019 03:29:50AM

via free access 